\title{
Dirk Koob
}

\section{Sozialkapital zur Sprache gebracht}

Eine bedeutungstheoretische

Perspektive auf ein sozialwissenschaftliches Begriffs- und Theorieproblem

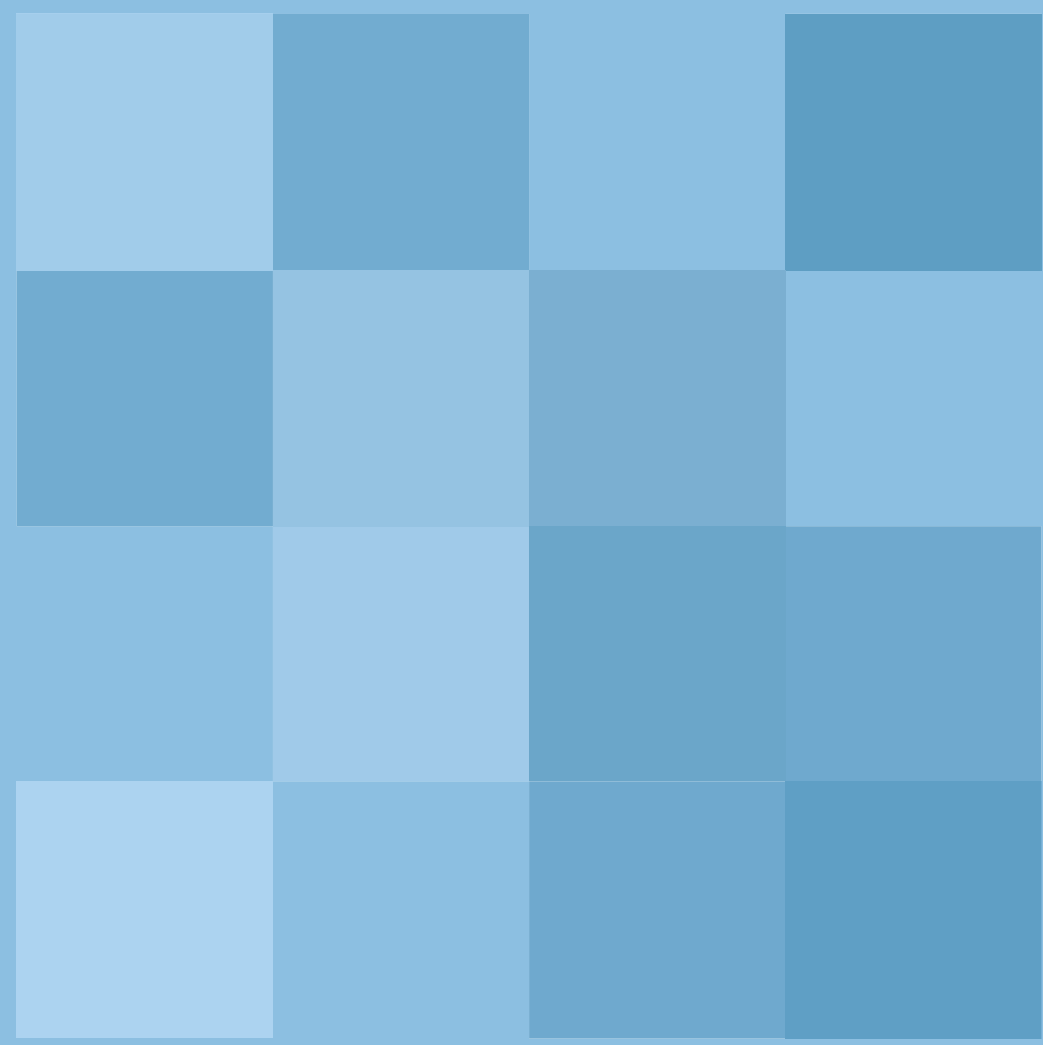





\section{Dirk Koob}

Sozialkapital zur Sprache

Except where otherwise noted, this work is licensed under a Creative Commons License

$$
\text { () }
$$

SORAE RIGHIS RESERVED 
erschienen im Universitätsverlag Göttingen 2007 
Dirk Koob

Sozialkapital

zur Sprache gebracht

Eine bedeutungstheoretische

Perspektive auf ein

sozialwissenschaftliches

Begriffs- und Theorieproblem

Universitätsverlag Göttingen 2007 


\section{Bibliographische Information der Deutschen Nationalbibliothek}

Die Deutsche Nationalbibliothek verzeichnet diese Publikation in der Deutschen Nationalbibliographie; detaillierte bibliographische Daten sind im Internet über $<$ http://dnb.ddb.de> abrufbar

\section{Kontakt:}

Priv.-D oz. Dr. Dirk Koob

e-mail: dirk_koob@web.de

Dieses Buch ist auch als freie Onlineversion über die Homepage des Verlags sowie über den OPAC der Niedersächsischen Staats- und Universitätsbibliothek (http://www.sub.uni-goettingen.de) erreichbar und darf gelesen, heruntergeladen sowie als Privatkopie ausgedruckt werden Es gelten die Lizenzbestimmungen der Onlineversion. Es ist nicht gestattet, Kopien oder gedruckte Fassungen der freien Onlineversion zu veräußern.

Satz und Layout: Dirk Koob

Umschlaggestaltung: Kilian Klapp

(C) 2007 Universitätsverlag Göttingen

http://univerlag.uni-goettingen.de

ISBN: 978-3-938616-79-6 
"Nehmen wir ein Wort, das auf einen Gegenstand hinweist - 'Schirm' zum Beispiel. Wenn ich das Wort 'Schirm' ausspreche, sehen Sie im Geiste das Ding. ... Ein Schirm ist nicht nur ein Ding, er ist ein Ding, das eine Funktion erfüllt - mit anderen Worten, den Willen des Menschen ausdrückt. Wenn Sie darüber nachdenken, ähnelt jeder Gegenstand insofern dem Schirm, als er einer Funktion dient. Ein Bleistift ist zum Schreiben da, ein Schuh zum Tragen, ein Auto zum Fahren. Meine Frage lautet nun: Was geschieht, wenn ein Ding nicht mehr seine Funktion erfüllt? Ist es noch das Ding, oder ist es etwas anderes geworden? Ist der Schirm noch ein Schirm, wenn Sie den Stoff herunterreißen? Sie öffnen das Gestell, halten es über den Kopf, gehen in den Regen hinaus und werden naß. Ist es möglich, diesen Gegenstand noch einen Schirm zu nennen? Im allgemeinen tun es die Leute. Allenfalls werden sie sagen, der Schirm sei kaputt. Für mich ist das ein schwerwiegender Fehler, die Quelle aller unserer Nöte. Da er seinem Zweck nicht mehr dienen kann, hat der Schirm aufgehört ein Schirm zu sein. ... Und wenn wir nicht einmal einen gewöhnlichen, alltäglichen Gegenstand benennen können, den wir in der Hand halten, wie wollen wir dann von Dingen sprechen, die uns wirklich etwas angehen?" (Paul Auster, Stadt aus Glas) 



\section{Inhalt}

Vorwort.

Abstract

1. Einleitung.

Ausgangsproblem (15), Zielsetzung und Vorgehensweise (17), Forschungsoutput und -nutzen (23)

2. Forschungsstand und Forschungslücke. 25

Mikro- und makrosoziologisches Begriffsverständnis (27), Vorliegende Beiträge zur Begriffsdebatte (33), Originalität der durchzufübrenden Begriffs- und Theorienanalyse (38)

3. Präzisierung von Fragestellung und Vorgehensweise 41

Bedeutung als Problem der Sprache (42), Erläuterungen zur ontologischen

Fragedimension (45), Zusammenfassung und ergänzende Hinweise (48)

\section{Grundlagenteil: Entwicklung eines Analyseinstrumentariums als} "kleine" analytische Sprachphilosophie der Sozialwissenschaften........53

4. Erkenntnis- und wissenschaftstheoretischer Grundlagenteil .............................59

4.1. Zum Zusammenhang von Erkenntnis- und Wissenschaftstheorie.

4.2. Linguistisches wissenschaftliches Erkenntniskonzept 64

Die analytisch-synthetisch-Dichotomie (64), Signifikanzkeriterium und Zweistufenkonzept (67)

4.3. (Neo-) Strukturalistisches wissenschaftliches Erkenntniskonzept 70

Verwerfung der analytisch-synthetisch-Dichotomie (71), T-Theoretizität (72), Mengentheoretische Theoriendarstellung (75), Methode der Rationalen Rekonstruktion (80)

4.4. Der Moderate Strukturalismus 84

4.4.1. Abweisung einer Eliminierung T-theoretischer Terme 85

Die Theoriebeladenheit der Erfahrung (87), Die Propositionalität und Synthetizität des Wissens (90), Die Hypothesentheorie der (sozialen) Wahrnehmung und der Radikale Konstruktivismus (92)

4.4.2. Theorieanwendung als Kompatibilitätsprüfung 97

4.4.3. Strukturalismus als Aussagenkonzeption und

Vereinfachung der mengentheoretischen Rekonstruktionsweise.

4.4.4. Zusammenfassung. 103

4.4.5. Ausblick auf die Theorienanalyse 106 
5. Ontologischer Grundlagenteil................................................................................. 111

5.1. Sein und Letztbegründungen..................................................................... 113

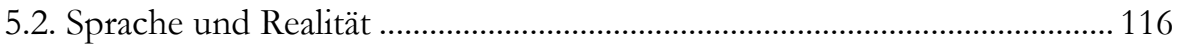

Das Linguistische Relativitätstheorem (117), Der Quinesche Holismus

(118), Begriffs-/Weltbildrelativismus (121), Sein als Wert einer gebundenen Variable (123)

5.3. Bedeutung und Sprache.

Bedeutung und Bezug (129), Bedeutung und Struktur (133), Bedeutung und Gebrauch (135), Bedeutung und Sprechakte (138), Bedeutung und konstitutive Regeln (141), Bedeutung und sinnhaftes Handeln (144), Zusammenfassung (147)

5.4. Bedingungen der Möglichkeit sozialer Realität: Sprachphilosophische Perspektive.

Beobachterrelativität und ontologische Subjektivität (150), Intentionalität, Funktionszunveisung und institutionelle Tatsachen (152), Die sprachlogische

Struktur institutioneller Tatsachen (154), Zusammenfassung (156)

5.5. Bedingungen der Möglichkeit sozialer Realität: Wissenssoziologische Perspektive

Objektivation (162), Externalisierung (166), Internalisierung (168), Zusammenfassung (170)

5.6. Der Bedeutungskonstruktivismus.

Komplementarität der Ontologien (171), Verfügbarmachung der Ontologien (173)

5.7. Exkurs: Zur ontologischen Argumentationsweise

Phänomenologische Argumentation (178), Sprachanalytische Argumentation (183)

6. Zwischenbilanz: Was Wissen und Bedeutung mit der sozialen Welt machen

\section{Anwendungsteil: Analyse ausgewählter Sozialkapitalbegriffe / -konzepte und integrative Begriffs- und Theoriebildung.}

7. Einführende Bemerkungen zur Vorgehensweise.

7.1. Sozialkapital und gesellschaftliche Position: Das Konzept Pierre Bourdieus

Definition (207), Ebene (210), Lokalisierung (211), Entstehung (211), Wirkung (213), Operationalisierung (214), Wissenschaftstheoretischer Status (214), Strukturalistische Darstellung (217) 
7.2. Sozialkapital und schulischer Erfolg: Das Konzept James S. Colemans. 227

Definition (228), Ebene (231), Lokalisierung (232), Entstehung (233),

Wirkung (235), Operationalisierung (236),Wissenschaftstheoretischer

Status (237), Strukturalistische Darstellung (239)

7.3. Sozialkapital und Bürgergesellschaft: Das Konzept Robert D.

Putnams 244

Definition (245), Ebene (250), Lokalisierung (251), Entstehung (252),

Wirkung (253), Operationalisierung (257), Wissenschaftstheoretischer

Status (259), Struketuralistische Darstellung (263)

7.4. Sozialkapital und beruflicher Erfolg: Das Konzept der

Netzwerktheoretiker.

Definition (269), Ebene (271), Lokalisierung (271), Entstehung (272),

Wirkung (273), Operationalisierung (275), Wissenschaftstheoretischer

Status (277), Strukturalistische Darstellung (277)

8. Eine integrative Theorie über Sozialkapital und Bestimmung des ontologischen

Status. 283

8.1. Sozialkapitalbegriff und theoretisches Aussagensystem

Definition (286), Ebene (298), Lokalisierung (300), Entstehung (303),

Wirkung (306), Operationalisierung (313), Wissenschaftstheoretischer

Status (313), Strukturalistische Darstellung (314)

8.2. Sozialkapitalbegriff und sozialer Gegenstand

Sozialkapital und "innere" Sprechakte (322), Sozialkapital und

vorwissenschaftliche Theorie (324), Sozialkeapital und sprachlogische

Struktur (327), Sozialkapital und Bedeutungsnormativität (333),

Sozialkapital und Externalisierungen (341)

9. Epilog

9.1. Zusammenfassende Ergebnisbewertung ................................................. 351

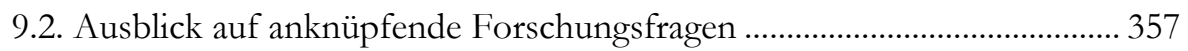

Literatur 


\section{Abbildungsverzeichnis}

Abbildung 1: Eine Begriffsanalyse von "Sozialkapital" ................................................. 22

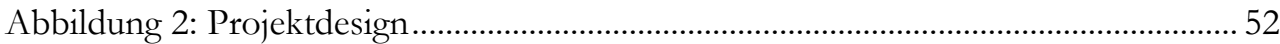

Abbildung 3: Wissenschaftstheorie zwischen Erkenntnis- u. Gegenstandstheorie ..... 64

Abbildung 4: Das Zweisprachen-/Zweistufenkonzept Carnaps ................................... 70

Abbildung 5: Erkenntnis als Syntheseleistung ............................................................. 103

Abbildung 6: Bedeutungskonstitution sprachlicher Zeichen und Äußerungen ............ 148

Abbildung 7: Searles Ontologie institutioneller Tatsachen .......................................... 157

Abbildung 8: Berger/Luckmanns Ontologie institutioneller Tatsachen ...................... 170

Abbildung 9: Die Zirkularität institutioneller Wirklichkeit ........................................... 192

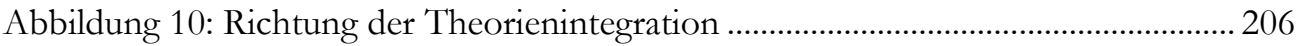

Abbildung 11: Die Funktionalität von Sozialkapital .................................................... 310

Abbildung 12: Eine sprachphilosophische Ontologie des Sozialkapitals ..................... 331

Abbildung 13: Eine wissenssoziologische Ontologie des Sozialkapitals ..................... 349

Abbildung 14: Alltagssprache, Sozialkapital und Wissenschaftssprache ...................... 357

\section{Tabellenverzeichnis}

Tabelle 1: Bourdieus Sozialkapitalkonzept ................................................................... 217

Tabelle 2: Colemans Sozialkapitalkonzept.................................................................. 240

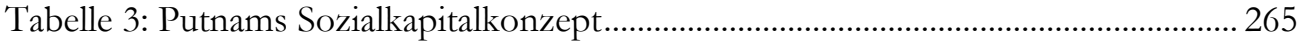

Tabelle 4: Netzwerkanalytisches Sozialkapitalkonzept ................................................2 278

Tabelle 5: Gemeinsamkeiten der rekonstruierten Sozialkapitalkonzepte ..................... 315

Tabelle 6: Sozialwissenschaftliche Semantik und Ontologie des Sozialkapitals ........... 355 


\section{Vorwort}

Die Idee zur vorliegenden Untersuchung entstammte meiner Mitarbeit an einem internationalen Forschungsprojekt zur vergleichenden Analyse von innovativen Kooperationsformen in der dezentralen Arbeitsmarkt- und Beschäftigungspolitik in Europa. Die diversen wie dispersen Forschungsinteressen bzw. -traditionen und - wie man wohl auch sagen darf - Eitelkeiten der einzelnen Teilnehmerteams machte eine einheitliche konzeptionelle Austichtung, die doch unabdingbar für einen systematischen und sinnvollen Vergleich gewesen wäre, schon nach kurzer Zeit unmöglich.

Da dem deutschen Team die verantwortliche Leitung des Projektes oblag, bestand unsererseits aber ein großes Interesse daran, dem Auftrag- und Geldgeber theoriegeleitete, kohärente und vergleichbare Ergebnisse zu präsentieren. Zu diesem Zweck erwies sich der Sozialkapitalbegriff als äußerst nützliches Instrument. Zum einen wurde er von der auftraggebenden Institution selbst verwendet. Damit war es schlichtweg opportun, sich dieses Ausdrucks zu bedienen. Zum anderen wurde (und wird) der Begriff relativ vage und heterogen bestimmt; er war (und ist nach wie vor) offen für vielfältige Interpretationen. Jedes an dem oben genannten Forschungsprojekt teilnehmende Team sah sich dementsprechend in die Lage versetzt, seine eigenen konzeptionellen Vorstellungen irgendwie hierunter zu subsummieren. "Sozialkapital" bildete gewissermaßen ein Dach, das jeder Forschungsausrichtung ausreichend Schutz bot.

Was unter kooperationsstrategischen Aspekten betrachtet zweifellos als glückliche Fügung (bzw. als geschickter Schachzug des Projektleiters) anzusehen war, konnte wissenschaftlich - und dies bedarf sicherlich keiner näheren Begründung wenig zufrieden stellen. Insofern erschien es mir mit Blick auf die Erzielung sozialwissenschaftlichen Erkenntnisfortschritts ausgesprochen sinnvoll, mich auf dezidiert metatheoretischer Grundlage mit dem Sozialkapitalbegriff und den theore- 
tischen Aussagensystemen, in denen er auftaucht, auseinanderzusetzen, um so zu versuchen, einen fundierten wie kommunikativ notwendigen Konsensvorschlag für Begriff und Theorie vorzulegen.

Damit wird nun aber innerhalb dieser Untersuchung ein Zugang zur Sozialkapitalthematik gewählt, der so bislang in der Literatur nicht zu finden ist und daher als desiderat gelten darf. Meiner Beobachtung zu Folge setzen sich erfahrungswissenschaftliche Fachvertreter - gleich welcher Provenienz - i.d.R. allenfalls notgedrungen denn freiwillig mit philosophischen Metareflexionen auseinander. Die entsprechenden Inhalte scheinen schwer verständlich, trocken und mithin nicht wirklich etwas mit den eigentlichen Fachproblemen zu tun zu haben. Insbesondere erkenntnis- und wissenschaftstheoretische Überlegungen sind aber eine unerlässliche Vorbedingung jeden vernünftigen wissenschaftlichen Arbeitens. Ohne eine sinnvolle, exakte und konsensuale Festlegung von Begriffen muss unsere Kommunikation zwangsläufig missverständlich bleiben; wissenschaftlicher Fortschritt wird behindert.

Freilich bin ich mir der mit interdisziplinär angelegten Untersuchungen vielfach verbundenen Kosten bewusst. Zwar betont heutzutage nahezu jede Wissenschaftseinrichtung die Notwendigkeit und den Nutzen von Interdisziplinarität; aber wenn es um die Kommentierung entsprechender Arbeiten geht, dann finden die jeweiligen Fachvertreter reichlich Veranlassung zur Kritik. So mag etwa der Soziologe eine (aus seiner Sicht) nicht weit genug reichende Beachtung soziologischer Klassiker, der Philosoph eine nicht durchgängige sprachanalytische Orientierung, der Psychologe einen zu starken Einbezug phänomenologischer Überlegungen oder der Politologe eine lediglich marginale Anbindung an öffentliche Diskurse beklagen. Aus meiner Sicht kann Interdisziplinarität jedoch nicht heißen, es allen Fachvertretern Recht zu machen. Wie sollte dies in Anbetracht der immer stärker zunehmenden Ausdifferenzierung einzelwissenschaftlicher Teilbereiche auch möglich sein? Das Fruchtbare einer interdisziplinären Perspektive erweist sich vielmehr in dem innovativen Blick auf festgefahrene Probleme oder in der Formulierung und Beantwortung weiterführender, bislang so noch nicht gestellter Fragen.

Bedanken möchte ich mich an dieser Stelle beim sozialwissenschaftlichen Methodenzentrum und dem Graduiertenkolleg "Die Zukunft des Europäischen Sozialmodells" der Georg-August-Universität Göttingen sowie insbesondere bei Professor Ulrich Druwe und Professor Wolfgang Knöbl für ihre konstruktive Kritik und hilfreichen Hinweise. Für die Inhalte dieser Arbeit bin ich freilich alleine verantwortlich.

Göttingen im März 2006

Dirk Koob 


\section{Abstract}

\section{Ausgangsüberlegung, Ziel und Gang der Untersuchung}

"Sozialkapital" hat seit geraumer Zeit Konjunktur. Sowohl namhafte Sozialwissenschaftler, etwa Robert D. Putnam oder Anthony Giddens, als auch internationale politische Institutionen, wie die Weltbank oder die OECD, haben den Begriff an eine exponierte Stelle ihrer Agenda gesetzt. Ein Blick auf die vorliegende Literatur zur Thematik offenbart allerdings eine semantisch-theoretische Ambiguität und Heterogenität, die vor dem Hintergrund der Bemühungen um wissenschaftlichen Fortschritt als problematisch zu kennzeichnen ist. Die Frage nach der Bedeutung von "Sozialkapital" lässt sich bislang weder konsensual noch kohärent beantworten.

Ausgangspunkt meiner Beschäftigung mit der Sozialkapitalthematik ist damit eine Bedeutungsvarianz, und insofern ein begriffstheoretisches Problem. Will man im Anschluss an diese Diagnose den Versuch einer klärenden Analyse unternehmen, so muss man sich den Begriff dort anschauen, wo er vorkommt, d.h. innerhalb elaborierter theoretischer Aussagensysteme; diese legen die Bedeutung von "Sozialkapital" fest und propagieren bestimmte Erkenntnisse über den so bezeichneten Gegenstand. Damit wird die Einnahme bzw. Konstruktion einer metatheoretischen Perspektive erforderlich, denn Objekt der Analyse ist nun ein sozialwissenschaftliches Konstrukt mitsamt der ihm Bedeutung verleihenden sprachlichen Konzepte.

Über eine Rationale Rekonstruktion schulenbildender Konzepte (namentlich der von Pierre Bourdieu, James S. Coleman, Robert D. Putnam und Ronald S. Burt) gilt es zunächst herauszuarbeiten, welche semantische Vielfalt derzeit mit "Sozialkapital" verknüpft ist und welche sozialwissenschaftlichen Probleme sich über das Konstrukt beschreiben und erklären lassen. Eine systematische synopti- 
sche Gegenüberstellung auf Grundlage wissenschaftstheoretischer Kriterien soll dann in eine integrative Begriffs- und Theoriebildung münden, um so vor dem Hintergrund der Diskussion um wissenschaftlichen Erkenntnisfortschritt einen präzisen, einheitlichen sowie regelgeleiteten begrifflichen Gebrauch im Rahmen einer weitgehend axiomatisierten Theorie zu ermöglichen.

Im Anschluss daran ist zusätzlich zu prüfen, ob es vor dem Hintergrund gebrauchstheoretischer Überlegungen hinsichtlich sprachlicher Bedeutung überhaupt sinnvoll ist, das, was von mir schließlich als "Sozialkapital" bezeichnet wird, als Kapitalform auszuweisen. Eine Bedeutungsanalyse hat daher zu klären, inwiefern das Ergebnis der Begriffsexplikation der empirisch feststellbaren Verwendungsweise von "Kapital" gerecht wird. Sollte es bspw. nicht möglich sein, einen Eigentümer für Sozialkapital zu bestimmen, dann wäre zu fragen, warum dann überhaupt von einer Kapitalform die Rede ist.

Damit ist aber zugleich deutlich, dass begriffliche und theoretische Probleme im vorliegenden Kontext keinesfalls nur etwas mit dem wissenschaftlichen Erkenntnisproblem zu tun haben. Wer nach der Bedeutung eines Begriffes fragt, gelangt i.d.R. geradewegs zu dem Gegenstand, der über den Begriff bezeichnet wird.

Der Zusammenhang zwischen Begriff und Gegenstand ist aber insbesondere auch von ontologischem Interesse: "Sozialkapital" bezeichnet etwas, was es gibt. Dieses Etwas - so meine Argumentation - verdankt seine Existenz sprachlichen Ordnungsprozessen. Wie verhalten sich nun diese gegenstandskonstitutiven Prozesse zu dem Begriff, der den Gegenstand bezeichnet? Zur Beantwortung dieser Frage wird man sich zunächst mit allgemeinen Überlegungen zu einer Ontologie des Sozialen beschäftigen müssen, um diese dann problemspezifisch anzuwenden. Ein integratives Theoriemodell über Sozialkapital, das über solche ontologischen Reflexionen angereichert wird, ist geeignet, unser Wissen insbesondere hinsichtlich der Entstehungsbedingungen des Gegenstandes zu vertiefen.

Durch die vorgeschlagene Analyse kann der wissenschaftliche Reifegrad der Sozialkapitaldebatte erheblich gesteigert werden. Indem "Sozialkapital zur Sprache gebracht" wird, lässt sich eine wissenschaftstheoretischen Anforderungen genügende, integrative Begriffs- und Theoriebildung vornehmen. Über sich anschlieBende ontologische Überlegungen führt dies dann zu einer Präzisierung des Objektbereiches. So kann in der Art einer logischen Propädeutik geklärt werden, was sich mit "Sozialkapital" überhaupt vernünftigerweise sagen lässt. 


\section{Einleitung}

\section{Ausgangsproblem}

"Hilf dir selbst, sonst hilft dir keiner!" Sicherlich ist jeder schon einmal dieser Aussage begegnet - hat sie gehört oder selbst ausgesprochen. Menschen artikulieren mit ihr ein tiefsitzendes Misstrauen gegenüber ihren Nächsten. Wir können bestimmt alle einige Situationen anführen, in denen ein solches Misstrauen ganz offensichtlich seine Berechtigung besaß. Dennoch sind wir wohl nicht minder häufig in der Lage, von Fällen zu berichten, in denen man uns sogar Hilfe anbot, ohne dass damit wirklich zu rechnen gewesen wäre. U.a. in solchen Fällen greifen wir auf etwas zurück, was in der Sprache der Sozialwissenschaften heute oftmals als "Sozialkapital" bezeichnet wird.

"Sozialkapital" ist einer der derzeit am heftigsten diskutierten sozialwissenschaftlichen Begriffe (vgl. Kapitel 2). Ganz grundlegend wird hierüber ein auf den ersten Blick relativ trivial erscheinender und im Alltag als selbstverständlich hingenommener Aspekt menschlichen Zusammenlebens thematisiert: Menschen unterstützen sich gegenseitig. Oder, aus einem anderen Blickwinkel heraus formuliert: Individuen ziehen Nutzen aus ihren Sozialkontakten. Folgt man dem wohl populärsten Sozialkapitalexponenten, Robert D. Putnam, dann haben die Sozialwissenschaften dank des Begriffs sogar "the key to making democracy work" entdeckt (Putnam 1993: 185). Gemäß Putnam wird "aus einer Vielzahl von Gründen ... das Leben in einer Gemeinschaft leichter, wenn sie über einen substantiellen Bestand an Sozialkapital verfügt" (Putnam 1999: 29).

Trotz dieser nahezu euphorischen Einschätzung handelt es sich bei der Sozialkapitaldebatte um einen noch relativ jungen sowie - was weiter unten zu belegen sein wird - heterogen bzw. bisweilen diffus strukturierten wissenschaftlichen Bereich, "in dem", so der angesprochene Putnam selbst, "ernsthafte Forschungspro- 
gramme eben erst eingeleitet werden" (Putnam/Goss 2001: 40). Michael Taylor (1993: 73) sprach vor gut 10 Jahren sogar noch von "still very embryonic claims that have recently been made on behalf of 'social capital'".

In einer aller ersten Annäherung lassen sich auf Basis der vorliegenden Literatur grob zwei begriffliche Bedeutungen identifizieren, die im Kontext unterschiedlicher Wirkungsargumentationen auftauchen:

1. Insbesondere der schon angesprochene Robert D. Putnam verwendet den Begriff vorwiegend auf der makrosoziologischen Ebene. "Sozialkapital" beschreibt dabei zusammenfassend zwischenmenschliche Vernetzung, gegenseitiges Vertrauen und Normen generalisierter Reziprozität innerhalb von Gemeinschaften. Die zentrale Behauptung lautet: Je höher der Bestand an Sozialkapital eines Kollektivs (also etwa: je zahlreicher die Bürger eines Staates in Vereinen organisiert sind, je stärker das Vertrauen, das die Bürger sich untereinander aber auch den politischen Institutionen entgegenbringen und je mehr Normen effektiv auf kooperatives Handeln hinwirken), desto "besser" die demokratische und ökonomische Performanz dieses Kollektivs.

2. Netzwerktheoretiker wie bspw. Ronald S. Burt (z.B. 1999) verorten Sozialkapital hingegen weitgehend auf der mikrosoziologischen Ebene. "Sozialkapital" bezieht sich hier auf die in Beziehungsrelationen eingebetteten Ressourcen, mit deren Hilfe Individuen ihre Ziele verwirklichen. Umgangssprachlich würde man wohl von "Vitamin B" (Vitamin Beziehung) sprechen. "The human capital explanation is that the people who do better are better people (smarter, more attractive, more skilled etc.). The social capital explanation is that the people who do better are better connected." (ebenda: 48) In zahlreichen Studien konnte auf Basis dieser Begriffsfassung bspw. immer wieder die Nützlichkeit von Sozialkontakten bei der Jobsuche nachgewiesen werden.

Sozialforscher sehen sich heute also verschiedenen Verständnisweisen von und Theorien bzw. Konzepten über Sozialkapital gegenüber ${ }^{1}$. Nach Alejandro Portes (1998: 2) nähert sich die Debatte einem Punkt an, "at which social capital comes to be applied to so many events and in so many different contexts as to lose any distinct meaning". Vor der Durchführung einer empirischen Analyse steht daher notwendigerweise zunächst der Blick auf vorhandene Gebrauchsweisen, dann die Entscheidung für eine Bedeutungsvariante und abschließend eine untersuchungsorientierte Begriffspräzisierung. (Kromrey [2000: 130ff.] spricht für die Sozialforschung in diesem Zusammenhang allgemein von einer "semantischen Analyse".) So kann man sich etwa zur Betrachtung der Effizienz kommunalpolitischen Verwaltungshandelns des Putnamschen Verständnisses bedienen und dabei den analytischen Schwerpunkt auf das institutionelle Vertrauen der Bürger richten, während

$1 \mathrm{Zu}$ diesem Zeitpunkt der Argumentation spreche ich hinsichtlich von elaborierten Ausarbeitungen zu Sozialkapital wahlweise von "Theorien", "Konzepten", "Ansätzen" oder "Aussagensystemen"; der tatsächliche wissenschaftstheoretische Status wird später genauer zu bestimmen sein. 
man zugleich bürgerschaftliche Assoziationsformen weniger stark gewichtet und normative Komponenten weitgehend ausblendet ${ }^{2}$.

Bei einer solchen Vorgehensweise handelt es sich aber um den Idealfall. Viele Wissenschaftler, die heute mit dem Sozialkapitalbegriff arbeiten, kommen dieser Minimalforderung nicht nach; sie argumentieren implizit auf Grundlage von Realdefinitionen oder behandeln begriffliche Probleme allenfalls am Rande, ganz so, als gäbe es verschiedene definitorische Bestimmungen sowie konzeptionelle Probleme überhaupt nicht ${ }^{3}$. In einer Disziplin, die um die Erzeugung wissenschaftlichen Erkenntnisfortschritts bemüht ist, kann dieser Zustand nicht als befriedigend angesehen werden.

Zur Verbesserung der wissenschaftlichen Kommunizierbarkeit eines Begriffes ist eine konsensuale Verwendungsweise wünschenswert bzw. sinnvoll - auch in der Chemie und der Physik versteht man ja bspw. unter "Gravitation" grundlegend dasselbe. Diese Disziplinen werden gerade auch wegen eines nahezu durchgängigen, nicht zuletzt dank mathematisch-logischer Formulierungen erzielten, einheitlichen Begriffsinventars als "reife" Wissenschaften bezeichnet. Wer aber etwa innerhalb der Soziologie einen Berufs-, einen Bildungs- und einen Wohlfahrtsstaatsforscher nach der Definition von "Sozialkapital" befragt, der dürfte mit hoher Wahrscheinlichkeit voneinander abweichende Antworten erhalten. Dieses Problem verschärft sich zusehends, da mittlerweile nicht nur Soziologen, sondern ebenso Politikwissenschaftler, Pädagogen, Volks- und Betriebswirtschaftler, Historiker sowie Philosophen über "Sozialkapital" reden.

\section{Zielsetrung und Vorgehensweise}

Vor diesem Hintergrund möchte ich innerhalb der vorliegenden Untersuchung grundlegende Fragen im Vorfeld der Anwendung von "Sozialkapital" klären. Insofern richtet sich der Fokus hier auf sprachliche Aspekte wissenschaftlichen Erkenntnisfortschritts. Dabei soll es aber nicht in der Tradition Poppers, Lakatos oder Stegmüllers unmittelbar um einen kumulativen oder evolutionären Fort-

\footnotetext{
2 Vgl. bspw. Cusack 1999.

3 Ohne jeglichen Bezug zu vorliegenden theoretischen Erörterungen behauptet etwa Immerfall (1999: 121): "Sozialkapital sind Vertrauens-Vorleistungen von Gruppenmitgliedern für und in ihren sozialen Beziehungen." Für Gehmacher (2004: 2) fallen ohne Angabe von Gründen oder Quellen "Liebe, Verbundenheit und Vertrauen" sowie "das Wesen und das Funktionieren von Gesellschaft überhaupt" (ebenda: 4) unter den Begriff. Zugleich soll Sozialkapital eine "soziale Kraft" sein, die aus "Bindungen - Normen - Vertrauen" "besteht" (ebenda: 11). Ist Vertrauen damit Sozialkapital, nur ein Bestandteil davon oder sogar beides? Beispielhaft kann in diesem Zusammenhang auch auf einen viel zitierten Artikel von Knack/Keefer (1997) verwiesen werden. Zu Beginn heißt es dort lediglich: "Trust, cooperative norms, and associations within groups each fall within the elastic definitions that most scholars have applied to the term social capital." (ebenda: 1251f.) Es genügt den Autoren, Vertrauen und zivilgesellschaftliche Normen als Gegenstände zu identifizieren, auf die Coleman und Putnam den Sozialkapitalbegriff anwenden, um ihre umfangreichen statistischen Analysen zu beginnen. Es bleibt völlig unklar, wozu hier überhaupt der Sozialkapitalbegriff notwendig sein soll; eine Verbindung zwischen Theorie und Messung wird nicht geleistet.
} 
schritt in der empirischen Gegenstandsbeschreibung bzw. -erfassung gehen. Es ist gerade kennzeichnend für die Sozialkapitaldebatte, dass ein gemeinsamer Gegenstandsbereich nur schwer auszumachen ist. Thomas Kuhn würde sicherlich von einer "vor-paradigmatischen Phase" sprechen. Bei Alan F. Chalmers (2001: 89) heißt es allgemein: "Die typische Geschichte eines Begriffes, ob es sich nun um den Begriff 'chemisches Element', 'Atom' oder 'das Unbewusste' handelt, beginnt zunächst einmal mit einer vagen Vorstellung, die dann erst allmählich in dem MaBe deutlich wird, in dem die Theorie, deren Bestandteil er ist, eine präzisere und kohärentere Form annimmt."

Der Versuch, eine solch "präzisere und kohärentere Form" nicht nur für einen Begriff von, sondern damit (wie noch deutlich werden wird) automatisch auch für eine Theorie über Sozialkapital herbeizuführen, kennzeichnet nun mein Forschungsinteresse. Aus Gründen der Systematik erfordert dies das Aufsuchen eines metatheoretischen Analyseortes: Der Gegenstandsbereich wird zunächst einmal durch den sozialwissenschaftlichen Sozialkapitalbegriff und theoretische Aussagensysteme, in denen dieser Begriff eingebettet ist, konstituiert. Die Notwendigkeit der Einnahme einer solchen Forschungsperspektive resultiert aus der derzeit nicht zufriedenstellend beantwortbaren, grundlegenden Fragestellung dieser Untersuchung: Was bedeutet "Sozialkapital"?

Eine Begriffsexplikation soll den heterogen bzw. unscharf verwendeten Sozialkapitalbegriff durch eine einheitliche, präzise und weitgehend axiomatisierte Variante ersetzen, um so eine Annäherung an ein Idealbild exakter Wissenschaftlichkeit in diesem Bereich und das heißt eine Erhöhung des begrifflichen und theoretischen Reifegrades zu erzielen.

Begriffsexplikationen sind aber - und das wurde gerade auch über die letzte Formulierung thematisiert - ohne die Beschäftigung mit Aussagensystemen nicht durchführbar. Wissenschaftliche Begriffe sind als theoretische Konstrukte zu kennzeichnen; ihre Bedeutung wird durch den semantischen Kontext bestimmt, in dem sie vorkommen. Ob man mit "Sozialkapital" etwa eine Hilfestellung, ein Beziehungsnetzwerk oder Vertrauen konzeptualisiert, hängt davon ab, was ein Theoriekonstrukteur zum Ausdruck bringen und welche Erkenntnisse er über die Wirklichkeit systematisiert darstellen möchte.

Um nun eine einheitliche begriffliche Verwendungsweise herbeizuführen, sollen bestehende Sozialkapitalkonzepte auf Grundlage eines wissenschaftstheoretischen Kriterienkatalogs rekonstruiert und synoptisch gegenübergestellt werden. Ausgehend von identifizierbaren Gemeinsamkeiten lässt sich dann auch ein Vorschlag für eine integrative und systematisch weiterentwickelte Theorie ausarbeiten"; "in diesem Fall besteht die Begriffsexplikation also in der Aufstellung einer

4 In der "massiven Konkurrenz der Theorien spielen wissenschaftstheoretische Fragen eine erhebliche Rolle, Fragen also zu den Voraussetzungen und Charakteristika von Wissenschaft und wissenschaftlicher Theoriebildung." (Joas/Knöbl 2004: 15) Die grundlegenden Methoden für einen Theorienvergleich können also nicht aus der Erfahrungswissenschaft Soziologie, sondern nur aus der deren Praxis reflektierender - Formalwissenschaft Wissenschaftstheorie stammen. Matthes (1978: 14) 
ganzen Theorie." (Essler 1982: 61) Deren Sozialkapitalbegriff ist dann noch daraufhin zu befragen, ob er den gängigen Gebrauchskriterien von "Kapital" im Alltag wie in der Ökonomie genügt. Nur unter dieser Bedingung kann das Ergebnis der Begriffsexplikation bedeutungstheoretisch überzeugen.

"Sozialkapital zur Sprache gebracht" - wie es im Titel zu dieser Arbeit heißt meint ganz allgemein, über Sozialkapital zu reden, die Thematik zum Objekt der Analyse zu machen. Es meint spezifisch, den semantischen Problemen des theoretischen Konstrukts nachzugehen. Möchte man sich aber umfassend mit sprachlichen Aspekten von "Sozialkapital" beschäftigen, dann sind nicht nur erkenntnisund wissenschaftstheoretische, sondern ebenso ontologische Überlegungen zu berücksichtigen. Die Ontologie fragt nach den allgemeinsten Strukturen der Wirklichkeit. Weite Teile dieser Strukturen sind nun allerdings - wie noch zu zeigen sein wird - sprachlicher Natur. Damit wird die ontologische Frage zu einem Problem der Sprache ${ }^{5}$. Was hat das aber mit einer Begriffsanalyse von "Sozialkapital" zu tun?

Es hat vor allem deshalb etwas damit zu tun, weil begriffliche und gegenständliche Probleme in Zusammenhang mit der Sozialkapitaldebatte vielfach auf eine unzulässige Art und Weise vermischt werden. So behaupten Serageldin/Grootaert (1999: 45) "examples of social capital are easier to provide than one specific definition." Was sind das aber für Beispiele, zu deren Bezeichnung das begriffliche Rüstzeug nicht zur Verfügung steht? Von welchen sozialen Gegenständen redet man denn dann überhaupt?

Francis Fukuyama fordert, die Hauptfragen, die innerhalb der Sozialkapitaldebatte beantwortet werden müssten, seien, "what social capital is, how it can be measured, where it comes from, and particularly how to get more of it" (Fukuyama 1997: 377). Was Sozialkapital ist, unterliegt aber einer definitorischen Bestimmung, d.h. möchten wir wissen, was es ist, müssen wir klären, was wir unter "Sozialkapital" verstehen wollen. Fukuyama stellt implizit eine ontologische Frage ohne deren Begründungsproblematik zu beachten. Dies wird vor allem dann deutlich, wenn er die Forderung nach einer größeren Kenntnis darüber, wie man

beklagte Ende der siebziger Jahre, kennzeichnend für die Soziologie sei "ein einhelliger Verzicht auf einen systematisch betriebenen Konzeptvergleich". Opp (1978: 218) sprach sogar von "der Hilflosigkeit der meisten Sozialwissenschaftler in Situationen, in denen sie zwei Theorien diskutieren oder zwischen zwei Theorien wählen sollen." Auch gut 20 Jahre nach der auf dem Kasseler Soziologentag 1974 eingeleiteten Theorienvergleichsdebatte konstatiert Schmid (1996: 69), es gebe mit Blick auf grundlegende Theorieangebote nach wie vor "nur außerordentlich selten Untersuchungen darüber, wo die Unterschiede genau liegen". Nach Seipel (1999: 22) fristen "Theorienvergleiche in den Sozialwissenschaften ein Mauerblümchendasein". Die Vergleichsthematik ist dennoch jüngst wieder einmal auf die soziologische Tagesordnung gesetzt worden: Im Juni 2005 veranstaltete die DGS Sektion "Soziologische Theorie" eine Tagung zum "Vergleich der Theorienvergleiche in der deutschen Soziologie".

5 Das heißt freilich keinesfalls, die Dinge seien alle sprachabhängig (oder es gebe außer Sprache nichts anderes). 
"mehr" von diesem Gegenstand bekommen kann, aufstellt. Warum sollte man aber mehr von etwas bekommen wollen, von dem man doch noch gar nicht weiß, was es ist?

M.a.W.: Serageldin/Grootaert und Fukuyama (sowie - was im Verlauf der Arbeit noch deutlich wird - zahlreiche andere Autoren) begehen einen Kategorienfehler, wenn sie unreflektiert von semantischen Problemen zu Überlegungen hinsichtlich realweltlicher Eigenschaften springen. Angesichts des derzeitigen Entwicklungsstandes der Sozialkapitaldebatte ist dieser Einwand weit mehr als eine philosophische Spitzfindigkeit. Es ist notwendig, eine systematische metatheoretische Begriffsanalyse durchzuführen, "so lange nämlich Sprachprobleme nicht geklärt sind, kann auch über Sachprobleme keine Verständigung erzielt werden." (Prim/Tilmann 1997: 28)

Begeben wir uns also zurück auf die Sprachebene. Wenn wir uns fragen, was (sozialwissenschaftliche) Begriffe eigentlich sind, so werden wir nach gängiger Vorstellung zunächst einmal antworten: Sie sind (i.d.R.) Entitäten, die sich auf Gegenstände, die es in der (sozialen) Welt gibt, beziehen ${ }^{6}$. Bei Frege und Carnap finden wir die Unterscheidung zwischen Begriffs-Extension und BegriffsIntension - eine Terminologie, die heute zum standardmäßigen Vokabular der empirischen Sozialforschung gehört (vgl. etwa Schnell/Hill/Esser 1999: 50). Im Falle der Extension handelt es sich um das Referenzpotential, d.h. die Menge aller Objekte, auf die ein Begriff zutrifft. Die Intension charakterisiert die inhaltliche Bedeutung bzw. die invarianten Eigenschaften oder Merkmale, die alle diese Objekte aufweisen.

Folgt man dieser Unterscheidung, dann sind begriffliche Probleme eben auch empirische Referenz- und somit ontologische Probleme. Wie kommt es aber dazu, dass wir mit einem Begriff einen Gegenstand meinen können? Verdankt ein Begriff seine Bedeutung dem Gegenstand auf den er verweist? Ordnen wir einem Begriff eine Bedeutung und dieser dann über Korrespondenzregeln einen Gegenstand einfach so zu? Ist der Gegenstand vielleicht sogar konstitutiv auf die Bedeutung des Begriffes angewiesen? Damit geht es also letztlich darum, das Zusammenspiel zwischen dem Sozialkapitalbegriff - so wie er im Anschluss an die von mir zuvor vorgenommene erkenntnis- und wissenschaftstheoretische Analyse festgelegt wurde - sowie dem hierüber bezeichneten Gegenstand zu klären.

Wenn es im vorliegenden Zusammenhang bei den ontologischen Überlegungen um die für die Gegenstände der sozialen Realität ${ }^{7}$ konstitutiven sprachlichen Ordnungsleistungen geht, dann wird hierüber zugleich auch ein klassisches Thema

6 Wenn es um Begriffe geht (seien sie nun wissenschaftlich oder umgangssprachlich), dann wird dies innerhalb dieser Untersuchung durch das Setzen von Anführungszeichen verdeutlicht. Ist hingegen der realweltliche Gegenstand gemeint, wird auf das Setzen von Anführungszeichen verzichtet. Man spricht in diesem Zusammenhang von einem "semantischen Aufstieg": "Dieses Verfahren ist der Übergang von Aussagen über Kilometer zu Aussagen über 'Kilometer'." (Quine 1980: 467)

7 Ich werde in dieser Arbeit die Ausdrücke "soziale Realität / Wirklichkeit" und "soziale Welt" synonym verwenden. 
der Gesellschafts- bzw. Sozialtheorie aufgegriffen: "Wie ist es möglich, daß subjektiv gemeinter Sinn zu objektiver Faktizität wird?" (Berger/Luckmann 1980: 20) Als Sozialwissenschaftler mag man geneigt sein, diese Frage weniger stark sprachlich zu interpretieren. Spätestens seit Max Weber (1980: 1) sind wir davon überzeugt, dass die soziale Realität durch sinnhafte Handlungen von aufeinander Bezug nehmenden Individuen gekennzeichnet ist. Alfred Schütz geht der daraus folgenden "besonderen Einstellung der Sozialwissenschaften zu ihrem Gegenstand" (Schütz 1993: 9) in der Tradition Husserls nach und erweitert die Webersche Perspektive, indem er Handlung zusätzlich als eine sich intentional auf die Außenwelt richtende bedeutungsstiftende Bewusstseinsaktivität begreift. Im Symbolischen Interaktionismus geht man davon aus, "daß Menschen 'Dingen' gegenüber auf der Grundlage der Bedeutungen handeln, die diese Dinge für sie besitzen" (Blumer 1973: 81).

Menschen sind allerdings nur dann in der Lage, den Dingen bzw. Gegenständen gegenüber auf der Grundlage - wie ich es nennen möchte - "soziologischer" Bedeutung zu handeln ${ }^{8}$, wenn sie über hierfür notwendige linguistische bzw. symbolische Mittel verfügen. Besonders augenfällig ist die Verbindung zwischen linguistischer und soziologischer Bedeutung in jenen Fällen, in denen soziale Gegenstände qua Deklaration geschaffen werden. Eine Versammlungsvertagung wird bspw. erst möglich, weil der sprachlichen Äußerung "Hiermit vertage ich die Versammlung" (X) die Bedeutung zugewiesen wird, als Versammlungsvertagung (Y) zu zählen. Dies ist gleichwohl an die Gelingensbedingung geknüpft, dass der Sprecher innerhalb eines bestimmten Kontextes zu der Äußerung befugt ist (K). Gemäß dieser Überlegung beruht die Schaffung dieses Typus von sozialen Gegenständen auf der konstitutiven Regel "X zählt als Y in K"9. Um nun von X nach Y zu gelangen, benötigen wir Sprache bzw. Symbole. Eine ontologische Analyse sozialer Realität richtet sich insofern auf gegenstandsbegründende sprachliche Ordnungsprozesse.

Die bislang nicht geklärte Bedeutung von "Sozialkapital" erfordert also eine umfassende Begriffsanalyse, um so sowohl über eine erkenntnis- und wissenschaftstheoretische als auch über eine ontologische Betrachtung problemrelevanter Aspekte des sprachlichen Ausdrucks zu einem Fortschritt in der exakten Begriffs-

\footnotetext{
8 Obwohl diese Bedeutung in einem dem methodologischen Individualismus entsprechenden Sinne nur von einzelnen Individuen und insofern psychologisch prozessiert wird, kennzeichne ich sie hier (nicht zuletzt vor dem Hintergrund des Symbolischen Interaktionismus) als "soziologisch", da es im vorliegenden Zusammenhang um die von Menschen geteilten Bedeutungen und darauf aufbauend um eine objektiv vorhandene, allgemein anerkannte soziale Wirklichkeit gehen wird.

9 Diese Formel geht auf den amerikanischen Sprach- und Bewusstseinsphilosophen John R. Searle (2001: 127f.) zurück. Dessen Lehrer, der Sprechakttheoretiker John L. Austin, hat das beschriebene Vermögen der Sprache in besonders pointierter Form in dem Buchtitel "How to do things with words" zum Ausdruck gebracht (Austin 1962). Sprechakte sind damit Teil einer Handlungstheorie, weswegen vielfach auch von "Sprechhandlungen" die Rede ist (vgl. etwa Brinker 2001).
} 
und damit auch Gegenstandsbestimmung beizutragen. Dabei ist das Bedeutungsproblem in dreifacher Weise ausdifferenzierbar, womit zugleich das forschungspraktische Vorgehen in kompakter Weise zusammengefasst werden kann:

Erstens geht es um die Bedeutung von "Soziakapital" als zentralen Bestandteil sozialwissenschaftlicher Aussagensysteme: Was meinen Autoren, wenn sie den Begriff verwenden und kann der Begriff einen einheitlichen sowie präzisen Gebrauch innerhalb einer klar strukturierten Theorie finden? (Wissenschaftstheoretische Fragedimension)

Zweitens wird untersucht, welche Bedeutungen Menschen im Alltag sprachlich wie prozessieren müssen, um den sozialen Gegenstand, auf den sich der wissenschaftliche Begriff bezieht, überhaupt hervorzubringen: Welche Bedeutungen werden wie benötigt, damit es das geben kann, was als "Sozialkapital" bezeichnet wird? (Ontologische Fragedimension)

Drittens schließt sich daran die Frage nach einem potentiellen Zusammenhang von begrifflicher und gegenstandskonstitutiver Bedeutung an: Besteht eine Verbindung zwischen der Bedeutung des wissenschaftlichen Sozialkapitalbegriffs und den sprachlichen Bedeutungen, die notwendig für die Existenz des Gegenstandes sind? (Verknüpfung von wissenschaftstheoretischer und ontologischer Fragedimension)

Dies lässt sich nun auch in Form untersuchungsleitender Thesen formulieren: Die Semantik von "Sozialkapital" wird in der Wissenschaft festgelegt. Sie korrespondiert weitgehend mit den alltäglichen sprachlichen Gebrauchsweisen, die in einem ontologischen Sinne konstitutiv für den sozialen Gegenstand sind, um den es geht. Der Gegenstand ist also keineswegs einfach so in der Welt und wird dann von Wissenschaftlern lediglich aufgenommen und bezeichnet; vielmehr bedarf er konstitutiv sprachlicher Operationen, die sich dann im wissenschaftlichen Sozialkapitalbegriff widerspiegeln (müssen).

Abbildung 1: Eine Begriffsanalyse von "Sozialkapital"

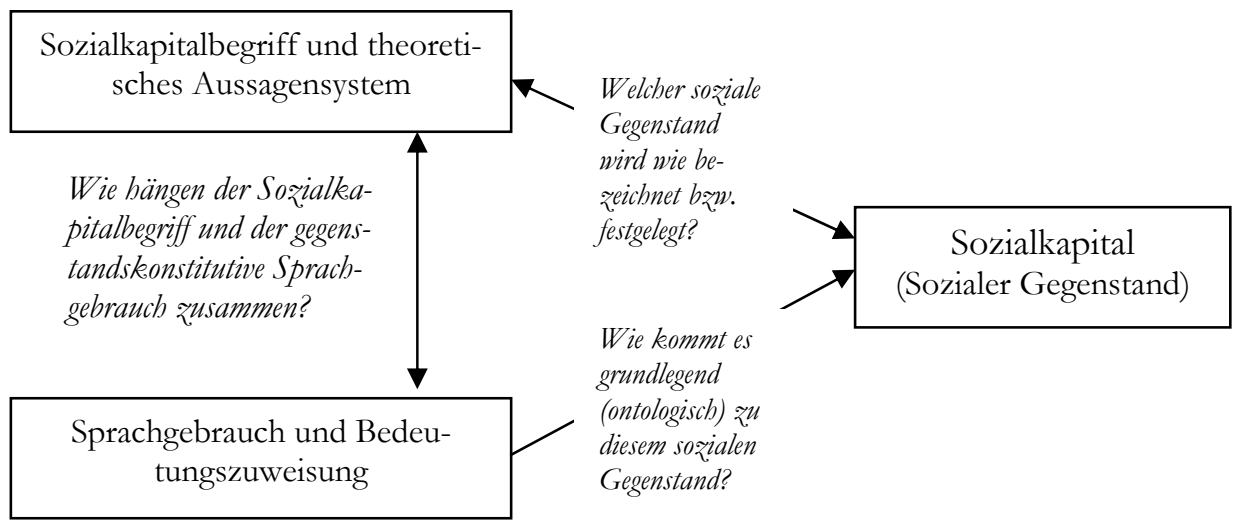




\section{Forschungsoutput und -nutzen}

Zum Abschluss dieser Einleitung möchte ich den sozialwissenschaftlichen und insbesondere den mit der Sozialkapitaldebatte schon vertrauten Leser einladen, sich mit mir auf den skizzierten gedanklichen Weg zu begeben. Dass diese etwas ungewöhnliche, innovative Art der Reflexion über die Thematik einen ausführlichen sprachphilosophischen "Abstecher" notwendig macht, um entsprechende Analysekriterien an die Hand zu bekommen, dürfte nach den vorangegangenen Ausführungen kaum überraschen. Die Grundlagen der Argumentation dienen über ihre inhaltlich-analytische Funktion hinausgehend dazu, die sozialwissenschaftlichen Relevanzstrukturen wissenschafts- und erkenntnistheoretischer, aber vor allem auch ontologischer Probleme aufzuzeigen. Der Zugang zu diesen Problemen soll dadurch erleichtert werden, dass an zentralen Stellen immer wieder knappe, illustrierende Verweise auf allgemeine sozialwissenschaftliche Themenbereiche und spezifisch auf die im Anwendungsteil erfolgende Diskussion des Sozialkapitalbegriffs angeführt werden.

Insgesamt expliziert die Arbeit den Sozialkapitalbegriff und konkretisiert dabei den wissenschaftstheoretischen Status unterschiedlicher Sozialkapitalkonzepte. Sie präzisiert, axiomatisiert und vergleicht die jeweiligen Konzeptinhalte. AbschlieBend wird auf dieser Grundlage dann ein integratives Theoriemodell und eine Ontologie über Sozialkapital formuliert. Um dies alles überhaupt in systematischer Weise leisten zu können, sind jedoch zunächst eigenständige sprachphilosophische Überlegungen anzustellen. So ist ein komplexes metasprachliches Analyseraster zur Untersuchung sozialwissenschaftlicher Aussagensysteme (Moderater Strukturalismus) zu entwickeln. Ferner werden zwei unterschiedliche Ontologien des Sozialen zusammengeführt, um so ein allgemeines Bestimmungsschema über die sprachlichen Bedingungen der Möglichkeit sozialer Gegenstände (Bedeutungskonstruktivismus) zu konzipieren.

Über eine Kombination einer wissenschaftstheoretischen und ontologischen Analyse wird insgesamt ein dringend benötigter Beitrag zur Erhöhung des wissenschaftlichen Reifegrades der Sozialkapitaldebatte sowie allgemein zur Etablierung eines wohlfundierten Systems sozialwissenschaftlicher Begriffe geleistet. Sozialkapital wird "zur Sprache gebracht", indem über eine integrative Begriffsund Theoriebildung eine Präzisierung des Objektbereiches erarbeitet wird, die eine Bestimmung der sprachlichen Konstitutionsbedingungen der Sozialkapital darstellenden Gegenstände beinhaltet. 



\section{Forschungsstand und Forschungslücke}

Der erstmals schon 1916 bei L. J. Hanifan (1916) im Kontext der Gemeindesoziologie auftauchende Sozialkapitalbegriff verdankt seine Anziehungskraft und seinen "kometenhaften Aufstieg" (Fine 2001: 5) wohl nicht zuletzt der Tatsache, dass sich u.a. solch populäre und (in Teilen doch sehr) unterschiedlich argumentierende Sozialwissenschaftler wie Pierre Bourdieu, James S. Coleman, Robert D. Putnam, Ronald S. Burt, Claus Offe, Hartmut Esser oder Ronald Inglehart dieses Konstrukts angenommen haben. Durch Autoren wie Kenneth J. Arrow, Robert M. Solow oder Gary Becker wurde "Sozialkapital" mittlerweile - wenngleich vielfach mit skeptischem Unterton - auch auf die Agenda ökonomischer Forschung gesetzt ${ }^{10}$.

10 Der genannte skeptische Unterton findet sich etwa bei Solow, wenn dieser die von Fukuyama (1995: 356f.) aufgestellte (aber auch bei Putnam anzutreffende) Behauptung, eine gesunde Ökonomie und eine starke Demokratie seien auf Sozialkapital zurückzuführen, kontert: "He (Fukuyama, D.K.) has some interesting things to say, or at least Tocqueville had some interesting things to say. ... But imprecision ist not a virtue, and 'for example' is not an argument." (Solow 1995: 39) Als Beispiele für die Behandlung der Sozialkapitalthematik außerhalb von Soziologie und Politikwissenschaft siehe etwa Schechler 2002 (Volkswirtschaft), Kröll 2003 (Betriebswirtschaft), Stecher 2001 (Pädagogik), Rotberg 2001 (Geschichtswissenschaft) oder Taylor 1993 (Philosophie). Waldstrom (2003: 1) behauptet: "As a concept with an undoubtedly intuitive appeal, social capital is likely to be adopted by scholars from a variety of fields and for a number of different purposes using distinct methodological and theoretical perspectives. While this is not in itself a problem - ... - it may result in uses and definitions that are not mutually congruent." M.E. ist das dann aber sehr wohl ein Problem. In diesem Zusammenhang möchte ich zumindest erwähnen, dass in den Wirtschaftswissenschaften noch ein Sozialkapitalbegriff existiert, der überhaupt keine Verwandtschaft mit der in der vorliegenden Arbeit diskutierten Begrifflichkeit aufweist und aus der Literatur zum Investementgeschäft stammt: "Unter Sozialkapital werden hier (finanzielle, D.K.) Mittel verstanden, die - insbesondere zur Alterssicherung - gemeinschaftlich bei Anlageinstitutionen angelegt sind" (Schleef 2001: 6), wobei "gemeinschaftlich bedeutet, daß das Vermögen von oder zugunsten einer Vielzahl von Berechtigten aufgebracht wurde." (ebenda, Fußn. 2) 
Neben der OECD und der Europäischen Kommission hat insbesondere die Weltbank als politische Institution den Begriff für sich entdeckt. Mit Blick auf regionale Antworten hinsichtlich globalpolitischer Herausforderungen glaubt ihre Development Research Group vor allem unter intellektueller Federführung des Sozialwissenschaftlers Michael Woolcock und in weitgehender Anlehnung an Putnams konzeptionelle Äußerungen in den durch "Sozialkapital" bezeichneten Entitäten einen Grundpfeiler der weltweiten sozio-ökonomischen Entwicklungen erkannt zu haben. Im Internet bietet die Weltbank Mailforen zur Thematik an, und in ihren Datenbanken hält sie eine mittlerweile nahezu unüberschaubare Anzahl von Referenzen bereit ${ }^{11}$. Die Fülle der vorliegenden Literatur sollte jedoch nicht über elementare Defizite der Diskussion hinwegtäuschen ${ }^{12}$. "We do not have a strong consensus on what social capital is: it seems that the more popular the concept becomes, the further we get from such a consensus." (Adam/Roncevic 2003: 160) Gerade das Fehlen eines Konsenses über Begriff, Theorie und Gegenstand könnte - wie Sabatini (2005: 2) vermutet - sogar ein Grund für den "Erfolg" von "Sozialkapital" sein: "conceptual vagueness may have promoted the use of the term".

Diekmann (2004a: 488) spricht etwa von "a great variety of definitions" und identifiziert keine Theorie, sondern lediglich "a heuristic framework". Poulsen/Svendsen (2003: 18) sehen in diesem Sinne "a need for further theoretical clarification". Unter Bezugnahme auf den Forschungsstand resümiert Haug (2000: 74): "Es lässt sich kein einheitliches Konzept von sozialem Kapital herauskristallisieren. Sowohl theoretische als auch empirische Studien verwenden den Begriff soziales Kapital in gänzlich unterschiedlichen Kontexten. (...) Es besteht demnach ein dringender Bedarf an einer (einheitlichen?) theoretischen Konzeptualisierung". Schechler (2002: 14) macht "widersprüchliche Argumentationsketten und Sichtweisen" aus. Fine (1999: 9) kritisiert "a web of eclecticism in which the

11 Wer sich mit Hilfe des Internets einen Eindruck über die Sozialkapitaldebatte verschaffen möchte, dem sei die von Fabio Sabatini erstellte Seite www.socialcapitalgateway.org empfohlen.

12 An dieser Stelle kann es nicht darum gehen, eine kommentierte Literaturübersicht über die Sozialkapitaldebatte vorzulegen. Angesichts der Masse des mittlerweile vorliegenden Materials wäre dies m.E. zeitlich auch kaum mehr realisierbar. Gerade für Sozialkapital gilt, was der Wissenschaftssoziologe Robert K. Merton (1985: 159) schon vor knapp 40 Jahren unter Rekurs auf allgemeine Entwicklungen wie folgt charakterisierte: "Es besteht Grund zu der Annahme, daß angesichts des exponentiellen Anwachsens der Masse wissenschaftlicher Publikationen, ... es für die Wissenschaftler immer schwieriger (wird, D.K.), sich in ihrem Gebiet auf dem Laufenden zu halten ... . Bentley Glass ist nur einer von vielen, die zu dem Schluß gelangt sind, daß 'für den heutigen Wissenschaftler vielleicht nichts entmutigender ist als das Bemühen, die Flut wissenschaftlicher Publikationen auch nur auf seinem eigenen kleinen Spezialgebiet zu bewältigen."' Putnam/Goss (2001: 19) sprechen in einem Artikel aus dem Jahre 2001 von einer "Explosion von Forschungsarbeiten" bzw. von einer "sich rapide vermehrenden Literatur" zur Sozialkapitalthematik. Vor 1981 seien gerade einmal 20 und zwischen 1991-1995 lediglich 109 Beiträge gezählt worden. Zwischen 1996 bis März 1999 ließen sich dann aber schon 1003 Publikationen in einschlägigen Übersichten nachweisen (ebenda: 18). Meine Überzeugung ist, dass man hinsichtlich der letzten sieben Jahre sogar noch von einem forcierten Anstieg ausgehen darf. Überdies müssen hier eigentlich auch noch all jene Beiträge mit eingerechnet werden, die sich zwar nicht explizit mit "Sozialkapital", aber doch mit dem, was der Begriff vielfach impliziert - wie z.B. Netzwerke, Reziprozität oder Vertrauen -, befassen. Damit ist das Gebiet dann aber in quantitativer Hinsicht definitiv unüberschaubar geworden. 
notion of social capital floats freely from one meaning to another with little attention to conceptual depth or rigour." Schuller et al. (2000: 24f.) sprechen von einer "definitional diversity" bzw. "over-versatility". Lin/Fu/Hsung (2001: 57) vertreten die Auffassung, "the proliferation of meanings attached to the concept ... has threatened its integrity." Johnston/Percy-Smith (2003: 332) propagieren, "the status of social capital as a concept should ... be characterised as chaotic" (nahezu gleichlautend auch Warden/Tampubolon 2002: 177). Van Deth (2001: 280) sieht den Sozialkapitalbegriff als "Opfer" eines "conceptual stretchings". Fukuyama (2002: 27) behauptet, "there is still no general agreement as to what it (social capital, D.K.) is" und Twickel (2002: 52) beobachtet eine "babylonische Sprachverwirrung".

Auch Robert D. Putnam hat die Heterogenität der Sozialkapitaldebatte konstatiert. Gleichwohl warnt er davor, "eine falsche theoretische Einheitlichkeit herbeizwingen zu wollen"13 (Putnam/Goss: 2001: 39), ohne doch zu erläutern, was eine "falsche theoretische Einheitlichkeit" sein soll. Wenn Sozialkapital in der Tat - wie hier suggeriert wird - uneinheitlich zu konzeptualisieren wäre, dann werden augenscheinlich verschiedene Gegenstände bzw. Gegenstandsbereiche prädikatiert. Wissenschaftstheoretisch betrachtet, wäre es dann aber wünschenswert, auch auf verschiedene Begriffe zurückzugreifen.

\section{Mikro- und makrosoziologisches Begriffsverständnis}

In einer allerersten Annäherung lassen sich grob zwei unterschiedliche Verwendungsweisen des Sozialkapitalbegriffs (bzw. - sprachphilosophisch korrekt formuliert - zwei unterschiedliche Sozialkapitalbegriffe) identifizieren ${ }^{14}$. Ein dem ökonomischen Wissenschaftsparadigma zuzuordnender, netzwerkanalytischer Forschungszweig lokalisiert demnach Sozialkapital primär auf der Mikro- (und sekundär auf der Meso-) Ebene. Besonders prägnant wird diese Position von Henk Flap vertreten. Er definiert: "Someone's social relations can be interpreted as his social capital since they are instrumental for his goal attainment." (Flap 1995: 1) Sozialkapital setzt sich danach aus den für ein Individuum potentiell hilfreichen Personen, der Beziehungsintensität (womit die potentiellen Hilfestellungen spezifizierbar sind) sowie den aus den Beziehungen zu anderen resultierenden nutzbaren Ressourcen zusammen (vgl. Flap 2002: 36). (Hier können bspw. auch monetäre Ressourcen gemeint sein, was auf die Transformation von sozialem in ökonomisches Kapital und vice versa verweist.)

Sozialkapital ist in diesem Verständnis ein aus interpersonalen Relationen erwachsendes Gut, das als Folge von Tauschbeziehungen entsteht. Als individuelle

13 Der Aufsatz von Putnam/Goss stellt in weiten Teilen mehr oder minder eine deutsche Übersetzung der konzeptionellen Ausführungen in Putnam 2000 dar; aus diesem Grund werde ich häufig (wenn ich paraphrasiere) vereinfachend lediglich auf Putnam als Autor verweisen.

14 Dies kann nur eine erste, einführende Bestimmung sein; später werde ich vier verschiedene Sozialkapitalkonzepte bzw. "school of thoughts" für die Analyse heranziehen. 
Ressource kann es strategisch eingesetzt werden, um etwa über Bekannte Zugang zu den Ressourcen Fremder zu erlangen. In der Literatur wird diesbezüglich bspw. auf die private Jobsuche verwiesen (vgl. Granovetter 1973 u. 1974), wenn Beziehungsbroker über unterschiedliche Netzwerke hinweg vermitteln und zur Überbrückung sog. structural holes beitragen. Nicht das intrinsische Interesse an einer Beziehung, sondern die gezielte Ausnutzung von Sozialkontakten steht somit im Vordergrund dieser instrumentellen Variante. Man investiert in eine Beziehung, um Verpflichtungen zu erzeugen, d.h. der Aufbau von Sozialkapital ist als individuelle, egoistische Nutzenmaximierung interpretierbar. "Seilschaften aller Art, pardon: Netzwerke, sind nichts anderes als institutionalisiertes Sozialkapital, und wer es nutzt, ist Sozialkapitalist"15 (Strasser 1999: 5).

In Differenz zum instrumentellen Aspekt besitzen über "Geselligkeit motiviert(e)" (Esser 2000: 254) interpersonelle Relationen einen intrinsischen bzw. sozio-emotionalen Nutzen für die beteiligten Personen. Nicht-intendiertes Resultat der erzeugten Muster ist Sozialkapital, das als kollektive - gleichwohl lediglich individuell erfahrbare - Gewinnauszahlung interpretierbar ist und einen Anreiz zur Konservierung oder sogar zum Ausbau relationaler Strukturen bietet. Auf der Aggregatebene wird über die reziprok-vorteilhafte Kooperation ein Gemeingut produziert, denn alle Beteiligten erhalten (i.d.R.) einen Kooperationsgewinn ${ }^{16}$.

Im Unterschied zu den skizzierten mikrosoziologischen Verwendungsweisen, in denen Sozialkapital primär einen individuellen Nutzen generiert, bringt insbesondere Robert D. Putnam - geleitet von demokratietheoretischen Überlegungen Tocquevilles ${ }^{17}$ - den Begriff mit abgrenzbaren Sozietäten wie Schulen, Kommu-

15 Die instrumentelle Begriffsfüllung scheint insbesondere einen großen Reiz auf Autoren populärer Businessliteratur auszuüben. Uwe Scheler (2000) beschreibt etwa in seinem Buch "Erfolgsfaktor Networking - Mit Beziehungsintelligenz die richtigen Kontakte knüpfen" wie man über 'Vitamin B' (also dem Beziehungsvitamin; so könnte man Sozialkapital in dieser [nepotistischen] Variante umgangssprachlich bezeichnen) zu beruflichem Aufstieg und finanziellem Reichtum gelangen kann. Beim "Networking" geht es demnach "um eine methodische und systematische Art der Beziehungspflege, die in der offenen Absicht der gegenseitigen Förderung, des Austauschs und des persönlichen Vorteils geschieht." (ebenda: 22) Ute Diefenbach hat die hinter einer solchen Anwendung stehende Logik in einem in der Frankfurter Rundschau veröffentlichten Essay m.E. auf den Punkt gebracht. Die Überschrift zu ihren Ausführungen lautet nämlich: "Schöner schleimen"; und im Untertitel: "Dem Chef begegnen wir mit Ehrfurcht - aber so oft wie möglich" (Diefenbach 2000). Hartmut Esser (2000: 253) macht auf eine Schwierigkeit dieser Vorgehensweise aufmerksam: "Jede 'intensionale' und 'strategische' Investition in eine Beziehung muß wenigstens so tun, als ginge es um mehr als nur um die Optimierung der Zugänge und um die eigensüchtige Kontrolle der Ressourcen anderer. Der Aufbau von Vertrauen durch Verläßlichkeiten und die Errichtung von Verpflichtungen durch Vorleistungen vertragen offen vorgetragene 'rationale' und 'egoistische' Erwägungen nicht." Schon Goethe wusste: „So fühlt man die Absicht, und man ist verstimmt.“

16 Volker G. Täube (2002: 73ff.) spricht hinsichtlich der instrumentellen Nutzung des Sozialkapitals von "leverage capital" und hinsichtlich der intrinsischen Nutzung von "support capital". (Aus den Ausführungen Täubes geht leider nicht hervor, woher diese Begriffe stammen bzw. ob sie sogar von ihm selbst geprägt wurden.)

17 Tocqueville war Mitte des 19. Jh. mit ähnlichen Fragen wie Putnam befasst, nämlich mit der USamerikanischen Demokratieentwickung. Als deren Eckpfeiler identifizierte er vor allem die Assoziationsneigung der Bürger: "Die Amerikaner jeden Alters, jedes Standes, jeder Geistesrichtung schließen sich fortwährend zusammen." (Tocqueville 1976: 595) Bei Evers (2002: 61) heißt es mit 
nen, regionalen Gemeinschaften oder Nationen in Verbindung. Sozialkapital wird in dieser "expansionistischen Position" (Ostrom/Ahn 2003: 41) zu einem spezifischen Aspekt der sozio-kulturellen Ausgestaltung einer Gesellschaft bzw. Gemeinschaft, zu einem Mix aus institutionellen Strukturvorgaben und organisatorischer Ordnung, womit die Sozialkapitaldebatte durchaus in der Tradition des civic culture-Ansatzes von Almond/Verba (1965) steht.

Berg-Schlosser (1990) konzeptualisiert diesen Ansatz im Parsonschen AGILSchema. Hier ist es dann das sozio-kulturelle Teilsystems, das über den Diskurs allgemeine Werthaltungen und politische Orientierungen produziert und darüber erst Gemeinschaftsbildung ermöglicht. Über den Sozialkapitalbegriff findet nun dezidiert dieser Gemeinschaftsaspekt, seine Quellen sowie seine möglichen Formen und Inhalte eine Thematisierung. Sozialkapital-Forschung in diesem Sinne untersucht das - zumeist als pfadabhängig erachtete - Ausmaß an gemeinschaftlichem Solidarpotential; es geht also um "'kommunitäre' Erscheinungsformen" (Offe 1999: 115) von Sozietäten, um "the ... essence of communal vitality" (Siisiäinen 2000: 4), um verlässliche freiwillige interpersonale Beziehungen bzw. tradierte Kooperationspraktiken, die Generierung und Wirkung von Vertrauen oder die Fähigkeit und Bereitschaft, sich mit anderen zu assoziieren. Damit ist das "Sozialkapital einer Gesellschaft ... eine hoch aggregierte und mehrdimensionale Größe" (Diekmann 2004b: 21).

Als empirische Ausgangsprobleme des "expansionistischen" Sozialkapitalverständnis lassen sich u.a. soziale Desintegrationsprozesse identifizieren, die als eine Folgeerscheinung der sich im Zuge der Moderne forcierenden funktionalen Differenzierung gelten können. Offensichtlich untergraben solche Prozesse gewachsene Formen gesellschaftlicher Solidarität, ohne genügend neue Integrationspotentiale generieren zu können. Letztlich geht es also um den Zusammenhalt bzw. die sozio-moralischen Ressourcen moderner Gesellschaften und damit um ein Problem,

Blick auf Putnams Begriffsverständnis: "Die Rede vom 'sozialen Kapital' ist in gewissem Grad eine neue Sprache für eine sehr alte Debatte, in der es seit jeher um die Rolle der Gemeinschaft in der Gesellschaft und um die Wechselbeziehungen zwischen Staat und Gesellschaft" bzw. um eine - wie Evans (1996: 178) sagt - "state-society synergy" geht. Esser (2000: 264) formuliert: "Das Konzept des sozialen Kapitals ist seit einiger Zeit in aller Munde. So neu ist es aber gewiß nicht. Es ist ein anderer Ausdruck für den Kooperationsgewinn, den im Prinzip antagonistische und egoistische Akteure dadurch erzielen können, daß sie sich aufeinander einlassen." Sowohl Evers (und Evans) wie Esser bewerten damit die Sozialkapitaldebatte unisono als Beispiel der biblischen Metapher vom alten Wein in den neuen Schläuchen - und doch lässt schon ein flüchtiger Blick auf diese relativ allgemein gehaltenen Aussagen vermuten, dass es sich um durchaus unterschiedliche Rebsorten handeln könnte. Ich verzichte innerhalb der vorliegenden Arbeit weitgehend auf theoriegeschichtliche Verweise bzw. eine Betrachtung ab ovo der Sozialkapitaldebatte, um den systematischen Theorienvergleich und die anschließende Theoriebildung nicht zu überfrachten (vgl. zu möglichen historischen Wurzeln in prägnanter Form etwa Woolcock 1998: 159ff.). Mit Carnap (1992: 90) darf man theoriegeschichtliche Überlegungen sogar aus wissenschaftstheoretischen Analysen weitgehend ausschließen: In der Wissenschaftstheorie (bzw. Wissenschaftslogik) werden "die in den verschiedenen Gebieten der Wissenschaft auftretenden Begriffe, Sätze, Beweise, Theorien ... analysiert, und zwar weniger unter dem Gesichtspunkt der geschichtlichen Entwicklung der Wissenschaft, oder der soziologischen und psychologischen Bedingungen ihres Betriebes, als vielmehr unter dem logischen Gesichtspunkt." 
das etwa in den Auseinandersetzungen zwischen Kommunitarismus und Liberalismus oder in den Debatten um einen neuen Gesellschaftsvertrag theoretisch thematisiert und ideengeschichtlich reflektiert wird.

Insofern ist diese Betrachtung von Sozialkapital insbesondere auch unter sozialpolitischer Perspektive von Belang. Seit den neunziger Jahren werden sowohl von neo-liberal wie von basisdemokratisch orientierten Kräften Forderungen nach einer Forcierung von Gemeinsinn und bürgerschaftlichem Engagement erhoben. Ausgehend vom britischen "third way"-Projekt (Giddens 2000) gilt auch in Deutschland die Stärkung zivilgesellschaftlicher Strukturmuster als Schlüssel zur Reorganisation sozialstaatlicher Leistungen. Bundespräsident Köhler sprach kurz nach seiner Wahl 2004 davon, in Zeiten des Umbruchs benötige Deutschland "Vertrauen als Sozialkapital" (Köhler zitiert nach Füllberth 2004). Politiker wie Sozialwissenschaftler beklagen die "Unterversorgung moderner Gesellschaften mit Sozialkapital" (Diekmann 1993: 33) und werten dies teilweise sogar als Resultat des traditionellen Wohlfahrtsmodells (vgl. Etzioni 1997; vgl. Karstedt 1997; vgl. Meier 1996). Hieraus lässt sich dann die Überzeugung ableiten, über Subsidiarität sowie die "angemessene Zufuhr von Sozialkapital" (Putnam 1996: 71) dem Auseinanderdriften unterschiedlicher kultureller und ökonomischer Milieus Einhalt gebieten zu können (vgl. hierzu Gittel/Vidal 1998 oder Brown 1998).

Sozialkapital wird in der makrosoziologischen Interpretation gewissermaßen zu einem "gesellschaftlichen Allzweckkleber" (Immerfall 1999: 122), mit dem vielfach "enthusiastische Behauptungen und 'Heilsversprechen'" (Landolt 2004: 40) verknüpft werden: $\mathrm{Ob}$ zur Reduzierung von Arbeitslosigkeit (Evers/Koob 2001), zur Verbesserung kommunalpolitischen Verwaltungshandelns (Cusack 1999), zur Anregung politischer Partizipation (Kunz/Gabriel 2000), zur Vitalisierung familialer und nachbarschaftlicher Hilfesysteme (Kistler/Schäfer-Walkmann 1999), zum reibungslosen Ablauf ökonomischer Transaktionen (Sterbling 1998), zur Stärkung des Wirtschaftsstandortes im globalen Wettbewerb (Meier 1996), zur Verbesserung der Marktposition multinationaler Unternehmen (Habisch 1998) etc. - überall werden die (nahezu durchweg) positiven Effekte von Sozialkapital ins Feld geführt. Die britische Commission for Social Justice behauptet sogar: "Social capital is a good in itself; it makes life possible." (zitiert nach Johnston/Percie-Smith 2003: 322)

In Abgrenzung hierzu wird von anderen Autoren auch auf negative Effekte aufmerksam gemacht. Besonders beliebt ist der Verweis auf kriminelle Assoziationsformen wie etwa Mafiastrukturen (vgl. bspw. Harriss/de Renzio 1997). Levi (1996) spricht hinsichtlich der negativen Effekte des sozialen Kapitals sogar von "unsocial capital". Hierüber konkretisiert sie zwar pointiert ihr Unbehagen bezüglich der aus ihrer Sicht einseitig positiven Wirkungsannahmen, gleichwohl büßt der Sozialkapitalbegriff in einer solchen Diktion sein analytisches Potential weitgehend ein und degeneriert zu einer rein normativen Kategorie respektive zu einem moralischen Urteil. Irritierend ist dies vor allem dann, wenn dieser Sprach- 
gebrauch von anderen Autoren aufgegriffen wird und es so zu einem unreflektierten Wechsel zwischen analytischer und normativer Verwendung kommt (siehe als illustratives Beispiel hierfür etwa Geißel et al. 2004).

Problematisch am makrosoziologischen Sozialkapitalverständnis ist u.a., dass die exakte Verortung des Gegenstandes häufig im Dunkeln bleibt. So behauptet etwa die Weltbank: "Social capital refers to the institutions, relationships and norms that shape the quality and quantity of a society's interactions. (...) Social capital is not just the sum of the institutions which underpin a society - it is the glue that holds them together."18 Genau in der Spezifizierung dieses "Klebstoffes" liegt aber eine wesentliche Brisanz des Begriffes, so dass der vorliegende Definitionsversuch m.E. eher verwirrt als erhellt ${ }^{19}$. Jungbauer-Gans (2004) sieht eine "Entscheidung darüber erforderlich, ob soziales Kapital als Makro- oder als Mikrophänomen verstanden werden soll." Haug schlägt vor, dass das "soziale Kapital als individuelle Ressource, die als Nebenprodukt aus der Beziehungsarbeit oder als Folge direkter Investitionen in Beziehungen entsteht, betrachtet wird, während das positive gesellschaftliche Nebenprodukt, das dabei gleichzeitig entsteht, wie bisher als Kollektivgut, z.B. in Form von Beziehungsnetzen, Institutionen, Normen, Kooperationshandlungen, Staaten usw. bezeichnet wird" (Haug 1997: 47f.).

In der Tat ist es wissenschaftstheoretisch problematisch, mit einem Begriff zu arbeiten, der (mindestens) zwei unterschiedliche Gegenstandsbereiche anvisiert. Man hat nun etwa die Möglichkeit, dem Vorschlag Haugs zu folgen oder umgekehrt, "Sozialkapital" für die makrosoziologische Ebene zu reservieren und im Mikrobereich nach einer neuen Vokabel zu suchen. Eine dezidierte Mikroverwendung würden möglicherweise Psychologen ablehnen, da sie - anders als Haug diese Ebene bereits begrifflich "besetzt" sehen. So verwendet etwa Röhrle (1994) in seiner psychologischen Habilitationsschrift "Soziale Netzwerke und soziale Unterstützung" an keiner Stelle den Sozialkapitalbegriff, obwohl der Gegenstandsbereich - wie schon der Titel verrät - dies durchaus nahe legen könnte.

Esser (2000: 241ff.) wiederum versucht sowohl die Mikro- wie die Makroebene bzw. die Differenzierung zwischen Kollektiv- und Privatgutaspekten durch die Bezeichnungen "Beziehungskapital" und "Systemkapital" in die Begriffsbestimmung mit einzubeziehen. Ähnliche Bemühungen finden sich bei Warden/Tampubolon (2002), die von "associational social capital" (ebenda: 163) und "interpersonal social capital" (ebenda: 177) sprechen oder bei Krishna (1999: 76), der zwischen "institutional capital" und "relational capital" unterscheidet. Ob diese Differenzierungen notwendig sind oder eher zu einer begrifflichen Proliferation

18 www1.worldbank.org/prem/poverty/scapital/whatsc.htm

19 Robinson/Robinson (2002: 61) setzen sich kritisch mit der genannten Perspektive der Weltbank auseinander. Die Rede vom "glue" sei eine "clumsy and imprecise analogy": "Basically the glue analogy fails the test of encouraging interaction and flexibility, which is at the core of the suggestion that social capital can reduce transaction costs. Preventing movement appears to be a strange way of encouraging social exchange and innovation." Stattdessen schlagen die Autoren vor, Sozialkapital als eine Art Magnetismus zu begreifen (vgl. ebenda: 41). 
beitragen, soll hier noch nicht beurteilt werden. Jedenfalls ist die Propagierung eines "Doppelcharakter(s) des Sozialkapitals" (Gabriel et al. 2002: 25) keine Seltenheit ${ }^{20}$.

Innerhalb der vorliegenden Arbeit werde ich mich auf vier unterschiedliche Sozialkapitalkonzepte beziehen: das Konzept Pierre Bourdieus, das James S. Colemans, das Robert D. Putnams und das einiger Netzwerkanalytiker, vertreten durch Ronald Burt, Nan Lin und Henk Flap. Hierbei handelt es sich nicht nur um die einschlägigsten, d.h. in der Literatur am häufigsten referierten Konzepte, sondern die genannten Autoren entwickeln ihre Vorstellungen überdies mit dezidiert theoretischem Anspruch. Darüber hinaus deckt das sample auch die Bandbreite der bisher vorliegenden definitorischen Bestimmungen weitgehend ab und kann gewissermaßen - wenn man dies in Entlehnung eines Ausdrucks aus der qualitativen Sozialforschung (vgl. etwa Rosenthal 2005: 87) einmal so sagen darf - als "theoretisch gesättigt" gelten.

In keinem mir bekannten Forschungsüberblick zur Sozialkapitaldebatte (vgl. für eine Auswahl die weiter unten genannten Veröffentlichungen) fehlt eine Darstellung bzw. wenigstens eine Nennung der Positionen Bourdieus, Colemans und Putnams. Auch das netzwerkanalytische Konzept wird insbesondere unter Verweis auf Burt in den meisten reviews berücksichtigt. In die hier vorgenommene Analyse findet dieses Konzept im Unterschied bspw. zu dem Fukuyamas oder Portes vor allem deshalb Eingang, weil es Sozialkapital vorwiegend auf der Mikroebene ansiedelt und daher (a) stark in Abgrenzung zum derzeit wohl populärsten Sozialkapitalkonzept, dem Putnams, zu sehen ist, (b) in Folge der mikrotheoretischen Schwerpunktlegung aus wissenschaftstheoretischer Perspektive betrachtet einen soliden Anknüpfungspunkt für eine integrative Theoriebildung bietet, d.h. diesbezüglich "fruchtbar" genannt werden kann und (c) Fukuyama und Portes m.E. keine wirklich originären Konzepte vorlegen.

Der intellektuelle Debattenbeitrag der beiden letztgenannten Autoren soll hier keineswegs in Abrede gestellt werden; gleichwohl gilt es wegen der metatheoretischen Schwerpunktlegung eine Auswahl zu treffen. Die theoretischen Formulierungen Fukuyamas, Portes oder auch Ostroms lassen sich zumindest annäherungsweise jeweils einer der vier von mir ausgewählten "schools of thoughts" zuordnen (womit ihre zentralen Überlegungen daher hier auch berücksichtigt werden): Fukuyama und Ostrom der durch Putnam geprägten und Portes der durch Coleman geprägten "school of thought". Unter Bezugnahme auf die Verwendung des Sozialkapitalbegriffs bei Ostrom äußert bspw. Putnam (2002: 257), er stimme ihr "voll und ganz zu". Portes entwirft weniger ein eigenes Konzept,

20 Leicht (2000: 51) sieht den Doppelcharakter dessen, was bei ihm Sozialkapital darstellen soll in einer "moral dimension of just cooperation (civil social capital) and the necessary structural component to enforce cooperation by organizational means (government social capital)." 
sondern tritt vielmehr als Colemans "Advokat" in Abgrenzung zu Putnam auf ${ }^{21}$ (vgl. etwa Portes 2000).

\section{Vorliegende Beiträge zur Begriffsdebatte}

Schauen wir uns an dieser Stelle einmal schlaglichtartig einige Erörterungen zum Sozialkapitalbegriff an. Schechler (2002) wählt bspw. eine ökonomietheoretische Perspektive, d.h. er möchte die "Idee" des Sozialkapitals für ökonomische (insbesondere volkswirtschaftliche) Forschungszusammenhänge nutzbar machen ${ }^{22}$. Unter Verweis auf Popper spricht er sich dabei zu Gunsten eines "methodologischen Nominalismus" und gegen einen "methodologischen Essentialismus" aus. Letzterer läge vielen Auseinandersetzungen mit dem Sozialkapitalbegriff zugrunde. Aber, so Schechler (2002: 9), "statt der Frage nach den wesentlichen Eigenschaften des Sozialkapitals nachzugehen, sollte die Suche nach regelmäßigem Verhalten des Sozialkapitals im Vordergrund stehen." Damit wird aber so getan, als sei die Negation des Essentialismus eine fakultative Forschungsentscheidung: Man kann - so scheint es auf Basis der Schechlerschen Aussage - der Frage nach den wesentlichen Eigenschaften des Sozialkapitals zwar nachgehen, es ist aber nicht ratsam. Tatsächlich ist die positivistische Ablehnung des begründungsphilosophischen Essentialismus aber eine grundsätzliche, da dieser insbesondere mit dem Fallibilismus nicht zu vereinbaren ist. Ferner kann die "Suche nach dem regelmäBigen Verhalten von Sozialkapital" kaum als "nominalistisch" bezeichnet werden, denn bei dieser Suche wird ja gerade vom Gegenstand ausgegangen (wobei diskussionswürdig ist, inwiefern man diesem sinnvoll ein "Verhalten" unterstellen kann).

In nominalistischer Diktion ist unter "Sozialkapital" das zu verstehen, was ein Theoriekonstrukteur mit dem Terminus aus Gründen einer Präzisierung, Systematisierung oder Erweiterung wissenschaftlicher Erkenntnis ausdrücken möchte; das Anliegen besteht in der Regelung des Sprachgebrauchs. Eine essentialistische Position hingegen wird gewissermaßen von einem einzig "richtigen" Verständnis aus-

21 In Portes 2000 findet sich auch eine auf Colemans theoretischem Konzept und inhaltlichen Forschungsinteressen, nämlich schulischer Erfolg und Migration, gründende empirische Untersuchung; auf Basis dieser Untersuchung schwächt Portes dann am Ende seiner Ausführungen die Leistungsfähigkeit des Sozialkapitalansatzes ganz generell ab: "The key point of this analysis is that the ready attribution of positive effects to social capital, be it in its individual garb as social networks or in its collective one as civic spirit, is premature because observed effects may be spurious or because they are compatible with alternative explanations arising from different theoretical quarters" (Portes 2000: 10).

22 Auf die (natürlich völlig legitime) weitgehende Ausblendung wissenschaftstheoretischer Fragen durch Schechler lassen im Übrigen schon die Anmerkungen zu seiner Methode schließen: "Die zentrale Methode der vorliegenden Untersuchung ist der methodologische Individualismus" (Schechler 2002: 7). Bei diesem - und damit sind wir an dieser Stelle schon inmitten einer wissenschaftstheoretischen Betrachtung - handelt es sich allerdings nicht um eine Methode, sondern um eine philosophische Prämisse hinsichtlich sozialwissenschaftlicher (bzw. auch ökonomischer) Erklärungsprobleme. Wie sollte der methodologische Individualismus also Darstellungen und Vergleiche unterschiedlicher Aussagensysteme und eine anschließende (als "Drei-Ebenen-Modell" firmierende) Theoriekonstruktion anleiten? 
gehen, um an diesem dann die Angemessenheit konkreter Vorkommnisse des Begriffs zu beurteilen. Beispielhaft für ein solches Vorgehen sei etwa Hellmann (2004: 134, Fußn. 6) genannt, der zunächst Putnam zitiert, um anschließend auf dem Hintergrund einer impliziten Realdefinition dessen Festlegungen als fraglich zu klassifizieren: "'Es gibt jedoch auch sehr dünn geflochtene, fast unsichtbare Gewebe von Sozialkapital, beispielsweise flüchtige Grußbekanntschaften ... oder auch nur eine flüchtige Begegnung in einem Fahrstuhl.' (Putnam/Goss) Inwieweit solche Begegnungen, insbesondere letzteres, tatsächlich substantiell dazu beitragen, Sozialkapital zu generieren, ..., bleibt jedoch zweifelhaft."

Unter Zugrundelegung des von Hellmann angeführten Zitats von Putnam/Goss macht es aber keinen Sinn, in Zweifel zu ziehen, ob Grußbekanntschaften und Begegnungen im Fahrstuhl Sozialkapital generieren können, denn beide fallen unter das Putnamsche Begriffsverständnis, d.h. es handelt sich dabei um Sozialkapital (die Sinnhaftigkeit einer solchen Perspektive ist eine andere Frage und ihre Beantwortung wird erst nach einem Standortwechsel möglich). Putnams Aussage wird damit von Hellmann nicht nur missverstanden, sondern anhand eines einzig "richtigen" Verständnis von "Sozialkapital" beurteilt ${ }^{23}$.

Ostrom/Ahn (2003: 36) erachten es insbesondere in Hinblick auf das Problem kollektiven Handelns als sinnvoll "die Begriffe 'soziales Netzwerk', 'geteilte Normen' und 'Vertrauen' sowie 'formelle und informelle Regeln', die weiter unten (im Text, D.K.) als gesonderte Formen sozialen Kapitals behandelt werden, unter der Rubrik 'soziales Kapital' zusammenzufassen." Als gesonderte Formen sozialen Kapitals lassen sich aber keinesfalls die genannten Begriffe, sondern lediglich die hierüber bezeichneten Gegenstände behandeln. "Die Aussage also, welche von einem Begriffe gemacht wird, paßt gar nicht auf einen Gegenstand." (Frege 1892: 201) Unter wissenschaftstheoretischer Perspektive betrachtet, liegt hier ein gravierender Kategorienfehler vor; dies ist vor allem deshalb zu kritisieren, da beim derzeitigen Entwicklungsstand der konzeptionellen Debatte schon genügend Unklarheiten bestehen ${ }^{24}$.

23 Wobei dieses "richtige" Verständnis von Hellmann nirgends expliziert wird (daher ist die realdefinitorische Bestimmung auch so schwer zu erkennen). Hellmann bezieht sich auf Putnam, kritisiert diesen aber weder inhärent, noch aus einer zuvor dezidiert bezogenen Position heraus: "Freilich generiert nicht jedes Netzwerk, wie lose geknüpft das Netz auch sein mag, automatisch Sozialkapital. Vielmehr eignen sich dazu nur solche Netzwerke, deren Mitglieder ein Minimum an wechselseitiger Vertrautheit füreinander aufweisen. Hier sind Putnams Beispiele aufschlussreich: 'Die erweiterte Familie stellt eine Form von Sozialkapital dar, ebenso die Sonntagsschule, ..., das Netzwerk beruflicher Kontakte im Adressbuch."' (Hellmann 2004: 134) Woher weiß Hellmann, dass nicht jedes Netzwerk automatisch Sozialkapital generiert? Auf Grundlage welcher Definition wird hier eigentlich mit und dann doch zugleich auch gegen Putnam argumentiert? Wer vorgibt, zu wissen, was Sozialkapital ist, benötigt einen entsprechenden Begriff. Wenn man sich des Begriffs eines anderen Autors bedient, diesen Begriff aber gleichzeitig ohne Entfaltung einer Referenzfolie kritisiert, dann deutet dies auf einen impliziten Essentialismus hin; "Sozialkapital" wird reifiziert.

24 Insbesondere die Vermischung von Begriff und Gegenstand indiziert damit eine fehlende metatheoretische Reflexion der meisten Autoren, die sich bislang mit unterschiedlichen Sozialkapitalbegriffen auseinander gesetzt haben. Kromrey (2000: 138) kritisiert eine solche Vermischung auf einer allgemeinen Ebene: "Unversehens wird beim Versuch des Herausarbeitens der Bedeutung eines 
So benötigen Serageldin/Grootaert (1999: 44) zur Definition anscheinend überhaupt keine Begriffe, sondern lediglich realweltliche Entitäten, wobei auch nicht klar ist, ob hier von "Sozialkapital" oder Sozialkapital geredet wird: "A 'glue that holds society together' is generally recognized as necessary to a functioning social order, along with a certain degree of common cultural identifications, a sense of 'belonging', and shared behavioral norms. This internal coherence helps to define social capital."

Freitag (2004: 7) hält realweltliche Entitäten, Begriffe, Aspekte von beiden und Konzepte nicht exakt auseinander: "Soziales Kapital findet sich (...) in Wissenschaft und Öffentlichkeit unter so vielfältigen Begrifflichkeiten wie 'soziale Netzwerke', 'bürgerschaftliches Engagement', 'Freiwilligenarbeit', 'Zivilgesellschaft', 'Bürgergesellschaft', 'soziales Vertrauen', 'Gemeinsinn' und 'Ehrenamtlichkeit'. Jeder dieser Aspekte bedient dabei eine besondere Komponente des Konzeptes." Was ist mit "Soziales Kapital" hier gemeint? Der Begriff? Der Gegenstand? Die Debatte darüber? Und was heißt das überhaupt, wenn die angeführten "vielfältigen Begrifflichkeiten" "besondere Komponenten des Konzeptes" "bedienen"25?

Maurer (2003: 22) glaubt, "begriffliche Probleme des Sozialen Kapitals von Netzwerken von Biotechnologie Start-Ups" zu klären und bezeichnet Kontextspezifität und Komplexität als "definierende Merkmale" (ebenda: 25). Tatsächlich aber diskutiert er lediglich Eigenschaftsdimensionen des realweltlichen Gegenstandes, den er als "Soziales Kapital" verstanden wissen möchte. Wobei dem über-

Begriffs zu Überlegungen über Eigenschaften eines realen Sachverhalts 'umgeschaltet'; oder umgekehrt: An die Stelle der Begründung relevanter Eigenschaften eines Gegenstandes wird die Definition eines Begriffs gesetzt." Zur Illustration der Problematik greift Kromrey (ebenda, Fußn. 29) auf einen Satz eines Schlagertextes zurück: "'Du bist ein anderes Wort für Glück.' - Wie kann der angesungene Partner ein 'Wort' sein? Offenbar ist auch 'Glück' hier lediglich ein Wort und nicht entweder ein (auch ohne Worte) außerordentlich angenehmer Gefühlszustand oder ein sehr erfreuliches Ereignis." Problematisch daran ist nun allerdings, dass Kromrey nicht mehr zwischen "Begriff" und "Wort" differenziert (worauf in den Kapiteln 4.2. und 5.3. noch zurückzukommen sein wird).

25 Ein weiteres Beispiel für die Begriffs-Gegenstands-Konfusion bei Freitag stammt aus einer früheren Arbeit: "Während die Ökonomie dem Begriff des physischen Kapitals das Humankapital beifügt, verweisen soziologische und politikwissenschaftliche Forschungsbeiträge auf die zentrale Rolle des Sozialkapitals bei der Erklärung politischer, gesellschaftlicher und wirtschaftlicher Entwicklungen." (Freitag 2000: 186) Damit ist hinsichtlich der Verwendung des Wortes "physisches Kapital" der Begriff gemeint; hinsichtlich der Verwendung der Worte "Humankapital" und "Sozialkapital" wird de fakto aber etwas Gegenständliches ausgesagt. Im gleichen Artikel heißt es noch: "Die Fülle an Definitionen ergibt sich nicht zuletzt aus der Palette verschiedener Aspekte und Dimensionen des Begriffs vom sozialen Kapital." (ebenda: 189) Damit liegt aber ein geradezu lehrbuchartiges Beispiel einer Tautologie vor: Dass es diese Palette verschiedener Aspekte und Dimensionen des Sozialkapitalbegriffs gibt, impliziert ja nichts anderes, als dass es eine Fülle an Definitionen gibt. Dabei handelt es sich nun aber nicht um eine kausale, sondern um eine analytische Verknüpfung. Johnson (2003: 3) meint, "because of the diverse interests in studying social capital, there is no single definition of social capital." Diese Perspektive kann ebenfalls nicht überzeugen, denn damit wird behauptet, unterschiedliche Interessen an einem sozialen Gegenstand erforderten abweichende Begriffsbestimmungen. Angenommen, ein Parteienforscher interessierte sich einmal für die Bildungspolitik und ein anderes Mal für die Wirtschaftspolitik einer Volkspartei, so wäre es sicherlich wenig vernünftig, würde er jeweils eine andere Definition von "Volkspartei" zugrunde legen. 
dies ein impliziter Essentialismus zugrunde liegt: Maurer kritisiert die seiner Ansicht nach in der Literatur vorfindbare Trennung zwischen einer "strukturellen" und einer "ressourcenorientierten Sicht" auf Sozialkapital als "nur analytisch sinnvoll", denn "Soziales Kapital umfasst sowohl die soziale Struktur als auch die durch sie bereitgestellten Ressourcen" (Maurer 2003: 24). Der vorgenommene Verweis auf Bourdieu zur Stützung dieser Position ist nicht nur kaum haltbar (vgl. Kapitel 7.1.), sondern verschleiert, dass an dieser Stelle definitorische Festlegungen mit einer hiervon scheinbar gänzlich unabhängigen "Natur" des über diese Festlegungen doch erst bezeichneten Gegenstandes angegriffen werden ${ }^{26}$.

May (2004: 81) gelangt auf Grundlage seiner Literaturanalyse zu der Auffassung, dass "unter den Protagonisten des Sozial-Kapital-Konzeptes ... eine weitgehende Einigkeit darüber zu bestehen (scheint, D.K.), dass sich soziales Kapital sowohl vom finanziellen als auch vom Humankapital unterscheide(t)." Diese Einigkeit haben die "Protagonisten" bei aller Differenz in der Tat erzielt. Aber das ist nun wirklich nicht verwunderlich: Warum sollte man auch von "Sozialkapital" reden, wenn es doch um Finanz- oder Humankapital geht? May möchte - so denke ich jedenfalls - den unter allen Wissenschaftlern herrschenden Konsens darüber herausstreichen, dass sich der Kapitalbegriff in "Sozialkapital" von dem in "Finanzkapital" und "Humankapital" unterscheidet. Ferner glaubt May (sich in der Marxschen Tradition wähnend) den Sozialkapitalbegriff zu "entmystifizieren", indem er "die inhaltliche Dimension und Qualität konkreter Beziehungsarbeit theoretisch, wie auch in der empirischen Vergewisserung, stärker fokussiert" (ebenda: 85). Damit wird abermals behauptet, man könne eine Begriffsanalyse über eine Debatte realweltlicher Gegenstände führen. Dies ist aber entweder unsinnig oder essentialistisch.

Was Sozialkapital konkret darstellen soll, wird von Kröll (2003: 119f.) als "Merkmalsausprägung" beschrieben. Allerdings legt sich Kröll auf keine einzige Ausprägung fest, sondern verweist lediglich in knapper Form auf definitorische Bestrebungen bei Coleman, Burt, Lin, Putnam, Portes, Tsai/Goshal und Leana/Van Buren. Im Anschluss resümiert sie mit Blick auf ihre Untersuchung: "Hier geht es darum, möglichst breit solche Ausprägungen Sozialen Kapitals zu identifizieren, die im Hinblick auf verschiedene strategische Ziele eines Unternehmens, wie z.B. einem Markteintritt von Belang sind. Anders ausgedrückt, wie kann ein

\footnotetext{
26 Das wäre - zugegebenermaßen etwas polemisch formuliert - ungefähr so, als definierte man "Apfel" auf eine bestimmte Art und Weise, um dann auf eine Birne zu schauen und die Definition von "Apfel" als problematisch zu kennzeichnen. Bei Maurer (2003) werden die unterschiedlichsten Autoren samt ihren Begriffsfassungen und empirischen Untersuchungsergebnissen bunt durcheinander geworfen und immer wieder in Bezug zu einem augenscheinlich als fraglos richtig angenommen aber nie dezidiert explizierten Verständnis gesetzt. Von einem fundierten Modellbau kann keine Rede sein. In ähnlicher Weise kontrastiert auch Nielandt (2002) die Sozialkapitalkonzepte von Putnam und Bourdieu vor dem empirischen Hintergrund einer gesellschaftlich ungleichen Verteilung von Sozialkapital. Problematisch daran ist jedoch, dass zunächst einmal geklärt werden müsste, ob Putnam und Bourdieu überhaupt die gleichen Gegenstände anvisieren.
} 
Unternehmen aus einem interorganisationalen Netzwerk Soziales Kapital für den Markteintritt ziehen?" (ebenda: 120)

Mit der letzten Frage wird dann eine Unterscheidung zwischen Netzwerk und Sozialkapital getroffen (Letzteres soll augenscheinlich aus Ersterem hervorgehen), obgleich beide Entitäten später in eins fallen, wenn synonym von der "Effizienz von Sozialkapital" bzw. von der "Effizienz des Netzwerks" gesprochen wird (ebenda: 120f.). Effektivität, Effizienz und Flexibilität gelten Kröll als "Attribute Sozialen Kapitals" (ebenda: 120). Aber schon kurz danach ist aus einem "Attribut" ein "Aspekt" geworden und zwischen Sozialkapital und einem Netzwerk wird wie gesagt - gar nicht mehr unterschieden: "Ein zweiter Aspekt Sozialen Kapitals neben Effektivität, ist die Effizienz des Netzwerks"27 (ebenda: 121).

Besonders aufschlussreich ist Krölls Lesart des Colemanschen Sozialkapitalbegriffs. Coleman verstehe "Obligationen bei Vertrauen, Informationskanäle und Normen mit effektiven Sanktionsmöglichkeiten als drei verschiedene Ausprägungen Sozialen Kapitals, die alle durch ähnliche Strukturen realisiert werden können. Diese Strukturen sind die Ursachen Sozialen Kapitals, die hier als Quellen bezeichnet werden." (Kröll 2003: 124) Was aber ist genau unter "Ausprägungen", "ähnliche Strukturen" und "realisieren" hier zu verstehen? Und wieso sind die Strukturen wiederum Ursachen, die aus welchem Grund heraus "Quellen" genannt werden?

Schubert et al. (2001: 27) sprechen nicht von "Aspekten" oder "Merkmalsausprägungen", sondern behaupten, "nach Coleman wird Sozialkapital als das Potenzial verstanden, das im Zusammenleben der Menschen in Gemeinschaften erzeugt wird." (Schubert et al. 2001: 27) Aber Sozialkapital soll bei Coleman auch "eine verbindende 'Währung' ..., durch die die Ressourcen der Akteure gegenseitig ausgetauscht werden können" (ebenda: 34) sowie eine "Kombinationsmöglichkeit der humanen Ressourcen" (ebenda) sein.

An keiner Stelle in Colemans definitorischen Äußerungen zu Sozialkapital tauchen jedoch die Begriffe "Potenzial" oder "Kombinationsmöglichkeit" zur Klassifizierung jener Entitäten auf, die unter "Sozialkapital" subsummierbar sein sollen ${ }^{28}$ - und ich vermag auch nicht zu erkennen, inwiefern solche Etikettierungen auf Basis einer Coleman-Lektüre berechtigt sind. Was freilich nicht bedeutet, Coleman argumentiere sonderlich präzise. Vielmehr werden von ihm - und dies sei schon im Vorgriff auf die spätere Rekonstruktion seines Konzeptes gesagt - u.a. solch heterogene Dinge wie Organisationen, Normen, Gutschriften, Verpflichtungen, Erwartungen, Beziehungsrelationen, Herrschaftsbeziehungen, elterliche Fürsorge,

27 Insbesondere bei Putnam findet sich ein reges Nebeneinander von Begriffen wie "Aspekte", "Eigenschaften", "Konturen", "Dimensionen", "Formen", "Komponenten", "Facetten" etc. zur Bezeichnung bzw. Charakterisierung unterschiedlicher Sozialkapitalien. Mehrdeutigkeit ist aber keineswegs dasselbe wie Mehrdimensionalität (siehe hierzu Kapitel 7.3.)

28 Den Währungsbegriff verwendet Coleman (1991: 402) zwar; allerdings ist keinesfalls von einer "verbindenden Währung", sondern von "einer schwachen" und einer "starken Währung" die Rede. 
Netzwerkschließung oder Vertrauenswürdigkeit zu Sozialkapital erklärt (vgl. Kapitel 7.2.). Nicht zuletzt die Diffusität der Originaltexte dürfte eine zentrale Ursache für die Begriffskonfusion innerhalb bzw. - schärfer formuliert - den "chaotic character" (Fine 2001: 99) der Sekundärliteratur sein.

In ähnlicher Weise lässt sich dies auch im Zusammenhang mit Putnams Definition formulieren. Geißel et al. (2004: 9) behaupten bspw., "zivilgesellschaftliches Engagement führe, so eine zentrale Annahme von Putnam, zu Sozialkapital". Handelt es sich bei diesem Engagement aber nicht vielmehr schon um Sozialkapital bzw. indiziert es dieses? In ähnlicher Weise erachten Warden/Tampubolon (2002) Vereinsmitgliedschaft einmal als eine Form von Sozialkapital (vgl. ebenda: 158f.), dann aber ist ebenso von "social capital deriving from associational membership" die Rede (ebenda: 163). Für beide Interpretationen lassen sich bei Putnam irgendwie Hinweise finden: "Networks of civic engagement are an essential form of social capital" (Putnam 1993: 173); "social capital (is, D.K.) embodied in horizontal networks of civic engagement" (ebenda: 176); und die "relevanten Wesensmerkmale der Bürgergesellschaft" sollen "Konturen des Sozialkapitals" sein (Putnam/Goss 2001: 20).

Peter Hall (2001: 48) meint in Anknüpfung an Putnam: "Im Zentrum der konventionellen Definition des Sozialkapitals steht die Mitgliedschaft in ehrenamtlichen Vereinigungen". Eine Mitgliedschaft kann aber nichts zu einer Definition beitragen bzw. in deren Zentrum stehen; sie kann allenfalls unter diese fallen. Auch - wie man sie nennen könnte - "erweiternden Modifizierungen" an Putnams Sozialkapitalbegriff ist dank der definitorischen Unschärfe der Originaltexte Tür und Tor geöffnet: "Temkin and Rohe make significant advances in refining Putnam's concept of social capital. They describe social capital as consisting of two main components: sociocultural milieu and institutional infrastructure." (Gittell/Vidal 1998: 16) Bei Brown und Ostrom/Ahn werden im Anschluss an Putnam etwa auch die "norm of tolerance" (Brown 1998: 229) sowie "formelle und informelle Regeln" (Ostrom/Ahn 2003: 35) kurzerhand zu Sozialkapital erklärt.

\section{Originalität der durchzuführenden Begriffs- und Theorienanalyse}

Darstellungen und Vergleiche ausformulierter Sozialkapitalkonzepte sind in der Literatur also keineswegs eine Seltenheit und indizieren die Relevanz der von mir behaupteten begrifflichen und theoretischen Problematik ${ }^{29}$ (vgl. u.a. Haug 1997 u. 2000, Harriss/de Renzio 1997, Fukuyama 1997, Portes 1998 u. 2000, Woolcock 1998, Hardin 1999, Fine 1999 u. 2001, Ostrom 1999, Paxton 1999, Leicht 2000, Schuller et al. 2000, Siisiäinen 2000, Braun 2001, Cody 2002, Schechler 2002, Täube 2002, Warden/Tampubolon 2002, Twickel 2002, Adam/Roncevic 2003, John-

29 "There is a considerable debate over definitions, and a number of articles have discussed the implied differences among, and strenghts of, competing appoaches." (Warden/Tampubolon 2002: 156) 
son 2003, Johnston/Percy-Smith 2003, Kröll 2003, Ostrom/Ahn 2003, Quibria 2003, Schnur 2003, Swain 2003, Jungbauer-Gans 2004, Kern 2004, May 2004, Ponthieux 2004, Freitag 2004). Auch "originäre" Sozialkapitaltheoretiker fassen (mitunter geprägt von Einseitigkeiten und Vorurteilen) die Konzepte anderer Vertreter zusammen, um ihre eigenen Positionen durch eine Abgrenzung zu verdeutlichen (vgl. etwa Lin 2001 oder Putnam/Goss 2001).

Dabei sind diese begrifflichen und theoretischen Analysen nicht durchführbar, ohne zumindest implizit ein Minimum an wissenschaftstheoretischer Reflexion anzustellen, richtet sich die Wissenschaftstheorie doch gerade auf realwissenschaftliche Aussagensysteme - und solche werden von den angeführten Autoren dar- bzw. gegenübergestellt ${ }^{30}$. Im Unterschied zu den bisher vorliegenden Arbeiten wird hier jedoch dezidiert eine wissenschaftstheoretische Auseinandersetzung und zwar auf Grundlage (neo-)strukturalistischer Überlegungen durchgeführt. Ziel ist die Klärung eines sinnvollen Gebrauchs des Sozialkapitalbegriffs - den ich sprachlich als T-theoretischen Term kennzeichne - sowie damit unmittelbar zusammenhängend die Ausarbeitung einer wissenschaftstheoretisch akzeptablen, integrativ angelegten Gegenstandstheorie.

Insbesondere die durchzuführende logische Analyse und Axiomatisierung von vorhandenen Sozialkapitalkonzepten (Verfahren der Rationalen Rekonstruktion) ist ein ebenso wichtiger wie innovativer Baustein zur Einlösung dieses Vorhabens, da hierüber - wie der Blick auf die Naturwissenschaften zeigt - Präzision und im Anschluss konsensuale Verständigung über Begriff, Theorie und Gegenstandsbereich ermöglicht werden. Einer der Gründungsväter der strukturalistischen Wissenschaftstheorie hat dies so formuliert: "Formalisierung liefert einen Grad an Objektivität, der für Theorien, die nicht in dieser Weise gegeben sind, unmöglich ist. In Wissensgebieten, wo schon über die elementarsten Begriffe Kontroversen bestehen, kann der Wert solcher Formalisierung wesentlich sein."31 (Suppes zitiert nach Troitzsch 1990: 35)

Von den Autoren, die sich wirklich kritisch mit unterschiedlichen Begriffsfassungen und Konzepten auseinandersetzen, argumentiert lediglich Haug (1997 u. 2000) (mit Abstrichen auch Portes 1998) wenigstens in Teilen explizit wissenschaftstheoretisch. Allerdings sind bei dieser Argumentation grundsätzliche methodologische wie methodische Erörterungen zur Begriffsexplikation sowie zur Rekonstruktion und zum Vergleich von Theorien nicht zu finden ${ }^{32}$. Damit fehlt

30 Mit Wolfgang Balzer (1982: 1f.) können wir festhalten, dass Wissenschaftstheoretiker "versuchen, über empirische (...) Theorien im allgemeinen Aussagen zu machen, genauso wie es die Physiker über bewegte Teilchen, die Biologen über Zellen und die Ökonomen über Märkte tun."

31 Wenn von Formalisierung bzw. Axiomatisierung gesprochen wird, dann meint dies hier: "In der Terminologie der Mengen, Relationen und Strukturen wird ein Konzept durch explizite Angabe von notwendigen und hinreichenden Bedingungen definiert" (Westermann 2000a: 130; vgl. ausführlich hierzu Kapitel 4.3.).

32 Dabei handelt es sich gleichwohl um ein häufig anzutreffendes Spezifikum sozialwissenschaftlicher Theorienvergleiche. So gehen etwa auch Haller (1999) oder Etzrodt (2003) bei ihren ausführ- 
aber die Konstruktion einer oder doch zumindest der explizite Zugriff auf eine Metasprache, mit der über die objektsprachlichen Theorien von einem dezidiert externen Standpunkt aus "geredet" wird, mit der man also, wie Kron (1999: 69) es formuliert, "die Gegenstandstheorien auf Begriffe und Systeme bringen" kann (in der vorliegenden Arbeit wird dies hingegen geleistet). Ferner steht Haug auf positivistischem Boden. Ihr Interesse richtet sich nicht auf sprachanalytische Aspekte sozialwissenschaftlicher Erkenntnis sowie schon gar nicht auf begrifflichontologische, und das heißt tieferliegende Probleme der Gegenstandsbestimmung ${ }^{33}$. Deren Verbindung zur Sozialkapitaldebatte und ihr Originalitätscharakter soll erst im nun folgenden Kapitel genauer behandelt werden, da hierfür zunächst einige weiterführende Überlegungen anzustellen sind.

lichen Vergleichen sozialwissenschaftlicher Handlungs- bzw. Systemtheorien auf metatheoretische Überlegungen nicht ein. Man mag nun einwenden, aufwendige metatheoretische Betrachtungen solle man doch den Philosophen überlassen. Indes befindet sich der philosophisch denkende Sozialwissenschaftler in einer privilegierten Position, kann er doch die theoretischen Debatten seiner Herkunftsdisziplin nicht nur rekonstruieren, sondern zusätzlich konstruktiv intervenieren (was ich insbesondere in Kapitel 8. auch tun werde). Dies dürfte einem Wissenschaftstheoretiker philosophischer Herkunft i.d.R. nicht möglich sein. Dieser, "meist geschult in den methodologischen Problemen der exakten Naturwissenschaften, ist in den meisten Fällen kein Spezialist für die genuin sozialwissenschaftlichen Forschungsmethoden und die Probleme ihrer Anwendung." (Lenk 1986: 164)

33 Haug fokussiert vielmehr insbesondere sozialtheoretische Thematiken wie das Aggregations- oder das Kollektivgutproblem sowie die empirische Anwendung von "Sozialkapital" im Kontext von Kettenmigration. Eine eigene oder integrative Begriffs- oder Theoriebildung wird von ihr ebenfalls nicht vorgenommen; ihre empirische Untersuchung rekurriert weitgehend auf einem netzwerkanalytischen Sozialkapitalansatz. 


\section{Präzisierung von Fragestellung und Vorgehens- weise}

Der Sozialkapitalbegriff wird derzeit also weitgehend heterogen und ambiguitär bestimmt und die den Ausdruck enthaltenden theoretischen Aussagensysteme projektieren unterschiedliche empirische Gegenstandsbereiche. Damit führt aber die Anwendung des Begriffs weder zu einem einheitlichen noch zu einem eindeutigen Resultat. Es ist notwendig, sich mit Blick auf wissenschaftlichen Fortschritt bzw. die Erhöhung des Reifegrades sozialwissenschaftlicher Begriffs- und Theoriebildung auf einer metatheoretischen Analyseebene mit "Sozialkapital" und der Verbindung zu dem hierüber bezeichneten Gegenstand (bzw. den Gegenständen) zu befassen. Wenn es noch nicht einmal einen grundlegenden Konsens über die semantische Bedeutung von "Sozialkapital" gibt, "then it's a nightmare" (Ponthieux 2004: 18). "If every time social capital is used, it has to be re-defined according to the question addressed, the level of the analysis and maybe the data at hand, it will remain a big shapeless carry-all"34 (ebenda: 19). M.a.W.: "To move the literature forward, it would be useful first to get the concept right." (Quibria 2003: 14)

34 Nur exakt definierte Begriffe erlauben die Formulierung informativer, gegenstandsadäquater Aussagen. "In manchen Fällen reichen unscharfe Begriffe aus. So wird sich z.B. niemand daran stoßen, daß der Begriff 'Gemüse' in dem einen oder anderen Anwendungsfall nicht zu eindeutigen Resultaten führt." (Essler 1982: 56). In der Wissenschaft hingegen ist sprachliche Klarheit und Präzision unerlässlich, "da sonst jedes wissenschaftliche Arbeiten zusammenbrechen müßte." (Druwe 1991: 18) 


\section{Bedeutung als Problem der Sprache}

Innerhalb der vorliegenden Untersuchung wird also nicht von einem empirischen Problem ausgegangen, um dann dessen wissenschaftssprachliche Bewältigung ins Auge zu fassen. Vielmehr soll in der Art einer "logischen Propädeutik" (Kamlah/Lorenzen 1996) geklärt werden, um was es bei "Sozialkapital" überhaupt sinnvoll gehen kann bzw. was sich vernünftigerweise hiermit sagen lässt. Umgangssprachlich äußern wir häufig, wir müssten uns noch einen Begriff von einer Sache machen, wenn wir Erkenntnis bzw. Wissen hierüber gewinnen möchten. Einige sozialwissenschaftliche Theoretiker haben sich nun den Begriff "Sozialkapital" über eine Sache (bzw. über gleich mehrere Sachen) gemacht. Aber über welche, aufgrund welcher Überlegungen und mit welcher Berechtigung? Die grundlegende Fragestellung innerhalb des Anwendungsteils dieser Untersuchung lautet: Was bedeutet "Sozialkapital"? (Hauptfragestellung)

$\mathrm{Zu}$ beantworten ist demnach,

was unter dem theoretischen Konstrukt "Sozialkapital" zu verstehen ist (semantische Bedeutung innerhalb wissenschaftlicher Aussagensysteme und damit primär als innersprachliches Problem),

wie der hierüber bezeichnete Gegenstand konstitutiv auf menschlichen Sprachgebrauch (semantische Bedeutung und sprachliche Logik im Alltag und damit primär als Problem des Bezugs zwischen Wort und Gegenstand) bzw. der Zuweisung von Bedeutung (in einem soziologischen Sinn) angewiesen ist, sowie

welches Verhältnis zwischen gegenstandskonstitutivem Sprachgebrauch und Sozialkapitalbegriff besteht.

In allen drei Fällen handelt es sich also methodisch gesprochen um eine Bedeutungsanalyse, um den Versuch - im Sinne Wittgensteins -, Probleme "durch eine Einsicht in das Arbeiten unserer Sprache" zu lösen ${ }^{35}$ (PU \ 109). Insofern stehen im vorliegenden Kontext die funktionalen Zusammenhänge und Leistungen sprachlicher Einheiten im Zentrum der Betrachtung. Ich möchte dies noch etwas näher erläutern. Während zunächst dem idealsprachlichen Philosophieprogramm folgend die definitorische Bestimmung des sozialwissenschaftlichen Begriffs, die logische Struktur der Aussagen, in der dieser eingebettet ist sowie die in den Konzepten behaupteten inhaltlichen Erkenntnisse den Fragehorizont abstecken, richtet eine ontologische Begriffsdebatte den Fokus auf den alltäglichen, gegenstandskonstitutiven Gebrauch sprachlicher Zeichen. Wenn man etwa - an dieser Stelle

35 Wenn Giddens (1992: 338) fordert, "soziologische Beschreibungen haben die Aufgabe, die Bedeutungssysteme zu vermitteln, an denen die Akteure ihr Verhalten ausrichten", dann wird innerhalb der vorliegenden Untersuchung der Standpunkt vertreten, dass diese Bedeutungssysteme zum überwiegenden Teil sprachlich konstituiert sind und man daher eben "eine Einsicht in das Arbeiten unserer Sprache" (PU \109) benötigt. (Auf Textstellen aus den beiden Hauptwerken Wittgensteins werde ich - wie dies in der Literatur allgemein üblich ist - mit "PU" [Philosophische Untersuchungen] sowie "Traktat" [Tractatus logico-philosophicus] verweisen.) 
lediglich zu Illustrationszwecken und um die argumentative Komplexität zu reduzieren - über "Sozialkapital" eine Hilfeleistung bezeichnet, dann wäre zu klären, wie es überhaupt zu einer solchen kommen kann, was die Bedingungen ihrer Möglichkeit sind.

Dabei wird die Wie-kommt-es-dazu-Frage aber auf zwei unterschiedlichen Erklärungsebenen beantwortet. Schon innerhalb der wissenschaftstheoretischen Betrachtungen lassen sich über die unabhängigen Variablen jene Entitäten bestimmen, die zur Entstehung einer Hilfeleistung in einem klassischen soziologischen Verständnis beitragen; hierzu gehören etwa Tauschprozesse, Investitionen in Beziehungen oder spezifische Antecedenzbedingungen wie Normen ${ }^{36}$. Die ontologische Betrachtung setzt explanativ tiefer an, liegt gewissermaßen innerhalb eines zunächst verborgenen Bereichs. Hier wird es dann - wie schon mehrfach erwähnt - um konstitutive sprachliche Ordnungsbestimmungen gehen. Auf eine Hilfeleistung bezogen, könnte bspw. zu klären sein, wie wir von Schallwellen, die von menschlichen Kehlköpfen erzeugt werden (also von physikalischen Entitäten) zur Semantik und dann zu "wichtigen" Informationen und "nützlichen" Hilfeleistungen gelangen (also zu sozialen Entitäten) ${ }^{37}$. Welche sprachlogischen Prozesse führen dazu?

Die ontologischen Faktoren sind aber nicht nur konstitutiv für die Entstehung, sondern ebenso für den Fortbestand des Gegenstandes, d.h. linguistische Regeln begründen nicht nur Sozialkapital, sondern solange Sozialkapital besteht, ist es auf das kontinuierliche Weiterlaufen dieser Regeln angewiesen. Für Finanzkapital wissen wir bspw.: Sobald Menschen aufhören, ein Stück Papier (X) als Zahlungsmittel $(\mathrm{Y})$ innerhalb eines bestimmten Kontextes $(\mathrm{K})$ anzusehen, handelt es sich bei diesem Stück Papier auch nicht mehr um ein Zahlungsmittel. Insofern lässt sich eine Ontologie des Sozialen nicht nur im Sinne einer Tiefenerklärung sozialer Sachverhalte interpretieren, sondern sie benennt die Komponenten und ihre Verbindungen, aus denen der Sachverhalt besteht ${ }^{38}$.

Ich fasse zusammen: Wer sich mit wissenschaftlicher Erkenntnis über Sozialkapital auseinandersetzen möchte, der muss sich mit dem Sozialkapitalbegriff beschäftigen und insofern jene wissenschaftlichen Aussagensysteme bzw. Theo-

36 Es sei denn, man begreift Normen als Sozialkapital (diese Problematik wird innerhalb des Anwendungsteils noch ausführlich diskutiert, denn wir befinden uns damit schon inmitten der Analyse).

37 Oder mit einem anderen Beispiel: Warum veranlassen uns auf die Retina prallende Photonenteilchen mitunter dazu, "Danke für die Unterstützung bei der Wohnungsrenovierung" zu sagen? Dazu bedarf es mehr als nur eines physikalischen Geschehens in der Außenwelt: Möglicherweise hat jemand fünf Stunden lang mehrere ca. $260 \mathrm{~cm}$ lange, $50 \mathrm{~cm}$ breite, aufgerauhte und bunt bedruckte Papierstreifen mit einer Masse von eigenartiger Konsistenz gegen eine senkrecht stehende Fläche geklebt - aber wieso bedanken wir uns deswegen und fühlen uns diesem Jemand nun auf eine ganz spezifische Weise verbunden? Ontologisch gefragt: Wie gelangen wir von der Physik zur Semantik und dann zu immer elaborierteren Formen sozialer Realität?

38 Und institutionelle Sachverhalte bestehen eben - so meine noch ausführlich zu begründende Position - zentral aus sprachlich vorliegenden Bewusstseinsprozessen; ungefähr so, wie ein Stein aus Atomen besteht. 
rien rekonstruieren, in denen der Begriff vorkommt; die Aussagensysteme - als ein Teil sozialer Realität - werden so auf einer metatheoretischen Ebene selbst zu Gegenständen wissenschaftlicher Erkenntnis. Eine vergleichende Bestandsaufnahme und wissenschaftstheoretische Bewertung der Verwendung des Sozialkapitalbegriffs innerhalb theoretischer Konzepte soll in einem ersten Schritt zur Formulierung einer konsensfähigen Begriffsdefinition sowie eines integrativen Theoriemodells führen ${ }^{39}$ :

Was verstehen die innerbalb der Sozialkapitaldebatte mit dezidiert theoretischem Anspruch auftretenden Autoren unter "Sozialkapital", was geben sie diesbezüglich zu wissen vor, worin unterscheiden sich ibre jeweiligen Konzepte und wie könnte auf Basis eines rekonstruktiven Vergleichs und einer integrativen wie weiterführenden Systematisierung ein wissenschaftstheoretisch akzeptables Theoriemodell über Sozialkapital aussehen? (Unterfragestellung 1)

Wer sich mit den Bedingungen der Möglichkeit von Sozialkapital auseinandersetzen möchte, der muss sich in erster Linie mit dem über den Sozialkapitalbegriff bezeichneten sozialen Gegenstand beschäftigen. Da es - wie bereits erwähnt scheint, als wüssten wir über den Gegenstand vor allem deshalb etwas, weil es einen wissenschaftlichen Begriff dafür gibt, setzt diese Analyse die Auseinandersetzung mit wissenschaftlichen Aussagensystemen voraus. Wie wollte man etwas ontologisch untersuchen, wenn man nicht exakt angeben könnte, um was es sich bei diesem Etwas eigentlich handelt? Wir müssen also zunächst den Gegenstand kennen lernen, dem - mit Wittgenstein (PU \15) gesprochen - ein "Namenstäfelchen" mit der Aufschrift "Sozialkapital" angeheftet wurde (und dabei wird festzustellen sein, dass dieses Täfelchen derzeit nicht nur ein, sondern gleich mehrere ganz verschiedenartige Gegenstände ziert) ${ }^{40}$.

Im Unterschied zu den bereits vorliegenden Betrachtungsweisen hinsichtlich von Sozialkapital wird damit innerhalb einer solchen bedeutungstheoretischen Analyse nicht schwerpunktmäßig von Kooperation und interpersonellem Austausch die Rede $\operatorname{sein}^{41}$. Stattdessen wird "Sorialkapital zur Sprache gebracht", in-

39 Das zu entwickelnde Aussagensystem wird schon hier als "Theoriemodell" bezeichnet, da es zwar die Grundbedingungen einer wissenschaftlichen Theorie (die in Kapitel 4 noch zu diskutieren sind) erfüllen wird, aber nicht ein Ergebnis empirischer Forschungsarbeit, sondern eines integrativen Theorienvergleichs und weiterführender analytischer Überlegungen ist.

40 "Es wird sich oft nützlich erweisen, wenn wir uns beim Philosophieren sagen: Etwas benennen, das ist etwas Ähnliches, wie einem Ding ein Namenstäfelchen anheften." (PU \ 15) Grundsätzlich begegnet der späte Wittgenstein in seiner gebrauchstheoretischen Sprachphilosophie solchen abbildtheoretischen Positionen freilich mit äußerster Skepsis: "Die Fragen 'Was ist Länge?', 'Was ist Bedeutung?', 'Was ist die Zahl Eins?' etc. verursachen uns einen geistigen Krampf. Wir spüren, daß wir auf nichts zeigen können, um sie zu beantworten" (Wittgenstein 1984b [Das blaue Buch]: 15).

$41 \mathrm{Im}$ Laufe der Arbeit an diesem Buch musste ich mich mit der Behauptung auseinandersetzen, eine integrative Theorie über Sozialkapital sei nur aus allgemeinen Überlegungen zur Tauschtheorie oder zur Theorie kollektiver Güter zu entwickeln. Dies - so möchte ich antworten - wäre indes ein sozialtheoretisches Projekt, was schon eine definitorische Vorentscheidung implizierte. Warum sollte man aber Sozialkapital etwa vor dem Hintergrund des Kollektivgutproblems diskutieren, wenn man u.a. gerade klären will, ob der Sozialkapitalbegriff - sprachanalytisch betrachtet - hiermit überhaupt sinnvoll in Zusammenhang gebracht werden kann? Insofern beruht die genannte Behauptung auf 
dem der Begriff, die sprachliche Konstitution des hierüber bezeichneten Gegenstandes und das Zusammenspiel zwischen Begriff und Gegenstand untersucht werden. Der Anwendungsteil dieser Arbeit reflektiert in einem zweiten Schritt, was die ontologischen Voraussetzungen dafür sind, dass es Sozialkapital überhaupt geben kann:

Welcher sprachliche Ordnungsapparat ist konstitutiv für Sozialkapital und in welchem Verhältnis steht dieser Apparat zu dem in der Wissenschaft formulierten Sozialkapitalbegriff? (Unterfragestellung 2)

\section{Erläuterungen zur ontologischen Fragedimension}

Die Frage nach dem Zusammenspiel zwischen sprachlichem Ordnungsapparat und wissenschaftlichem Begriff mag zunächst etwas kryptisch klingen; dahinter verbirgt sich die Frage, ob nun der Begriff zum Gegenstand oder der Gegenstand zum Begriff kommt bzw. wie beide zueinander finden. Eine einfache Verbindung zwischen sprachlichem Zeichen und realweltlichem Bezug kann - wie Hilary Putnam (1975: 23) es formuliert - nur als "eine extreme Idealisierung" gelten. Wir können uns einen ersten Zugang zu dieser Problematik verschaffen, wenn wir "Sozialkapital" (ganz gleich, was auch immer wir später genau darunter verstehen wollen) als einen Allgemeinbegriff betrachten, der durch seine Intension festgelegt wird.

Erkenntnistheoretisch lässt sich nun sagen: Bestimmte realweltliche Entitäten, die den intensionalen Merkmalsbestimmungen genügen, sind als Komponenten der Begriffs-Extension identifizierbar; sie fallen unter den sprachlichen Ausdruck. M.a.W.: Um Sozialkapital erkennen zu können, brauchen wir eine allgemeine, die konkreten Einzelerscheinungen transzendierende Vorstellung über Sozialkapital, denn wie sonst sollten wir in der Lage sein, über eine immer nur singulär vorhandene realweltliche Entität etwas auszusagen bzw. diese zu einem Objekt menschlicher Erfahrung zu machen. Auch um eine Rose - auf die man im Vergleich zu Sozialkapital (ja noch relativ) direkt zeigen kann - als Rose zu sehen, benötigt man eine abstrakte Vorstellung davon, was eine Rose zu einer Rose macht.

Gegenstände sind für uns Menschen immer erfahrene Gegenstände ${ }^{42}$, und die Erfahrungsbedingungen liegen überwiegend in unseren Allgemeinbegriffen. Dies hat nun aber ontologische Implikationen. So möchte ich in Anlehnung an John R. Searle (1997a: 11) in einer vordergründig etwas widersprüchlich klingenden Weise

einem tiefen Missverständnis meines Vorhabens: Der Kritiker wendet sich der Sozialkapitalthematik mit einem Interesse zu, das von meinem Anliegen in fundamentaler Weise abweicht. In der Folge neigt er dann dazu, mein Vorgehen als Versuch anzusehen, seine Fragestellung zu bearbeiten. Dies muss dann freilich zwangsläufig zu einer irrigen Auseinandersetzung mit meinem Vorgehen führen.

42 Dies impliziert keinesfalls die Übernahme eines phänomenalistischen Standpunktes: Die Welt ist für uns zwar immer eine von uns erfahrene Welt, aber damit doch nicht grundsätzlich nur dank menschlicher Erfahrung Welt oder Welt nur in der Erfahrung. Gegenständliche Erkenntnis ist aber grundsätzlich sprachgebunden und ein großer Teil der sozialen Realität wiederum erkenntnisgebunden. 
behaupten, dass viele (nicht jedoch alle) Gegenstände der sozialen Realität konstitutiv menschlicher Erfahrung bedürfen, d.h. diese Gegenstände existieren zwar empirisch-objektiv, aber sie existieren nur, weil Menschen glauben, dass sie existieren.

Wenn bspw. keiner davon überzeugt wäre, man könne ein in einer bestimmten Weise bedrucktes Stück Papier gegen eine Tafel Schokolade eintauschen, dann würde es sich bei diesem Stück Papier auch nicht um Geld handeln. Geld ist kein Bestandteil der Realität wie dies etwa Steine oder Blumen sind - auch wenn es für uns zumeist die gleiche Selbstverständlichkeit besitzt ${ }^{43}$. Seine Erfahrungsbedingungen - und d.h. konsensuale, sprachlich vorliegende, abstrakte Vorstellungen von bzw. über Geld - sind konstitutiv für seine Existenz. Ich möchte im Verlaufe dieser Arbeit prüfen, inwiefern für Sozial- das Gleiche wie für Finanzkapital gilt. (Ob es sich allerdings bei Sozialkapital tatsächlich um Kapital handelt, wird im Rahmen der wissenschaftstheoretischen Erörterungen erst noch zu bewerten sein.)

Einen unmittelbaren Anknüpfungspunkt in der Literatur gibt es für die Klärung des Anteils der Sprache an der Existenz von Sozialkapital nicht. Daher werde ich zunächst in der Auseinandersetzung mit Ontologien des Sozialen von Searle und Berger/Luckmann ein Analyseraster konzipieren, um es im Anschluss auf Sozialkapital (und d.h. auf den zuvor spezifizierten Gegenstand) anzuwenden. Auch wenn es hier grundlegend um eine Betrachtung von Sozialkapital aus der Perspektive der analytischen Sprachphilosophie gehen soll - der Titel der vorliegenden Untersuchung lautet ja nicht umsonst "Sozialkapital zur Sprache gebracht"-, so lassen sich doch wissenssoziologisch-phänomenologische Überlegungen in sinnvoller Weise integrieren ${ }^{44}$.

Ich möchte mich daher im Laufe der ontologischen Analyse aus beiden "Angeboten" bedienen, um einerseits dem sozialwissenschaftlichen Leser den Zugang zu den Vorstellungen der analytischen Sprachphilosophie zu erleichtern und um andererseits einige weiterführende handlungstheoretische Überlegungen anschlieBen zu können. Generell ist darauf hinzuweisen, dass sowohl Searle wie Berger/Luckmann den gleichen Gegenstand anvisieren: die soziale Realität. Genauer gesagt - und diese nähere Bestimmung ist von zentraler Relevanz - ihren institutio-

43 Es tritt uns i.d.R. so zwingend wie eine Naturgegebenheit gegenüber. Nicht zuletzt daher empfahl Durkheim (1999: 115) (in seinen "Regeln der soziologischen Methode") "die soziologischen Tatbestände wie Dinge zu betrachten." Kennzeichnend für die hier vorgenommene Analyse wird jedoch sein, dass soziale Tatbestände - wie es Meinefeld (1995: 198) in Paraphrasierung Mannheims formuliert - "nur in ihrer Sinnhaftigkeit dinghaft werden können." Bei Schütz/Luckmann (1975: 42f.) heißt es, es sei wichtig, "zu betonen, daß die (sozialen, D.K.) Wirklichkeitsordnungen nicht durch eine etwaige ontologische Struktur ihrer Objekte, sondern durch den Sinn unserer Erfahrung konstituiert werden."

44 Zumal auch Searle m.E. wenigstens partiell phänomenologisch argumentiert und es insofern durchaus Parallelen zwischen einer Philosophie der Normal- bzw. Umgangssprache (ordinary language philosophy) und einer phänomenologischen Lebensweltsoziologie zu diskutieren gibt (vgl. hierzu Kapitel 5.4. und 5.7.). 
nellen Teil, d.h. jenen Teil, der über die reine Physik sozialer Sachverhalte (etwa zwei Personen schütteln sich die Hände) hinausgeht, nur dank menschlicher Bedeutungszuweisung entsteht und eine Deontik, ein System von Rechten und Pflichten etabliert (ein Händeschütteln kann etwa eine Vertragssituation begründen $)^{45}$.

Die institutionelle Realität wird von Menschen über Sprache, Bedeutung und Interaktion konstituiert und grenzt sich von all jenen Aspekten der Realität ab, die wir als unabhängig von menschlichen Bewusstseinsleistungen existierend unterstellen dürfen. Während Searle jedoch auf sprachlogischem Weg "die kontinuierliche Linie aufzeigen (möchte, D.K.), die von Molekülen und Bergen zu Schraubendrehern, Hebeln und schönen Sonnenuntergängen und dann zu Gesetzgebungen, Geld und Nationalstaaten führt" (Searle 1997a: 51), fragen Berger/Luckmann, wie es möglich ist, "daß subjektiv gemeinter Sinn zu objektiver Faktizität wird ..., daß menschliches Handeln (...) eine Welt von Sachen hervorbringt?" (Berger/Luckmann 1980: 20)

Ian Hacking sieht den Unterschied zwischen Searle und Berger/Luckmann vor allem in der nur marginal vorhandenen Handlungsperspektive bei Searle: "There is very little doing in Searle's book. What people do with words is a basic logical precondition for social reality, but what people have actually done with words in datable social interactions has little role in Searle's philosophy. Berger and Luckmann, in contrast, were abuzz with activity - but one cannot discern any literal building-up of something out of elements. Thus the same word in the two titles, 'construction', directs us to distinct aspects of the very idea of construction, a product of building blocks on the one hand, and a process of interacting on the other." (Hacking 1997: 85)

Berger/Luckmann legen eine wissenssoziologisch-phänomenologische bzw. eine (in Entlehnung und leichter Verfremdung der Husserlschen Diktion) materiale Ontologie sozialer Realität vor, weil hier eine Reflexion auf geistige sowie die im Geist wirkenden historischen und sozio-kulturellen Bedingtheiten gesellschaftlicher Realität erfolgt. Die konkrete Ausgestaltung dieser Realität, das Wissen um und das Vertrauen in sie sowie die sie bewirkenden und aufrechterhaltenden konketen produktiven, vor allem kommunikativen Prozesse sind das Thema. Searle hingegen problematisiert die allgemeinen konstitutiven Regeln, welche institutionelle Tatsachen begründen können. Es geht ihm um eine logisch-stringente Ableitungsbeziehung zwischen Physik, Linguistik und sozialer Realität und insofern um eine formale

45 Insofern verallgemeinere ich Searles Begriff der "institutionellen Tatsachen" (vgl. hierzu ausführlich Kapitel 5.4.), d.h. ich verwende ihn auch im Kontext der Berger/Luckmannschen Ontologie, um so einen einheitlichen Terminus zu erhalten (vgl. auch Kapitel 5.6.). Zugleich möchte ich an dieser Stelle darauf hinweisen, dass institutionelle Tatsachen für mich sowohl methodologisch wie ontologisch soziale Gegenstände darstellen (womit ich "Tatsachen" bzw. "Sachverhalte" unter den Gegenstandsbegriff subsummiere; bei sozialen Gegenständen kann es sich hier um so unterschiedliche Dinge wie Verwaltungsgerichte, Geld, Fremdenfeindlichkeit, Eheschließungen, Vereinsmitgliedschaften, Eigentümerschaften, Führerscheinen etc. handeln). 
Ontologie ${ }^{46}$. Mit wieder anderen Worten ließe sich die Perspektive Berger/Luckmanns als vergleichsweise dynamisch, die Searles als eher statisch begreifen. Searle arbeitet in gewisser Weise die Voraussetzungen heraus, unter denen konkrete Praktiken (im Sinne Berger/Luckmanns) erst zu einer objektiven sozialen Wirklichkeit führen können ${ }^{47}$.

Was heißt das nun für die Analyse eines institutionellen Gegenstandes, etwa von Sozialkapital? Während die Anwendung des auf Berger/Luckmann rekurrierenden Rasters die Sozialkapital generierenden sozialen Prozesse und institutionalisierten Kontextbedingungen benennt, spezifiziert eine Analyse auf Basis des sprachphilosophischen Konstruktivismus - gemäß dem Diktum Wittgensteins, nach welchem Bedeutung in seinen linguistischen und sozialen Dimensionen zu erfassen ist - die sprachlogische Tiefen- bzw. Regelstruktur der Schaffung von Sozialkapital. Die sozialen Bedingungen von Sozialkapital können eben genauso wenig sprachlos gedacht werden wie Sprache ohne soziale Einbindung möglich wäre - ein einheitlicher Prozess wird hier also analytisch aufgetrennt.

\section{Zusammenfassung und ergänzende Hinweise}

Zusammenfassend lässt sich für das verfolgte Vorgehen festhalten ${ }^{48}$ :

1. Innerhalb des vorwiegend sprachphilosophisch geprägten Grundlagenteils dieser Arbeit geht es (a) um das Verhältnis von Bedeutung und Gegenstand und damit um die Frage, inwiefern weite Teile der sozialen Wirklichkeit untrennbar mit menschlichem Wissen - und zwar gerade auch dem Wissen um die Bedeutung von etwas - zusammenhängt sowie (b) um die Erarbeitung eines wissenschaftstheoretischen wie eines ontologischen Analyseschemas für die Auseinandersetzung mit sozialwissenschaftlichen Begriffen sowie den über diese Begriffe behaupteten Erkenntnissen und bezeichneten Gegenständen.

2. Im ersten Schritt des Anwendungsteils wird untersucht, was "Sozialkapital" innerhalb wissenschaftlicher Aussagensysteme bedeutet und wie das Konstrukt konzeptualisiert wird. Eine Rationale Rekonstruktion der einschlägigen Ansätze soll neben einer begrifflichen Präzisierung auch eine Bewertung der logischen Kohärenz der behaupteten Erkenntnisse und der argumentativen Begründung derselben beinhalten. Dies mündet dann in einen Konzeptvergleich und schließlich in die Entwicklung eines integrativen, axiomatisierten Theoriemodells.

46 Gilbert Ryle hat in ähnlichem Zusammenhang von der "logical geography of concepts" gesprochen (Ryle 1965: 8); forschungspraktisch betrachtet, sind die notwendigen Regelbedingungen, unter denen ein realer Gegenstand als möglich gedacht werden kann, ausfindig zu machen.

47 Nachdem ich die Ontologien von Searle und Berger/Luckmann in den Kapiteln 5.4. und 5.5. ausführlich dargestellt habe, werde ich die Frage nach ihrem Verhältnis in den Kapiteln 5.6., 5.7. und 8.2. wieder aufgreifen.

48 Detaillierte Ausführungen zur Methodik sind den entsprechenden Kapiteln vorbehalten. 
3. Im zweiten Schritt des Anwendungsteils wird dann der Zusammenhang von Begriff und Gegenstand unter die Lupe genommen. Zu untersuchen ist, welche sprachlichen Ordnungsbestimmungen Menschen konkret vorzunehmen haben, damit es überhaupt zu einem realweltlichen Gegenstand kommen kann, der wissenschaftlich dann als "Sozialkapital" bezeichnet wird. Um dies zu klären, werden sprachphilosophische und wissenssoziologische Überlegungen zur Ontologie des Sozialen in Beziehung zu jenem Gegenstand gesetzt, der zuvor über das entwickelte Theoriemodell festgelegt wurde ${ }^{49}$.

Methodologisch betrachtet, wird die Auseinandersetzung mit Sozialkapital über einen interdisziplinären Zugriff geleistet, wobei sich sowohl die Disziplinen als auch die anzuwendenden Methoden hinsichtlich der einzelnen Arbeitsschritte gleich mehrfach überschneiden: Die Rekonstruktionen der diversen Sozialkapitalkonzepte sowie die Errichtung eines integrativen Theoriemodells basieren vor allem auf Ansätzen der analytischen Wissenschaftstheorie ${ }^{50}$. Das Analyseschema zur Bestimmung der Bedingungen der Möglichkeit von Sozialkapital verbindet sprachphilosophische zumindest partiell auch mit sozial- und kognitionspsychologischen aber vor allem mit wissenssoziologischen Blickrichtungen auf die Entstehung sozialer Realität, wobei jeweils ein bedeutungstheoretischer Fokus kennzeichnend sein wird.

Dieses Vorgehen mag insofern ungewöhnlich erscheinen, als bspw. einigen phänomenologisch arbeitenden Wissenssoziologen die Ausrichtung an Kriterien der analytischen Philosophie ebenso befremdlich anmuten könnte wie etwa dem experimentell forschenden Kognitionspsychologen die Verbindung seiner Ergebnisse mit den vielfach auf Introspektion beruhenden Resultaten interpretativer Sozialforschung. Dass die diversen Positionen in der hier vorgenommenen Anwendung jedoch nicht nur kompatibel, sondern ihre Kombination mit Blick auf die Lösung des formulierten Forschungsproblems sogar angezeigt ist, werden die Ausführungen in den folgenden Kapiteln verdeutlichen. Das Spezifische an einer insbesondere an neueren Entwicklungen innerhalb der Analytischen Philosophie orientierten Sozialwissenschaft wird dabei sein, dass sie dem linguistic wie dem cognitive turn folgt, d.h. dass sie sowohl die Struktur sprachlicher Aussagen (in Theorie und Lebenswelt) als auch die diese bedingenden bzw. die hiermit unmit-

$49 \mathrm{Da}$ ontologische Probleme - wie zu zeigen sein wird - nur auf dem Hintergrund eines begrifflichen Schemas, das den Gegenstandsbereich ordnend benennt, diskutiert werden können, ist die wissenschaftstheoretische Auseinandersetzung und das hierüber erarbeitete integrative Theoriemodell eine unabdingbare Voraussetzung für diesen zweiten, ontologischen Schritt des Anwendungsteils.

$50 \mathrm{Da}$ es um formalwissenschaftliche Überlegungen gehen wird, kann eine Erfahrungswissenschaft wie die Soziologie an dieser Stelle keinen genuinen methodologischen Beitrag leisten (dennoch finden sich insbesondere bei analytischen, explanativ orientierten Soziologen zahlreiche wissenschaftstheoretische Rekurse, die von mir im Folgenden natürlich auch berücksichtigt werden). 
telbar zusammenhängenden Bewusstseinsprozesse in den Vordergrund der Betrachtungen rückt ${ }^{51}$.

Zur Vermeidung von Missverständnissen sei schon an dieser Stelle angemerkt, dass diese Arbeit ontologierealistisch ansetzt. Die Frage lautet nicht so sehr, was es gibt, sondern in Folge welcher sprachlichen Ordnungsprozesse es die Dinge der sozialen Realität gibt. Dieser Hinweis scheint mir vor allem deswegen notwendig, als einiges von dem, was heute als "Konstruktivismus" bezeichnet wird, in dezidiert anti-realistischer Haltung vorgetragen wird ${ }^{52}$. Aus der m.E. sehr gut begründbaren Auffassung, derzufolge soziale Realität "durch nichts als durch die Aktivitäten von Menschen ständig neu hervorgebracht wird und damit in keiner Weise ein davon unabhängiges Eigenleben führt" (Esser 1996b: 480), lässt sich jedoch nicht ableiten, dass diese Realität irgendwie nicht "echt" wäre ${ }^{53}$.

Die Wirklichkeit der Welt wird von mir zu keinem Zeitpunkt der Argumentation in Frage gestellt; sie wird jedoch - um eine Unterscheidung von Searle (1997a) aufzugreifen - in ihrem ontologisch objektiven (d.h. von menschlichen Ordnungs- bzw. Systematisierungsleistungen unabhängigen) Teil grundsätzlich als über unser Bewusstsein vermittelt und in ihrem ontologisch subjektiven Teil als auf basaler Ebene über menschliche Bedeutungsproduktion hergestellt bewertet. M.a.W.: Ein Stein hat zunächst einmal ontologisch objektive Eigenschaften wie etwa eine bestimmte Masse und Oberflächenstruktur; sobald er jedoch als Wurfgeschoss genutzt wird, kommen ihm zusätzlich ontologisch subjektive Eigenschaften zu. Insofern vertrete ich hier sowohl eine ontologierealistische Position

51 Die Analytische Philosophie geht nämlich davon aus, das "Denken und Erfahrung letztlich in der Sprache gründen und wir nichts über das Sein, das Wesen unserer Erkenntnis oder unsere Gedanken sagen können, ohne den Umweg über eine Analyse der Sprache zu nehmen." (Blume/Demmerling 1998: 9f.) Gipper (1987) verwendet in diesem Zusammenhang in Anlehnung an Kant den Begriff "Sprachapriori". Auch die von Luckmann (2002: 160) beklagte frühere "sprachtheoretische Armut der Gesellschaftstheorie" wird vielerorts (etwa in der Ethnomethodologie) von einer "sprachtheoretischen Wende der Sozialwissenschaften" (Bublitz 2001: 231) abgelöst, bei der Sprache ihren "Sekundärstatus" verliert (ebenda).

52 Oder aber mit negativem Unterton: "Die meisten jedoch, die sich begeistert auf die Idee der sozialen Konstruktion stürzen, möchten irgendein X, das ihnen an der bestehenden Ordnung der Dinge mißfällt, kritisieren, verändern oder zunichte machen." (Hacking 1999: 20). "Mitunter wirkt die bloße Äußerung der Worte 'soziale Konstruktion' nicht wie eine These oder ein Projekt, sondern eher wie das öffentliche Bekenntnis bei einem Sektenkonventikel." (ebenda: 62) Hacking wendet sich mit seinen Äußerungen insbesondere gegen eine ethnomethodologische Soziologie. Gleichwohl möchte ich in Zweifel ziehen, ob er etwa Garfinkel so gerecht wird, denn auch Garfinkel zweifelt die Objektivität der sozialen Wirklichkeit nicht an, sondern er vertritt lediglich die wohl kaum von einem Soziologen heute ernsthaft bestrittene Auffassung, dass "die objektive Wirklichkeit sozialer Tatsachen als eine fortwährende Hervorbringung und Leistung der gemeinsamen Tätigkeiten des Alltagslebens" zu gelten hat (Grafinkel zitiert nach Bergmann 2004: 121). Weder der gesellschaftskritische Impetus, den Garfinkel und seine Anhänger im Anschluss daran vielfach aufweisen, noch die radikal partikularistische Interpretation (von nicht nur) sozialer Realität, den die ethnomethodologische Forschung mit ihrer Exponierung von Indexikaliät beschwört, sind notwendige Konsequenzen aus dieser Position.

53 Tatsächlich steht die Aussage Essers sogar ein wenig unter Tautologieverdacht: Wenn es sich bei der sozialen Realität um die Realität zwischenmenschlichen Zusammenlebens handelt, dann folgt rein logisch, dass sie kein hiervon unabhängiges Eigenleben führen kann. 
als auch die Überzeugung einer Unhintergehbarkeit von menschlicher Sprache und Bewusstsein ${ }^{54}$; beide Komponenten, die Außenwelt wie das innere Erleben, werden als real vorausgesetzt.

Am Ende dieser Einleitung möchte ich noch dem potentiellen Einwand begegnen, die aufwendig anmutende Anlage dieser Studie stehe in gewisser Weise im Gegensatz zu der Grundsätzlichkeit des Anliegens. Diese Einschätzung könnte vor allem dann nahe liegen, wenn man Sprachprobleme für die Sozialwissenschaften als vernachlässigbar erachtet oder unter "Sozialkapital" die relativ trivial erscheinende Tatsache thematisiert, dass Individuen bzw. Akteure Nutzen aus ihren Beziehungen zu anderen ziehen. Gerade die Selbstverständlichkeiten unseres Alltags - wie etwa der Nutzen von Sozialkontakten - erweisen sich jedoch bei näherer Betrachtung vielfach als derart voraussetzungsvoll, dass eine wissenschaftliche Analyse dem nur über einen hohen Grad an Komplexität gerecht werden kann.

Mit Glasperlenspielerei hat es somit nichts zu tun, wenn ganz unproblematisch erscheinende Dinge in ihrer Abhängigkeit von menschlicher Leistung, Fähigkeit und Kreativität untersucht werden. Bertrand Russell (1967: 138) hat einmal gesagt, wer erkenne, dass selbst die alltäglichsten Dinge zu Fragen führen könnten, die sich nur unvollständig beantworten ließen, der schlage "die etwas arrogante Gewissheit derer nieder, die sich niemals im Bereich des befreienden Zweifels aufgehalten haben". So werde "unsere Fähigkeit zu erstaunen" wachgehalten, indem sich "uns vertraute Dinge von uns nicht vertrauten Seiten" zeigten ${ }^{55}$. U.a. die nicht vertrauten Seiten des vertrauten Sachverhaltes, dass man von anderen Menschen Hilfe und Unterstützung mit Blick auf die Realisierung eigener Zielstellungen erwarten darf, sind Thema der vorliegenden - hoffentlich den ein oder anderen Leser angenehm erstaunenden - Untersuchung.

\footnotetext{
54 Dabei handelt es sich bei Bewusstsein zweifellos um einen unförmigen Gegenstand: Gedanken, Absichten, Ängste etc. finden im "Kopf" des Einzelnen statt, sind überaus flüchtig und insofern sehr schwer analysierbar. In Anlehnung an Gadenne (1996: 9) lassen sich "grob drei Denk- und Forschungsrichtungen unterscheiden, die einen jeweils anderen Blick auf das Bewußtsein eröffnen": Bewusstsein als subjektive innere Erfahrung (Phänomenologische Philosophie), Bewusstsein als Informationsverarbeitung (Kognitive Psychologie) und Bewusstsein als neuronaler Prozess (Neurobiologie). Im ersten Fall ist Bewusstsein subjektiv erlebtes psychisches Geschehen, dessen Struktur zum Gegenstand einer Reflexion wird. Betrachtet man Bewusstsein als Informationsverarbeitungssystem, so fragt man nach der Art und Weise, wie Menschen Informationen aus ihrer Umwelt selegieren und prozessieren. Drittens beschäftigen sich Neurowissenschaftler mit den biologischen Grundlagen des Bewusstseins, also den Vorgängen und Abläufen innerhalb des Nervensystems und des Gehirns. Insbesondere die erst- und die zweitgenannte Perspektive werden in dieser Arbeit von Belang sein.

55 "Der gesellschaftliche Nutzen dieses Unternehmens", so möchte ich mit Soeffner/Hitzler auch aus der Perspektive der verstehenden, phänomenologisch orientierten Soziologie behaupten, "liegt darin, die Menschen auf die vom Alltagsverstand gemeinhin nicht thematisierten Umstände, Zusammenhänge und Regeln aufmerksam zu machen, in deren Rahmen sie ihr Leben vollziehen." (Soeffner/Hitzler 1994: 35) Alfred Schütz (1993: 17) sieht die Aufgabe der Soziologie darin, "gerade das 'Selbstverständliche' in Frage zu stellen."
} 
Die folgende Abbildung gibt einen zusammenfassenden Überblick über das Projektdesign.

Abbildung 2: Projektdesign

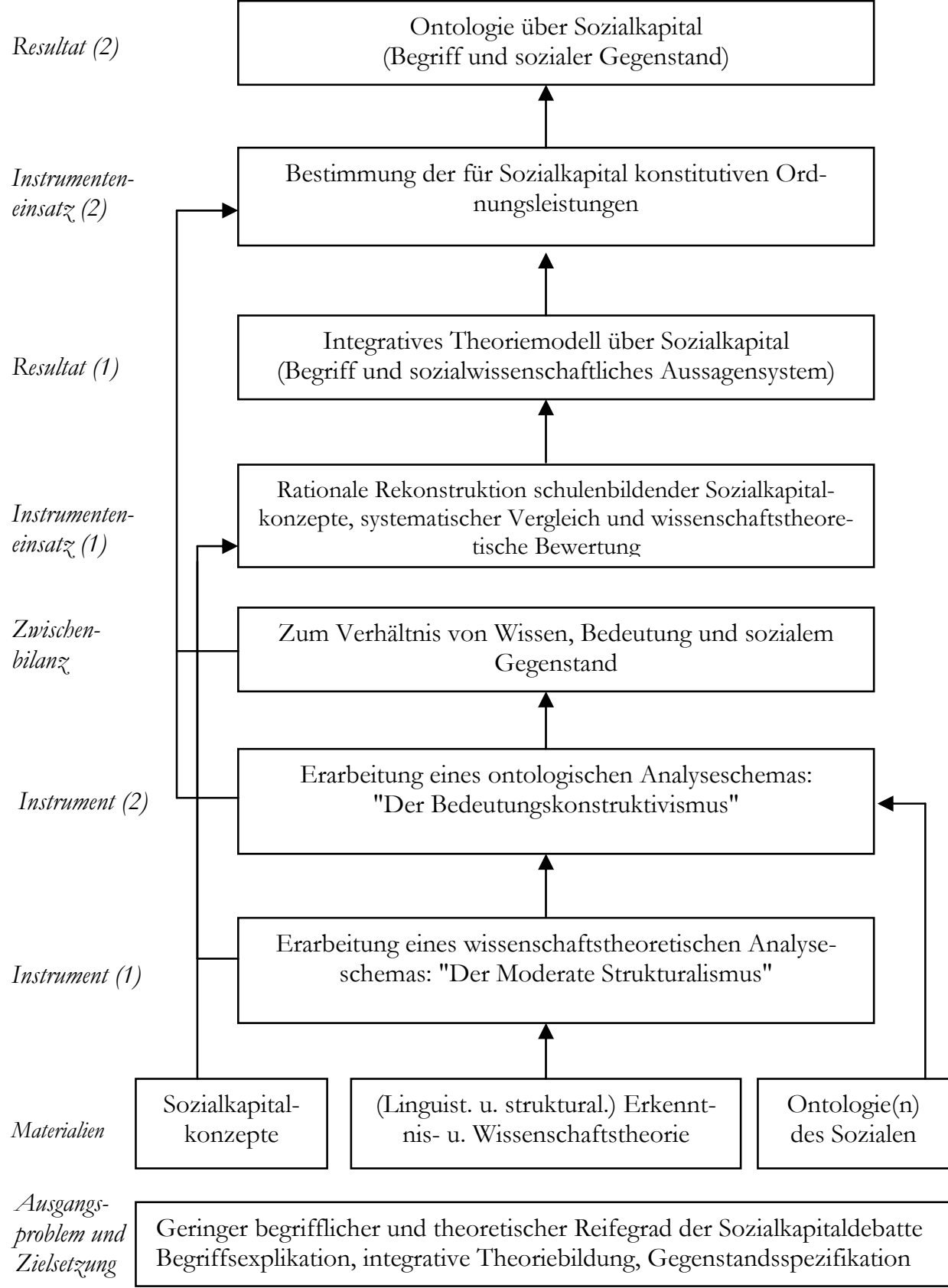




\section{GRUNDLAGENTEIL}

Entwicklung eines Analyseinstrumentariums als "kleine" analytische Sprachphilosophie der Sozialwissenschaften 

Innerhalb der Sozialwissenschaften - so die Ausgangsüberlegung der vorliegenden Untersuchung - wird derzeit intensiv über Sozialkapital diskutiert und gestritten, ohne dass ein einheitliches und präzises Begriffsverständnis, das doch eine sinnvolle Diskussion über einen sozialen Gegenstand erfordern würde, vorhanden wäre. Um diesem Problem zu begegnen, möchte ich über eine Begriffsexplikation, eine Rationale Rekonstruktion ausgewählter Konzepte und einer sich daran anschließenden synoptischen Gegenüberstellung dieser Konzepte einen Vorschlag für ein integratives Theoriemodell über Sozialkapital erarbeiten. Im Anschluss daran lässt sich mit Hilfe eines ontologischen Bestimmungsschemas eine weitere Gegenstandspräzisierung erzielen.

Die Konstruktion der benötigten Analyseinstrumentarien macht eine ausführliche sprachphilosophische Herleitung erforderlich, die als eine eigenständige Forschungsleistung gelesen werden darf, denn komplexe wissenschaftstheoretische Explikations-, Rekonstruktions-, Vergleichs-, und Theoriebildungs- sowie ontologische Gegenstandsbestimmungswerkzeuge fallen leider nicht einfach so vom Himmel. Es handelt sich gewissermaßen um eine Untersuchung innerhalb der Untersuchung, bei der es - wie gesagt - instrumentell zwar um die Entwicklung notwendiger Werkzeuge, inhaltlich aber zugleich um den Zusammenhang zwischen (sozial-)wissenschaftssprachlichem und alltagssprachlichem Wissen (nicht zuletzt dem Wissen um Bedeutungen) sowie den sozialen Gegenständen, über die dieses Wissen formuliert wird, geht.

Der genannte Zusammenhang bildet sozusagen den intellektuellen Reflexionsrahmen des vorliegenden Buches. Die entsprechenden Ergebnisse werden in Kapitel 6. unter der Überschrift "Was Wissen und Bedeutung mit der sozialen Welt machen" auf allgemeiner Ebene resümiert, bevor sie dann die Auseinandersetzung mit der Sozialkapitalthematik anleiten und somit im Anwendungsteil mit konkretem Gegenstandsbezug wieder auftauchen.

Alternativ dazu wäre es grundsätzlich möglich gewesen, die Analyseinstrumente lediglich zu setzen, ohne den aufwendigen Prozess ihrer Herleitung und Konstruktion zu begründen oder zu dokumentieren. Wenn dies dennoch nachfolgend geschieht, dann nicht zuletzt deshalb, weil es für einen Sozialwissenschaftler mitunter schwer sein kann, einen Zugang zu komplexen sprachphilosophischen Überlegungen zu bekommen. Nur wenn diese in Form einer "kleinen" analytischen Sprachphilosophie relativ ausführlich erörtert werden, wird es später möglich, meine Art der Beschäftigung mit der Sozialkapitalthematik wirklich einzuschätzen und nachzuvollziehen. Sozialkapital soll hier nicht irgendwohin, sondern zur Sprache gebracht werden. Um auf dem Weg dorthin nicht orientierungslos zu werden, ist eine genaue Charakterisierung des "Zielortes" und eine vorangehende "Streckenbesichtigung" angezeigt.

Ferner bietet es sich gerade dann an, zentrale sprachphilosophische Themen zu erörtern, wenn elementare begrifflich-theoretische Probleme einer aktuellen sozialwissenschaftlichen Debatte durchleuchtet werden. In einem solchen Kontext 
werden die forschungspraktischen Implikationen sprachphilosophischer Überlegungen unmittelbar erkennbar. Wären Sozialwissenschaftler mit diesen Implikationen weitläufig vertraut, dann würde es gar keine Begriffskonfusion um "Sozialkapital" geben.

Der "eilige" Leser, der trotz der soeben vorgetragenen Argumentation dezidiert ausschließlich an der Auseinandersetzung mit "Sozialkapital" interessiert ist, kann sich auf die Kapitel 4.3. und 4.4. sowie 5.3. bis 5.6. beschränken und dabei von den zahlreichen, weiterführenden Fußnoten gänzlich absehen. Gleichwohl ist ein vertieftes Verständnis der dargelegten Zusammenhänge ohne die komplette Lektüre des Grundlagenteils nicht zu erreichen. Grundsätzlich möchte ich daher den Leser an dieser Stelle nochmals einladen, sich auf die zugegebenermaßen relativ komplexe Thematik einzulassen und mich bei deren Erörterung zu begleiten.

Der nun folgende Grundlagenteil zielt auf die Diskussion der wissenschaftsund alltagssprachlichen Erfassung der sozialen Welt sowie des Anteils der Sprache an der Konstruktion dieser Welt. Während es innerhalb des erkenntnis- sowie wissenschaftstheoretischen Teils um die Frage geht, wie eine als objektiv vorhanden vorausgesetzte soziale Welt soweit als irgend möglich "korrekt" repräsentiert werden kann - wie man also die Worte in "angemessener" Weise auf die Welt auszurichten hat -, hebt die ontologische Perspektive auf den konstitutiven Charakter der Sprache ab. Hier geht es um die Art und Weise, wie weite (nämlich die institutionellen) Teile der sozialen Welt - als der allgemeine Gegenstandsbereich der Sozialwissenschaften - qua Sprache entstehen, d.h. wie sich die Welt dabei gleichsam auf unsere Worte ausrichtet ${ }^{56}$.

Das der Arbeit vorangestellte Zitat aus Paul Austers Roman "Stadt aus Glas" soll diese beiden Ausrichtungen und ihre Verbindung illustrieren. Einer von Austers Protagonisten, Peter Stillman, beklagt die menschliche Gewohnheit, mit einem Wort unreflektiert auf ein Ding hinzuweisen. Ein Schirm habe aufgehört ein Schirm zu sein, wenn er seine Funktion nicht mehr erfüllen könne, wenn also ein bestimmtes Merkmal nicht mehr gegeben sei. Folgt man dieser Einschätzung, dann steht eine Bezeichnung in einer Abhängigkeitsbeziehung zu einem Gegenstand.

Nun handelt es sich bei einem Schirm um ein von Menschen gemachtes Etwas, das, wie Stillman zugespitzt formuliert, "den Willen des Menschen ausdrückt": Es soll uns vor Regen schützen. Insofern ist ein Schirm eben durchaus ein Gegenstand der sozialen Welt; wir finden ihn nicht einfach so in der Natur. Dennoch aber erfüllt er für uns seinen Zweck in Folge seiner materiellen Beschaffenheit. Schon hinsichtlich einer solch einfachen Sache kann es sehr schnell zu (wenn auch wohl kaum folgenschweren) Repräsentationsproblemen kommen: Ist ein Schirm noch als "Schirm" zu bezeichnen, wenn er nicht mehr vor Regen schützt (Problematik der Wort-auf-Welt-Ausrichtung)? Wir benötigen exakte,

56 Die Unterscheidung zwischen Wort-auf-Welt- und Welt-auf-Wort-Ausrichtung findet sich bei John R. Searle (2001: 127). 
augenscheinlich auf menschliches Wollen relativierte (denn es geht ja um Funktionen für Menschen) Definitionskriterien, um diese Frage zu beantworten ${ }^{57}$.

Wie aber steht es, um erneut Stillman sprechen zu lassen, mit den Dingen, "die uns wirklich etwas angehen?" Nehmen wir bspw. Finanzkapital. Mit einem Papierstreifen mit dem Aufdruck "5 Euro" können wir nur dann etwas "anfangen", wenn die soziale Gemeinschaft ihm dezidiert einen Tauschwert zugewiesen hat. Hierfür benötigt sie allerdings in konstitutiver Weise Sprache, denn an dem Streifen ist nichts, was aus sich heraus die Bedeutung eines Tauschwerts aufweist (Problematik der Welt-auf-Wort-Ausrichtung; der Schirm hingegen erfüllt seine Dienste auf Grundlage seiner Physik, d.h. sprachliche Bedeutung wird konstitutiv keineswegs benötigt). Damit müssen wir also erst ein nicht-materielles Etwas schaffen, um auf einen Papierstreifen als "Geldschein" referieren zu können, wodurch die Beziehung zwischen Sprache und Gegenstand enorm an Komplexität gewinnt.

Übertragen wir diese Überlegungen nun auf die Sozialkapitaldebatte. Hier ist es - wie gezeigt - derzeit nicht möglich, "Sozialkapital" einem bestimmten Gegenstand konsensual zuzuordnen. Insofern bedarf es der Erarbeitung eindeutiger Gebrauchsregeln. Diese sollen aber nicht einfach so gesetzt, sondern aus einem systematischen, von außen kommenden metatheoretischen Vergleich schulenbildender Konzepte gewonnen werden. Im Ergebnis liegt dann ein Konsensvorschlag darüber vor, wie man mit "Sozialkapital" in erkenntnis- und wissenschaftstheoretisch haltbarer und sinnvoller Weise auf einen sozialen Gegenstand hinweisen kann (Wort-auf-Welt-Ausrichtung). Auf dieser Basis können wir dann ontologisch weiterfragen und klären, welcher sprachlichen Bedeutungszuweisungen denn nun dieser Gegenstand konstitutiv bedarf, d.h. wie wir mit unseren Worten umgehen müssen, um die soziale Welt so zu verändern, dass es darin Sozialkapital gibt (Welt-auf-Wort-Ausrichtung).

\footnotetext{
${ }^{57}$ In Abhängigkeit von unserer Perspektive können wir einen Gegenstand einmal als "physikalisch" und ein anderes Mal als "sozial" klassifizieren. Den naturalistisch orientierten Sprachphilosophen möchte ich bitten, seine Einwände so lange zurückzustellen, bis dieser Gedanke im weiteren Verlauf der Arbeit voll entfaltet wurde.
} 



\section{Erkenntnis- und wissenschaftstheoretischer Grundlagenteil}

Was soll nun also alles konkret in diesem erkenntnis- und wissenschaftstheoretischen Grundlagenteil geleistet werde?

Erstens wird erläutert, um was es bei der analytischen Erkenntnis- und Wissenschaftstheorie überhaupt geht (Kapitel 4.1.).

- Zweitens wird dargestellt, welches wissenschaftliche Erkenntniskonzept vom Logischen Positivismus vertreten wird, also derjenigen wissenschaftstheoretischen Position, die nicht nur innerhalb der Sozialwissenschaften nach wie vor dominiert (Kapitel 4.2.).

- Drittens wird gezeigt, welches wissenschaftliche Erkenntniskonzept aus einer Kritik am Logischen Positivismus heraus vom neuen wissenschaftstheoretischen Strukturalimus formuliert wird. Dabei soll insbesondere die Art und Weise Berücksichtigung finden, mit der man im Strukturalismus theoretische Aussagensysteme rekonstruiert bzw. präzisiert und axiomatisiert (Kapitel 4.3.).

Viertens setze ich mich im Anschluss daran meinerseits kritisch mit dem Strukturalismus auseinander und entwickle hierüber ein modifiziertes (bzw. "moderates") strukturalistisches Erkenntniskonzept sowie damit unmittelbar zusammenhängend ein Instrumentarium zur systematischen Rekonstruktion theoretischer Aussagensysteme (Kapitel 4.4.).

Beginnen wir nun mit einer vorsichtigen Annäherung an wissenschaftliche Theorien und Begriffe. Wissenschaftliche Theorien lassen sich als abstrahierende Aussagensysteme, die prüfbare Erkenntnisse über die Wirklichkeit formulieren, verstehen. Begriffe, die darin von zentraler Relevanz sind, können dann als theoreti- 
sche Konstrukte aufgefasst werden, mit denen wir die behauptete Erkenntnis gleichsam verdichten. Beispiele aus den Sozialwissenschaften wären etwa "Demokratie", "Norm", "Exklusion", "funktionale Differenzierung" oder "deviantens Verhalten". Bei einer metatheoretischen Beschäftigung mit ausformulierten sozialwissenschaftlichen Theorien stehen insofern die über die zentralen Begriffe behaupteten Erkenntnisse im Mittelpunkt.

Um diese jedoch fundiert beurteilen zu können, stellen sich ganz grundlegende Fragen: Um was handelt es sich bei Erkenntnissen eigentlich? Wie gelangen wir überhaupt zu ihnen? Welchen Anforderungen müssen sie genügen, um als gesichert gelten zu können? Wie lassen sie sich darstellen und rekonstruieren? Wie können wir sie überprüfen (bzw. können wir dies überhaupt)? In welchem Verhältnis stehen sie zu den tatsächlichen Gegenständen in der (sozialen) Welt? Wie lassen sich unterschiedliche Erkenntnisbehauptungen vergleichen? Um uns einer Beantwortung dieser Fragen anzunähern, wollen wir uns zu Beginn anschauen, was Erkenntnis- und Wissenschaftstheorie eigentlich leisten.

\subsection{Zum Zusammenhang von Erkenntnis- und Wissen- schaftstheorie}

Wenn es sich bei der Wissenschaftstheorie dem Namen nach um eine auf Wissenschaft bezogene Theorie handelt, dann erscheint es sinnvoll, sich zwecks einer konzeptionellen Klärung den Begriffen "Wissenschaft" und "Theorie" zuzuwenden. Aus deren Zusammensetzung müsste sich gewissermaßen errechnen lassen, worum es geht ${ }^{58}$. In der Sprachphilosophie spricht man bezüglich dieser Form einer Analyse eines zusammengesetzten Ausdrucks vom "Kompositionalitätsprinzip" (vgl. Newen/Savigny 1996: 187).

Nun wurde aber in der Einleitung zu dieser Arbeit angedeutet, das, was "Sozialkapital" (bzw. "soziales Kapital") bedeute, ließe sich feststellen, indem man rekonstruiere, was die Autoren, die den Begriff mit theoretischem Anspruch entwickelten, darunter verstünden. Die Bedeutung des Begriffs soll also nicht dadurch ergründet werden, dass man "sozial" und "Kapital" gewissermaßen auf einer abstrahierenden Ebene aufaddiert, sondern indem man einen finiten sprachlichen Kontext untersucht. Dieses insbesondere auf Frege (1987: 23) zurückgehende "Kontextprinzip" ist offensichtlich eine weitere Variante, begriffliche Bestimmungen vorzunehmen. Kann man es nun aber als logisch stringentes Vorgehen erachten, "Sozialkapital" entlang des Kontext-, "Wissenschaftstheorie" jedoch entlang des Kompositionalitätsprinzips zu explizieren? Augenscheinlich befindet man sich

\footnotetext{
58 Dieses Vorgehen wählt etwa Kron (1999: 65) in seiner "Wissenschaftstheorie für Pädagogen", wenn er die "beiden Begriffe Theorie und Wissenschaft, die den Begriff Wissenschaftstheorie konstituieren", diskutiert.
} 
schon inmitten wissenschafts- und erkenntnistheoretischer Turbulenzen, von denen man - da man ja noch keine Definition besitzt - eigentlich gar nichts wissen kann.

Um derartigen Problemen an dieser Stelle aus dem Weg zu gehen, wird ein pragmatisches Vorgehen angestrebt: Untersuchungsobjekt innerhalb des Anwendungsteils dieser Arbeit sind Konzepte, die den Sozialkapitalbegriff ins Zentrum theoretischer Reflexionen rücken. Im Grundlagenteil geht es jedoch um die Entwicklung und Darstellung eines zu dessen Analyse notwendigen Instrumentariums. Entsprechend werden die Ausdrücke "Wissenschaftstheorie" und "Erkenntnistheorie" hier lediglich im Sinne einer Nominaldefinition so festzulegen sein, dass sie die Entwicklung dieses Instrumentariums ermöglichen.

Einen Versuch einer Bestimmung dessen, was Wissenschafts- aber auch was Erkenntnistheorie sein soll und wie beide Disziplinen miteinander verknüpft sind, unternimmt Wolfgang Balzer (1982: 4f.) unter Rekurs auf Kant: "Nach Kant ist eine der Hauptfragen der Philosophie: 'Was können wir wissen?'; und die wissenschaftlichen Bemühungen zur Beantwortung dieser Frage fallen in eine der philosophischen Grunddisziplinen, nämlich der Erkenntnistheorie. Wie immer man zu einer genaueren Bestimmung der Erkenntnistheorie ansetzt, so dürfte doch folgendes klar sein: Eine Antwort auf die obige Kantsche Frage kann nur der geben, der auch sagt, was Wissen (...) eigentlich ist und wie der Erwerb von Wissen funktioniert. Und ein wesentlicher Weg, dies zu schaffen, besteht sicher darin, zu schauen, was in den Wissenschaften als Wissen angesehen wird und wie die Wissenschaften funktionieren. Genau dies tut aber die Wissenschaftstheorie".

Während also die Erkenntnistheorie allgemein nach den Bedingungen der Möglichkeit menschlicher Erkenntnis bzw. menschlichen Wissens über die Welt fragt ${ }^{59}$, spezifiziert die Wissenschaftstheorie den Sonderfall der systematischen, wissenschaftlichen Erkenntnis, indem sie rekonstruiert, wie Wissenschaften betrieben werden, welche Ergebnisse sie hervorbringen und wie deren Strukturen beschaffen sind. Unter "Wissenschaft" soll hier in einer Arbeitsdefinition ein Prozess sowie ein dazugehöriges, in Aussagenform festgehaltenes Ergebnis methodisch angeleiteter, reflektierter Forschung begriffen werden, wodurch das menschliche Wissen über die Welt in systematischer, grundsätzlich revidierbarer Weise erweitert wird ${ }^{60}$.

\footnotetext{
${ }^{59}$ Die Begriffe "Erkenntnis" und "Wissen" werden von mir durchgehend synonym verwendet (trotz der unten noch zu diskutierenden Problematik des Synonymiebegriffs). Im Englischen spricht man hinsichtlich der Erkenntnistheorie auch von der "theory of knowledge"; insofern wäre es m.E. ebenfalls im Deutschen statthaft, die Erkenntnistheorie als "Theorie des Wissens" zu bezeichnen.

${ }^{60}$ Damit ist für mich die Institutionalisierung von Wissenschaft kein notwendiges Definitionskriterium. Zwar stimme ich der an Popper angelehnten Vorstellung zu, "die gewonnenen Ergebnisse müssen allgemein zugänglich sein, sie müssen zirkulieren, und sie müssen tatsächlich kritisiert werden" (Meleghy 2001: 290). Lediglich jenen Untersuchungen Wissenschaftlichkeit zu attestieren, die innerhalb eines institutionalisierten Kontextes entstanden sind und auch tatsächlich innerhalb eines solchen kritisiert werden, erscheint mir hingegen in einen fragwürdigen Formalismus bzw. Bürokratismus zu münden. Es bedarf wohl keiner allzu großen Phantasie, um sich Forschungen vorzustel-
} 
Auf Basis einer logischen Analyse konkreter Vorgehensweisen und Resultate versucht die Wissenschaftstheorie, allgemeine Regeln der wissenschaftlichen Erkenntnisbegründung zu entdecken, um sie im Anschluss zu systematisieren, zu korrigieren und in Richtung eines Anforderungskatalogs bzw. einer Qualitätssicherung für wissenschaftliche Geltung weiter zu entwickeln. Ergebnisse dürfen i.d.R. Geltung beanspruchen, insofern sie (empirisch) wahr sind, anerkannten methodischen Verfahren entstammen, den Gütekriterien der Forschung genügen, vor dem Hintergrund des aktuellen wissenschaftlichen Erkenntnisstandes akzeptabel erscheinen sowie logisch widerspruchsfrei sind ${ }^{61}$.

Zusätzlich zu diesem, auf wissenschaftliche Verfahren, Forschungslogik und Geltungsanspruch gerichteten methodologischen Aspekt ist die Wissenschaftstheorie auch eine Theorie über Theorien, also explizit eine Metatheorie, deren Objektbereich alle elaborierten theoretischen Aussagensysteme umfasst, die Wissensbehauptungen über die Wirklichkeit aufstellen.

Bewusst verzichte ich darauf, hinsichtlich des genannten Objektbereiches von "empirischen" Gegenstandstheorien zu sprechen. Insbesondere in den Sozialwissenschaften haben wir es nämlich vielfach mit wenig ausgereiften empirischen Gegenstandstheorien zu tun, die weder raumzeitlich unabhängig noch allgemeingültig sind - ganz zu Schweigen von begrifflichen Problemen, die ja den Ausgangspunkt für die in dieser Arbeit vorzunehmende Auseinandersetzung mit der Sozialkapitalthematik bilden. Insofern müsste ein eng gefasstes Verständnis von "Wissenschaftstheorie" den Umfang dieser Metatheorie enorm einschränken. M.E. würde dies jedoch degenerative Entwicklungstendenzen des Forschungsalltags begünstigen, weil die Nicht-Beachtung wissenschaftstheoretischer Überlegungen im Resultat einer weitgehend beliebigen Wissenschaftspraxis Vorschub leisten müsste ${ }^{62}$.

\footnotetext{
len, die allen hier genannten Bedingungen für Wissenschaftlichkeit entsprechen, aber niemals von irgendwem oder doch nur von nicht innerhalb des Wissenschaftsbetriebes autorisierten Personen gelesen werden. Freilich halte auch ich die Institutionalisierung von Wissenschaft aus zahlreichen Gründen heraus für äußerst sinnvoll. Wissenschaftlichkeit sollte m.E. aber ausschließlich von der Erkenntnisbegründung und nicht von der formalen bzw. bürokratischen Einbindung her bestimmt werden.

${ }^{61}$ In diesem Sinn handelt es sich bei der Wissenschaftstheorie um "eine beurteilende, bewertende (normative) Disziplin." (Lenk 1986: 13) Eine Aufforderung zu einer forschungspraktischen Innovationsfeindlichkeit lässt sich daraus m.E. jedoch nicht ableiten. Die hinter dem normativen Impetus stehende Absicht, die Wissenschaftler letztlich selbsttätig "instand zu setzen, ihre wissenschaftliche Arbeit eigenverantwortlich zu kontrollieren, steht im diametralen Gegensatz zu den Ordnungsrufen der Zensoren, die mit ihrem keinen Widerspruch duldenden Negativismus lediglich die Furcht vor dem Irrtum und den resignativen Rückzug auf eine mit Beschwörungsfunktion befrachtete Technologie zu provozieren vermögen." (Bourdieu/Chamboredon/Passeron 1991: 3f.)

62 Im Übrigen werden sogar normative ethische Theorien mittlerweile wissenschaftstheoretisch rekonstruiert (vgl. Ott 2005 [Ott bedient sich dabei des weiter unten noch vorzustellenden strukturalistischen Ansatzes]).
} 
Innerhalb der vorliegenden Untersuchung wird Wissenschaftstheorie vorrangig (aber keineswegs ausschließlich) als Theorie über Theorien interpretiert ${ }^{63}$. Während Wissenschaftstheorie als Methodologie wissenschaftliche Verfahren untersucht und einen normativen Anforderungskatalog an wissenschaftliches Arbeiten formuliert, stehen hier die in Form theoretischer Ansätze vorliegenden Ergebnisse von Forschung, d.h. das behauptete Wissen über die Welt im Vordergrund. Freilich wird es nicht möglich sein, dessen Geltung ohne einen Nachvollzug seines Zustandekommens und das heißt vor allem der jeweils angewandten Methoden zu bewerten. Insofern sind beide dargestellten Verständnisweisen von Wissenschaftstheorie keineswegs absolut trennscharf zu unterscheiden (vgl. Mittelstraß 1981: 98ff.), und beide befragen ihre Gegenstände grundlegend mit Hilfe des von Wolfgang Stegmüller (1973: 5f.) formulierten Rationalitätspostulats, demzufolge Wissenschaft sprachlich präzise, widerspruchsfrei, intersubjektiv nachprüfbar und begründet sein soll.

Der konkrete Anwendungsbereich des zu entwickelnden Instrumentariums wird durch theoretische Konzepte konstituiert, in denen der Sozialkapitalbegriff im Zentrum steht. Auf Basis einer rekonstruktiven Analyse sowie einen sich daran anschließenden Vergleich dieser Konzepte wird neben einer Begriffsexplikation die Entwicklung eines integrativen Theoriemodells angestrebt, was ein dritte, nämlich konstruktive, d.h. theorienbildende Bestimmung von Wissenschaftstheorie impliziert, die so in der Literatur i.d.R. explizit nicht anzutreffen und freilich stark erfahrungswissenschaftlich affiziert ist ${ }^{64}$.

In keiner innerhalb dieser Untersuchung vorkommenden Wendungen ist Wissenschaftstheorie ein Selbstzweck, sondern sie ist ein Instrumentarium zur Rekonstruktion, Präzisierung, Systematisierung und Bewertung der Geltung sozialwissenschaftlicher Erkenntnis. Die nachfolgenden Erörterungen sollen nun den Leser mit diesem Werkzeug vertraut machen. Dabei wird über die Darstellung der wissenschaftstheoretischen Positionen des Logischen Positivismus (der Grundkonzeption des Wiener Kreises, die nachfolgend auch als "Logischer Empirismus" bezeichnet wird) und des Strukturalismus ${ }^{65}$ ein vermittelnder, als "Moderater

\footnotetext{
${ }^{63}$ Problematisch an dieser Formulierung ist gleichwohl, dass die Analytische Wissenschaftstheorie (sowohl in ihrer positivistischen als auch in ihrer strukturalistischen Variante) bestimmte Anforderungen an den wissenschaftlichen Theoriebegriff stellt, den sie selbst nicht erfüllt (und auch gar nicht erfüllen möchte): Die Wissenschaftstheorie ist eben keine Theorie wie etwa die psychologische Theorie sozialer Vergleichsprozesse. Daher sollte man m.E. besser von einem "Rekonstruktionsmodell über erfahrungswissenschaftliche Theorien" reden. Dennoch halte ich mich im Folgenden an die gebräuchliche Diktion.

${ }^{64}$ Dass es sich bei der später vorgenommenen Theoriebildung sehr wohl um ein wissenschaftstheoretisch interpretierbares Verfahren handelt, wird innerhalb des entsprechenden Kapitels noch begründet. Schon an dieser Stelle soll jedoch Kriz et al. widersprochen werden, die einen "ernstzunehmenden Nachteil" der noch ausführlich vorzustellenden strukturalistischen Wissenschaftstheorie darin sehen, "daß die Frage nach der Verbesserung und Veränderung von Theorien hier konzeptionell ausgeblendet wird." (Kriz et al. 1987: 195)

${ }_{65}$ Man spricht auch von einem "Neuen wissenschaftstheoretischen Strukturalismus"; weder die Positionen de Saussures, noch die Levi-Strauss oder Althussers sind hiermit direkt verwandt.
} 
Strukturalismus" bezeichneter Ansatz entwickelt, der dann innerhalb des Anwendungsteils der Auseinandersetzung mit ausgewählten Sozialkapitalkonzepten zugrunde liegen soll.

Abbildung 3 fasst den Zusammenhang von Wissenschafts-, Erkenntnis- und Gegenstandstheorie - so wie er innerhalb dieser Arbeit instrumentell vertreten wird - nochmals graphisch zusammen.

Abbildung 3: Wissenschaftstheorie zwischen Erkenntnis- und Gegenstandstheorie

\begin{tabular}{|c|c|c|}
\hline $\begin{array}{c}\text { Erkenntnistheorie } \\
\text { Wie ist es möglich, } \\
\text { dass wir etwas } \\
\text { wissen können } \\
\text { und was können } \\
\text { wir wirklich sicher } \\
\text { wissen? }\end{array}$ & $\begin{array}{c}\text { Wissenschaftstheorie } \\
\text { Wie lässt sich das } \\
\text { behauptete Wissen } \\
\text { logisch rekonstruieren } \\
\text { und seine Geltung } \\
\text { begründen bzw. be- } \\
\text { werten? }\end{array}$
\end{tabular}$\longrightarrow$\begin{tabular}{c}
$\begin{array}{c}\text { Gegenstandstheorien } \\
\text { Was wissen wir } \\
\text { (vermeintlich) } \\
\text { sicher über die } \\
\text { Welt? }\end{array}$ \\
\\
\hline
\end{tabular}

\subsection{Linguistisches wissenschaftliches Erkenntniskonzept}

In der Analytischen Philosophie werden vor allem zwei partiell unterschiedliche wissenschaftstheoretische Auffassungen vertreten, die nachfolgend vorgestellt werden sollen. Dem linguistischen Wissenschaftskonzept liegt die Annahme zugrunde, menschliche Erkenntnis sei sowohl in ihrem Prozess wie in ihrem Inhalt nur sprachlich zu denken. Davon ausgehend hat sich die Wissenschaftstheorie mit den sprachlichen Formen (i.d.R. ausformulierte Theorien) zu beschäftigen, in denen wissenschaftliche Erkenntnis gewonnen und festgehalten wird. Konkret unterscheidet man im Logischen Positivismus eine analytische und eine synthetische (bzw. empirische) Form wissenschaftlicher Erkenntnis.

\section{Die analytisch-synthetisch-Dichotomie}

Die analytisch-synthetisch-Dichotomie geht insbesondere auf die Kantsche Transzendentalphilosophie zurück ${ }^{66}$. Angetrieben von der Zerstörung metaphysischen Denkens und beeinflusst vom Empirismus der schottischen Aufklärung (insbesondere Hume) versucht Kant eine Antwort darauf zu geben, welche Bedingungen Erkenntnis erst möglich machen. Mit Hume teilt Kant die Orientierung auf sinnliche Wahrnehmung; zugleich bezweifelt Kant jedoch als rationalistisch denkender Leibnizianer, diese allein könne Fundament untrüglicher Erkenntnis

${ }^{66}$ Auf Textstellen zu Kants "Kritik der reinen Vernunft" werde ich - wie in der Literatur im Allgemeinen üblich - mit "A" für die erste und "B" für die zweite Auflage verweisen. 
$\operatorname{sein}^{67}$. Es sei der menschliche Verstand, der unsere Sinneseindrücke erst in eine transzendentale Einheit bringe 68 . Unsere Behauptungen über die Welt, wie etwa naturwissenschaftliche Gesetzesaussagen, seien synthetischer Natur, insofern sie das Resultat einer Synthese von Verstandesleistung (etwa Verbindungen knüpfen, Vergleiche anstellen, Ursachen einführen etc.) und Sinneserfahrung darstellten. "Der Verstand vermag nichts anzuschauen, und die Sinne nichts zu denken. Nur daraus, daß sie sich vereinigen, kann Erkenntnis entspringen." (B 75f.) Kants Sprachkonzept enthält damit eine a priorische, d.h. analytische, sowie eine a posteriorische, d.h. synthetische, Sprachklasse.

Analytische Sätze sind dadurch gekennzeichnet, dass das Subjekt das Prädikat bereits impliziert ${ }^{69}$. Die Aussage "Menschen sind Lebewesen" eröffnet keinen Erkenntnisgewinn, sondern das Prädikat erläutert in Folge einer fixen semantischen Relation lediglich die Bedeutung des Subjekts näher: "Lebewesen zu sein" ist ein erläuterndes Definitionskriterium für den Begriff "Mensch"; Sinneswahrnehmung ist hier nicht erforderlich. Synthetische Sätze hingegen erweitern durch das Prädikat die Erkenntnis über das Subjekt. Die Aussage "Viele Menschen sind unsportlich" fügt dem Wissen über Menschen etwas hinzu, was nicht schon per definitionem festgelegt ist: "Unsportlich zu sein" ist eine empirische Zuschreibung, die (zumindest nach weitläufiger Überzeugung) nicht darüber entscheidet, ob etwas als Mensch bezeichnet werden kann oder nicht ${ }^{70}$.

${ }^{67}$ Hume war radikaler Gegner einer sich nicht auf Sinneswahrnehmung stützenden Wissenschaft: "Sehen wir ... die Bibliotheken durch, welche Verwüstungen müssen wir da nicht anrichten? Greifen wir irgend einen Band heraus, etwa über Gotteslehre oder Schulmetaphysik, so sollten wir fragen: ... Enthält er irgend einen auf Erfahrung gestützten Gedankengang über Tatsachen und Dasein? Nein. Nun, so werft ihn ins Feuer, denn er kann nichts als Blendwerk und Täuschung enthalten." (Hume 1955: 193) Kant, obgleich davon überzeugt, dass "alle unsere Erkenntnis mit der Erfahrung anhebt" (B 1), war weiterhin an unzweifelhaft letzten Erkenntnissen interessiert, die sich der empirischen Betrachtung notwendig entziehen müssen: "Und gerade in diesen letzteren Erkenntnissen, welche über die Sinnenwelt hinausgehen, wo Erfahrung gar keinen Leitfaden noch Berichtigung geben kann, liegen die Nachforschungen unserer Vernunft, die wir, der Wichtigkeit nach, für weit vorzüglicher und ihre Endabsicht für viel erhabener halten, als alles, was der Verstand im Felde der Erscheinungen lernen kann" (B 7). Kant kritisierte also die Form der Metaphysik, insistierte aber auf ihrer Aufgabe, "über Gott, Freiheit und Unsterblichkeit Auskunft zu geben" (Weißmahr 1985: 16). Für Kant war die Metaphysik (lange vor Camus) "der Stein des Sisyphus, an dem man rastlos wältzt und ohne ihn jemals an seine bleibende Stelle zu bringen." (Kant zitiert nach Pieper 1994b: 1)

68 "Ich nenne alle Erkenntnis transzendental, die sich nicht so wohl mit Gegenständen, sondern mit unserer Erkenntnisart von Gegenständen, so fern diese a priori möglich sein soll, überhaupt beschäftigt. Ein System solcher Begriffe würde Transzendental-Philosophie heißen." (B 25) Diese Art der Philosophie ist aber keineswegs übersinnlich orientiert; sie ist vielmehr eine "Analytik des reinen Verstandes", eine "Wissenschaft von den allgemeinsten Begriffen und Grundsätzen aller natürlichen und sittlichen Dinge überhaupt" (Kant zitiert nach Lensing 1999: 1141).

${ }^{69}$ Als Prädikate werden hier im logischen Sinne jene Elemente eines Satzes begriffen, die das Subjekt näher bestimmen. Im oben folgenden Beispielsatz wird das Subjekt "Menschen" näher als zu der Gattung der Lebewesen zählend bestimmt.

70 Bei Kant heißt es allgemein: "Analytische Urteile (...) sind also diejenige, in welchen die Verknüpfung des Prädikats mit dem Subjekt durch Identität, diejenige aber, in denen diese Verknüpfung ohne Identität gedacht wird, sollen synthetische Urteile heißen. Die erstere könnte man auch Erläuterungs-, die andere Erweiterungsurteile heißen, weil jene durch das Prädikat nichts zum Begriff des Subjekts hinzutun, sondern diesen nur durch Zergliederung in seine Teilbegriffe zerfällen, die in 
Die analytischen Sätze fußen also auf einer Erkenntnis a priori, weil sie unabhängig von unserer Wahrnehmung entweder logisch gültig (und das meint tautologisch) oder ungültig sind. Im Hintergrund steht hier die Kohärenztheorie der Wahrheit, wonach lediglich die innere Struktur von Aussagen als Entscheidungskriterium der Wahrheit oder Falschheit bzw. der Gültigkeit oder Ungültigkeit von Sätzen dient. Eine Erkenntnis a posteriori finden wir in synthetischen Sätzen, da nur wahrnehmende Erfahrung uns sagen kann, ob eine Aussage wahr oder falsch ist. In diesem Zusammenhang gilt insofern die Korrespondenztheorie der Wahrheit; ein Satz ist demnach wahr, wenn ein geäußerter Inhalt mit einem von diesem unabhängig existierenden tatsächlichen Sachverhalt korrespon$\operatorname{diert}^{71}$.

Hatte Kant in seiner "Kritik der reinen Vernunft" versucht, die Möglichkeit synthetischer Urteile a priori (also erfahrungstranszendente Erkenntnisurteile über die von Menschen unabhängig existierende Welt, wie etwa "Es gibt Gott") zu ergründen, so wird dies - und damit eine dritte Erkenntnisart, die man als Empirie ohne sinnliche Beobachtung fassen könnte - vom Logischen Positivismus zurückgewiesen. "Gerade in der Möglichkeit der Ablehnung synthetischer Urteile a priori besteht die Grundthese des modernen Empirismus. Die wissenschaftliche Weltauffassung kennt nur Erfahrungssätze über Gegenstände aller Art und die analytischen Sätze der Logik und Mathematik" (Carnap et al. 1929: 18).

Das hier von Carnap propagierte Zweisprachenkonzept der Wissenschaft weist insofern lediglich eine analytische und eine synthetische Klasse auf. Hinsichtlich Letzterer ist mit Blick auf wissenschaftliche Forschung zunächst einmal weniger die Syntheseleistung des Verstandes, als vielmehr der Erfahrungsbezug relevant, weshalb hier vereinfachend von einer "empirischen" Klasse gesprochen werden soll ${ }^{72}$. Alles innerhalb dieser Dualität (analytisch/empirisch) nicht Verortbare gilt als Metaphysik. Die Rede von "Gott", "Vernunft", "Würde", "Prinzip", "Geist" etc. wird daher von den (meisten) Vertretern des Wiener Kreises als sinnlos bzw. Unsinn (eben nicht sinnlich) bezeichnet, weil hier weder eine empirische noch eine analytische Erkenntnis vorliegen kann. Es handelt sich um Scheinbegriffe, d.h. "substantivische Begriffe, von denen irgendwelche adjektivischen Wirkungen nicht ausgehen und denen in der Wirklichkeitswelt nichts entspricht." (Bochumer Arbeitsgruppe 2000: 14) Demnach war die "leading idea of the early critical philosophy the thesis that metaphysical sentences are nonsense because they transcend the limits of language." (Katz 1990: 3) Insofern darf Carnaps Arti-

selbigen schon (obgleich verworren) gedacht waren: dahingegen die letztere zu dem Begriffe des Subjekts ein Prädikat hinzutun, welches in jenem noch gar nicht gedacht war, und durch keine Zergliederung desselben hätte können herausgezogen werden." (B 10f.)

${ }^{71}$ Inwiefern es solche Sachverhalte überhaupt geben kann, wird weiter unten noch einer näheren Betrachtung unterzogen.

72 "Die synthetischen Sätze sind das, was man in üblicher Redeweise 'Behauptungen über die Wirklichkeit' nennt." (Carnap 1992: 96) 
kel "Überwindung der Metaphysik durch logische Analyse der Sprache" (Carnap 1931a) als programmatisch für den Logischen Positivismus gelten.

\section{Signifikanzkriterium und Zweistufenkonzept}

Als ein zentrales Vorhaben des Logischen Positivismus kann der Versuch angesehen werden, eine Wissenschaftssprache zu entwickeln, die lediglich direkt beobachtbare Begriffe aufweist (oder besser: Begriffe, die sich auf unmittelbar Beobachtbares beziehen). Die insbesondere von Wittgensteins Traktat anvisierte sog. "Philosophie der Idealsprache" des 20. Jahrhunderts zielte in diesem Sinne auf eine wissenschaftliche Einheitssprache, in welcher alltagsweltliche Aussagen von ihren Unschärfen und Mehrdeutigkeiten gereinigt sowie die Grenzen menschlicher Rationalität erkennbar sein sollten. Carnap (1928) sprach vom "Logischen Aufbau der Welt", d.h. man wollte über die Entwicklung einer auf der formalen Logik fußenden künstlichen Semantik eine strukturelle Kongruenz zwischen Sprache und Welt erreichen (vgl. Newen/Savigny 1996: 67f.).

Es war dieser Ansatz, der den linguistic turn - also das Wechseln des Untersuchungsgegenstandes, weg von der Sache, hin zu den Begriffen, mit denen über die Sache geredet wird - innerhalb der Wissenschaften begründete ${ }^{73}$. Dabei werden neben Begriffen, die sich auf unmittelbar Beobachtbares beziehen - deren Bedeutungen also in gewissem Sinne mit den bezeichneten Gegenständen in eins fallen lediglich noch formal-logische Verknüpfungen zugelassen ${ }^{74}$. Durch die sprachliche Erfassung des logischen Aufbaus der Welt - so die Überlegung - gelangt man direkt zur Erkenntnis über die Struktur der Wirklichkeit.

Die Frage, welche Begriffe in eine solche Sprache Eingang finden dürfen, wollte man über das sog. Empirische Signifikanzkriterium entscheiden. Empirisch signifikant sind demnach all jene Sätze, die verifizierbar sind, d.h. Sätze, in denen die verwendeten Begriffe Aussagen über sinnlich direkt Beobachtbares möglich machen und auf die demnach das Wahr-Falsch-Kriterium anwendbar ist. "Heute regnet es in Göttingen" ist in diesem Sinne eine empirisch signifikante Aussage,

\footnotetext{
${ }^{73}$ Diese analytische Perspektive charakterisiert die Philosophie ganz allgemein als "Disziplin höherer Ordnung": Es geht um "die Wendung von den Sachverhalten zur Bezugnahme auf Sachverhalte." (Tetens 2004: 18)

${ }^{74}$ Diese reine Bebachtungssprache soll vornehmlich eine physikalische (respektive physikalistische) Sprache sein, denn nur dann gilt die intersubjektive Verständigung zwischen Personen über die Zustände der Welt als unproblematisch. In Folge dessen sind Sätze aus anderen Disziplinen in dieser Sprache auszudrücken (man spricht auch vom "Brückenproblem"). Für Carnap war "die physikalische Sprache eine Universalsprache ..., d.h. eine Sprache, in die jeder Satz übersetzt werden kann. ... Der Physikalismus ist nicht so zu verstehen, als wolle er (bspw., D.K.) der Psychologie vorschreiben, nur physikalisch ausdrückbare Sachverhalte zu behandeln. Es ist vielmehr gemeint: die Psychologie mag behandeln, was sie will, und ihre Sätze formulieren, wie sie will; in jedem Fall sind diese Sätze in die physikalische Sprache übersetzbar" (Carnap 1932: 107f.) Der Satz "Hans ist depressiv", würde in physikalischer Sprache etwa wie folgt lauten: "Hans weist eine erniedrigte Pulsfrequenz auf, er reagiert nur selten auf externe Stimuli, Fragen nach seinem Befinden werden von ihm in sachlich unbefriedigender Weise beantwortet etc."
} 
insofern das über die Äußerung Bezeichnete einer direkten Beobachtung zugänglich ist. Je nachdem, ob es in Göttingen heute regnet oder nicht, ist der Satz entweder wahr oder falsch. Tertium non datur. Nur empirisch signifikante Sätze gelten im Logischen Positivismus als sinnvoll; alle anderen Sätze sind als metaphysisch abzulehnen.

Nun gibt es aber Begriffe, die zwar nicht direkt beobachtbar, dennoch aber innerhalb synthetischer Urteile unverzichtbar sind, wenn man zu einer vollständig(er)en Beschreibung dessen, was Menschen als Welt erfahren, gelangen will. Dispositionsprädikate wie etwa "löslich", "dehnbar" oder "zerbrechlich" sind solche Begriffe. Ein Krug aus Ton weist bspw. die Disposition auf, zerbrechlich zu sein. Der Begriff "zerbrechlich" entzieht sich jedoch einer unmittelbaren Wahrnehmung: Wir können wohl einen zerbrochenen, keinesfalls jedoch einen zerbrechlichen Krug direkt sehen. Die Aussage "Dieser Krug ist zerbrechlich" fußt damit auf nicht unmittelbar beobachtbarem Zusatzwissen - nämlich vor allem dem, dass Krüge zerbrechen können. Insbesondere die Sozialwissenschaften weisen eine Fülle von nicht direkt wahrnehmbaren Prädikaten auf. Als Beispiele seien etwa "intelligent", "fremdenfeindlich", "kommunistisch", "reformorientiert", "sozial mobil" etc. genannt ${ }^{75}$.

Vor allem am Problem der Dispositionsprädikate scheiterte das Ansinnen der Philosophie der Idealsprache, einzig die unmittelbare Erfahrung als Erkenntnisbasis zuzulassen ${ }^{76}$. Stegmüller sah insofern den "Empirismus ... von der Gefahr bedroht, sich zu verflüchtigen." (Stegmüller 1974: 293) Carnap glaubte das Problem über die Einführung einer modifizierten Wissenschaftssprache beseitigen zu können. Im ursprünglichen Zweisprachen-Konzept wurde nur zwischen einer analytischen und einer empirischen Sprachklasse differenziert. Nun zerfällt die empirische Klasse zusätzlich noch in eine beobachtbare Sprache $\mathrm{L}_{\mathrm{B}}$, die direkt zugängliche Terme enthält, sowie eine theoretische Sprache $\mathrm{L}_{\mathrm{T}}$, die Terme, die nicht unmittelbar beobachtbar sind, umfasst ${ }^{77}$. Diese neue Sprachklasse nennt

\footnotetext{
${ }^{75}$ So meinen wir etwa mit "reformorientiert" kein beobachtbares Handeln einer Regierung, sondern eine Klassifizierung eines bestimmten Regierungsstils, welcher durch spezifische Gesetze, Verordnungen etc. indiziert wird.

76 Die Idealsprachenphilosophie scheiterte überdies an der Unmöglichkeit der Formulierung einer von einem archimedischen Standpunkt aus vorgetragenen Kritik an der Umgangssprache: "Jede Sprachnormierung mittels einer geregelten Syntax muß sich der Umgangssprache bedienen, um die Verknüpfungsregeln überhaupt festlegen zu können, da man Regeln nur festlegen kann, wenn man schon Regeln besitzt. Dies ist der Grund für die Normierungsaporie, in die das Idealsprachenprogramm geraten mußte." (Tietz 2004: 29)

77 Die Bezeichnungen "Begriff" und "Term" werden von mir hier synonym verwandt. Grundsätzlich geht es um Denkeinheiten, mit denen wir etwas vermeinen. Um dazu in der Lage zu sein, benötigen wir sprachliche Zeichen bzw. Worte. So können wir mit den Worten "Baum", "Tree" und "Arbre" dasselbe vermeinen, d.h. wir benutzen drei verschiedene Worte für nur einen Begriff. I.d.R. spricht man in der Sprachphilosophie davon, die Bedeutung eines Wortes sei der Begriff für einen Gegenstand (wobei es sich bei diesen Gegenständen um Materielles wie Immaterielles um Empirisches wie Nicht-Empirisches handeln kann), und die in der Wissenschaft verwendeten Zeichen für Begriffe werden "Terme" genannt (womit Terme also - entgegen meiner obigen Festlegung - eigentlich
} 
Carnap nun "empiristisch"; $\mathrm{L}_{\mathrm{T}}$ gilt in ihr als uninterpretierter Kalkül, d.h. um die hier enthaltenen Terme beobachten zu können, müssen sie empirisch interpretiert, also über Korrespondenzregeln mit $\mathrm{L}_{\mathrm{B}}$ in Verbindung gebracht werden, um so einen Kontakt mit der unmittelbar erfahrbaren Welt herzustellen ${ }^{78}$. Damit steht der Logische Positivismus jedoch vor dem Dilemma, Begriffe ausweisen zu müssen, für die ein Signifikanzkriterium nicht direkt anzugeben ist, d.h. deren Bedeutung (innerhalb der positivistischen Bedeutungskonzeption) eine abgeleitete ist.

Zusammenfassend gilt es festzuhalten, dass das Zweisprachen- durch ein Zweistufenkonzept präzisiert wird. Zu unterscheiden ist zwischen einer analytischen und einer empiristischen Wissenschaftssprache. Um Aussagen in diesen Sprachen zu formulieren, stehen auf einer ersten Stufe direkt beobachtbare und auf einer zweiten Stufe theoretische Begriffe zur Verfügung; Letztere werden über Korrespondenzregeln auf die erste Stufe heruntergeführt. Zusätzlich existieren logische Partikel, mit denen Verknüpfungen in und zwischen Sätzen ermöglicht werden.

\footnotetext{
Worte und keine Begriffe sind). Innerhalb der hier vorgenommenen wissenschaftstheoretischen Erörterungen wird es um Denkeinheiten gehen, deren Inhalt durch theoretische Aussagensysteme bestimmt werden; wahlweise spreche ich hinsichtlich dieser Denkeinheiten von bedeutungstragenden "Begriffen" oder "Termen". Eine Differenzierung zwischen Begriffen und Termen verwiese m.E. auf die im mittelalterlichen Universalienstreit anzutreffende Betrachtung von Begriffen als Entitäten (seien sie mental [Wilhelm von Ockham] oder außermental [Thomas von Aquin]), denen keine syntaktische Funktion zukommt (vgl. hierzu bspw. Werner 2003). Begriffe werden dann aber zu etwas Sprachunabhängigem, zu "geistigen Inhalten ..., die durch Worte (lediglich, D.K.) benannt werden" (Lay 1992: 62), stilisiert - eine Position, die ich hier ablehne, denn ohne Worte könnte es überhaupt keine Begriffe geben; "ein Begriff ist also nicht ein 'gedankliches Gebilde', das der Verlautbarung im Wort vorausginge" (Kamlah/Lorenzen 1996: 86). In der Diskussion um den Status von Begriffen ist man sich grundsätzlich einig, dass Begriffe "sich am ehesten am Leitfaden sprachlicher Ausdrücke erkunden lassen." (Charpa 1996: 76) Für die Zwecke dieser Untersuchung ist es daher - insofern nicht entsprechend kenntlich gemacht - im Allgemeinen ausreichend, Kromrey (2000: 154, Fußn. 41) zu folgen: "Hier wird unter 'Begriff' ein sprachliches Zeichen und dessen Bedeutung verstanden." (Wenngleich dies unter sprachphilosophischer Perspektive betrachtet eine Vereinfachung darstellt.)

${ }^{78}$ Dies kann jedoch immer nur partiell geschehen, weil man nie alle Bedeutungskomponenten eines theoretischen Begriffs über Korrespondenzregeln zu erfassen vermag. Man kann etwa in einer Untersuchung eine Anzahl von Indikatoren zur Messung des Konstrukts "Fremdenfeindlichkeit" benennen (indem bspw. bestimmte Antworten auf Items eines Fragebogens als Fremdenfeindlichkeit indizierend bewertet werden [Anwendung von Reduktionssätzen]). Immer sind jedoch auch noch zusätzliche Operationalisierungsmöglichkeiten und damit Bestimmungen dessen, wie sich "Fremdenfeindlichkeit" empirisch zeigt, denkbar, da der Begriff, weil eben im Sinne des Logischen Positivismus nicht direkt beobachtbar, interpretationsbedürftig ist und es einer definitorischen Festlegung des Zusammenhanges zwischen Theorie und Erfahrung bedarf.
} 
Abbildung 4: Das Zweisprachen-/Zweistufenkonzept Carnaps

Zwei Sprachklassen: Analytische Klasse Empiristische Klasse

Vokabular: $\quad$ Korrespondenzregeln

Formal-logische Ver-

knüpfungspartikel

Theoretische

Begriffe

Empirische Begriffe

\section{3. (Neo-) Strukturalistisches wissenschaftliches Erkennt- niskonzept}

Das nicht gelöste positivistische Problem, ein überzeugendes Signifikanzkriterium für theoretische Begriffe anzugeben (also zu explizieren, wie man von hier aus zu eindeutigen Beobachtungsdaten gelangen kann) sowie die lediglich in Abgrenzung zur Beobachtungssprache $L_{B}$ vorgenommene und insofern negative Definition der theoretischen Sprache $\mathrm{L}_{\mathrm{T}}$ (sog. "Putnam-Herausforderung" - man weiß eigentlich nur, was $\mathrm{L}_{T}$ nicht ist $^{79}$ ) führte schließlich zur Ausbildung einer neuen wissenschaftstheoretischen Position.

Theorien werden nun nicht mehr in Gestalt von Aussagen, sondern als eine mengentheoretische Struktur, die mit konkreten empirischen Anwendungen verknüpft ist, dargestellt. Man spricht wahlweise von "Strukturalismus" oder von dem "Non-statement-view" (= Nicht-Aussagenkonzeption) von Theorien ${ }^{80}$. Diese Form einer analytischen Wissenschaftstheorie rekurriert u.a. auf dem weiter unten noch darzustellenden Quineschen Holismus, wurde zu Beginn der 1970er Jahre von David Sneed (1971) formuliert und in der Folge insbesondere von Wolfgang Stegmüller (vgl. z.B. 1979) ausgearbeitet.

\footnotetext{
79 In Putnams Artikel "What theories are not" heißt es (1962: 243): "The almost untouched problem in thirty years of writing about 'theoretical terms' is what is really distinctive about such terms".

${ }^{80}$ Dies bedeutet keineswegs, im Logischen Positivismus sei nicht formalisiert worden. Vielmehr war es gerade ein Anliegen der Philosophie der Idealsprache, eine logische Semantik (Aussagen- und Prädikatenlogik) zu entwickeln. Allerdings war diese Semantik - wie der Name verrät - immer noch als linguistisches Aussagensystem konzipiert. Im Strukturalismus hingegen überführt man Aussagen in den Bereich der Mathematik, indem man aus ihnen mengentheoretische Prädikate macht. Weiter unten wird zu diskutieren sein, ob damit tatsächlich der Aussagencharakter von Theorien zum Verschwinden gebracht wird.
} 
Der Strukturalismus negiert nun auch die Carnapsche Zweistufenkonzeption der Wissenschaftssprache. Damit wird sowohl die Behauptung der Existenz zweier unterschiedlicher Sprachklassen, wie sie in der analytisch-synthetisch-Dichotomie zum Ausdruck kommt, als auch die Differenzierung zwischen den in $\mathrm{L}_{\mathrm{B}}$ sowie den in $\mathrm{L}_{\mathrm{T}}$ enthaltenen Begriffe abgewiesen.

\section{Verwerfung der analytisch-synthetisch-Dichotomie}

In seinem Aufsatz "Die zwei Dogmen des Empirismus" kritisiert der amerikanische analytische Philosoph Willard van Orman Quine (1979) die Trennung in analytische und synthetische Sätze sowie den Reduktionismus, d.h. die Ansicht, Aussagen seien einzeln verifizierbar und insofern unmittelbar auf Erfahrung gründend.

In seiner Argumentation gegen die Analytizität-Synthetizität-Dichotomie hebt Quine insbesondere auf die naive Einführung von Synonymierelationen ab. So kann etwa der (immer wieder gern angeführte) Satz "Kein Junggeselle ist verheiratet" eigentlich nicht als analytisch wahre Aussage gelten, da hier de facto die Ausdrücke "Junggeselle" und "unverheirateter Mann" eine synonyme Verwendung finden ${ }^{81}$. Sicherlich ließe sich dies zuvor definitorisch bestimmen ("Junggeselle = Def "unverheirateter Mann"). "Doch wie finden wir heraus, daß 'Junggeselle' als 'unverheirateter Mann' definiert ist? Wer hat es so definiert und wann?"82 (Quine 1979: 30). Eine lexikalische Festlegung ist lediglich ein sozio-historischer Hinweis auf ein erlerntes, empirisches Sprechverhalten, d.h. wenn Sprecher den Begriff "Junggeselle" verwenden, dann meinen sie damit dasselbe wie bei der Äußerung von "unverheirateter Mann". Definitionen hängen dann aber von der Unterstellung ab, es gebe so etwas wie Synonymie zwischen Ausdrücken. Damit kann der Definitionsbegriff nicht dazu verhelfen, den Synonymiebegriff zu erläutern. Um zu klären, was "Analytizität" ist, hat man also lediglich einen anderen fraglichen Begriff, nämlich den der "Synonymie", eingeführt.

\footnotetext{
${ }^{81}$ Denn von unverheirateten Männern wissen wir durch logisches Schließen, dass sie nicht verheiratet sind. Mittels der Ersetzung von "Junggeselle" durch "unverheirateter Mann" entsteht im Beispielsatz also eine logisch wahre Aussage: "Kein unverheirateter Mann ist verheiratet." "Junggeselle" und "unverheirateter Mann" gelten als synonyme Begriffe. Quine (1979: 29) unterscheidet insofern zwei Klassen analytischer Aussagen: eine logische und eine durch Synonymie errichtete Klasse (und zu Letzterer gehört der Satz "Kein Junggeselle ist verheiratet"). Egal, was für das Subjekt innerhalb der logischen Klasse (im Beispielsatz also "unverheirateter Mann") und für das Prädikat (im Beispielsatz also "ist verheiratet") auch immer eingesetzt wird, die Aussage bleibt wahr (Bsp.: "Kein ungeschickter Maschinenanlagenbauer ist geschickt") ("un-" ist ein logischer Partikel, ein Negativoperator $[\neg]$, der nicht ersetzt werden kann).

82 Ethymologische Nachforschungen könnten angestellt werden. Keil weist unter Bezugnahme auf die Brockhaus Enzyklopädie darauf hin, dass "Junggeselle" im 15. Jahrhundert einen sich auf der Wanderschaft befindlichen Handwerksgesellen bezeichnete (vgl. Keil 2002: 164, Fußn. 33). Waismann (1976: 230) führt weitere Beispiele an: "'Keck' hatte ursprünglich den Sinn von 'lebendig' (vgl. Quecksilber), 'schlecht' den von 'schlicht' (schlechtweg), 'Empfindung' bedeutete soviel wie 'Gefühl' (empfindsam) etc."
} 
Zwecks Lösung dieses Problems könnte man versuchen, Synonymie wie folgt zu bestimmen: Begriffe sind synonym, wenn sie in allen Kontexten austauschbar sind und sich der Wahrheitswert der Aussage dabei nicht verändert. Nun weist aber der Satz "'Junggeselle' hat weniger als 12 Buchstaben" eindeutig einen anderen Wahrheitswert auf als der Satz "'Unverheirateter Mann' hat weniger als 12 Buchstaben"83 (vgl. Quine 1979: 34). Die Abgrenzung zwischen analytischen und synthetischen Sätzen ist nach Quine daher "ein unempirisches Dogma der Empiristen, ein metaphysischer Glaubensartikel"84 (ebenda: 42). Es ist demnach auch unmöglich, "einen Teil innerhalb der Sprache auszusondern, der allein aufgrund von sprachlichen Festlegungen (...) wahr ist und aus diesem Grund prinzipiell immun gegen empirische Revisionen ist." (Naumann 1990: 232) Es gibt keine Aussagen, die alleine in Folge ihrer Sinnkomponente als analytisch auszuweisen wären. Der Unterschied zwischen einer faktischen und einer Sinnkomponente für Aussagen ist ausschließlich mit Blick auf ein Sprachsystem zu beurteilen, womit die Abgrenzung zwischen Analytizität und Synthetizität ebenso sprachrelativ ist.

\section{T-Theoretizität}

Im neuen wissenschaftstheoretischen Strukturalismus wird die Unterscheidung zwischen beobachtbaren und theoretischen Begriffen, wie sie in Carnaps Zweistufenkonzept durch die Einführung von $\mathrm{L}_{B}$ und $\mathrm{L}_{\mathrm{T}}$ ihren Ausdruck fand, strikt an eine bestimmte Theorie gebunden. D.h. "theoretisch in bezug auf eine Theorie T sind genau diejenigen Größen oder Funktionen, deren Werte sich nicht berechnen lassen, ohne auf diese Theorie T selbst (...) zurückzugreifen." (Stegmüller 1985: 47) M.a.W.: Beobachtbar sind relativ zu einer Theorie all jene Begriffe, die ohne diese Theorie empirisch bestimmbar sind; theoretisch sind umgekehrt all jene Begriffe relativ zu einer Theorie, bei denen die empirische Bestimmung nur unter Zugrundelegung dieser Theorie erfolgen kann.

83 Allerdings ließe sich kritisch anmerken, dass es hier weder um die inhaltliche Bedeutung - wenn man diese Formulierung an dieser Stelle in Kontrast zu Quine einmal beibehalten darf - noch um den realweltlichen Bezug geht, sondern um die Anzahl der Buchstaben der sprachlichen Zeichen "Junggeselle" und "unverheirateter Mann". Hat Quine damit aber wirklich ein Argument gegen Synonymie formuliert?

84 Der Vollständigkeit halber sei angemerkt, dass Quine noch weitere (Schein)Lösungsmöglichkeiten des Analytizitätsproblems diskutiert: Die Einführung einer künstlichen Sprache sowie die Berufung auf semantische Regeln. Im ersten Fall wird jedoch Analytizität vorausgesetzt, um Analytizität zu klären: "Kurz, bevor wir eine Regel verstehen, die beginnt 'Eine Aussage $S$ ist analytisch für die Sprache $L_{0}$ dann und nur dann, wenn ...' müssen wir den allgemeinen relativen Term 'analytisch für' verstehen" (Quine 1979: 39). Im zweiten Fall wird wiederum anstelle von Analytizität ein neuer ungeklärter Begriff, der der "semantischen Regel", eingeführt: "Wir können allerdings sagen, daß eine Aussage dann und nur dann analytisch-für- $L_{0}$ ist, wenn sie aufgrund der und der spezifisch angefügten 'semantischen Regeln' wahr ist ...; der Relativterm 'semantische Regel von' bedarf der Klärung ... mindestens so sehr wie 'analytisch für'." (ebenda: 40) Für eine Auseinandersetzung mit Quines Kritik an den Termen "Synonymie" und "Analytizität" siehe Müller 1998. Müller versucht in seiner Argumentation unter Beibehaltung der naturalistischen Position Quines die beiden Terme eliminativ, d.h. ohne Rückgriff auf andere semantische Terme, zu bestimmen. 
Dies bedeutet gerade nicht, dass ein als nicht-theoretisch klassifizierter Begriff in einem absoluten Sinn empirisch genannt werden könnte. Vielmehr ist er selbst wiederum theoretisch in Bezug auf eine andere Theorie. Im Strukturalismus spricht man im Unterschied zum Positivismus nicht mehr von "theoretischen", sondern von "T-theoretischen" Termen, um damit die Relativität der Bezeichnung herauszustreichen. Allerdings wird "die Unterscheidung theoretischer und nichttheoretischer Komponenten ... in abstracto nicht begründet. Sie ist bei der Anwendung der Meta-Theorie auf bestimmte Objekt-Theorien jeweils konkret zu treffen und zu verantworten" (Diederich 1981: 55).

In seiner Rekonstruktion der Freudschen Theorie des Unbewussten "verantwortet" Wolfgang Balzer die Bestimmung T-theoretischer Terme bspw. wie folgt: "Die Wörter 'Unbewußtes' und 'psychischer Akt' kommen vor Freud nicht (oder zumindest nicht wesentlich) in der Umgangssprache vor. Sie sind vielmehr (T-) theoretische Terme, die von Freud in Zusammenhang mit seiner Theorie erstmals eingeführt wurden. Eine typische Eigenschaft (T-)theoretischer Terme ist aber, daß sie ihre Bedeutung erst im Rahmen der für sie zuständigen Theorie erlangen" (Balzer 1982: 35).

Allgemein lässt sich also festhalten, dass im Strukturalismus der Versuch, ein Kriterium für eine reine Beobachtungssprache zu definieren, überwunden wird, indem man die generelle Theoriegebundenheit sprachlicher Aussagen herausstreicht. In diesem Sinne hat Quine in seinem oben schon genannten Aufsatz "Die zwei Dogmen des Empirismus" die positivistische Überzeugung, menschliches Wissen fuße auf einfachen Beobachtungssätzen, zurückgewiesen ${ }^{85}$. Da diese Position in ähnlicher Form bereits um die Wende zum 20. Jahrhundert von dem franzö-sischen Physiker und Wissenschaftsphilosophen Pierre Duhem (1996) vertreten wurde, spricht man in der Wissenschaftstheorie von der "Duhem-QuineThese". Die Frage, ob ein Term theoretisch oder empirisch aufzufassen ist, lässt sich nur noch auf dem Hintergrund einer finiten Theorie klären ${ }^{86}$.

Während das Dilemma des Logischen Positivismus darin bestand, empirische Begriffe ausweisen zu müssen, die sich doch einer unmittelbaren Beobachtung entziehen, gelten nun gewissermaßen umgekehrt auch die vermeintlich direkt beobachtbaren Begriffe als prinzipiell theoretisch; Theorien können und müssen sich den Gegenständen also vor dem Hintergrund des Sprachganzen stellen. Dies bedeutet keineswegs ein intellektuell-spitzfindiges Ausweichen vor dem ungelösten Problem des empiristischen Signifikanzkriteriums für theoretische Terme.

\footnotetext{
85 Quine behauptet, "dass unsere Aussagen über die Außenwelt nicht als einzelne Individuen, sondern als ein Kollektiv vor das Tribunal der sinnlichen Erfahrung treten". (Quine 1979: 45)

86 Daraus nun allerdings zu folgern, "der Begriff des Empirischen, ..., weist daher in dieser (der strukturalistischen, D.K.) Konzeption auch gar keinen wesentlichen Zusammenhang mehr mit sinnlicher Beobachtbarkeit oder sinnlicher Erfahrung auf" (Rusch 2001: 110), halte ich für eine grundlegende Fehlinterpretation des Strukturalismus, ist dieser doch nach wie vor um die Eliminierung theoretischer Terme und insofern um empirische Erkenntnis im positivistischen Sinne bemüht.
} 
Vielmehr fußt die Behauptung auf philosophischen und linguistischen Überlegungen zur sprachlichen Relativität allen menschlichen Wissens über die Wirklichkeit. Aus darstellungsökonomischen und -systematischen Gründen erfolgen die diesbezüglichen Erörterungen erst innerhalb des ontologischen Grundlagenteils dieser Arbeit.

Mit der Verwerfung der analytisch-synthetisch-Dichotomie und mit der Ablehnung einer absoluten Unterscheidung zwischen direkt beobachtbaren und theoretischen Begriffen wird die Carnapsche Einteilung der Wissenschaftssprache fragwürdig. Analytizität ist nicht mehr sinnvoll einführbar und Empirizität wie Theoretizität sind ausschließlich relativ zu begründen. Theorien - etwa über prosoziales Verhaltens, Genetik, Gravitation etc. - sind untereinander in manigfacher Weise verflochten und aufeinander angewiesen. Als beobachtbar gelten in ihnen jeweils all die Begriffe, zu deren Bestimmung auf andere als eine gerade in Frage stehende Theorie zurückgegriffen werden kann ${ }^{87}$. Dies wiederum verweist auf die soziale Bedingtheit der Postulierung empirischer Terme, denn diese anderen Theorien müssen - will man nicht in einen infiniten Regress geraten - innerhalb eines spezifischen Handlungskontextes als korrekt bzw. gültig anerkannt werden.

Bis hierhin wurde insbesondere darauf abgehoben, die vom Strukturalismus betonte relative Theoretizität aller Begriffe darzustellen. Führt man diesen Gedanken zu Ende, so sind - wie bereits erwähnt - alle Begriffe (vermeintlich) absolut theoretisch, insofern sie nur innerhalb eines sprachlichen Kontextes ihre Bedeutung erlangen. Die Rede von nicht-theoretischen Begriffen kann also nur meinen, dass man im Kontext einer finiten Theorie gewissermaßen naiv unterstellt, hier handele es sich um eindeutig empirisch bestimmbare Terme. Im Zusammenhang mit der Ausarbeitung des Moderaten Strukturalismus werden die hieraus resultierenden wissenschaftstheoretischen Konsequenzen noch detailliert erörtert.

Die folgenden Betrachtungen zeigen nun, welche formalen Ansprüche der Strukturalismus mit Theorien verbindet bzw. mit welcher metasprachlichen Konzeption objektsprachliche Aussagensysteme strukturalistisch zu rekonstruieren sind. Aufgrund der für Sozialwissenschaftler im Allgemeinen wohl eher schwer

\footnotetext{
${ }^{87}$ Ein anschauliches Beispiel bietet etwa Troitzsch: "Bezüglich sozialwissenschaftlicher Theorien ist z.B. die Zeit ein beobachtbarer Begriff, weil es keiner sozialwissenschaftlichen Theorie (mehr) bedarf, um Zeit messbar oder beobachtbar zu machen." (Troitzsch 1990:136f.) Allerdings wäre hier zu kritisieren, dass nicht "die Zeit", sondern "Zeit" in den Sozialwissenschaften ein beobachtbarer Begriff ist. Durch die Voranstellung eines Artikels sowie das Fehlen von Anführungszeichen (also die fehlende Markierung des semantischen Aufstiegs) entsteht der Eindruck, es ginge um den über den Begriff bezeichneten Sachverhalt und nicht um den Begriff selber. In seiner Rekonstruktion von Festingers Theorie der kognitiven Dissonanz sind für Westermann die Begriffe "magnitude of dissonance", "dissonance reduction pressure", "dissonance within pairs" sowie "consonance within pairs" T-theoretische Terme, da sie erstmals bei Festinger auftauchen. Alle weiteren zentralen Begriffe ("time", "raw elements of cognition", "actual elements of cognition", "dissonant cognitions", "consonant cognitions") sind nach Westermann nicht T-theoretisch. Sie sind entweder aus anderen psychologischen Theorien (insbesondere der Heiderschen Balance-Theorie) oder aber aus der Umgangssprache bereits bekannt (vgl. Westermann 2000: 195).
} 
zugänglichen Thematik werde ich ausschließlich die Grundlagen erläutern und auf eine allzu starke Mathematisierung verzichten.

Schon an dieser Stelle sei erwähnt, dass ich den Strukturalismus angesichts der sozialwissenschaftlichen Praxis in seiner klassischen Form für ein zu aufwendiges und ineffizientes wissenschaftstheoretisches Konzept halte. Daher soll über die nachfolgende Darstellung mit Blick auf die in dieser Untersuchung innerhalb des Anwendungsteils zu leistende Theoriearbeit eine - wie ich sie nennen möchte "moderate" Form des Strukturalismus ausgearbeitet werden. Eine moderate wird von einer klassischen Form insbesondere durch vier (später noch genauer zu bestimmende) Merkmale zu unterscheiden sein:

Verzicht auf eine kategorische Abgrenzung zum Logischen Positivismus,

Verzicht auf eine allzu detaillierte Formalisierung sowie vor allem

Verzicht auf eine Eliminierung theoretischer Terme und damit zusammenhängend

Verzicht auf die Vorstellung, Theorien könnten anhand der Realität verifiziert, falsifiziert oder doch zumindest auf die Realität angewendet werden ${ }^{88}$.

\section{Mengentheoretische Theoriendarstellung ${ }^{89}$}

Im Unterschied zur Theorienkonzeption des Logischen Positivismus werden Theorie und Empirie im Strukturalismus nicht mehr getrennt, sondern die Empirie wird gewissermaßen zur Theorie dazugehörig gedacht. Eine Theorie besteht aus:

(a) einer logischen (mengentheoretischen) Struktur, dem sog. "Theoriekern" $K$, sowie

(b) einem empirischen Anwendungsteil, d.h. einem Bereich, auf den dieser Kern gleichsam gerichtet ist, welchen er anvisiert bzw. intendiert, den sog. "intendierten Anwendungen" I.

Demnach ist eine Theorie mengentheoretisch definiert als geordnetes Paar der Form

$\mathrm{T}=<\mathrm{K}, \mathrm{I}>90$

\footnotetext{
88 Weiter unten werde ich argumentieren, dass man allenfalls die Komplementarität zwischen zwei Theorien, nicht jedoch jene zwischen Theorie und Realität testen kann.

89 Vgl. hierzu etwa Balzer 1982 und 1997, Balzer/Moulines 2000, Diederich 1981, Dreier 1997, Druwe 1985, Klein 1995, Kühnel 1993, Stegmüller 1979 u. 1986a, Westermann 2000a, Zoglauer 1991. Eine mengentheoretische Theoriendarstellung wurde Ende der sechziger Jahre erstmals von Patrick Suppes (vgl. Suppes 1993) zur Axiomatisierung der Mechanik eingeführt. (Ganz kurze strukturalistische Rekonstruktionen zweier Theorien ohne Verwendung des mengentheoretischen Vokabulars finden sich bei Wenturis/Van hove/Dreier [1992: 348ff.] - für den Einstieg mögen die dortigen Ausführungen daher besonders geeignet sein.)
} 
Der Kern einer jeden Theorie weist nun eine bestimmte formale Struktur auf ${ }^{91}$. Intendierte Anwendungen, also empirische Gegenstandsbereiche, die dieser formalen Struktur entsprechen, die also demgemäß darstellbar sind, werden entweder als

(a) potentielle Modelle $M_{p}$, als

(b) Modelle $M$ oder als

(c) partielle potentielle Modelle $M_{p p}$

der Theorie bezeichnet ${ }^{92}$.

Ein potentielles Modell $\left(M_{p}\right)$ ist eine formale Darstellung eines Extensionsbereichs, auf den die begrifflich konkretisierten Komponenten bzw. Teilelemente der Theorie anwendbar sind ${ }^{93}$. Angenommen, die Struktur einer Rationalen Handlungsthe-

${ }^{90}$ I.d.R. spricht man innerhalb der strukturalistischen Wissenschaftstheorie von "Theorieelementen"; sind diese über Relationen miteinander verbunden, entsteht ein "Theorienetz" (vgl. etwa Stegmüller 1979: 139f.). "Der Begriff 'Theorie' wird auf diese Weise in die beiden Begriffe 'Theorieelement' und 'Theorienetz' ausdifferenziert."(Kühnel 1993: 40) Diese Sprachregelung soll andeuten - und darauf wurde mit dem Hinweis auf T-Theoretizität schon aufmerksam gemacht -, dass das, was wir gemeinhin als "Theorie" bezeichnen, kein in sich abgeschlossenes Gebilde darstellt, sondern Veränderungen unterliegt und in manigfachen Bezügen zu anderen Theorien steht bzw. von diesen abhängig ist. Ich werde dennoch im Folgenden weiterhin von "Theorien" reden, da nicht der Veränderungs- oder Vernetzungsaspekt, sondern vorrangig die innere, logische Struktur von Aussagensystemen im Blickpunkt des Interesses steht (was freilich nicht bedeutet, dass etwa der Vernetzungsaspekt damit in Abrede gestellt würde) (außerdem wird hier nicht mit dem Begriff "Spezialgesetze" gearbeitet, der im Strukturalismus ebenfalls die Einführung von "Theorie-Netzen" begründet).

91 Strukturalisten selbst sehen ihren Entwurf allerdings als "informell" an und grenzen ihn von der "formalen" Wissenschaftssprache des Positivismus ab. Für Stegmüller ist die mengentheoretische Theoriendarstellung "einerseits 'so etwas wie eine Formalisierung', da hierdurch der Präzisionsgrad der modernen Mengenlehre erreicht wird. Andererseits wird auf den Gebrauch formaler Sprachen verzichtet, da man nur die informelle, d.h. in der Umgangssprache formulierte Mengenlehre benützt." (Stegmüller 1986b: 475) Insofern im Strukturalismus verbale Aussagen in eine mengentheoretische und damit mathematische Struktur überführt werden, spreche ich im folgenden dennoch von einer "formalen" Darstellungsweise (um beide Aspekte zu berücksichtigen, kann man auch von einer "informellen Formalisierung" sprechen [Dreier 1997: 207]).

92 Zoglauer (1991: 61) versteht unter den intendierten Anwendungen lediglich "empirische Systeme, die als Kandidaten für Theorie-Modelle in Frage kommen." Insofern kann es sich in dieser Lesart bei intendierten Anwendungen ausschließlich um partielle potentielle Modelle handeln $\left(\mathrm{I} \subset \mathrm{M}_{\mathrm{PP}}\right.$ ). Zusätzlich enthält der Kern neben $\mathrm{M}, \mathrm{M}_{\mathrm{p}}$ und $\mathrm{M}_{\mathrm{pp}}$ als weitere Glieder auch noch eine Restriktionsfunktion $r$ und Constraints $C$. Die Restriktionsfunktion wird formal benötigt, um die verschiedenen Modellformen ineinander zu übersetzen (um etwa aus $\mathrm{M}_{\mathrm{p}} \mathrm{M}_{\mathrm{pp}}$ zu machen und umgekehrt) (vgl. Dreier 1997: 205f.). Bei Constraints handelt es sich um spezifische Querverbingungen wie etwa der, dass gleichen Elementen in unterschiedlichen Systemen die gleichen Merkmale zugeordnet werden (sog. Identitätsquerverbindung, vgl. Stegmüller 1986b: 491). "Zum Beispiel ist die Erdmasse in den beiden Teilsystemen 'Erde-Sonne' und 'Erde-Mond' identisch." (Zoglauer 1991: 62) Da eine Einbeziehung der Restrinktionsfunktion und von Constraints im vorliegenden Zusammenhang weder notwendig ist (so wird es etwa nicht um die Anwendung, sondern um die Rekonstruktion und den Vergleich von Theorien gehen), noch der Verständlichkeit dienen würde, sei dies hier nur der Vollständigkeit halber vermerkt.

${ }^{3}$ Genauer gesagt, werden Modelle (ob nun $\mathrm{M}, \mathrm{M}_{\mathrm{p}}$ oder $\mathrm{M}_{\mathrm{pp}}$ ) als ein "'Stück' Realität in dem Sinne betrachtet, als jede(s) von ihnen eine formale, die wesentlichen Aspekte dieser Realität synthetisierende Repräsentation eines bestimmten Gebietes unserer Erfahrung darstellt. Jedes Modell einer Theorie fokussiert die Aufmerksamkeit des Forschers auf bestimmte Arten von Dingen und auf 
orie enthalte als Teilelemente einen Akteur (A), Ursachen von Handlungen (U), Handlungsalternativen $(\mathrm{H})$, eine Präferenzstruktur $(\mathrm{P})$, Konsequenzen bzw. Wirkungen von Handlungen (W), erwartete Eintrittswahrscheinlichkeiten von Handlungskonsequenzen (E) und Nutzen von Handlungskonsequenzen $(\mathrm{N})$, dann lässt sich die Struktur als $\langle A, \mathrm{U}, \mathrm{H}, \mathrm{P}, \mathrm{W}, \mathrm{E}, \mathrm{N}\rangle$ beschreiben. Hierbei handelt es sich um ein mengentheoretisches Tupel, d.h. eine zusammenfassende Darstellung von miteinander in Verbindung stehenden Komponenten ${ }^{94}$.

Ordnet man einer realen Gegebenheit nun diese Komponenten zu, so entsteht ein potentielles Modell der Theorie. Wenn etwa ein Akteur (A), nennen wir ihn "Peter", aufgrund einer bestimmten Ursache (U), nennen wir diese "Interesse an Politik", in Folge einer Präferenzstruktur (P), für "gemeinwohlorientierte Aktivitäten", eine bestimmte Handlungsalternative $(\mathrm{H})$, wie etwa die "Aufnahme eines Soziologiestudiums", selegiert und sich hiervon als wahrscheinlich eintretende (E) Wirkungen (W) eine "erhöhte Lebenszufriedenheit" sowie langfristig "einen gesicherten Arbeitsplatz" und insofern einen bestimmten Nutzen (N) erwartet, dann lässt sich dies u.a. als ein potentielles Modell dieser Rationalen Handlungstheorie auffassen 95 .

Man spricht von einem potentiellen bzw. einem möglichen Modell der Theorie, weil an dieser Stelle nur das Begriffsgerüst auf die Realität angewandt wird, d.h. im Falle von Peter und seiner Studienfachwahl handelt es sich möglicherweise (potentiell) um einen Sachverhalt, der im Sinne einer Rationalen Handlungstheorie analysiert werden könnte - er enthält jedenfalls alle begrifflichen Komponenten, welche die Theorie voraussetzt.

Zusätzlich spezifiziert man in einem potentiellen Modell noch die verwendeten Terminologien. So ließen sich etwa "Ursachen" (U) als eine endliche, nicht-leere Menge bestimmen, d.h. eine Handlung ist immer auf eine (daher nicht-leere Menge) oder mehrere, in jedem Fall aber auf endlich viele Ursachen (daher endliche

bestimmte Beziehungen zwischen ihnen" (Moulines o.J.). Der Modellbegriff bezeichnet also demnach eine strukturelle Konstruktion, mit der ein empirischer Gegenstandsbereich vereinfacht, unter Beschränkung auf die als zentral erachteten Komponenten und Zusammenhänge, abstrahierend dargestellt werden soll. Problematisch daran ist, dass Modelle dann gleichsam formales Begriffsgerüst wie empirisches System sein sollen. Am Ende dieses Kapitels wird hierauf noch zurückzukommen sein.

${ }^{94}$ Exakter gesprochen, handelt es sich um ein kartesisches Produkt, d.h. eine mehrstellige Relation der Menge A auf die Menge U auf die Menge H etc. "Unter einer Menge versteht man dabei den Umfang eines Begriffs". (Kutschera/Breitkopf 1992: 150) Man fasst also die begrifflich bezeichneten Komponenten der Theorie (auch etwa Relationen oder Funktionen) als Mengen auf und die Zusammenschau der Mengen, d.h. das In-Beziehung-Setzen der einzelnen Elemente dieser Mengen in Form einer geordneten 7-stelligen Folge A x U x H x P x W x E x N (also etwa ein Akteur, wählt aufgrund einer bestimmten Ursache, eine Handlung etc.) ist dann eine Teilmenge des kartesischen Produkts.

${ }^{95}$ Es geht an dieser Stelle nicht um eine exakte und detaillierte Rekonstruktion einer speziellen Theorie. Hier sollen lediglich die Grundlagen der strukturalistischen Wissenschaftstheorie in verständlicher Form innerhalb eines sozialwissenschaftlichen Kontextes einführend plausibilisiert werden. 
Menge) zurückführbar. Im Beispielfall wurde der Einfachheit halber nur von einer Ursache ("Interesse an Politik") ausgegangen.

Ein Modell (M) der Theorie beinhaltet nun zusätzlich zu den im potentiellen Modell bereits zugeordneten Begriffe die substantiellen Axiome bzw. theoretischen Postulate, d.h. die eigentlichen Zusammenhänge oder die fundamentalen Gesetze der Theorie. Wichtige Komponenten werden also inhaltlich in Beziehung zueinander gesetzt. Für eine Rationale Handlungstheorie ließe sich etwa als ein zentrales Axiom formulieren, dass ein Akteur unter mehreren möglichen Handlungsalternativen jene auswählt, die in der Zusammenschau der erwarteten Eintrittswahrscheinlichkeiten der mit der Handlung verbundenen Wirkung[en] sowie der diesbezüglichen persönlichen Nutzeneinschätzungen den größten Vorteil verspricht.

Sollte also Peter (unser Akteur) alternativ zu einem Soziologie- auch mit einem Politikstudium geliebäugelt haben (zwei Handlungsalternativen; $H=\left\{h_{1}, h_{2}\right\}$ ), dann kann seine tatsächlich vorgenommene Entscheidung als Modell einer Rationalen Handlungstheorie bezeichnet werden, wenn er nach Zusammenschau (a) der erwarteten Eintrittswahrscheinlichkeiten der möglichen Wirkungen einer konkreten Studienfachwahl sowie (b) einer Abwägung des jeweils mit den möglichen Wirkungen verbundenen Nutzens zu der Auffassung gelangt ist, Soziologie zu studieren $^{96}$. (Zur Illustration: Peter könnte bspw. denken, mit einem Politikstudium würde er sein Interesse an Politik sicherlich am stärksten befriedigen, aber ein Soziologiestudium, so seine Überzeugung, bietet ihm später besserer Berufschancen; da Peter später auf gar keinen Fall arbeitslos sein möchte, wählt er Soziologie.)

In einem partiellen potentiellen Modell $\left(M_{p p}\right)$ werden nun in empiristischer Tradition die theoretischen Terme des potentiellen Modells entfernt. Hier stellt sich also die Frage, welche der innerhalb des potentiellen Modells genannten Begriffe nur auf Grundlage der Theorie beobachtbar sind. Im Fall einer Rationalen Handlungstheorie ließe sich wohl vor allem der Nutzenbegriff als T-theoretisch ausweisen, da dieser hier im Unterschied zu anderen soziologischen Handlungstheorien strikt ökonomistisch auf den Akteur relativiert ist. In seinen "metatheoretischen Reflexionen über Handlungs- und Entscheidungstheorie(n)" begreift Dreier aus einer Vergleichsperspektive heraus den Handlungsbegriff als T-theoretisch. Die Frage nach der Semantik des Handlungsbegriffs könne nicht in der Form "'Was ist eine Handlung?' beantwortet werden, sondern nur über ihre methodologische Funktion innerhalb einer bestimmten Theorie." (Dreier 1996: 61)

Der Bereich der intendierten Anwendungen (I) umfasst nun sämtliche realen Systeme, welche die Auflagen des Kerns erfüllen, auf die also das mengentheoretische Prädikat zutrifft. Oben wurde das beispielhaft an "Peters Studienfachwahl" illus-

\footnotetext{
${ }^{96}$ Formal: $\forall\left(\mathrm{h}_{1}\right) \forall\left(\mathrm{h}_{2}\right)$

$\left(\Sigma \mathrm{E}\left[\mathrm{W}_{\mathrm{h} 1}\right] * \mathrm{~N}\left[\mathrm{~W}_{\mathrm{h} 1}\right] \geq \Sigma \mathrm{E}\left[\mathrm{W}_{\mathrm{h} 2}\right] * \mathrm{~N}\left[\mathrm{~W}_{\mathrm{h} 2}\right] \rightarrow \mathrm{h}_{1}\right)(\mathrm{Um}$ die Darstellung an dieser Stelle nicht unnötig zu verkomplizieren, sei dies hier zunächst nur der Vollständigkeit halber erwähnt.)
} 
triert. Alle intendierten Anwendungen einer Theorie, die sowohl der begrifflichen Struktur als auch den zentralen Zusammenhängen der Theorie genügen, sind somit Modelle der Theorie. Für eine Rationale Handlungstheorie ist der Bereich der intendierten Anwendungen enorm groß. Er reicht von politischen Entscheidungen über Abwägungsprozesse beim Autokauf bis hin zur Wahl zwischen Chianti und Trollinger.

Folgt man den Aussagen der Strukturalisten, dann macht eine strukturalistisch formulierte Theorie keine Aussagen über die Wirklichkeit; sie ist lediglich ein die Aufstellung empirischer Behauptungen ermöglichendes Instrument. Eine Verifikation oder Falsifikation von Theorien ist daher ausgeschlossen. Selbst wenn konkrete intendierte Anwendungen die Bedingungen der Theorie nicht erfüllen, wird die Theorie als $\mathrm{T}=\langle\mathrm{K}, \mathrm{I}\rangle$ davon nicht tangiert, insofern hier lediglich ein mengentheoretisch formulierter und daher empirieunanfälliger mathematischer Kern sowie ein Bereich möglicher Anwendungen genannt sind. Es kann sich also allenfalls herausstellen, dass ein empirischer Objektbereich keine intendierte Anwendung bzw. kein Modell darstellt und insofern das Begriffsgerüst und/oder die Axiome der Theorie nicht erfüllt. M.a.W. strukturalistische Theorien sind "immun" gegenüber "aufsässigen Erfahrungen"97 (Stegmüller 1980: 121).

Diese Perspektive - so lässt sich kritisch anmerken - kann auf dem Hintergrund der definitorischen Festlegungen nicht wirklich überzeugen: Einerseits konstituieren Modelle den angeblich empirieunanfälligen formalen Kern einer Theorie; andererseits werden sie aber auch zugleich als ein "'Stück' Realität" (Moulines o.J.) aufgefasst. Modelle gehören also irgendwie genauso zu K wie zu I. K und I sind wiederum das geordnete Paar, das T konstituiert, womit angedeutet werden soll, dass innerhalb einer strukturalistischen Theoriendarstellung die Empirie zur Theorie hinzugedacht wird. Dann bleibt aber unklar, warum eine solche Theorie falsifikationsresistent sein soll. Dies kann allenfalls - wie gesagt - vom Kern behauptet werden, der nun jedoch leider mit M ein "'Stück' Realität" enthält.

Man könnte dies u.U. vermeiden, indem man Modelle strikt analytisch begreift und ihre Aufgabe darin sieht, stringente Ordnung zu simulieren; Modelle wären dann erst über die Bildung eines empirischen Relativs auf einen konkreten Gegenstandsbereich übertragbar. Sprachphilosophisch fiele man dann aber wieder in die analytisch-synthetisch-Dichotomie zurück. Um dies zu vermeiden, sollte man zum Kern einer Theorie nur die "Menge" bzw. die "Klasse" der Modelle rechnen (vgl. Lütkemeier 2001: 56), während die Modelle selbst (im Unterschied zu ihrer Menge bzw. Klasse) der Extension des mengentheoretischen Prädikates entsprechen und damit dem empirischen Gegenstandsbereich zuzuordnen sind.

\footnotetext{
97 Interessanterweise - und dies möchte ich dem Leser nicht vorenthalten - hat Edmund Husserl (von dem man dies wohl eher nicht erwarten würde) sich einmal in durchaus nicht unähnlicher Weise geäußert: "Würden alle der Gravitation unterliegenden Massen verschwinden, so wäre das Gravitationsgesetz damit nicht aufgehoben, sondern würde einfach ohne mögliche Anwendung weiter bestehen" (Husserl zitiert nach Camus 2000: 63).
} 


\section{Methode der Rationalen Rekonstruktion}

Eine Rationale Rekonstruktion ist eine Methode zur wissenschaftstheoretischen Untersuchung theoretischer Aussagensysteme; es handelt sich um ein Verfahren, das in der logischen Analyse und axiomatisierten Beschreibung von Theoriegebäuden besteht. Dabei geht es nicht darum, eine "richtige Interpretation" eines theoretischen Aussagensystems vorzulegen, vielmehr wird dieses reformuliert. In gewisser Weise handelt es sich bei Rationalen Rekonstruktion von sozialwissenschaftlichen Theorien in wissenschaftstheoretischer Erweiterung der (wissens)soziologischen Überlegungen von Alfred Schütz um (metasprachliche) Konstruktionen dritten Grades, also um Konstruktionen jener Konstruktionen, die Sozialwissenschaftler über die Konstruktionen der in der Alltagswelt Handelnden errichten ${ }^{98}$.

Traditionellerweise ${ }^{99}$ versucht man bei einer Rationalen Rekonstruktion

die zentralen Begrifflichkeiten,

den Aufbau und die logische Struktur,

die Kernaussagen und zentralen Zusammenhänge,

die sprachliche Präzision sowie

die empirische Basis

des Untersuchungsgegenstandes (also eines theoretischen Aussagensystems) exakt zu bestimmen, um so dann auch Bewertungen hinsichtlich seines wissenschaftstheoretischen Status anstellen zu können (handelt es sich um eine Heuristik, ein analytisches Modell, eine empirische Theorie etc. ${ }^{100}$. Darüber hinaus sind jedoch auch ganz spezifische Fragestellungen denkbar, die eine Rekonstruktion anleiten können. So rekonstruiert bspw. Hartmut Esser (1991) die Handlungs- und Sozialtheorie von Alfred Schütz hinsichtlich ihrer Kompatibilität mit dem RationalChoice-Ansatz. Insofern sind "verschiedene, sich voneinander unterscheidende Rekonstruktionen desselben Textes durchaus möglich" (Burth 1999: 28).

\footnotetext{
98 Schütz (1971: 7) bezeichnet die Konzepte der Sozialwissenschaftler als "Konstruktionen zweiten Grades: Konstruktionen jener Konstruktionen, die im Sozialfeld von den Handelnden gebildet werden, deren Verhalten der Wissenschaftler beobachtet und in Übereinstimmung mit den Verfahrensregeln seiner Wissenschaft zu erklären versucht."

${ }_{99}$ Siehe für eine philosophiegeschichtliche Analyse des Ausdrucks "Rationale Rekonstruktion" Mittelstraß 1981. "In Zusammenhang mit Kennzeichnungen wie 'rational', 'logisch' und 'konstruktiv' hat sich in der Rede von 'Rekonstruktion', zum Unwillen mancher professioneller Historiker und Philologen, ein ungewohnter philosophischer Ton breitgemacht. Er wirkt gegenüber der bisherigen hermeneutischen Kultur in den Geisteswissenschaften eigentümlich ungeschlacht und ungebildet; eigentlich also gar nicht philosophisch, wenn man Philosophie vorrangig an ihrem spekulativen Vermögen mißt." (ebenda: 89)

100 Bei Stegmüller heißt es u.a., eine Rationale Rekonstruktion "soll dazu dienen, den inneren logischen Aufbau von Theorien, deren 'empirische Basis' sowie 'theoretische Superstrukturen' und deren Anwendungsweisen ebenso zu klären wie die zwischen Theorien bestehenden Relationen." (Stegmüller 1986b: 473)
} 
Im Stegmüllerschen Verständnis ist eine Rationale Rekonstruktion ferner "weder ein rein deskriptives noch ein rein normatives Unterfangen, sondern der Versuch, ein erklärendes Modell bestimmter Aspekte der menschlichen Erkenntnis zu liefern." (Stegmüller 1980: 171) Überträgt man diese Perspektive auf die Analyse einer sozialwissenschaftlichen Theorie, dann arbeitet eine Rekonstruktion die Beziehung zwischen dieser Theorie und des hierüber tatsächlich oder potentiell propagierten Wissens hinsichtlich der Beschaffenheit eines Aspekts der sozialen Realität heraus. Aber auch eine Analyse unterschiedlicher Argumentationsmuster bezüglich eines Sachverhaltes bzw. ein Theorienvergleich wird über eine Rationale Rekonstruktion systematisch ermöglicht, "da sich mit ihrer Hilfe die Wurzeln der Meinungsverschiedenheiten aufdecken lassen und eine Klärung herbeigeführt werden kann." (Stegmüller 1985: 6)

In der strukturalistischen Theorienrekonstruktion werden nun die Strukturen einer Theorie "in terms of the models of a theory" (Suppes 1993: 67), d.h. in Form mengentheoretischer Prädikate ausgedrückt. Im Grunde genommen wurde das Verfahren oben mit Hinweis auf eine rationale Handlungstheorie schon skizziert $^{101}$. An dieser Stelle soll nun über ein von Balzer/Moulines stammendes Beispiel die Rekonstruktionssystematik sowie die Mathematisierung einer Theorie veranschaulicht werden (vgl. Balzer/Moulines 2000: 12ff.).

Obwohl es sich im Folgenden nicht um eine sozialwissenschaftliche, sondern um eine physikalische Theorie handelt, scheint mir das Beispiel für eine einführende Illustration besonders geeignet, da die entsprechende Theorie relativ leicht verständlich und wenig komplex ist sowie vielen Lesern noch aus dem Schulunterricht bekannt sein dürfte ${ }^{102}$. Als Anwendungsfall wählen die genannten Autoren nämlich die klassische Kollisionsmechanik. Diese besagt grundlegend, dass die Produktsumme aus Masse mal Geschwindigkeit (= Impuls) zweier Körper bei einer Kollision konstant bleibt. Man spricht vom "Impulserhalt". Der Gesamtimpuls zweier Billardkugeln ist bspw. vor und nach dem Zusammenstoß genau gleich groß.

Ein potentielles Modell der klassischen Kollisionsmechanik enthält nun die wichtigsten Elemente der Theorie:

$\mathrm{P}=$ Partikel

$\mathrm{T}=$ Zeitpunkte

$\mathrm{v}$ (velocity) $=$ Geschwindigkeit

$\mathrm{m}=$ Masse

real $=$ Realisierungsrelation.

\footnotetext{
101 Redundanz ist hier durchaus beabsichtigt.

102 Vorliegende Rekonstruktionen sozialwissenschaftlicher Theorien sind m.E. wesentlich komplexer und bieten sich für eine einführende Betrachtung daher kaum an. Außerdem war ich ja oben einleitend zur Problematik einer strukturalistischen Rekonstruktion schon auf eine rationale Handlungstheorie eingegangen.
} 
Die Realisierungsrelation "real" wird benötigt, um das tatsächliche und gemeinsame Auftreten der einzelnen Komponenten zu unterstellen (bspw. haben bestimmte Partikel zu bestimmten Zeitpunkten bestimmte Geschwindigkeiten etc.; nur bei Erfüllung der Realisierungsrelation kann es überhaupt zu einer Kollision [das zu realisierende Ereignis] und damit auch zum Impulserhalt kommen). Ein konkreter Anwendungsfall - wie der Zusammenstoß zweier Billardkugeln - weist nun die genannten Grundkomponenten auf und kann somit als ein Element aus der Menge aller möglichen potentiellen Modelle der klassischen Kollisionsmechanik bezeichnet werden. Eine mengentheoretische Rekonstruktion hat nun folgendes Aussehen:

$\langle\mathrm{P}, \mathrm{T}, \mathrm{real}, \mathrm{v}, \mathrm{m}\rangle \in \mathrm{M}_{\mathrm{p}}$ (der klassischen Kollisionsmechanik) gdw (= genau dann wenn)

(1) P ist eine endliche, nicht-leere Menge mit mindestens 2 Elementen

(2) $\mathrm{T}=\left\{\mathrm{t}_{1}, \mathrm{t}_{2}\right\}$

(3) v: $\operatorname{PxT} \rightarrow \mathfrak{R}_{0+}$

(4) $\mathrm{m}: \mathrm{P} \rightarrow \mathfrak{R}_{0+}$

wobei

(1) bedeutet, dass mindestens zwei Partikel vorhanden sein müssen, damit es zu einer Kollision kommen kann;

(2) bedeutet, dass man lediglich zwei Zeitpunkte benötigt, um die klassische Kollisionsmechanik darzustellen (einen Zeitpunkt [ $\left.\mathrm{t}_{1}\right]$ vor und einen $\left[\mathrm{t}_{2}\right]$ nach der Kollision);

(3) bedeutet, dass die Geschwindigkeit eine Funktion von Partikeln und Zeitpunkten ist (eine Billardkugel [P] rollt bspw. mit einer bestimmten Geschwindigkeit [v] pro Sekunde bzw. in der Zeit $[\mathrm{T}]$ auf eine andere zu) (" $\mathfrak{R}_{0+}$ " gibt an, dass das Ausmaß bzw. die Höhe der Geschwindigkeit über eine positive reelle Zahl darstellbar ist ${ }^{103}$ [metrische Skalierung]);

(4) bedeutet, dass Masse eine positive und konkret bestimmbare Funktion von Partikeln ist.

Ein Modell muss nun noch dem substantiellen Gesetz der Kollisionsmechanik genügen, nämlich dem Prinzip des Impulserhaltes.

$\langle\mathrm{P}, \mathrm{T}, \mathrm{real}, \mathrm{v}, \mathrm{m}\rangle \in \mathrm{M}$ (der klassischen Kollisionsmechanik) gdw $\mathrm{t}_{1}, \mathrm{t}_{2}$ so dass

(1) $\langle\mathrm{P}, \mathrm{T}, \mathrm{real}, \mathrm{v}, \mathrm{m}\rangle \in \mathrm{M}_{\mathrm{p}}$

(2) $\sum_{\mathrm{p} \in \mathrm{P}} \mathrm{m}(\mathrm{p}) * \mathrm{v}\left(\mathrm{p}, \mathrm{t}_{1}\right)=\sum_{\mathrm{p} \in \mathrm{P}} \mathrm{m}(\mathrm{p}) * \mathrm{v}\left(\mathrm{p}, \mathrm{t}_{2}\right)$

103 Bzw. - etwas mathematischer gesprochen - dass die Geschwindigkeitsfunktion eine Abbildung des kartesischen Produkts von P und T in die Menge der positiven reelen Zahlen darstellt. 
Zum einfacheren Verständnis können die beiden Zeilen etwa wie folgt gelesen werden:

Ein Modell der klassischen Kollisionsmechanik liegt genau dann vor, wenn

(1) es die Komponenten Partikel, Zeitpunkte, eine Realisierungsrelation, Geschwindigkeit und Masse enthält (und damit in jedem Falle schon einmal ein potentielles Modell der Theorie ist) und wenn

(2) die Produktsumme aus Masse mal Geschwindigkeit der Partikel vor einer Kollision $\left(\mathrm{t}_{1}\right)$ genauso groß ist wie nach einer Kollision ( $\left.\mathrm{t}_{2}\right)$ (zentrales Axiom).

Das partielle potentielle Modell vermeidet nun noch die T-theoretischen Terme. In diesem Fall sind (nach Auffassung Balzer/Moulines) P, T und v aus der Kinetik bereits bekannt, d.h. $\mathrm{m}$ ist der eigentliche T-theoretische Term. Strukturalistischmengentheoretisch formuliert, hat dies folgendes Aussehen:

$\mathrm{M}_{\mathrm{pp}}=\left\{\langle\mathrm{P}, \mathrm{T}, \mathrm{v}\rangle / \exists \mathrm{m}(\langle\mathrm{P}, \mathrm{T}, \mathrm{v}, \mathrm{m}\rangle) \in \mathrm{M}_{\mathrm{p}}\right\}$

Der "Kunstgriff" besteht in partiellen potentiellen Modellen darin, dass man die T-theoretischen Terme über die sog. Ramsey-Elimination ausgliedert und sie anschließend über Existenzquantoren bindet, um so den Satzcharakter wieder herzustellen. Dieses für viele Sozialwissenschaftler zunächst einmal sicherlich nicht ganz einfach nachvollziehbare Verfahren soll an dieser Stelle nicht weiter erläutert werden, denn unten werde ich argumentieren, dass partielle potentielle Modelle bei einer Rationalen Rekonstruktion verzichtbar sind, da es nicht sinnvoll ist, theoretische Begriffe auszuscheiden ${ }^{104}$.

Der Bereich der intendierten Anwendungen $I$ umfasst alle Beispiele der Theorie. So ließe sich - wie einleitend schon angemerkt - das Aufeinanderprallen zweier Billardkugeln als intendierte Anwendung und damit als Modell der Kollisionsmechanik begreifen. I.d.R. wird der Begründer einer Theorie an einigen Beispielen seine Vorstellungen erläutern; man spricht dann von $\mathrm{I}_{\mathrm{p}}$ - der Menge der paradigmatischen intendierten Anwendungen. Ausgehend von $\mathrm{I}_{\mathrm{p}}$ lassen sich dann weitere, ähnliche Anwendungsfälle bestimmen. Wenn es sich beim Aufprall zweier Billardkugeln um ein Modell der klassischen Kollisionsmechanik handelt, dann liegt es bspw. nahe, auch einen Auffahrunfall als intendierte Anwendung zu begreifen, um dann empirisch zu prüfen, ob dieser den Axiomen der Theorie genügt.

\footnotetext{
104 Durch den Ramsey-Satz wird in nominalistischer Tradition nur behauptet, dass ein Etwas eine bestimmte Eigenschaft besitzt (hier also, dass ein Partikel die Eigenschaft besitzt, eine Masse aufzuweisen). Damit kann die ontologische Annahme einer Dinglichkeit für Masse vermieden werden (innerhalb des ontologischen Grundlagenteils werde ich hierauf noch einmal zurückkommen).
} 


\subsection{Der Moderate Strukturalismus}

Innerhalb der analytischen Wissenschaftstheorie existieren - so lassen sich die wichtigsten Ergebnisse der vorangegangenen Erörterungen nochmals in knapper Form festhalten - grundsätzlich zwei unterschiedliche Wissenschaftskonzepte: ein linguistisches und ein strukturalistisches. Im ersten, zumeist als Logischer Positivismus bezeichneten Konzept - zu dem hier sowohl der Standpunkt Carnaps wie (bei aller gebotenen Vorsicht) die weitestgehend in dessen Tradition entstandenen Positionen Poppers oder Lakatos gerechnet werden -, unterscheidet man eine analytische und eine empiristische Sprachklasse, deren jeweiliges Vokabular aus direkt beobachtbaren und theoretischen Termen sowie logischen Verknüpfungsworten besteht.

Insbesondere die Ablehnung der analytisch-synthetisch-Dichotomie und die nicht mögliche direkte Beobachtbarkeit theoretischer Terme führte zur Ausarbeitung des Strukturalismus, der Begriffe strikt theorierelativ begreift. Ein Begriff kann demnach innerhalb einer Theorie A als T-theoretisch, innerhalb einer Theorie B aber, welche die Angemessenheit von A unterstellt, als Nicht-T-theoretisch ausgewiesen werden. Zur Rekonstruktion von Theoriegebäuden bedient sich der Strukturalismus eines mengentheoretischen Instrumentariums, um so Theorien nicht mehr als Aussagensysteme, sondern als mathematische Strukturen auffassen zu können. Eine solche Struktur lässt sich nun weder verifizieren noch falsifizieren, da sie keine Sätze über die Realität formuliert; sie kann lediglich auf die Realität Anwendung finden, um so ihre Passung zu testen.

In diesem Kapitel soll nun aus einer Kritik bzw. einer Weiterführung der dargestellten erkenntnis- und wissenschaftstheoretischen Grundlagen ein Rekonstruktionsschema für die Auseinandersetzung mit den später zu untersuchenden Sozialkapitalkonzepten gewonnen werden. Dieses zielt jedoch nicht nur auf eine Begriffsanalyse sowie die Modellierung der behaupteten sozialwissenschaftlichen Erkenntnis über Sozialkapital, sondern ebenso auf einen Vergleich unterschiedlicher Konzepte sowie die Konstruktion eines integrativen Theoriemodells ab.

Obgleich vorrangig erkenntnis- und wissenschaftstheoretische Probleme erörtert werden, sind viele der festzuhaltenden Ergebnisse auch für die später noch folgenden ontologischen Überlegungen relevant. Erneut möchte ich daher darauf verweisen, dass eine strikte disziplinäre Trennung zwischen Ontologie und insbesondere Erkenntnistheorie aus inhaltlichen Gründen heraus nicht vorgenommen werden darf. Die Gegenstände, über die wir sinnvoll reden können, sind von Menschen erfahrene Gegenstände. Damit ist aber eine Reflexion der Bedingungen menschlicher Erfahrung notwendig, will man ontologische Aussagen formulie$\operatorname{ren}^{105}$.

105 Dies impliziert keineswegs die Behauptung, die Welt sei lediglich eine phänomenale Welt, und wir Menschen würden nicht Gegenstände, sondern immer nur Bewusstseinsinhalte wahrnehmen. 
Die nachfolgenden Ausführungen streichen die Folgen, die sich aus der Theoriegebundenheit sprachlicher Aussagen für menschliche Erkenntnis ergeben, radikal heraus und kennzeichnen den Umgang des Strukturalismus mit theoretischen Termen vor diesem Hintergrund als inkonsequent. Aus der Kritik an der klassischen Version des Strukturalismus werde ich eine - wie ich sie nennen möchte "moderate" Form dieses wissenschaftstheoretischen Ansatzes erarbeiten, die später auch der metatheoretischen Auseinandersetzung im Anwendungsteil zugrunde liegen soll.

Ein solch kritischer Umgang mit dem strukturalistischen Wissenschaftsprogramm ist angesichts seines eigenen Reifegrades als "noch relativ junger metatheoretischer Konzeption" (Westermann 2000a: 222) keineswegs ungewöhnlich. Moulines sieht den Strukturalismus seit Ende der achtziger Jahre in einer "Weiterentwicklungsphase", die sich durch "kritische Revisionen einiger Grundkonzepte des Ansatzes" auszeichnet (Moulines o.J.). Nach Dreier befindet sich der Strukturalismus "noch immer in einem fruchtbaren Entwicklungsprozeß ..., der sowohl Erweiterungen als auch Modifikationen beinhaltet." (Dreier 1997: 204) Wie oben bereits kurz angedeutet, wird meine Argumentation insbesondere darauf abzielen:

die Eliminierung theoretischer Terme als nicht sinnvolles Verfahren auszuweisen,

wissenschaftliche Theorien als Aussagengebilde zu interpretieren, die im eigentlichen Sinne nicht überprüft, sondern deren Kompatibilität mit vorwissenschaftlichen Theorien zu bestimmen ist,

die Sinnhaftigkeit einer prinzipiellen Unterscheidung zwischen statement-view und non-statement-view in Zweifel zu ziehen sowie

die sehr anspruchsvolle Formalisierung innerhalb eines sozialwissenschaftlichen Kontextes als zu aufwendig und zugleich ineffizient darzustellen.

\subsubsection{Abweisung einer Eliminierung T-theoretischer Ter- me}

Führen wir uns zunächst noch einmal vor Augen, warum theoretische Terme ein Problem für eine strikt empiristisch orientierte Wissenschaftstheorie sind. Der Logische Positivismus erachtet es als notwendig, Theorien ausschließlich durch direkt Beobachtbares zu begründen; wissenschaftliche Erkenntnis - so die antimetaphysische Diktion - darf einzig auf Erfahrung basieren. "Das Fiasko der Dispositionsprädikate" (Wuchterl 1999: 30) bedeutet jedoch, dass für viele unverzichtbare Begriffe kein überzeugendes empirisches Signifikanzkriterium formulierbar ist. Im Strukturalismus wird dieses Problem umgangen, indem man die Theoretizität von Begriffen direkt an eine Theorie bindet. Dennoch erscheinen auch hier (T-)theoretische Terme hinsichtlich des Umgangs mit Erfahrung nach 
wie vor als problematisch; sie werden in partiellen potentiellen Modellen über die Ramsey-Lösung ausgeschieden.

Ist dies aber nicht lediglich ein empiristisches Dogma, ein Festhalten an einem sensualistischen Fundamentalismus, wonach nur die ausschließlich auf sinnlicher Wahrnehmung fußende Erfahrung Grundlage menschlichen Wissens über die Welt sein kann? Warum bleibt es unbedingt notwendig, theoretische Begriffe zu eliminieren? Empiristen antworten auf diese Frage zumeist mit dem Verweis auf den epistemologischen Zirkel: Die empirische Bestimmung theoretischer Terme setzt die Gültigkeit der in Frage stehenden Theorie schon voraus; eine theorieunabhängige Prüfung ist damit ausgeschlossen.

Um diesen Zirkel in einem sozialwissenschaftlichen Kontext zu plausibilisieren, sei bspw. Luhmanns Steuerungsverständnis genannt (vgl. Luhmann 1984). Nach Luhmann steuern soziale Systeme sich auf Basis eines sog. autopoietischen Operationsmodus selbsttätig; eine unmittelbare externale Einflussnahme ist ausgeschlossen. Wenn nun etwa eine Regierung ein Gesetz zur Reduzierung des Schadstoffausstoßes von Industrieanlagen erlässt und die hiervon betroffenen Unternehmen in der Folge den staatlichen Auflagen gemäß handeln, dann kann es sich nicht um einen Fall gelingender politischer Steuerung handeln. So wie Luhmann "Steuerung" definiert, wird man allenfalls von autopoietischer Selbst-steuerung innerhalb des Wirtschaftssystems in Folge einer Umweltirritation sprechen können. M.a.W.: Die von Luhmann vorgenommene Kategorisierung der Wirklichkeit fungiert als Schablone, die, einmal angelegt, nur das erkennbar werden lässt, was begrifflich zuvor als Möglichkeit festgelegt wurde ${ }^{106}$. Damit wird das verwendete begriffliche Gerüst - jedenfalls an der Stelle, wo es T-theoretische Terme enthält zum Maßstab seiner eigenen Gültigkeit; eine Falsifizierung ist ausgeschlossen.

Wenn man nun dennoch behauptet, im genannten Beispiel habe das politische System erfolgreich in das Wirtschaftssystem eingegriffen, dann argumentiert man auf Basis einer anderen modelltheoretischen Konzeption, d.h. einer anderen Ordnung der Wirklichkeit (etwa der behavioristischen Systemtheorie Eastons oder von Policy-Netzwerkansätzen). Die hier skizzierte Problematik wird später noch unter ontologischen Gesichtspunkten unter Verweis auf den Wissenschaftshisto-

\footnotetext{
${ }^{106}$ Dies trifft freilich nicht nur auf Luhmanns autopoietisches Steuerungs-Konzept, sondern auf alle theoretischen Entwürfe zu. Mit der Annahme einer Theorie stellen wir Behauptungen hinsichtlich der Beschaffenheit der Wirklichkeit auf. Dies meint jedoch nicht, dass wir damit die Gegenstände der Theorie zum Existieren bringen würden. Kant - zu dem in diesem Kontext weiter unten noch einiges zu sagen sein wird - hat dieses unaufhebare Dilemma u.a. mit Blick auf Gallilei, der "seine Kugeln die schiefe Fläche mit einer von ihm selbst gewählten Schwere herabrollen" ließ, wie folgt in Worte gefasst: "So ging allen Naturforschern ein Licht auf. Sie begriffen, daß die Vernunft nur das einsieht, was sie selbst nach ihrem Entwurfe hervorbringt, daß sie mit Prinzipien ihrer Urteile nach beständigen Gesetzen vorangehen und die Natur nötigen müsse auf ihre Fragen zu antworten, nicht aber sich von ihr allein gleichsam am Leitbande gängeln lassen müsse; denn sonst hängen zufällige, nach keinem vorher entworfenen Plane gemachte Beobachtungen gar nicht in einem notwendigen Gesetze zusammen, welches doch die Vernunft sucht und bedarf." (B XIII) Der vernünftige Wissenschaftler gleicht damit einem Richter, "der die Zeugen nötigt, auf die Fragen zu antworten, die er ihnen vorlegt." (ebenda)
} 
riker Thomas S. Kuhn (1967) thematisiert: Zwei Theorien werden nach Kuhn als inkommensurabel bezeichnet, wenn ihre jeweiligen, durch die begrifflichen Rasterungen bedingten Wirklichkeitsperspektiven wechselseitig ausschließend sind, wenn also das, was durch die eine Theoriebrille zu erkennen ist, durch die andere unsichtbar bleibt.

Um dem Dilemma der apriorischen Gültigkeit von Theorien zu entgehen, wurde im Logischen Positivismus versucht, ein Empiristisches Signifikanzkriterium einzuführen. Eine Theorie darf nicht schon vorab festschreiben, was überhaupt erkannt werden kann. Zwar können wir Aussagen nur dank Sprache formulieren, die Operation der Verifikation scheint jedoch gänzlich ohne Sprache auszukommen - die Welt antwortet irgendwie "aus sich heraus" auf unsere Fragen.

Der Strukturalismus hingegen verwirft das Diktum einer theorieunabhängigen Prüfung von Theorien und geht stattdessen von einer theoriegeleiteten Messung aus; er propagiert, dass (mengentheoretisch formulierte) Theorien weder verifiziert noch falsifiziert werden können. Und dennoch - trotz dieser nüchternen Haltung hinsichtlich dessen, was wissenschaftliche Theorien zur Möglichkeit unzweifelhaft wahrer Erkenntnis beitragen können - möchte man sich über die Ramsey-Lösung der theoretischen Terme entledigen. Warum sollte dies aber ein Erfordernis sein, wenn es ohnehin nicht mehr darum geht, die Gültigkeit einer Theorie zu tes$\operatorname{ten}^{107}$ ?

\section{Die Theoriebeladenheit der Erfahrung}

Gibt es in einem positivistischen Sinne Beobachtungsbegriffe, die für sich allein verständlich sind, dann ist eine Welterschließung ohne dazwischengeschaltete theoretische Instanz möglich; Sprache und Welt fallen gleichsam in eins - etwa "Tisch" mit dem hierüber bezeichneten Beobachtungsphänomen. Der Strukturalismus hingegen behauptet mit der Einführung von T-Theoretizität, dass man eine Theorie benötigt, um etwa einen Tisch als "Tisch" zu sehen (wobei "Theorie" in diesem Zusammenhang erst einmal wenig anspruchsvoll lediglich eine sprachlich strukturierte Ordnung der Wirklichkeit meint).

Paul Feyerabend (1978) - obgleich kein Strukturalist im engeren Sinne - hat sich u.a. in seinem Aufsatz "Das Problem der Existenz theoretischer Entitäten" mit dieser Thematik auseinandergesetzt. Seine vorwiegend mit naturwissenschaftlichen Beispielen und Plausibilisierungen arbeitende Argumentation wird von mir

\footnotetext{
107 Selbst Stegmüller sieht an einer Stelle seines Werkes die Relevanz des Ramsey-Satzes "nicht in dessen praktischer Verwendbarkeit, sondern allein in seiner wissenschaftstheoretischen Bedeutung" (Stegmüller 1974: 414). Und Rings gibt zu bedenken: "Zwar sind die theoretischen Begriffe in einem Ramsey-Satz verschwunden, doch ist es durchaus fraglich, ob sich damit auch die mit den theoretischen Begriffen aufgetauchten Probleme aufgelöst haben." (Rings 1987: 299) Immerhin ist ja die die theoretischen Terme enthaltene Ursprungstheorie Voraussetzung des Ramsey-Satzes, der wiederum die lediglich über die theoretischen Terme zustande gekommenen zentralen Axiome des Originals nicht zerstören darf.
} 
4. Erkenntnis- und Wissenschaftstheoretischer Grundlagenteil

im Folgenden sozialwissenschaftlich aufbereitet und steht an dieser Stelle paradigmatisch für die Diskussion um die Theoriebeladenheit menschlicher Erfahrung 108 .

Ein Begriff - so Feyerabend - gilt in positivistischer Diktion dann als direkt beobachtbar, wenn über den Wahrheitswert eines Satzes, der den in Frage stehenden Begriff enthält, unmittelbar auf Basis von Wahrnehmung eine Entscheidung gefällt werden kann. Die Aussage "Dies ist ein Tisch" wird - in Abhängigkeit vom Vorliegen des entsprechenden Gegenstandes - sofort entweder als wahre oder als falsche Aussage zu kennzeichnen sein. Sind für diese Entscheidung auch noch Theorien nötig, spricht man von theoretischen Begriffen.

Der Satz "Dies ist eine fremdenfeindliche Handlung" wird erst dann als wahr oder falsch klassifizierbar, wenn man zuvor bestimmt hat, welche direkt beobachtbaren Entitäten (etwa ein Schlag ins Gesicht eines Ausländers, eine Teilnahme an einer Demonstration einer nationalen Gruppierung etc.) dem Begriff "Fremdenfeindlichkeit" zugeordnet sein sollen. "Kurz und ungenau: ein Beobachtungssatz wird akzeptiert (oder verworfen) durch bloßes Hinschauen (Hinhören usw.); ein theoretischer Satz wird akzeptiert oder verworfen durch Hinschauen und Denken" (Feyerabend 1978: 40).

Aber - so lässt sich diese scheinbare Eindeutigkeit erschüttern - ist nicht Fremdenfeindlichkeit für einen etwa in sozial deprivierten Stadtvierteln tätigen Sozialarbeiter zu einem unmittelbar beobachtbaren Etwas geworden, d.h. kann er nicht aufgrund seiner möglicherweise jahrelangen Erfahrung auch ohne weiteres Nachdenken allein durch "bloßes Hinschauen" Fremdenfeindlichkeit erkennen ${ }^{109}$ ?

Dagegen ließe sich einwenden, in diesem Fall lägen schon Interpretationen vor. Der Schluss bspw. von einer Teilnahme einer Person an einer Demonstration der NPD auf Fremdenfeindlichkeit basiere auf einer entsprechenden Theorie der Fremdenfeindlichkeit, auch wenn dies dem Sozialarbeiter nicht direkt bewusst sei. Dieser Einwand klingt plausibel. Ein amerikanischer Tourist wird die genannte Demonstrationsteilnahme vielleicht als Zeichen der Verbundenheit mit folkloristischem Brauchtum bewerten. Erst wenn man ihn darüber unterrichtet, dass es sich hier um ein politisches statement einer nationalistischen Gruppierung handelt, wird er in der Lage sein, Fremdenfeindlichkeit "zu sehen".

\footnotetext{
108 Eine Diskussion, die in dieser Diktion in erster Linie auf Norwood Hanson (1969) zurückgeht. 109 "Es gab Zeiten", so Fleck, "in denen man Hexen sah, sie sofort erkannt haben soll, eventuell am satanischen Ausdruck der Augen, am teuflischen Grinsen, wenn sie einen Augenblick aufhörten, sich zu maskieren." Tatsächlich war dieses Erkennen aber lediglich "ein Prozeß zwischen dem Individuum, seinem Denkstil, der aus der Zugehörigkeit zu einer sozialen Gruppe folgt, und dem Objekt." (Fleck zitiert nach Bochumer Arbeitsgruppe 2000: 18)
} 
Ganz ähnlich verhält es sich nun aber auch mit einem Tisch. Hier beruht die vermeintlich direkte Beobachtbarkeit ebenfalls auf Interpretationen ${ }^{110}$. Nur sind uns diese überhaupt nicht mehr bewusst, weil sie qua Sozialisation sozusagen in "Fleisch und Blut" übergegangen sind, d.h. der zeitliche Abstand zwischen der Wahrnehmung und der Bezeichnung des Gegenstandes tendiert gegen null. Um einen Tisch zu sehen, benötigen wir - so zumindest meine Position - tatsächlich aber eine Theorie des Tisches. Diese Theorie umfasst all jene Vorstellungsinhalte, die wir gemeinhin mit dem Begriff verbinden - etwa dass ein Tisch vier Beine hat, dass eine Platte waagrecht auf diesen Beinen ruht, dass man auf Tischen essen kann etc. Schon diese kurze Auflistung zeigt, inwiefern Fälle möglich sind, in denen zwei Beobachter sich keineswegs einigen werden können, ob es sich bei einem bestimmten Gegenstand nun um einen Tisch handelt oder nicht. Was ist bspw. eine nahezu senkrecht stehende Platte, die auf nur zwei Beinen ruht ${ }^{111}$ ?

Feyerabend verweist in diesem Zusammenhang auf einen von Geburt an blinden Menschen, der plötzlich sehend werde; dieser werde keineswegs unmittelbar einen Tisch beobachten. "Das Haben von Gesichtseindrücken", so etwa Michael Dummett, "ist zwar nötig zum Sehen der Dinge, aber nicht hinreichend." (Dummett 1992: 75) Ludwik Fleck (1983: 147) stimmt dem zu, wenn er äußert: "Um zu sehen, muß man zuerst wissen." Um ein Etwas als "Tisch" zu identifizieren, bedarf es eines aktiven Prozesses, den Schnädelbach (2002: 92) als "epistemisches Sehen" begreift: "Die Fähigkeit des Sehens zu haben, d.h. nicht mehr blind zu sein, ist noch nicht dasselbe wie die Fertigkeit des Sehens zu besitzen. Wahrnehmen ist offenbar primär eine Fertigkeit" und der Wahrnehmungsbegriff ein "Erfolgswort"112 (ebenda). Somit lässt sich vorläufig festhalten, dass es eigentlich

\footnotetext{
110 Von einem naturalistischen Standpunkt aus mag man hinsichtlich materieller Gegenstände nicht von "Interpretation", sondern von "Zuordnung" sprechen. Um aber ein sprachliches Zeichen einem Tisch zuzuordnen, benötigt man ein Verständnis davon, was ein Tisch ist. Ansonsten könnte ein weiteres Objekt aus der Klasse gar nicht mehr als "Tisch" erkannt werden, denn die Identifikation bedarf des Wissens um charakteristische Merkmale. Damit muss aber die Kennntis der Bedeutung von "Tisch" vorausgesetzt werden.

111 Hilary Putnam verdeutlicht die Problematik am Beispiel von "Baum": "Wohl gibt es Dinge, auf die der Ausdruck 'Baum' eindeutig zutrifft, und auch Dinge, auf die er eindeutig nicht zutrifft; doch es gibt Grenzfälle en masse. Schlimmer noch, die Trennlinie zwischen den eindeutigen und den Grenzfällen ist ihrerseits 'fuzzy'." (Putnam 1975: 23)

112 Etwas als etwas zu sehen, heißt etwas zu wissen. Sehr illustrativ wird dies von Burchardt (1986: 35) ausgeführt: "Das zufällige und chaotische Durcheinander von Einzelphänomenen nimmt vor dem Auge des abstrakten Geistes geordnete und in systematischem Zusammenhang stehende Züge an. Man kann diese Veränderung in der Wahrnehmungswelt z.B. mit einem zweimaligen Besuch einer Kunstausstellung vergleichen. Der erste Rundgang erfolge ohne besondere inhaltliche Vorbereitung, der zweite nach einem intensiven Katalogstudium. Man verfügt dann über Kenntnisse und Informationen hinsichtlich der Künstlerpersönlichkeit, über das Sujet, die historischen und kulturellen Bedingungen der betroffenen Epoche usw. Obwohl die Ausstellungsstücke sich nicht verändert haben, sieht der Betrachter jetzt mehr". Diese Perspektive wird im übrigen auch von Vertretern anderer Wissenschaftstraditionen geteilt. Bei Bourdieu (1987: 19) heißt es etwa: "Die Fähigkeit des Sehens bemißt sich am Wissen, oder wenn man möchte, an den Begriffen, ..., über die man zur Bezeichnung der sichtbaren Dinge verfügt und die gleichsam Wahrnehmungsprogramme erstellen."
} 
keine direkt beobachtbaren, sondern (vermeintlich) ausschließlich theoretische Begriffe gibt.

\section{Die Propositionalität und Synthetizität des Wissens}

Für Popper (1982: 61) stellte sich die geschilderte Theoretizität vor allem als Problem der Nicht-Verzichtbarkeit von Allgemeinbegriffen. Schon der Satz "Hier steht ein Glas Wasser" weist die sortalen Ausdrücke "Glas" und "Wasser" auf, d.h. um auf bestimmte Entitäten demonstrierend Bezug nehmen zu können (im Beispielsatz "dies Glas" und "das Wasser in diesem Glas"), müssen wir eine Vorstellung von Allgemeinbegriffen haben, die allein die genannte Bezugnahme ermöglichen. Wenn nun der sinnlichen Erfahrung lediglich raum-zeitlich lokalisierbare Gegenstände (also etwa ein ganz bestimmtes Glas) zugänglich sind, wir zur Etablierung dieses Zugangs jedoch der Vorstellung abstrakter Klassen bedürfen - denn wie wollte man ein bestimmtes Glas identifizieren, wenn man nicht wüsste, was ein Etwas zu einem Glas macht - dann ist sinnliche Erfahrung offenbar auf erfahrungstranszendente kognitive Leistungen, auf qua Verstand erzeugte Allgemeinheiten, angewiesen ${ }^{113}$.

Kants Projekt in seiner "Kritik der reinen Vernunft" war es, die soeben thematisierten apriorischen Voraussetzungen menschlicher Erfahrung zu bestimmen, um hierüber auch die Notwendigkeit einer Zusammenführung von Rationalismus und Empirismus aufzuzeigen. Kant hat die Theoriebeladenheit der Erfahrung in seiner Konzeption synthetischer Sätze zumindest in Teilen vorweg genommen, denn Erkenntnis - so eine seiner grundlegenden Aussagen - sei nur durch eine Verbindung von Sinneswahrnehmung und Verstandesleistung möglich: "Gedanken ohne Inhalt sind leer, Anschauungen ohne Begriffe sind blind." (B 75). Und "ein leerer Gedanke wäre dasselbe, wie etwas zu denken, ohne dabei etwas zu denken" (McDowell 2001: 27); m.a.W.: eine logische Unmöglichkeit.

Schon im zweiten Absatz der Einleitung zur "Kritik der reinen Vernunft" schreibt Kant: "Wenn aber gleich alle unsere Erkenntnis mit der Erfahrung anhebt, so entspringt sie darum doch nicht eben alle aus der Erfahrung. Denn es könnte wohl sein, daß selbst unsere Erfahrungserkenntnis ein Zusammengesetztes aus dem sei, was wir durch Eindrücke empfangen, und dem, was unser eigenes Erkenntnisvermögen (durch sinnliche Eindrücke bloß veranlaßt) aus sich selbst hergibt, welchen Zusatz wir von jenem Grundstoffe nicht eher unterscheiden, als bis lange Übung uns darauf aufmerksam macht und zur Absonderung desselben geschickt macht."114 (B 1f.)

\footnotetext{
113 Damit wird freilich noch kein unabhängiger ontologischer Status sortaler Ausdrücke bzw. von Universalien behauptet, denn zunächst ist nur von sprachlichen Zeichen die Rede, die eine realweltliche Bezugnahme ermöglichen.

${ }^{114}$ Hierzu auch Bertrand Russell (1967: 66): "Während wir also auch zugeben, daß unser gesamtes Wissen von der Erfahrung hervorgerufen und verursacht wird, halten wir andererseits doch fest, daß
} 
Selbst das, was wir als Anschauung bzw. Sinneswahrnehmung bezeichnen, bedingt schon eine kognitive Strukturierung und damit Verstand, stellt insofern eine Form relativ gering elaborierter Erkenntnis dar. Wenn Menschen keine voraussetzungslose Anschauung von etwas haben können, sondern erst die Syntheseleistung des Verstandes das "Gegebene" in Form eines Wahrnehmungsurteils für uns zu einem erfahrenen Etwas macht, dann haben wir es grundsätzlich mit propositionalem Wissen, d.h. mit Wissen der sprachlichen Form "Es ist der Fall, dass ..." zu $\operatorname{tun}^{115}$. Die Gegenstände der Welt sind uns also nur in Form von Tatsachen zugänglich (etwa: "Dies ist ein Stein"). Diese wiederum liegen sprachlich vor: Was wir wissen, wissen wir, weil wir wissen, was unsere Worte und Sätze bedeuten ${ }^{116}$.

Freilich müssen wir noch die Fähigkeit des Verstandes zur Syntheseleistung von den Inhalten, die der Verstand benutzt, um überhaupt zu einer Synthetisierung zu gelangen, trennen. Mit "Fähigkeit" ist gemeint, dass der Verstand über die Disposition zur Kognition verfügt, um Wissen und damit eine - psychologisch formuliert - geordnete Erfahrungswelt herzustellen. Mit "Inhalt" ist nun das über die Zeit hinweg akkumulierte, sprachlich strukturierte Hintergrundwissen gemeint, welches bei einer Wahrnehmung und ihrer Verarbeitung zum Tragen kommt. Wissenssoziologisch würde man vom "Sediment von Erfahrungen (d.h. 'sinnvollen', bewußt erfassten und thematisierten, erinnerungsfähigen Erlebnissen im Bewußtseinsstrom)" sprechen (Luckmann 1981: 40). Dieses Hintergrundwissen bzw. Sediment ist kein Apriori im Sinne Kants, sondern gewissermaßen ein Aposteriori, der in Bezug auf eine konkrete Wahrnehmung apriorisch wirkt, weil hier all jene Inhalte enthalten sind, die zur konkreten Bestimmung eines Gegenstandes führen. Um etwa eine Rose als Rose zu sehen, muss der Verstand bestimmte, in unserem Hintergrundwissen enthaltene, Vorstellungsinhalte liefern und ihre Synthetisierung mit der Anschauung bewirken können; die Anschauung selbst ist (sowohl im linguistischen wie im soziologischen Sinne) völlig bedeutungslos, sie kann alleine nicht zu einem nur begrifflich denkbaren Gegenstand menschlicher Erfahrung führen ${ }^{117}$.

Was für singuläre, raum-zeitlich lokalisierbare Entitäten gilt, trifft umso mehr auf komplexe Sachverhalte zu: Mit Ausnahme des Bereichs der Körper-

ein Teil unseres Wissens a priori ist, in dem Sinne, dass die Erfahrung, die uns auf den Gedanken bringt, nicht ausreicht, ihn zu beweisen." Prauss (1993: 10) begreift die philosophische Erkenntnistheorie daher auch "als nichtempirische Wissenschaft von Empirischem".

115 Wenn wir ein blaues Buch sehen, so weist der Bewusstseinszustand des Sehens die Proposition "das Buch ist blau" auf. Unter einer "Proposition" wird hier also in der Fregeschen Tradition das verstanden, was mit einem Satz inhaltlich ausgedrückt wird. So haben etwa die Sätze "Gras ist grün" und "grass is green" den gleichen propositionalen Gehalt. Nicht nur Wissen, sondern auch Uberzeugungen und Absichten sind propositional (so bin ich etwa überzeugt davon, "dass keiner der beiden Veranstalter der Fußball-Europameisterschaft 2008 den Titel holen wird").

116 Und lediglich in Folge dieser Propositionalität sind wir überhaupt in der Lage, das Wahr-FalschKriterium einzuführen.

117 Kybernetisch formuliert: "In all our attempts to portray reality the output is a function not of the 'external' inputs alone, but of the mind's transformational mechanisms as well." (Rescher 1986: 2) 
empfindungen (etwa den auf eine Ohrfeige folgenden Schmerz) ist Kausalität (worauf vor allem Hume hingewiesen hat) sinnlich nicht direkt wahrnehmbar. Sie stellt das Ergebnis einer begrifflichen Syntheseleistung des Verstandes dar, bei der mindestens zwei Ereignisse (die ihrerseits in propositionaler und damit auch synthetischer Form vorliegen müssen) per Ableitung in eine abhängige Beziehungsrelation gebracht werden ${ }^{118}$. Mit Blick auf die vermeintlich notwendige Eliminierung theoretischer Terme ist daher festzuhalten: Das, was Strukturalisten über den Ramsey-Satz eliminieren wollen, ist letztlich erkenntnistheoretisch (und auch - wie noch detailliert zu zeigen sein wird - ontologisch) unverzichtbar. Ohne begriffliche oder zumindest symbolische Strukturen ist Erfahrung nicht zu bewerkstelligen.

\section{Die Hypothesentheorie der (sozialen) Wabrnehmung und der Radikale Konstruktivis- mus}

Ein kurzer, exkursartiger Abstecher soll zeigen, inwiefern die bisherigen philosophischen Überlegungen zu Erfahrung und Erkenntnis in durchaus ähnlicher Weise auch in der Sozial- und Kognitionspsychologie sowie der Neurobiologie auftauchen. Insbesondere die beiden letztgenannten Disziplinen erörtern die empirischen Möglichkeiten und Grenzen unserer kognitiven Fähigkeiten, d.h. die zuvor gemachten philosophischen Aussagen müssen hierzu zumindest kompatibel sein, setzen sie sich doch ansonsten dem Verdacht aus, gegen empirische Forschungsergebnisse zu verstoßen und damit auch interdisziplinär nicht anschlussfähig zu $\operatorname{sein}^{119}$.

Die insbesondere auf Jerome S. Bruner zurückgehende Hypothesentheorie der (sozialen) Wahrnehmung besagt grundlegend, dass ein sinnlicher Reiz nicht in invarianter Weise unsere Wahrnehmung bestimmt, sondern dass jeder Wahrnehmungsvorgang mit einer letztlich sprachlich formulierten Hypothese ex ante beginnt; unser kognitives System ist demnach ganz entscheidend dafür verantwortlich, was wir zu erkennen glauben ${ }^{120}$. Die Vorstellung, kognitive Prozesse seien Prozesse der Informationsverarbeitung, hat in der Psychologie dazu geführt, diese als etwas passives, reaktives $\mathrm{zu}$ beschreiben. Die Hypothesentheorie betont

\footnotetext{
118 Für Kant war Kausalität allerdings ein "reiner" Verstandesbegriff, da Veränderungen nicht anders als über kausale Verknüpfungen denkbar seien: "Die Ordnung und Regelmäßigkeiten also an den Erscheinungen, die wir Natur nennen, bringen wir selbst hinein, und würden sie auch nicht darin finden können, hätten wir sie nicht, oder die Natur unseres Gemüts ursprünglich hineingelegt. Denn diese Natureinheit soll eine notwendige, d.i. a priori gewisse Einheit der Verknüpfung der Erscheinungen sein." (A 125) Das Kausalitätsprinzip wird damit von Kant in das erkennende Subjekt hineinverlagert und gilt als ein synthetisches Urteil a priori (vgl. kritisch hierzu etwa Tetens 2004: 104).

${ }^{119}$ Freilich wäre ein Verstoß gegen empirische Forschungsergebnisse dann unproblematisch, wenn zuvor die Güte und Sinnhaftigkeit einheitswissenschaftlich orientierter Forschung (wie sie in Psychologie und Biologie weitgehend Standard ist) per se bestritten worden wäre. Davon kann hier aber keine Rede sein.

${ }^{120}$ Vgl. zum Folgenden vor allem Lilli 1984 sowie Irle 1975: 52-90 aber auch generelle Ausführungen zu sozialer Kognition, etwa Sears et al. 1991: 73-101.
} 
hingegen das konstruktive Moment menschlicher Kognition ${ }^{121}$. Informationsverarbeitung gilt nun als konzeptgesteuert, d.h. Menschen leiten aus früheren Erfahrungen sogenannte Wahrnehmungs-Erwartungs-Hypothesen ab, die mit konkreten Reizinformationen konfrontiert werden. Eine Überprüfung erfolgt dann durch die Herstellung einer Beziehungsrelation zwischen beiden ${ }^{122}$.

Auf Basis empirischer Forschungsergebnisse ließen sich drei zentrale (Kovariations-) Theoreme formulieren: Je stärker eine Hypothese ist, desto (a) höher ist die Wahrscheinlichkeit, dass sie durch Ereignisse erregt wird, (b) geringer muss die Menge der unterstützenden Reizinformationen sein, die zu ihrer Bestätigung notwendig ist, (c) größer muss die Menge widersprechender Reizinformationen sein, um sie zu widerlegen. In Abwesenheit passender Reizinformationen kann der Konsens mit Bezugspersonen einen Hypothesentest ersetzen ${ }^{123}$.

Finden Wahrnehmungs-Erwartungs-Hypothesen keine Bestätigung, dann werden sie modifiziert oder verworfen und andere treten an ihre Stelle. Der Prüfvorgang gilt als abgeschlossen, wenn Erwartung und Reizsituation zur Übereinstimmung gebracht werden (man könnte von einer konsistenztheoretischen Implikation sprechen) ${ }^{124}$. Wahrnehmung kann demzufolge auch als "compromise between expectation and sensation" begriffen werden (Estany 2001: 212).

Insbesondere innerhalb der sozialen Realität ist die Hypothesentheorie von enormer Bedeutung, insofern hierüber viele sich selbst erfüllende Prophezeiungen erklärbar werden. Es mag sich wahrscheinlich im überwiegenden Teil der Fälle als wenig relevant erweisen, mit welcher Wahrnehmungs-Erwartungs-Hypothese wir uns hinsichtlich ihres Duftes einer Rose zuwenden. Wer sich anderen Personen aber etwa mit der Einstellung nähert, "Mich mag sowieso keiner", wird im überwiegenden Teil der Fälle nicht nur seine Befürchtungen in Folge seines mit den Kognitionen einhergehenden Verhaltens bestätigt sehen, er wird auch Stimulus-

121 "Throughout the history of modern psychology, ..., perception has been treated as though the perceiver were a passive recording instrument of rather complex design. ... Such psychology, ..., has fallen short of clarifying the nature of perception in everyday life much as did the old nerve-muscle psychophysiology felt short of explaining behavior in everyday life." (Bruner/Goodman 1947)

122 Wobei dies vor dem Hintergrund der bisherigen Überlegungen dieses Kapitels insofern problematisch erscheint, als die Hypothese die Reizinformation ja schon beeinflusst und man es daher nicht mit zwei voneinander unabhängigen Komponenten zu tun hat.

123 Zahlreiche Beispiele empirischer Untersuchungen in Zusammenhang mit der Hypothesentheorie finden sich bei Lilli 1984 (die letzte Auflage aus dem Jahr 2000 weist wesentlich weniger empirische Illustrationen auf; aus diesem Grund wird hier auf die Auflage von 1984 verwiesen). So ließ sich etwa experimentell zeigen, dass ärmeren Familienverhältnissen entstammende Kinder ("poor group") die Größe von ihnen als Stimulus dargebotenen Münzen im Vergleich zu Kindern, deren familiärer Hintergrund in finanzieller Hinsicht ungleich vorteilhafter war ("rich group"), signifikant häufiger überschätzten; die "poor group" - so die Erklärung auf Basis der Hypothesentheorie - maß den Münzen größeren Wert bei.

124 Wendet man diese Überlegungen auf die empirische Forschungspraxis an, dann kann es sich bei der Aufstellung wissenschaftlicher Hypothesen gemäß des Schemas deduktiv-nomologischerErklärung keinesfalls, wie Popper behauptet, um "unbegründete und unbegründbare Antizipationen" handeln (vgl. zur Kritik der Popperschen Konzeption wissenschaftlicher Hypothesen Kelle/Erzberger 1999: 511ff.). 
situationen vor dem Hintergrund seiner Erwartungen perzipieren und abweichende Aspekte der Situation kaum zur Kenntnis nehmen (vgl. Pfingsten 2000).

Harold Kelley konnte bspw. zeigen, dass Schüler in Abhängigkeit von der Art der allgemeinen Information, die sie mit Blick auf einen neuen Lehrer erhielten (charakterlich "warm" versus "kühl"), bestimmte Wahrnehmungs-ErwartungsHypothesen bildeten, die dann im Sinne eines Halo-Effektes ihre Wahrnehmung und Einschätzung sowie in der Folge auch ihr Verhalten dem Lehrer gegenüber maßgeblich bestimmten (vgl. Lilli 1984: 38f.). Aus der Ökonomie ist bekannt, wie sehr die Einschätzung der zukünftigen konjunkturellen Entwicklung die Wahrnehmung ökonomischer Realität und letztlich die Investitionsneigung der Akteure beeinflusst.

Wahrnehmungs-Erwartungs-Hypothesen lassen sich auch als "mentale Modelle" bzw. "kognitive Schemata" kennzeichnen, worunter die je individuellen gedanklichen Repräsentationen über einzelne Aspekte der Welt verstanden werden. Vermittels der genannten Ausdrücke versuchen Psychologen daher nicht nur auf die konzeptionelle Wahrnehmungssteuerung aufmerksam zu machen, vielmehr werden mentale Modelle bzw. kognitive Schemata als unmittelbar handlungsleitend angesehen (vgl. hierzu ausführlich und empirisch Brauner 1994), d.h. sie bestimmen demnach die Art der Auseinandersetzung eines Individuums mit seiner (sozialen) Umwelt.

So wird bspw. ein mentales Modell bzw. ein kognitives Schema hinsichtlich einer Cocktail-Party unser kontextpezifisches Auftreten zunächst einmal in maßgeblicher Weise beeinflussen - jedenfalls solange, bis modellinkonsistente Stimuli auftreten: "We know that cocktail parties usually are held in the late afternoon or evening, usually in someone's home. They have guests and usually a host and hostess; they have some food and a lot of alcoholic drinks (...). Normally people interact by standing and talking to each other rather than by watching one common event (like a singer) or sleeping or running in circles. In short, we have a clear, well-developed, somewhat abstract picture in our minds about a 'cocktail party'. It has a standard sequence, a number of elements, and clear causal interrelationships among them." (Sears et al. 1991: 84)

Das mentale Modell/kognitive Schema der Cocktail-Party ist demzufolge nichts weiter als eine Theorie der Cocktail-Party, womit auf die Anschlussfähigkeit an philosophisch-erkenntnistheoretische Überlegungen zur Theoriebeladenheit der Erfahrung verwiesen wäre ${ }^{125}$; und in der Philosophie selbst befindet sich u.a.

125 Die Kernaussagen der Hypothesentheorie sowie der Konzeption mentaler Modelle werden innerhalb der kognitiven Verhaltenspsychologie mit Blick auf den individuellen Erlebnisaspekt (durchaus unter Rekurs auf die antike Lebensphilosophie etwa eines Epiktet) noch weiter generalisiert und münden in einen Therapieansatz, der sich grundlegend von der Vorstellung leiten lässt, dass unsere Kognitionen unser Erleben - und damit auch unsere Emotionen - in zentraler Weise bestimmen (eine Trennung von Emotion und Kognition, wie sie für die Psychologie oder die Soziologie i.d.R. kennzeichnend ist, wird dezidiert abgelehnt; in radikaler Konsequenz sind dann Emotionen nur noch Kognitionen mit "einer bestimmten Stärke bzw. Qualität ... affektive[r] Valenzen" [Heidbrink 1996: 24]). Wer etwa der Überzeugung ist, "nur konfliktfreie zwischenmenschliche Beziehungen sind 
Hans Lenk in direkter Verbindung zum psychologischen Sprachgebrauch: "Alles Erkennen, ..., alles Erfassen ist ein Schematisieren, wird durch Schemata erst möglich, geschieht aufgrund von - u.U. unterbewußter - Aktivierung oder durch die Anwendung von Schemata." (Lenk 1998: 31; auch nach Chalmers [2001: 14] bedarf die Erkenntnis eines "geeigneten konzeptuellen Schemas und des Wissens, wie dies angewendet wird.")

Der Radikale Konstruktivismus zählt zu den sog. "Selbstorganisationsansätzen" (wie etwa auch die Synergetik oder die Chaostheorie) und geht insbesondere auf die beiden chilenischen Neurobiologen Humberto Maturana und Fancesco Varela zurück. Gemäß ihres Konzeptes stellt ein lebendes System seine Bestandteile in einem rekursiven Prozess selbsttätig her. Daher sprechen die Autoren auch von der "Autopoiesis des Lebendigen" (autos = selbst; poiein = machen bzw. schaffen). Jeglicher Umweltkontakt gilt als systemrelativ, wird also vom System herbeigeführt und eigenbestimmt verarbeitet. Innen und Außen sind von Beobachtern eingeführte Unterscheidungskategorien.

So lassen sich bspw. keine Korrelationen zwischen Umwelt und menschlichem Gehirn feststellen; Sinnesrezeptoren geben lediglich Reize an die Nervenzellen weiter, d.h. Umwelt wird in elektrische Nervenpotentiale transformiert und verliert dabei ihre Spezifität. Inwiefern eine Erregung auf optische, akustische oder sensomotorische Signale zurückzuführen ist, lässt sich auf Grundlage des neuronalen Erregungszustandes nicht sagen. Wir wissen bspw. lediglich: "Alles, was an neuronalen Impulsen in den Hinterhauptcortex gelangt, ist ein Seheindruck, und was in bestimmten Regionen des Hinterhauptcortex verarbeitet wird, ist eine bestimmte Farbe"126 (Roth 1987: 234).

Menschliche Erkenntnis gilt daher im Radikalen Konstruktivismus als Produkt der Geschlossenheit des Gehirns, als Resultat einer Relationierung neuronaler Relationen. "In diesem Sinne werden wir ständig festzuhalten haben, dass man das Phänomen des Erkennens nicht so auffassen kann, als gäbe es Tatsachen und Objekte da draußen, die man nur aufzugreifen und in den Kopf hinein zu tun habe." (Maturan/Varela 1987: 31) Damit ist auch im Radikalen Konstruktivismus

befriedigende Beziehungen", wird Streit vollkommen anders erfahren und bewerten als jemand, der Konflikte zum produktiven Element seiner Sozialkontakte erklärt. In klinischen Untersuchungen konnte insbesondere George A. Kelly solche personalen Konstrukte (also quasi generalisierte mentale Modelle von Individuen) über ein spezielles Testverfahren (Role Construct Repertory-Test) immer wieder empirisch sichtbar machen, neurotische Störungen hierauf zurückführen und diese wiederum vor allem über kognitive Reattributionstechniken auflösen (vgl. Kelly 1986, vgl. aus persönlichkeitspsychologischer Perspektive zusammenfassend Pervin/John 2001; ähnlich argumentiert die Rational-Emotive-Therapy von Albert Ellis, vgl. hierzu Ellis 1983).

126 Wobei hier einschränkend zu sagen wäre, dass die neurobiologische Komponente hier nicht hinreichend ist und um eine soziale ergänzt werden muss, da "unsere Farbbegriffe in letzter Instanz auf einer durch Schulung erworbenen Fähigkeit beruhen, Farben durch Anschauung als solche zu erkennen." (Dummett 1992: 71) 
die Welt für den Menschen Erfahrungswelt; das Subjekt, das "Ich", kann nicht wissen, ob die Welt so ist, wie es sie repräsentiert. Selbst dieses "Ich" als erkennendes Subjekt ist in dieser Lesart dann eigentlich nicht mehr Produzent, sondern nur ein Element der durch die Gehirnvorgänge bewirkten Konstruktionsprozesse, es ist eine "Fiktion, ein Traum des Gehirns, von dem wir nichts wissen können"127 (Roth 1987: 253).

Kritisch gilt es festzuhalten, dass die meisten Radikalen Konstruktivisten objektive Erkenntnis (als ob sie wüssten, was dies sei) für unmöglich halten und hiervon ausgehend den Realismus als metaphysisch erachten. Eine solche deontologische Vorstellung ${ }^{128}$ wird von mir in dieser Untersuchung - wie schon mehrfach erwähnt - abgelehnt. "Wenn auch der grundlegende konstruktive Charakter des Erkennens nicht in Frage zu stellen ist, so sind doch die überschießenden erkenntnistheoretischen Schlußfolgerungen des Radikalen Konstruktivismus zurückzuweisen." (Meinefeld 1995: 111)

Im vorliegenden Zusammenhang sollte mit dem Verweis auf den Radikalen Konstruktivismus sowie die Hypothesentheorie der (sozialen) Wahrnehmung kursorisch bzw. exkursartig gezeigt werden, inwiefern auch über Ansätze und empirische Forschungsresultate aus Neurobiologie und Psychologie philosophische Überlegungen hinsichtlich menschlicher Erkenntnismöglichkeiten bzw. restriktionen unterstützt werden. Innerhalb des (ontologischen) Anwendungsteils dieser Untersuchung wird auf mentale Modelle nochmals zurückzukommen sein.

\footnotetext{
127 In ähnlicher Weise argumentiert auch Lenzen aus Sicht der allgemeinen Kognitionswissenschaften: "Wir sind demnach Systeme, die sich selbst mit dem von ihnen selbst erzeugten Modell ihrer selbst verwechseln und so eine stabile Ich-Illussion erzeugen." (Lenzen 2002: 139) Diese Perspektive war gewissermaßen schon bei Kant angelegt: "Durch dieses Ich, oder Er, oder Es (das Ding), welches denket, wird nun nichts weiter, als ein transzendentales Subjekt der Gedanken vorgestellt $=\mathrm{x}$, welches nur durch die Gedanken, die seine Prädikate sind, erkannt wird, und wovon wir, abgesondert, niemals den mindesten Begriff haben können" (B 404). Damit ist das Ich aber bei Kant im Unterschied zu Roth keine Fiktion, sondern eine gedankliche Konstruktion (eine abweichende Ansicht vertritt Kaiser-El-Safti 2001: 144). Rom Harré sieht das Ich bzw. das Selbst in diesem sprachkonstitutiven Sinne als "an organizational feature of experience, imposed through the power of certain grammatical models." (Harré 1987: 41)

128 Schmidt spricht von einer durch den Radikalen Konstruktivismus bewirkten "DeOntologisierung der Realität" (Schmidt 1992: 9) - m.E. ein Widerspruch in sich. Heinz von Foerster möchte den Ontologiebegriff augenscheinlich sogar vollständig aus der Diskussion verbannen, wenn er von "dieser schrecklichen Idee der Ontologie" spricht und weiter ausführt: "Schon der Satz 'Es gibt da etwas' scheint mir mit den Präsuppositionen des Realismus vergiftet." (von Foerster 2001: 19) Für Gerhard Roth stellen Realismus und Radikaler Konstruktivismus indes keineswegs Gegensätze dar; er geht davon aus, "daß es eine Realität gibt, in der ein Gehirn existiert" (Roth 1995: 321). Das Gehirn erzeugt nun eine phänomenale Welt, die Roth im Unterschied zur Realität "Wirklichkeit" nennt: "Die Realität bringt die Wirklichkeit hervor, aber die Realität existiert nicht in der Wirklichkeit" (Roth 1992: 321). Hieran wiederum wird die subjektivistische Argumentation kritisiert, die Wissen quasi als nicht-sozial ausweist. "Man sollte zudem sehen, dass der Konstruktivismus selbst ein Ausdruck sozial-kultureller Entwicklung ist." (Reich 2001: 366)
} 


\subsubsection{Theorieanwendung als Kompatibilitätsprüfung}

Nach den vorangegangenen Erörterungen lässt sich nun das in der analytischen Wissenschaftstheorie auftauchende Problem der (T-)theoretischen Terme allenfalls als ein Problem der Beobachtungsterme auffassen (wenn man dies einmal im Rückgriff auf eine positivistische Diktion so formulieren darf). Die Theoretizität aller Begriffe im Verbund mit der sprachlichen Struktur menschlicher Erfahrung bedingt die Theoriebeladenheit aller Erfahrung, womit die These, Theorien müssten an einer hiervon unabhängigen Erfahrung scheitern können, als unhaltbar abzuweisen ist. Unsere Erfahrung ist sprachlich geordnet, d.h. wir werden niemals in der Lage sein, eine theorieunabhängige Beschreibung der Welt zu liefern. "Jede Aussage über die Verläßlichkeit der Welt ist bereits ... eine Anwendung sprachlicher Verläßlichkeit und kann diese daher auch in keiner wie auch immer gearteten Weise ihrerseits begründen." (Mittelstraß 1974: 167)

Ob wir also tatsächlich Erkenntnis über die "Sache selbst" - was immer dies auch sein mag - gewinnen können, lässt sich nicht feststellen ${ }^{129}$. Insofern sollte man - und genau dies wird ja nun eigentlich von den Vertretern des Strukturalismus auch propagiert - nicht mehr von Verifizierung oder Falsifizierung, sondern nur noch von einer Anwendung von Theorien sprechen ${ }^{130}$. Eine solche Theorieanwendung wird gelingen, wenn ein betrachteter Realitätsausschnitt entsprechend der Theorie, die gewissermaßen eine Vermutung über die Beschaffenheit dieses Realitätsausschnitts darstellt, strukturierbar ist; sie wird misslingen, wenn dies nicht der Fall ist.

\footnotetext{
${ }^{129}$ Es ist aber auch m.E. nicht überzeugend, zu behaupten, wir könnten definitiv keine Erkenntnis über die Sache selbst bzw. die noumenale Welt gewinnen, denn das setzte ja bereits voraus, dass wir wüssten, um was es sich hierbei handelt. Wir müssten also einen archimedischen Standpunkt beziehen und von dort aus behaupten, dass wir dies eigentlich gar nicht vermögen; die Metaphysik würde bekämpft, indem man implizit metaphysisch argumentiert. Heidegger umgeht das Problem bzw. positiv formuliert - bietet eine elegante Lösung an, wenn er die cartesianische Trennung zwischen dem Menschen - dem "Dasein" - und der Außenwelt für artifiziell hält, weil Letztere immer schon im Dasein enthalten sei. "Der Mensch" so Wolfgang Stegmüller mit Blick auf das Heideggersche Existential des In-der-Welt-seins, "braucht ... nicht mehr Schranken seines Bewußtseins oder das Ich zu durchbrechen, um zur Welt hinauszugelangen, sondern er ist in all seinem Tun und Lassen, seinem Besorgen, Erkennen, ja selbst im Vergessen immer schon bzw. bei der Welt 'draußen'." (Stegmüller 1978: 143) Die Heideggersche Position lässt sich m.E. auch in ähnlicher Form bei Wittgenstein finden: "Moores Behauptung über seine Hände (Moore glaubte, die Aussage, dass er Hände habe, dadurch beweisen zu können, indem er seine Hände in die Höhe hielt, D.K.) und entsprechend jede Behauptung über grundlegende Tatsachen in bezug auf die Existenz materieller Dinge, die ununterbrochene Geschichte der Welt usw. sind ... kein legitimer Gegenstand des Zweifels, denn sie bilden den Bezugstahmen für unser gesamtes Handeln. 'Mein Leben', sagt Wittgenstein, 'besteht darin, daß ich mich mit manchem zufriedengebe."' (Grayling o.J.: 123)

130 Die Grenzen des Verifikationismus hat Popper durch den Hinweis auf die Unzulänglichkeit von Induktionsschlüssen aufgezeigt. Der Falsifikationismus erweist sich als ungeeignet zur Begründung sicherer Erkenntnis, insofern er mit logischen Mitteln nicht klären kann, ob nun eine Beobachtungsaussage oder die theoretische Aussage, die der Beobachtungsaussage widerspricht, zurückzuweisen ist - bei beiden handelt es sich um Formen sprachlich propagierter Erkenntnis.
} 
Selbst dieser Satz muss vor dem Hintergrund der Theoriebeladenheit der Erfahrung kritisch bewertet werden, suggeriert er doch erneut eine nicht begründbare Theorie-Erfahrungs-Dichotomie. Wenn die Welt nur symbolisch zugänglich ist und insbesondere durch sprachliche Strukturierung in irgendeiner Weise immer schon geordnet erscheint, dann wird die Frage nach der Passung von Theorie und empirischem Anwendungsbereich letztlich zur Frage nach der Passung zweier Theorien; nämlich (a) einer stärker strukturierten wissenschaftlichen und (b) einer weniger stark, unreflektiert sowie möglicherweise diffus bzw. inkohärent strukturierten alltagsweltlichen (bzw. vorwissenschaftlichen "Theorieversatzstücken" oder "Theoriemosaiken") 131 .

Man könnte an dieser Stelle von einer Meta- und einer Objekttheorie sprechen, wir setzen die eine in Bezug zu der anderen, reden mittels Sprache über Sprache. "The limit of language", so Wittgenstein, "shows itself in the impossibility of describing the fact which corresponds to a sentence ... without simply repeating the sentence." (Wittgenstein zitiert nach Apel 1991: 35) Die NichtAnwendbarkeit einer Theorie kann nur noch meinen, dass ein elaborierter sprachlicher Strukturierungsvorschlag inkompatibel mit einem vergleichsweise unsystematischen ist; theoretische Aussagen (Aussagen über die Sprache) stimmen mit Beobachtungsaussagen (Aussagen über die Welt ${ }^{132}$ ) nicht überein. Eine strukturalistische Theorieanwendung ist dann eigentlich eine Behauptung der Form:

$\mathrm{M} \Leftrightarrow \mathrm{T}$ (ein Modell ist einer wissenschaftlichen Theorie strukturell äquivalent), wobei

$\mathrm{M}=\mathrm{T}^{\prime}$, womit

$\mathrm{T}^{\prime} \Leftrightarrow \mathrm{T}$ (ein Modell ist einer Theorie strukturell äquivalent und ist selbst eine Theorie, d.h. eine Theorie ist einer anderen strukturell äquivalent).

Vor diesem Hintergrund können wissenschaftliche Theorien nun im Sinne des Pragmatismus interpretiert werden ${ }^{133}$. Theorien lassen sich zwar weder verifizie-

131 An dieser Stelle haben wir es insofern mit einer anderen Formulierung für das Poppersche Basissatzsatzproblem zu tun. Und zwischen umgangssprachlicher Beobachtungs- und wissenschaftssprachlicher Beschreibungs-/Erklärungstheorie steht i.d.R. noch eine eigens konstruierte Mess- bzw. Instrumententheorie (und über allem steht eine Wahrheitstheorie).

132 In phänomenalistischer Diktion wären Beobachtungsaussagen Aussagen über Bewusstseinsinhalte; das würde jedoch bedeuten, "daß wir die Sprache, in der wir reden, nicht als über einen Bereich von Dingen, sondern als über einen Bereich von (mentalen) Urteilen über die Dinge interpretiert voraussetzen" (Essler 1972: 255).

${ }^{133}$ Hinsichtlich dieser Überlegung rekurriere ich vor allem auf Schnädelbach, der in seinen erkenntnistheoretischen Erörterungen den Problemen des klassischen Empirismus in der Tradition von Locke und Hume eine "pragmatische Antwort, die freilich bei Bacon und Kant schon vorgezeichnet ist", entgegensetzt. Wissenschaftliche Erfahrung sei in reale Handlungsprozesse "eingelassen"; sie entspringe "einer faktischen Verunsicherung der Verhaltensgewohnheit, die die vertrauten Überzeugungen, an denen wir bisher unser Verhalten orientierten, in Frage stellt. Das Forschen (inquiry) ist dann nichts anderes als die tätige Anstrengung, die Überzeugungen erneut festzulegen, um so die Verhaltensgewohnheiten zu restabilisieren." (Schnädelbach 2002: 140f.) Bei Quine heißt es ganz in diesem Sinne: "Jeder hat einerseits sein wissenschaftliches Erbe und ist andererseits einem unaufhörlichen Sperrfeuer sinnlicher Reize ausgesetzt; und die Erwägungen, die ihn beim Anpassen seines 
ren noch falsifizieren, sie sind jedoch bei absichtsvoller Konstruktion und Anwendung im Rahmen zweck- und regelgeleiteten Handelns sehr wohl als wenig sinnvoll oder unbrauchbar, weil inkompatibel mit vorwissenschaftlichen Theorien (bzw. Theorieversatzstücken), zu klassifizieren ${ }^{134}$. Sofern sich die Zwecke unseres Handelns oder unsere alltagsweltlichen Theorien wandeln, verändern sich auch die Kriterien für wissenschaftliche Theorien. Als Cartesianer mögen wir Menschen zwar nach absolut sicherem Wissen und unumstößlicher Wahrheit streben; als Pragmatiker müssen wir jedoch akzeptieren, dass wir in Folge unserer unhintergehbaren Einbettung in Handlungskontexte allenfalls in der Lage sind, (relativ betrachtet) nützliches Wissen und eine konsensuale Wahrheit ${ }^{135}$ hervorzubringen.

Inwieweit diese Absage an einen "orthodoxen Repräsentationalismus (Theorien als Abbilder der Wirklichkeit)" (Zoglauer 1991: 13) sich auch in einer entsprechenden Forschungsmethodologie niederschlagen sollte bzw. inwiefern dies überhaupt möglich sein kann, ist eine mit diesen Überlegungen noch nicht beantwortete Frage. Ich werde im Folgenden argumentieren, dass der Strukturalismus (in meiner oben ausgeführten Lesart) zwar im Vergleich zu positivistischen Wissenschaftsansätzen als erkenntnistheoretisch reifer bzw. aufgeklärter bezeichnet werden kann, dass dies jedoch nicht meint, die positivistische einheitswissenschaftliche Methodologie sei mit dem Strukturalismus völlig unvereinbar und deswegen nicht mehr sinnvoll einsetzbar.

wissenschaftlichen Erbes an die fortwährende sinnliche Herausforderung leiten, sind, insofern sie rational sind, pragmatisch." (Quine 1979: 50) In diesem Zusammenhang wird in der Wissenschaftstheorie auch von einem "methodologischen Instrumentalismus" gesprochen. Darunter wird die Auffassung verstanden, "wonach wissenschaftliche Theorien 'Instrumente' zur Erklärung und Prognose von empirischen Phänomenen sind. Ein Werkzeug oder Instrument ist brauchbar, wenn es einen Zweck erfüllt. Wissenschaftliche Theorien sind demnach brauchbar, wenn sie zu plausiblen Erklärungen und zu korrekten Vorhersagen führen (...). (...) Der methodologische Instrumentalismus bestünde demnach in der These, daß das eigentliche Ziel der Wissenschaft nicht die Entdeckung wahrer Theorien, sondern die Konstruktion empirisch adäquater Theorien ist." (Lauth/Sareiter 2002: 187)

134 Damit soll an dieser Stelle keineswegs behauptet werden, die Realität spiele keine Rolle oder Realität sei eine Fiktion. Wenn sie sich aber nur in Form sprachlicher Repräsentation für uns zeigt bzw. in Form sprachlicher Struktur für uns sinnhaft konstituiert, dann gibt es keine andere Deutung von ihr als eine perspektivistische und die Kompatibilität oder Inkompatibilität zweier Theorien wird zur Frage der reziproken Übersetzbarkeit. Die Unmöglichkeit, über Sprache Welt unmittelbar zu beschreiben, lässt sich allerdings insofern relativieren, als man Sachverhalte (als eine bestimmte Form von Gegenständen, die "nicht in derselben Weise in der Welt [sind, D.K.] wie Wohnungen, Gier und Gerichtsvollzieher" [Hacking 1999: 43f.]) mit Propositionen in eins fallen lässt. Sachverhalte sind also nicht bloß nur sprachlich zu denken, sondern sie sind sprachlich - jedenfalls dann, wenn man Propositionen in nicht-sprachlicher Form ablehnt. Castaneda (1982: 414) spricht in diesem Zusammenhang von einem "Perzeptuellen Propositionalismus". Vgl. für eine kritische Analyse des Verhältnisses von Proposition, Satz und Wahrheit die Auseinandersetzung zwischen Austin (1974) und Strawson (1974).

135 Grunwald sieht die Erzielung eines solchen Konsenses nicht als dikursives, sondern sogar als prädiskursives Unternehmen an. Über eine konsensuale Vereinbarung hinsichtlich der verwendeten Terminologien sowie der rationalen Regeln der Argumentation werde ein gemeinsames Situationsverständnis unter den Diskursteilnehmern hergestellt, um von hier aus überhaupt nach Wahrheit fragen zu können. Da dieses "prädiskursive Einverständnis" aber nur sprachlich erzielt werden kann, ist ein solcher Wahrheitsbegriff auf der metasprachlichen Ebene angesiedelt (vgl. Grunwald 1998). 


\subsubsection{Strukturalismus als Aussagenkonzeption und Vereinfachung der mengentheoretischen Rekonstruk- tionsweise}

Will man herausstreichen, inwiefern Positivismus und Strukturalismus keineswegs deutlich voneinander abweichende wissenschaftstheoretische Positionen darstellen, so kann man erneut auf die jeweiligen Sprachkonzeptionen verweisen. Die mit der T-Theoretizität im Strukturalismus einhergehende Unmöglichkeit theorieunabhängiger Forschung wurde gerade auch von Popper immer wieder betont: "Ich bin der Auffassung, daß die Theorie - mindestens eine rudimentäre Theorie der Erwartung - stets der Beobachtung vorausgeht". (Popper 1973: 285) Und an anderer Stelle: "Unsere Sprache ist von Theorien durchsetzt; es gibt keine reinen Beobachtungssätze (...). Sogar in einer sogenannten 'phänomenalen' Sprache, die etwa 'jetzt hier rot' zuläßt, würde das Wort 'jetzt' eine (rudimentäre) Theorie der Zeit implizieren; das Wort 'hier' eine Theorie des Raumes; und das Wort 'rot' eine Theorie der Farben. Es gibt keine reinen Beobachtungen: Sie sind von Theorien durchsetzt und werden von Problemen und von Theorien geleitet." (Popper 1982: 76)

T-Theoretizität - und hier schließe ich direkt an die Überlegungen im vorangehenden Abschnitt an - lässt sich auch auf Basis eines heuristisch und graduell interpretierten Zweistufenkonzeptes beibehalten. "Heuristisch" soll hier indizieren, dass die Propagierung eines Zweistufenkonzeptes der Forschungssystematisierung dient, wenngleich alle Begriffe grundsätzlich im Sinne von $\mathrm{L}_{T}$ zu deuten sind (und dennoch eine empirische Verankerung aufweisen). Graduell ist es insofern, als man nun sagen muss, dass die Analytizität und Synthetizität von Aussagen sowie die direkte Beobachtbarkeit und Theoretizität von Begriffen relativ auf eine Sprechergemeinschaft zu bewerten ist ${ }^{136}$.

Die Behauptung eines grundlegenden Unterschiedes zwischen der positivistischen und der strukturalistischen Wissenschaftstheorie scheint darüber hinaus auch auf der m.E. irreführenden Formulierung zu beruhen, beim Strukturalismus handele es sich um eine Nicht-Aussagenkonzeption von Theorien. Laut Stegmüller muss man "die herkömmliche Vorstellung preisgeben, ... Theorien bestünden in Systemen von Behauptungen. Statt dessen ist eine solche Theorie zu interpretieren als eine mathematische Struktur, verbunden mit einer Menge von Anwendungen" (Stegmüller 1986a: 114).

\footnotetext{
136 An dieser Stelle soll nochmals auf die Quinesche Argumentation gegen Kants analytischsynthetisch-Dichotomie verwiesen werden. Kant würde etwa sagen, die Feststellung, dass zwei parallel zueinander laufende Linien sich nicht kreuzen können, ist eine analytische Wahrheit. Da diese Wahrheit aber nur sprachlich einführbar ist, Sprache jedoch eine empirische Entität darstellt, kann man mit Quine allenfalls auf Grundlage ein und desselben Sprachverständnisses Analytizität behaupten (für einen Vergleich des Kantschen und des Quineschen Analytizitätsverständnisses siehe Wendel 1990).
} 
Nun setzt sich aber kein Wissenschaftler hin, konzipiert eine mathematische Struktur und macht sich im Anschluss Gedanken darüber, ob diese wohl bestimmten realweltlichen Zusammenhängen genügen könnte (jedenfalls kenne ich keinen, der dies täte). Vielmehr ist die Mengenlehre innerhalb des (vorgeblichen) non-statement-views lediglich ein Instrument zur Darstellung bestimmter Behauptungen über die Realität, welche auf mehr oder weniger systematischen, in jedem Fall aber theoriebeladenen Beobachtungen gründen (das würde wohl auch kein Strukturalist bestreiten; deswegen spricht man ja auch von Theorie-rekonstruktionen). Durch die Transformation dieser Behauptungen in eine mathematische Struktur verschwindet nun aber keinesfalls der Inhalt der verbalen Aussage (was für ein Interesse sollte man auch daran haben?), sondern er erscheint lediglich in anderer, nun eben logisch fundierter, sprachökonomischer und präziser Form.

An der von Balzer/Moulines vorgenommenen, oben geschilderten Rekonstruktion der Kollisionsmechanik lässt sich dies nochmals illustrieren. Schon der ein potentielles Modell beschreibende Tupel $\langle\mathrm{P}, \mathrm{T}, \mathrm{real}, \mathrm{v}, \mathrm{m}\rangle$ enthält (mit Ausnahme der Realisierungsrelation) lediglich Kürzel für die zentralen Begrifflichkeiten der Theorie. Das zentrale Axiom

$\sum_{\mathrm{p} \in \mathrm{P}} \mathrm{m}(\mathrm{p}) * \mathrm{v}\left(\mathrm{p}, \mathrm{t}_{1}\right)=\sum_{\mathrm{p} \in \mathrm{P}} \mathrm{m}(\mathrm{p}) * \mathrm{v}\left(\mathrm{p}, \mathrm{t}_{2}\right)$

beschreibt nichts anderes, als dass die Produktsumme aus Masse mal Geschwindigkeit zweier Körper bei einer Kollision konstant bleibt. Warum sollte nun der Satz "Die Produktsumme aus Masse mal Geschwindigkeit zweier Körper bei einer Kollision bleibt konstant" eine Behauptung, die obige, nichts anderes ausdrückende Darstellungsweise aber dezidiert keine Behauptung, sondern "nur" eine mathematische Struktur sein? Die mathematischen bzw. logischen Zeichen symbolisieren etwas und sind daher sehr wohl eine Form assertiver Artikulation; sie sind sehr leicht in eine positivistische Sprache übersetzbar.

Dies scheinen auch Balzer/Moulines (2000: 6) implizit so zu sehen: "What really matters in science is the conceptual representation of empirical systems, not the particular sentences of particular languages in which the representation is quite contingently expressed." Aber auch Stegmüller (1980: 177) äußert an einer Stelle hinsichtlich einer apodiktischen Trennung von Aussagen- und NichtAussagenkonzeption: "Möglicherweise war es der von Sneed geprägte Ausdruck 'nonstatement view', der einige Leser zu der Ansicht verleitete, hier werde ein mit dem herkömmlichen Aussagenkonzept von Theorien logisch unverträgliches Verfahren entwickelt ... . Dies ist jedoch ein grundlegender Irrtum." Insofern ist festzuhalten, "daß mengentheoretische Formeln nichts anderes sind als Aussagen, die in der Sprache der Mengenlehre hingeschrieben werden." (Balzer 1982: 270)

Ein entscheidender Unterschied zwischen Positivismus und Strukturalismus besteht darin, dass im zuletzt genannten Theorie und Empirie gleichsam zusammengezogen werden, womit Theorien nur noch appliziert, jedoch nicht mehr verifiziert oder falsifiziert werden können. Wir müssen allerdings insofern noch 
einen Schritt weitergehen, als zumindest sozialwissenschaftliche Theorien (in Folge der Beschaffenheit ihrer Gegenstände; vgl. die Ausführungen im ontologischen Grundlagenteil) auch nicht direkt auf die Realität Anwendung finden können. Vielmehr ist nur noch ihre Kompatibilität mit vorwissenschaftlichen Theoriemosaiken prüfbar ${ }^{137}$.

Eine so interpretierte strukturalistische Wissenschaftstheorie weiß um die Limitierungen des Logischen Positivismus und ist daher vergleichsweise reifer, aufgeklärter. Damit zusammenhängend ist die Darstellungsweise im Strukturalismus eine mengentheoretische. Man kann sagen, dass die Metasprache des Positivismus eine linguistische, die des Strukturalismus hingegen eine mathematische ist, welche erst im Prozess der Theorieanwendung im eigentlichen Sinne bedeutungstragend wird. Dies stellt indes keinen intransferablen Bruch mit anderen formalen Vorgehensweisen dar, sondern steht in deren Tradition und ist insbesondere für die Sozialwissenschaften nur dann sinnvoll, wenn sie in eine linguistische Aussagenform übersetzbar bleibt, da sie ansonsten Gefahr läuft, ihren sprachlich konstituierten Gegenstand aus den Augen zu verlieren ${ }^{138}$.

137 Auf den kompletten Bereich der Physik, etwa auf Theorien über 10-dimensionale Raumstrukturen, möchte ich meine Argumentation indes nicht ausdehnen. Dafür sind mir die diesbezüglichen Argumentationen zu wenig bekannt (und zugegebenermaßen auch zu wenig verständlich).

138 Angesichts vieler extrem aufwendiger Formalisierungen wissenschaftlicher Theorien möchte ich der häufig aufgestellten Behauptung ein wenig widersprechen, die Formalisierung von empirischen Theorien trage generell zu einer Entmythologisierung der Wissenschaft bei. Formalisierungen können auch zu einer Mythologisierung führen, wenn sie den sprachlich konstituierten Gegenstand aus dem Auge verlieren und vom überwiegenden Teil einer Wissenschaftsgemeinschaft nicht mehr gelesen werden können. Generell gilt m.E. jedoch: Hat man sich erst einmal an die Symbole gewöhnt, dann kann man relativ exakt angeben, was gesagt wird, da die logische Struktur von Aussagen deutlich erkennbar ist. Dies ist dann aber zweifellos ein Indiz für wissenschaftlichen Fortschritt, zumal so auch eine Kritik eines Aussagensystems erleichtert und systematisch ermöglicht wird. 


\subsubsection{Zusammenfassung}

Zusammenfassend kann die von mir bezogene erkenntnis- und wissenschaftstheoretische Position folgendermaßen festgehalten werden:

a) Es gibt eine der menschlichen Anschauung zugängliche Welt (hierbei handelt es sich um eine ontologische Prämisse; ontologische Fragen werden im nächsten Kapitel detailliert behandelt) ${ }^{139}$.

b) Menschen verfügen über die Disposition zur Kognition und zur bezugnehmenden Repräsentation von Gegenständen der Außenwelt ${ }^{140}$.

c) Eine Synthetisierung von Anschauung mit der Disposition zur Kognition und der bezugnehmenden Repräsentation der Außenwelt führt zu Erkenntnis (im Sinne, von "wissen, dass ...").

d) Durch permanente Syntheseleistungen akkumulieren Menschen Hintergrundwissen.

e) Das akkumulierte Hintergrundwissen stellt dann die begrifflichen Inhalte bereit, mittels derer Menschen über ihre Fähigkeit zur Repräsentation der AuBenwelt Anschauung zu immer neuen und je unterschiedlichen Erkenntnissen synthetisieren (jede neue Erkenntnis ist von dem affiziert, was bereits gewusst wird).

f) Intersubjektiv überprüfbare Erkenntnis ist möglich, weil Sprache als ein Medium sozialer Übereinkunft bestimmten kodifizierten Gebrauchsregeln folgt (siehe hierzu ausführlich das Kapitel 5.3. "Bedeutung und Sprache").

\section{Abbildung 5: Erkenntnis als Syntheseleistung}

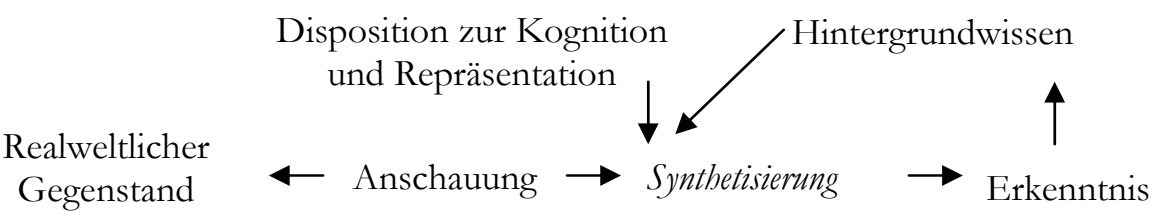

\footnotetext{
139 Nochmals sei erwähnt, dass hier kein phänomenalistischer Standpunkt vertreten wird, auch wenn diese Einschätzung durch die Bezugnahme auf Kant naheliegen mag. Die Gegenstände der Welt, über die wir sinnvoll reden können, gelten hier als von Menschen erfahrene Gegenstände, nicht jedoch als ausnahmslos nur dank menschlicher Erfahrung Gegenstände oder als Gegenstände allein in der Erfahrung.

140 "Unsere intellektuellen Grundfunktionen sind also 'präformiert', sie sind, wie Popper mit Hinweis auf eine Kantische Passage sagt, 'subjektive, uns mit unserer Existenz zugleich eingepflanzte Anlagen zum Denken'." (Albert 1987: 36) Chomsky (1977: 165) spricht diesbezüglich von einem "Anfangszustand des Geistes".
} 
All unser Wissen über die Welt ist synthetisch, d.h. es basiert auf einer Verbindung von Sinneswahrnehmung und Verstandesleistung ${ }^{141}$. Die Behauptung der Existenz direkt beobachtbarer Terme stellt eine pragmatische Vereinfachung, eine "nützliche Fiktion" (Kutschera 1982: 437) dar ${ }^{142}$. Eine Operationalisierung theoretischer Terme meint aber nichts weiter als ihre Ersetzung durch andere theoretische Terme, hinsichtlich derer eine Sprechergemeinschaft sich innerhalb eines bestimmten historischen Zeitraumes implizit oder explizit verständigt, sie als Beobachtungsterme anzuerkennen.

Im Unterschied zu den Vorstellungen innerhalb des Logischen Positivismus ist dies aber keinesfalls eine second-best-Lösung, sondern vielmehr die einzige Option, um überhaupt Erfahrungen machen zu können. Eine solche Perspektive ist wie noch ausführlich zu beschreiben sein wird - ontologierealistisch aufzufassen, insofern sie eine Welt voraussetzt und in dieser u.a. die Existenz eines Strukturierungsmediums namens "Sprache" propagiert, dank dessen wir Bedeutung generieren und hierüber eine soziale Wirklichkeit (bzw. deren institutionellen Teile) konstruieren können.

Mit der hier vorgenommenen Kritik an der klassischen Form des Strukturalismus verändert sich nun auch die Art und Weise, wie Theorien zu rekonstruieren sind. Eine Theorierekonstruktion auf Grundlage des Moderaten Strukturalismus wird folgende Schritte umfassen:

Schritt 1: Benennung des Problems, auf welches die Theorie bzw. das Aussagensystem eine Antwort geben möchte.

Schritt 2: Prüfen, ob es sich bei der zu rekonstruierenden Theorie (bzw. dem vorliegenden Aussagensystem) um eine Heuristik, eine empirische Theorie, ein analytisches Modell oder um ein gedankliches Konstrukt handelt und damit auch die Methode der Theoriekonstruktion identifizieren ${ }^{143}$; Reichweite der Theorie bestimmen.

\footnotetext{
141 "Auch jener Teil unseres Wissens, der von der Erfahrung logisch unabhängig ist (in dem Sinne, daß er nicht aufgrund von Erfahrungen bewiesen werden kann), (wird, D.K.) doch erst durch Erfahrung hervorgerufen und verursacht. Erst anlässlich bestimmter Vorkommnisse in unserer Erfahrung werden uns die allgemeinen Gesetze bewußt, die sich in ihren Strukturen exemplifizieren." (Russell 1967: 66)

142 Deutlich kritischer als Kutschera formulieren es Kamlah/Lorenzen (1996: 18), wenn sie in diesem Zusammenhang von einem "absonderlichen Dogma" sprechen.

${ }^{143}$ Für Dreier (1997: 151) ist es kennzeichnend, "daß die Wissenschaftstheorie sich gerade nicht mit dem Prozeß der Erkenntnisgewinnung befaßt". In der klassischen Form des Strukturalismus wird der Konstruktion einer Theorie in der Tat wenig Beachtung geschenkt. Im Hinblick auf die strukturalistische Rekonstruktion der klassischen Partikelmechanik (KPM) kritisiert Zoglauer (1991: 79) daran: "Die Beziehung zwischen einem physikalischen System S und einer Theorie T wird auf die einfache Form gebracht 'S ist ein T', z.B. 'x ist eine KPM'. Daß ein solcher Satz aber bereits das Endergebnis einer langwierigen Forschung ist, wird völlig ignoriert." M.E. ist es aber durchaus legitim, wenn sich wissenschaftstheoretische Rekonstruktionen nicht mit den Verfahren der Theorienkonstruktion auseinandersetzen. Indes möchte ich bei meinen Rekonstruktionen von Sozialkapitalkonzepten mein Augenmerk auch darauf richten, weil ich die Bewertung der Geltung theore-
} 
Schritt 3: Die wichtigsten Grundbegriffe - im Sinne von Bausteinen bzw. Komponenten - der Theorie benennen, indem die basalen Postulate der Theorie übersichtlich formuliert werden.

Schritt 4: (Mengentheoretische) Charakterisierung der Grundbegriffe der Theorie (handelt es sich um nicht-leere Mengen, um Funktionen, wie viele Zeitpunkte müssen vorliegen etc.) und ihrer Beziehungen zueinander (sog. terminologische Axiome [was muss es also geben, damit eine Theorie gehaltvoll ist, und wie sind diese Komponenten untereinander verknüpft]).

Empirische Beispiele, die den Bestimmungen aus Schritt 3 und 4 genügen, sind potentielle Modelle einer Theorie. Modelle erhält man, wenn diese Beispiele nun noch die substantiellen Axiome der Theorie erfüllen:

Schritt 5: Die substantiellen Axiome (im Unterschied zu lediglich terminologischen Axiomen) - also die propagierten wichtigsten Zusammenhänge - auflisten.

Kritisch ist hier allerdings anzumerken, dass eine strikte Trennung zwischen potentiellem Modell und Modell nicht zu begründen ist. Wenn Begriffe nämlich lediglich in einem finiten sprachlichen Kontext Sinn machen, dann wird dieser Kontext durch die anderen Begriffe in maßgeblicher Weise mitbestimmt; insofern sind inhaltliche Zusammenhänge schon impliziter Bestandteil des potentiellen Modells. Besonders deutlich wird dies, wenn man innerhalb des potentiellen Modells Funktionen ausweist (etwa Geschwindigkeit als Funktion von Partikeln und Zeitpunkten), da man so unvermeidlich Abhängigkeiten und Zusammenhänge benennt (nicht zuletzt wegen der Klärung der deduktiven Folgerungen zwischen den Begriffen wird die terminologische Axiomatisierung ja durchgeführt).

Durch die mengentheoretische Rekonstruktionsweise soll erreicht werden, dass die Systematik und die zentralen Zusammenhänge einer Theorie in übersichtlicher, ökonomisch-komprimierter, prägnanter und präziser Form vorliegen. Aussagen über komplexe Sachverhalte sind in einfachen Sätzen ausdrückbar, ihre logische Stringenz wird ersichtlich, Ableitungen können einfacher vorgenommen werden, die axiomatischen Komponenten sind deutlich zu erkennen, hypothetische Behauptungen über die Beschaffenheit der Welt lassen sich in transparenter Weise aufstellen und Vergleiche mit anderen Theorien werden in normierter Fassung durchführbar ${ }^{144}$.

Gleichwohl birgt eine solche Rekonstruktion immer die Gefahr, wichtige Inhalte einer Theorie in Folge des mathematisch-formalen Charakters nicht einfangen und vor allem von vielen Sozialwissenschaftlern nicht gelesen werden zu können. Insofern werde ich alle innerhalb der vorliegenden Arbeit zu untersuchenden

tischer Aussagensysteme als eine Aufgabe der wissenschaftstheoretisch-methodologischen Analyse betrachte und unter Geltungsfragen den Aspekt der Theorienkonstruktion für sozialwissenschaftlich relevant einschätze.

144 "Besondere Anforderungen an die Wissenschaftstheorie werden von dem Vergleichsinstrumentarium gestellt, weil es allgemein gültig und inhaltsneutral sein muß. Dies liegt daran, daß Theorien vergleichbar sein müssen, deren Objektbereich sich unterscheidet." (Druwe 1985: 151) 
Theorien bzw. Aussagensysteme zunächst in "herkömmlicher" Weise rekonstruieren, bevor sie dann in eine mengentheoretische Struktur transformiert werden ${ }^{145}$. Im Moderaten Strukturalismus wird diese Struktur im Vergleich zur klassischen Variante vereinfacht, da auf die Bildung eines partiellen potentiellen Modells sowie die Berücksichtigung von Constraints und einer Realisierungsrelation verzichtet wird $^{146}$.

\subsubsection{Ausblick auf die Theorienanalyse}

Wenn soeben davon die Rede war, eine axiomatische Darstellung erhöhe die Transparenz von Theorien und erleichtere insbesondere wegen der erzielten Einheitssprache einen Theorienvergleich, so ist dies natürlich nur ein erster Schritt. Nach welchem Maßstab soll bspw. später beurteilt werden, welche Aussagen von welchen Sozialkapitalkonzepten sich als Bestandteil eines zu erarbeitenden integrativen Theoriemodells eignen?

Wissenschaftstheoretisch wäre diese Frage auf einer allgemeinen Ebene mit dem Hinweis auf mindestens vier verschiedene Kriterien zu beantworten. Zunächst ist das wissenschaftliche Rationalitätspostulat zu nennen, wonach von Aussagen gefordert wird, dass sie präzise formuliert, argumentativ begründet und intersubjektiv nachvollziehbar sein müssen (vgl. Stegmüller 1973: 5f.). Alle Aussagen, die gegen diese Auflagen verstoßen, kommen für eine integrative Theoriebildung nicht in Frage. Ferner zeigt sich die Überlegenheit eines Aussagensystems

145 Eine verbale Rekonstruktion von Theorien nimmt bei Strukturalisten vielfach lediglich minimalen Raum ein.

146 Die Realisierungsrelation (real) unterstellt das tatsächliche Vorliegen der Komponenten und der Zusammenhänge; das Ereignis, um das es geht, wird hierüber realisiert. Da ich dies aber bei der Rekonstruktion einer Theorie schon implizit unterstelle (sonst würde ich sie erst gar nicht als Untersuchungsgegenstand in Betracht ziehen), besitzt sie keinen nennenswerten zusätzlichen Informationswert; auf sie wird daher in einer vereinfachten mengentheoretischen Darstellungsweise verzichtet (und damit auch auf die Variable "Zeit", die real impliziert [es sei denn, "Zeit" spielt in einem Aussagensystem eine exponierte Rolle; so bspw., wenn es um demographische Veränderungen in der Zeit geht]). Constraints (Querverbindungen) sollen gewährleisten, dass gleichen Elementen in unterschiedlichen Systemen die gleichen Merkmale zugeordnet werden. Auch dies werde ich vereinfachend als selbstverständlich unterstellen und Constraints mit Blick auf die leichtere Lesbarkeit der Rekonstruktionen nicht aufführen. Ferner spielen Constraints vorrangig bei der Anwendung von Theorien eine Rolle, d.h. unterschiedliche Modelle (empirische Beispiele) einer Theorie müssen untereinander in Beziehung stehen. Hier wird es später aber nicht um die Anwendung, sondern um den Vergleich von Theorien gehen. Constraints werden aber auch ganz grundsätzlich in Frage gestellt. Sie dienen dazu - wie gesagt - gleichen Elementen in unterschiedlichen Systemen die gleichen Merkmale zu zuordnen. Die Masse der Erde muss also sowohl für das System "Erde-Mond" wie für das System "Erde-Sonne" identisch sein. Aber warum sollte man hier überhaupt von unterschiedlichen Systemen reden, "zumal sie doch beide ein Teil unseres Sonnensystems sind"? (Zoglauer 1991: 78) Und weiter: "Allein die Newtonsche Mechanik besitzt vielleicht Milliarden von verschiedenen intendierten Anwendungen, die alle miteinander zusammenhängen. Kein Mensch kann alle Constraints praktisch angeben und niederschreiben! Es wäre sicherlich vorteilhafter, wenn man auf Constraints ganz verzichten würde" (ebenda: 78). (Vgl. für eine hiervon abweichende Einschätzung bspw. Westermann 2000 oder Kühnel 1993.) 
darin, ob es in der Lage ist, ein auf den gleichen Gegenstand zielendes System zu reformulieren.

Hierbei handelt es sich um eine reduktive Rekonstruktion: "Wenn man die Frage stellt, ob eine gegebene Theorie $T$ mittels einer anderen Theorie $T$ ' 'erklärbar ist' oder 'auf diese reichere Theorie reduziert werden kann' - oder in nochmals anderer Formulierung: ob sich $\mathrm{T}$ in ' $\mathrm{T}$ ' 'einbetten' läßt -, so formuliert man damit ein Problem, welches eine intertheoretische Relation betrifft." (Stegmüller 1973: 128) Ist eine solche Reformulierung nur in eine Richtung möglich, liegt also eine asymmetrische intertheoretische Relation vor, so weist das überlegene Konzept einen höheren theoretischen Gehalt auf. Damit sind für die Theoriebildung jene Aussagen zu selegieren, die über einen solch höheren Gehalt verfügen.

Schließlich ist noch auf die Vergleichskriterien Einfachheit und Nützlichkeit hinzuweisen: Je einfacher ein Konzept mit Blick auf einen realweltlichen Erklärungsgegenstand formuliert ist und je nützlicher es sich in der Auseinandersetzung mit empirischen Problemen erweist, desto stärker sind seine Aussagen denen eines anderen Konzeptes vorzuziehen.

Überlegungen zur Theoriendynamik wie sie im Strukturalismus in Anlehnung und gleichzeitig in Abgrenzung zu Kuhn zu finden sind, sollen im Anwendungsteil nicht angestellt werden. Wissenschaftlicher bzw. theoretischer Fortschritt wird bei Kuhn als historisch-revolutionärer und damit irrationaler Prozess rekonstruiert. "Folglich ist die Überlegenheit einer Theorie über eine andere in der Diskussion nicht nachzuweisen." (Kuhn 1967: 210) Stegmüller (vgl. etwa 1979 u. 1985) übersetzt den Kuhnschen Ansatz in die strukturalistische Sprache und glaubt so zeigen zu können, dass wissenschaftlicher Fortschritt - entgegen der Behauptung Kuhns - doch rational verläuft bzw. verlaufen kann ${ }^{147}$. Sozialkapitalkonzepte sind aus meiner Sicht in Folge ihrer historisch nahezu synchronen Entwicklung, ihres noch jungen Reifegrades sowie aufgrund der unterschiedlichen, bisweilen doch äußerst unpräzisen Begriffsdefinitonen und der Verschiedenheit der anvisierten Gegenstandbereiche für eine theoriendynamische Untersuchung kaum geeignet.

Betrachtungen zu wissenschaftlichem Erkenntnisfortschritt sind hier - wie in der Einleitung angeführt - ausschließlich mit Blick auf die Klarheit und Einheitlichkeit der Begriffs- und Theoriebildung von Interesse. Möchte man für die-

\footnotetext{
147 "Stegmüller unterscheidet sich von anderen Wissenschaftstheoretikern, beispielsweise Lakatos, darin, daß er Kuhn im Kern seiner Thesen zustimmt und versucht, die Thesen Kuhns mit den Mitteln einer mengentheoretischen Modelltheorie (im Anschluß an Sneed) zu rekonstruieren." (Gethmann 1981: 20) Insbesondere die durch Kuhns Hinweis auf Theorien-Inkommmensurabilität behauptete "Rationalitätslücke im Falle einer Theorienverdrängung kann durch einen geeigneten Begriff von 'Reduktion einer Theorie auf eine andere' geschlossen werden." (ebenda) "'Normale Wissenschaft' im Sinne Kuhns besteht jetzt in der Erweiterung des Strukturkerns einer Theorie und deren Anwendung (...), 'außergewöhnliche Wissenschaft' in einem durch zunehmende Schwierigkeiten im Anwendungsbereich nahegelegten Übergang zwischen Theorien mit verschiedenen Strukturkernen " (Mittelstraß 1981: 95). Vgl. hierzu im Hinblick auf die Sozialwissenschaften ausführlich Druwe 1985.
} 
sen Fortschrittsbegriff einen wissenschaftstheoretischen "Paten" benennen, so böte sich in erster Linie Larry Laudan an. Laudan (1977) kritisiert an den "empiricist theories of science" (ebenda: 47), als deren Vertreter er u.a. Popper, Carnap, Kuhn und Lakatos identifiziert, eine zu starke Fokussierung auf EmpirieProbleme; begrifflich-theoretische Fragen würden hingegen unter Fortschrittsgesichtspunkten zu wenig beachtet, obgleich Veränderungen auf dieser Ebene doch elementare wissenschaftliche Umgestaltungen nach sich zögen: "The increase of the conceptual clarity of a theory through careful clarifications and specifications of meaning is, ..., one of the most important ways in which science progresses. ... Many important scientific revolutions (e.g., the emergence of the theory of special relativity, the development of behavioristic psychology) have depended largely on the recognition, and subsequent reduction, of the terminological ambiguity of theories within a particular domain."148 (ebenda: 50) (Spezifische Überlegungen in Zusammenhang mit dem im Anwendungsteil vorzunehmenden Theorienvergleich sind dem entsprechenden Kapitel vorbehalten.)

Nach den erkenntnis- und wissenschaftstheoretischen Erörterungen verfügen wir jetzt mit dem Moderaten Strukturalismus über ein metatheoretisches Analyseschema sowie einen Kriterienkatalog, mit deren Hilfe wir verschiedene Sozialkapitalkonzepte rekonstruieren, bewerten und in axiomatisierter Form darstellen können, um von hier aus dann auch einen Vergleich durchzuführen.

"Sozialkapital" können wir nun als ein von Wissenschaftlern konzipiertes Erkenntniskonstrukt zur Systematisierung bestimmter realweltlicher Probleme kennzeichnen. Der Begriff kam zuvor überhaupt nicht und kommt derzeit noch immer selten in der Alltagssprache vor, d.h. es handelt sich um einen T-theoretischen Term ${ }^{149}$. Ohne eine präzise Semantik - und das heißt eine exakte Theorie - werden wir jedoch nur schwer wirklich gültige empirische Erkenntnisse über den bezeichneten Gegenstand erzielen können. Die Diskussion um die Theoriebeladenheit und Propositionalität menschlicher Erkenntnis zeigt, dass sozialwissenschaftliche Erkenntnis aus einer komplexen Verbindung zwischen Wirklichkeit (wobei Sozialkapital - wie zu zeigen sein wird - auch noch sprachlich konstituiert ist) und begrifflicher Ausstattung des Forschenden resultiert.

\footnotetext{
148 Und weiter: "The solved problem - empirical or conceptual - is the basic unit of scientific progress" (Laudan 1977: 66). Auch Essler (1982: 116) sieht daher die über Begriffsanalysen erzielte Beendigung kommunikativer Verwirrungen als "erheblichen" Wissenschaftsfortschritt an.

149 Wäre der Sozialkapitalbegriff mittlerweile schon ein fester Bestandteil der Alltagssprache, dann handelte es sich nicht nur um keinen T-theoretischen Term, man würde auch - wie Matthes (1987: 123ff.) allgemein mit Blick auf die Übernahme soziologischer Termini in die Alltagssprache bemerkt - bei einer empirischen Untersuchung genau jenem Konstrukt begegnen, mit Hilfe dessen man doch das empirische Material erst systematisieren wollte. Gleichwohl dürfte das Konstrukt in der Alltagswelt - wie Luckmann (1981: 50) ebenfalls auf allgemeiner Ebene zu bedenken gibt - an "Genauigkeit und Eindeutigkeit" einbüßen.
} 
Davon ausgehend ist zu untersuchen, ob "Sozialkapital" in ein und demselben Aussagensystem jeweils eine präzise und kohärente Bestimmung erfährt. Dies soll hier schon im Vorgriff auf den Anwendungsteil ganz kurz illustriert werden. Ist bspw. Colemans Festlegung sinnvoll, zum Umfang von "Sozialkapital" sowohl gesellschaftliche Normen als auch die dank ihrer Befolgung einzelnen Personen oder einem Kollektiv zufließenden Ressourcen zu zählen? Lässt sich Sozialkapital - wie die Netzwerktheoretiker dies tun - als ein Faktor innerhalb des soziophysiologischen Produktionsprozesses von Menschen begreifen, wenn man zugleich eine funktionale Begriffsdefinition ablehnt? Kann man mit Bourdieu eine Eigenschaft des Sozialkapitals darin erblicken, dass es auf informeller Anerkennung gründet und dann zugleich institutionelle Garantieansprüche für dieses Kapital unterstellen?

Die Behauptungen innerhalb der Aussagensysteme, in denen sich der Sozialkapitalbegriff findet, sind insofern gerade auch hinsichtlich ihrer logischen Stringenz zu untersuchen. U.a. verdeckten Tautologien, also der Präsentation lediglich analytischer Erkenntnis im Gewand empirischen Wissens, wird das Augenmerk gelten. Welchen Informationsgehalt besitzt etwa Putnams Aussage, zivilgesellschaftliche Netzwerke seien als Ursache freiwilliger interpersoneller Kooperation zu betrachten? Ist diese Kooperation nicht schon impliziert, wenn man von "zivilgesellschaftlichen Netzwerken" spricht? Oder kann eine Verpflichtung - wie von Bourdieu und Coleman unterstellt - zugleich Sozialkapital und eine seiner Vorbedingungen sein?

Damit spielen an dieser Stelle aber dann Konzeptualisierungen von "Sozialkapital" als unabhängiger und abhängiger Variable in die Analyse mit hinein. So sind die von den Autoren genannten Wirkungs- aber ebenso Entstehungszusammenhänge des Sozialkapitals mit in die Rekonstruktion einzubeziehen. Muss man hinsichtlich der netzwerkanalytischen Sozialkapitalüberlegungen bspw. von einer "investment theory" (Henk Flap) ausgehen, oder ist es nicht auch möglich, dass Sozialkapital ohne bewusste Vorleistungen entsteht? Sollte Letzteres tatsächlich möglich sein, dann wäre zu klären, inwiefern dann noch sinnvoll von "Kapital" gesprochen werden darf.

Nach den intratheoretischen Betrachtungen können dann auch Vergleichsfragen auf systematisch-axiomatisierter Grundlage gestellt werden, um hierauf fuBend dann eine integrativ angelegte Begriffs- und Theoriebildung zu leisten. 



\section{Ontologischer Grundlagenteil}

Nachdem die wissenschafts- und erkenntnistheoretischen Grundlagen der Arbeit entfaltet wurden, soll es nun um eine Betrachtung der Art und Weise gehen, mit der sich insbesondere die Analytische Philosophie (aber auch die Wissenssoziologie) Fragen nach den konstitutiven Ordnungsmerkmalen der Realität nähert ${ }^{150}$, um hiervon ausgehend dann das Verhältnis zwischen Sprache und den Gegenständen der sozialen Realität diskutieren zu können. Die Erörterungen münden in die Entwicklung eines Analyseschemas, das später klären soll, welche Bedeutungen Menschen im Alltag wie produzieren bzw. prozessieren müssen, um Sozialkapital hervorzubringen - eine Problem, das so bislang überhaupt noch nicht thematisiert wurde.

\footnotetext{
150 Die weitgehende Konzentration auf diese Form der Ontologie resultiert aus der prinzipiellen Entscheidung, diese Arbeit an Überlegungen der Analytischen Philosophie zu orientieren. In diesem Bezugsrahmen bewege ich mich - Sozialkapital soll ja "zur Sprache gebracht" werden. Und "eine analytische Ontologie wird ihren Ausgang an einer philosophischen Analyse sprachlicher Strukturen nehmen." (Runggaldier/Kanzian 1998: 15) Obgleich es also ganz grundlegend um Sprache gehen wird, integriere ich Überlegungen der wissenssoziologischen Ontologie Berger/Luckmanns, weil dies auch einige weiterführende handlungstheoretische Ergänzungen möglich macht. Darüber hinaus sehe ich Åhnlichkeiten zwischen einer phänomenologisch orientierten Soziologie und einer ordinary language philosophy, die ich insbesondere am Ende der Kapitel 5.3. und 5.4. sowie in Kapitel 5.7. diskutiere. Insgesamt werden die Ontologien von Searle und Berger/Luckmann zunächst auf einer allgemeinen Ebene und später dann mit konkretem Gegenstandsbezug (Sozialkapital) gegenübergestellt, um so auch deren Verhältnis genauer bestimmen zu können. Dennoch möchte ich darauf verweisen, dass es mit Blick auf das "Zur-Sprache-Bringen" von Sozialkapital prinzipiell ausreichend wäre, nur auf Searles Ontologie einzugehen. Der Rekurs auf Berger/Luckmann hat in erster Linie instrumentellen Charakter: Hierüber soll der sozialwissenschaftliche Zugang zu den philosophischen Ausführungen erleichtert werden.
} 
Übersichtlich lässt sich das Vorgehen in die folgenden Schritte unterteilen:

Erstens wird ganz allgemein in ontologisches Denken eingeführt (Kapitel 5.1.).

Zweitens wird erörtert, welchen Anteil die Sprache an der Realität (bzw. an unseren Perspektiven über die Realität) besitzt und wie wir sinnvoll ontologisch diskutieren können (Kapitel 5.2.).

Drittens geht es um das Dreiecksverhältnis von sprachlichen Zeichen, Bedeutung und Welt bzw. um die Frage, wie es überhaupt zu so etwas wie Bedeutung kommen kann (Kapitel 5.3.).

Viertens werden zwei ausformulierte Ontologien des Sozialen vorgestellt, die Bedeutung als zentrales Konstitutionskriterium institutioneller Wirklichkeit begreifen (Kapitel 5.4. und 5.5.).

Fünftens wird die Komplementarität dieser beiden Ontologien betrachtet und hiervon ausgehend dann ein Bestimmungsschema zur Analyse von Gegenständen der institutionellen Wirklichkeit präsentiert (Kapitel 5.6.).

Im Anschluss daran möchte ich noch in Form eines Exkurses auf methodologische Aspekte ontologischer Argumentationsweisen aufmerksam machen (Kapitel 5.7.), bevor ich dann die Ergebnisse des kompletten Grundlagenteils resümiere und insofern gewissermaßen ein Kompendium der hier vorgelegten "kleinen" Sprachphilosophie der Sozialwissenschaften erstelle (Kapitel 6.).

Beginnen wir mit einigen klassischen (sozial-)ontologischen Fragen, die uns nachfolgend begleiten werden: Was macht eigentlich soziale Realität (als deren Bestandteil Sozialkapital unterstellt wird) generell aus? Unterscheidet sie sich grundsätzlich von der physikalischen Realität und falls ja, auf welche Art und Weise? Ist sie als menschliche Konstruktion zu begreifen oder naturalistisch aufzufassen? Sind dies überhaupt Gegensätze? Hat nicht jeder Mensch seine eigene Realität, die sich nur innerhalb des Bewusstseins vollzieht? Wie gelangen Menschen zum Einverständnis darüber, welche Dinge existieren? Welche Rollen spielen dabei Sprache und Bedeutung? Und was heißt dies alles dann für die Entstehung und Existenz eines konkreten sozialen Gegenstandes? 


\subsection{Sein und Letztbegründungen}

Der Ontologiebegriff taucht zum ersten Mal im 17. Jahrhundert auf und fällt zunächst mit "Metaphysik" mehr oder weniger zusammen. Bei der Metaphysik handelt es sich um jene philosophische Disziplin, in der es um die Klärung letzter Gründe bzw. erster Prinzipien des Seienden geht. Der entsprechende Ausdruck geht auf Andronikos von Rhodos zurück, der damit die Schriften Aristoteles kennzeichnete, die dieser nach (griechisch "meta") seinen Büchern über die Physik verfasste.

Im Allgemeinen begreift man unter Metaphysik Reflexionen über Gegenstände, die sich einer empirischen Analyse entziehen. Damit stellt sich die Frage, ob es überhaupt möglich ist, hierüber wahre Aussagen zu formulieren. Mit dem insbesondere durch die schottische Aufklärung beförderten empiristischen Wissenschaftsverständnis muss eine Antwort hierauf negativ ausfallen. Demnach gilt die Metaphysik als spekulative Lehre, der es an Wahrheitskriterien für die von ihr behaupteten Aussagen fehlt, und die damit als für erfahrungswissenschaftliche Zwecke unbrauchbar anzusehen ist ${ }^{151}$.

Heute werden vormals metaphysische Fragen in der Ontologie vielfach nicht mehr transzendental, sondern durchaus unter Rekurs auf erfahrungswissenschaftliche Erkenntnisse betrachtet. Damit entfällt vor allem eine onto-theologische Vermischung wie sie in Form erster Prinzipien des Seienden (Gott, das Gute, das Absolute etc.) traditionell innerhalb der Metaphysik zu finden war. Dennoch ist die Ontologie weiterhin jene Disziplin, die um die Ergründung der allgemeinsten, konstitutiven Strukturen der Realität bemüht ist; sie ist die Lehre vom Sein. Was gibt es und was sind die Bedingungen der Möglichkeit dessen, was es gibt?

"Interessant am Problem der Ontologie", so Willard van Orman Quine im ersten Satz eines der wohl einflussreichsten philosophischen Aufsätze des 20. Jahrhunderts ${ }^{152}$, "ist seine Einfachheit. Es kann mit drei deutschen Worten

${ }^{151}$ Schon an dieser Stelle soll gleichwohl angemerkt werden, dass Wissenschaft ohne metaphysische Voraussetzungen nicht denkbar wäre. Hält man an der positivistischen Einteilung in analytische und synthetische Erkenntnis fest, so lässt sich Erstere (und damit auch die Logik) durchaus als metaphysisch begreifen, insofern sie ja nicht auf empirischer Erfahrung gründet. Zur Propagierung von Kausalität wird man letztlich auf Evidenz verweisen müssen, um einen infiniten Regress oder einen circulus vitiosus abzuwenden. Da Evidenz aber "eine Glaubenssache und damit nicht begründbar" ist (Druwe 1991: 32), ist Kausalität ebenfalls metaphysisch; überdies hat Kausalität (mit Ausnahme im Bereich der Körperempfindungen) noch nie ein Mensch wahrgenommen, denn sie kann als eine durch den Verstand bewirkte, intellektuelle Zusammenziehung mindestens zweier Ereignisse interpretiert werden. Auch Induktionsschlüsse sind metaphysisch, sie dürfen allesamt niemals Wahrheit oder Geltung beanspruchen; gleichwohl sind sie in der Wissenschaft (wie natürlich erst recht im Alltag) unverzichtbar.

152 Moulines bezeichnet Quines Aufsatz als "Paukenschlag", insofern Quine damit die Rückführung ontologischer Fragestellungen in die analytische Philosophie "auf dem Höhepunkt des neopositivistischen Kreuzzugs gegen die Metaphysik" bewirkt habe (Moulines 1994: 176). Tegtmeier verweist hinsichtlich der Zuwendung der Analytischen Philosophie zur Ontologie insbesondere auf Gustav Bergmann, einen Angehörigen des Wiener Kreises, der ontologische Fragen nach seiner Emigration 
beschrieben werden: 'Was gibt es?' Mehr noch, es kann mit einem einzigen Wort beantwortet werden: 'alles' - und jeder würde diese Antwort als wahr akzeptieren." (Quine 1979: 9) Gibt es wirklich alles? Zweifellos gibt es alles, was es gibt. Aber dies ist nicht mehr als eine Tautologie. Nun beginnt das ontologische Nachdenken jedoch erst, denn was fällt warum und wie unter den Bereich dieses "alles"?

In der alltagsweltlichen Umgebung würde man wohl kaum die Frage stellen, ob konkrete Dinge wie etwa Tische oder Stühle existieren. Immerhin handelt es sich hierbei um in Raum und Zeit bestimmte Entitäten - sie haben Masse und sind sowohl lokalisier- wie messbar. Dennoch behauptet bspw. van Inwagen: "My position vis à vis tables and other inanimate objects is simply that there are none. Tables are not defective objects or second-class citizens of the world; they are just not there at all." (van Inwagen 1990: 100)

Rein intuitiv möchte man van Inwagens Behauptung als völligen Unfug zurückweisen. Doch bei genauerem Nachdenken verwischt plötzlich die nur vermeintliche Klarheit. Ist es nicht die spezifische relationale Anordnung von Eigenschaften - etwa von Farbe, Höhe, Oberflächenstruktur, Solidität etc. -, die einen bestimmten Tisch zu dem macht, was er "ist"? So betrachtet, wären Eigenschaften ontologisch basal und konkrete Dinge lediglich Zusammenfassungen von Eigenschaftsbündeln; diese Perspektive wird daher als "Bündeltheorie" bezeichnet ${ }^{153}$. Dahinter verbirgt sich wiederum die Position, Universalien, also abstrahierende Begriffe bzw. hierüber bezeichnete Eigenschaften oder Allgemeinheiten, als seiend anzusehen ${ }^{154}$. In der Denktradition Platons gibt es Universalien auch ohne Träger (universalia ante rem). So ist bspw. "Schönheit" etwas, was unabhängig von schönen Personen oder Dingen existiert.

Ein Vorschlag zur Güte wäre, sowohl konkrete Dinge als auch Universalien als existent anzunehmen. Philosophen fühlen sich nun aber vielfach einem Prinzip der Denkökonomie verpflichtet, das in Anlehnung an den mittelalterlichen Philosophen und Theologen Wilhelm von Ockham, der sich gegen eine extramen-

in die USA in den dreißiger Jahren strikt im Sinne der ideal language philosophy bearbeitete (vgl. Tegtmeier 1992: 14f.).

153 Die folgenden Ausführungen zu einer kategorialen Ontologie sind vor allem an die Argumentation in Rungaldier/Kanzian 1998 bzw. Kanzian 1999 angelehnt. Im Anschluss an Aristoteles meint eine Kategorienlehre vom Sein, "daß 'sein' (im Sinne von 'existieren') mehrdeutig ist, daß man verschiedene Seinsweisen unterscheiden muß" (Tegtmeier 1992: 11). Tegtmeier selbst behauptet allerdings in seinem eigenen ontologischen Entwurf, "daß Sein univok ist (...), daß eine kategoriale Verschiedenheit keine im Sein ist (...). Daher werden in meiner Ontologie die Kategorien nicht vom Sein abgeleitet, sondern unabhängig davon eingeführt." (ebenda: 12) Damit erhält die Kategorisierung nicht mehr eine ontologische, sondern eine bloß systematisierende Qualität.

${ }^{154}$ U.a. lassen sich Gleichheiten zwischen Einzeldingen konzeptionell als "Universalien" auffassen; es handelt sich also um abstrahierende Vorstellungsbilder, wie etwa dem der Röte bzw. wie der Eigenschaft des Rotseins, welche unterschiedlichen "Realien" (einer bestimmten Blume, einem bestimmten Auto etc.) zukommen können. Auch Gerechtigkeit kann bspw. in der Welt nicht existieren wie ein raum-zeitlich lokalisierbarer Gegenstand, sondern kommt bestimmten individuellen Entitäten gemeinsam zu. "Das Universalienproblem besteht nun in der Frage, auf welche Art und Weise dieses Gemeinsame existiert." (Ferber 1998: 144) 
tale (außerhalb des menschlichen Geistes bestehende) Realität von Universalien aussprach, "Ockhams Razor" genannt wird. Hier wird zu ontologischer Sparsamkeit angehalten; es sollen keine Entitäten eingeführt werden, auf die auch verzichtet werden könnte (entia non sunt multiplicanda sine necessitate). Nur diejenigen Kategorien dürfen in eine Ontologie Aufnahme finden, die als grundlegend angesehen werden und die ferner durch (natur-) wissenschaftliche Theorien abgesichert sind (Redundanz soll also gleichsam "wegrasiert" werden).

Wenn man nun dennoch die Existenz sowohl von Dingen wie universeller Eigenschaften annimmt, argumentiert man im Rahmen des sog. "DingEigenschafts-Schemas". Kann man hierüber aber auch über das Vorhandensein von Sachverhalten entscheiden? Wie oben gezeigt, lassen sich Eigenschaften als Merkmale den Dingen zusprechen. Dinge ohne Eigenschaften - bspw. Tische ohne Farbe oder ohne Oberflächenstruktur - sind nicht vorstellbar. Wenn der Satz: "Dieser Tisch ist rot" einen Sachverhalt beschreibt, dann werden Dinge und Eigenschaften quasi zusammengezogen. Negiert man also die Existenz von Eigenschaften - wie Nominalisten dies tun - oder von konkreten Dingen - wie Bündeltheoretiker dies tun - so kann es viele Sachverhalte eigentlich nicht geben, d.h. die Hereinnahme von relationalen Sachverhalten in eine Ontologie setzt augenscheinlich die Existenz von Eigenschaften und Dingen voraus, ohne doch auf diese beiden Elemente reduzierbar zu sein. Innerhalb eines reinen DingEigenschafts-Schemas besitzt etwa Peter die Eigenschaft, fünf Meter weit zu springen, während Michael lediglich vier Meter erreicht. Die Formulierung einer relationalen Beziehung aus den genannten Angaben bedarf nun ontologisch des folgenden Sachverhalts: Peter springt weiter als Michael. Die Existenz von Peter und Michael sowie ihrer jeweiligen Sprungweiten ist hierfür zwar eine notwendige aber keineswegs eine hinreichende Bedingung.

Trotzdem gibt es Philosophen, die sich ausgehend von einem physikalistischen Weltbild sowie unter Bezugnahme auf Ockhams Razor gegen eine kategoriale Ontologie, die Dinge, Eigenschaften und Sachverhalte umfasst ${ }^{155}$, aussprechen und atomare Einheiten - sog. "simples" - als einzig grundlegend ausweisen. Menschen sind hier bspw. nichts weiter als Mengen dieser simples und besitzen daher auch keinen eigenen unabhängigen ontologischen Status.

Dagegen ließe sich einwenden, auch die vermeintlich grundlegenden simples seien prinzipiell wieder zerlegbar. Insofern gibt es eigentlich nur Emergenzphänomene auf unterschiedlichen Stufen aber keine wirklichen "kleinsten Teile". Ferner nehmen wir als Menschen auf Ganzheiten, auf "vollendete Gestalten" (Fleck 1983: 154), handelnd Bezug, womit doch augenscheinlich die Art und Weise der Zusammensetzung von simples, das spezifische Konglomerat atomarer oder molekularer Strukturen, ontologisch relevant ist. Freilich ist in dieser Perspektive die ontologische Frage eine auf den Menschen hin relativierte,

155 Bei Rungaldier/Kanzian (1998) werden zusätzlich noch Ereignisse, bei Tegtmeier (1992) Beziehungen eingeführt. 
insofern die handelnde Bezugnahme hinsichtlich der Aufnahme von Entitäten in eine Ontologie als entscheidend gilt. Dies kann zumindest für naturwissenschaftliche Gegenstände keine befriedigende Lösung darstellen.

\subsection{Sprache und Realität}

In der Tat wurden bis hierhin die geistigen und sprachlichen Implikationen ontologischer Überlegungen weitgehend beiseite gelassen. $\mathrm{Ob}$ und wie etwas existiert oder nicht, scheint nach den obigen Ausführungen von menschlichem Dasein nicht abhgängig sein zu dürfen - natürlich mit Ausnahme ontologischer Fragen, die den Menschen selbst betreffen ${ }^{156}$. Was-es-gibt-Fragen können wir zwar nur formulieren, weil wir Menschen sind, aber unsere Antworten müssen hiervon sozusagen bereinigt werden, denn inwiefern ein Berg existiert oder nicht, kann - so ließe sich dies nochmals zuspitzen - wohl nicht damit zusammenhängen, dass es sprach- und bewusstseinsbegabte Wesen gibt. Das Problem ist jedoch: Sobald wir Menschen die Welt wahrnehmen, ist sie gewissermaßen ein Teil von uns, insofern wir sie über in unseren Köpfen produzierte Bilder und Vorstellungen erschließen. Wenn die Wirklichkeit der Welt uns aber ausschließlich über unsere eigenen geistigen Prozesse zugänglich ist, wie können wir dann wissen, ob es sich in der Welt tatsächlich so zuträgt, wie es uns erscheint?

Stellen wir diese Frage noch einen Moment zurück. Ganz gleich, wie wir einen Tisch ontologisch fassen wollen, ob nun als Dingart, als Ansammlung von simples oder als Bündel von Eigenschaften, immer reden wir von etwas, wir benutzen Worte. Insofern müssen wir in der Diskussion über das, was es gibt, konstatieren, dass es augenscheinlich Sprache - also zunächst einmal ein physikalisches Klangphänomen (mit ganz außergewöhnlichen Eigenschaften) - gibt $^{157}$. In welcher Beziehung steht nun aber die Sprache zu der von ihr bezeichneten Welt? Repräsentiert sie die Entitäten lediglich, fügt sie ihnen etwas hinzu oder bringt sie gar etwas gänzlich Neues hervor? Was für eine eigenartige Angelegenheit ist Sprache also?

Zunächst werde ich argumentieren, dass die Frage, was wir in eine Ontologie aufnehmen wollen, nicht von menschlichem Bewusstsein und Sprachvermögen

\footnotetext{
156 Damit ist auch deutlich, dass hier die ontologischen Wendungen der Existenzphilosophie nicht vollzogen werden. Heidegger bestimmt in seinem Hauptwerk "Sein und Zeit" die Ontologie radikal vom Menschen her: "Ausarbeitung der Seinsfrage besagt demnach: Durchsichtigmachen eines Seienden - des fragenden - in seinem Sein. ... Dieses Seiende ... fassen wir terminologisch als Dasein". (Heidegger: 1977: 10) "Einen Zugang zum Seinsproblem (bei Heidegger, D.K.) finden wir ... nur über das Seinsverständnis des Menschen; daher muß der Frage nach dem Sein überhaupt die Frage nach dem menschlichen Sein vorausgehen." (Stegmüller 1978: 178)

157 Aber auch dieser hier von mir vertretene ontologische Standpunkt ist keineswegs konsensual. Bei Donald Davidson heißt es etwa: "Und wir reden ja tatsächlich alle derart locker über Sprache oder Sprachen, daß wir zu vergessen geneigt sind, dass es solche Dinge auf der Welt gar nicht gibt; es gibt nur Sprecher und ihre verschiedenen geschriebenen oder akustischen Produkte." (Davidson 2000: 396)
} 
abgekoppelt zu klären ist. Besonders pointiert hat Wittgenstein diese Position zum Ausdruck gebracht: "Die Grenzen meiner Sprache", so eine seiner wohl meist zitiertesten Aussagen, "sind die Grenzen meiner Welt" (Tractatus 5.6.). Letztlich, und dies sollen die nachfolgenden Erörterungen zeigen, fallen Sprache und menschliches Wissen über die Welt - und damit Wissen über das, was wir als Wirklichkeit erfahren können - in eins. Wenn dies jedoch tatsächlich so ist, dann müssen erkenntnistheoretische und ontologische Überlegungen eng miteinander verknüpft sein.

\section{Das linguistische Relativitätstheorem}

Nach Wittgenstein ist unsere Welt- und Wirklichkeitsauffassung unvermeidlich sprachlicher Natur. Dies scheint zu implizieren, dass es so viele Auffassungen wie Sprachen bzw. individuelle Verständnisweisen und Ausdrucksfähigkeiten gibt. Eine solche Perspektive wird u.a. auch als linguistisches Relativitätstheorem (bzw. Sapir-Whorf-These) bezeichnet und zählt gewissermaßen schon zum Kanon des verschulten Standardwissens. Begründer dieses Theorems war in erster Linie der amerikanische Linguist Benjamin L. Whorf. Seine Kernaussage lautet, dass verschiedene Sprecher in Abhängigkeit von ihrem linguistischen Hintergrund die Welt unterschiedlich repräsentieren, sich ein unterschiedliches Bild von ihr machen, womit "kein Individuum (die, D.K.) Freiheit hat, die Welt mit völliger Unparteilichkeit zu beschreiben" (Whorf 1963: 13).

Insbesondere relativ zur Grammatik einer Sprache werden Sprecher zu unterschiedlichen Beobachtungen sowie zu verschiedenartigen Bewertungen äußerlich vermeintlich ähnlicher Dinge geführt. Ein Gedankenexperiment mag dies für den sozialen Bereich einleitend plausibilisieren. Man stelle sich einmal vor, eine Sprache kenne kein Possessivpronomen. Müsste dies nicht mit einem ganz spezifischen Verständnis von Eigentum einhergehen (und zwar selbst dann, wenn es alternative Möglichkeiten gäbe, besitzanzeigende Aussagen zu formulieren)?

Whorf selbst kann als vergleichender empirischer Sprachforscher bezeichnet werden. Seine Thesen entwickelte er vor allem in Auseinandersetzung mit der Sprache der Hopi-Indianer, da die Kontrastierung zweier sehr unterschiedlicher Sprachen wie Englisch und Hopi deren jeweilige Relevanz hinsichtlich unserer Sicht der Welt in besonders pointierter Weise verdeutlicht. Im indogermanischen Sprachraum (bzw. dem Standard Average European) würde man die Varianz der durch den Sprachgebrauch erzeugten klassifikatorischen Ordnungen der Welt kaum registrieren. Im Folgenden sollen einige zentrale Ergebnisse der Whorfschen Analysen kurz skizziert werden (vgl. hierzu Whorf 1963).

Im Englischen werde durch die Verwendung von Substantiven und Verben eine bipolare Aufteilung der Welt suggeriert. Warum, so Whorf, sei "schlagen" als kurzzeitiges Ereignis ein Verb und "Faust" als nicht minder kurzzeitiges Ereignis ein Substantiv? Dieses "linguistische Strukturdogma" bewirke, dass man für 
Ereignisse immer einen "Täter" hinzukonstruieren müsse, was bspw. durch Sätze wie "Es blitzt" oder "Ein Licht blitzt" sichtbar werde. Die Hopi hingegen sagten in diesem Fall lediglich "rehpi", d.h. das, was im Englischen eine Handlung darstelle, erscheine den Hopis als Zustand. Umgekehrt rede man im indogermanischen Sprachraum häufig über Dinge, wenn der Hopi glaube, es mit Ereignissen zu tun zu haben. Eine "Welle" sei etwa in der Hopi-Sprache nicht denkbar und insofern quasi gegenstandslos; hier formuliere man stattdessen etwas wie "Wogen ereignet sich". Insofern mache es einen Unterschied, ob man Natur als unendlich fließenden Vorgang oder aber als Zusammensetzung von Einzelelementen betrachte.

In ähnlicher Weise verdinglichten wir unsere Jahreszeiten in Form von Phasenbegriffen. Den Hopis sei eine Quantifizierung temporärer Abschnitte fremd. Anstelle des Substantivs "Sommer" würde man hier eher sagen "Die zeitliche Relation zwischen A und B mit sommerlichem Charakter". Auch könne man in der Hopi-Sprache nicht formulieren "Ich blieb fünf Tage", denn der Zeitbegriff der Hopi weise null Dimensionen auf. Für "Tag" existiere kein Plural, was dazu führe, dass man den Singular in Verbindung mit einer Ordinalzahl benutze, um den entsprechenden Satz aussprechen zu können: "Ich ging am fünften Tag". Während man im indogermanischen Sprachraum also eine Zeitspanne quasi als Längenmaß, als Ergebnis einer Bewegung im Raum perzipiere, empfänden die Hopis eine Relation des Späterseins zwischen zwei Ereignissen. Insofern "gibt es im Hopi keine Basis für ein formloses Etwas nach Art unserer Zeit." (Whorf 1963: 84)

\section{Der Quinesche Holismus}

Auch in dem von Willard van Orman Quine vertretenen Holismus wird die Beziehung zwischen Sprache und Realität zum primären Analysegegenstand. Gleichwohl hebt Quine wesentlich stärker als Whorf auf die subjektive Komponente und die begriffliche Diffusität unseres Sprachgebrauchs ab ${ }^{158}$. Der Holismus besagt im vorliegenden Zusammenhang, dass einzelnen Sätzen kein eindeutiger empirischer Gehalt zukommt, sondern dass ein Satz nur im Kontext des Sprachganzen Bedeutung aufweisen kann. Sprache und Wissen über die Welt sind somit identisch; oder anders formuliert: Nichtsprachliches Wissen ist unmöglich ${ }^{159}$.

\footnotetext{
158 Das linguistische Relativitätsprinzip und der Quinesche Holismus weisen in weiten Teilen große Unterschiede auf. Insbesondere Whorfs Bezug auf mentale Kategorien wie Bewusstsein oder Inneres wird von Quine mit seiner nominalistischen Orientierung nicht geteilt. Im vorliegenden Zusammenhang ist gleichwohl die Relativität der Ontologie eines Menschen zu seiner Sprache entscheidend und diese lässt sich sowohl mit Quine als auch mit Whorf herausarbeiten.

${ }^{159}$ Im erkenntnistheoretischen Grundlagenteil dieser Untersuchung wurde dies als die "Propositionalität des Wissens" bezeichnet.
} 
Quine (1980: 63ff.) gelangt zu seinen Ergebnissen vor allem über ein Gedankenexperiment: Ein linguistischer Feldforscher versucht ein Übersetzungshandbuch einer ihm völlig fremden Eingeborenensprache $\mathrm{zu}$ erstellen. Sein einziges Hilfsmittel ist eine als Heuristik dienende Unterstellung: Zwischen den sprachlichen Äußerungen der Eingeborenen und den außersprachlichen Gegebenheiten besteht ein systematischer Zusammenhang. Ein plötzlich vorbeihoppelndes Kaninchen und eine darauf einsetzende Verbalisierung, die wie "Gavagai" klingt, wird nun gemäß der genannten Heuristik in dem Wörterbuch als "'Gavagai' = 'Kaninchen"' notiert.

Tatsächlich aber könnte der Eingeborene auch "Sieh da, ein Kaninchen", "Gottheit", "kurzes Zeitsegment eines Kaninchen", "Kaninchen bei diesem Wetter", "Kaninchen mit schönem Fell" usw. gesagt haben. Diese "Unerforschlichkeit der Referenz" meint nun, dass die präzise Bedeutung von Worten sich einer exakten Festlegung entzieht und unbestimmt ist, weil Menschen in Folge eines weiten Interpretationsspielraumes etwas nie völlig identisch verstehen. Damit können auch Aussagen ("Gavagai" ist bei Quine ein Einwortsatz und insofern eine Aussage etwa im potentiellen Sinne von "Sieh da, ein Kaninchen") verschieden übersetzt werden, ohne dass sich exakt sagen ließe, welche Übersetzung denn nun die Richtige ist. Mehr noch: Alle Übersetzungen könnten u.U. sogar korrekt sein, insofern sie mit den empirischen Daten in Einklang stehen (Quine [1980: 61] spricht von der "Unbestimmtheit der Übersetzung"160).

Dies trifft nicht nur auf die Übersetzung einer vollkommen fremden Sprache, sondern auch auf die eigene Muttersprache zu. Auch hier können wir bestimmten Worten durch die Einsetzung von Stellvertretern einen anderen Sinn verleihen, ohne doch in Widerspruch zu den beobachtbaren Daten zu gelangen. Genau dies wird illustriert, wenn der linguistische Feldforscher einmal "Kaninchen", dann aber auch "Sieh da, ein Kaninchen" oder "kurzes Zeitsegment von Kaninchen" in sein Handbuch notiert - alles ist mit der ("reinen") Empirie kompatibel. "Mit etwas Phantasie lassen sich vielfältige ... Möglichkeiten vorstellen, ontologische Differenzen zuzulassen; sie müssen nur so an beobachtbare Äußerungsumstände gekoppelt sein, dass sie dem Interpreten zugänglich sind." (Glüer 1993: 134)

Da Theorien nach Quine nun Aussagensysteme bzw. "ein Gewebe von Sätzen, die durch den Mechanismus der Konditionierung vielfältig miteinander und mit nichtverbalen Reizen verknüpft sind" (Quine 1980: 34), darstellen, sind auch diese unterbestimmt. Die sog. "Unterbestimmtheit von Theorien" (Quine 1980: 146)

\footnotetext{
${ }^{160}$ Freilich erscheint es auf einen ersten Blick relativ abwegig, zu behaupten, mit "Gavagai" könne der Eingeborene u.U. "kurzes Zeitsegment eines Kaninchen" gemeint haben. Dies liegt jedoch Quine zu Folge an einer von uns implizit mitgeführten Unterstellung: Wir gehen davon aus, "daß der Eingeborene uns hinreichend ähnlich ist, einen kurzen allgemeinen Terminus für Kaninchen, aber keinen allgemeinen Terminus für Kaninchenstadien oder Kaninchenteile" hat (Quine 1980: 101). Mit Wittgenstein lässt sich an dieser Stelle auch formulieren: "Ob ein Wort eines Stammes richtig durch ein Wort der deutschen Sprache wiedergegeben wurde, hängt von der Rolle ab, die jenes Wort im ganzen Leben des Stammes spielt." (Wittgenstein zitiert nach Heringer et al. 1977: 69)
} 
besagt damit nichts anderes, als dass die jeweilige Wirklichkeitsauffassung eines Menschen und damit auch seine Ansichten über realweltliche Zusammenhänge relativ zu seinem sprachlichen Ordnungsschema erfolgt - und dies sowohl im Alltag wie in der Wissenschaft ${ }^{161}$.

Quines Ausgangspunkt für diese sprachliche Ordnung der Wirklichkeit ist in einem behavioristischen Verständnis die einfache Benennung von sinnlich Wahrnehmbarem. Er spricht in diesem Zusammenhang von "Beobachtungssätzen" und von "Reizbedeutungen" (Quine 1980: 86). Im Gavagai-Beispiel wird nun (kybernetisch ausgedrückt) auf einen spezifischen physikalischen Umweltreiz (auf der Inputseite) mit "Gavagai" oder "Kaninchen" (auf der sprachlichen Outputseite) reagiert, womit "Gavagai" und "Kaninchen" dieselbe Reizbedeutung aufweisen $^{162}$.

Einfache Beobachtungssätze sind nun Quine zufolge Grundlage auch der abstraktesten Sprache, die sich sehr weit von unmittelbarer Wahrnehmung entfernt haben kann. Selbst ein Satz, der eine kaum erkennbare Reizbedeutung aufweist, gründet letzten Endes auf Erfahrung, weil er in Verbindung zu anderen Sätzen steht und nur so überhaupt verstehbar ist. Auch Präpositionen, Konjunktionen oder Begriffe wie etwa "Anbetracht" gebrauchen wir immer in Analogie zu ihrem Vorkommen in uns bereits bekannten Aussagen ${ }^{163}$ (vgl. Quine 1980: 39). Demnach verfügen auch logische und mathematische Gesetze über empirischen Gehalt, da sie innerhalb des Sprachganzen für die notwendigen Verbindungen sorgen, um realweltliche Aussagen überhaupt formulierbar und im Anschluss einer Überprüfung zugänglich zu machen.

161 Dies soll für den Bereich der Wissenschaft kurz illustriert werden: Die psychologische Impression-Management-Theorie erklärt etwa einstellungsdiskrepantes Verhalten mit dem Verweis auf soziale Erwünschtheit. Kinder, die nicht mit einem bestimmten Spielzeug spielen, weil ihnen dies von ihren Eltern unter Androhung einer relativ geringen Strafe verboten wurde, fürchten nicht die mögliche, unerhebliche Sanktion, sondern sie entsprechen einem sozial erwünschten Handlungsmuster und sind um eine konsistent-konforme Darstellung ihrer selbst bemüht. Alternativ kann der gleiche Sachverhalt (also einstellungsdiskrepantes Verhalten) auch auf Basis der Theorie der kognitiven Dissonanz erklärt werden. Hier wird das Verhalten des Kindes damit begründet, dass es bei einer nur geringen Strafandrohung deshalb nicht mit dem Spielzeug spielt, weil es das Spielzeug kognitiv in seiner Attraktivität abwertet ("So toll kann das Spielzeug nicht sein, wenn das Spielen damit kaum bestraft wird"). Es ist durchaus denkbar, dass beide Theorien "recht" haben.

162 "Es ist wichtig, daß man das, was den Eingeborenen zur Zustimmung zu 'Gavagai?' veranlaßt, als Reiz und nicht als Kaninchen auffasst." (Quine 1980: 66f.) "Reizbedeutungen sind die einzigen unabhängigen Kontrollinstanzen bei der Erstellung von Übersetzungshandbüchern" (Bühler 1990: 241), denn "Reizbedeutung" lässt sich nach Quine im Unterschied zum Bedeutungsbegriff "durch Angabe intersubjektiv zugänglicher Kriterien exakt und zirkelfrei definieren. Die Reizbedeutung eines Satzes setzt sich zusammen aus der Summe der Rezeptorreizungen, die mit Zustimmungsverhalten, und der Summe der Reizungen, die mit Ablehnungsverhalten verbunden sind." (Blume/Demmerling 1998: 172) Hier tritt demzufolge die behavioristische Grundhaltung Quines deutlich zu Tage.

163 In Quines Worten: Die menschliche Theorie über die Welt "besteht aus Sätzen, die auf mannigfaltige, nicht einmal durch Vermutungen leicht zu rekonstruierende Weise miteinander verknüpft sind. Hier gibt es sogenannte logische Verbindungen, und daneben sogenannte kausale Verknüpfungen, aber alle Verknüpfungen dieser Art müssen letztlich darauf zurückgehen, daß Sätze als Reaktionen auf Sätze als Stimuli konditioniert werden." (Quine 1980: 33f.) 


\section{Begriffs- und Weltbildrelativismus}

Wenn ontologische Fragen nach den obigen Ausführungen immer nur relativ zu einer Sprache zu beantworten sind, so muss dies in der Konsequenz auch für wissenschaftliche Theorien gelten, stellen diese doch Erfahrung strukturierende begriffliche Schemata dar. Sprachtheoretische Überlegungen fallen dann quasi mit wissenschaftstheoretischen zusammen. Thomas S. Kuhn (1967) behauptet in diesem Sinne denn auch die "Inkommensurabilität" von Theorien. Für ihn wird der wissenschaftliche mainstream - die "Normalwissenschaft" - durch ein "Paradigma" konstituiert, das innerhalb seiner begrifflichen Strukturen nur ganz bestimmte Wirklichkeitsperspektiven anbieten, Probleme aufwerfen und damit Lösungsmöglichkeiten vorschlagen kann. Erst bei einem Scheitern des "rastlosen und hingebungsvollen Versuch(s), ... die Natur in die von der Fachausbildung gelieferten Begriffsschubladen hineinzuzwängen" (Kuhn 1967: 22), also erst dann, wenn die Normalwissenschaft in eine "Krise" gerät, wenn plötzlich Fragen gestellt werden, die sich mit dem herkömmlichen Paradigma nicht mehr beantworten lassen, kommt es zur "außerordentlichen Forschung", die nach Kuhn eine "wissenschaftliche Revolution" einleitet ${ }^{164}$.

Ein gängiges und oft genanntes Beispiel aus der Physik mag verdeutlichen, was damit gemeint ist. Nach Newton gehörten Lichtstrahlen zur allgemeinen Dingart der Partikel. Erst hundert Jahre später wurden diese begrifflich als "Wellen" erfasst. In Abhängigkeit davon, ob man die Ausbreitung des Lichtes nun vor dem Hintergrund der Wellen- oder der Korpuskularoptik untersucht, gelangt man zu völlig unterschiedlichen Hypothesen, Versuchsanordnungen, Beobachtungen und auch Ergebnissen ${ }^{165}$. Für die Sozialwissenschaften ließe sich in diesem Zusammenhang etwa erneut Luhmanns autopoietische Systemtheorie als inkommensurabel mit traditionellen Handlungstheorien begreifen, da Sozialsysteme hier nicht mehr über Menschen, sondern über Kommunikationsprozesse konstituiert werden.

Sowohl das linguistische Relativitätstheorem wie Quines Holismus und Kuhns Paradigmenkonzept sind freilich nicht unumstritten geblieben. Widerspruch entzündete sich insbesondere am impliziten Begriffs-/Weltbildrelativismus, also der Vorstellung, eine bestimmte Sprache führe unweigerlich zu einem Weltbild, das notwendig unvereinbar mit von anderen Sprachen erzeugten ontologischen

\footnotetext{
164 In ähnlicher Weise hatte in den 1930er Jahren schon Ludwik Fleck (1980) in seinem Werk "Entstehung und Entwicklung einer wissenschaftlichen Tatsache" argumentiert und dabei das, was Kuhn "Paradigma" nennt mit den Begriffen "Denkstil" und "Denkkollektiv" bezeichnet. Insofern könnte man in Analogie zur Rede von der "Duhem-Quine-These" oder der "Sapir-Whorf-These" auch von der "Fleck-Kuhn-These" sprechen.

165 "Beispielsweise wäre es völlig unsinnig, in eine Glasplatte möglichst gleichmäßig und möglichst dicht beieinander mit einem Diamanten parallele Linien zu ritzen, wie dies Rayleigh erstmals tat, wenn man nicht die Vorstellung hätte, auf diese Weise (im Sinne der Wellenoptik, D.K.) Interferenzphänomene beobachten zu können." (Poser 2001: 148)
} 
Ordnungsmustern sei (ontologische Relativität bzw. ontologischer Pluralismus). Eine solche These - so gibt etwa Donald Davidson zu bedenken - sei unhaltbar, denn wenn Begriffsschemata völlig verschieden seien, dann könnten sie auch nicht miteinander verglichen werden. Hierzu bedürfe es zumindest eines kleinsten gemeinsamen Nenners, von dem aus überhaupt Unterschiede feststellbar wären bzw. eingeführt werden könnten. "Whorf, der nachweisen möchte, daß die Hopisprache eine Metaphysik beinhaltet, die der unseren so fremd ist, daß Hopi und Englisch nicht einander entsprechend 'adjustiert' werden können (wie er es formuliert), bedient sich des Englischen, um den Inhalt von Mustersätzen der Hopisprache mitzuteilen. Kuhn gelingt es glänzend, darzulegen, wie die Dinge vor der Revolution standen, indem er unsere nachrevolutionäre Ausdrucksweise verwendet - welche sonst?"166 (Davidson 1987: 390f.)

Heute wird daher zumeist von einer "schwachen Version" des linguistischen Relativitätsprinzip oder einem "moderaten" Holismus gesprochen: Eine bestimmte Weltauffassung wird uns von der Sprache nicht in unabänderlicher Weise aufgezwungen, sondern lediglich nahegelegt. Durch das Erlernen einer neuen Sprache sind Menschen selbstverständlich in der Lage, andere Perspektiven auf die Wirklichkeit zu übernehmen, d.h. innerhalb eines anderen begrifflichen Schemas die Welt zu repräsentieren und dabei zugleich sinnhaft zu organisieren. Wohl alle uns bekannten Begriffsschemata sind also zumindest partiell ineinander überführbar.

Die Kuhnsche historische Wissenschaftsphilosophie argumentiert ebenfalls auf Basis eines Begriffs-/Weltbildrelativismus, der in eine inhärente Kontradiktion mündet: Wären Theorien tatsächlich vollkommen inkommensurabel, ließe sich dies überhaupt nicht feststellen. Und so kann es auch nicht verwundern, dass es etwa in der Soziologie - um das obige Beispiel nochmals aufzugreifen - zahlreiche Versuche gibt, Luhmanns autopoietische Systemtheorie handlungstheoretisch zu reinterpretieren (vgl. etwa Schimank 1992). Insofern bietet es sich auch mit Blick auf Kuhn an, erneut lediglich von einer "moderaten" Inkommensurabilitätsthese zu sprechen: Wissenschaftliche Theorien strukturieren einen Ausschnitt der Wirklichkeit auf je individuelle Weise, woraus dann auch spezifische Fragestellungen, Hypothesen, Methoden und Antworten resultieren. Dies bedeutet jedoch nicht, all dies ginge mit dem Vokabular eines anderen Paradigmas überhaupt nicht zusammen.

Die durch die Sprache erzeugte Weltsicht führt darüber hinaus keineswegs in einen ontologischen oder erkenntnistheoretischen Skeptizismus, denn warum sollte "es auf irgendeine Weise erforderlich (sein, DK), die Wirklichkeit von keinem Standpunkt aus zu kennen, um sie direkt so zu kennen, wie sie an sich

\footnotetext{
166 Mit Wittgenstein (PU \67) könnte man an dieser Stelle auch von "Familienähnlichkeiten" sprechen, d.h. bestimmte Sprachspiele - also sprachliche Tätigkeiten, die eine Lebensform respektive eine bestimmte Erfahrung von Welt zum Ausdruck bringen - ähneln einander (auf Sprachspiele wird im Rahmen der bedeutungstheoretischen Ausführungen noch zurück zu kommen sein).
} 
ist?" (Searle 2001: 32) "Es muß ... zugegeben werden, daß - so wie die Welt geartet ist - unterschiedliche ontologische Konzeptionen mit gleichem Recht vertreten werden können." (Strasser 1980: 83) Unser Wissen von der Welt und unser Verständnis von Wahrheit bleibt zwar an unsere jeweilige sprachliche Ausdrucksgestaltung gebunden, "aber objektiver geht es nun einmal nicht." (Davidson 1987: 404) "Was wir haben sind Objektivität und Rationalität nach Menschenmaß; sie sind besser als nichts" (Hilary Putnam zitiert nach Sandkühler 1999: 1058).

\section{Sein als Wert einer gebundenen Variable}

Folgt man dem Quineschen (moderaten) Holismus, dem linguistischen Relativitätstheorem (in seiner schwachen Version) oder Kuhns (moderatem) Paradigmenkonzept, so sind zwar nicht Sprache und Welt, aber doch Sprache und das Wissen über die Welt identisch; Ontologie wird damit zur Lehre von den von Menschen vorgenommenen Ordnungs- und Begriffsbestimmungen des Seienden. Wie bereits betont, resultiert daraus freilich nicht, dass nur das existiert, was sprachlich ausgedrückt werden kann. Aber nur von dem, was wir sinnvoll sprachlich ausdrücken können, lässt sich überhaupt sagen, es existiere ${ }^{167}$. Quine hat diese Sichtweise in Anlehnung an Russell innerhalb seiner kanonischen Notation radikalisiert $^{168}$. Kriterium des Seienden ist, ob etwas als Wert einer gebundenen Variablen vorkommen kann. "Was die Sache entscheidet, ist die Quantifikation ' $(\exists x)(x=a)^{\prime}$. (...) Der Gegenstandsbereich der gebundenen Variable ' $x$ ' ist das Universum, und die Existenzquantifikation sagt, daß mindestens einer der Gegenstände im Universum die angefügte Bedingung erfüllt - in diesem Falle die Bedingung, a zu sein." (Quine zitiert nach Glüer 1993: 92)

Variablenwerte machen nun auf Grundlage des Holismus (aber auch des linguistischen Relativitätstheorems und des Kuhnschen Paradigmenkonzepts) nur innerhalb eines konkreten begrifflichen Kontextes Sinn, d.h. das, was im obigen

\footnotetext{
${ }^{167}$ Bermes stellt in seinem Artikel "Die Sprache der Welt und die Welt der Sprache" folgende Frage: "Ist die Sprache nicht die einzige Wirklichkeit, von der gesprochen werden kann?" (Bermes 1999: 12) Auf Basis der obigen Erörterungen müsste man ihm nun antworten: Nein; die Sprache ist Teil der Wirklichkeit über die wir ohne sie nichts wissen können. Dies impliziert, dass ebenfalls das Wissen über die Sprache als Teil der Wirklichkeit nur sprachlich ist. Sprache ist also in gewisser Weise - wie Searle sagt - eine "sich selbst identifizierende Kategorie" (Searle 1997: 83).

168 "Kanonische Notation" meint, dass Aussagen in quantorenlogischer Form vorliegen. Man unterscheidet die Quantoren "Für alle x gilt" ( $\forall=$ Allquantor) und "Es gibt mindestens ein $\mathrm{x}$, für das gilt" ( $\exists=$ Existenzquantor). Diese Quantoren binden nun Variablen. Bsp.: "Für alle Schwäne gilt, dass sie weiß sind" (in kanonischer Notation: $\forall \mathrm{x}$ [x sind Schwäne, und $\mathrm{x}$ sind weiß]). Durch dieses Binden entstehen Existenzaussagen; die kanonische Notation hebt also hervor, worauf sich Sprecher bei ihren Aussagen ontologisch verpflichten. Die Werte, die wir für die gebundenen Variablen einsetzen (im Beispielsatz etwa für die gebundene Variable x den Wert "Schwäne"), teilen uns mit, was Sprecher als seiend voraussetzen (im Beispielsatz, dass es Schwäne gibt und dass diese alle weiß sind; ob es so etwas wie Weiße bzw. Weißheit gibt, bleibt unbeantwortet, denn darüber wird im Beispiel nicht quantifiziert).
} 
Zitat Quines als "Universum" firmiert, wird von dem jeweiligen Sprachsystem determiniert, ist insofern theorieabhängig. Was muss es also geben bzw. was muss als existent angenommen werden, damit unsere Aussagen wahr sein können?

Ob es etwa - um ein bekanntes Beispiel Quines anzuführen (vgl. Quine 1979) Pegasus gibt, hängt davon ab, ob es innerhalb des Universums einen Gegenstand gibt, der die Bedingung erfüllt, ein Pferd mit Flügeln zu sein. Da dies von keinem uns bekannten naturwissenschaftlichen Aussagensystem behauptet wird, heißt dies: Es existiert nichts (bzw. nicht etwas), von dem sich sagen ließe, es sei Pegaus (bzw. es pegasiere) $(\neg \exists \mathrm{x}[\mathrm{x}=\text { Pegasus }])^{169}$. Nochmals allgemein, in den Worten des sich von der Idealsprachenphilosophie entfernenden Carnaps formuliert: "Etwas als wirkliches Ding oder Ereignis anerkennen heißt: es an einer bestimmten Raum-Zeit-Stelle so in das System der Dinge einordnen können, daß es nach den Regeln des Sprachsystems zu den anderen als wirklich anerkannten Dingen paßt." (Carnap 1976: 54)

Es wäre nun missverständlich, würde man Quines ontologische Überlegungen wie sie in der Formel "Sein heißt Wert einer gebundenen Variablen zu sein" ihren Ausdruck finden, nun als unumstößliche Behauptungen darüber lesen, was in der Welt tatsächlich existiert. Bei der kanonischen Notation geht es nicht darum, "zu erfahren, was es gibt, sondern (dar)um zu erfahren, was eine bestimmte Aussage oder Doktrin, sei es eine eigene oder die eines anderen, sagt, daß es gebe; und insoweit haben wir es ganz regulär mit einem Problem der Sprache zu tun." (Quine 1979: 22)

Die quantorenlogische Schreibweise enthüllt also die ontologischen Verpflichtungen der Sprecher und gibt so an, welche Bedingungen vorhanden sein müssen, damit unsere Aussagen über die Welt wahr sein können. Insofern hängt das, was es gibt, für Quine auch keinesfalls von Wörtern ab. Aber die Frage nach dem, was es gibt, ist einzig auf dem Hintergrund einer gewählten Sprache zu beantworten ${ }^{170}$

169 Innerhalb dieses Argumentationszusammenhanges soll noch nicht ausführlich auf die Problematik hingewiesen werden, die Quine zu seinem Pegasus-Beispiel motivierte. Im Rahmen der Diskussion des Bedeutungsbegriffes wird die Frage nach dem Sinn leerer Namen ("Pegasus" gilt als ein solch leerer Name, weil er keinen Objektbezug aufweist) bzw. von negativen Existenzaussagen noch eine detaillierte Erörterung erfahren.

170 Zumindest in einer längeren Fußnote soll darauf hingewiesen werden, dass Quines Beitrag zur Ontologie ein zweifacher ist. Einerseits führt er mit seinen sprachphilosophischen Überlegungen ein Kriterium dafür ein, worauf Sprecher sich mit ihren Aussagen ontologisch verpflichten. Andererseits legt er aber auch eine eigene, physikalistische Ontologie vor. Diese Ontologie vermeidet mentale Gegenstände und erscheint mir zu reduziert, um die Spezifik sozialer Tatsachen in den Blick zu bekommen (Runggaldier/Kanzian [1998: 51] sprechen von einer "asketischen" ontologischen Position). Ich werde sie daher zwar nicht weiterverfolgen, der Vollständigkeit halber hier aber wenigstens kurz erwähnen (im Folgenden rekurriere ich neben Originalquellen [Quine 1979 u. 1980] vor allem auf Keil 2002: 105ff. u. 125ff., Bühler 1990 und Tetens 2004: 257ff.). Kriterium des Seienden ist für Quine, ob eine Entität genau eine Raum-Zeit-Stelle einnimmt, die sie von anderen Gegenständen derselben Art unterscheidbar macht (denn diese anderen Gegenstände können unmöglich dieselbe raum-zeitliche Lokalisierung aufweisen; eine Position, die in ähnlicher Weise schon der frühgriechische Philosoph Parmenides [1986: 27] formulierte: "Denn mit sich selbst von allen Seiten her gleich, ist es gleichmäßig in seinen Grenzen seiend.") Quine spricht vom "Individuationsprinzip". Neben den konkreten Dingen enthält Quines Ontologie lediglich noch 
(vgl. Quine 1979: 23). "Jede Zerlegung unserer Erfahrungswelt in ontologische Kategorien ist theorieabhängig." (Moulines 1994: 182) Das, was als existierend akzeptiert wird, hängt von den zur Verfügung stehenden sprachlichen Strukturen ab.

Daraus resultiert nun aber eine eigentümliche Ambivalenz: Zum einen fallen Sprache und Wissen über die Welt (d.h. unsere Auffassung von Wirklichkeit) in eins, d.h. wir können unsere sprachlichen Limitierungen nicht transzendieren. Zugleich gründet dieses Wissen über die Welt jedoch auf einer ganz basalen Stufe auf Reizbedeutungen und ist insofern untrennbar an sinnliche Wahrnehmung geknüpft. Die theoriebeladene Sicht des Menschen von der Welt - sei sie alltäglich oder wissenschaftlich - fußt auf Erfahrung. Wie lässt sich diese Ambivalenz aber plausibilisieren?

Ein kurzer Rekurs auf erkenntnistheoretische Überlegungen mag hier abschließend zur Klärung beitragen. Argumentiert man auf Grundlage der Theoriebeladenheit der Erfahrung, so müsste man eigentlich alle Begriffe als theoretisch begreifen. Eine solche Kennzeichnung wäre dann aber irreführend, da sie lediglich vor dem Hintergrund eines Unterscheidungskriteriums Sinn machen würde theoretisch können Begriffe nur dann sein, wenn andere empirisch (oder was auch immer sonst) sind; Letzteres wurde aber zuvor negiert. Hier soll daher im Sinne einer pragmatischen Arbeitshypothese festgehalten werden: Als Vorstellungsinhalte über die Wirklichkeit sind alle Begriffe theoretisch aufzufassen. Da sie aber untereinander in vielfältig verwobener Verbindung stehen und nur eine physikalistisch gedachte Fundierung als ernst $\mathrm{zu}$ nehmender Kandidat für die basalen

Klassen. Dies wird damit begründet, dass wissenschaftliches Arbeiten ohne Klassen unmöglich sei; insbesondere die Mathematik stecke "bis zum Hals in Verpflichtungen auf eine Ontologie abstrakter Entitäten" (Quine 1979: 20). Als Grund für Quines ausgesprochen sparsame Ontologie lässt sich anführen, dass mentale Entitäten für Quine in seiner behavioristischen Perspektive lediglich Verhaltensdispositionen darstellen, die auf physikalische bzw. physiologische Mechanismen zurückführbar sind - Umweltreize werden einfach qua Verhaltensdispositionen verarbeitet. Diese Sichtweise kann leicht dazu führen, weite Teile der Sozialwissenschaften als gegenstandslos zu erklären (bzw. erfordert zumindest einen sehr großen Übersetzungsaufwand, um die entsprechenden Gegenstände erfassen zu können; es ist für mich insofern auch nur schwer vorstellbar, dass eine solche ontologische Reduktion eine Anziehungskraft auf Sozialwissenschaftler ausüben kann). Ich argumentiere in dieser Untersuchung mit John R. Searle aber, dass es soziale Tatsachen in weiten Teilen nur deswegen gibt, weil Menschen über mentale Fähigkeiten verfügen, die zwar naturalisiert, jedoch weder in der dualistischen noch in der materialistischen Tradition gedacht werden können (vgl. Kapitel 5.4.). Letztlich dürfte Quine aber auch einer solchen Ontologie ihre Berechtigung nicht abgesprochen haben. So schreibt er nämlich hinsichtlich seiner eigenen Auffassung vom "Mythos physikalischer Objekte", dieser sei "den meisten anderen darin überlegen, dass er sich darin wirksamer als andere Mythen erwiesen hat, dem Fluß der Erfahrungen eine handliche Struktur aufzuprägen." (Quine 1979: 49) Und an anderer Stelle spricht Quine auch von einem "zahmen Physikalismus": "Er (der zahme Physikalismus, D.K.) erklärt, es gebe keine unüberbrückbaren kategorialen Unterschiede zwischen dem Geistigen und dem Physikalischen." (Quine 1980: 457) Quine ist also - eine gute Begründung vorausgesetzt - ontologisch tolerant, besteht sein Verständnis von Ontologie doch gewissermaßen in einer "Vermutung über das, was es gibt. Wenn man dies akzeptiert, dann ist einsichtig, daß die Wahl der Hypothese, in diesem Falle der Ontologie, eine Frage der Plausibilität, der (subjektiven) Vernunft, der Einfachheit oder ähnlicher Gründe ist." (Druwe 1995: 389) 
Aspekte menschlichen Sprechverhaltens in Frage kommt, sind sie letztlich empirisch verankert. Man erlernt etwa den Einwortsatz "Kaninchen" (der potentiell genau dasselbe meinen könnte wie "Sieh da, ein Kaninchen") als konditionierte Reaktion auf einen ganz bestimmten visuellen Stimulus.

Freilich kann man Quine insofern widersprechen, als die Identifizierung einer vorbeihoppelnden Entität als "Gavagai" (oder eben "Kaninchen") schon eine (theoretische) Vorstellung darüber voraussetzt, was ein Gavagai zu einem Gavagai macht (wir stoßen hier also auf das Universalienproblem). Ferner könnte es sich u.U. lediglich um eine Gavagaiattrappe handeln, womit die sprachliche Identifikation sogar als fehlerhaft zu klassifizieren wäre. Die Quinesche "Reizbedeutung" steht daher in Spannung zu Quines (semantischem) Holismus; ihr Wert liegt in ihrer pragmatisch-heuristischen Funktion: Menschen lernen Sprachen und überprüfen Theorien "und beides muss an irgendeiner Stelle beginnen, sei der Holismus theoretisch noch so gut begründet." (Keil 2002: 49)

In der Tat: Wenn Sprache das einzige Zugangsinstrument zur Realität darstellen würde, dann bliebe rätselhaft, warum sich Neugeborene überhaupt in der Welt zurechtfinden bzw. wie sie Sprache erwerben können. Wenn alle Beobachtung eine apriorische Theorie verlangt und Theoriebeladenheit das Gleiche wie Sprachbeladenheit meint, wie sollten Säuglinge dann in der Lage sein, zu beobachten, da sie doch noch über kein sprachliches Instrumentarium verfügen? Die Quinesche Reizbedeutung ist zumindest in der Lage, diese Argumentationslücke plausibel (gleichwohl nicht völlig zufriedenstellend) zu schließen: Ostensiv, d.h. durch einen Hinweis, werden auf rudimentärer Basis von Kindern dank genetischer Disposition Gegenstände erlernt ${ }^{171}$. Von hier aus können dann qua Steigerung des sprachlichen Ausdrucksvermögens - gewissermaßen dem Baron Münchhausen gleich, der sich am eigenen Schopfe aus dem Sumpf zog - immer elaboriertere und komlexere Theorieentwürfe über die Welt und damit Wirklichkeitsverständnisse resp. -auffassungen entwickelt werden, die letzten Endes nahezu vollständig sprachlich strukturiert sein dürften.

\footnotetext{
171 Piaget (1973) hat in seinen Untersuchungen zum kindlichen Spracherwerb auf vorsprachliche kognitive Konstrukte verwiesen, an die die Sprache dann später anknüpft. Diese Konstrukte werden gewissermaßen durch den interaktiven Umgang des Kindes mit seiner Umwelt getriggert. Vor allem über das Ertasten von Gegenständen erwirbt das Kind ein Wissen, das die theoretische Grundlage für die Erfahrung bildet (in ähnlicher Weise argumentiert auch Chomsky [1988] mit seinen Hinweisen auf eine dem Menschen angeborene Grammatik). Dass es sich bei den ersten sprachlichen Leistungen des Menschen ganz im Sinne der Quineschen Reizbedeutung zunächst einmal lediglich um die Bezeichnung einfacher physikalischer Gegenstände handelt, die mit einem Substantiv belegt werden, wird durch neuere entwicklungspsychologische Forschungen von Bornstein/Cote bestätigt (vgl. Speck 2005: 15). Wittgenstein spricht in einem ähnlichen Zusammenhang von "primitiven Formen der Sprache": "Das Lehren der Sprache ist hier kein Erklären, sondern ein Abrichten." (PU \5)
} 


\subsection{Bedeutung und Sprache}

Bis hierhin wurde argumentiert, dass Sprache und Wissen über die Welt in eins fallen. Was es tatsächlich gibt, lässt sich ausschließlich sprachlich bestimmen. Dies heißt aber keineswegs, dass es nur das gibt, was wir wissen bzw. was sprachlich bestimmt ist, oder dass es sogar - im Sinne eines linguistischen Idealismus - nur Sprache gibt ${ }^{172}$. Was den physikalischen Bereich der Welt betrifft, wäre es hoministisch (und damit m.E. naiv), zu glauben, die Dinge existierten nur dank menschlicher Sprachfähigkeit.

Etwas anders stellt sich die Sachlage allerdings für die soziale Realität dar. Diese - so die von mir in dieser Arbeit vertretene Position - wird in weiten Teilen (aber eben keineswegs vollständig) über die Zuweisung sprachlich prozessierter Bedeutung hergestellt, d.h. erst der bedeutungstragende Sprachgebrauch schafft Entitäten, die ansonsten überhaupt nicht vorhanden und sowieso nicht denkbar wären. Ausgehend von dieser Überlegung, die es in den folgenden Abschnitten herzuleiten und zu begründen gilt, wird im Anwendungsteil der vorliegenden Arbeit schließlich danach gefragt, welche Bedeutungen Menschen wie produzieren bzw. prozessieren müssen, damit Sozialkapital entstehen kann. Eben das ist gemeint, wenn in einem ontologischen Sinne gefragt wird: Was bedeutet "Sozialkapital"?

"Bedeutung" ist der Zentralbegriff sprachphilosophischer Analysen. Paul Horwich drückt das Forschungsinteresse m.E. sehr plastisch aus: "How, ..., does it come about that the word 'dog' means precisely what it does? How is it possible for this intrinsically inert ink-marks (...) to reach out into the world and latch on to a definite portion of reality: namely, the dog?" (Horwich 1998: 1) Insofern gilt es an dieser Stelle, wenn man dies einmal unter absichtlicher Verwendung eines logischen Zirkels und in Anlehnung an Hilary Putnam (1979) so sagen darf, zu erläutern, was "Bedeutung" eigentlich bedeutet ${ }^{173}$, um nicht zuletzt hierauf fußend

\footnotetext{
172 "Die Philosophie des 20. Jahrhunderts war besessen von dem Thema Sprache und Bedeutung, und aus diesem Grund war es wohl unvermeidlich, dass jemand auf die Idee verfiel, ohne Sprache und Bedeutung existiere überhaupt nichts." (Searle 1997a: 177) Problematisch erscheint ferner die Zirkularität des Wissensbegriffs: "Es ist ... so, daß ich, um von etwas als diesem Etwas wissen zu können, wissen muß, daß ich weiß, und damit sind mir mein wissendes Ich und mein eigenes Wissen in Einheit mitgegeben. Dieses Wissen um das eigene Wissen und um die eigene Existenz kann als Möglichkeitsbedingung meines Objektwissens selbst kein Objektwissen, sondern nur dessen Hintergrund sein." (Weißmahr 1985: 41) Radikale Konstruktivisten würden dies freilich nicht so sehen: Das Wissen darum, dass ich weiß, ist ebenfalls Objektwissen und hat daher keine andere Qualität als das Wissen um die Gegenstände der Außenwelt - beides ist Resultat neurobiologischer Konstruktionsleistungen.

173 Die gewählte Schreibweise soll pointiert auf die Problematik der Bedeutungsthematik aufmerksam machen.
} 
dann ein Analyseschema zu präsentieren, dass später nach Bedeutung als Bedingung der Möglichkeit von Sozialkapital fragen kann ${ }^{174}$.

Dabei werde ich mich vorwiegend mit sprachphilosophischen Beiträgen befassen. In der Soziologie wird zwar (mittlerweile weitgehend über alle Paradigmen hinweg) vorausgesetzt, "daß Menschen 'Dingen' gegenüber auf der Grundlage der Bedeutungen handeln, die diese Dinge für sie besitzen" (Blumer 1973: 81); was Bedeutung eigentlich ist bzw. sein soll, wie es ganz grundlegend zu ihr kommen kann und was eigentlich genau geschieht, wenn wir, "Dingen" gegenüber auf der Grundlage von Bedeutungen handeln, bleibt jedoch unthematisiert (auch wenn nach Blumer "die Bedeutung solcher Dinge aus der sozialen Interaktion, ..., abgeleitet ist oder aus ihr entsteht"175 [ebenda]). Dies kann freilich nicht überraschen, denn "ein Kontext, in dem wir dem Wort 'Bedeutung' normalerweise nicht begegnen, ist die Wendung 'eine Bedeutung ist das und das' - und daher, so folgert Quine, sei die Frage 'Was ist eine Bedeutung?' eine spezifisch philosophische Frage."176 (Hofmann 1995: 15)

In die verstehende Soziologie haben bedeutungstheoretische Konzeptionen der analytischen Philosophie bislang - so jedenfalls meine Beobachtung - kaum Eingang gefunden; verstehende Soziologen setzen (häufig phänomenologisch orientiert) analytisch erst später an, d.h. sie problematisieren nicht den inneren Funktionsmodus oder das logische Arbeiten der Bedeutung, sondern fokussieren soziale Wirkungen bzw. die sinnhafte Konstitution von Handlungen. Wenn dennoch immer wieder bei Autoren des interpretativen Paradigmas von Sprache die Rede ist, dann geht es - sprachphilosophisch gewendet - um Propositionen, d.h. um das, was durch einen Satz an Information ausgedrückt wird. Sätze und Propositionen sind also verschiedene Dinge ${ }^{177}$; Letztere sind gleichwohl auf grammatisch wohlgeformte Folgen von Worten - also auf Sätze - angewiesen. Eine ontologische Untersuchung wird zunächst einmal versuchen, auf die

174 Die Frage "Do there exist such things as the things we mean?" (Schiffer 2003: 1) wird insofern nicht problematisiert, sondern vielmehr als positiv beantwortet unterstellt. Es geht nicht darum ob, sondern wie es diese Dinge gibt.

175 Aus Sicht einer phänomenologisch-verstehenden Soziologie heißt es bei Hitzler/Eberle (2004: 114): "Wenn unsere Alltagswelt ... nicht einfach nur aus 'brute facts', sondern aus - mannigfaltigen Bedeutungen besteht, dann geht es (auch) soziologisch wesentlich darum, rekonstruierend zu verstehen, wie Bedeutungen entstehen und fortbestehen". Ich werde im Folgenden argumentieren, dass soziologische Bedeutung auf sprachliche Bedeutung angewiesen ist - Letztere wird aber innerhalb soziologischer Analysen (jedenfalls) nicht unmittelbar in den Blick genommen (einschränkend möchte ich hier allerdings auf die sprachphilosophischen Reflexionen Bourdieus [1993] verweisen, die weit über den Rahmen der Soziologie oder der Ethnologie hinausreichen).

176 Wir können sie freilich auch theologisch auffassen. Dann aber nimmt der Analysegang eine andere Richtung, muss er doch die göttliche Transzendenz bzw. den Logos zum Ausgangspunkt nehmen, um von hieraus die Schöpfungsfrage zu reflektieren (vgl. hierzu etwa Ratzinger 2006: 3450).

177 Nochmals sei in diesem Zusammenhang auf die Debatte zum Verhältnis von Satz, Proposition (bzw. Aussage) und Wahrheit zwischen Austin (1974) und Strawson (1974) verwiesen. 
grundlegendsten - und d.h. die semantischen und pragmatischen - Strukturen sozialer Realität vorzustoßen, welche Propositionen erst ermöglichen.

Sprache, so die Ausgangsüberlegung, ist das "Medium, mit dem Bedeutungen in den menschlichen Verkehr eingebracht werden"178 (von Stenglin 1990: 138). Daher wird es im Folgenden vorwiegend um eine Betrachtung linguistischer Probleme aus Sicht der analytischen Philosophie gehen. Abschließend wird die Verbindung zwischen sprachphilosophischem und soziologischem Bedeutungsverständnis jedoch einer näheren Bestimmung unterzogen.

Eine Beantwortung des Rätsels um den grundlegenden Algorithmus der Bedeutung darf der Leser hier natürlich nicht erwarten; an diesem Rätsel haben sich schon Generationen von Philosophen abgearbeitet. Sobald man damit beginnt, zu explizieren, wie es überhaupt zu so etwas wie Bedeutung kommt, verwendet man Sprache und greift damit unreflektiert schon auf Bedeutung zurück, setzt ihre Existenz also voraus. Ich kann nicht erkennen, wie dieser Zirkel jemals zu vermeiden sein sollte. Peter Strawson bezeichnet denn auch die Bedeutungsproblematik als "an issue which, in one form or another, is likely to provide philosophers with matter for argument as long as there are philosophers left to argue." (Strawson 1985: 92)

\section{Bedeutung und Bezug}

Wie schon im Kapitel über die wissenschaftstheoretischen Grundlagen dieser Arbeit beschrieben, zielt die Philosophie der Idealsprache auf die Beseitigung der Unschärfen und Mehrdeutigkeiten alltagsweltlicher Aussagen. Ein neu zu schaffendes Vokabular soll ausschließlich direkt Beobachtbares umfassen. Die Realität - so der dahinterstehende Gedanke - ist dann einfach dadurch erkennbar, dass man die Art und Weise untersucht, in der man sie begrifflich geordnet hat, wobei diese Ordnung keineswegs willkürlich erfolgt, sondern von der Welt diktiert wird (vgl. Newen/Savigny 1996: 67f.).

Wenn eine strikte Unterscheidung zwischen Welt und Sprache in diesem Sinne eigentlich nicht mehr vorgenommen wird, dann fällt die Bedeutung von Zeichen mit den von ihnen symbolisierten Gegenständen in eins. Semantik meint so Gegenstandsbezug; die Erkenntnis von Bedeutung resultiert aus der Wortreferenz und Worte bedeuten das, worauf sie sich beziehen ${ }^{179}$. So ergibt sich die Bedeu-

178 "Um zu verstehen", so Searle (2001: 162f.), "wie erstaunlich Sprache ist, erinnern wir uns vielleicht am einfachsten an folgendes: In der unteren Gesichtshälfte des Menschen gibt es eine Höhle, die sich mittels einer eingehängten Klappe öffnet. In regelmäßigen Abständen öffnet sich die Höhle und vielfältige Geräusche kommen heraus. Diese Geräusche werden meistenteils durch Luft verursacht, die über schleimbedeckte Bänder im Kehlkopf strömt. ... Bemerkenswert daran ist nun, daß wir von der akustischen Emission zu diesen erstaunlichen semantischen Eigenschaften gelangen, die ja nicht nur rethorische und sprachliche Phänomene umfassen, sondern auch sogar politische, literarische und kulturelle Phänomene anderer Art."

179 Wenn von "Worten" die Rede ist, dann soll in diesem Zusammenhang damit auf den Zeichenaspekt der Sprache abgehoben werden. Bei den Zeichen "Buch", "Book" und "Livre" handelt es sich 
tung des Satzes "Jennifer Lopez ist schön" aus der Bedeutung von "Jennifer Lopez" - die Bedeutung ist eine US-amerikanische Sängerin und Schauspielerin und der Bedeutung von "(ist) schön" - die Bedeutung ist die Eigenschaft bzw. Universalie Schönheit. Diese insbesondere auf Russell zurückgehende, stark nominalistisch geprägte Bedeutungstheorie "war ganz direkt: Namen bedeuteten Objekte, und Prädikate hatten Universalien als ihre Bedeutung"180 (Read 1997: 157).

Geht man nun davon aus, die Bedeutung eines Satzes könne in diesem Sinne aus der Bedeutung seiner Teile erschlossen werden, dann resultiert daraus u.a. ein Problem bezüglich negativer Existenzaussagen. Betrachten wir bspw. den Satz: "Es gibt kein Rumpelstilzchen"181. Nun ist Rumpelstilzchen eine Märchenfigur der Gebrüder Grimm und als solche nicht Teil der Realität. Die genannte Aussage scheint insofern wahr zu sein: Es gibt kein Rumpelstilzchen. Wenn nun aber "Rumpelstilzchen" auf kein reales Objekt referiert und insofern als ein "leerer Name", d.h. als ein Name ohne Objektbezug, zu lesen ist, dann hat das Wort keine Bedeutung und es muss folglich - da die Bedeutung eines Satzes sich aus den Bedeutungen der in ihm vorkommenden Worte gleichsam errechnet - auch ein bedeutungsloser Satz vorliegen. Angenommen, es gebe Rumpelstilzchen tatsächlich, dann wäre die obige Aussage falsch. Damit scheinen negative Existenzaussagen der Form "Es gibt kein X" entweder falsch oder bedeutungslos zu sein.

Schon der frühgriechische Philosoph Parmenides hatte erkannt, wie schwer es ist, davon zu reden, dass "nicht ist" ist ${ }^{182}$. Rein "intuitiv" macht es uns aber überhaupt keine Schwierigkeiten, die Aussage "Es gibt kein Rumpelstilzchen" als wahr zu klassifizieren und ihr einen Sinn zuzusprechen. Also muss doch das

um verschiedene Worte aber nur um einen Begriff (da damit das Gleiche gemeint ist). Wort und Begriff stehen damit zueinander wie Satz und Proposition.

180 Als Kopula wird "ist" im obigen Zusammenhang lediglich dazu benutzt, "Jennifer Lopez" und "schön" miteinander zu verbinden; die Bedeutung von "Jennifer Lopez" soll im Beispielsatz über das Kopula "ist" mit der Bedeutung von "schön" angereichert bzw. näher expliziert werden. Formuliert man hingegen eine Aussage wie "Dieser Planet ist die Venus", dann "wird das 'ist' wie in der Arithmetik das Gleichheitszeichen gebraucht, um eine Gleichung auszusprechen." (Frege 2002: 48f.) Für Wittgenstein (PU \ 561) hat "ist" daher zwei Bedeutungen - es wird sowohl als Kopula wie als Gleichheitszeichen gebraucht (auf die Gebrauchstheorie Wittgensteins wird später noch explizit hinzuweisen sein).

181 Die folgende Argumentation ist (natürlich) eine weitgehende Analogie zum Pegasus-Beispiel Quines (1979).

182 Dabei hat Parmenides aber eine relativ klare Position bezogen: "Denn es ist nicht sagbar noch denkbar, daß (etwas) nicht ist. ... Also muß es entweder ganz und gar sein oder nicht." (Parmenides 1986: 21) Und kurz zuvor: "Nichts ist nicht: das, sage ich dir, sollst du dir klarmachen. Denn das ist der Weg des Suchens von dem ich dich abhalte; sodann aber vor dem, worauf ja die Sterblichen, die nichts wissenden, umherwanken, die doppelköpfigen: denn Ohnmacht lenkt in ihrer Brust ihren schwankenden Verstand, und sie treiben dahin so taub als blind, blöde, verdutzte Gaffer, unterscheidungslose Haufen, bei denen Sein und Nichtsein dasselbe gilt und nicht dasselbe, und es in allen Dingen einen umgekehrten Weg gibt. Denn dazu werden sich die Dinge gewiß niemals zwingen lassen: zu sein, wenn sie nicht sind." (ebenda: 17f.) (Zum Seinsverständnis Parmenides siehe bspw. auch Heinrich 1966: 183ff.) 
"Nicht-Sein sein, was anderenfalls wäre das, was es nicht ist?"183 (Quine 1979: 9) Augenscheinlich ist es wenig praktikabel, die Bedeutung eines Satzes davon abhängig zu machen, ob die in ihm vorkommenden Worte auf existierende Gegenstände referieren oder nicht ${ }^{184}$.

Das Problem der negativen Existenzaussagen entsteht vor allem im Rahmen einer Abbild- bzw. Gegenstandstheorie der Bedeutung, in welcher die Idee einer vollkommenen Kongruenz zwischen sprachlicher Struktur und einer hiervon unabhängigen Struktur der Welt propagiert wird - Bedeutungsgehalt und Deskription werden hier nicht wirklich getrennt. Wenn wir "Rumpelstilzchen" sagen, verpflichten wir uns ontologisch darauf, Rumpelstilzchen die "Last des Objektbezugs" (Runggaldier/Kanzian 1998: 26) aufzubürden, d.h. Rumpelstilzchen als existierend anzunehmen ${ }^{185}$.

183 Diese Problematik wurde von Quine als "Platons Bart" bezeichnet (Quine 1979: 9), da Platon davon ausging, alles, über das wir sinnvoll nachdenken könnten, müsse in irgendeinem Sinne auch "Sein" haben, selbst wenn es nicht wirklich existiere. In der Existenzphilosophie hat dann das "Nichts" bei Heidegger und Sartre eine besonders exponierte Position eingenommen, um in Abgrenzung von diesem das "Sein" bestimmen zu können. Aus "nichts" im Sinne des logischen "es ist nicht der Fall, dass" wird das Nominativ "das Nichts", welches fortan eine Gegenstandsbeziehung suggeriert, die es de fakto nicht aufweisen kann (denn auf was sollte "Nichts" referieren?). "Das grammatikalische Taschenspielerkunststück ist getan, und alle weiteren Spekulationen stützen sich auf dieses!" (Stegmüller 1978: 193) (Freilich wäre es auch möglich, dass Stegmüller aus sprachanalytischem Übereifer die Quintessenz der Heideggerschen und Sartreschen Ontologie hier ein bisschen absichtlich missversteht.)

${ }^{184}$ Eine auf Russell zurückgehende und später von Quine (1979) weiter ausgearbeitete Lösung dieses Problems besteht darin, die logische Struktur negativer Existenzaussagen herauszuarbeiten. Ganz im Sinne der Philosophie der Idealsprache geht es dabei darum, durch eine logische Analyse alltagssprachliche Unklarheiten und Widersprüche zu beseitigen. Logisch besagt unser obiger Beispielsatz, dass es nichts gibt, was Rumpelstilzchen ist (bzw. was rumpelstilzt) ( $\neg \exists \mathrm{x}[\mathrm{x}=$ Rumpelstilzchen]). Der Existenzquantor "es gibt" unterstellt, dass in der Realität mindestens ein Gegenstand existiert, dem die behauptete Prädikation zukommt, bzw. im Falle des NegativOperators, dass es nichts gibt, dem die behauptete Prädikation zukommt. Im Beispielsatz wird nach der logischen Analyse nun eben nicht mehr von dem Subjekt "Rumpelstilzchen" "präsupponiert" (so der gängige philosophische Ausdruck), es existiere nicht, sondern von der Eigenschaft "Rumpelstilzchen zu sein" bzw. zu "rumpelstilzen". Durch die kanonische Notation wird behauptet, dass kein Element des Wertebereiches der gebundenen Variable Rumpelstilzchen ist, d.h. die Aussage "Es gibt nicht ein Etwas, das Rumpelstilzchen ist" lässt sich nun bspw. auf dem Hintergrund der deutschen Sprache als wahre Aussage kennzeichnen. Ontologisch verpflichtend ist nicht mehr "Rumpelstilzchen", sondern der Partikel "Etwas". Die Eigenschaft "Rumpelstilzchen zu sein" bzw. zu "rumpelstilzen", die innerhalb der kanonischen Notation auftaucht, ist ontologisch unproblematisch, da sie nicht verpflichtend sein kann: In nominalistischer Denkweise handelt es sich hierbei lediglich um Namen, auf die Existenzbehauptungen nicht angewandt werden können, denn diese Entitäten sind raum-zeitlich nicht lokalisierbar (für "Rumpelstilzchen" hingegen wird raum-zeitlicher Bezug propagiert) (nebenbei bemerkt, handelt es sich hierbei auch um die Argumentation, die innerhalb des wissenschaftstheoretischen Strukturalismus der Ramsey-Elimination theoretischer Terme zugrundeliegt). Bedeutung kann in der Abbildtheorie im Anschluss an Frege lediglich Namen zukommen, die auf solche raum-zeitlichen Größen referieren. Dies führt dann aber bspw. zu der Frage, was Worte wie "puh" oder "ach" bedeuten. Etwa nichts? Wie weiter unten noch zu zeigen sein wird, kann eine Gebrauchstheorie der Bedeutung eine solche Frage beantworten.

185 Letzlich verbirgt sich hinter der Gleichsetzung von Bedeutung und Bezug auch ein Kategorienfehler: "Ich kann der Person nachtrauern, auf die sich der Ausdruck 'die verstorbene Gemahlin von Prinz Charles' bezieht, nicht aber seiner Bedeutung." (Glock 2000: 433) 
Neben negativen Existenzaussagen ist eine Abbildtheorie der Bedeutung ebenso hinsichtlich von Universalien problematisch. Die Aussage "Gras ist grün" setzt nämlich bspw. voraus, dass wir überhaupt in der Lage sind, uns eine repräsentierende Vorstellung von "Gras" und "grün" zu machen. Tatsächlich können wir uns vielleicht einen bestimmten Grashalm oder auch eine bestimmte Rasenfläche vorstellen, niemals jedoch Gras "im Allgemeinen", als Abstraktum. Ähnlich verhält es sich mit Farben. Doch hier ist noch nicht einmal ein bestimmtes Grün denkbar, insofern Farben nie in sich selbst (ante rem), losgelöst von Trägern vorkommen können (zumindest bis zu diesem Zeitpunkt der Argumentation). Und selbst wenn ein bestimmtes Grün unseren Gedanken zugänglich wäre, dann wohl kaum "Grüne" als Abstraktum. Wir können etwa sagen: "Dieses Auto ist dunkelgrün" - dann haben wir es mit einem gemeinten Sachverhalt, jedoch nicht mit einem individuierten Gegenstand zu tun. Die syntaktische Struktur von Sätzen erzeugt den Anschein, als sei es möglich, sich Universalien unmittelbar vorstellbar und bezeichenbar zu machen.

Die Abbildtheorie der Bedeutung liegt auch der Korrespondenztheorie der Wahrheit zugrunde. Hier erscheint sie in der Form, dass eine Proposition - also der Inhalt bzw. Informationsgehalt einer Aussage - dann wahr ist, wenn diese mit einer Tatsache korrespondiert. So ist die Proposition der obigen Aussage "Gras ist grün" wahr, wenn Gras grün ist. Aber hiermit wird die Unterscheidung zwischen Sprache und Welt gleichsam eingeebnet. Der Vordersatz soll eine Bezugnahme auf Sachverhalte indizieren, während der Nachsatz etwas Nicht-Sprachliches als Wahrheitsbedingung für die sprachliche Aussage des Vordersatzes suggeriert.

Warum Sprache und Welt diese Symbiose eingehen, bleibt unklar und wird lediglich behauptet. Um zu verstehen, was mit der Proposition gemeint ist, muss man ihre Bedeutung kennen. Diese soll sich aber nun unabhängig von dem geäußerten Satz in dem bezeichneten Sachverhalt als etwas bereits Gegebenes manifestieren, denn nur so lässt sich sinnvoll von einer Korrespondenzbeziehung sprechen. Da Bedeutung aber ohne Worte gänzlich unvorstellbar ist, steht Korrespondenz unter Metaphysikverdacht; sie kann kein bewusstseinsunabhängiges Kriterium für die Realität sein. Was als Gegenstand für uns firmiert, ist abhängig von Bedeutung. Diese wiederum ist nur sprachlich einführbar, womit eine naive Korrespondenz zwischen Gegenstand und Sprache nicht zu begründen ist. Erkenntnis- und wissenschaftstheoretisch wurde dies unter Verweis auf die Theoriebeladenheit der Erfahrung sowie die damit zusammenhängende Problematik einer Verifikation, Falsifikation oder Anwendung von Theorien oben schon erläutert.

Die Korrespondenztheorie lässt sich allerdings in reformulierter Form beibehalten, wenn man von einem "hypothetischen Realismus" ausgeht (Ferber 1998: 110), d.h. eine Proposition korrespondiert einer Tatsache lediglich so, wie sie uns erscheint (Chalmers [2001: 194] bevorzugt den Ausdruck "nicht-repräsentativer Realismus"). Eine so reformulierte Korrespondenztheorie folgt dann m.E. der 
semantischen Wahrheitsauffassung Tarskis. Die "Pointe" bei Tarski liegt in der Unterscheidung zwischen einer Objekt- und einer Metasprache (vgl. Tarski 1972). Eine in einer Objektsprache formulierte Aussage ist dann wahr, wenn sie mit einer metasprachlichen Aussage korrespondiert: "'Gras ist grün', ist wahr, wenn Gras grün ist". Wahrheit ist nun nicht mehr eine Beziehung zwischen einer Proposition und einer Tatsache, sondern nur noch eine Beziehung zwischen zwei Propositionen, so dass man auch auf Basis wahrheitstheoretischer Überlegungen die Unhintergehbarkeit von Sprache und Bewusstsein propagieren muss ${ }^{186}$.

Wenn Realität immer nur sprachlich gedacht werden kann resp. zugänglich ist, dann machen Menschen niemals Aussagen über eine nicht-sprachliche Welt, sondern immer nur metasprachliche Aussagen über eine objektsprachlich firmierende Welt. "Wahrheit" kann insofern nur als metasprachliches Prädikat gelten. Die daraus resultierenden Konsequenzen für wissenschaftliches Arbeiten wurden oben unter dem Stichwort "Kompatibilitätsprüfung von Theorien" erörtert, ohne dabei schon explizit auf Tarski eingegangen zu sein.

\section{Bedeutung und Struktur}

Kehren wir noch einmal zu dem Märchen der Gebrüder Grimm zurück. Neben der von Quine vorgeschlagenen Lösung, negative Existenzaussagen über eine logische Transformation so zu reformulieren, dass sie wahr sein können, gibt es nun natürlich die Möglichkeit, Rumpelstilzchen als eine Idee des Geistes zu begreifen. Frege (2002) hat in seinem Aufsatz "Über Sinn und Bedeutung" etwa zwischen "Bedeutung" im Sinne von Referenz und "Sinn" im Sinne von inhaltlicher Bedeutung unterschieden und damit Sinn quasi in zwei voneinander unabhängige Teileinheiten zerlegt ${ }^{187}$. Bspw. haben die Worte "Morgenstern" und "Abendstern" die gleiche Bedeutung, da sie sich beide auf den Planeten Venus beziehen; aber der Sinn ist jeweils ein anderer: Mit "Morgenstern" wird die Venus am Morgen und mit "Abendstern" die Venus am Abend bezeichnet. So mag mit Frege ein leerer Name - wie etwa "Rumpelstilzchen" - zwar keine Bedeutung (=

186 Tarskis Ausgangspunkt war vor allem die Lügner-Paradoxie, in die die Korrespondenztheorie mündet. Die Behauptung "Alle meine Aussagen sind gelogen" ist in der Korrespondenztheorie dann falsch, wenn das, was ich da behauptet habe, wahr ist (denn dann habe ich ja eben gerade nicht gelogen - wie kann ich dann aber sagen, ich würde immer lügen?). Mit Tarskis Metasprache lässt sich diese Paradoxie nun vermeiden. Formuliere ich in der von der Objektsprache unabhängig zu denkenden Metasprache "Alle meine Aussagen sind gelogen", dann bezieht sich diese Aussage auf meine in der Objektsprache getätigten Äußerungen. Sind diese objektsprachlichen Äußerungen tatsächlich immer gelogen, dann ist die metasprachliche Behauptung wahr, ohne dass dies paradox wäre, denn die Objektsprache bezieht sich umgekehrt nicht auf die Metasprache.

187 Dies ist zweifellos eine von mir nicht sonderlich glücklich gewählte Formulierung, da "Sinn" hier sowohl als Überbegriff als auch als Teileinheit fungiert. Sprachlicher Sinn war für Frege weder eine Entität der Außenwelt, noch eine psychische Vorstellung: "Ein drittes Reich muß anerkannt werden. Was zu diesem gehört, stimmt mit den Vorstellungen darin überein, daß es nicht mit den Sinnen wahrgenommen werden kann, mit den Dingen aber darin, daß es keines Trägers bedarf, zu dessen Bewußtseinsinhalte es gehört." (Frege zitiert nach Wendel 1990: 174, Fußn. 4) 
Referenz bzw. Begriffs-Extension) aufweisen, er kann aber sehr wohl sinnhaft (= inhaltlich bedeutungsvoll bzw. begrifflich intensional) sein. Genau diese Perspektive entspricht ja auch unserer Alltagsintuition - Rumpelstilzchen ist eine Märchenfigur, die für Generationen von Kindern und deren Eltern inhaltlich bedeutungsvoll war und ist ${ }^{188}$.

Im linguistischen Strukturalismus kommt Sinn ausschließlich als inhaltliche Bedeutung vor. Sprache - so Ferdinand de Saussure, der wohl exponierteste Vertreter dieser Denkrichtung - soll unabhängig von der Referenz als eine Struktur betrachtet werden (vgl. de Saussure 1967). Demnach wird Bedeutung über die Relationen von Worten konstituiert, womit das jeweilige Sprachsystem Bedeutung erst generiert ${ }^{189}$. Saussure sieht ein sprachliches Zeichen als unzertrennliche Einheit von Signifikant - also das gesprochene oder geschriebene Wort, das etwas bezeichnet (bzw. genauer "das innere Bild der lautlichen Erscheinung" [ebenda: 77]) - und Signifikat - das, worauf wir uns inhaltlich beziehen, wenn wir das Wort verwenden. Die Beziehung zwischen Signifikant und Signifikat gilt nun als arbiträr; das Wort "Baum" bzw. seine "lautliche Erscheinung" hat etwa nichts Baumiges an sich (genausowenig wie das englische "tree").

Damit ist "Baum" nicht in Bezug auf einen tatsächlichen Baum bedeutungsvoll, sondern lediglich in Bezug auf seine differierende Bedeutung hinsichtlich jener Wörter und der mit ihnen verbundenen Vorstellungsinhalte, mit denen "Baum" gemeinsam auftreten kann und die eben keinen Baum bezeichnen ${ }^{190}$. Referenz ist damit ebenfalls strikt sprachrelativ, womit auch mit de Saussure für die ontologische Entscheidung über einen Gegenstand die Extension eines Begriffes (mit welchem Wort dieser auch immer bezeichnet wird [im Beispiel etwa "Baum" oder "tree"]) nach wie vor zentral bleibt; gleichwohl wird abermals deutlich, dass dies nicht unabhängig von der sprachlichen Struktur zu beurteilen ist. Eben dies betont Saussure, wenn er Signifikant und Signifikat als beide zum Zeichen dazugehörig betrachtet.

\footnotetext{
188 Damit wird natürlich nicht über die Hintertür hypostasiert, Rumpelstilzchen müsse es dann also doch irgendwie geben; was es gibt, ist die Geschichte über Rumpelstilzchen.

189 Diese Vorstellung begegnet uns in ähnlicher Form in Freges Kontextprinzip sowie Quines semantischem Holismus. "Nach der Bedeutung der Wörter muß im Satzzusammenhange, nicht in ihrer Vereinzelung gefragt werden." (Frege 1987: 23) Quines Holismus geht allerdings hierüber hinaus: "Mit Frege wurde statt des Terms die Aussage als Einheit anerkannt, die einer empiristischen Kritik verantwortlich ist. Doch worauf ich hier den Nachdruck lege, ist, daß wir, selbst wenn wir die Aussage als Einheit nehmen, noch zu fein sieben. Die Einheit empirischer Signifikanz (und damit die der Bedeutung [was Quine als Bedeutungsskeptiker jedoch nicht so formulieren kann], D.K.) ist die Wissenschaft als gesamte." (Quine 1979: 46)

190 "Es gibt zwar onomatopoetische Ausdrücke. Aber sie sind eine seltene Ausnahme, und selbst bei ihnen ist der Zusammenhang zwischen Wort und Bedeutung nicht automatisch: so machen z.B. deutsche Hähne 'kikeriki', schweizer 'güggerügü', französische 'coquerico', britische 'cock-a-doodledoo' und russische 'kukareku'." (Glock 2000: 433f.) Sprachliche Zeichen sind von Menschen eingeführte und das heißt qua Konvention vereinbarte Zeichen; ein natürliches Zeichen hingegen ist bspw. Rauch, der in keineswegs arbiträrer Weise oder auf Basis einer Abmachung Feuer indiziert (Menschen legen nicht fest, dass der Rauch dies tut) (vgl. Menne 1993: 12).
} 
Eine solch strukturell (Saussure), kontextuell (Frege) oder auch holistisch (Quine) konzipierte Sprachauffassung ist nun von einer reinen Abbildtheorie der Bedeutung abzugrenzen, insofern die Satzstrukturen, der Kontext, das semantische Sprachganze hier als bedeutungs- und wirklichkeitsbestimmend gelten ${ }^{191}$. Wort und Objekt fallen eben nicht mehr naiv zusammen, sondern die Sprache strukturiert unsere Erfahrung von Wirklichkeit. Dies impliziert keinesfalls - um darauf erneut hinzuweisen - dass die Wirklichkeit grundsätzlich eine Leistung der Sprache wäre; aber die Art und Weise, wie Menschen Wirklichkeit erfahren, wie sie sie ordnen und damit erfassbar sowie für sie relevant machen, ist sprachrelativ.

\section{Bedeutung und Gebrauch}

Eine weitere Richtung innerhalb der Sprachphilosophie betont insbesondere, dass sich die Bedeutung sprachlicher Zeichen über ihren Gebrauch konstitutiv vollzieht. "Wenn ich eine Sprache denke", so der späte Wittgenstein, "schweben mir nicht neben dem sprachlichen Ausdruck noch (zusätzlich, DK) 'Bedeutungen' vor; sondern die Sprache selbst ist das Vehikel des Denkens" (PU \329). "Wenn wir ... irgendetwas, das das Leben des Zeichens ausmacht, benennen sollten, so würden wir sagen müssen, daß es sein Gebrauch ist." (Wittgenstein 1984b [Das blaue Buch]: 20) Unsere über Sprache hergestellte Sicht der Welt wird demnach verständlich, wenn man die Regeln menschlichen Sprechverhaltens expliziert.

So erhält etwa "schön" nicht dadurch Bedeutung, dass es eine Universalie wie "Schönheit" bezeichnet oder innerhalb eines Ding-Eigenschafts-Schemas an einen bestimmten Träger gebunden ist; "schön" erhält vielmehr seine Bedeutung durch die innerhalb von Sprechergemeinschaften akzeptierten sprachlichen Regeln des Gebrauchs von "schön". Ein Wort bedeutet damit das, was Sprecher im Allgemeinen qua (revidierbarer) Konvention meinen, wenn sie es verwenden. Hilary Putnam spricht auch von einem "Stereotyp" des Terms (Putnam 1979: 41), "dieses ist zugleich die sprachliche Minimalkompetenz, (um, D.K.) an Diskussionen einer Gemeinschaft teilnehmen zu können" (Wuchterl 1999: 238).

Bedeutung ist hier also ein öffentliches, sozial bestimmtes und sanktioniertes Prinzip; verändern sich die Regeln für den Gebrauch eines Ausdrucks, so verändert sich auch dessen Bedeutung. Benutzt ein Sprecher ein Wort entgegen der üblichen Verwendungsweise, dann bedeutet es immer noch das, was damit im Allgemeinen ausgedrückt wird, auch wenn der Sprecher etwas völlig anderes meint. Michael Dummett vertritt diese Position in konsequenter Form: "Wir sprechen eine gemeinsame Sprache, und diese Sprache haben wir ausschließlich anhand solcher Vorgänge gelernt, die sich vor den Augen aller abspielen, anhand der Praxis anderer Sprecher und durch ihre Beziehungen zu uns, wozu auch

191 Frege und Quine stehen philosophiegeschichtlich sowohl für die Abbildtheorie der Bedeutung (Bedeutung eines Namens als sein realweltlicher Bezug) als auch für eine strukturalistische Bedeutungsauffassung (Kontextprinzip, semantischer Holismus). 
gehört, daß sie unsere Fehler korrigieren. Alles, was zur Bestimmung der Bedeutungen von Wörtern der betreffenden Sprache beiträgt, muss daher ebenfalls offen sichtbar sein; ihre Bedeutungen können nicht von dem abhängen, was sich in unserem Bewußtsein abspielt und anderen Sprechern nicht zugänglich ist"192 (Dummett 1992: 131).

Führen wir uns hingegen nochmals die Quinesche Übersetzungsunbestimmtheit vor Augen, so lässt sich dort die Bedeutung von Worten bzw. Äußerungen niemals exakt bestimmen - was ein Sprecher tatsächlich ausdrücken wollte, kann nicht sicher erschlossen werden. Hier wird also weitgehend ein Verständnis von Sprache als Idiolekt, als Sprache des Einzelnen, unterstellt ${ }^{193}$. Als Anhänger einer solchen Position können neben Quine wohl vor allem Donald Davidson (1987) und Noam Chomsky (1988) gelten. Davidson ist der Auffassung, entscheidend für gelingende Kommunikation seien generelle Interpretationsprinzipien. Chomsky geht von der Existenz einer universalen Transformationsgrammatik aus, welche die Möglichkeit von Verständigung eröffnen soll. Aber sind diese Interpretationsprinzipien bzw. ist diese universale Transformationsgrammatik nicht auch nur über Sprache einführbar und somit - da es sich um generelle Entitäten handelt Ergebnis einer Konvention? Man kann diese Konsequenz allenfalls umgehen, wenn man sie als dem Menschen angeboren begreift (was insbesondere Chomsky auch tut). Damit wird die Problematik bis zu einem Punkt hinausgeschoben, an dem man wohl den Neurobiologen das Feld überlassen oder aber mit einem transzendentalen Apriori argumentieren muss ${ }^{194}$.

In der Sprachphilosophie bezeichnet man die Auffassung, Bedeutung werde über allgemein gültige soziale Regeln hergestellt als "Konventionalismus", den Standpunkt, Bedeutung werde über die Sprecherabsicht vermittelt, als "Intentionalismus": "'Intention oder Konvention?', so lautet die Frage, an der sich die Geister

\footnotetext{
192 "Die Alternative ist die: den Begriff des Idiolekts in den Mittelpunkt zu rücken - d.h. den Begriff einer Sprache, wie sie von einem Einzelsprecher verstanden wird - und zunächst zu erklären, was es heißt, dieser Einzelsprecher verknüpfe diese oder jene Bedeutungen mit den Wörtern seines Idiolekts und anschließend die Gemeinsprache als eine Menge sich überlagernder Idiolekte zu kennzeichnen." (Dummett 1992: 137f.) Und weiter: "Das, was ein Schachzug bedeutet, rührt nicht von der Kenntnis der Spielregeln auf seiten der Schachspieler her, sondern von den Spielregeln selbst. Freilich müssen die Spieler die Regeln kennen, um zu spielen." (ebenda: 150)

193 Wenngleich Quine Sprache eben auch als soziale Fertigkeit ansieht, d.h. er oszilliert in gewisser Weise zwischen einem idiolektischen und einem soziolektischen Standpunkt. Insofern ließe sich fragen: "If an idiolect is socially constituted, what is idiolectical about it?" (Bilgrami 1994: 71)

${ }^{194}$ Immerhin aber kann so vermieden werden, die Sprache als Produktionsinstrument eben jener Konventionalisierung zu betrachten, die Sprache ja eigentlich erst ermöglichen soll. Wie bereits erwähnt, glaubt Searle diese Paradoxie ganz einfach dadurch aufzulösen, indem er Sprache als eine "sich selbst identifizierende Kategorie" begreift (Searle 1997a: 83). M.E. muss der Mensch über angeborene, unsprachliche Konzepte verfügen, weil sich ansonsten die Erwerbung eines linguistisch geprägten Weltverständnisses nicht plausibilisieren ließe. Irgendwo muss der Mensch anfangen; da wir Sprache erlernen, kann sie selbst nicht am Anfang stehen. Kamlah/Lorenzen (1996: 15) nennen dies "das Problem des Anfangs (der 'Fundamentalphilosophie')" (vgl. zu dieser Problematik ausführlicher H.J. Schreiber 2002 u. 2003 aber auch K.O. Apel 1991, der sich mit der Spannung zwischen einer linguistischen und einer prelinguistischen Bedeutungstheorie im Rahmen einer Auseinandersetzung mit dem Searleschen Intentionalitätsbegriff befasst).
} 
scheiden. Können wir sagen, was wir meinen, oder müssen wir meinen, was wir sagen? Können wir wie Humpty-Dumpty sagen: 'Wenn ich ein Wort verwende, bedeutet es genau das, was ich will - nicht mehr und nicht weniger' - oder ist es die intersubjektiv geteilte Bedeutung gemäß konventioneller Regeln, die uns vorzeichnet, was wir sie bedeuten lassen können?"195 (Tietz 2003: 63)

Schon an dieser Stelle soll festgehalten werden, dass Bedeutung und Sprache nur innerhalb eines regelhaft konstituierten sozialen Kontextes sinnvoll konzipiert werden können, handelt es sich doch um jene Entitäten, die genuin der interpersonellen Verständigung dienen und sozial erlernt wie überwacht werden - soweit wird dem Konventionalismus zugestimmt. Gleichwohl sind Sprache und Bedeutung nichts, was ohne individuelles Bewusstsein auskommen könnte ${ }^{196}$, weil schon allein die Befolgung der in einer Gemeinschaft geltenden Regeln des sprachlichen Gebrauchs Intentionalität bedingt ${ }^{197}$. Bewusstsein, Sprache und

195 Ferner könnte man Bedeutung auch an den Rezipienten koppeln; ein Wort würde dann das bedeuten, was verstanden wird (vgl. Langenmayr 1997: 546ff.). Damit ist der Streit freilich nicht beigelegt, denn die Frage bleibt in veränderter Form erhalten: Wird das, was verstanden wird, verstanden, in Folge der Intentionalität des Hörers oder der sprachlichen Konvention? Verwirrend ist dann auch die Aussage, "meaning is the cognitive effect of expression; that is, the effect of expression on the minds of those who receive it" (Lamb 2004: 489). Einerseits soll Bedeutung damit von den Kognitionen des Rezipienten abhängen, andererseits empfangen diese Rezipienten aber schon eine unabhängig von ihnen vorhandene Bedeutung (jedenfalls dann, wenn sich das abschließende "it" im zitierten Satz auf "meaning" beziehen würde; bezieht es sich indes auf "expression", dann wäre zu klären, wie eine expression ohne meaning zu denken ist).

${ }^{196}$ Die Konzeption, Bedeutung komme ohne Bewusstsein aus, geht vor allem auf Frege zurück, der zwischen Vorstellungen und Gedanken unterschieden hat, um so die Philosophie von der Psychologie abzugrenzen. Dem Psychologismus, dem zufolge die Psychologie als grundlegende Wissenschaft zu verstehen ist, weil Erkenntnis ausschließlich psychologisch bestimmbar sei, wird von Frege eine Absage erteilt. Gedanken sind nun etwas, was alle Menschen prinzipiell teilen können. Der Gedanke "zwei plus zwei ist gleich vier" kann bspw. nicht zum individuellen Bewusstsein - und d.h. zugleich nicht zu den empirischen Gegenständen psychologischer Forschung - zählen. $\mathrm{Ob}$ zwei plus zwei gleich vier ist, lässt sich durch eine Beobachtung konkreter Denkvorgänge nicht entscheiden; hierfür sind apriorische Grundsätze des logischen Schließens erforderlich (Freges Logizismus reformuliert die Mathematik als Teilgebiet der Logik). Dennoch aber - so möchte ich hinzufügen - lassen sich diese apriorischen Grundsätze nicht ohne empirisches Bewusstsein vorstellen; Bewusstsein muss beteiligt sein.

${ }_{197}$ Wenn Bewusstsein aber eine (emergente) Eigenschaft von Nervensystemen ist, dann sind auf tieferer Ebene auch biologische, chemische bzw. physikalische Prozesse involviert. Mit dieser Perspektive auf das "psychophysische Problem" (Nagel 1990: 25) schließe ich mich weitgehend Whorf und Searle an. Bei Whorf heißt es: "Meine eigenen Forschungen lassen mich annehmen, Sprache sei, so königlich auch ihre Rolle ist, gewissermaßen nur ein oberflächliches Muster tieferer Bewußtseinsprozesse, welche die Bedingung aller Kommunikation ... sind" (Whorf 1963: 39). Searle subsummiert in diesem Sinne die Sprach- unter die Bewusstseinsphilosophie: "On my view, the philosophy of language is a branch of the philosophy of mind; therefore no theory of language is complete without an account of the relations between mind and language and of how meaning - ... is grounded in the more biologically basic intrinsic intentionality of the mind/brain." (Searle 1992: xi) Man könnte dies auch dahingehend begreifen, dass eine neuronale Erregung $(\mathrm{N})$ mit einer bestimmten Form kognitiver Informationsverarbeitung (I) und diese wiederum mit einem bestimmten phänomenalen Erleben (E) korrespondiert (was sich im Übrigen auch bei Quine finden lässt, wenn dieser von einem "zahmen Physikalismus" spricht, bei dem es "keine unüberbrückbaren kategorialen Unterschiede zwischen dem Geistigen und dem Physikalischen" gebe [Quine 1980: 457]; vgl. hierzu unter besonderer Berücksichtigung des Problems menschlicher Willensfreiheit auch Beckermann 2002). Bewusstsein wäre in einer solchen Lesart ein dreistelliges Prozessereignis der 
(soziale) Welt stehen in einem reziprok abhängigen Verhältnis - es ist ihre Kopplung, die Bedeutung erst möglich macht. In dieser Arbeit wird das Prozessieren von Bedeutung als eine von bewussten Individuen ausgehende Leistung angesehen, die gleichwohl nur möglich ist, weil es eine soziale Regelhaftigkeit der Sprache gibt, die bestimmte Optionen bereithält und andere ausschließt und die in Folge dieser Optionen einen großen Möglichkeitsraum zur Übermittlung unterschiedlicher Bedeutung bietet.

\section{Bedeutung und Sprechakte}

Wurde soeben eine gewissermaßen vermittelnde Position hinsichtlich der Frage, ob Bedeutung nun genuin sozial (konventionalistisch) oder individuell (intentionalistisch) zu konzipieren ist, bezogen, so soll nun hervorgehoben werden, dass die Bedeutung sprachlicher Zeichen vielfach nur durch die Verwobenheit von Sprache und nichtsprachlichen Praktiken erschlossen werden kann. Dies ist die zentrale Überlegung der ebenfalls zur Philosophie der Normalsprache zählenden Sprechakttheorie John L. Austins (1962) (die von John R. Searle weitergeführt wurde). "Die Grundeinheit der sprachlichen Kommunikation ist nicht, wie allgemein angenommen wurde, das Symbol, das Wort oder der Satz ..., sondern die Produktion oder Hervorbringung des Symbols oder Wortes oder Satzes im Vollzug des Sprechaktes." (Searle 1973: 30)

In diesem Zusammenhang ist u.a. von einer pragmatischen Bedeutungstheorie die Rede, da die Bedeutung sprachlicher Zeichen grundsätzlich vor dem Hintergrund des gesamten menschlichen Lebenszusammenhanges zu sehen ist. Je nach Verwendungskontext kann etwa eine Äußerung einmal dies und ein anderes mal jenes bedeuten. Wittgenstein hat in ähnlichem Zusammenhang den Begriff des "Sprachspiels" geprägt ${ }^{198}$, womit er hervorheben wollte, "daß das Sprechen der

Form N-I-E. Allerdings ist uns nicht jede neuronale Erregung bewusst; eine Erweiterung der Blutgefäße ruft bspw. keineswegs grundsätzlich ein bewusstes Erleben hervor. Umgekehrt ist das bewusste Erleben gleichwohl auf die tiefer liegenden Schichten angewiesen. Damit bleibt aber weiterhin unklar, "wie ein physischer Zustand, etwa ein bestimmtes Bitmuster oder das Feuern bestimmter Neuronen für etwas anderes stehen, etwas bedeuten soll." (Lenzen 2002: 36) Um dies zu klären, müsste die Transformation von $\mathrm{N}$ zu I und die von I zu E untersucht werden - insofern sie sich denn untersuchen lässt. (Weiter kann und soll das Supervenienzproblem hier nicht erörtert werden.)

198 "Ich werde auch das Ganze der Sprache und der Tätigkeiten, mit denen sie verwoben ist, das 'Sprachspiel' nennen." (PU \7) Einzelne "kleine" Sprachspiele, die die Gesamtheit des übergreifenden Sprachspiels ausmachen, sind Handlungskontexte, in denen gesprochen wird; es sind kontextspezifische, "funktional definierte Sprechsysteme" (Lay 1992: 58). Allerdings sollte das Konzept des Sprachspiels nicht all zu nahe an die Sprechakttheorie herangerückt werden: "Wittgenstein war sehr an der Beziehung zwischen der Sprache und außersprachlichen Institutionen interessiert; er war dagegen nicht speziell am Phänomen der Sprechakte interessiert." (Stegmüller 1980: 88) Während Wittgenstein vor allem den Gebrauch der Sprache untersuchte, um hierüber Bedeutung erfassen zu können, bemühte sich Austin primär um die Aufdeckung des Handlungsaspektes von Äußerungen. Zumindest erwähnt werden soll, dass Thomas Luckmann mit seinen "kommunikativen Gattungen" konzeptionell an Wittgensteins Sprachspiele anschließt, ohne diese 
Sprache ein Teil ist einer Tätigkeit, oder einer Lebensform." (PU \23) Menschen vollziehen über ihre Äußerungen - sog. Sprechakten - Handlungen, die allein auf Basis der verwendeten Worte und Sätze nicht vollständig erfassbar sind. "Haben wir uns einmal klargemacht, dass wir nicht den Satz, sondern die Äußerung in einer Sprechsituation untersuchen müssen, dann können wir überhaupt nicht mehr übersehen, daß eine Handlung vollzieht, wer eine Feststellung trifft." (Austin 1979: 158) Besonders prägnant hat Austin dies durch einen seiner Buchtitel ausgedrückt: "How to do things with words"199. Austin unterscheidet:

a) einen lokutionären Akt, welcher die bloße semantische Satzbedeutung bezeichnet (der also angibt, was der Fall war, ist oder sein wird),

b) einen illokutionären Akt, welcher die qua lokutionärem Akt vollzogene Handlung bezeichnet (also etwa eine Bitte, ein Versprechen, eine Aufforderung, eine Warnung etc.) sowie

c) einem perlokutionären Akt, welcher die (intendierte) Wirkung der Äußerung bei den Adressaten bezeichnet (die über ein bestimmtes Verhalten operationalisiert wird).

Die Verwendung dieser zentralen Termini der Sprechakttheorie sei beispielhaft an dem Satz "Ich habe eine 1 in Mathematik geschrieben", geäußert von einem Sohn gegenüber seinen Eltern, illustriert.

a) Der lokutionäre Akt ist die Aussage, dass die den Satz äußernde Person in Mathematik eine 1 geschrieben hat (dies kann wahr, aber auch unwahr sein).

b) Das Verständnis des illokutionären Aktes setzt nun eine Kontextualisierung der Äußerung voraus; hier also die Situation, in der ein Sohn seinen Eltern gegenüber äußert, er habe eine 1 in Mathematik geschrieben; der illokutionäre Akt ist die mit dem Satz vollzogene Aufforderung, für die schulische Leistung doch bitte belobigt (bzw. belohnt) zu werden (dies kann glücken, aber auch nicht-glücken).

\footnotetext{
Verbindung allerdings zu explizieren. Bei kommunikativen Gattungen handelt es sich nämlich um "gesellschaftlich vorgeprägte und mit mehr oder minder verbindlichen Gebrauchsanweisungen versehenen Muster kommunikativen Handelns" (Luckmann 2002: 165) wie bspw. Belehrungen, Klatsch oder Telefonanrufen (vgl. ebenda 175f.).

199 Der Titel der deutschen Übersetzung klingt zwar akademischer, ist aber gleichwohl weit weniger plastisch: "Zur Theorie der Sprechakte". Wie wir Dinge mit Worten tun, beschreibt Austin gleich zu Beginn seines Buches: "'I name this ship Queen Elizabeth' - as uttered when smashing the bottle against the stem. 'I give and bequeath my watch to my brother' - as occurring in a will. ... In these examples it seems clear that to utter the sentence (in, of course, the appropriate circumstances) is not to describe my doing of what I should be said in so uttering to be doing or to state that I am doing it: it is to do it." (Austin 1962: 5f.)
} 
c) Der perlokutionäre Akt der Beispielsäußerung ist die vom Sohn durch seine Aufforderung intendierte Motivation der Eltern, ihn für seine sehr gute Klassenarbeit zu loben (bzw. zu belohnen) (dies kann erfolgreich, aber auch nichterfolgreich sein) ${ }^{200}$.

Während der illokutionäre Akt die über den Sprechakt vollzogene Handlung des Sprechenden beleuchtet, rückt der perlokutionäre Akt gewissermaßen den Adressaten in den Vordergrund. Der aktive Vorgang des Verstehens impliziert damit eine Interaktion zwischen den an einer Sprechsituation beteiligten Personen - auch dann, wenn der Sprecher nicht unmittelbar präsent ist (wie etwa beim Lesen oder Fernsehen).

Die Ausführungen zur Sprechakttheorie veranschaulichen den grundlegenden Unterschied zwischen der ideal und der ordinary language philosophy hinsichtlich ihrer jeweiligen Zielsetzung in pointierter Weise. Während Erstere den Wahrheitswert assertativer Aussagen zu bestimmen sucht und daher - gewollt oder ungewollt - weitgehend als Wissenschaftstheorie firmiert, geht es Letzterer vorrangig um Gelingens- bzw. Erfüllungsbedingungen von Wünschen und Absichten, d.h. hier wird i.d.R. die Alltagswelt projektiert ${ }^{201}$.

200 Oder mit einem von Austin gegebenen Beispiel: "Act (A) or Locution: He said to me 'Shoot her!' meaning by 'shoot' shoot and referring by 'her' to her. Act (B) or Illocution: He urged (or advised, ordered, etc.) me to shoot her. Act (Ca) or Perlocution: He persuaded me to shoot her, Act (Cb): $\mathrm{He}$ got me (or made me, etc.) shoot her." (Austin 1962: 101f.) In der Kommunikationspsychologie dies sei hier zumindest angemerkt - werden zentrale Aspekte der sprechakttheoretischen Überlegungen insbesondere im "Nachrichtenquadrat" von Schulz von Thun (1981) konzeptualisiert. Dabei werden folgende Ebenen einer Botschaft differenziert: 1. die Sachebene (was wird ausgesagt), 2. die Ebene der Selbstoffenbarung (was berichtet der Kommunikationssender über sich), 3. die Beziehungsebene (was hält der Sender vom Empfänger bzw. was gibt er über seine Beziehung zu diesem preis) sowie 4. die appellative Ebene (wozu soll der Empfänger veranlasst werden). Ferner kann in diesem Zusammenhang auch auf die Theorie der Implikatur von Paul Grice (1979) verwiesen werden, die m.E. zumindest in Teilen große Ähnlichkeiten mit der Sprechakttheorie aufweist. Grice fragt danach, wie man vom semantischen Gehalt eines Satzes zu einer bestimmten, situativen Äußerungsbedeutung, dem tatsächlich Gemeinten, übergehen kann.

201 Gemäß der Idealsprachenphilosophie versteht die Bedeutung einer Aussage, so ein zentrales bedeutungstheoretisches Postulat in Anlehnung an Freges Aufsatz "Über Sinn und Bedeutung" aus dem Jahre 1892 (Frege 2002), wer angeben kann, unter welchen Bedingungen eine Aussage wahr wäre. Dies heißt, dass wir einen Behauptungssatz dann verstehen, wenn wir die Bedingungen kennen, unter denen der über die Aussage behauptete Sachverhalt wahr ist. Der frühe Wittgenstein hat dies wie folgt formuliert: "Einen Satz verstehen heißt, wissen was der Fall ist, wenn er wahr ist." (Tractatus 4.024) Die Bedeutung eines einzelnen Ausdrucks ist dann die Kenntnis darüber, wie der Ausdruck zum Wahrheitswert des Satzes beiträgt. Eine solche Sichtweise wurde von Austin scharf kritisiert: "It was for too long the assumption of philosophers that the business of a 'statement' can only be to 'describe' some state of affairs, or to state some facts, which it must do either truely or falsely." (Austin 1962: 1) Veranschaulichen wir uns noch einmal an einem Beispiel, was die Idealsprachenphilosophie behauptet. Wenn A etwa zu B sagt "C sitzt in der Küche", dann würde gemäß der Idealsprachenphilosophie - derjenige die Bedeutung erfassen, der in der Lage ist, anzugeben, wann die Bedingungen erfüllt sind, damit dieser Satz wahr ist. Als Bedingungen ließen sich etwa anführen, dass es eine Person $C$ und eine Küche gibt und dass $C$ in dieser Küche sitzt (freilich ist damit noch nicht beantwortet, was es überhaupt heißt, in der Lage zu sein, Wahrheitsbedingungen angeben zu können [siehe ausführlich zu diesem tiefer liegenden Problem Dummett 1976]). Aber wenn A "C sitzt in der Küche" B gegenüber äußert, kann er damit weit mehr gemeint haben. Er könnte z.B. gemeint haben - und dies wäre dann die "eigentliche" (Äußerungs-)Bedeutung 
In der Wissenschaft wollen wir mit unseren Aussagen (so weit dies möglich ist) wahre Behauptungen über die Beschaffenheit und die Zusammenhänge in der Welt formulieren. In unserer unmittelbaren Lebenswelt hingegen - und das kann jeder Leser sehr schnell und unmittelbar an seinen eigenen Alltagserfahrungen überprüfen - geht es uns doch vielfach erst in zweiter Linie um die Frage, ob Aussagen nun wahr oder falsch sind. Vielmehr verfolgen wir mit unseren Äußerungen Zwecke; wir wollen uns unterhalten, etwas in Erinnerung rufen, eine Warnung aussprechen, jemanden von unseren Argumenten überzeugen, uns einer ungeliebten Verpflichtung entziehen etc. Aussagen sind hier Sprachspiele und als Teil einer Handlungstheorie zu konzipieren ${ }^{202}$.

Diese Position bezüglich symbolhafter Interaktion findet sich auch bei Alfred Schütz, womit die Verzahnung von linguistischer und soziologischer Bedeutung hier schon angedeutet werden soll: "Wenn also nicht gefragt wird: Was bedeutet das Schütteln der Faust? (Antwort: ein Drohen), sondern: Was meint dieser damit, daß er die Faust gegen mich schüttelt, daß er mir also droht? (Antwort z.B.: er erwartet ein bestimmtes Verhalten meinerseits) - dann ist uns dieser 'gemeinte Sinn' keineswegs in der inneren Wahrnehmung schlicht erschlossen." (Schütz 1993: 32)

\section{Bedeutung und konstitutive Regeln}

Das Hauptargument hinsichtlich einer Ontologie sozialer Realität ist nun, dass Menschen qua ihrer Fähigkeit, Bedeutung zu prozessieren, realweltliche Gegenstände zum Entstehen bringen können, die dann ihr Leben und Handeln bestimmen. Soziale Realität (bzw. jener Teil von ihr, der später als "institutionell" ausgewiesen wird) ist in diesem Sinne weitgehend ein Resultat kontinuierlicher

des Satzes - dass C jetzt nicht beim Aufräumen helfen könne, dass C sich in Folge einer melancholischen Stimmung zurückgezogen habe, dass B jetzt nicht mehr auf C warten solle etc. Searle spricht daher bezüglich von Wahrheitsbedingungen von einer "Geist-auf-Welt-Ausrichtung", weil es hier darum geht, ob die Welt über Aussagen richtig dargestellt wird. Ganz in diesem Sinne verstand Frege unter "Urteilen" das "Fortschreiten von einem Gedanken (worunter Frege das, was in einem Satz als Information ausgesagt wird, meint, D.K.) zu seinem Wahrheitswert". (Frege 2002: 32) Eine "Welt-auf-Geist-Ausrichtung" finden wir hingegen in Zusammenhang mit Erfüllungsbedingungen, da die Welt entsprechend unserer Absichten verändert werden soll (vgl. Searle 2001: 123f.) (im Beispiel geht es um die Veränderung von Bs Wissen hinsichtlich der Befindlichkeit von C und dem Nahelegen damit verbundener Handlungskonsequenzen).

202 Daher spricht man in der Sprechakttheorie auch von "performativen Äußerungen". "The name is derived, of course, from 'perform', the usual verb with the noun 'action': it indicates that the issuing of the utterance is the performing of an action." (Austin 1962: 6) Dies heißt jedoch nicht, über Sprechakte könnten keine deskriptiven Aussagen über die Beschaffenheit der Welt getroffen werden. "Wenn ich z.B. sage 'Morgen wird es regnen', kann dies eine Beschreibung des morgigen Wetters sein und eine Voraussage und eine Warnung usw." (Williams 1986: 54; Williams argumentiert mit der Sprechakttheorie im Rahmen moralphilosophischer Ausführungen gegen den von Moore behaupteten naturalistischen Fehlschluss, wobei seine Überlegungen letztlich in dieAussage münden, "daß bei zahlreichen Einsetzungen für ' $\mathrm{x}$ ' in der Formel 'Das ist ein gutes $\mathrm{x}$ ' das Wissen, was dieses $\mathrm{x}$ ist oder tut und was es faktisch mit diesem x auf sich hat - d.h. eine Kombination von Begriffs- und Fakteninformation -, ausreichend ist, um [...] zu entscheiden, ob das resultierende Urteil wahr oder falsch ist." [ebendA: 55]) 
menschlicher Bedeutungsproduktion, deren Logik sowie deren konkrete Ausgestaltung hinsichtlich sozialen Kapitals im Anwendungsteil dieser Untersuchung zum Gegenstand gemacht wird.

Dabei muss diese Bedeutungsproduktion jedoch seitens der Individuen nicht immer voll bewusst erfolgen. Ähnlich wie bei automatisierten menschlichen Aktivitäten - wie etwa dem Autofahren - bedarf es in den wenigstens Fällen einer ausführlichen oder gar erschöpfenden Explikation der hinter der Aktivität liegenden linguistischen Prozesse. Wichtig ist im Sinne der Gebrauchstheorie der Bedeutung lediglich die Anwendung erlernter Regeln, die jedoch ausschließlich über Sprache bzw. zumindest symbolisch einführbar sind; es geht insofern um die "Beherrschung einer Technik" (PU \199).

Searle spricht in diesem Zusammenhang von im Hintergrund wirkenden "konstitutiven Regeln". So sind etwa die Regeln des Schachs "konstitutiv in dem Sinn, daß Schachspielen eben dadurch konstituiert wird, daß man den Regeln gemäß spielt." 203 (Searle 1997a: 38) Die Spieler beachten diese handlungsleitenden Regeln - denn sonst könnten sie nicht spielen - sie werden diese aber nicht permanent in das aktuelle Bewusstsein heben. Was bspw. das Schlagen eines Läufers meint, wird jedoch nur vermeintlich unsprachlich erfasst, da die Aktivität durch und durch "linguistically loaded" (Searle 1999b) ist. Wer wissen möchte, welche Bedeutungszuweisungen sozialen Gegenständen zugrunde liegen, muss diese linguistische Ladung zum Vorschein bringen, d.h. er muss die Indexikalität von Symbolen berücksichtigen und die von Menschen vielfach gewissermaßen vorbewusst prozessierten und implizit angewandten sprachlich-konstitutiven Regeln explizieren ${ }^{204}$.

Das von mir hier verwendete Adjektiv "vorbewusst" soll ausdrücken, dass menschliches Bewusstsein zwar grundsätzlich an Bedeutungsproduktion beteiligt ist (und man deshalb m.E. nicht von "unbewusst" reden sollte), die Bewusstheit sich aber nicht erschöpfend auf alle notwendigen linguistischen und sozialen Bedingungen der Möglichkeit dieser Produktion, sondern vor allem auf die Akzeptanz und Befolgung konstitutiver (und sprachlich bzw. symbolisch

\footnotetext{
203 "Es ist nicht der Fall, daß es eine Menge Leute gab, die kleine Holzstücke auf Brettern hin- und hergeschoben haben und wir diese Aktivität regulieren mußten, um zu verhindern, daß sie die ganze Zeit aufeinanderprallten und Verkehrsstaus erzeugten. Vielmehr schaffen die Regeln des Schachspiels eben gerade die Möglichkeit, Schach zu spielen." (Searle 1997a: 38) Die Verankerung der konstitutiven Regeln im einzelnen Individuum könnte man in Anlehnung an psychologische Konzeptionen als "mentales Modell" bzw. "kognitives Schema" kennzeichnen.

204 "Wir besitzen also z.B. die Wörter ähnlich wie Tanzschritte - die wir wahrlich auch nicht fort und fort aktuell ausführen" (Kamlah/Lorenzen 1996: 61). Vorsorglich sei hinzugefügt, dass mit der Betonung von (für soziale Sachverhalte) konstitutiven Regeln nicht behauptet wird, diese seien von einem autorisierten Personenkreis irgendwann einmal allgemeinverbindlich festgelegt worden. Historisch gesehen - so meine Vermutung - wird sich der Prozess der Regelentstehung als sozialer Anpassungs- und Machtprozess rekonstruieren lassen (phylogentisch wohl als evolutionärer Anpassungs- und Reifungsprozess); hier geht es aber einzig um die Anwendung und nicht um die Entstehung der Regeln.
} 
eingeführter) Regelsysteme erstreckt ${ }^{205}$. Wer an einer sozialen Praxis erfolgreich teilnehmen möchte, der muss die dahinter stehenden konstitutiven Regeln beherrschen; der muss über ein linguistisches Know-how verfügen, hinsichtlich dessen er in der Lage ist, es auf einen Hinweis hin prinzipiell erkennen bzw. gegebenenfalls bei Nachfrage auch explizieren zu können - und zwar auch dann, wenn er sich dieser Regeln bzw. dieses Know-hows bis dato nicht unmittelbar bewusst war ${ }^{206}$.

Mit dieser Auffassung wird eine sprachphilosophische Position vertreten, die u.a. auch als die "Normativitätsthese der Bedeutung" bezeichnet und zumeist in Gegensatz zu naturalistischen Ansätzen gesehen wird ${ }^{207}$. Quine ist etwa in einem naturalistischen Sinne ein ausgesprochener Bedeutungsskeptiker, weil innerhalb seines behavioristischen Wissenschaftsverständnis mentale Entitäten lediglich

205 In gewisser Weise wird damit an die Freudsche Konzeption des Vorbewussten angeschlossen:
"Wir heißen das Latente, das nur deskriptiv unbewußt ist, nicht im dynamischen Sinne, vorbewu $\beta$,
den Namen unbewn 3 beschränken wir auf das dynamisch unbewußte Verdrängte, so daß wir jetzt
drei Termini haben, bewußt $(b w)$, vorbewußt $(v b w)$ und unbewußt $(u b w) "$ (Freud 1988: 173). Das
Vorbewusste ist also bei Freud nicht aktuell bewusstes, aber dennoch bewusstseinsfähiges Material.
Insofern können wir in philosophisch-pragmatischer Tradition immer dann von bewusst-
seinsmäßigen Leistungen reden (seien sie nun voll oder lediglich vorbewusst), "wenn wir in einer seinsmäßigen Leistungen reden (seien sie nun voll oder l
Situation auf ein Problem stoßen." (Joas/Knöbl 2004: 189)

206 "The behavior is sensitive to the rules even though the rules are not part of my consciousness then and there." (Searle 1999b) In einer Kritik Max Webers gelangt Schneider zu dem Schluss, "wie wenig die erklärende Relevanz von Sinn an dessen bewußtseinsförmige Repräsentation gebunden ist." (W.L. Schneider 2002: 48) Dass genau dies von mir an dieser Stelle nicht gemeint ist, soll nochmals betont werden. Zur Illustration seiner These konstruiert Schneider ein Beispiel einer Gemeinschaft, in der in Folge bestimmter Bedingungen "die Regeln des Rechnens aus allen Köpfen verschwunden sind, deren Mitglieder jedoch auf Basis einer überlieferten Praxis bloßen Auswendiglernens im Stande wären, eine große Zahl von Rechenaufgaben richtig zu lösen ... . Auch für die historische Genese einer solchen Form des 'Rechnens' behielten die nun nicht mehr bekannten arithmetischen Regeln ihre kausale Bedeutung." (ebenda: 47) Dies ist aber nun keineswegs der Fall, denn ohne die prinzipielle Möglichkeit einer Explikation der Regeln (durch die Mitglieder der fiktiven Gemeinschaft) kann überhaupt nicht mehr sinnvoll von "Rechnen" gesprochen werden. Die Gemeinschaftsmitglieder würden lediglich Zahlen aneinanderreihen. Für was sollten die Regeln der Arithmetik hier von kausaler Bedeutung sein? Allenfalls ließe sich sagen, dass und warum diese Aneinanderreihung von Zahlen den Regeln der Arithmetik korrrespondiert (es ist etwas völlig anderes, wenn jemand Schach spielen kann, ohne ad hoc die Regeln explizieren zu können; implizit beherrscht er sie, d.h. in diesem Fall sind die Regeln von kausaler Bedeutung). Ferner ist das von Schneider konstruierte Beispiel insofern problematisch, als dass die Regeln der Arithmetik zunächst einmal unabhängig von menschlicher Bedeutungsproduktion sind (es sei denn, man argumentiert mit dem Quineschen Holismus oder steigt tief in den mathematischen Konstruktivismus der Philosophie ein; beides dürfte Schneider aber wahrscheinlich in Zusammenhang mit seinem Beispiel fernliegen). Wenn die Regeln der Arithmetik tatsächlich aus allgemein menschlichen Vernunftprinzipien ableitbar sind, dann könnte die im Beispiel genannte fiktive Gemeinschaft die Regeln auch dann noch erschließen, wenn sie nicht per Überlieferung mit ihnen vertraut gemacht worden wäre. Damit aber ist der Kern der Schneiderschen Argumentation unsoziologisch. Schneiders Behauptung, "unser Beispiel, so ausgedacht und künstlich es zunächst erscheinen mag, beschreibt ein typisches Schicksal historisch wirksamer Ideen" (ebenda), behandelt die Arithmetik genauso wie etwa die von Weber analysierte protestantische Ethik. Kurzum: Schneider gelingt auf diese Weise nicht der Nachweis, dass Bedeutung von subjektivem Bewusstsein abgekoppelt werden kann.

207 Der interessierte Leser sei in diesem Zusammenhang auf den von Kathrin Glüer betreuten Schwerpunkt "Sprache und Regeln. Ist Bedeutung normativ?" der Deutschen Zeitschrift für Philosophie, 3/2000 verwiesen. 
Verhaltensdispositionen darstellen, die auf physikalische bzw. physiologische Reize bzw. Mechanismen zurückführbar sind. Sprachgebrauch und insofern das Prozessieren von Bedeutung wird hier kausal als verbale Reaktion auf konditionierte Stimuli bewertet.

Gleichwohl glaube ich, dass sich eine normative und eine naturalistisch-kausale Bedeutungskonzeption nicht zwangsläufig ausschließen müssen. Insofern man etwa die Anwendung konstitutiver Regeln als ein qua Sozialisation erlerntes Sprechverhalten begreift, lässt sich diese Anwendung kausal hierauf zurückführen - Normativität wäre damit gleichsam naturalisiert (zumindest dann, wenn man Sozialisation als einen natürlichen Prozess begreift ${ }^{208}$ [der freilich sehr unterschiedliche Ausprägungen aufweisen kann; aber das macht ihn noch lange nicht zu etwas Künstlichem]). Ferner ist fraglich, inwiefern man hinsichtlich von konstitutiven Regeln überhaupt von "Normativität" sprechen sollte, da hier ja nichts direktiv vorgeschrieben wird; Normativität ist hier also lediglich in einer schwachen Form, im Sinne eines Wegweisers, aufzufassen: "Der Wegweiser sagt uns, welche Richtung wir einschlagen müssen, aber er zwingt uns nicht, in diese Richtung zu gehen" (Grayling o.J.: 104).

\section{Bedeutung und sinnhaftes Handeln}

Bei einer Ontologie des Sozialen wird es vielfach nicht unmittelbar um die Bedeutung sprachlicher Zeichen, sondern insbesondere um die Bedeutung von Handlungen, wie etwa der, dass eine Person A einer anderen Person B Hilfe leistet, gehen ${ }^{209}$. Solche Handlungen sind sinnhaft motiviert und die Akteure weisen ihnen eine Bedeutung zu. Wenn oben nun lediglich von Worten, Begriffen, Sätzen und Äußerungen die Rede war, wie lässt sich dies in diesem Zusammenhang integrieren?

Interaktion läuft über In-der-Sprache-sein ab. Handlungen (aber auch soziale Rollen) bedeuten eben lediglich dann etwas, wenn sie in propositionaler Form vorliegen und das heißt letztlich irgendwie sprachlich repräsentiert werden, weil nur hierüber Bedeutung überhaupt prozessierbar wird. Wenn A aus freien Stücken heraus die Wohnung von B renoviert (und hier sind wir schon ganz dicht bei der Sozialkapitalthematik), kann dies für die beteiligten Akteure erst dann "bedeutungsvoll" (im soziologischen Verständnis) sein, wenn sie über entsprechende, innerhalb der Sprachgemeinschaft akzeptierte, sprachliche Mittel verfügen. D.h. der Sachverhalt, dass A aus freien Stücken heraus Bs Wohnung renoviert, erhält bspw. nur dann die Bedeutung, eine Hilfestellung zu sein, wenn

\footnotetext{
208 Was etwa Hastedt (2005: 76) auf die griffige Formel "Kultur ist eine Erscheinungsform der Natur" bringt.

209 Bedeutung in einem soziologischen Sinne kommt also nicht Worten oder Sätze, sondern - wie Blumer (1973: 81) es formuliert - "Dingen" (womit alle möglichen Gegenstände der Realität und insbesondere auch Handlungen gemeint sind) $\mathrm{zu}$.
} 
1. das, was A tut (Wände tapezieren, Heizkörper streichen, Teppichboden verlegen etc.), sprachlich als "A renoviert aus freien Stücken heraus Bs Wohnung" (oder in einer vergleichbaren sprachlichen Wendung [die insbesondere auch vom sprachlichen Hintergrund und den Wertesystemen der beteiligten Akteure abhängig sein wird]) repräsentiert und erst so überhaupt zur Handlung bzw. zum Sachverhalt - A renoviert aus freien Stücken heraus Bs Wohnung - wird, wenn

2. der Begriff der "Hilfestellung" (oder eine vergleichbare sprachliche Wendung) zur Verfügung steht und wenn

3. der Hilfestellungsbegriff auf die Repräsentation dessen, was A tut, angewendet wird.

Soziologische Bedeutung kommt also den Gegenständen der Welt zu (im Beispiel der beschriebenen Handlung). Sowohl diese Gegenstände als auch die Fähigkeit des Menschen, diesen eine Bedeutung zuzuweisen, um so neue Gegenstände zu schaffen, sind nun jedoch parasitär abhängig von sprachlicher Bedeutung und damit von dem einer Sprachgemeinschaft zur Verfügung stehenden symbolischen Zeichenvorrat samt den erlaubten Verknüpfungen zwischen den Bestandteilen dieses Vorrates. Daher wurde Eingangs dieses Kapitels auch auf die sprachphilosophische Art und Weise einer Erörterung der Bedeutungsproblematik verwiesen. Soziologische Theorien blenden den linguistischen Funktionsmodus der Bedeutung weitgehend aus, d.h. sie setzen später an: Menschen produzieren nun einmal Bedeutung und hiervon ausgehend wird der Sinnszusammenhang der Sozialwelt zum primären Untersuchungsgegenstand.

Von diesem, vor allem durch den symbolischen Interaktionismus geprägten Bedeutungsverständnis ist innerhalb der Soziologie ein zweites nuanciert abzugrenzen, das unter Rekurs auf Alfred Schütz und Max Weber der "subjektive Sinn" genannt wird, den Akteure mit ihrem Handeln verbinden ${ }^{210}$. Verdeutlichen wir uns die Abgrenzung am obigen Beispiel: A renoviert aus freien Stücken heraus Bs Wohnung - hierbei handelt es sich um eine soziale Handlung, der die Bedeutung zugewiesen wird, eine Hilfestellung As an B zu sein. Der subjektive Sinn, den A mit dieser Handlung verbindet, könnte nun etwa sein, dass er sich irgendwann eine Gegenleistung von B erhofft, dass er also gewissermaßen in die Beziehungsrelation investiert, um eine Verpflichtung zu erzeugen. Daher versteht Schütz (1993: 115ff.) unter subjektivem Sinn auch das "Um-zu-Motiv", also die Intention des Akteurs. Aber auch um diesen subjektiven Sinn zu produzieren,

210 Ein weiteres soziologisches Sinnverständnis, nämlich das der autopoietischen Systemtheorie Luhmanns, wird von mir hier nicht berücksichtigt, da es analytisch im vorgezeichneten Zusammenhang nur schwer anschlussfähig ist. Sinn ist bei Luhmann ein systemisches Konstitutionskriterium, das für die Selbstreferenz eines Sozialsystems verantwortlich zeichnet: "Sinn trägt sich selbst, indem er seine eigene Reproduktion selbstreferentiell ermöglicht." (Luhmann 1984: 141) Bei dem an Luhmann orientierten Helmut Willke (1996: 40) ist Sinn das Steuerungskriterium sog. nicht-trivialer Systeme (vgl. kritisch zu unterschiedlichen Formen von Sinn Esser 1996: 485ff.). 
benötigt der Akteur ein symbolisches Repräsentationsmedium. Man kann nur dann etwas anstreben, wenn man weiß was. Und da alles Wissen propositional ist, kommt man erneut nicht umhin, Worte zu verwenden - und zwar jene, deren Bedeutung das Um-zu-Motiv zum Ausdruck bringen ${ }^{211}$.

Die Verwobenheit von soziologischem und sprachphilosophischem Bedeutungsverständnis lässt sich auch auf eine aussagentheoretische Weise herausstreichen:

'"Anteilnahme' bedeutet, dass sich jemand den Sorgen eines anderen mitfühlend zuwendet, dass er teilnimmt an den Problemen seines Nächsten und diesen in einer schwierigen Zeit nicht im Stich lässt."

"Deine Anteilnahme hat eine große Bedeutung für mich."

"Meine Anteilnahme soll bedenten, wie wichtig du für mich bist."

Im ersten Fall handelt es sich um die Wortbedeutung von "Anteilnahme" und damit um ein sprachphilosophisches bzw. linguistisches Problem. Dieses wird gelöst, indem man expliziert, wie das in Frage stehende Wort innerhalb des sozialen Handlungskontextes gebraucht wird ${ }^{212}$. Im zweiten Fall geht es um die soziologische (d.h. vor allem symbolisch interaktionistische) Bedeutung, um die Relevanz, die ein Akteur der Tatsache zuspricht, dass jemand Anteilnahme zeigt. Um diese zu explizieren, müsste ein Sprecher etwas äußern; die linguistische Bedeutung dieser Äußerungen fällt dann aber mit der soziologischen Bedeutung in eins. Im dritten Fall schließlich wird der subjektive (phänomenologisch zu interpretierende) Sinn zum Ausdruck gebracht, den ein Akteur mit seiner Anteilnahme verbindet. Die in den beiden letztgenannten Aussagen enthaltenen soziologischen Bedeutungsverständnisse sind Bewusstseinsweisen, die konstitutiv darauf angewiesen sind, dass es die Wortbedeutung von "Anteilnahme" (oder einer vergleichbaren sprachlichen Wendung) und Satzbedeutungen, in denen Anteilnahme zum Ausdruck gebracht wird, gibt. Während es in der Soziologie damit so scheint, als stehe die Sprache nur für eine dahinter liegende Bedeutung, gilt in einer philosophischen Gebrauchstheorie diese Bedeutung als ausschließlich sprachlich einführbar und stellt insofern nicht irgendetwas metaphysisches dar, dessen wir nur qua Symbolisierung habhaft werden können. Hierdurch wird nun aber der Ausdruck "Symbol" fraglich, beschreibt dieser doch eine Verweisung auf ein Etwas. Gebrauchstheoretisch betrachtet, ist dieses Etwas aber nur ein Etwas dank der Symbolverwendung.

211 Bei dem Kommunikationswissenschaftler Klaus Merten (1995: 82) klingt dies in etwas abgewandelter Form so: "Sinn ist eine Struktur, die nur auf der pragmatischen Ebene denkbar ist und die Bedeutungszuweisungen bereits voraussetzt. Sinn meint - grob gesagt - nicht die konkrete Bedeutung (...), die ein Zeichen hat, sondern die Handlungsrelevanz, die Aktualität, die ein Zeichen in einer bestimmten Situation für einen bestimmten Rezipienten hat."

${ }^{212}$ Genauso kann man auch die Bedeutung von Worten wie "ach" explizieren: "Wenn man einem das Wort erklären will, so sagt man etwa: 'Ach, es regnet schon wieder', und zwar mit dem entsprechenden Tonfall und der andere versteht nun, was es heißt." (Waismann 1976: 230) 


\section{Zusammenfassung}

Fassen wir die bisherigen Ergebnisse dieses Kapitels zunächst noch einmal knapp zusammen: In der u.a. von der Idealsprachenphilosophie vertretenen Abbildtheorie fällt die Bedeutung sprachlicher Zeichen mit den von ihnen bezeichneten Gegenständen in eins, oder in einer etwas vorsichtigeren Formulierung: Sprache und Gegenstände gelten als isomorph. Eine solche Perspektive ist insbesondere deswegen unhaltbar, weil sie einen nicht-sprachlichen Zugang zur Realität impliziert. Da Realität aber immer nur sprachlich bzw. zumindest symbolisch erfahrbar ist, kann die Bedeutung sprachlicher Zeichen niemals direkt mit unsprachlichen Gegenständen korrespondieren; zumindest werden wir wohl niemals wissen, ob sie es tun.

Bedeutung wird hingegen über einen semantischen Kontext ermöglicht, d.h. sprachliche Zeichen sind nur in Differenz zu anderen sinnhaft. Semantik alleine reicht aber vielfach nicht aus, um Bedeutung zu bestimmen. Zusätzlich muss eine soziale Kontextualisierung erfolgen, um erschließen zu können, was Sprecher mit ihren Äußerungen meinen. Diese soziale Kontextualisierung impliziert sowohl die Beachtung des Handlungszusammenhanges, in dem eine Äußerung steht, als auch die Berücksichtigung der innerhalb einer Sprechergemeinschaft akzeptierten Regeln des sprachlichen Gebrauchs, die konstitutiven Charakter für Bedeutung aufweisen $^{213}$.

Um der Bedeutung sprachlicher Zeichen und Äußerungen Rechnung tragen zu können, müssen also unterschiedliche (gleichsam zwiebelartige) Tiefenschichten analytisch Berücksichtigung finden; Bedeutung wäre damit eine Funktion von sprachlichen Zeichen, einem semantischen Kontext, Gebrauchsregeln, einem sozialen Handlungszusammenhang und einer als unabhängig unterstellten physikalischen Außenwelt.

\footnotetext{
213 Eine reine Privatsprache - einmal unterstellt, sie sei konzeptionell entwickelbar - wäre nicht viabel, ihr Benutzer würde permanent an seiner Umwelt scheitern, weil er Bedeutungen inkorrekt verwendete. Für Wittgenstein ist eine Privatsprache unmöglich, da für sie kein unabhängiges Überprüfungskriterium angebbar wäre. Wenn etwa eine Person eine bestimmte Körperempfindung mit dem Zeichen "E" belegen würde, so könnte sie das neuerliche Auftreten dieser Empfindung und die nachfolgende Zuordnung des festgelegten sprachlichen Zeichens nur durch das eigene Erinnerungsbild an die vormalige Empfindung - und damit keinesfalls in unabhängiger Weise überprüfen. Das wäre so "als kaufte Einer mehrere Exemplare der heutigen Morgenzeitung, um sich zu vergewissern, daß sie die Wahrheit schreibt." (PU \ 265) Akzeptiert man eine Gebrauchstheorie der Bedeutung, dann kann nur die korrekte Anwendung der innerhalb einer Sprachgemeinschaft geltenden Regeln des sprachlichen Gebrauchs verbürgen, dass den Zeichen überhaupt eine Bedeutung zukommt. Anderenfalls wäre das richtig, "was immer mir als richtig erscheinen wird. Und das heißt nur, daß hier von 'richtig' nicht geredet werden kann." (PU \ 258) Dies impliziert nun nicht - um bei der körperlichen Empfindung zu bleiben -, dass Empfindungswörter keine Bedeutung aufweisen können; aber wenn wir sie verwenden, "dann müssen die Verwendungsregeln, auf denen diese Bedeutung beruht, also unabhängig von allem sein, von dem nur jede Person selbst wissen kann, ob es vorliegt oder nicht." (Beckermann 1999: 74) M.a.W.: Erst "die Tatsache, dass sich mehrere an die Regel halten, macht die Regel zur Regel." (Werner 2003: 16)
} 
Abbildung 6: Bedeutungskonstitution sprachlicher Zeichen und Äußerungen

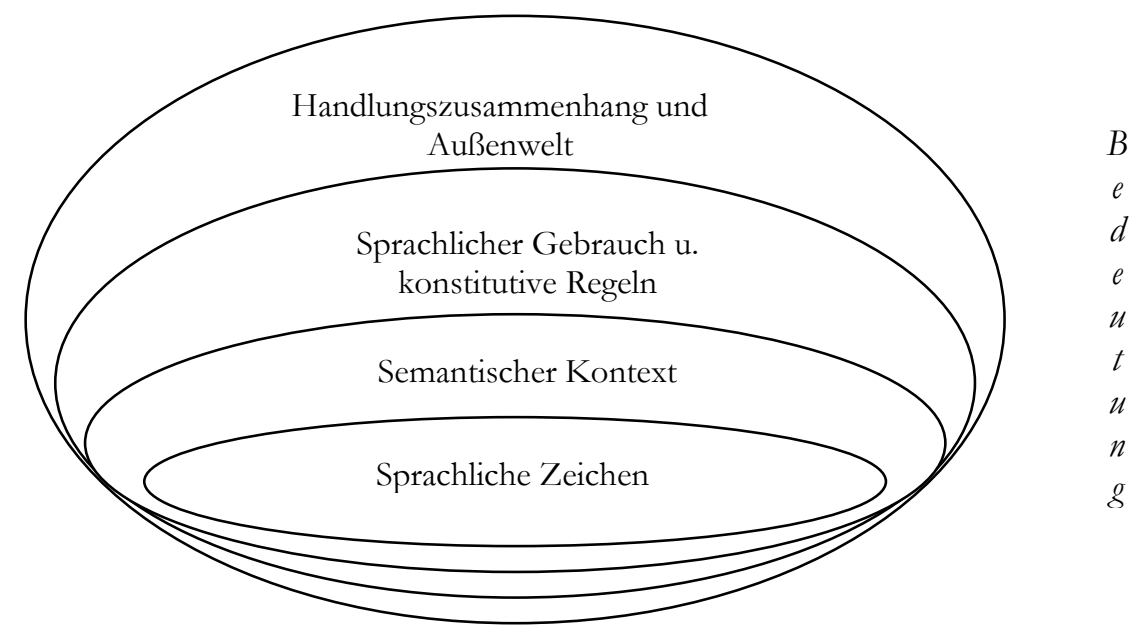

Allerdings bewirken sprachliche Bedeutungen alleine zunächst einmal recht wenig. Dennoch handelt es sich bei ihnen um die Grundbausteine desjenigen Teils sozialer Realität, der schon innerhalb der Einleitung zu dieser Arbeit unter Rekurs auf John R. Searle als "institutionell" ausgewiesen wurde. Sie werden benötigt, um subjektiven Sinn bzw. soziologische Bedeutung einführen zu können. Ihre Bestimmung antwortet auf die Frage, was eigentlich genau geschieht, wenn man in einem soziologischen Verständnis - Bedeutung zuweist oder Sinn mit seinem Handeln verbindet. Umgekehrt ist diese Bestimmung aber abhängig von Sprachspielen und insofern von sozialen Praktiken in gegebenen situativen Kontexten, d.h. eine Bedeutungsanalyse hat sowohl linguistische wie soziale Dimensionen zu berücksichtigen. 


\subsection{Bedingungen der Möglichkeit sozialer Realität: Sprachphilosophische Perspektive}

Ontologische Fragen lassen sich nur sprachlich diskutieren; wir sind nicht in der Lage, Entitäten in eine Ontologie aufzunehmen oder auch nur zu denken, die unsere sprachlichen Limitierungen transzendieren. Letztlich determiniert unser sprachliches Ausdrucksvermögen unsere Vorstellungen hinsichtlich dessen, was wir als real erfahren können.

Bedeutung wiederum wird durch das Zusammenwirken von sprachlichem Zeichen, semantischem Kontext, regelhaftem Sprachgebrauch und Handlungszusammenhang etabliert. Für sich alleine genommen bedeuten Worte zunächst einmal nichts; sie fallen weder mit den von ihnen bezeichneten Gegenständen zusammen, noch lassen sie sich hinreichend über einen semantischen Strukturzusammenhang bestimmen.

Eine Ontologie des Sozialen wird nun zu beantworten haben, wie Menschen auf Basis sprachlich zur Verfügung stehender Bedeutungen Dinge eine soziologische Bedeutung zuweisen, die ansonsten nicht vorhandene Entitäten erst hervorbringt. Nachfolgend soll eine sprachphilosophische Ausarbeitung einer solchen Ontologie vorgestellt werden, die dann später in etwas modifizierter Form die Auseinandersetzung mit Sozialkapital als alltagsweltlichem Gegenstand anleitet $^{214}$.

Zur Elaborierung der Bedingungen der Möglichkeit sozialer Tatsachen ${ }^{215}$ aus sprachphilosophischer Perspektive beziehe ich mich auf den amerikanischen analytischen Philosophen John R. Searle, der ausgehend von seinen früheren sprechakttheoretischen und bewusstseinsphilosophischen Überlegungen eine explizite Ontologie sozialer Tatsachen entwickelt hat. Searle ist Professor an der Universität of California in Berkeley und zweifellos einer der meist diskutiertesten Philosophen der Gegenwart. Dies mag nicht zuletzt darin begründet liegen, dass er sich in seinen Schriften mit nahezu allen grundlegenden Fragen der Philosophie auseinandersetzt: dem Körper-Geist-Problem, der Natur menschlichen Bewusstseins (und dem hiermit verwandten Problem künstlicher Intelligenz), dem Funktionieren der Sprache sowie nicht zuletzt der Entstehung sozialer Realität.

\footnotetext{
214 Searle selbst hat sich um die Anwendung seiner Überlegungen im Rahmen sozialwissenschaftlicher Forschungszusammenhänge keine Gedanken gemacht: "I never gave any thought to what consequences my book ("The Construction of Social Reality", D.K.) might have for the actual practice of working social scientists." (Searle 1997b: 109)

215 Searle (1997b: 104) greift in einer Antwort auf Hacking dezidiert auf die Kantsche Terminologie zur Beschreibung seiner Fragestellung zurück. Während es bei Kant jedoch um erkenntnistheoretische Bedingungen geht, richtet Searle sein Augenmerk auf die ontologischen "conditions of the possibility of".
} 
Ausgangsfrage in Searles Buch "Die Konstruktion gesellschaftlicher Wirklichkeit" ist, wie wir basierend auf (sowie unter Beibehaltung) einer naturalistischen Ontologie zur Existenz gesellschaftlicher Tatsachen gelangen können. Searle möchte "die kontinuierliche Linie aufzeigen, die von Molekülen und Bergen zu Schraubendrehern, Hebeln und schönen Sonnenuntergängen und dann zu Gesetzgebungen, Geld und Nationalstaaten führt" (Searle 1997a: 51). Ziel ist die Entwicklung einer "allgemeinen Ontologie gesellschaftlicher Tatsachen und gesellschaftlicher Institutionen" (ebenda: 8).

Eine naturalistische Ontologie sagt uns - so Searle -, dass die Welt aus in Kraftfeldern existierenden und zu Systemen organisierten Teilchen besteht. Bewusstsein ist nun eine Eigenschaft von Nervensystemen, mit der Intentionalität einhergeht. "Intentionalität ist das Merkmal des Geistes, durch das Geisteszustände auf Sachverhalte in der Welt gerichtet sind, von ihnen handeln, sich auf sie beziehen oder auf sie abzielen."216 (Searle 2001: 82). Aber: "Wie können wir im Rahmen dieser Ontologie die Existenz gesellschaftlicher Tatsachen erklären?" (Searle 1997a: 17)

\section{Beobachterrelativität und ontologische Subjektivität}

Um diese Frage zu beantworten, differenziert Searle in einem grundlegenden Schritt zwischen immanenten und beobachterrelativen Eigenschaften der Welt.

216 Searle entwickelt seine Bewusstseinskonzeption in Ablehnung von sowohl dualistischen wie materialistischen Positionen: "Einerseits der Dualismus: Er macht in jeder seiner Varianten den Status und die Existenz von Bewusstsein völlig mysteriös. ... Andererseits der Materialismus: Er scheint offenkundig falsch zu sein. Er führt dazu, dass die Existenz von Bewusstsein geleugnet wird, und damit wird die Existenz desjenigen Phänomens geleugnet, das die Frage (nach der Existenz, D.K.) überhaupt erst entstehen ließ." (Searle 2002: 62) Searle begreift Bewusstseinszustände als höherstufige Merkmale des Gehirns. "Somit haben wir Bewusstsein 'naturalisiert', und die Bezeichnung 'biologischer Naturalismus' ist denn auch in der Tat mein Etikett für diese Auffassung, weil der Geist dieser Auffassung zufolge ein Teil der Natur ist." (Searle 2001: 69f.) "My entire approach is deliberately and self-consciously naturalistic." (Searle 2003: 300) Oder noch deutlicher: "I think of intentional states, processes, and events as part of our biological life history in the way that digestion, growth, and the secretion of bile are part of our biological life history." (Searle 1983: 160) Auch Hilary Putnam scheint Searle hier zuzustimmen: "Too often nowadays it is assumed that a question of the form 'What is the nature of X?' has only one meaning worth discussing, namely, 'How can X be reduced to physics, chemistry, neurophysiology etc.?' Some of these philosophers who hold that the nature of consciousness is a mystery that cannot be in any way resolved by science as we know it, believe, indeed, that some change at the level of fundamental physical theory will be needed before consciousness can be reduced to physics." (Putnam, H. 1999: 171) Bei Richard Rorty (1981: 37f.) heißt es: "Warum sollten wir sagen wollen, die Gedanken oder die mentalen Bilder einer Person seien aufgrund des einfachen Umstandes, daß wir sie nicht in der Begrifflichkeit von Teilen der Person erklären können, schon etwas Nichtphysisches?" In ähnlicher Weise wendet sich auch Thomas Nagel (1990: 28) gegen einen dogmatischen Physikalismus und augenscheinlich - ohne freilich einen Namen zu nennen - in diesem Punkt wohl insbesondere gegen Quine (vgl. für eine Kritik an Quines Physikalismus aber vor allem dessen Behaviorismus auch Chomsky 1977: 210-228). Gerade die Psychologie hat sich seit ca. vier Jahrzehnten vom Physikalismus (wie er insbesondere in den behavioristischen Modellen von Skinner, Pawlow oder Watson in Erscheinung tritt) entfernt. Vom Thema "Bewusstsein" kann die Psychologie derzeit "nicht genug bekommen." (Solso 2005: 132) 
Ein Objekt etwa, das Menschen in deutscher Sprache "Schraubendreher" nennen, weist eine bestimmte Masse oder eine bestimmte chemische Konsistenz auf; hierbei handelt es sich um immanente Eigenschaften, die gänzlich unabhängig von menschlichem Dafürhalten sind ${ }^{217}$.

Die (logisch-philosophische) Eigenschaft desselben Objekts, ein Schraubendreher zu sein, ist hingegen beobachterrelativ, denn in diesem Falle verbinden Menschen mit diesem Objekt etwas; sie betrachten bzw. nutzen es unter für sie funktionalen Aspekten. So kann etwa auch ein Stein, der möglicherweise Jahrhunderte lang mit einer bestimmten Oberflächenstruktur (immanente Eigenschaft) am Rande eines Feldweges gelegen hat, von einem in der Sonne arbeitenden Studenten plötzlich dazu verwendet werden, Klausurunterlagen zu beschweren, damit diese nicht vom Wind hinweg geweht werden. Plötzlich hat der Stein, für den sich doch zuvor niemand wirklich interessierte, eine beobachterrelative Eigenschaft erhalten, nämlich die, ein Papier- bzw. Briefbeschwerer zu sein.

Beobachterrelative Eigenschaften der Welt sind nun grundsätzlich ontologisch subjektiv. Dies trifft etwa auf die Eigenschaft bzw. das Merkmal "Bundeskanzler zu sein" zu; die Aussage "Gerhard Schröder war am 10.05.05 Bundeskanzler" beschreibt deshalb eine nicht-physikalische Tatsache, denn Gerhard Schröder war nur deswegen an diesem Tag Bundeskanzler, weil Menschen einer bestimmten Person - in diesem Fall dem aus Hannover stammenden Gerhard Schröder - den Status zugewiesen haben, Bundeskanzler zu sein. Allein aus der physiologischen Beschaffenheit der genannten Person - die unabhängig von der menschlichen Fähigkeit, Aussagen über sie zu formulieren, existiert und somit als ontologisch objektiv zu bezeichnen ist - geht nicht im mindesten hervor, dass man es hier am 10.05.05 mit dem deutschen Bundeskanzler zu tun hatte. Wir müssen also "diejenigen unter unseren wahren Aussagen, welcher der Welt Eigenschaften zuschreiben, die völlig unabhängig von jeder beliebigen von uns eingenommenen Einstellung oder Haltung bestehen, von denjenigen Feststellungen unterscheiden, die ihr Eigenschaften zusprechen, die nur relativ auf unsere Interessen, Einstellungen, Haltungen, Zwecke usf. bestehen" (Searle 1997a: 22).

Ontologische Subjektivität impliziert damit jedoch keinesfalls Skeptizismus oder gar Anti-Realismus. Die Aussage "Gerhard Schröder war am 10.05.2005 Bundeskanzler" ist als "epistemisch objektiv" zu klassifizieren, d.h. es handelt sich um ein propositionales Urteil, für das es unpersönlich definierte Erkenntniskrite-

217 Oder mit Michael Dummett: "Wenn es von überhaupt keinen menschlichen Empfindungen und Reaktionen abhängt, ob ein Gegenstand diese Eigenschaft besitzt." (Dummett 1992: 72) Aber: Die Benennung einer immanenten Eigenschaft eines Gegenstandes beruht auf sprachlich strukturierter Erkenntnis und ist damit keineswegs unabhängig von menschlichem Dafürhalten. Der Punkt in Searles Argumentation ist allerdings, dass ein Gegenstand selbst dann über immanente Eigenschaften verfügt, wenn es niemanden gäbe, der dies erkennen könnte oder eingeführt hätte. Wie kann ein Gegenstand aber eine Eigenschaft aufweisen, wenn Eigenschaften zuvor nicht eingeführt wurden? Auf Basis eines Außenweltrealismus hat ein Stein eine bestimmte Masse unabhängig von sprachlicher Repräsentationsfähigkeit; wenn wir uns darüber verständigen wollen, können wir das freilich nur dank dieser Kompetenz. 
rien gibt und dessen Wahrheit oder Falschheit nicht von subjektiven Einstellungen abhängt. "Epistemisch gesprochen sind 'objektiv' und 'subjektiv' primär Prädikate von Urteilen. ... Im ontologischen Sinn sind 'objektiv' und 'subjektiv' Prädikate von Gegenständen und Gegenstandstypen, und zwar Zuschreibungen von Existenzarten." (ebenda: 18)

Obwohl die obige Aussage epistemisch objektiv ist, konnte Schröder am 10.05.05 nur deshalb Bundeskanzler sein, weil Menschen über die - im Folgenden genauer zu spezifizierende - Fähigkeit verfügen, Entitäten zu schaffen, die zwar eine physikalische Fundierung aufweisen, darüber jedoch hinausweisen; und eben in diesem Sinne beschreibt die genannte Aussage in Bezug auf (den mittlerweile nur noch ehemaligen) Bundeskanzler Schröder eine ontologisch subjektive Existenzart.

\section{Intentionalität, Funktionszuweisung und institutionelle Tatsachen}

Zentral hinsichtlich der Entstehung sozialer Realität ist sprachlich organisiertes Bewusstsein und damit die Fähigkeit des menschlichen Geistes zur Intentionalität, also zur bezugnehmenden Repräsentation der Gegenstände der Außenwelt. Der schon mehrfach erwähnte Ausdruck "Intentionalität" geht auf Franz von Brentano sowie Edmund Husserl zurück und findet sich daher insbesondere in der Phänomenologie. Als analytischer Bewusstseins- und Sprachphilosoph setzt auch Searle "Intentionalität" an eine exponierte Stelle innerhalb seiner Ontologie sozialer/institutioneller Tatsachen. Mit Hilfe des Begriffs kann ein Bewusstseinsakt von dem Gegenstand, auf den er sich richtet, analytisch unterschieden werden: Man ärgert sich (intentionaler Bewusstseinsakt) bspw. über etwas (intendierter Gegenstand) - aber man ärgert sich eben nicht schlechthin. Umgekehrt wird über den Intentionalitätsbegriff zugleich die Verbindung von Bewussteinsakt und Gegenstand betont: Der Ärger über eine Sache ist ein Aspekt der Erkenntnis dessen, über was man sich ärgert ${ }^{218}$.

Über Intentionalität sind Menschen in der Lage, bestimmten Entitäten eine grundsätzlich beobachterrelative Funktion zuzuweisen bzw. eine Bedeutung (im

\footnotetext{
${ }^{218}$ Die Unmöglichkeit, eine von alleine nicht sinnhaft strukturierte Welt ohne intentional bedingte Werttönung zu sehen und damit die Gegenstände von den Bewusstseinsakten tatsächlich zu separieren, hat Jean-Paul Sartre (1991) schließlich davon sprechen lassen, der Mensch sei zur Freiheit verurteilt, also zur Freiheit, seinem Leben einen subjektiven Sinn zu verleihen. In der Individualpsychologie Alfred Adlers klingt dies so: "Wir sind nicht in der Lage zu denken, zu fühlen, zu wollen, zu handeln, ohne daß uns ein Ziel vorschwebt." (Adler 1974: 21) Diese Perspektive wurde dann von Carl R. Rogers in die humanistische Psychotherapie aufgenommen: Neurosen betrachtet man als eine existentialistische Störung des Selbst (vgl. Rogers 2004). Brentanos "Idee" der Intentionalität ("Die Realitäten, die in unsere Wahrnehmung fallen, sind psychische, d.h. sie zeigen eine intentionale Beziehung; eine Beziehung auf ein immanentes Objekt" [Brentano 1982: 131]) hat also in unterschiedlichen Bereichen (Phänomenologie, Existenzialismus, Analytische Philosophie, Klinische Psychologie aber auch Wissenssoziologie) sichtbare Spuren hinterlassen.
} 
soziologischen Sinne) aufzuerlegen ${ }^{219}$. "Im Fall einiger Artefakte bauen wir ein Objekt zu dem Zweck, einer Funktion zu dienen. Stühle, Badewannen und Computer sind offenkundige Beispiele. Im Fall vieler natürlich vorkommender Objekte wie Flüsse und Bäume weisen wir eine - ästhetische, praktische usf. Funktion einem schon bestehenden Objekt zu. Wir sagen 'Dieser Fluss ist gut zum Schwimmen' oder 'Diese Art Baum ist gut für Bauholz"' (Searle 1997a: 24).

Wenn nun "diese Art von Baum gut für Bauholz ist" und damit einem bestimmten, von Menschen bewusst intendierten Zweck dient, dann handelt es sich um eine "Verwendungsfunktion", die "dieser Art von Baum" zugeschrieben wird. Die Funktion des Herzens, Blut zu pumpen, ist hingegen eine "NichtVerwendungsfunktion", insofern Menschen hier lediglich einen kausalen Prozess teleologisch interpretieren: Das Herz pumpt Blut, weil die physiologischen Abläufe nun einmal so sind, wie sie sind; die Natur selbst hat kein Bewusstsein und kann daher keine Absichten und Funktionen kennen ${ }^{220}$ (vgl. Searle 2001: 146f.). Hinsichtlich der Konstruktion gesellschaftlicher Realität sind nun insbesondere jene Entitäten relevant, deren Verwendungsfunktion es ist, jenseits ihrer physikalischen Eigenschaften etwas zu repräsentieren bzw. - wie ich sagen möchte - zu bedeuten.

Searle verdeutlicht dies m.E. am anschaulichsten am Beispiel des Geldes. Hierbei handelt es sich physikalisch betrachtet um Zellulose, Farbpigmente, Metall, Plastik etc. - nichts an der Physik des Geldes macht es zu dem, was es für uns Menschen ist. Geld wird nur deshalb zu Geld, weil wir es dafür halten; "wenn keiner jemals glaubt, daß diese Art von Ding Geld ist, dann ist es kein Geld." (Searle 1997a: 42) Dennoch erscheint uns Geld ontologisch kaum eigentümlicher als Steine. Erst wenn unsere Gewohnheiten durchbrochen werden - etwa wie im Jahre 2001 durch eine Währungsumstellung - bekommen wir eine Ahnung davon, dass es sich bei Geld eigentlich nur um Metall, Papier oder Plastik handelt, und dass es seine Existenz als wertbeinhaltendes Zahlungsmittel einer entsprechenden Funktionszuweisung sowie einer dauerhaften Anerkennung verdankt. Der entscheidende Punkt ist, dass wir qua kollektiver Intentionalität einer Entität (z.B. einem Stück Papier oder einer Person) eine Funktion zuweisen bzw. eine

219 Die Frage, inwiefern es sich im Kontext institutioneller Wirklichkeit bei der Searleschen Funktions- um eine Bedeutungszuweisung im soziologischen Sinne handelt, wird am Ende dieses Kapitels diskutiert.

220 Wenn man die Existenz eines Schöpfergottes propagiert, mag man zu einer anderen Bewertung gelangen. Hier jedoch wird von der auch innerhalb der Wissenssoziologie geteilten Auffassung ausgegangen, dass "natürliche Ereignisse keinen Sinn 'in sich' tragen und deshalb ihre Bedeutung vom Beobachter definiert wird" (Soeffner/Hitzler 1994: 50). In ähnlicher Weise - wenngleich mit der Betonung auf Normativität - hatte sich schon Kant geäußert: "Das Sollen drückt eine Art von Notwendigkeit und Verknüpfung mit Gründen aus, die in der ganzen Natur sonst nicht vorkommt. Der Verstand kann von dieser nur erkennen, was da ist, oder gewesen ist, oder sein wird. Es ist unmöglich, daß etwas darin anders sein soll, als es in allen diesen Zeitverhältnissen in der Tat ist, ja das Sollen, wenn man bloß den Lauf der Natur vor Augen hat, hat ganz und gar keine Bedeutung". (A 547) 
soziologische Bedeutung auferlegen, die nicht aus der Physik dieser Entität ableitbar ist, wobei kollektive Intentionalität meint, dass Menschen "intentionale Zustände wie etwa Überzeugungen, Wünsche und Absichten teilen."221 (ebenda: 34).

An diesem Punkt führt Searle auch die zentrale Differenzierung zwischen gesellschaftlichen und institutionellen Tatsachen ein: "Der radikale Schritt, der uns von einfachen gesellschaftlichen Tatsachen wie der, daß wir zusammen auf einer Bank sitzen oder einen Faustkampf miteinander ausfechten, zu institutionellen Tatsachen wie Geld, Eigentum und Ehe führt, ist die kollektive Funktionszuweisung an Gebilde, die - anders als Hebel, Bänke oder Autos - diese Funktion nicht einzig und allein dank ihrer Struktur verrichten können." (Searle 1997a: 51) Institutionelle Tatsachen sind nun durchweg ontologisch subjektiv, wenngleich sie i.d.R. epistemisch objektiv sind, d.h. sie existieren tatsächlich, aber sie existieren eben nur, weil Menschen qua kollektiver Intentionalität eine notwendige Funktionszuweisung vorgenommen haben.

\section{Die sprachlogische Struktur institutioneller Tatsachen}

Weil Menschen also bspw. davon überzeugt sind, dass ein bestimmtes Stück Papier einen spezifizierbaren Tauschwert aufweist, zählt dieses Stück Papier als Zahlungsmittel. Die logische Struktur dieser Operation ist denkbar einfach. Sie lautet: $X$ zäblt als $Y$ in $K$

"This little device is the foundation stone of all institutional reality." (Searle 1998: 153) Der X-Terminus bezeichnet ein Phänomen, dem über kollektive Intentionalität ein Status zugewiesen wird, der durch den Y-Terminus repräsentiert wird; der K-Terminus beschreibt nun noch den Kontext, in dem diese Zuweisung Akzeptanz beanspruchen darf. Ein bestimmtes "Stück Papier" (XTerminus) zählt bspw. als ein "Zahlungsmittel im Wert von fünf Euro" (YTerminus) innerhalb der "Europäischen Währungsunion seit dem Jahr 2002" (KTerminus). In einem "Basketballspiel" (K-Terminus) zählt ein "Wurf eines Balles in einen Korb" (X-Terminus) "zwei Punkte" (Y-Terminus) (und "mehr Punkte als

\footnotetext{
${ }^{221}$ In einem Fußballspiel teilen etwa die Spieler einer Mannschaft i.d.R. die Absicht, das Spiel zu gewinnen. Ein einzelner Spieler weist sowohl individuelle ("Ich muss den Ball flanken") als auch kollektive Intentionalität ("Wir dürfen den Gegner nich zum Kontern kommen lassen") auf. Im Falle sozialer Tatsachen muss es sich für Searle augenscheinlich um eine Funktionszuweisung qua kollektiver Intentionalität handeln, insofern die Intentionalität nur eines Einzelnen die Ebene des Sozialen unterlaufen würde: Wenn nur einer behauptet, mit Legosteinen könne man ab sofort Joghurt kaufen, bleibt dies gesellschaftlich folgenlos. Gebauer versteht in seinem aus soziologischer Perspektive angestellten Vergleich der konstruktivistischen Positionen Searles und Bourdieus den Intentionalitätsbegriff m.E. vollkommen miss, wenn er behauptet, individuelle Intentionalität werde von Searle vorsozial konzipiert und unterlaufe damit die Bedingung seiner Möglichkeit: "Intentionalität geht also nach Searles Entwurf der Gesellschaft voraus." (Gebauer 2000: 435). Insofern Intentionalität aber von Searle als sprachlich ausgewiesen und Sprache sozial konzipiert wird, ist dieser Vorwurf haltlos, womit der Argumentation Gebauers das Fundament fehlt.
} 
der Gegner zu erzielen" $[\mathrm{X}]$ zählt in einem "Basketballspiel" $[\mathrm{K}]$ als "Sieg" $[\mathrm{Y}]$ ). Damit einem Wurf eines Balles in einen Korb die Bedeutung zukommen kann, zwei Punkte zu zählen, und damit einem Stück Papier die Bedeutung zukommen kann, ein Zahlungsmittel im Wert von fünf Euro zu sein, bedarf es der nur sprachlich einführbaren Regel, dass einem Etwas (X) eine die physikalischen Eigenschaften dieses Etwas transzendierende Funktion/Bedeutung $(\mathrm{Y})$ zugewiesen wird, welche innerhalb eines spezifizierbaren Kontextes bzw. unter bestimmten Bedingungen $(K)$ Gültigkeit beanspruchen darf.

"X zählt als Y in K" ist somit die Regel, deren Anwendung konstitutiv für die Existenz institutioneller Tatsachen ist, denn an dem X (etwa einem bestimmten Stück Papier) ist nichts, was es aus sich heraus zu einem Y (etwa einem Zahlungsmittel im Wert von 5 Euro) machen könnte. Und "solange die Leute fortfahren anzuerkennen, dass X die Statusfunktion Y hat, wird die institutionelle Tatsache ... am Leben erhalten", (Searle 1997a: 57) d.h. institutionelle Tatsachen wie etwa Universitäten, Regierungen oder Geld sind nichts weiter als kontinuierliche soziale Bestätigungsakte, sie sind "tatsächlich einfach Platzhalter für Tätigkeitsstrukturen." (ebenda: 67)

Warum benötigen wir nun Worte, um solche Funktionszuweisungen und damit letztlich institutionelle Tatsachen zu schaffen? "And the answer is in some cases you do not. Suppose we kept score in a soccer match by piling up stones. I score a goal so I get a white stone to put on my side and you score a goal so you put a white stone on your side, and these are points. ... These stones now play a linguistic role. They are now symbolic. ... So the language or some other symbolism has to be constitutive because there isn't an independent ontology." (Searle 1998: 156)

Institutionelle Tatsachen werden also geschaffen, indem einer Entität sprachlich eine deontische Komponente bzw. ein kollektiv anerkannter bzw. anzuerkennender Status zugewiesen wird. Bei derartigen Verwendungsfunktionen handelt es sich daher um "Statusfunktionen"; die den Status indizierenden Symbole sind "Statusindikatoren" (vgl. Searle 1997a: 51). "Einen Ehering oder eine Polizeiuniform tragen, das ist ein dauernder Sprechakt, der sagt: 'Ich bin verheiratet' oder 'Ich bin Polizist'" (Searle 2001: 185).

Eine exponierte Bedeutung hinsichtlich der Entstehung institutioneller Tatsachen kommt eben jenen Sprechakten zu. Geben sich etwa zwei heiratswillige Menschen auf einem Standesamt das "Ja-Wort", dann wird hierüber eine Ehe geschlossen. "Die Verrichtung der und der Sprechakte (der X-Terminus) in Anwesenheit eines Standesbeamten (dem K-Terminus) zählt jetzt als EheschlieBung (der Y-Terminus)."222 (Searle 1997a: 92) "Performative spielen bei der

\footnotetext{
222 Moscovici beschreibt diese Leistung der Sprache wie folgt: "One of the most obscure faculties of ... our language is the ability to materialize an abstract entity. This power is based on our ability to change a representation, the word of a thing into the thing of the word." (Moscovici 1981: 199) Man erkennt nicht mehr, dass es sich doch bloß um eine Übereinkunft handelt: "Ein Ding ist, was es heißt, und es kann nicht anders sein." (Berger/Luckmann 1980: 63)
} 
Schaffung institutioneller Tatsachen eine besondere Rolle, weil die Statusfunktion, die von dem Y-Terminus in der Formel 'X zählt als $Y^{\prime}$ bezeichnet wird, oft, wenngleich nicht immer, einfach dadurch zugewiesen werden kann, daß man erklärt, sie sei zugewiesen worden. Das gilt besonders dort, wo der X-Terminus selbst ein Sprechakt ist." (ebenda: 65)

Typen von Tönen und Zeichen werden also Statusfunktionen zugewiesen. Eine Äußerung bestimmter Töne zählt als Äußerung eines bestimmten deutschen Satzes, die Äußerung eines bestimmten deutschen Satzes zählt als ein bestimmtes Versprechen, ein bestimmtes Versprechen zählt als ein bestimmter Vertrag etc. (vgl. Searle 2001: 154f.) Augenscheinlich lässt sich die Formel "X zählt als Y in K" iterieren, um so immer komplexere bzw. höherstufige institutionelle Sachverhalte und damit ein engmaschiges Netz von Rechten und Pflichten zu etablieren. Die Iterationslogik lässt sich auch am Beispiel der Eheschließung verdeutlichen. Hier ist der "Standesbeamte" zwar der K-Terminus, um aber überhaupt Standesbeamter sein zu können (soziologisch gesprochen: um die soziale Rolle ausüben zu dürfen), muss die betreffende Person (X) diese Y-Statusfunktion zuvor erworben haben (vgl. Searle 1997a: 90).

An dieser Stelle ist auch auf die Unterscheidung von gesellschaftlichen und institutionellen Tatsachen auf der einen sowie rohen (bzw. nackten) Tatsachen auf der anderen Seite hinzuweisen. Letztere sind rein physikalischer Natur; auf ihnen ruht - sehr naturalistisch gedacht - das gesamte institutionelle Gebilde. Von einer creatio ex nihilo kann also bezüglich dieses Gebildes keine Rede sein.

Searle erläutert dies wie folgt: "Why is there this priority of brute facts over institutional facts? And the answer to that is, because the iterated structure of 'X counts as $Y^{\prime}$ has to bottom out somewhere. For instance, my making a contract can be derived from my signing my name, and my signing my name can be a matter of certain words being written on a page. But then you reach the point where there isn't anymore ' $\mathrm{X}$ counts as $\mathrm{Y}$ '; you just have the brute fact, e.g. the marks on the page, as X-term. So institutional reality of ownership and obligations is built on top of physical reality, it has to bottom out in physical reality." (Searle 1998: 157)

\section{Zusammenfassung}

Abschließend soll Searles Analyse über die Entstehung institutioneller Tatsachen

nochmals übersichtlich nachvollzogen werden:

Ein begrifflich repräsentierter sozialer Sachverhalt (etwa Geld) wird hinsichtlich seiner

physischen Eigenschaften untersucht (Geld besteht etwa aus Kupfer, Silber, Zellulose etc. und ist an Träger gebunden), um im Anschluss über die ihm durch kollektive Intentionalität zugewiesenen abstrakten Eigenschaften seine konkrete 
Verwendungsfunktion bzw. Statusfunktion (Geld fungiert als Zahlungsmittel) und deren

- Statusindikatoren (Münze, Geldschein, Kreditkarte etc.) aufzuzeigen; dabei sind die

- Kontextbedingungen zu eruieren, unter denen Statusfunktion und indikatoren Akzeptanz beanspruchen können.

Graphisch möchte ich dies wie folgt veranschaulichen:

Abbildung 7: Searles Ontologie institutioneller Tatsachen

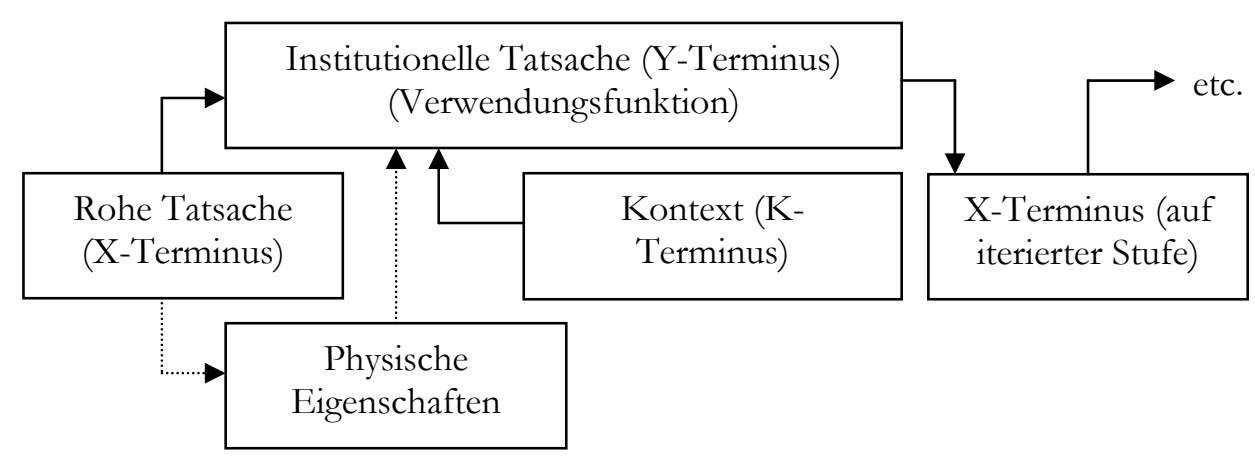

Institutionelle Wirklichkeit basiert auf der menschlichen Fähigkeit zur Intentionalität und zur sprachlichen Repräsentation. Die konstitutive Regel, die zur Entstehung einer institutionellen Tatsache (als Teil der institutionellen Wirklichkeit) führt, folgt der allgemeinen Formel "X zählt als Y in K". Damit ein X als Y in $\mathrm{K}$ zählen kann, muss diesem $\mathrm{X}$ eine entsprechende Funktion/Bedeutung zugewiesen werden. Diese Zuweisung bedarf der kollektiven Intentionalität, da anderenfalls die Ebene des Sozialen unterlaufen würde. Um die Komplexität institutioneller Tatsachen zu steigern, muss die Formel $\mathrm{X}$ zählt als $\mathrm{Y}$ in $\mathrm{K}$ iteriert werden. Zur Sicherung des Fortbestandes institutioneller Tatsachen ist die kontinuierliche Anerkennung einmal zugewiesener Statusfunktionen notwendig.

In Abweichung zu Searle werde ich im Verlauf dieser Arbeit nicht von "Funktionszuweisung", sondern von "Bedeutungszuweisung" sprechen, da die zu konstruierende Ontologie über Sozialkapital insbesondere auf den Bedeutungsbegriff abstellt. M.E. sollte man die Begriffe "Bedeutung" und "Funktion" in diesem Zusammenhang einfach stärker zusammenziehen: Hat etwas Bedeutung, dann ist es in irgendeiner Form mit Blick auf menschliches Wollen relevant, d.h. es hat eine Funktion bzw. einen Gebrauchswert ${ }^{223}$. Wenn Searle etwa behauptet, "once

${ }^{223}$ Wie der Regenschirm in dem dieser Arbeit vorangestellten Zitat aus Paul Austers "Stadt aus Glas". 
you introduce the notion of function you introduce normativity" (Searle 1998: 148) oder "we don't talk about better and worse stones, unless we assign a function to the stone" (ebenda), dann sind das m.E. klare Hinweise darauf, dass es hier um die Zuweisung von soziologischer Bedeutung geht. Da Searle aber von "Bedeutung" nur im Kontext von Worten, Sätzen und Äußerungen spricht, benötigt er hier einen anderen Begriff: Über Sprache wird einem sprachlich repräsentierten Gegenstand eine Funktion zugewiesen - das ist etwas anderes als die Bedeutung der Worte, Sätze und Äußerungen, mit denen man dies tut.

Die Searlesche Funktionszuweisung ist also m.E. konzeptionell durchaus mit der subjektiven Sinnkategorie der Soziologie verwandt. Schütz spricht - wie schon erwähnt - diesbezüglich unter Bezug auf Weber vom "Um-zu-Motiv" des Handelns, d.h. in Philosophie wie Soziologie wird Funktionalität als eine menschliche Leistung betrachtet, die notwendig ist, um institutionelle Realität entstehen zu lassen. Zugleich gibt es aber auch eine Nähe zwischen der Searleschen Funktionszuweisung und dem Bedeutungsverständnis des symbolischen Interaktionismus.

Wenn etwa - soziologisch gesprochen - ego einer Handlung alters die Bedeutung beimisst, eine Hilfestellung zu sein, dann wäre dies philosophisch als eine Funktionszuweisung an X ("Handlung alters" [= X-Terminus] zählt als "Hilfestellung" [= Y-Terminus]) zu rekonstruieren (siehe zum Verhältnis von soziologischem und sprachphilosophischem Bedeutungsverständnis nochmals die Ausführungen im vorangegangenen Kapitel). Im Unterschied zu den genannten Soziologen untersucht Searle in der Tradition der analytischen Philosophie die Sprachlichkeit und die logische Form solcher sozialen Prozesse; ihn beschäftigt jedoch nicht, warum - historisch oder sozio-kulturell betrachtet - gerade jene und nicht andere Funktions- bzw. Bedeutungszuweisungen vorgenommen werden / wurden.

Da ich eine enge Beziehung zwischen "subjektivem Sinn" bei Schütz und "Funktionszuweisung" bei Searle behaupte (eine Funktionszuweisung qua kollektiver Intentionalität wäre gewissermaßen eine Identität von subjektivem Sinn bei mehreren Akteuren), sehe ich Searle mit seiner Betonung von Intentionalität zumindest partiell durchaus in phänomenologischer Tradition. Zwischen Searle und Hubert L. Dreyfus entzündete sich Ende der 90er Jahre ein Streit darüber, wie "phänomenologisch" Searle nun eigentlich argumentiere.

Dreyfus sah seinen Kollegen aus Berkeley zunächst in der Tradition Husserls: "Like Husserl and Heidegger, Searle begins with a description of everyday phenomena from within the everyday practical world. ... But then, like Husserl but unlike Heidegger, Searles switches to a detached logical stance and tells us: 'The important thing to see at this point is that functions are never intrinsic to the physics of any phenomenon but are assigned from outside by conscious observers and users.' When I first read this sentence I took it to be the claim that we 'conscious observers and users' actually 'assign' functions to brute stuff from 
'outside'. It thus sounded to me like Husserl's claim in 'Logical Investigation' that, for there to be language, the subject has to assign meaning to otherwise meaningless noises and squggles ... Since Searle was talking about functions of tables and chairs, he sounded to me exactly as if he were making Husserl's claim in 'Cartesian Mediations' that mere physical things are encountered first and then are given meaning as cultured objects." 224 (Dreyfus o.J.)

Searle hat dem widersprochen und darauf verwiesen, seine Analyse sei rein logischer Art (vgl. Searle 1999b). In der Tat zielt Searle in erster Linie auf die logischen Konstruktionsbedingungen sozialer Realität. Dennoch aber muss er wie bereits gesagt - mit der Exponierung von Intentionalität und seiner Funktionszuweisung in einem ersten Schritt phänomenologisch orientiert ansetzen: "A bare fact $\mathrm{X}$ counts as an institutional fact $\mathrm{Y}$ if and only if it is represented as counting as Y. This claim can be granted by phenomenologists and by logical analysts". (Dreyfus o.J.) Eine phänomenologische Ausgangsorientierung muss wie der polnische Logiker Bochenski (1993: 24) in seinen Ausführungen zu "zeitgenössischen Denkmethoden" zu Bedenken gibt - keineswegs inkompatibel mit anderen Vefahren sein: "Wer phänomenologisch vorgeht, verzichtet deshalb noch lange nicht darauf, später auch noch andere Verfahren anzuwenden und die außer acht gelassenen Aspekte auch noch zu betrachten."

${ }^{224} \mathrm{Zu}$ einer ähnlichen Einschätzung gelangt auch Karl Otto Apel (1991: 32): "Related to Husserl's theory of meaning is the intentionalist-meaning theory elaborated by John Searle". 


\subsection{Bedingungen der Möglichkeit sozialer Realität: Wis- senssoziologische Perspektive}

Wie schon innerhalb der Einleitung zu dieser Untersuchung unter Rekurs auf Alfred Schütz und Max Weber angemerkt, finden ontologische Überlegungen auch eine soziologische Konzeptualisierung. Insbesondere die beiden Wissenssoziologen Peter L. Berger und Thomas Luckmann haben eine umfassende Konstruktionsanalyse sozialer Realität vorgelegt. Ihr 1966 gemeinsam veröffentlichtes Buch "Die gesellschaftliche Konstruktion der Wirklichkeit - Eine Theorie der Wissenssoziologie" darf wohl als ein Klassiker der soziologischen Literatur bezeichnet werden. Zumindest gilt das Werk "für viele als Bezugsrahmen dessen, was die moderne Wissenssoziologie heutzutage umtreibt." (Maasen 1999: 26) Ausgehend vor allem von den Überlegungen George Herbert Meads, Alfred Schütz, Arnold Gehlens, Karl Mannheims, Max Schelers sowie Karl Marx analysieren die Autoren, wie sich gesellschaftliche Wirklichkeit als objektiv erfahrbare konstituiert.

Vielfach wird das Theoriegebäude als "Sozialkonstruktivismus" gekennzeichnet (vgl. etwa Knorr-Cetina 1989), um so den (vermeintlich) denaturalistischen Charakter sozialer Realität herauszustreichen. Paradigmatisch bringt dies Helmuth Plessner im Vorwort zur deutschen Ausgabe zum Ausdruck: "'Die gesellschaftliche Konstruktion der Wirklichkeit' nennen die beiden Autoren das vorliegende Buch, nicht etwa 'Die Konstruktion der gesellschaftlichen Wirklichkeit', was durchaus nicht auf das gleiche hinausliefe, da in solcher Fassung die soziale Welt als gegeben vorausgesetzt wäre und man es mit einem der vielen Versuche zu ihrer theoretischen Bewältigung zu tun hätte." (Plessner im Vorwort zu Berger/Luckmann 1980: IX)

Folgt man Plessner in dieser Einschätzung, so müsste es John R. Searle dessen Buch eben genau "Die Konstruktion der gesellschaftlichen Wirklichkeit" heißt - exakt um diese theoretische Bewältigung gegangen sein. Ich glaube jedoch, dass Plessner irrt, wenn er behauptet, die Platzierung des Adjektivs "gesellschaftlich" mache einen Unterschied. Der Gegenstand Berger/Luckmanns wie der Searles ist nicht die "komplette" Wirklichkeit. Beide Bücher setzen ontologierealistisch an und könnten weniger missverständlich "Die gesellschaftliche Konstruktion der gesellschaftlichen Wirklichkeit" lauten, weil sie nahezu ausschließlich von jenem Teil der Wirklichkeit handeln, der auf Bewusstsein gründet sowie Ergebnis zwischenmenschlicher Aushandlung ist, und welchen wir im Allgemeinen als "gesellschaftlich" oder "sozial" klassifizieren. Damit ist auch schon das treibende Motiv der Bücher entfaltet: Gesellschaftliche Wirklichkeit entsteht in Folge 
zwischenmenschlichen, sprachlichen und ergo gesellschaftlichen Handelns gesellschaftliche Wirklichkeit ist gesellschaftlich konstruiert ${ }^{225}$.

Gegenstand der Erörterungen in "Die gesellschaftliche Konstruktion der Wirklichkeit" ist, was Menschen in ihrem Alltag als Wissen über die Welt, als "Allerweltswissen" (Berger/Luckmann 1980: 16) begreifen und wie sie dazu gelangen. Wenn - wie oben schon mehrfach erläutert - Sprache und Wissen über die Welt in eins fallen, dann beschreibt dieses Allerweltswissen "die mehr oder minder systematische Weise menschlicher Orientierung in der Welt" (Luckmann 1981: 39) und "antwortet auf die dort vorliegenden Handlungsprobleme" (Keller 2001: 120). Die Wissenssoziologie fragt also nicht, was Menschen als wahres Wissen von der Welt begreifen können oder wie insbesondere die Wissenschaft zu wahrer bzw. geltungsfähiger Erkenntnis gelangen kann ${ }^{226}$.

Wissenssoziologie ist vielmehr die Betrachtung des objektivierten Wissens innerhalb einer Gesellschaft und der Art und Weise, wie dieses generiert und prozessiert wird. Die soziale Welt gilt demnach zwar als objektiv vorhanden, sie ist gleichwohl für den Einzelnen in erster Linie "der selbstverständliche, unbefragte Boden ... jeglichen alltäglichen Handelns und Denkens" (Hitzler/Eberle 2004: 110), d.h. seine subjektive Lebenswelt, die er im Verbund mit anderen über noch genauer zu bestimmende Mechanismen konstruiert bzw. "ontologisiert" (Luckmann 2002: 157). "Der Mensch macht seine eigene Natur - oder, noch einfacher: der Mensch produziert sich selbst" (Berger/Luckmann 1980: 52).

Dabei verweisen Berger/Luckmann auf den "Doppelcharakter der Gesellschaft als objektive Faktizität und subjektiv gemeinter Sinn, der sie zur 'Realität sui generis' macht ... . Die Grundfrage der soziologischen Theorie darf demnach so gestellt werden: Wie ist es möglich, dass subjektiv gemeinter Sinn zu objektiver Faktizität wird? Oder, in der Terminologie Webers und Durkheims: Wie ist es möglich, dass menschliches Handeln (Weber) eine Welt von Sachen hervor-

\footnotetext{
225 Mitunter ist auch von der "menschlichen" Wirklichkeit die Rede: "Die Wissenssoziologie sieht die menschliche Wirklichkeit als eine gesellschaftlich konstruierte Wirklichkeit. Da das Wesen der Wirklichkeit von jeher ein zentrales Problem der Philosophie war, hat diese Auffassung auch gewisse philosophische Aspekte." (Berger/Luckmann 1980: 200f.) Die Wirklichkeit, die Berger/Luckmann und Searle im Sinn haben, umfasst im Weberschen Verständnis nicht nur Vergesellschaftungsformen (also Beziehungen, die "auf rational [wert- und zweckrational] motiviertem Interessensausgleich oder auf ebenso motivierter Interessensverbindung beruh[en]" [Weber 1992: 21]), sondern genauso Vergemeinschaftungsformen (also Beziehungen, die "auf subjektiv gefühlter [affektueller oder traditionaler] Zusammengehörigkeit beruh[en]" [ebenda]). Diese Unterscheidung wird mit Blick auf die Ausarbeitung einer Ontologie nicht eingeführt; sie sei hier aber erwähnt, weil anderenfalls u.U. der Eindruck entstehen könnte, mit "gesellschaftlicher" Wirklichkeit werde ausschließlich auf Vergesellschaftungsformen abgezielt.

226 "Im Rahmen der Wissenssoziologie beziehen sich die Worte 'Wissen', 'Wissensbestand, 'Wissensvorrat' immer auf das, was für 'Wissen' gehalten oder woran als 'Wissen' geglaubt wird. Der Terminus 'Wissen' ist, mit anderen Worten, streng neutral gegenüber der Frage, ob das in der Gesellschaft 'Gewußte' letztlich wahr oder falsch ist." (Berger 1991: 26)
} 
bringt?"227 (Berger/Luckmann 1980: 20) In einer solchen Wendung wird zugleich die Priorität der Wie- vor der Was-Frage deutlich: "Wie Wirklichkeit konstruiert wird, muß beantwortet werden, um zu klären, was diese ausmacht." (Knorr-Cetina 1989: 92)

Grundlegend unterscheiden Berger/Luckmann zur Beantwortung dieser WieFrage die Begriffe "Objektivation", "Externalisierung" und "Internalisierung", weil sie hierüber in der Lage sind, Gesellschaft sowohl als objektive wie subjektive Wirklichkeit zu beschreiben. In ihrer objektiven Form begegnet sie den Menschen als Vergegenständlichung (Objektivation) menschlicher Selbstentäußerung (Externalisierung); diese bedarf jedoch der je individuellen Bewusstwerdung und Repräsentation (Internalisierung), um Eingang in die subjektive Wirklichkeit des Einzelnen finden zu können. "Als gesamtgesellschaftliches Phänomen sind die drei Komponenten nicht etwa im Sinne einer Aufeinanderfolge in der Zeit vorzustellen. Sie sind vielmehr simultan für die Gesellschaft und alle ihre Teile charakteristisch, so dass jede Analyse, die nur eine oder zwei ins Auge fasst, nicht ausreichte." (Berger/Luckmann 1980: 139)

Als Elemente zur Herstellung objektiver gesellschaftlicher Faktizität nennen die Autoren neben der Objektivation, der Externalisierung und der Internalisierung noch Institution, soziale Rolle, Typisierung, habitualisierte Handlung (bzw. Habitualisierung), Legitimation sowie soziale Kontrolle. Diese sind gewissermaßen die Voraussetzung der Existenz objektivierter sozialer Ordnung. Um das sozialkonstruktivistische Konzept Berger/Luckmanns darzustellen, sollen diese Komponenten im Folgenden erläutert und systematisiert werden. Beginnen möchte ich mit der Objektivation sowie ihren spezifischen Unterformen Institution und soziale Rolle. Objektivationen können als das Ergebnis des über Externalisierung bewirkten Konstruktionsprozesses verstanden werden; sie sind es, in denen sich gesellschaftliche Wirklichkeit letztlich für uns zeigt. Die Externalisierung lässt sich wiederum in Typisierung, habitualisierte Handlung, Legitimation und soziale Kontrolle unterteilen; lediglich die Internalisierung besitzt keine Subkategorien und soll am Schluss dargestellt werden.

\section{Objektivation}

Mit "Objektivation" rekurrieren Berger/Luckmann vor allem auf Dilthey (1970), der hierunter Manifestationen des Geistes, d.h. die von Menschen qua ihres Bewusstseins erzeugten Gegenstände der Sozial- und Kulturwelt begreift. Dabei kann es sich insofern um materielle Dinge wie etwa Bauwerke oder Schriftstücke,

\footnotetext{
227 Auch Simmel (1999: 45f.) beschäftigte sich in seiner "Soziologie" zentral mit dieser Frage und insofern mit den Herstellungsmechanismen sozialer Ordnung. In seinen Überlegungen sucht er "die schließlich in Individuen sich vollziehenden Vorgänge auf, die das Gesellschafts-Sein dieser bedingen - nicht als zeitlich vorangehende Ursachen für dieses Resultat, sondern als Teilvorgänge der Synthese, die wir zusammenfassend die Gesellschaft nennen."
} 
aber auch um Ideen und Institutionen handeln. Die Sprache ist nicht nur selbst eine Objektivation, sie ist darüber hinaus auch das Medium, über welches die anderen Objektivationen gewusst und auf Dauer gestellt werden. "Sprache versorgt mich mit Vorfabrikationen für ständige Objektivationen meiner zunehmenden Erfahrung." (Berger/Luckmann 1980: 40f.) So ist eine politische Ideologie bspw. nur sprachlich einzuführen, zu repräsentieren und insofern überhaupt existent. Auch innerhalb der Wissenssoziologie erscheint somit die Einheit von Sprache, Wissen und Welt.

Im Unterschied zur Vergegenständlichung ist die Verdinglichung ein Zustand, in dem die soziale Welt als quasi naturalisiert, nicht von Menschen gemacht und damit als unveränderbar erlebt wird. "Das Grund-'Rezept' für die Verdinglichung ist, ihnen (den Dingen, D.K.) einen ontologischen Status zu verleihen, der unabhängig von menschlichen Sinnen und Trachten ist." (Berger/Luckmann 1980: 97) Durch den Hinweis auf die Verdinglichung scheint in Anlehnung an Mannheim (1985) ein ideologiekritisches Moment im Berger/Luckmannschen Konzept auf: "Wenn eine Wirklichkeitsbestimmung so weit ist, dass sich ein konkretes Machtinteresse mit ihr verbindet, so kann sie 'Ideologie' genannt werden."228 (Berger/Luckmann 1980: 132)

Unter einer "Institution" verstehen Berger/Luckmann eine spezifische, hochverregelte und zugleich verbindliche Form vergegenständlichter menschlicher Tätigkeit (vgl. Berger/Luckmann 1980: 65); es geht um "handelnd vorgebrachte Ordnungen, die existent sind, weil und solange sie von Handelnden kontinuierlich

\footnotetext{
228 An anderer Stelle geht es insbesondere um hegemoniale Deutungsmuster: "Konkrete Personen und Gruppen sind die Bestimmer von Wirklichkeit. Will man den Zustand der gesellschaftlich konstruierten Sinnwelt zu beliebiger Zeit oder ihren Wandel im Laufe der Zeit verstehen, so muss man die gesellschaftliche Organisation durchschauen, die es solchen Bestimmern ermöglicht, dass sie bestimmen. Etwas gröber ausgedrückt, verschiebt sich die Frage nach historisch greifbaren Wirklichkeitskonzeptionen zwangsläufig vom abstrakten 'Was?' zum soziologischen 'Wer?"' (Berger/Luckmann 1980: 124f.) Hier lässt sich dann auch diskurstheoretisch weiterdenken. Die an Foucault (1991) angelehnte Diskursanalyse richtet ihren Fokus auf die Art und Weise, wie gesellschaftlich verbindliche Deutungsmuster etabliert werden. Diskurse werden hier als Medien gesellschaftlicher (Be-) Deutungsproduktion und Wirklichkeitskonstitution gesehen. Vereinfacht gesagt, ist ein Diskurs eine (vorwiegend) sprachliche Form der Interaktion, in der definitorisch festlegt wird, wie man die Welt zu sehen hat und die hierüber zugleich bestimmt, wie die Welt beschaffen ist, d.h. was der Fall ist bzw. was "wahr" ist. In diesem Zusammenhang sind außerdem wissens- bzw. wissenschaftssoziologische Orientierungen anzuführen, die eine relativistische Sicht auf jede Art von Wirklichkeit - also auch auf die physikalische - bevorzugen (Vertreter einer solchen Orientierung sind etwa Barry Barnes, Bruno Latour oder Karin Knorr-Cetina). Schofer (2000: 697) fasst diese Position wie folgt zusammen: "Wenn soziale Kontextfaktoren beeinflussen, welche Annahmen und Theorien als gültig bewertet werden, dann ist dieses Wissen nicht an sich absolut gültig, sondern seine Gültigkeit ist an den soziokulturellen Kontext gebunden, der die Bewertung beeinflusst." $\mathrm{Da}$ in dieser Arbeit weder eine Diskursanalyse noch eine ideologiekritische oder wissenschaftssoziologisch-relativistische Untersuchung durchgeführt werden soll, mögen diese Hinweise hier genügen (zur Diskursanalyse siehe bspw. den Sammelband von Keller/Hirseland/Schneider 2001, zur ebenfalls auf die kommunikative Konstruktion lebensweltlicher Wirklichkeiten gerichteten ethnographisch orientierten Wissenssoziologie den Sammelband von Knoblauch 1996, zusammenfassend zum wissens- bzw. wissenschaftssoziologischen Relativismus und seinen Problemen Schofer 2000 oder Meinefeld 1995 und zu einer Kritik an diesem Relativismus aus Sicht der analytischen Philosophie Hacking 1999 oder List 1983).
} 
reproduziert werden" (Iványi 2003: 182). Von Gehlen übernehmen Berger/Luckmann die Perspektive, der Mensch sei ein instinktunsicheres Mängelwesen, das diesen Mangel durch den Aufbau von Institutionen kompensieren müsse ${ }^{229}$. Die institutionale Welt gilt als eine historisch gewachsene Welt, die für die in ihr lebenden Individuen sinnhafte Strukturen und somit "integrationsfähige Bedeutungen" (Berger/Luckmann 1980: 89) bereitstellt. Spezifische Verhaltensmuster werden über Institutionen den Menschen nahegelegt und viele theoretisch ebenso denkbare weitere ausgeschlossen. Daher betonen Berger/Luckmann insbesondere den inhärenten Zwangscharakter: "Wenn ein Bereich menschlicher Tätigkeit institutionalisiert ist, so bedeutet das eo ipso, dass er unter sozialer Kontrolle steht." (ebenda: 59)

Damit sind Institutionen "nun etwas, das seine eigene Wirklichkeit hat, eine Wirklichkeit, die dem Menschen als äußeres, zwingendes Faktum gegenübersteht" (ebenda: 62). Dies impliziert zugleich auch eine hartnäckige Änderungsresistenz, denn der Mensch erlebt sie zunächst einmal als quasi naturgegeben, als Wirklichkeit, wie sie nun einmal ist. Normen verkörpern die imperative Dimension der Institution, da sie lediglich bestimmte Verhaltensweisen als zulässig erklären und somit einen Mechanismus sozialer Kontrolle etablieren ${ }^{230}$.

Neben der Institution stellt die soziale Rolle eine zweite wichtige Objektivation dar. "Soziale Rollen sind in ihrer sprachlichen Vergegenständlichung ein wesentlicher Bestandteil der objektiv faßbaren Welt einer Gesellschaft." (Berger/Luckmann 1980: 78) Hierüber konkretisiert sich die Institution erst, denn der Rollenträger repräsentiert die Institution, in der er wirkt, über sein Verhalten und macht sie so erfahrbar. Die Übernahme einer sozialen Rolle vermittelt ihrem Träger das Wissen um die kognitiven wie normativen Implikationen, die mit dieser Rolle verbunden sind (vgl. ebenda: 81). So "weiß" etwa ein Universitäts-Dozent, welche Aufgaben er wahrzunehmen und wie er sich den Studenten gegenüber zu

${ }^{229}$ Bei Gehlen heißt es u.a.: "Morphologisch ist nämlich der Mensch im Gegensatz zu allen höheren Säugern hauptsächlich durch Mängel bestimmt, die jeweils im exakt biologischen Sinne als Unangepaßtheiten, Unspezialisiertheiten, als Primitivismen, d.h. als Unentwickeltes zu bezeichnen sind: also wesentlich negativ. Es fehlt das Haarkleid und damit der natürliche Witterungsschutz; es fehlen natürliche Angriffsorgane, aber auch eine zur Flucht geeignete Körperbildung; der Mensch wird von den meisten Tieren an Schärfe der Sinne übertroffen, er hat einen geradezu lebensgefährlichen Mangel an echten Instinkten und er unterliegt während der ganzen Säuglings- und Kinderzeit einer ganz unvergleichlichen Schutzbedürftigkeit." (Gehlen 1950: 34f.) Schelsky ergänzt Gehlens Vorstellungen vor allem durch die Betonung menschlicher Subjektivität in der Moderne und begründet von hieraus die Unverzichtbarkeit der Institutionalisierung: "Die Entzweiung zwischen dem Allgemeinen, ..., und der Subjektivität des modernen Menschen ist eine solche Spannung, ja sie ist die entscheidende Spannung unserer gegenwärtigen Kultur und bedarf deswegen der Institutionalisierung." (Schelsky 1970: 24) (Durchaus nicht unähnlich argumentiert im Übrigen der Individualpsychologe Alfred Adler, wenn er behauptet, "Mensch sein heißt, sich minderwertig fühlen" (Adler 1977: 67) und in der wohlwollenden Orientierung an der Gemeinschaft den einzig erfolgversprechenden Ansatz einer Überwindung dieses Minderwertigkeitsgefühls erblickt [vgl. etwa ebenda: 75]). 230 "Zusätzliche Kontrollmaßnahmen sind nur erforderlich, sofern die Institutionalisierung selbst zur eigenen Erfahrung nicht ausreicht." (Berger/Luckmann 1980: 59) 
verhalten hat; er "weiß" sogar, welche Gefühle in mit seiner Rolle zusammenhängenden Situationen angemessen bzw. unangemessen sind.

Damit impliziert eine soziale Rolle ein Set an relativ starr festgelegten Rechten und Pflichten (vgl. Goffman 2001: 18), deren Ausübung das Wissen um situations- und (reziprok-) personenbezogene Typisierungen voraussetzt - werden weder die Situation noch die in ihr wirkenden Personen "richtig" (also in Bezug auf einen sozialen Kontext in angemessener Weise) typisiert, so wird ein aufeinander angepasstes Verhalten verunmöglicht ${ }^{231}$. Mit der diskursiven Psychologie ließe sich in diesem Zusammenhang auch von festen und kollektiv geteilten "Interpretationsrepertoires" (Flick 1999: 35) - also begrifflich strukturierten Ordnungsmustern - sprechen, ohne die Institutionen jede Strukturierungskraft verlören und sich schließlich auflösen müssten.

Berger/Luckmann verwenden den Objektivationsbegriff uneinheitlich. Zum einen beschreibt er bei ihnen ein vergegenständlichtes soziales Phänomen ("Die Waffe als Objekt ist sowohl ein menschliches Erzeugnis, als auch eine Objektivation menschlicher Subjektivität" [Berger/Luckmann 1980: 37]), zum anderen aber auch den Vorgang, der hierzu führt ("Der Vorgang, durch den die Produkte tätiger menschlicher Selbstentäußerung objektiven Charakter gewinnen, ist Objektivation" [ebenda: 64f.].)

Nun ließe sich etwa eine Institution durchaus sowohl als vergegenständlichtes soziales Phänomen (z.B. der Deutsche Bundestag), als auch als Vorgang (der Deutsche Bundestag ist nur deswegen eine Institution, weil er von Menschen kontinuierlich über deren Tätigkeiten aufrechterhalten wird) begreifen. Wenn im Folgenden von "Objektivationen" die Rede ist, dann ist aus systematischen Erwägungen heraus allerdings lediglich die erste Denotation gemeint, d.h. Objektivationen sind mehr oder minder stark veränderliche Ergebnisse jener Prozessereignisse, die als "Externalisierung" beschrieben werden.

Neben dem Objektivations- ist ferner der Institutionenbegriff in problematischer Weise mehrdeutig angelegt. So heißt es an einer Stelle: "Institutionalisierung findet statt, sobald habitualisierte Handlungen durch Typen von Handelnden reziprok typisiert werden. Jede Typisierung, die auf diese Weise vorgenommen wird, ist eine Institution." (Berger/Luckmann 1980: 58) Wenn eine Typisierung jedoch eine Institution wäre, dann würde in letzter Konsequenz auch der grundlegende Unterschied zwischen Objektivation (die eine Institution ja darstellt)

231 Wenn Berger/Luckmann davon sprechen, "meine Einstellung auf mich selbst ist ein typischer Spiegelreflex auf Einstellungen des Anderen zu mir" (Berger/Luckmann 1980: 32), dann knüpfen sie an dieser Stelle u.a. an Mead an, der "ein nach innen verlagertes Gespräch" identifiziert (Mead 1980: 245). Oder mit Goffman: "Denn während wir lernen, unsere Rollen im wirklichen Leben zu spielen, richten wir unsere eigenen Inszenierungen aus nach den uns allmählich vertraut werdenden Rollen derjenigen, an die wir uns wenden." (Goffman 2001: 67) "Ich weiß, daß er weiß, daß ich weiß" (Schütz/Luckmann 1975: 33). Bei Dilthey heißt es: "Das Verstehen ist ein Wiederfinden des Ich im Du" (Dilthey 1970: 235). (Zumindest am Rande sei erwähnt, dass mit der "Entdeckung" der im Bereich des Brocaschen Sprachzentrums angesiedelten Spiegelneuronen diese geisteswissenschaftliche Perspektive eine naturwissenschaftliche "Bestätigung" gefunden hat.) 
und Externalisierung (die eine Typisierung ja darstellt) verwischen, auf den die Autoren zu Beginn ihrer Ausführungen doch so viel Wert legen ${ }^{232}$.

\section{Externalisierung}

"Menschliche Existenz", so Berger/Luckmann, "ist ab initio eine ständige Externalisierung. Indem der Mensch sich entäußert, errichtet er die Welt, in die hinein er sich entäußert. Im Prozeß der Selbstentäußerung projiziert er seinen subjektiv gemeinten Sinn auf die Wirklichkeit." (Berger/Luckmann 1980: 112) In dieser Aussage steckt gewissermaßen die Quintessenz des ganzen wissenssoziologischen Ansatzes: Menschen konstruieren eine objektive soziale Wirklichkeit, weil in ihrem Verhalten subjektive Bedeutung zum Ausdruck gelangt.

Die wohl wichtigste Externalisierung stellt die Typisierung dar ${ }^{233}$. Hierunter kann eine bestimmte, nur sprachlich einführbare, kategoriale Einteilung der Wirklichkeit begriffen werden, die in Folge von Sozialisation oder Erfahrung nahezu unbewusst gewählt wird. So "wissen" Studenten etwa, wie sie sich in einem Universitätsseminar gegenüber den Kommilitonen oder dem Dozenten verhalten sollten. Sie wissen dies, weil sie zuvor die Situation, in der sie sich befinden, entsprechend kognitiv verorten. "Meine Kontakte in der Alltagswelt sind demnach fast immer im doppelten Sinne 'typisch': Ich erfasse den Anderen als Typus und befinde mich mit ihm in einer Kontaktsituation, die ebenfalls typisch ist." (Berger/Luckmann 1980: 34) Bei der Typisierung handelt es sich gewissermaßen um eine "routine induction" (Barnes 1983: 525), ein "'da wären wir wieder einmal'. Das entlastet ... Personen von beträchtlichen Spannungen. Sie sparen Zeit und Kraft nicht nur für beliebige äußere Aufgaben, die sie getrennt oder gemeinsam haben, sondern für ihre ganze seelische Ökonomie. Ihr Zusammenleben hat nun in einer sich ständig erweiternden Welt der Routinegewissheit seine Form gefunden."234 (Berger/Luckmann 1980: 61)

Die Typisierung bewirkt also, dass wir einer Person oder einer Situation einen bestimmten Platz innerhalb unseres persönlichen Koordinatensystems zuweisen, wir gewinnen Verhaltenssicherheit, weil wir so im Umgang mit anderen auf Erfahrung bzw. auf "Rezeptwissen" (Schütz/Luckmann 1975: 119) rekurrieren können. Erfolgen Typisierungen und Situationsdefinitionen in reziproker Weise, wird angepasstes Verhalten ermöglicht; es kommt zu einem dialogischen Aufbau sozialer Realität, weil geteilte Sinnordnungen und Rollenzuschreibungen etabliert

232 Freilich müssen wir die "Institutionalisierung" weiterhin von der "Institution" unterscheiden: Unter der "Institutionalisierung" ist der "Prozess der gemeinsamen Hervorbringung und Konsolidierung wissensbasierter (Handlungs-) Ordnungen" zu verstehen (Iványi 2003: 13).

233 Die Typisierung wird also hier als Vorgang begriffen; insofern kann sie nach der obigen Festlegung auch keine Objektivation darstellen. Das Ergebnis einer Typisierung kann etwa eine soziale Rolle sein.

234 Giddens (1992: 336) geht sogar noch weiter, wenn er in einer ontologischen Diktion von einer durch die Routinisierung bewirkten "Seinsgewißheit" spricht. 
wurden. "Indem ich die Rolle des anderen definiere, nehme ich selbst eine Rolle an. Indem ich das Verhalten des anderen typisiere, typisiere ich mein eigenes Verhalten, das mit dem seinigen verbunden ist, und ich versetze mich selbst, sagen wir, in einen Reisenden oder einen Verbraucher, einen Steuerzahler, einen Leser oder einen Beobachter."235 (Schütz 1971: 21)

Während Berger/Luckmann mit ihrer Exponierung der Typisierung insbesondere an Alfred Schütz anknüpfen, rekurriert dieser wiederum auf Edmund Husserl: "Die faktische Welt der Erfahrung ist typisiert erfahren. Die Dinge sind erfahren als Baum, Strauch, Tier, Schlange, Vogel". Und weiter: "Das als individuell Neues erfahrene ist zunächst nach dem eigentlich Wahrgenommenen bekannt; es erinnert an Gleiches (bzw. Ähnliches). Das typisch Erfasste hat aber auch einen Horizont möglicher Erfahrung mit entsprechenden Bekanntheitsvorzeichen; also eine Typik der noch unerfahrenen, aber erwarteten Merkmale: Sehen wir einen Hund, so sehen wir sofort sein weiteres Gehaben voraus, seine typische Art zu fressen, zu spielen, zu laufen, zu springen usw." (Husserl zitiert nach Dummett 1992: 101f.)

Typisierungen stehen damit in einem kontinuierlichen Verweisungszusammenhang mit bereits vorhandenem Wissen bzw. etablierten Vorstellungen über die Welt und sich hieraus speisenden Erwartungen (also das, was unter Rekurs auf psychologische Forschungsergebnisse oben [Kapitel 4.4.1.] schon als "mentale Modelle" bzw. "kognitive Schemata" bezeichnet wurde); das Subjekt greift auf Sinnbezüge, auf "Sets von Bedeutungen und ... Interpretationsentwürfe" (Blumer 1973: 100) zurück, "die sich in neuen Erfahrungssituationen immer wieder aktualisieren lassen." (Prechtl 2002: 116)

Unter einer "Habitualisierung" verstehen Berger/Luckmann ein etabliertes Handlungsmodell, das in bestimmten Situationen abrufbereit zur Verfügung steht. Die Habitualisierung ist insofern ein ökonomisches Prinzip, als sie die potentielle Handlungsvielfalt einschränkt bzw. auf eine einzige Alternative begrenzt. Eine habitualisierte Handlung ist dann die auf einem etablierten Handlungsmodell beruhende Handlungsselektion. Befinden wir uns etwa in Frankreich und wollen uns nach dem Weg zum nächstgelegenen Supermarkt erkundigen, so werden wir aller Voraussicht nach einen Passanten als französischsprachig typisieren und als

\footnotetext{
235 Typisierungsprozesse zählen auch zu den beliebtesten Gegenständen der Sozial- wie der kognitiven Psychologie. Es müsste den Rahmen dieser Arbeit sprengen, würde ich hierauf detaillierter eingehen wollen. Hier mögen deshalb zwei Zitate genügen, die insbesondere die oftmals sehr anschauliche Art psychologischer Darstellungen verdeutlichen: "The first step in ... bringing the object or person closer to us is accomplished by assigning it to a preferred category, to label it with a word belonging to our language. ... Indeed, representation is basically a classifying and naming process, a method of establishing relations between categories and labels." (Moscovici 1981: 193) Auch hier ist die Verbindung der sozialen Rolle einer Person mit der Typisierung von erheblicher Relevanz: "Once you recognize someone as filling a particular role (e.g., gas station attendant) on the basis of particular attributes (probably male, maybe wearing a jump suit, maybe with an oily rag in pocket, maybe approaching your car, perhaps helping others get gas), then you can apply your knowledge about the role to guide the subsequent interaction (this person can help you with your car)." (Fiske/Taylor 1991: 105)
} 
entsprechende habitualisierte Handlung innerhalb eines solchen Kontextes unsere Frage in französisch formulieren.

Mit "Legitimation" sind "Weisen" der "Erklärung und Rechtfertigung" gemeint. Ein "Dach aus Legitimationen" erstreckt sich "in Form kognitiver und normativer Interpretationen schützend" über die institutionelle Ordnung (Berger/Luckmann 1980: 66). Insbesondere qua Sozialisation werden Menschen mit den "stummen Gewissheiten" (Berger 1991: 64) einer historisch gewachsenen, objektivierten Ordnung vertraut gemacht bzw. in diese unter-/eingewiesen. Die "Legitimation sagt dem einzelnen nicht nur, warum er eine Handlung ausführen soll und die andere nicht ausführen darf. Sie sagt ihm auch, warum die Dinge sind, was sie sind." (Berger/Luckmann 1980: 100) Dabei arbeiten solche Erklärungen und Rechtfertigungen vielfach mit recht einfachen semantischen Formeln. "Die fundamentalen, legitimierenden 'Erklärungen' sind sozusagen in das Vokabular eingebaut. Wenn ein Kind also lernt, daß ein anderes Kind sein 'Vetter' ist, so ist dies ein Stück Information, das unmittelbar und als solches das Verhalten 'Vettern' gegenüber legitimiert, welches zusammen mit der Bezeichnung gelernt wird. Auf dieser ersten Ebene beginnender Legitimation bewegen sich alle die simplen, üblichen Versicherungen: 'So ist das eben', 'Das macht man so' -, die frühesten und im großen und ganzen wirkungsvollsten Antworten auf die 'Warum'-Fragen des Kindes."236 (ebenda: 100f.)

\section{Internalisierung}

Mit "Internalisierung" bezeichnen Berger/Luckmann eine "Einverleibung, durch welche die vergegenständlichte gesellschaftliche Welt im Verlauf der Sozialisation ins Bewußtsein zurückgeholt wird." (Berger/Luckmann 1980: 65) Internalisierung bedeutet, wie Bourdieu (1993: 107) es zugespitzt formuliert - die "performative Macht des Sozialen ernst zu nehmen." Wenn die Welt für uns immer nur als phänomenale Welt erfahrbar ist, dann meint dieses "ernst nehmen" jenen Prozess, durch den wir eine Vorstellung von der äußeren Welt entwickeln. "Zurückholen" kann dann allerdings lediglich bedeuten, dass das, was internalisiert wird, zuvor von Menschen über Externalisierung geschaffen wurde und gewissermaßen nun

\footnotetext{
236 Aus existenzphilosophischer Sicht ließe sich hinzufügen, dass nicht nur die Warum-Fragen des Kindes, sondern wohl auch die des Erwachsenen mit dem Verweis auf ein diffuses "Man" beantwortet werden, insofern wir uns in unserem Handeln an den gesellschaftlichen Gepflogenheiten orientieren, wie sie uns in der Form "man geht ins Kino", "man studiert", "man heiratet" etc. entgegentreten. Bei Heidegger heißt es: "Zunächst 'bin' ich nicht 'ich' im Sinne des eigenen Selbst, sondern die Anderen in der Weise des Man. ... Zunächst ist das Dasein Man und zumeist bleibt es so" (Heidegger 1977: 129). In expliziter Synthetisierung der Positionen Meads, Berger/Luckmanns und Luhmanns spricht Iványi hinsichtlich dessen, was Heidegger als "Man" begreift, von einem "generalisierten Dritten" (Iványi 2003: 188). Sprachphilosophisch betrachtet, hat damit die Verwendung des Indefinitpronomens "man" elementare soziale Konsequenzen im Bereich der Normsetzung und -befolgung (vgl. Heringer et al. 1977: 43).
} 
zurück zum Menschen gelangt ${ }^{237}$. Dies geschieht in erster Linie durch den "ontogenetischen Prozess" (Berger/Luckmann 1980: 140) der Sozialisation, d.h. durch eine "grundlegende und allseitige Einführung des Individuums in die objektive Welt einer Gesellschaft oder eines Teiles einer Gesellschaft". (ebenda: 140f.)

Insbesondere die qua Sozialisation und damit zu einem Großteil über Legitimation bewirkte Internalisierung gesellschaftlicher Werte und Normen ${ }^{238}$ wird von Berger/Luckmann sehr anschaulich beschrieben: "Der entscheidende Schritt wird getan, wenn das Kind erkennt, daß jedermann etwas gegen Suppeverschütten hat." (Berger/Luckmann 1980: 143) Sozialisation operiert vorwiegend sprachlich und "domestiziert" gewissermaßen den Erfahrungsbereich des Einzelnen in Richtung kollektiv akzeptierter Ordnungen einer Gemeinschaft; Deutungsmuster erhalten so Verbindlichkeitscharakter. Das so internalisierte Wissen ist insofern objektiv, als die in einer bestimmten Gesellschaft sozialisierten Individuen gelernt haben, "die Welt im Lichte dieses Wissens zu interpretieren." (Preglau 1997: 80) In diesem Sinne wurde oben unter Verweis auf Wittgenstein auf den sozialen Charakter von Sprache und Bedeutung verwiesen: Über sprachliche Bezeichnungen werden kollektive Sichtweisen auf Dauer gestellt und sozial kodifiziert. "Sprache ist das Behältnis, das unseren sozialen Wissensvorrat aufbewahrt." (Münch 2003: 212)

Die Sprache nimmt auch hinsichtlich der Internalisierung eine zentrale Position ein, weil alle Objektivationen ausschließlich hierüber subjektiv erfahrbar, repräsentierbar und speicherbar werden. "Als Sprache und mittels Sprache werden beliebige institutionell festgesetzte Begründungs- und Argumentationszusammenhänge internalisiert." (Berger/Luckmann 1980: 145) Rollenadäquates Handeln setzt die Befolgung der innerhalb gesellschaftlicher Teilbereiche vorherrschenden Sprechweise voraus, womit das individuelle, sprachlich vorliegende Wissen von der Welt nicht lediglich als privates, sondern ebenso als gesellschaftliches Wissen anzusehen ist. Man weiß, was in einer bestimmten Situation von einem erwartet wird und kann so entsprechende Handlungsselektionen vornehmen. Haben wir etwa eine Situation sprachlich als "Hilfeleistung" typisiert, so lässt sich unter Beachtung der kontextspezifischen Semantik das gesellschaftlich angemessene Rollenverhalten ableiten.

\footnotetext{
237 Gleichwohl finde ich die Bezeichnung "Zurückholen" etwas irreführend, da das internalisierende Subjekt zumeist nicht der Agent jener Externalisierung war, die es nun verinnerlicht. Es kann also allenfalls als Gattungswesen etwas "zurückholen". Bei Durkheim (1999: 105) heißt es dementsprechend mit Blick auf Externalisierungen aus dem religiösen Bereich: "Ebenso hat der gläubige Mensch die Bräuche und Glaubenssätze seiner Religion bei seiner Geburt fertig vorgefunden. Daß sie vor ihm da waren, setzt voraus, daß sie außerhalb seiner Person existieren."

238 Diese Internalisierung führt dann zu dem, was Freud innerhalb seines Strukturmodells der Persönlichkeit als das "Über-Ich" kategorisiert.
} 


\section{Zusammenfassung}

Abschließend soll das Zusammenwirken der beschriebenen Komponenten nochmals übersichtlich dargestellt werden.

Abbildung 8: Berger/Luckmanns Ontologie institutioneller Tatsachen

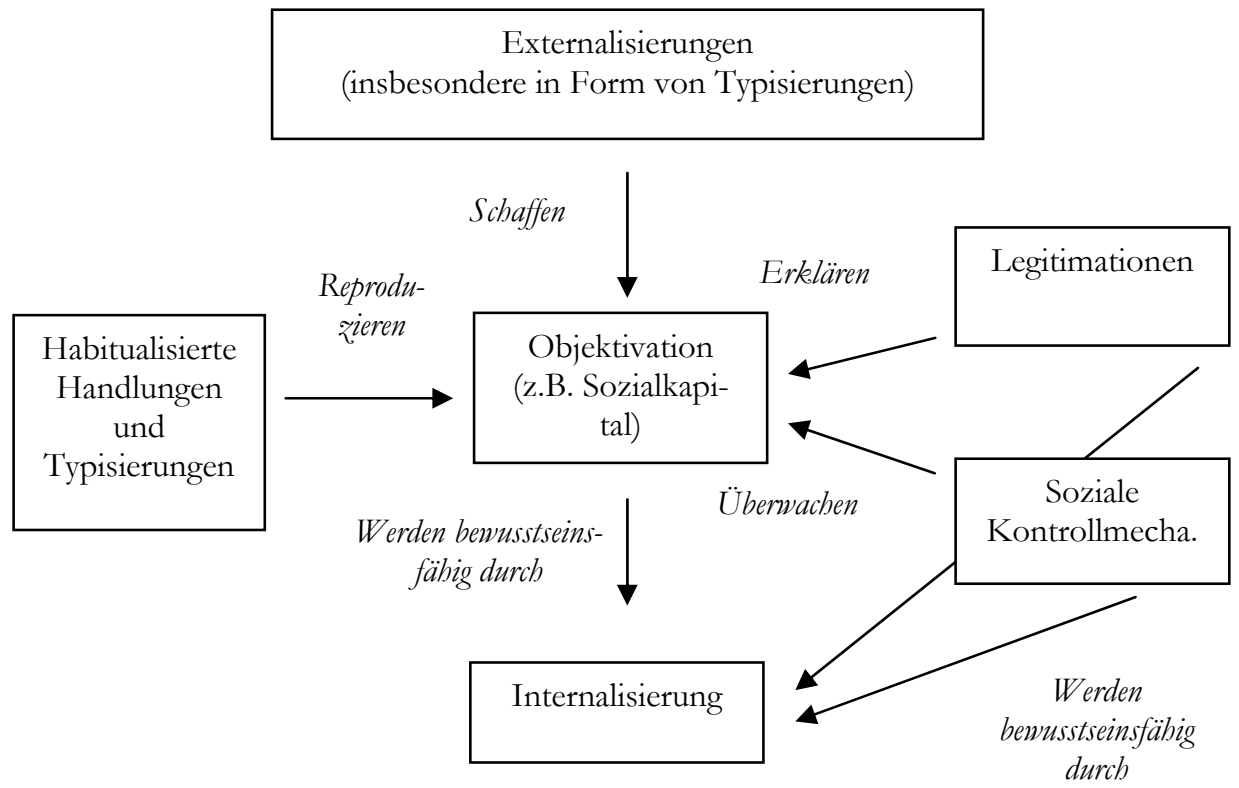

Soziale Wirklichkeit ist Resultat historischer wie aktueller Prozesse menschlicher, symbolischer Selbstentäußerungen (Externalisierungen). Diese bringen Produkte objektiven Charakters, also Objektivationen, hervor, welche zu einer intersubjektiv erfahrbaren, nicht weiter hinterfragten gesellschaftlichen Ordnung gerinnen. Institutionen und soziale Rollen sind Sonderfälle dieser Objektivationen, die kollektiv verbindliche Deutungsmuster darstellen, welche über Sozialisation von den Individuen internalisiert und durch reziproke Typisierungen von Situationen und Personen sowie habitualisierte Handlungen produziert, eingeübt und reproduziert werden. Gleichwohl bedürfen sie der Erklärung und Rechtfertigung - also der Legitimation - sowie der sozialen Kontrolle damit ihre Geltungsansprüche aufrechterhalten bleiben. 


\subsection{Der Bedeutungskonstruktivismus}

\section{Komplementarität der Ontologien}

Da ich - wie bereits in der Einleitung angemerkt - die vorgestellten Konstruktivismen als komplementär erachte ${ }^{239}$ und aus beiden "Angeboten" auswählen möchte, spreche ich der Einfachheit halber nur von einem "Bedeutungskonstruktivismus". Sowohl bei Berger/Luckmann wie bei Searle geht es um die menschliche Konstruktion der sozialen bzw. institutionellen Wirklichkeit. Während im ersten Fall der Fokus vorrangig (insbesondere in den späteren Arbeiten Luckmanns) auf kommunikativen Aushandlungsprozessen liegt, rückt Searle die vom einzelnen Bewusstsein unabhängigen sprachlogischen Tiefen- bzw. Regelstrukturen der Alltagswelt in den Mittelpunkt. Eine konkrete Handlung in Form eines explizit ausgeführten Sprechaktes ist keineswegs das, was den Sprachphilosophen interessiert. Vielmehr werden gewissermaßen die konstitutiven bzw. notwendigen und allgemeinen Spielregeln aufgedeckt, im Rahmen derer die Akteure unterschiedliche Formen objektiver institutioneller Wirklichkeit handelnd hervorbringen können. Die Sprachphilosophie zeigt insofern den Geltungsbereich möglicher wirklichkeitsschaffender sozialer Praktiken (im Sinne des Sozialkonstruktivismus) auf, indem sie auf die sprachlogischen Voraussetzungen aufmerksman macht, unter denen diese Praktiken überhaupt "funktionieren" können ${ }^{240}$.

Hinter dieser Formulierung verbirgt sich einerseits die auf Saussure zurückgehende Dualität von a) Sprache als System und b) Sprechen als tatsächliche kommunikative Operation sowie andererseits die zwischen c) einer Kantschen Analytik des reinen Verstandes, bei der es im vorliegenden Zusammenhang um

\footnotetext{
239 Searle selbst sieht eine solche Komplementarität augenscheinlich nicht: "I was not in fact responding to nor was I inspired by Berger and Luckmann's book The Social Construction of Reality. In fact I never heard of that book until the first draft of my book was done. After my Kant lectures in Stanford, various people pointed out to me that there already was a book with a related title. I looked at that book, but found it so totally different from what I was attempting to do that I neither made use of it nor referred to it." (Searle 1997b: 106f.) Umgekehrt betont Luckmann, die Phänomenologie der Lebenswelt sei keinesfalls "ein Anverwandter analytischer Philosophie in kontinentaler Verkleidung" (Luckmann 1980: 49).

240 Bei dieser Argumentation handelt es sich um eine ontologisch gewendete Interpretation der Bourdieuschen Einschätzung hinsichtlich des erkenntnistheoretischen Verhältnisses von Saussurescher Semiologie und Schützscher Phänomenologie. Saussures Semiologie erinnere daran, "daß ein unmittelbares Verstehen dann und nur dann möglich ist, wenn die Handelnden sich objektiv einig sind, beim selben Zeichen, Sprechakt, Handeln dieselbe Bedeutung und bei derselben Bedeutung dasselbe Zeichen zu assoziieren, bzw. sich bei ihren Chiffrier- und Dechiffrieroperationen auf ein und dasselbe System konstanter Relationen zu beziehen, die vom Willen des Bewußtseins des einzelnen unabhängig sind und auch nicht auf ihre Ausführung in Form von Praktiken oder Werken (beispielsweise Sprache als Code oder Chiffre) reduziert werden können. Doch widersprechen sie damit eigentlich nicht der phänomenologischen Analyse der Primärerfahrung der Sozialwelt als eines unmittelbaren Verstehens, sondern definieren lediglich deren Geltungsgrenzen durch Festlegung der besonderen Bedingungen, unter denen dieses Verstehen möglich ist (nämlich vollkommene Deckungsgleichheit der Chiffren zum Verschlüsseln und Entschlüsseln) und von denen die phänomenologische Analyse nichts weiß." (Bourdieu 1993: 51f.)
} 
die allgemeinsten sprachlichen Grundsätze der institutionellen Welt geht, und d) einer Analytik des (wie ich sagen möchte) sozio-historischen Verstandes, der für die konkreten Erscheinungsweisen und Varianzen dieser institutionellen Welt verantwortlich zeichnet.

Im Sozialkonstruktivismus wird gerade jener soziale, historische und mithin kulturelle Kontext, der in sprechakttheoretischen Überlegungen so entscheidend zur (illokutionären) Bedeutung von Aussagen beiträgt unter die Lupe genommen also das, was Searle an anderer Stelle auch als "Hintergrund" beschreibt (Searle 1997a: 139ff.), ohne sich doch vertieft um die konkrete Ausgestaltung und insbesondere die Bedingtheiten dieses Hintergrundes zu kümmern ${ }^{241}$. Gleichwohl wird dieser in Form des K-Terminus, also insbesondere der normativen Kontextbedingungen, unter denen es zu einer bestimmten Bedeutungszuweisung überhaupt erst kommen kann, innerhalb der Searleschen Ontologie berücksichtigt, denn die formale Logik muss ja an irgend einer Stelle mit empirischen Inhalten in Verbindung gebracht werden, soll sie über die institutionelle Wirklichkeit informieren.

So kann etwa ein bestimmtes Stück Papier nur deshalb als Zahlungsmittel in den USA gelten, wenn es bestimmte materielle Charakteristika aufweist und auf Geheiß des US-Schatzamtes vom Bureau of Engraving and Printing ausgegeben wurde $^{242}$ (vgl. Searle 2001: 154). Auf Basis dieses Hinweises wird aber Searles Konzeption des K-Terminus von mir insofern modifiziert, als eben - auf das genannte Beispiel bezogen - gerade nicht "in den USA" (wie Searle selbst suggeriert), sondern vielmehr die normativen Bedingungen in ihrer versprachlichten Form den K-Terminus darstellen: "Ein bestimmtes Stück Papier" (X) zählt als "Zahlungsmittel in den USA243"; dies unter der Bedingung "das Stück Papier wurde auf Geheiß des US-Schatzamtes vom Bureau of Engraving and Printing ausgegeben" (K). X zählt als $\mathrm{Y}$ in $\mathrm{K}$ ist insofern als $\mathrm{X}$ zählt als $\mathrm{Y}$ unter der Bedingung $\mathrm{K}$ zu lesen.

Die Ontologien Berger/Luckmanns sowie Searles sind - wie schon gesagt nicht Resultat einer systematischen empirischen Analyse. Dies können sie schon alleine in Folge des Umfanges, der Beschaffenheit und der Zugänglichkeit ihres Objektbereiches sowie des konzeptionellen Abstraktionsgrades gar nicht sein. Sie sind dennoch empirisch in dem Sinne, als sie auf einem Mix aus erfahrungswissenschaftlichen Forschungsergebnissen sowie sprachlicher und logischer Analyse beruhen (vgl. hierzu exkursartig Kapitel 5.7.).

${ }^{241}$ Soziologisch könnte man hier auch von sozialen Restriktionen bzw. Ermöglichungsstrukturen reden.

242 Daneben ist aber noch eine ganz komplexe Infrastruktur erforderlich, die ebenfalls zu diesem notwendigen Hintergrund zählt; diese beinhaltet z.B. Waren, Käufer, Staatsdiener, Rechtsverstöße, Zahlungsmodalitäten, Tauschhandlungen etc.

243 Aber eben nicht nur dort, denn der Dollar wird bekanntermaßen nahezu weltweit als Zahlungsmittel akzeptiert; vor diesem Hintergrund wäre es wenig plausibel, wollte man "in den USA" als KTerminus festlegen. 
Im Gegensatz zu Berger/Luckmann und Searle beanspruche ich im Anwendungsteil dieser Arbeit jedoch nicht, eine umfassende Ontologie sozialer Realität vorzulegen. Vielmehr richtet sich der Fokus auf nur einen Ausschnitt, nämlich Sozialkapital. Dabei unterstelle ich zunächst die Angemessenheit der präsentierten Ontologien und versuche zu klären, wie auf deren Basis nun eine gegenstandsspezifische Ontologie über Sozialkapital aussehen könnte. Ich sage "könnte", weil sich unter Zugrundelegung anderer allgemeiner Ontologien andere Analysen für Sozialkapital ergeben würden. Wenn man so will, wird Sozialkapital von mir in der Diktion des wissenschaftstheoretischen Strukturalismus zu einer paradigmatischen intendierten Anwendung des Bedeutungskonstruktivismus gemacht.

Die Festlegung dessen, was "Sozialkapital" bezeichnen und damit was Sozialkapital sein soll, wurde und wird nun in den Wissenschaften vorgenommen, d.h. "Sozialkapital" ist zunächst als T-theoretischer Term aufzufassen und damit innerhalb theoretischer Aussagensysteme zu untersuchen. Der metatheoretische "Umweg" wird gegangen, um letztlich nach wie vor die Alltagsgwelt zu projektieren; jene Alltagswelt, die eben ganz im Sinne der Methodologie des Sozialkonstruktivismus als "auf die Teilnehmerebene hin relativiert" betrachtet wird ${ }^{244}$ (Knorr-Cetina 1989: 92).

\section{Verfügbarmachung der Ontologien}

Searle möchte mit seinem Ansatz ein Antwort auf die Frage geben, wie wir basierend auf (sowie unter Beibehaltung) einer naturalistischen Ontologie zur Existenz gesellschaftlicher Tatsachen gelangen können. Wissenschaftstheoretisch betrachtet, handelt es sich um ein logisches Modell über die sprachlichen Konstruktionsprinzipien sozialer Realität. Searle bietet ein formales Schema jener logischen Begriffsreihen, in Folge derer ein sprachlich konstituierter Gegenstand wie etwa Sozialkapital - als Bedingtes entstehen kann ${ }^{245}$.

Die zentralen Begrifflichkeiten der Searleschen Ontologie sozialer/institutioneller Tatsachen lassen sich in Form von Postulaten nochmals übersichtlich wie folgt darstellen:

1. Institutionelle Wirklichkeit $\left(\mathrm{W}^{\mathrm{i}}\right)$ basiert auf der menschlichen Fähigkeit zur Intentionalität und zur sprachlichen Repräsentation.

\footnotetext{
244 Was gleichwohl nicht impliziert, im Anwendungsteil dieser Untersuchung würde nun eine ethnographische Studie durchgeführt. Vielmehr wird eine weit abstraktere Analyseebene gewählt.

245 Mit der Gewichtung der Logik geht Searle zugleich auch über seinen Lehrer Austin hinaus. Austin ging es in erster Linie um Gelingensbedingungen für Sprechakte; Searle hingegen versucht ein Regelsystem zu etablieren, das weite Teile sozialer Realität in seiner konstitutiven Logik erfassen kann. "Damit nähert er sich, wenngleich sein Gegenstand weiterhin die natürliche Sprache ist, tendenziell der Philosophie der Idealsprache an." (Lueken/Raatzsch 1999: 1236)
} 
2. Die konstitutive Regel, die zur Entstehung einer institutionellen Tatsache (als Teil der institutionellen Wirklichkeit) führt, folgt der allgemeinen Formel "X zählt als $\mathrm{Y}$ in $\mathrm{K} "$.

3. Damit ein $\mathrm{X}$ als $\mathrm{Y}$ in $\mathrm{K}$ zählen kann, muss dem $\mathrm{X}$ eine Bedeutung zugewiesen werden ( $\mathrm{Bz}[\mathrm{Bz}=$ Bedeutungszuweisung]).

4. Eine Bedeutungszuweisung bedarf der kollektiven Intentionalität ${ }^{246}$ (I), da anderenfalls die Ebene des Sozialen unterlaufen würde, und sie muss in einem bestimmten Kontext Akzeptanz (Ak) beanspruchen können.

5. Um die Komplexität institutioneller Tatsachen $\mathrm{zu}$ steigern, wird eine Iterierung (It) der Formel X zählt als Y in K erforderlich.

6. Um den Fortbestand institutioneller Tatsachen zu sichern, müssen einmal zugewiesene Bedeutungen kontinuierlich anerkannt bleiben (An $[\mathrm{An}=$ kontinuierliche Anerkennung]).

Das substantielle Axiom, also der von Searle angeführte zentrale Zusammenhang seiner Ontologie, lautet ${ }^{247}$ :

Für alle $\mathrm{X}$ gilt: Wenn einem $\mathrm{X}$ eine Bedeutung zugewiesen wurde $(\mathrm{Bz}[x])$, für die wiederum gilt, dass sie über kollektive Intentionalität erfolgte $(\mathrm{I} / b z /)$ und innerhalb eines spezifizierbaren Kontext Akzeptanz beanspruchen kann ( $\mathrm{Ak}\left[b_{z}, k_{3}\right)$, dann zählt X als Y. Y ist Element der institutionellen Wirklichkeit (und zwar so lange, wie die Bedeutungszuweisung kontinuierlich anerkannt bleibt). In formaler Schreibweise:

$\forall(x) \quad(\mathrm{Bz}[x] \wedge \mathrm{I}[b z] \wedge \mathrm{Ak}[b z, k]) \rightarrow \mathrm{x}=\mathrm{y}\left(\text { wobei } \mathrm{y} \in \mathrm{W}^{\mathrm{i}}\right)^{248}$

Ein Problem der Searleschen Ausführungen im Hinblick auf den Einsatz als Analyseschema im Rahmen des Anwendungsteils der vorliegenden Untersuchung besteht nun darin, dass Searle seine eigene Analyse vor allem mit Blick auf bekannte alltagsweltliche Sachverhalte durchführt (bestimmte Sprechakte in

\footnotetext{
246 Also der Intentionalität von mehreren Personen bspw. in der Form "Wir wollen das Spiel gewinnen" (vgl. die diesbezüglichen Ausführungen in Kapitel 5.4.).

247 Ich verzichte an dieser Stelle auf eine vollständige strukturalistische Rekonstruktion der Ontologie Searles (und später auch der Berger/Luckmanns), da dies hier sachlich nicht notwendig ist. Einzig das substantielle Axiom wird angeführt.

${ }^{248}$ Hierbei handelt es sich um eine prädikatenlogische Formalisierung. Über eine Subjektvariable $(\mathrm{X})$ wird mithilfe einer Prädikatenvariable $(\mathrm{Bz})$ etwas ausgesagt (dass nämlich $\mathrm{X}$ die Eigenschaft besitzt, dass ihm eine Bedeutung zugewiesen wurde). Subjektvariablen werden innerhalb des Ausdrucks klein-, Prädikatenvariablen großgeschrieben. Fungiert $\mathrm{Bz}$ zunächst als Prädikatenvariable, so transformiere ich sie im gleichen Ausdruck in eine Subjektvariable, über die prädiziert wird - nämlich dass die Bedeutungszuweisung die Eigenschaft besitzt, über kollektive Intentionalität zu erfolgen sowie in einem bestimmten Kontext Akzeptanz beanspruchen zu können. Die Verwendung von Ausdrücken sowohl als Subjekt- wie als Prädikatenvariable ist logisch unbedenklich: "Zum Beispiel kann der Begriff Mensch, der in dem Satz 'Der Mensch ist vernünftig' als Subjekt verwendet wird, in anderen Sätzen auch als Prädikat ('ist menschlich') auftreten: z.B. 'Herr Müller ist ein Mensch." (Zoglauer 1999: 72)
} 
Gegenwart eines Standesbeamten zählen als Eheschließung, ein Stück Papier mit dem Aufdruck "5 Dollar" zählt als Zahlungsmittel in den USA, ein touchdown zählt so und so viele Punkte in einem Footballspiel etc.). Über die Bedeutung der von Searle benutzten Begriffe zur Illustration seiner Argumentation ("Geld", "Ehe", "touchdown" etc.) dürften wenige Missverständnisse bestehen. Hingegen ist "Sozialkapital" zunächst einmal ein theoretisches Konstrukt zur Systematisierung realweltlicher Zusammenhänge. Eine ontologische Bestimmung setzt insofern die Beschäftigung mit wissenschaftlichen Aussagensystemen voraus, was dann in die Elaborierung eines integrativen Theoriemodells mündet. Auf Basis der darin getroffenen Begriffsfestlegung kann dann erst eine ontologische Auseinandersetzung mit dem bezeichneten Gegenstand vorgenommen werden.

$\mathrm{Zu}$ klären ist, wie Sozialkapital zu einer institutionellen Tatsache wird. Für alle $\mathrm{X}$ gilt nach Searle, sie werden ein $\mathrm{Y}$ und damit ein Teil der institutionellen Wirklichkeit, wenn einem X eine Bedeutung zugewiesen wurde, für die wiederum gilt, dass sie über kollektive Intentionalität erfolgte und innerhalb eines spezifizierbaren Kontext Akzeptanz beanspruchen kann. D.h.:

welchen Entitäten $(\mathrm{X})$ wird

über kollektive Intentionalität (I)

die unter bestimmten Bedingungen $(\mathrm{K})$ akzeptierte (Ak)

Bedeutung zugewiesen $(\mathrm{Bz})$,

als Sozialkapital (Y)

zu zählen? Ferner ist von Interesse,

- $\quad$ in Folge welcher Iterierungen (It) es dazu kommt und

welche Form kontinuierlicher Anerkennung (An) zum Fortbestand (und zur Akkumulation) von Sozialkapital beiträgt?

Ziel der Berger/Luckmannschen Überlegungen ist eine Antwort auf die Frage, was Menschen in ihrem Alltag als Wissen über die Welt - und damit als "Wirklichkeit" - begreifen und wie sie dazu gelangen. Methodisch geht es im Anschluss daran um "die Rekonstruktion der sinnkonstituierenden Alltagspraktiken" (Knoblauch/Raab/Schnettler 2002: 34). Damit kann der soziologische Ansatz wissenschaftstheoretisch als Realmodell über die sozialen Mechanismen der Konstruktion gesellschaftlicher Realität gefasst werden.

Die zentralen Begrifflichkeiten dieser Ontologie lassen sich nun auch in Form von Postulaten darstellen: 
1. Institutionelle Wirklichkeit $\left(\mathrm{W}^{\mathrm{I}}\right)^{249}$ ist Resultat historischer wie aktueller Prozesse menschlicher, symbolischer Selbstentäußerungen $(\mathrm{E}=$ Externalisierungen).

2. Externalisierungen bringen menschliche Produkte objektiven Charakters $(\mathrm{O}=$ Objektivationen) hervor, welche zu einer intersubjektiv erfahrbaren, nicht weiter hinterfragten gesellschaftlichen Ordnung gerinnen.

3. Institutionen (Ins) und soziale Rollen (Rs) sind Sonderfälle dieser Objektivationen.

4. Objektivationen stellen kollektiv verbindliche Deutungsrahmen dar, die über Sozialisation von den Individuen kollektiv internalisiert $\left(\mathrm{In}^{\mathrm{kol}}\right.$ ) (die Internalisierung des Einzelnen würde als In ${ }^{\text {sing }}$ symbolisiert) und

5. durch reziproke Typisierungen von Situationen $\left(\mathrm{T}^{\mathrm{S}}\right)$ und Personen $\left(\mathrm{T}^{\mathrm{P}}\right)$ sowie habitualisierte Handlungen $(\mathrm{H})$ produziert, eingeübt und reproduziert werden.

6. Gleichwohl bedürfen sie der Erklärung und Rechtfertigung - also der Legitimation (L) - sowie der sozialen Kontrolle (Ks) damit ihre Geltungsansprüche aufrechterhalten bleiben.

Nun gilt es erneut, das substantielle Axiom, also den von Berger/Luckmann angeführten zentralen Zusammenhang ihrer Ontologie, zu benennen:

Objektivationen sind das Ergebnis menschlicher Externalisierungen $(E \rightarrow O)$. Für alle Objektivationen gilt: Wenn sie kollektiv internalisiert sind und wenn für sie (wirksame) Legitimationen und soziale Kontrollmechanismen existieren, dann können sie als Teil der institutionellen Wirklichkeit angesehen werden. In formaler Schreibweise:

$\forall(0) \quad\left(\operatorname{In}^{\mathrm{kol}}[0] \wedge \mathrm{L}[0] \wedge \mathrm{Ks}[0] \rightarrow \mathrm{o} \in \mathrm{W}^{\mathrm{I}}\right)$

Damit liegen nun die Sortierungskriterien für die gegenstandsbezogene Fallanalyse vor. Wie wird (die Objektivation) Sozialkapital also Teil der institutionellen Wirklichkeit, d.h.:

welche symbolisch vermittelten Externalisierungsprozesse (E) und insbesondere

reziproken Typisierungen von Situationen $\left(\mathrm{T}^{\mathrm{S}}\right)$ und Personen $\left(\mathrm{T}^{\mathrm{P}}\right)$ (also situationsspezifische Festlegungen sozialer Rollen [Rs]) setzt die Bildung von Sozialkapital $(\mathrm{O})$ voraus,

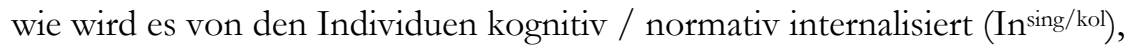

249 Wie schon erläutert, verwende ich bei Searle und Berger/Luckmann den gleichen Terminus, da es in beiden Fällen nur um diesen bestimmten Teil sozialer Wirklichkeit geht. 
welche habitualisierten Handlungsabläufe $(\mathrm{H})$ (verstehbar als eingeübte Interaktionsschemata) führen zu seiner Existenz oder dienen der Aufrechterhaltung eines bestehenden Kapitalstocks,

welche Legitimationen (L) führen dazu, dass es "eingefordert" resp. "geschuldet" werden kann,

welche sozialen Kontrollmechanismen (Ks) sorgen dafür, dass es auch zur "Auszahlung" gelangt (dass etwa Verpflichtungen auch als Hilfestellungen eingelöst werden)?

\subsection{Exkurs: Zur ontologischen Argumentationsweise}

Betrachtet man die Vorgehensweisen Berger/Luckmanns und Searles aus der Perspektive des einheitswissenschaftlich orientierten empirischen Sozialforschers, so könnte man in einer ersten Polemik u.U. behaupten: Die Autoren denken vor dem Hintergrund einer beachtlichen Belesenheit scharf nach ${ }^{250}$. Handelt es sich dann aber nicht um nach innen gerichtete Wahrnehmung, Selbsterfahrung, die Perspektive der ersten Person, eigenwillige Introspektion - oder wie immer man es auch nennen möchte -, was zu nicht belegbaren Aussagen führt ${ }^{251}$ ? Ist es nicht "unmöglich, durch reines Nachdenken und ohne eine empirische Kontrolle (mittels Beobachtungen) einen Aufschluss über die Beschaffenheit oder die Gesetze der wirklichen Welt zu gewinnen" (Stegmüller 1978: 346)? Nachfolgend möchte ich in Form eines methodologischen Exkurses diskutieren, was Searle und Berger/Luckmann genau tun und inwiefern sich ihre Problemstellungen und dazugehörigen Lösungsversuche insbesondere auf die Analyse von Bedeutung als Bedingung der Möglichkeit von Sozialkapital übertragen lassen.

Searle geht in der Tradition Brentanos davon aus, dass sich menschliches Bewusstsein immer auf etwas bezieht, dass es grundsätzlich Bewusstsein von etwas und also intentional ist. Was, so fragt er hierauf fußend, stellen Menschen

250 Mit Holm Tetens (2004: 15) können wir dies freilich auch schon zu Beginn der nun folgenden Reflexionen als gänzlich unproblematisch ansehen: "Philosophen denken nach und schlussfolgern aus dem, was sie aus dem Alltag und aus der Lektüre wissenschaftlicher Bücher wissen."

251 Ist es überhaupt möglich, unser inneres Erleben bzw. unsere inneren Vorstellungen wie Äußeres wahrzunehmen? Wenn es zur Wahrnehmung von Äußerem einer Synthese von Anschauung und Verstand bedarf, was ist denn dann hier die Anschauung? Das, was "man so leichthin als 'Introspektion' oder 'innere Wahrnehmung' zu bezeichnen pflegt und damit auch schon zu verstehen meint, erweist sich damit als ein schwerwiegendes Problem" (Prauss 1993: 73). Prauss hält es für unzulässig, von Anschauungen über eigene innere Anschauungen zu sprechen, zumal dies in einen infiniten Regress münden müsste. Andererseits wird in der kognitiven Psychologie aber von Metakognitionen, also Kognitionen über eigene Kognitionen ausgegangen, wobei dann die Metakognition die Wahrnehmung der Kognition voraussetzt. Ob man dabei freilich in einem erkenntnistheoretischen Sinne von "Anschauung" sprechen darf, mag hier dahingestellt bleiben. Abgestritten werden soll indes die von Micko (2001: 66) im Anschluss an den Radikalen Konstruktivismus aufgestellte Behauptung, es sei möglich, das Bewusstsein "theoriefrei zu studieren", insofern man nur eine "bedürfnislose und sorglose, kontemplative oder meditative Haltung" einnehme. 
mit dieser Intentionalität an bzw. genauer: Wie kommt es qua Intentionalität zu institutioneller Wirklichkeit? Diese Frage wird nun zumindest partiell über Introspektion beantwortet; eine empirische Untersuchung im soziologischen Sinne führt Searle jedenfalls genauso wenig durch, wie eine ausschließlich logische Analyse. Auch wenn die Welt für den Menschen nur über Bewusstsein zugänglich ist, macht es methodologisch betrachtet einen erheblichen Unterschied, ob man zu Aussagen allein auf Basis von Nachdenken oder Plausibilitätserwägungen oder aber durch systematische, kontrollierbare Beobachtung im Sinne des empirischanalytischen Wissenschaftsansatzes gelangt ${ }^{252}$. Oder ist es im Kontext ontologischer Fragen zur sozialen Realität erforderlich, auf phänomenologische Überlegungen Bezug zu nehmen ${ }^{253}$ ?

\section{Phänomenologische Argumentation}

Zur Beantwortung dieser Frage ist zunächst einmal zu klären, was es mit einer phänomenologischen Analyse überhaupt auf sich hat. In der Philosophie stellt die Phänomenologie u.a. eine methodische Strategie dar, um zu einer gewissermaßen "ungetrübten" Erkenntnis über die Gegenstände vorzustoßen ${ }^{254}$ : "Die Sache selbst müssen wir befragen." (Husserl 1910/11: 305) Sehen wir bspw. einen Stuhl, so sind es keineswegs unsere bloßen Sinneseindrücke, die diese Erscheinung ermöglichen. Vielmehr nehmen wir über unser Bewusstsein auf eine Bedeutungs-

${ }^{252}$ Freilich ist diese systematische, kontrollierbare Beobachtung auch nur eine dank und durch Bewusstsein stattfindende. Sie betont gleichwohl die intersubjektive und kommunikative Dimension des Forschungsprozesses. Im erkenntnis- und wissenschaftstheoretischen Grundlagenteil hatte ich überdies schon darauf verwiesen, inwiefern man auch im Rahmen eines strukturalistischen Wissenschaftsverständnisses aus pragmatischen Gründen an zentralen positivistischen Überlegungen zur Erkenntnisproduktion festhalten sollte.

253 Berger/Luckmann gründen ihr Konzept auf empirische Plausibilitäten über Vorgänge in der Alltagswelt und sprechen hinsichtlich ihrer Arbeit von einer "phänomenologischen Analyse" (Berger/Luckmann 1980: 22). Luckmann nennt das Ergebnis dann eine "deskriptive Phänomenologie der invarianten alltagsweltlichen Strukturen" (Luckmann 1980: 50). Bei Searle ist die Sachlage weit weniger eindeutig. Mit seiner Betonung von Intentionalität und Funktions- bzw. Bedeutungszuweisung sehe ich Searle jedoch zumindest partiell durchaus in phänomenologischer Tradition (eine ähnliche Sichtweise findet sich u.a. bei Eley 1974, Crosby 1990, Apel 1991 und Johansson 2003). "Searle spricht in der Regel zwar nur von Bewußtsein und nicht von phänomenalen Bewußtsein. Aus seinen Formulierungen geht aber deutlich hervor, daß er unter Bewußtsein eigentlich immer phänomenales Bewußtsein versteht." (Beckermann 1999: 280, Fußn. 30)

254 Die Interpretation von Phänomenologie als eine bestimmte Methode wird sicherlich vieler ihrer Wendungen nur unzureichend gerecht, wenngleich Plessner meint, Husserls "Phänomenologie war nicht als Lehrgebäude, sondern als Forschungsweise angelegt." (Plessner 1979: 45) Für Heidegger indes fiel die Phänomenologie nicht nur mit der Ontologie zusammen, sie war durch diese Synthese auch Philosophie schlechthin: "Ontologie und Phänomenologie sind nicht zwei verschiedene Disziplinen neben anderen zur Philosophie gehörigen. Die beiden Titel charakterisieren die Philosophie selbst. Philosophie ist universale phänomenologische Ontologie." (Heidegger 1977: 49) Und bei Sartre heißt es ganz in diesem Sinne: "Denn das Sein eines Existierenden ist genau das, als was es erscheint. So gelangen wir zur Idee des Phänomens, ..., oder Relativ-Absoluten. Relativ bleibt das Phänomen, denn das 'Erscheinen' setzt seinem Wesen nach jemanden voraus, dem etwas erscheint." (Sartre 1991: 10) 
einheit Bezug, welche sprachlich als "Stuhl" repräsentiert wird. Die "Sache selbst" ist viel mehr bzw. anders, als das, was uns alleine über die Sinneskanäle zugänglich wird.

Bis hierhin deckt sich diese Perspektive durchaus noch mit den Erörterungen im Kontext der wissenschafts- und erkenntnistheoretischen sowie ontologischen Grundlagen. Unter Rekurs auf Kant wurde die Propositionalität und Synthetizität aller menschlichen Erfahrung propagiert. Ganz im Sinne einer perspektivistischen Ontologie enthält sich auch die Phänomenologie eines Urteils über die tatsächliche Gestalt der Außenwelt, sie klammert diese sozusagen aus, setzt sie - so der Fachterminus - in "Epoché", weil Menschen eben keinen direkten Zugang zu ihr haben können. Nach dieser "methodischen Sistierung der Erfahrungsgewißheiten und des unreflektierten Glaubens an die Vorgegebenheit der Welt" (List 1983: 56) behaupten Phänomenologen dann in cartesianischer Tradition die Existenz elementarer, unzweifelhaft gegebener Bewusstseinsinhalte, die alles Wissen begründen ${ }^{255}$. Phänomene gelten hiervon ausgehend als evident. Wir erkennen sie mit Hilfe sog. "eidetischer Reduktion", d.h. indem wir von einer Erscheinung jene Urteile abziehen, die eben nicht zum Wesen des Phänomens gehören. "Was bleibt, ist also das Bewusstsein als Objekt unserer Betrachtung." (Prechtl 2002: 58) Ein Etwas als Etwas für einen Betrachter wird hierüber expliziert.

So könnte der Leser versuchsweise einmal all jene Komponenten isolieren, die nicht zwangsläufig zur Konstitution des Phänomens "Stuhl" beitragen. Während etwa eine bestimmte Farbe oder eine Armlehne diesbezüglich als irrelevant einzuschätzen sind, erweist sich eine Sitzfläche wohl als unverzichtbar. Für Husserl ist ein solches gedankliches Durchspielen von Variationen "der Weg, auf dem ... alles echte intuitive Apriori gewonnen wird." (Husserl 2003: 72) In der Phänomenologie gelangen Menschen also zur Erkenntnis des "Wesens" der Gegenstände, weil sie mit einer apriorischen Einsicht qua Intuition ausgestattet $\operatorname{sind}^{256}$. Phänomene sind damit nicht empirisch, sondern mit Hilfe einer ganz spezifischen Art des Denkens, zu untersuchen. Eine so nach dem Wesen der Dinge fragende Philosophie versteht sich dann als "'Erste Wissenschaft', denn sie sucht in dieser Frage nicht etwa bloß nach dem bestimmten Grund irgendeines Seienden in seiner zufälligen Erscheinungsform, sondern nach dem ersten Grund des Seienden als eines solchen" (Seibert 1997: 1).

\footnotetext{
255 Hannah Arendt formuliert dies wie folgt: "Da jeder Bewußtseinsakt seinem Wesen nach einen Gegenstand hat, kann ich zum mindesten einer Sache gewiß sein, nämlich daß ich die Gegenstände meines Bewußtseins 'habe'." (Arendt 1990: 7)

${ }^{256}$ Husserl spricht auch von "apodiktischer Evidenz". Diese "hat die ausgezeichnete Eigenheit, daß sie nicht bloß überhaupt Seinsgewißheit der in ihr evidenten Sachen oder Sachverhalte ist, sondern sich durch eine kritische Reflexion zugleich als schlechthinnige Unausdenkbarkeit des Nichtseins derselben enthüllt; daß sie also im voraus jeden vorstellbaren Zweifel als gegenstandslos ausschließt." (Husserl 1963: 56) "Was in seinem Wasgehalt erschaut ist, ist restlos, ohne perspektivische Brechung und ohne symbolische Vermittlung gegeben und kann durch keine außerphänomenologische Erfahrung, ..., erschüttert werden." (Waldenfels 1992: 25)
} 
Diese essentialistische, erkenntnistheoretisch wie ontologisch deutbare Perspektive wird freilich von der analytischen Philosophie so nicht geteilt und in der hier geschilderten Form weder von Berger/Luckmann (allenfalls von Berger in seinen religionssoziologisch-theologischen Schriften) noch von Searle vertreten. Der Versuch, in der metaphysischen Tradition zu unbezweifelbaren Letztbegründungen zu gelangen, führt zu den drei zentralen, von Hans Albert bekanntlich als "Münchhausen Trilemma" bezeichneten, philosophischen Begründungsproblemen: zum logischen Zirkel, zum infiniten Regress oder zum Abbruch des Hinterfragens durch den Verweis auf Evidenz oder ein Dogma ${ }^{257}$ (vgl. Albert 1991: 15).

Berger/Luckmann und Searle rekurrieren dennoch insofern auf die Phänomenologie, als sie um die Sinn- bzw. Bedeutungsklärung von sozialem Sein bemüht sind und sich dabei am Grundsatz der Bedeutungskonstitution qua sprachlich prozessierter Intentionalität - also qua Bewusstsein von etwas - orientieren ${ }^{258}$. Dieser Grundsatz ist im Kontext sozialontologischer Konzeptionen so zentral, weil die Frage nach der Entstehung und der Existenzweise sozialer Tatsachen "aus einer von sich aus sinnleer-natürlichen Welt" (Luckmann 2002: 159) heraus als Frage nach den die Gegenstände begründenden, sprachlich organisierten Bewusstseinsweisen gestellt wird.

Doch darüber hinaus geht es in Weiterführung des geschilderten Grundsatzes in beiden Bereichen insbesondere darum, gegenstandskonstitutive Bedeutung zu rekonstruieren. Und dies ist in erster Linie eine gedankliche Tätigkeit unter Zuhilfenahme empirischer Plausibilität. Wie wollte man bspw. über ein einheitswissenschaftlich ausgerichtetes Forschungsdesign klären, wieso zwischen einem Wurf eines Balles in einen Korb und Symbolen - wie etwa Punkten - eine Verbindung existiert? Zweifellos ist die Historie des Basketballspiels nur empirisch nachzuzeichnen; auch lässt sich auf diese Weise herausfinden, wieso sich einige verantwortliche Funktionäre im Weltbasketball ${ }^{259}$ irgendwann dazu entschlossen haben, einen sehr weiten Wurf eines Balles in einen Korb drei Punkte zählen zu lassen.

\footnotetext{
257 Überdies wird hier suggeriert, Erkenntnis sei theoriefrei zu gewinnen. Nach den bisherigen Erörterungen dürfte deutlich geworden sein, dass dies unmöglich ist. Irle setzt sich daher kritisch mit derartigen Strömungen in der Psychologie auseinander: "Die klassische phänomenologische Psychologie verlangt, daß sich der psychologische Forscher auf Introspektionen seines Bewußtseins konzentrieren solle und daß er sich mit dieser Methode der Introspektion an unmittelbar gegebenes halten solle. Seine Einsichten müßten nicht konzeptualisiert sein; er müße die reinen Bewußtseinstatsachen an sich registrieren, ohne sich selbst durch irgendwelche Inferenzen von abstrakten Kategorien stören zu lassen. Man kann diese strategische Forderung auch ironisch so formulieren, daß er sich frei von jeglichen theoretischen Vorurteilen halten sollte. Er wird aufgefordert, ohne Hypothesen wahrzunehmen." (Irle 1975: 85)

258 Bewusstsein ist dann ein zweistelliges Prädikat, d.h. es ist eben mehr als lediglich eine intrinsische Eigenschaft mentaler Zustände (vgl. Metzinger 1996b: 36f.).

259 Oder waren es Funktionäre der US-amerikanischen National Basketball Association?
} 
Demgegenüber ist jedoch mit den gängigen Methoden empirischer Forschung nicht zu klären, wie es dazu kommen konnte, dass zwischen einem physikalischen Ereignis, wie dem Wurf eines Balles in einen Korb und davon gänzlich unabhängigen Symbolen wie Punkten plötzlich eine Verbindung entsteht. Natürlich ließe sich sagen, dies sei eben Ergebnis eines Aushandlungsprozesses zwischen sinnhaft handelnden Personen gewesen. Fragen wir aber vor dem Hintergrund ontologischer Überlegungen, dann fragen wir nach den Ordnungsschemata die dahinter stecken; wir fragen nach den sprachlich organisierten Bewusstseinsprozessen, die zwischen "Wurf eines Balles in einen Korb" und "zwei Punkte" vermitteln.

Ausgangspunkt ist also ein Etwas als sinnhaft strukturiertes Gegebenes, das nun rekonstituiert wird, indem man die seine Existenz bewirkenden Mechanismen bzw. Zusammenhänge offenlegt, indem man die "invarianten Strukturen jener bewußten Aktivitäten, aus denen sich menschliches Handeln konstituiert" (Luckmann 1980: 44) erhellt. Hierzu werden - methodologisch betrachtet - die Selbstverständlichkeiten der Lebenswelt hinsichtlich der Bedingungen ihrer Möglichkeit hinterfragt (was steckt bspw. dahinter, dass es so etwas wie Punkte in einem Spiel gibt). Bei einer ontologischen Betrachtung zur sozialen Realität handelt es sich in diesem Sinne um eine gedankliche und somit theoretische bzw. begriffliche Untersuchung hinsichtlich von sozialen Regelsystemen konstituierender, sprachlich prozessierter Bedeutung als verborgener, sich nicht der Anschauung zeigender Voraussetzung menschlicher Erfahrung und sozialer Realität.

Da Bedeutung nicht a priori existiert, sondern von Menschen mit konkretem Bezug eingeführt und zugewiesen werden muss, ist diese Form der Ontologie dennoch nicht transzendental. Akzeptiert man einmal, dass in Folge ihrer spezifischen Art der Zugänglichkeit die hier diskutierten Probleme über begriffliche Analysen bearbeitet werden müssen, dass es sich aber zugleich um Probleme der von Menschen geschaffenen Sozialwelt handelt, dann lässt sich aus dem Begriffspaar theoretisch - empirisch keine Spannung ableiten: Die methodische Annäherung an den empirischen Gegenstand erfolgt sprachtheoretisch. Für Castaneda (1982: 25) ist eine ontologische Reflexion daher auch keineswegs "gänzlich apriorisch", denn "wir können mit unseren philosophischen Fragen anhand jedes beliebigen Objektes in dessen empirischen Kontext, ..., beginnen. Aber so zu beginnen heißt, mit empirischen Daten beginnen."

Die Art der Untersuchung ist also bei Berger/Luckmann wie bei Searle insofern immer auch empirisch, als es um die Analyse spezifischer Elemente einer als objektiv vorhanden angenommenen sozialen Wirklichkeit geht. Nur ist das Analyseinstrumentarium nicht die von außen kommende, systematische Beobachtung, sondern das gedanklich-sprachliche Simulieren von zumeist relativ einfach strukturierten Situationen bzw. Gegenständen, an denen dann Denkoperationen vollzogen werden ${ }^{260}$.

260 Ulrich Kühne (2005) rekonstruiert in seinem Buch "Die Methode des Gedankenexperiments" gerade auch die Erkenntnissuche analytischer Philosophen als Gedankenexperiment. Damit ist 
Bei Berger/Luckmann findet sich etwa eine solche Simulation, wenn geschildert wird, ein Mann wache morgens auf und nehme erschrocken zur Kenntnis, dass ein Messer in der Wand über seinem Bett stecke (vgl. Berger/Luckmann 1980: 37). Hierüber wollen die Autoren zum Ausdruck bringen, dass zwar empirisch lediglich ein Messer in der Wand beobachtbar sei, dass darüber hinaus aber dieses Messer auch eine Waffe und damit eine Objektivation einer bestimmten menschlichen Beziehungsstruktur darstelle.

Das Messer in der Wand verweist also auf Waffe als sozialen, über Bedeutung konstituierten Gegenstand. Dieser entzieht sich jedoch - und das ist der entscheidende Punkt - der sinnlichen Wahrnehmung und lässt sich ausschließlich über unser sprachlich strukturiertes Bewusstsein deduktiv herleiten: Wenn der Wurf eines Messers dazu bestimmt war, einen Menschen zu töten, dann kann das Messer in der Wand u.a. als eine Objektivation menschlicher Subjektivität und dies heißt hier der feindschaftlichen Gefühle des Werfers gegenüber seinem vermeintlichen Opfer interpretiert werden. Dies deshalb, weil die Intentionalität des Täters diesen Schluss nahelegt - unmittelbar ansehen kann man dem Messer in der Wand dies keineswegs.

Das Vorgehen zur Beantwortung der Frage, was die Bedingungen der Möglichkeit dafür sind, dass ein Messer in der Wand symbolisch für feindschaftliche Gefühle stehen und damit eine Waffe bedeuten kann, hat also folgendes Aussehen: Zunächst wird von einer bestimmten Sprache ausgegangen, über die sich unterschiedliche Operationen vollziehen lassen und die logischen Verknüpfungen unterliegt. Nun gilt es, die Operationen und Verknüpfungen zu bestimmen, die von "Messer in der Wand" zu "Waffe" führen. Der Gedankengang weist folgende Struktur auf:

Prämisse (bzw. Gesetzesaussage): a) Personen, die auf andere ein Messer werfen, hegen feindschaftliche Gefühle gegenüber diesen anderen; b) bei einem Messer, das jemand auf einen anderen wirft, dem er mit feindschaftlichen Gefühle gegenübersteht, handelt es sich um eine Waffe.

Empirische Situation (bzw. Antecedenzbedingung): A hat auf B ein Messer geworfen, dabei jedoch das Ziel verfehlt und lediglich die Wand getroffen.

Konklusion (bzw. Explanadum): a) A hegt feindschaftliche Gefühle gegenüber B; b) bei dem Messer in der Wand handelt es sich um eine Waffe.

Bedeutung als zentrale Kategorie einer Ontologie sozialer/institutioneller Tatsachen entzieht sich der direkten sinnlichen Wahrnehmung, ist insofern

jedoch nicht eine transzendentale Erkenntnismethode, sondern eine grammatische Untersuchung im Sinne Wittgensteins (vgl. etwa PU \& 90), d.h. eine Ausarbeitung der sprachlichen Gebrauchsregeln, die notwendig sind, wenn wir uns über bestimmte Gegenstände verständigen wollen, gemeint. Hoche/Strube (1985: 178f.) sehen durchaus Parallelen zwischen dem Wittgensteinschen Vorgehen und dem Husserls: "Man möchte dieses (Wittgensteins, D.K.) Verfahren fast als 'sprachanalytische Phantasievariation' bezeichnen, um damit auf die 'phänomenologische Phantasievariation' anzuspielen, die besonders von Husserl gepflegt und thematisiert worden ist". 
anschauungstranszendent ${ }^{261}$. Und dies gewissermaßen in zweifacher Weise: Man kann Bedeutung nicht "sehen" und man überschreitet ein Etwas durch die Zuweisung einer Bedeutung, weist also über dieses Etwas hinaus und etabliert gerade so ein neues Etwas - vom "Messer in der Wand" gelangt man bspw. zu "Waffe". Für den über Bedeutung etablierten Teil sozialer Wirklichkeit lässt sich demnach formulieren, was Chisholm (1996: 35) allgemein für ontologische Probleme behauptet: "By reflecting the nature of ourselves, we can best understand the ultimate categories of reality".

Wenn alle unsere Erkenntnis propositional und synthetisch ist, dann trifft dies auch auf die qua Bedeutungsanalyse gewonnene Erkenntnis über Bedeutung zu (sei es über ihr Zustandekommen oder ihre Wirkungen). Zwar ist schon die Erkenntnis "Da steckt ein Messer über dem Bett in der Wand" propositional und synthetisch (wenn wir jetzt einmal vereinfachend davon ausgehen, hier handele es sich nicht um einen von Berger/Luckmann erfundenen, sondern um einen [im positivistischen Sinne] tatsächlich beobachteten Sachverhalt), die Bedeutung als "Waffe" bzw. als "Feindschaft" ist gewissermaßen eine höherstufige Synthetisierung, da der Verstand hier zusätzliche logische Denkbewegungen auf Basis eines erweiterten Hintergrundwissens durchführen muss ${ }^{262}$.

\section{Sprachanalytische Argumentation}

Sprachanalytische Forschung auf Grundlage einer pragmatischen Bedeutungstheorie darf insofern als an phänomenologischen Überlegungen orientiert gelten, als die aus dem bloßen semantischen Gehalt einer Aussage alleine nicht hervorgehenden Bedeutungsimplikationen des Sprechverhaltens zum Gegenstand werden. So kann etwa ein Kind seinen Eltern mitteilen: "Ich habe eine 1 in Mathematik geschrieben." Der Philosoph der Idealsprache mag nun propagieren, die Bedeutung dieser Aussage verstehe, wer wisse, was damit gemeint ist, wenn die Aussage wahr wäre.

Tatsächlich ist diese assertorische Komponente bzw. die wörtliche, sich ausschließlich aus den verwendeten sprachlichen Mitteln ergebende Bedeutung des

\footnotetext{
${ }^{261}$ Bedeutung selbst ist zwar im klassischen Sinne kein empirisch analysierbares Phänomen, der Akt der (soziologischen) Bedeutungszuschreibung jedoch sehr wohl. Dieser lässt sich mit den Methoden der empirischen Sozialforschung erheben. Im Beispielfall könnte etwa der Messerwerfer hinsichtlich seiner Einstellung zu seinem intendierten Opfer befragt werden oder man betreibt kulturhistorischethnologische Symbolanalysen (vgl. hierzu etwa Geertz 1983; für eine theologische Symbolanalyse vgl. die aus meiner Sicht kanonisch zu nennende, gleichwohl viel zu wenig beachtete Arbeit von Thomas Walter [o.J.], in der es um "die Architektur und Kultsymbolik des ezechielischen Tempels und ihre theologische Bedeutung für die Dimension der Gottesnähe unter besonderer Berücksichtigung von Ez 43, 1-9.10-12" geht).

262 Dies widerspricht nun keineswegs den obigen Ausführungen hinsichtlich der Konstitutionsbedingungen von Bedeutung. Dort wurde festgehalten, dass Bedeutung über einen semantischen Kontext, über die Intentionalität des Bewusstsein, über sozio-linguistische Regelhaftigkeit und über einen sozialen Handlungszusammenhang etabliert wird. Hier hingegen stehen die NichtBeobachtbarkeit der Bedeutung und die daraus resultierenden methodologischen Konsequenzen im Vordergrund.
} 
Satzes hier aber nachrangig. Der Philosoph der Normalsprache bzw. der pragmatische Bedeutungstheoretiker muss den Satz als radikal unterbestimmt bewerten. Aufgrund unserer Alltagserfahrung wissen wir nämlich, dass in der Äußerung des Kindes i.d.R. eine indirekte Aufforderung mitschwingt, und zwar die, für diese Leistung doch bitte belobigt bzw. belohnt zu werden. In der Sprechakttheorie ist diesbezüglich - wie oben bereits dargestellt wurde - von der illokutionären Rolle eines Sprechaktes die Rede; gemeint ist damit jene Reformulierung einer Aussage, welche die "eigentliche" Intention des Sprechers zum Vorschein bringt.

Dieses selbstverständliche Voraussetzen dessen, was mit einer Äußerung eines Sprechers in einer Situation tatsächlich gemeint ist, kann als Form einer eidetischen Reduktion begriffen werden, da die Bedeutung des Satzes sich im genannten Kontext gleichsam unmittelbar erschließt ${ }^{263}$. Der Begründer der Sprechakttheorie John L. Austin spricht selbst von einer "linguistic phenomenology" (Austin zitiert nach Hoche/Strube 1985: 225). Diese unterscheidet sich von der klassischen Variante u.a. darin, dass Erkenntnis nicht als intuitives Erfassen einer irgendwie existierenden Essenz, sondern als kognitiv-sprachliches Begreifen einer sprachlich strukturierten Ordnung konzipiert wird, d.h. "daß man die gesamte Wesenslehre als Wortbedeutungslehre interpretiert und dabei auf die grammatischen Regeln zurückführt." (Wuchterl 1999: 215) Die Phänomenologie wird durch diese linguistische Wendung mit dem wissenschaftlichen Rationalitätspostulat vereinbar, denn deutet man die Gegebenheiten des Bewusstseins sprachlich und damit auch sozial, so wird intersubjektive Verständigung hierüber möglich.

Sicherlich ließe sich die illokutionäre Rolle im angeführten Beispielfall durch Befragung des Kindes und Validierung durch die Meinung der Eltern auch über empirische Methoden ausfindig machen. Ein solcher empirischer Test der sprachanalytischen eidetischen Reduktion - so mag man einwenden - könne doch bspw. zeigen, das Kind hätte lediglich sagen wollen, es habe ohne Vorbereitung eine 1 in Mathematik geschrieben (womit überhaupt keine Erhebung eines Anspruchs auf eine Belobigung bzw. eine Belohnung verbunden sei). Die eidetische Reduktion hätte dann zu einer falschen Behauptung geführt.

Dieser Hinweis ist natürlich berechtigt. Allerdings geht es bei der beschriebenen linguistisch-phänomenologischen Vorgehensweise um eine auf allgemeinabstrakter Ebene begrifflich-formulierte soziale Situation, die im überwiegenden Teil der Fälle - und das erschließt sich scheinbar intuitiv - die behauptete (illokutionäre) Bedeutung hat. Man weiß eben in Folge der innerhalb einer

\footnotetext{
263 Bei Variation der Situation verändert sich auch die Bedeutung des Satzes. In einem Lehrbuch der kognitiven Verhaltenstherapie findet sich diesbezüglich ein sehr anschauliches Beispiel: "Um Ihren Patienten zu demonstrieren, dass Worte selbst keine Gefühle auslösen können, sondern dass es die Bedeutung ist, die sie diesen Worten zuschreiben, lassen Sie laut den folgenden Satz dreimal vorlesen, und zwar mit der Information, der Ort der Handlung sei: 1. im Büro, 2. bei einer Krebsvorsorgeuntersuchung, 3. beim Sex: 'Du kommst zu spät!'" (Stavemann 2003: 34f.)
} 
Sprachgemeinschaft geltenden Konventionen, dass Kinder mittels solcher Formulierungen häufig genau die beschriebene Absicht verfolgen. Der semantische Gehalt von "Ich habe eine 1 in Mathematik geschrieben" alleine reicht nicht aus, um die geschilderte Deutung nahezulegen. Äußerungen sind in "einen Handlungs- bzw. Situationszusammenhang eingebettet; wir haben deshalb auch Kontextindikatoren (z.B. das jeweilige Rollenverhältnis, den institutionellen Rahmen, das Hintergrundwissen usw.) zu berücksichtigen." (Brinker 2001: 91) Ein großer Teil der Botschaft wird nicht mehr explizit ausgedrückt und funktioniert indexikalisch.

Das Hintergrundwissen, welches uns die über den rein semantischen Gehalt von Aussagen hinausgehende Bedeutung erschließt, stellt nun einen Erfahrungswert dar, der auf empirischer (wenn auch sicherlich unsystematischer) Beobachtung oder sozialisationsbedingter Überlieferung beruht. Damit kann aber das, was wir soeben als "intuitiv" bezeichnet haben, nichts Apriorisches sein. Die Vorstellung, es gebe synthetische Urteile apriori bzw. empirische Erkenntnis ohne sinnliche Wahrnehmung (denn genau das ist mit Intuition vielfach gemeint), muss somit auch in diesem Kontext zurückgewiesen werden ${ }^{264}$. Intuition lässt sich damit allenfalls begreifen als das durch eingeübte Beobachtung und Erfahrung ermöglichte, nahezu unmittelbare Erschließen von Bedeutung 265 . Oben hatte ich schon unter Verweis auf die nur vermeintlich unsprachliche und unbewusste Produktion von Bedeutung auf die Akzeptanz und Befolgung konstitutiver (sprachlich bzw. symbolisch eingeführter) Regelsysteme verwiesen; hier geht es nun um das Erkennen bzw. Erschließen dieser Systeme, d.h. um den korrekten Umgang mit sprachlichen Gebrauchsregeln ${ }^{266}$.

Dieses Verständnis eines sprachanalytischen Vorgehens zur Analyse von Bedeutungskonstitution grenzt sich zwar von Husserl $\mathrm{ab}^{267}$, gibt dabei allerdings

264 Ich möchte zumindest in einer Fußnote bekennen, dass sich meine Position zu dieser Problematik mittlerweile - da ich diese Arbeit im Januar 2007 nochmals zur Veröffentlichung überarbeite - etwas verändert hat. Vielleicht bietet sich mir zukünftig noch einmal die Gelegenheit, meine neue Perspektive in schriftlicher Form darzulegen.

265 Eine Perspektive, die im Übrigen heute auch weitgehend (allerdings weniger unter Betonung des Bedeutungsaspekts) in der Kognitionsforschung vertreten wird. Für den Neuropsychologen Elkhonon Goldberg (2005: 84) "ist Intuition eine Belohnung für harte geistige Arbeit."

266 Allerdings ließe sich nun nach einem überprüfbaren Kriterium fragen, nach dem sich bestimmen ließe, ob jemand einen solchen korrekten Umgang auch tatsächlich pflegt. Unter Verweis auf Searle sehen Hoche/Strube (1985: 231) dieses Kriterium nicht. "Man wird sich deshalb mit folgender These begnügen müssen: So wie ich mein Leben lang Zeit habe, beim Schachspielen zu beweisen, daß ich Schach spielen kann (die Schachregeln kenne), habe ich auch mein Leben lang Zeit, zu beweisen, daß ich eine Sprache - in der Regel meine Muttersprache - beherrsche." (Für eine zusammenfassende empiristische Kritik am Intuitionismus der Sprechakttheorie siehe ebenda: 234 ff.)

267 Nach Husserl ist es - wie oben diskutiert - durch die eidetische Reduktion möglich, die Phänomene theoriefrei - qua apodiktischer Evidenz - zu erkennen (vgl. Husserl 1963: 56). Apel (1991: 30) betrachtet Husserls Phänomenologie daher auch als "intentionalist theory of meaning which was prelinguistically oriented". Schütz (1993: 33) weicht in seiner phänomenologischen Soziologie m.E. von Husserl ab, wenn er davon spricht, dass das, was vielfach als Evidenz ausgewiesen würde, "auf hochkomplexen Sinnzusammenhängen fundiert ist", denn selbst wenn man 
keineswegs alle Implikationen der Phänomenologie auf. Es handelt sich gewissermaßen - wenn man dies einmal so sagen darf - um eine Phänomenologie aposteriori, d.h. ihre Ergebnisse gründen wie all unser Wissen auf einer Verbindung von Verstand und Anschauung und sind somit angreifbar. Umgekehrt wird durch die Einführung von Intentionalität in sprachphilosophische Betrachtungen der linguistic turn insofern relativiert, als ihm der cognitive turn zur Seite gestellt wird; das Verhältnis zwischen Sprache und Wirklichkeit ist vom Verhältnis zwischen Bewusstsein und Wirklichkeit nicht zu trennen ${ }^{268}$.

unterstellt, es gebe eine prelinguistische Bedeutung, dann kann diese für hochkomplexe Sinnzusammenhänge kaum Relevanz besitzen.

268 Hülst beschreibt diese Wechselseitigkeit, wenn er formuliert: "Nur durch Darstellung in Symbolen, Zeichensystemen, Sprache kommt die Wirklichkeit zum Bewußtsein, das Bewußtsein zur Wirklichkeit." (Hülst 1975: 57) Ein strikter Dualismus zwischen linguistic und cognitive turn wäre nur dann begründbar, wenn Sprache dezidiert als nicht-kognitives Geschehen klassifiziert würde. Eine solche Perspektive wurde oben bereits von mir abgelehnt und wird im Übrigen auch in der Sprachwissenschaft nicht vertreten (vgl. etwa Vater 1999: 22). Begreift man Kognition andererseits als soziales Phänomen, weil sie nicht losgelöst von einer sozialen Umwelt konzipiert werden kann, dann fiele der linguistic mit dem cognitive turn u.U. in eins. Dies lässt sich auch aus Chomskys generativer Grammatik ableiten, da Chomsky die strukturellen Eigenschaften der Sprache mit der Funktionsweise des menschlichen Geistes analogisiert. Dieses Problem soll hier zwar angedeutet, gleichwohl nicht weiter vertieft werden. In der kognitiven Psychologie gelten jedoch keineswegs ausschließlich sprachliche Prozesse als kognitiv und die Biologie verwendet den Kognitionsbegriff zur Bezeichnung neuronaler - und nicht sprachlicher - Prozesse. Außerdem müssen Kinder, um eine Sprache zu erlernen, zunächst einmal über unsprachliche Kognitionen verfügen, weil sich Spracherwerb ansonsten nicht plausibiliseren lässt (was erneut auf die generative Grammatik Chomskys verweist). 


\section{Zwischenbilanz}

\section{Was Wissen und Bedeutung mit der sozialen Welt machen}

Am Ende des Grundlagenteils dieser Arbeit soll nun nochmals zusammenfassend auf die innerhalb der Einleitung gestellte Frage nach dem Verhältnis von Wissen, Bedeutung und sozialem Gegenstand eingegangen werden: Wie hängt das, was wir innerhalb der sozialen Welt als existierend annehmen dürfen, von dem ab, was wir wissen bzw. wie hängt es von den Bedeutungen ab, die wir prozessieren? Diese Frage wurde im Verlauf der bisherigen Erörterungen von unterschiedlichen Seiten aus diskutiert. Nun gilt es, die an verschiedenen Stellen auftauchenden Argumentationen nochmals zusammenzuführen, um eine explizite Antwort zu formulieren und diese in Beziehung zu dem dann folgenden Anwendungsteil zu setzen.

Hatte Kant die Erkenntnistheorie gewissermaßen mit Descartes als primus inter pares der philosophischen Disziplinen bewertet, weil er die Bedingungen der Möglichkeit der Erfahrung zugleich als die Bedingungen der Möglichkeit der Gegenstände der Erfahrung ansah, so sind es die ontologischen Fragen, die für Searle prioritär behandelt werden müssen: "I think that more important than the question of how you know about the world is the question, what it is that you know about, when you do know about the world." (Searle 1999a) Da wir demnach aber auch nach Searle nur dann Seinsfragen stellen können, wenn wir über Wissen verfügen, sind ontologische Probleme ohne erkenntnistheoretische Überlegungen nicht diskutierbar. Behaupten wir die Existenz eines Gegenstandes, dann behaupten wir (trivialerweise) zu wissen, dass es diesen Gegenstand gibt. Erkenntnis ist sprachgebunden und institutionelle Wirklichkeit ist erkenntnisgebunden. Wenden wir uns daher zunächst noch einmal den sprachlichen Implikationen der Erkenntnistheorie $\mathrm{zu}^{269}$.

\footnotetext{
${ }^{269}$ Diese Reihenfolge steht in der Tradition Kants: "Die Bedingungen der Möglichkeit der Erfahrung überhaupt sind zugleich Bedingungen der Möglichkeit der Gegenstände der Erfahrung" (B 197). Bei Nicolai Hartmann hingegen bedarf die Erkenntnistheorie "ihrerseits einer ontologischen Vorarbeit" (Hartmann zitiert nach Strombach 1992: 90).
} 
Mit der Theoriebeladenheit der Erfahrung und der Synthetizität wie der Propositionalität unseres Wissens verneinen wir die Möglichkeit einer direkten Wahrnehmung der Außenwelt (was immer "Außenwelt" auch meinen kann). Menschen erschließen diese so, wie es ihre kognitiven Dispositionen und ihr akkumuliertes Hintergrundwissen ermöglichen. Theorien und Sinnesdaten sind untrennbar miteinander verflochten, denn "Sinnesdaten sind psychologisch gesprochen das Ergebnis unseres Glaubens an die Existenz gewisser theoretischer Entitäten. Eine Beseitigung dieses Glaubens würde also nicht nur zu einer Beseitigung unserer Theorien führen, sondern auch zur Beseitigung der Sinnesdaten selbst" (Feyerabend 1978: 53). Behaupten wir nun die Angemessenheit unserer Sinnesdaten, dann behaupten wir (in einer nicht-phänomenalistischen Diktion) die Existenz beobachtbarer Dinge.

Um also von einem realweltlichen Gegenstand sprechen zu können, bedarf es sprachlich organisierter (bzw. theoretischer) Vorstellungen. Nur hinsichtlich dessen, was wir begründet wissen (oder zu wissen glauben), lässt sich sagen, es existiere. Dies einfach deshalb, weil wir jenseits unserer symbolischen bzw. sprachlichen Fähigkeiten überhaupt keine Möglichkeit haben, Welt zu repräsentieren. Ob wir uns dafür entscheiden, einen Gegenstand als existierend (und insofern auch als direkt oder indirekt beobachtbar) zu klassifizieren, hängt einzig und allein davon ab, ob wir uns dafür entscheiden, eine Theorie über diesen Gegenstand zu akzeptieren. Zu behaupten, es gebe eine solche Theorie noch nicht, meint nichts anderes, als dass wir nicht wissen bzw. keine Vorstellung davon haben, dass es diesen Gegenstand gibt - ergo kann er auch nicht beobachtet werden. Allenfalls ließe sich formulieren, es gebe noch keine ausgereifte wissenschaftliche Theorie hierüber.

Wollen wir nun bspw. die Wahrheit der Proposition "Dies ist ein Stein" behaupten, so setzt dies neben einer Theorie des Steines auch eine Wahrheitstheorie voraus. Beide gemeinsam machen es möglich, einen Gegenstand der Außenwelt entsprechend zu identifizieren bzw. - genauer gesagt - ein Etwas zu einem Gegenstand menschlicher Erfahrung zu machen, denn das Etwas ist für uns immer nur in der Erfahrung gegenständlich (was nicht phänomenalistisch impliziert, alles sei grundsätzlich nur dank Erfahrung gegenständlich). Die Wahrheit einer Existenz-Aussage indiziert das Wissen um das Vorliegen des in der Aussage beschriebenen Gegenstandes respektive Sachverhaltes.

"Wahrheit" firmiert dabei jedoch lediglich als metasprachliches Prädikat, denn ein direkter epistemischer Zugang zur Realität ist unerreichbar. Dadurch wird der Wahrheitsbegriff aber nicht obsolet; er ist lediglich eingebunden in den soziohistorischen Kontext einer Sprechergemeinschaft und "innerhalb unserer unaufhörlich in Entwicklung begriffenen Gesamttheorie urteilen wir über Wahrheit so ernsthaft und absolut, wie es nur immer möglich ist." (Quine 1980: 58) "Denn die Frage zu beantworten, was die Dinge unabhängig von der Vernunft sind, hieße urteilen, ohne zu urteilen, den Pelz waschen, ohne ihn naß zu machen" 
(Frege zitiert nach Hoche/Strube 1985: 28). Welche Welt sollte das sein, die von einer "Null-Perspektive" aus wahrnehmbar wäre? Wir werden niemals eine Vorstellung von ihr entwickeln können. Das bedeutet nun aber keineswegs, alles sei konstruiert im Sinne von nicht-real. Wer das sagt, reklamiert genau jenen archimedischen Standpunkt für sich, dessen Vorhandensein er zugleich leugnen muss, um seine Konstruktionsbehauptung überhaupt formulieren zu können.

Nun kann auch keine Rede mehr davon sein, unsere wissenschaftlichen Theorien über die Welt ließen sich anhand der Realität in unabhängiger Weise verifizieren, falsifizieren oder doch zumindest auf die Realität anwenden. Wir können lediglich die Kompatibilität von wissenschaftlichen und vorwissenschaftlichen Aussagen testen, wobei unter pragmatischen Gesichtspunkten $\mathrm{zu}$ entscheiden ist, inwiefern unsere Forschungsbemühungen uns nahe legen, vertraute Überzeugungen zu restabilisieren, zu modifizieren oder aber aufzugeben.

Die Relativierung unserer sicheren Erkenntnis über die Welt hat jedoch nun nicht zur Konsequenz, dass es allenfalls die Gegenstände gibt, von denen wir wissen und hinsichtlich derer wir wahre Aussagen formulieren können. So haben z.B. Berge "einen Existenzmodus der dritten Person. Ihre Existenz hängt nicht davon ab, dass sie von einem Subjekt erlebt werden." (Searle 2001: 57) Gleichwohl hätten wir ohne unsere Symbolisierungs- bzw. Sprachfähigkeit keine Ahnung von ihnen. Daraus leitet sich entgegen manch anti-realistischer Position keinesfalls logisch ab, diese Dinge würden dann ohne uns nicht existieren. Warum sollte die Existenz des Matterhorns von uns Menschen abhängig sein?

Zugegeben: Sobald wir "Matterhorn" sagen, ist mit der so bezeichneten Entität eine Werttönung verbunden, die, abhängig vom subjektiven Bezug, bei verschiedenen Personen jeweils sehr unterschiedliche Ausprägungen aufweisen kann. Man mag etwa die Schönheit des genannten Berges bewundern oder seine Steilwände fürchten. Ein frisch verliebter Twen wird einen im Frühjahr erblühenden Kirschbaum auch anders "sehen" als ein chronisch-depressiver Greis. Es macht sicherlich einen Unterschied, ob wir von einer "Welle" oder - wie die von Whorf untersuchten Hopis - von "Wogen ereignet sich" reden. Aber die physikalischen/biologischen Entitäten werden durch unsere Kennzeichnung nicht tangiert - lediglich unsere Haltung, Wahrnehmung und Bewertung.

Natürlich lässt sich nicht mit absoluter Gewissheit behaupten, diese Gegenstände existierten auch ohne Menschen. Woher wollte man dies wissen? Wir leben nun einmal in der Welt und können keinen externen Standpunkt einnehmen. Aber es ist einfach vernünftig, eine von menschlichen Ordnungs- bzw. Systematisierungsleistungen ontologisch unabhängige Realität physikalischer Gegenstände anzunehmen. Mit Searle (1997b: 104) möchte ich deshalb festhalten: "Philosophy must start with the fact that the real world exists independently of us ... . That is not a 'theory', it is rather a condition of intelligibility of our discourse."270

${ }^{270}$ Kann man die Außenwelt ernsthaft leugnen ohne zugleich ihr 'es gibt' zu unterstellen? So zeigt sich im Skeptizismus der letztlich zum Scheitern verurteilte und dennoch beständige Kampf gegen 
Die Entitäten der realen Welt freilich, die wir als "sozial" oder "gesellschaftlich" kennzeichnen, können schon per definitionem nicht unabhängig von uns vorhanden sein (jedenfalls nicht, sofern sich das Attribut "sozial" auf menschliches Leben bezieht). Eine Ontologie der sozialen Realität hat dementsprechend zu beantworten, was Menschen ganz grundlegend tun, um ihre Gegenstände zum Entstehen zu bringen. Die hier vertretene Argumentation lautet dabei: Menschen produzieren qua ihrer Fähigkeit zur sprachlichen Intentionalität Bedeutung und konstruieren hierüber eine die physikalischen Gegenstände transzendierende, gleichwohl objektiv-vorhandene Welt.

Wenn nun alle unsere Erfahrungen synthetisch sind, also aus einer Verbindung von Anschauung und Verstand hervorgehen, dann schließt dies Bedeutungproduktion im soziologischen Sinne mit ein. Es handelt sich dabei nämlich um eine spezifische Erfahrung, welche das Vorliegen einer synthetischen Verstandesleistung indiziert, bei der Sinnesreiz und persönliches Relevanzsystem konfundieren, etwa in der propositionalen Form "es ist der Fall, dass ich weiß (oder zu wissen glaube), dass dies bedeutet, dass ..."271. Lediglich in Folge unserer kognitiven Fähigkeit auf dem Hintergrund unseres symbolisch bzw. sprachlich organisierten Wissens eine bestimmte Bedeutungserfahrung zu machen, kann es die institutionellen Sachverhalte der sozialen Realität geben.

Dabei können wir nun sagen, dass die Begriffe "Bedeutungserfahrung" und "Bedeutungsproduktion" (bzw. "Bedeutungszuweisung") zusammenfallen, denn Erfahrung ist - und das sollten die Ausführungen zur Theoriebeladenheit der Erfahrung aber auch zur Hypothesentheorie der Wahrnehmung verdeutlicht haben - ein konstruktiver, relativ zu einer Gemeinschaft verlaufender (und damit erlernter) sprachlicher Vorgang. Sie ist nichts Passives, sondern eine in zentraler Weise sozial bestimmte, aktive Tätigkeit; ein Etwas als ein Etwas zu erkennen, ist einzig qua Sprache bzw. Symbole möglich. Ohne die über Bedeutungsproduktion erfolgende Ordnung der Realität würden wir nur Chaos erkennen - und selbst diese Diktion setzt Bedeutung schon voraus, denn wie wollte man Chaos erkennen, wenn man um die Bedeutung der Worte "Chaos" und "erkennen" nicht wüsste. "Thanks to human beings", so Dreyfus (o.J.), "a meaningful world somehow develops upon a meaningless universe".

Daraus lässt sich nun aber - wie bereits mehrfach erwähnt - nicht folgern, alles sei von Menschen abhängig. Ontologisch objektiv sind alle Gegenstände, deren

die eigenen kognitiven Windmühlenflügel, der seinen Sinn nur aus der stillschweigenden und vor dem Hintergrund der eigenen Argumentationen paradoxen Unterstellung der Existenz einer Außenwelt bezieht. "Das Problem ist, daß der Skeptiker all unsere Überzeugungen zu bezweifeln können glaubt - und zwar alle auf einen Schlag. Genau diesen Zweifel will Wittgenstein sinnkritisch destruieren: 'Wer an allem zweifeln wollte, der würde auch nicht zum Zweifeln kommen. Das Spiel des Zweifelns selbst setzt schon die Gewißheit voraus.' Der Zweifel hängt parasitär von der Gewißheit ab. Er braucht Gründe, die sich nur relativ zu den Gründen für die Gewißheit angeben lassen." (Tietz 2004: 35)

271 "Wahrnehmungs und Deutungstätigkeit sind" nicht nur - wie Soeffner (2004: 114) schreibt - "von vornherein miteinander verknüpft", sondern sie sind de facto gar nicht voneinander zu scheiden. 
Existenz wir vernünftigerweise auch ohne Menschen annehmen dürfen. Ontologisch subjektiv hingegen sind alle Gegenstände, die nur dank Bedeutung, d.h. dank des aktiven Zutuns menschlicher Beobachter, überhaupt denkbar sind. Stellen wir uns eine Welt vor, in der niemals Menschen gelebt haben, so bereitet es uns dennoch keine Schwierigkeiten, dieser Welt Steine zuzusprechen ${ }^{272}$. Einen Briefbeschwerer werden wir hingegen dort nicht finden. Wird nun über die Bedeutungszuweisung ein Gegenstand geschaffen, dessen Bedeutung (bzw. dessen Verwendungsfunktion) nicht schon aus seiner Physik heraus ableitbar ist (aus ontologisch objektiven Eigenschaften von Joseph Ratzinger folgt etwa keineswegs, dass man es bei dieser Person mit Papst Benedikt XVI. zu tun hat) so sprechen wir von institutioneller Realität, d.h. verstetigten symbolischen Formen menschlichen Zusammenlebens.

Insofern müssen wir ein rationales Verhältnis von Erkenntnis und Gegenstand, bei dem darüber entschieden wird, welche Gegenstände wir vernünftigerweise als Teil der Realität annehmen dürfen und wollen, von einem konstitutiven Verhältnis von Erkenntnis und Gegenstand, das für die Gegenstände der institutionellen Realität verantwortlich zeichnet, unterscheiden. Da sich in diesem Verständnis die institutionelle Realität in den Akten ihrer Erfahrung herstellt, schlage ich in Entlehnung eines Begriffes von Moulines (1994: 178) die Bezeichnung "Onto-Epistemologie" vor ${ }^{273}$, um hierüber die unauflösliche, über Bedeutung etablierte Verbindung von menschlicher Erkenntnisleistung und institutioneller Wirklichkeit zu betonen.

Während die menschlichen Ordnungs- bzw. Systematisierungsleistungen in Bezug auf die physikalische Realität lediglich erkenntnistheoretische Implikationen besitzen, ist diese Leistung für die soziale Realität zusätzlich ontologisch relevant. Was es innerhalb des institutionellen Teils der sozialen Realität gibt, gibt es, weil

\footnotetext{
272 Natürlich können wir dieser (noumenalen) Welt nur deshalb Steine zusprechen, weil wir zuvor "Steine" begrifflich (und damit eine bestimmte Wortbedeutung) eingeführt haben. Insofern geht menschliche Erkenntnis der Unterstellung einer von Menschen unabhängigen Ontologie voraus. Wenn wir Existenz nur den Gegenständen unterstellen dürfen, von denen wir wissen, und wenn Wissen immer nur in sprachlicher Form vorliegen kann, dann ist diese argumentative Aporie einfach hinzunehmen. "The 'game' of language has no out-of-bounds. ... Any attempt to think about reality apart from language has to be done with language" (Stevenson 1998: 197). Dennoch stehe ich auf dem Standpunkt, alles andere als die Annahme der Existenz einer von Menschen unabhängigen physikalischen Außenwelt ist unter pragmatischen Gesichtspunkten inakzeptabel sowie - mit Searle (1997b: 104) gesprochen - ein Verstoß gegen die Bedingungen der Intelligibilität unseres Diskurses. Wenn die Phänomenologie in der Tradition Husserls fordert, "daß Sein jedweder Art und Form als konstituiert begriffen werden müsse insofern, als der Sinn, in dem es als dieses oder jenes Sein erscheint, auf 'sinnstiftende Leistungen' der transzendentalen Subjektivität zurückgeht" (Ströker 1999: 1015), so überzeugt dieses Konstitutionsargument im Bereich der physikalischen Realität lediglich in Bezug auf den Sinn des Seins bzw. das Sein der transzendentalen Subjektivität, nicht jedoch auf das Sein "jedweder Art und Form" - es sei denn, man begreift Sein grundsätzlich als ein auf den Menschen relativiertes Sein. Ein solches argumentum ad hominem wird von mir jedoch abgelehnt.

${ }^{273}$ Ich entlehne den Begriff "Onto-Epistemologie" lediglich, da ich ihn keineswegs analog zu Moulines gebrauche. Moulines bezieht den Begriff nämlich auf eine physikalistische Ontologie in der Tradition der Quineschen Bedeutungsskepsis.
} 
wir sozialen Sinn (also Bedeutung in einem soziologischen Verständnis) prozessieren und damit weil wir wissen, was die Worte bedeuten (linguistische Bedeutung), mit denen wir dies tun. Was die Worte bedeuten, wissen wir, weil wir ihren Gebrauch kennen. Ihren Gebrauch kennen wir, weil wir innerhalb einer Sprachgemeinschaft, in welcher der Gebrauch historisch gewachsen ist und aktuell hinsichtlich seiner Korrektheit überwacht wird, sozialisiert wurden. Diese Sprachgemeinschaft ist aber nun ihrerseits Teil der institutionellen Wirklichkeit, womit sich ein m.E. unauflösbarer zirkulärer Prozess ergibt, denn es ist genauso wenig möglich, eine Sprachgemeinschaft außerhalb der institutionellen Wirklichkeit zu platzieren, wie Letztere unsprachlich vorzustellen ${ }^{274}$.

\section{Abbildung 9: Die Zirkularität institutioneller Wirklichkeit}

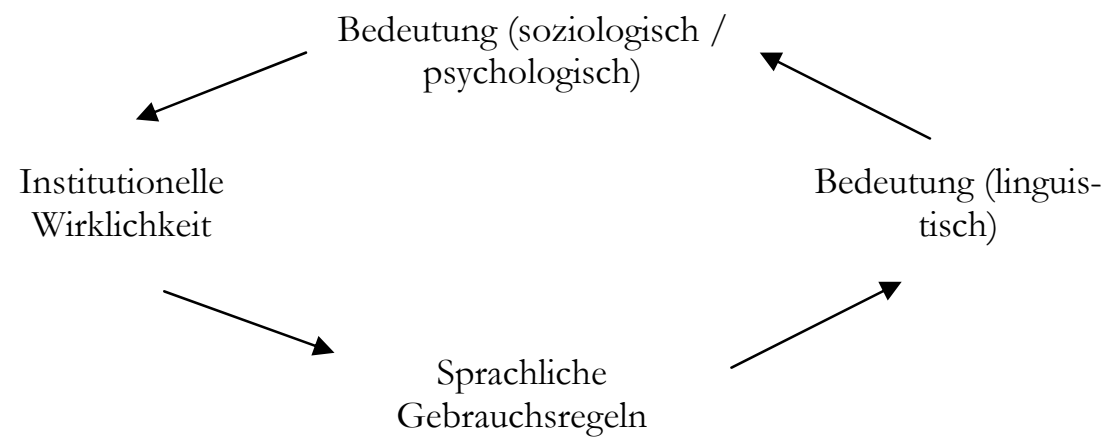

Da die Wissenschaftstheorie eine Erkenntnistheorie der Wissenschaften darstellt, hat die Festlegung dessen, was wir erkennen und als existent voraussetzen können, auch Auswirkungen darauf, wie unsere elaborierten Theorien über die Welt beschaffen sind. Umgekehrt können aber auch wissenschaftliche Theorien unsere Alltagserfahrungen und damit unser lebensweltliches Wissen beeinflussen: Wenn wissenschaftliche Begriffe Eingang in die Alltagssprache finden, dann verändert sich i.d.R. auch das Bewusstsein hinsichtlich der bezeichneten Gegenstände. Man denke hier etwa an Freuds "Unbewusstes" oder den u.a. im Zusammenhang mit der Sozialkapitaldebatte auftauchenden Begriff "Networking".

\footnotetext{
${ }^{274}$ Erneut sei darauf verwiesen, dass Searle diese Zirkularität aufzulösen versucht, indem er Sprache als eine "sich selbst identifizierende Kategorie" begreift (Searle 1997a: 83). Sprache wird damit aber einfach nur an den Anfang gesetzt und nicht weiter problematisiert. Dies ähnelt in der Argumentation ein wenig der Husserlschen Ablehnung, das Sein von Bewusstsein und Intentionalität - also jener Instanzen, die er als sinn- und damit seinskonstitutiv begriff - weiter zu hinterfragen. Da es bei Searle jedoch im Gegensatz zu Husserl um Regeln geht, ließe sich mit Schirn (1974a: 14) sagen: "Ein Handeln nach Regeln läßt sich nicht nach einer Letztbegründung hinterfragen, es rechtfertigt sich sozusagen durch sich selbst". Oder salopp mit Wittgenstein gesprochen: "'So handle ich eben'" (Wittgenstein zitiert nach ebenda).
} 
Obwohl die Welt grundsätzlich eine vom einzelnen Individuum kognitiv erfahrene Welt ist, kann keineswegs mit George Berkeley gesagt werden, die Gegenstände seien lediglich Ideen des menschlichen oder des göttlichen Geistes. Bei der Behauptung, da wir Menschen nur qua unserer geistigen Voraussetzungen Erkenntnis gewännen, könne es keine Außenwelt geben, handelt es sich um einen genetischen Fehlschluss. Um solche Überlegungen überhaupt anstellen zu können, muss man den Realismus schon voraussetzen. Bewusstsein sollte allerdings nicht mit seinen Gegenständen gleichgesetzt werden, denn "gibt es irgendeinen Grund anzunehmen, daß der erfaßte Gegenstand in irgendeinem Sinne geistig ist?" (Russell 1967: 38f.)

Dennoch ist es das Bewusstsein, welches es uns ermöglicht, qua Sprache und Intentionalität einen Gegenstand (sei es einen Baum, einen Bankangestellten, einen Eckball etc.) für uns zu individuieren, d.h. von anderen Entitäten abzugrenzen und zu "setzen". In diesem Sinne werden Gegenstände nun aber auch im Nominalismus (etwa bei Quine [1985: 95]) als Setzungen - "posits" - begriffen 275. Wir bilden über die Einführung von Begriffen Individuen, und durch Übereinstimmung im sozialen Kontext werden diese qua Gebrauch Teil der allgemein akzeptierten Wirklichkeit. Die Form der Gegenständlichkeit dieser Individuen ist jedoch in der Wirklichkeit aufzeigbar: Von einer nahezu unendlichen Anzahl an Möglichkeiten die Welt durch sprachliche Unterscheidungen ein- bzw. aufzuteilen, wurden mit Blick auf menschliche Problembewältigung (also unter pragmatischen Gesichtspunkten) bestimmte ausgewählt.

275 "Die hier hervorgehobene Einsicht ist daher auch als die Erkenntnis formulierbar, daß die Sprache Basis aller Unterscheidungssysteme ist." (Mittelstraß 1974: 160) Damit ist die Art des Unterscheidungssystems aber untrennbar an die Sprachgemeinschaft gekoppelt: "ein Unterscheidungsmerkmal, ..., wird nur dann zum sichtbaren, wahrnehmbaren, nicht indifferenten, sozial relevanten Unterschied, wenn es von jemandem wahrgenommen wird, der in der Lage ist, einen Unterschied zu machen - weil er selber in den betreffenden Raum gehört und daher nicht indifferent ist und weil er über Wahrnehmungskategorien verfügt, die Klassifizierungsschemata, den Geschmack, die es ihm erlauben, Unterschiede zu machen" (Bourdieu 1998: 22). Bei George Spencer Brown (1971) gelangen wir ganz in diesem Sinne zu Gegenständen durch "distinction and indication" - eine Diktion, die insbesondere Luhmann in der Soziologie populär gemacht hat. 



\section{ANWENDUNGSTEIL}

Analyse ausgewählter Sozialkapitalbegriffe /

- konzepte und integrative Begriffs- und Theoriebildung 

Die nachfolgenden Erörterungen zum Sozialkapitalbegriff sollen zunächst zeigen, wie das im Grundlagenteil entwickelte metatheoretische Analyseschema zur Rekonstruktion sozialwissenschaftlicher Erkenntnis (Moderater Strukturalismus) auf Sozialkapitalkonzepte Anwendung finden und wie hierauf fußend dann ein Konzeptvergleich sowie eine systematische integrative Begriffs- und Theoriebildung durchgeführt werden kann. Daran anschließend wird der ontologische Status des so festgelegten Gegenstandes zu bestimmen sein. Dabei stehen also dann konstitutive Ordnungsprozesse im Blickpunkt. Diese lassen sich über das im Grundlagenteil entwickelte ontologische Bestimmungsschema (Bedeutungskonstruktivismus) herausarbeiten.

Prinzipiell möchte ich darauf hinweisen, dass ein Komplexitätsgefälle zwischen Grundlagen- und Anwendungsteil nicht zu vermeiden ist. Die Ausführlichkeit meiner bisherigen Darstellungen war vor allem der Spezifik meines Erkenntnisinteresses an der Sozialkapitalthematik geschuldet. Ohne eine dokumentierte Herleitung der analytischen Werkzeuge würde sowohl der tiefere Sinn meiner Frage nach der Bedeutung von Sozialkapital, als auch meine Antwort hierauf nur schwer nachvollziehbar sein. Dennoch werden natürlich nicht alle Aspekte der vorgelegten "kleinen" analytischen Sprachphilosophie der Sozialwissenschaften im Folgenden eine anwendungsbezogene Berücksichtigung finden. 



\section{Einführende Bemerkungen zur Vorgehensweise}

In einem ersten Schritt geht es nun um eine Beschäftigung mit den sprachlichen Formen, mit Hilfe derer wissenschaftliche Erkenntnis über Sozialkapital behauptet wird. Was bedeutet der T-theoretische Term "Sozialkapital"276 innerhalb elaborierter Aussagensysteme exakt und wie wird der hierüber bezeichnete Gegenstand konkret modelliert? Die Begriffsexplikation und die Rationale Rekonstruktion liefern eine Entscheidungsgrundlage zur Beurteilung der Stringenz, der sprachlichen Präzision, der Operationalisierbarkeit sowie auch der Adäquanz eines theoretischen Aussagensystems hinsichtlich bestimmter empirischer Forschungsprobleme.

Als explikative Bewertungskriterien für die Akzeptabilität des jeweils vorgeschlagenen Sozialkapitalbegriffs werden dessen Nichtzirkularität (der Begriff darf nicht im Definiens auftauchen), Konsistenz (die Definition sollte am bestehenden Sprachgebrauch ansetzen), Klarheit (die Definition muss verständlich sein) und Problemrelevanz (der Begriff sollte sich in der Auseinandersetzung mit menschlichen Problemen als fruchtbar erweisen) herangezogen ${ }^{277}$.

276 Bei "Sozialkapital" handelt es sich um einen T-theoretischen Term, weil er a) bislang in der Alltagssprache kaum vorkommt und weil b) schon auf Basis einer flüchtigen Beobachtung eine abweichende definitorische Bestimmung in unterschiedlichen wissenschaftlichen Aussagensystemen feststellbar ist.

277 Schulze (2004: 21ff.) nennt außerdem noch die empirische und die theoretische Relevanz als Aspekte einer Begriffskritik. Nach den vorangegangenen Erörterungen lässt sich jedoch keine saubere Trennlinie zwischen diesen beiden Typen ziehen. Letztlich geht es Schulze bei der Anführung von begrifflicher Relevanz immer um Problemrelevanz bzw. Fruchtbarkeit: Es geht darum, "ob ein Sachverhalt auf den Punkt gebracht wird, der etwas mit menschlichen Interessen und Problemen zu tun hat." (ebenda: 23) 
Ferner wird der wissenschaftstheoretische Status der Soziakapitalkonzepte und damit die von den untersuchten Autoren vollzogene Form einer Erkenntnisbegründung geklärt: Sind die einschlägigen Sozialkapitalkonzepte Ergebnis methodisch angeleiteter, reflektierter Forschung? Sind sie analytische Modelle? Realmodelle? Empirische Theorien? Heuristiken ${ }^{278}$ ?

Auch das innovative Potential des Sozialkapitalbegriffs wird - wenngleich nicht im Mittelpunkt des Forschungsinteresses stehend - hinterfragt: Handelt es sich bei "Sozialkapital" um ein analytisch und/oder inhaltlich wirklich neues sozialwissenschaftliches Erkenntniskonstrukt oder lediglich um eine inkrementalistische Erweiterung bzw. Reformulierung bereits bekannter Paradigmen (wie etwa "Solidarität", "Reziprozität" oder "kollektive Güter") ${ }^{279}$ ? Schließlich soll die Auseinandersetzung zur Konstruktion eines unter wissenschaftstheoretischen Gesichtspunkten tragfähigen integrativen Theoriemodells führen.

278 Die genannten Entitäten sollen hier - positivistisch formuliert - folgende Differenzierung ermöglichen: Ein analytisches Modell stellt eine in analytischer Sprache formulierte, idealtypische Forschungsskizze dar, die insbesondere zum Zwecke einer explorativen Strukturierung auf ganz unterschiedliche Bereiche der Realität angewendet werden kann (etwa das formalisierte AutopoiesisModell von Maturana/Varela [1987]); als Realmodell gilt ein Modell mit empirischem Bezug, d.h. hier wird die Realität auf einige wenige, spezifische Aspekte reduziert, um so Erklärungsargumente für verwandte Objektbereiche zu erhalten (etwa der akteurszentrierte Institutionalismus von Mayntz/Scharpf [1995]); eine empirische Theorie ist ein aus empirischer Forschungsarbeit hervorgegangenes, (bislang) gesicherte Erkenntnisse über Wirkungszusammenhänge innerhalb eines spezifischen empirischen Objektbereichs formulierendes Aussagensystem (etwa die Hypothesentheorie der sozialen Wahrnehmung von Bruner [vgl. Lilli 1984]); eine Heuristik stellt vorläufige Vermutungen hinsichtlich von bislang ungeklärten bzw. wenig beachteten Variablenzusammenhängen bereit (siehe für eine ausführliche Diskussion dieser unterschiedlichen Entitäten Koob 1999: $30 \mathrm{ff}$. .).

${ }^{279}$ So behaupten etwa Warden/Tampubolon (2002: 156): "In the last few years, many scholars who would previously have analysed similar phenomena using a different battery of concepts, have joined the debate about the nature, provenance and effects of social capital." Wenn man mit "Sozialkapital" bspw. vorwiegend reziproke Hilfeleistungen konzeptualisieren wollte, dann stünde mit "Solidarität" bereits ein relativ bewährter Begriff zur Verfügung, der weniger auf Zusammengehörigkeitsgefühle, als "deutlicher auf die Gemeinsamkeit des Handelns" abhebt (Kaufmann 2002: 40). An dieser Stelle könnten dann auch empirische Theorienvergleiche ansetzen, bei denen ein Explanandum mit unterschiedlichen konzeptionellen Grundlagen untersucht wird, um so etwa das angemessenere, erklärungskräftigere, effizientere oder einfachere (also letztlich "bessere") theoretische Aussagensystem zu bestimmen (vgl. ausführlich zu empirischen Theorienvergleichen etwa den Sammelband von Opp/Wippler 1990a oder Seipel 1999). 
Um die Güte meiner wissenschaftstheoretischen Bewertungen zu gewährleisten, werde ich, soweit dies den Lesefluss nicht in erheblicher Weise behindert, die Autoren über Zitationen selbst zu Wort kommen lassen ${ }^{280}$. Die Ausführungen orientieren sich an zentralen Problemen des Forschungsfeldes, die als wissenschaftstheoretisch motivierte, textanalytische Sortierungskriterien zu interpretieren sind und den Fragehorizont der Rationalen Rekonstruktion abstecken.

Zu klären ist:

1. Wie wird "Sozialkapital" jeweils definiert, d.h. was soll Sozialkapital sein? (Definition)

2. Auf welchen soziologischen Ebenen findet sich Sozialkapital? (Ebenen)

3. Residiert Sozialkapital innerhalb von Beziehungsrelationen oder gehört es dem einzelnen Akteur? Handelt es sich um ein privates oder um ein kollektives Gut? (Lokalisierung)

4. Welche Gründe sind für die Entstehung von Sozialkapital als ursächlich anzusehen ("Sozialkapital" als abhängige Variable)? (Entstehung)

5. Welche Wirkungen weist Sozialkapital auf ("Sozialkapital" als unabhängige Variable)? (Wirkung)

6. Wie wird "Sozialkapital" operationalisiert? (Operationalisierung)

7. Wie gelangt der Theoriekonstrukteur zu seinen Aussagen? Was ist das Erkenntnisinteresse und auf welchem wissenschaftlichen Erkenntnisniveau befindet sich ein untersuchtes Sozialkapitalkonzept? (Wissenschaftstheoretischer Status)

8. Wie lässt sich das Konzept abschließend axiomatisieren, d.h. strukturalistisch darstellen? (Strukturalistische Darstellung)

Die Diskussion dieser Punkte erfüllt alle Anforderungen, die der Moderate Strukturalismus mit einer Rekonstruktion theoretischer Aussagensysteme verbindet (vgl. Kapitel 4.4.): Genannt wird das Erkenntnisproblem bzw. -interesse (Punkt 1, 2, 5 und 7), die Methode der Theoriekonstruktion (Punkt 7), der wissenschaftstheoretische Status (Punkt 7) sowie die Theoriereichweite (Punkt 2 und 5). Die wichtigsten Grundbegriffe - im Sinne von Bausteinen bzw. Komponenten - werden herausgearbeitet und mengentheoretisch spezifiziert (Punkt 1, 2, 3 und 8). Die basalen Postulate erscheinen (Punkt 8) und die zentralen Axiome -

\footnotetext{
${ }^{280}$ In den meisten Darstellungen und Vergleichen hinsichtlich verschiedener Sozialkapitalkonzepte finden sich nur wenige und ausgewählte Originalzitate; es wird vorwiegend paraphrasiert und auf Textstellen verwiesen (bei Schechler [2002] findet sich bspw. so gut wie kein einziger vollständig und unverändert wiedergegebener Satz aus einer Originalquelle; Leicht [2000] wiederum zitiert mitunter de fakto, obgleich er vorgibt, zu paraphrasieren). Da hier jedoch begriffstheoretische Probleme und somit die sprachlichen Strukturen wissenschaftlicher Aussagensysteme im Zentrum stehen, stützt sich die Argumentation schon alleine aus Gründen der inhaltlichen Präzision stark auf Zitate der untersuchten Autoren. Der dafür zu zahlende Preis wird freilich eine eher technische Darstellungsweise sein.
} 
also die propagierten substantiellen Zusammenhänge - werden verbal wie logischformal systematisiert (Punkt 2, 4, 5 und 8).

Bei den Punkten 1, 4 und 5 handelt es sich um jene Aspekte, die eine wissenschaftstheoretisch motivierte Auseinandersetzung mit einem sozialwissenschaftlichen Konstrukt i.d.R. beinhalten sollte. Lediglich unter der Voraussetzung einer Darlegung dessen, was man konkret unter einem im Blickpunkt stehenden Begriff verstehen möchte (Definition) sowie einer entsprechenden Konzeptualisierung als abhängiger (Entstehung) und unabhängiger Variable (Wirkung) lässt sich hinsichtlich eines Aussagensystems sinnvoll von einem sozialwissenschaftlichen Theoriegebäude sprechen, denn so sind (positivistisch formuliert) prüfbare Hypothesen ableitbar, was wiederum eine Betrachtung der jeweils genannten Operationalisierungsvorschriften unumgänglich macht ${ }^{281}$ (Punkt 6).

Mit Blick auf die Wirkung von Sozialkapital rückt zumeist auch unmittelbar die erkenntnisleitende Zielsetzung des Autors in den Fokus: Bourdieus Überlegungen sind im Kontext gesellschaftlicher Klassengegensätze und sozialer Schichtung angesiedelt, Coleman geht es schwerpunktmäßig um den Zusammenhang von Human- und Sozialkapital im Bildungs- bzw. Schulsystem, Putnam ordnet seine Theoriearbeit vor allem in die Diskussion um eine demokratische Bürgergesellschaft ein, und die Netzwerktheoretiker wollen mit dem Verweis auf Sozialkapital die Bedeutung von nützlichen Beziehungen insbesondere hinsichtlich der beruflichen Karriere bzw. der Jobsuche theoretisieren.

Die strukturalistische (mengentheoretische) Darstellungsweise fasst abschlieBend die zentralen Punkte 282 des jeweiligen Sozialkapitalkonzeptes in kohärenter und axiomatisierter Form zusammen. Dabei kann es allerdings zu der Schwierigkeit kommen, dass ein Aussagensystem zwar präzise (d.h. im Sinne des untersuchten Autors), dann aber logisch inkonsistent rekonstruiert wird - oder vice versa,

281 Robinson/Robinson (2002: 44) behaupten im Rahmen ihrer Diskussion des Sozialkapitalbegriffs: "The precise measurement of an imprecise concept is of less value than an adequate measurement of a concise concept." Eine solche Sichtweise erscheint mir indes verfehlt. Ein knappes, schlüssiges ("concise") Konzept mag ja durchaus eine lediglich zufriedenstellende empirische Umsetzung finden, aber ein unpräzises Konzept lässt sich niemals präzise messen, weil die Grundlagen hierfür gar nicht gegeben sind. Auch eine Diskussion der Entstehungsursachen und Wirkungen von Sozialkapital lässt sich sinnvoll ausschließlich vor dem Hintergrund definitorischer Überlegungen führen. Vielfach wird innerhalb der Begriffsdebatte jedoch eine definitorische Heterogenität konstatiert, und dennoch versucht man im Anschluss an diese Diagnose, die von unterschiedlichen Autoren genannten Entstehungsursachen und Wirkungen von Sozialkapital gegenüberzustellen (siehe etwa Adam/Roncevic 2003).

282 Würde man eine erschöpfende Darstellung anstreben, müsste die mengentheoretische Notation insbesondere in Anbetracht der Fülle von unterstellten Wirkungen des Sozialkapitals völlig unübersichtlich werden. Erläuterungen zur formalen Schreibweise finden sich grundlegend im Text und innerhalb der Fußnoten zu Bourdieu, da dort erstmals eine strukturalistische Rekonstruktion eines Sozialkapitalkonzeptes erfolgt. Der Leser, der sich bspw. lediglich für die Vorstellungen Putnams interessiert, wird also hier u.U. nachschlagen müssen (zumal ich bei der Formalisierung der im Anschluss an Bourdieus Aussagensystem vorzustellenden Konzepte [zur Verminderung von Redundanz] nur noch diejenigen terminologischen Axiome anführen werde, die zuvor noch nicht genannt wurden; vgl. allgemein zur strukturalistisch-mengentheoretischen Theorierekonstruktion nochmals die Ausführungen in Kapitel 4.3.). 
also logisch konsistent aber inhaltlich nicht valide ${ }^{283}$. Insofern wird hier eine klare Position bezogen: Etwaige Unklarheiten oder Widersprüche der einzelnen Sozialkapitalkonzepte gilt es argumentativ schon innerhalb der verbalen Ausführungen zu erörtern und - mit Blick auf die Bildung eines integrativen Theoriemodells - zu beseitigen. Damit werden die Aussagensysteme nicht nur vorgestellt, sondern zugleich kritisiert und dann soweit als möglich in prägnanter sowie kohärenter Form präsentiert, um sie später einfacher für eine Theorieintegration nutzen zu können (die Kritik erfolgt also nicht nur im abschließenden Vergleichsund Theoriebildungskapitel) ${ }^{284}$.

Mit Hilfe der strukturalistischen Darstellungsweise kann die Etablierung einer normierten Einheitssprache erzielt werden ${ }^{285}$. Bisher wurde der Sozialkapitalbegriff ungenau bestimmt; die Aussagensysteme, in denen er auftaucht, sind vielfach unpräzise, widersprüchlich und vieldeutig formuliert (worauf schon innerhalb der Äußerungen zum Forschungsstand hingewiesen wurde und was nachfolgend weiter zu belegen sein wird). "Wenn wir tatsächlich von diesem engen Zusammenhang, der zwischen der Genauigkeit der Bedeutung eines Terminus oder einer Aussage und der Rolle, die der Terminus oder die Aussage in einer Theorie spielt, ausgehen können, dann folgt hieraus unmittelbar, dass Bedarf an einheitlich strukturierten Theorien besteht." (Chalmers 2001: 88) Eben diesem Bedarf versucht die Rationale Rekonstruktion und später die strukturalistischaxiomatisierte Darstellung des integrativen Theoriemodells über Sozialkapital gerecht zu werden.

Da die vorzustellenden Autoren abweichende definitorische Bestimmungen vornehmen, wird hinter das Symbol "S" (für "Sozialkapital") der Anfangsbuch-

\footnotetext{
283 Westermann (2000a: 224) drückt dies so aus: "Die Rekonstruktion einer Theorie soll einerseits möglichst präzise, konsistent und sachgerecht sein, andererseits soll das Rekonstrukt den Originaldarstellungen und -absichten möglichst genau entsprechen. In der Regel sind beide Ziele nicht gleichzeitig zu erreichen, so dass die Rekonstruktionen von Theorien viele Entscheidungen, Kompromisse und Gratwanderungen beinhalten" (vgl. in ähnlicher Weise auch Kühnel 1993: 42).

${ }^{284}$ Bei Stegmüller heißt es: "Der Wissenschaftstheoretiker stellt die existierenden Wissenschaften nicht in Frage. Vielmehr versucht er deren Rekonstruktion unter der Voraussetzung, daß eine rationale Rekonstruktion möglich ist." (Stegmüller zitiert nach Mittelstraß 1981: 93) Daraus könnte nun - wie Mittelstraß (ebenda 93f.) anmerkt - gefolgert werden, die Erfahrungswissenschaften hätten "erst einmal für wissenschaftstheoriedienliche Verhältnisse zu sorgen." Unterstellt man der Einfachheit halber einmal die Sinnhaftigkeit der Stegmüllerschen Perspektive, dann ist der Autor der vorliegenden Untersuchung (also ich) gewissermaßen in einer privilegierten Position: Als "philosophisch denkender Sozialwissenschaftler" kann er die theoretischen Debatten seiner Herkunftsdisziplin nicht nur rekonstruieren, sondern er kann (und wird) konstruktiv intervenieren.

285 Dabei sollte der mit Sozialkapitalkonzepten "vertraute Leser sich ... nicht wundern, wenn eine solche Darstellung in Form und Sprache von dem abweicht, was er im Zusammenhang mit der jeweiligen Theorie bisher vorfand. Das Ziel der hier behandelten Darstellungen ist nicht, den Leser zu speziellem Weiterforschen auf dem jeweiligen Gebiet hinzuführen oder vorzubereiten; das Ziel ist, ihm die begriffliche und logische Struktur der jeweiligen Theorie möglichst präzise darzulegen" (Balzer 1982: 4), um darauf aufbauend dann theorieintegrativ und ontologisch weiterzudenken. (Gleichwohl werde ich - und hier unterscheide ich mich als Soziologe von dem Philosophen Balzer zum Abschluss meiner Untersuchungen natürlich auch auf weiterführende Forschungsfragen hinweisen.)
} 
stabe des jeweiligen Theoretikers hochgestellt (also $\mathrm{S}^{\mathrm{B}}, \mathrm{S}^{\mathrm{C}}, \mathrm{S}^{\mathrm{P}}, \mathrm{S}^{\mathrm{N}}$ ) ${ }^{286}$; so bleibt ersichtlich, dass hierüber keineswegs ein und dieselbe Begriffs-Intension und Extension gemeint ist. Alle anderen Komponenten sollen über die Konzepte hinweg konstant gehalten werden, um später einen Vergleich sowie eine eigene Theoriebildung zu erleichtern. Wenn etwa in Zusammenhang mit der Entstehung von Sozialkapital davon die Rede ist, Verpflichtungen müssten geschaffen werden, dann ist mit "Verpflichtungen" bei allen Autoren dasselbe gemeint.

Eine solche Behauptung ist natürlich nur dann statthaft, wenn sich dies anhand der Texte begründen lässt. Zugleich ist jedoch darauf hinzuweisen, dass hier Sozialkapitalkonzepte untersucht werden, d.h. "Sozialkapital" wird fokussiert und alle anderen Begriffe werden zunächst einmal als unproblematisch unterstellt. Nur bei offenkundiger Abweichung vom alltagssprachlichen oder sozialwissenschaftlichen Sprachgebrauch könnten diese anderen Begriffe über einzelne Konzepte hinweg nicht konstant gehalten werden. Ein Begriff lässt sich nur dann explizieren, wenn man andere als weitgehend unproblematisch unterstellt und sie bei einem Vergleich verschiedener Konzepte konstant hält - irgendwo muss man schließlich beginnen ${ }^{287}$.

Diese Vorgehensweise korrespondiert mit dem innerhalb des erkenntnis- und wissenschaftstheoretischen Grundlagenteils ausgeführten Überlegungen zu TTheoretizität: "Sozialkapital" wird als T-theoretischer Term interpretiert und alle anderen Begriffe gelten als unproblematisch. Bedeutungstheoretisch ließe sich formulieren, dass die Einführung eines T-theoretischen Terms als ein Vorschlag hinsichtlich eines regelhaften Gebrauchs eines bislang weitgehend un- bzw. unterbestimmt verwendeten Ausdrucks zu begreifen ist. Nicht T-theoretische Terme gelten hingegen als innerhalb einer Sprachgemeinschaft ausreichend konsensual bestimmt: Man weiß was sie bedeuten, weil man ihren Gebrauch kennt.

Zum Abschluss dieser einleitenden Bemerkungen zum Anwendungsteil dieser Untersuchung soll noch einmal darauf hingewiesen werden, dass es nun nicht darum gehen kann, einen kommentierten Literaturbericht zur Sozialkapitaldebatte vorzulegen. Hier werden vielmehr Konzepte jener Sozialforscher rekonstruiert und verglichen, die in dieser Debatte mit theoretischem Anspruch an- bzw. aufgetreten sind und deren Überlegungen prägend für nahezu alle anderen (vor allem empirisch arbeitenden) Autoren waren und nach wie vor sind.

Das metatheoretische Interesse richtet sich auf Probleme sozialwissenschaftlicher Begriffsbildung und Erkenntnis sowie hierauf fußend dann später insbesondere auf die konstitutiven sprachlichen Ordnungsmerkmale sozialer Gegenstände. Bei "Sozialkapital" handelt es sich um eine sehr aktuelle, noch relativ junge und

\footnotetext{
286 Wobei das hochgestellte " $\mathrm{N}$ " das von unterschiedlichen Autoren (hier Burt, Flap und Lin) vertretene Netzwerkkonzept symbolisieren soll.

287 Der bedeutungstheoretische infinite Regress ist unvermeidbar: Begriffe lassen sich nur über andere Begriffe definieren, deren Bedeutung als geklärt unterstellt wird.
} 
äußerst heterogen geführte Debatte. Unterschiedliche Wissenschaftler gebrauchen den Begriff in verschiedenen Kontexten, mit abweichenden Definitionen und analytischen Schwerpunktsetzungen, so dass eine übereinstimmende Kommunikation derzeit nicht möglich ist, womit der Begriff unter sprachpragmatischen Aspekten betrachtet als unzweckmäßig zu klassifizieren ist.

In Folge der meta- bzw. sprachtheoretischen Schwerpunktlegung sollte man etwa im Zusammenhang mit meiner Rekonstruktion des Putnamschen Konzeptes keine weitschweifigen inhaltlichen Ausführungen zu Themen wie "Bürgergesellschaft", "Kollektivgüter" oder "Regionalentwicklung" erwarten. Im Blickpunkt steht keineswegs primär das Erkenntnisinteresse und die diesbezügliche wissenschaftliche und/oder politische Wirkungsgeschichte eines Autors (und schon gar nicht eine empirische Überprüfung oder Anwendung seines Aussagensystems), sondern vielmehr ein Vorschlag zu einer konzeptionellen Klärung und damit verbunden zu einer exakten Bestimmung des Gegenstandes.

Es ist nicht mein Ziel, ein für alle Debattenteilnehmer akzeptables, womöglich sogar einzig "richtiges" Verständnis von "Sozialkapital" vorzulegen oder es insbesondere den Vertretern des derzeitigen (an Putnam orientierten) mainstreams innerhalb dieser Debatte Recht zu machen ${ }^{288}$. Hier wird der Anspruch erhoben, eine mögliche - unter wissenschaftstheoretischen Aspekten betrachtet - sinnvolle und haltbare integrative Begriffs- und Theoriebildung vorzunehmen. Daneben sind im Sinne theoretischer Pluralität natürlich zahlreiche andere Konzeptualisierungen denkbar. Mit Blick auf die Erhöhung des begrifflichen und theoretischen Reifegrades der Sozialkapitaldebatte ist jedoch ein konsensuales Verständnis (ausgesprochen) wünschenswert, womit meine Antwort auf die von Paldam (2000) aufgeworfene Frage "Social Capital: One or many?", schon vorgezeichnet ist.

Das integrative Theoriemodell bildet später den Rahmen für die Erarbeitung einer gegenstandsspezifischen Ontologie und damit den Ausgangspunkt für eine genauere Analyse der Begriffs-Extension. Die ausgewählten Sozialkapitalkonzepte müssen zunächst einmal vorgestellt und diskutiert werden, um auf Basis des hierüber entwickelten Konsensvorschlags überhaupt ontologische Reflexionen anstellen zu können. Zugleich kann das Theoriemodell aber partiell selbst ontologisch interpretiert werden: Mit seiner Annahme werden Behauptungen über die Beschaffenheit von Sozialkapital sowie über seine Entstehungsursachen in einem soziologischen Sinne getroffen. Auf dieser Basis lässt sich dann mit dem Bedeutungskonstruktivismus spezifischer weiterdenken, um die so erzielten

\footnotetext{
288 Was wissenschaftssoziologisch betrachtet zweifelsohne nicht unproblematisch ist, zumal dann, wenn man sich mit seiner Argumentation zwischen alle Stühle setzt. Mark Twain lässt uns in einem seiner Romane wissen: "Wissenschaftler haben ein abscheuliches Benehmen, es sei denn, Du unterstützt ihre Theorie; dann kannst du sogar Geld von Ihnen geliehen bekommen" (Twain zitiert nach Charpa 1996: 93).
} 
Ergebnisse dann wiederum an den wissenschaftlichen Sozialkapitalbegriff rückzubinden ${ }^{289}$.

Abbildung 10: Richtung der Theorienintegration

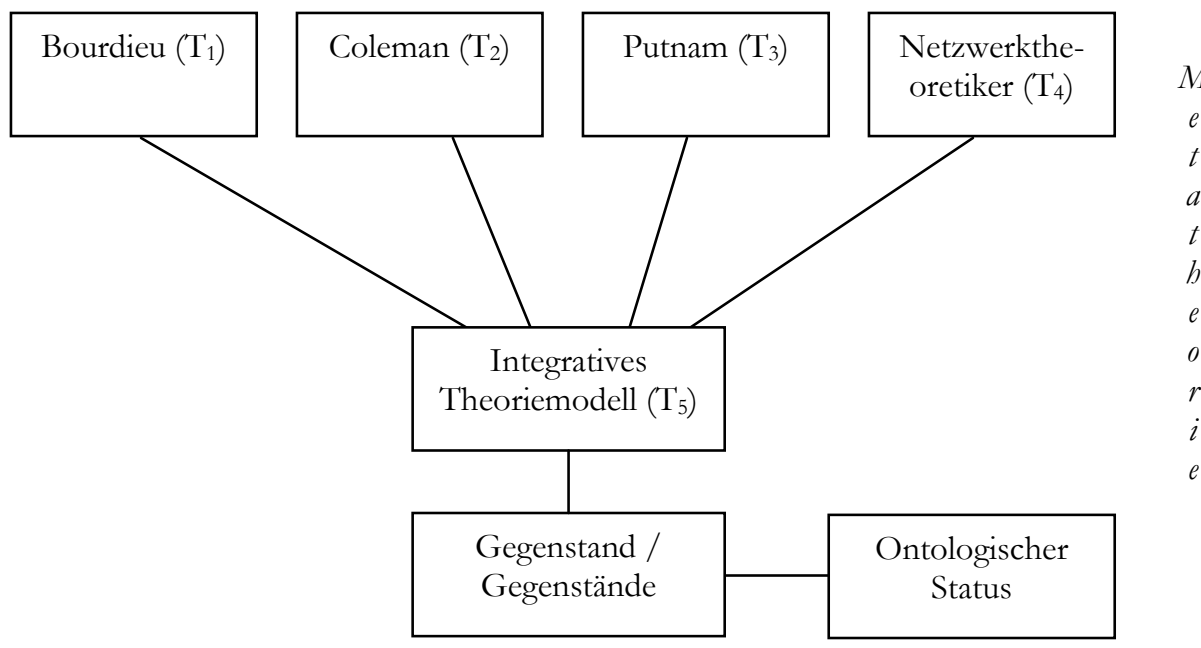

Ontologien des Sozialen

289 Allgemein soll der Unterschied zwischen Theorie und Ontologie an dieser Stelle nochmals wie folgt bestimmt werden: Mit dem Ausdruck "sozialwissenschaftliche Theorie" wird hier ein Aussagensystem bezeichnet, bei dem ein Gegenstand der sozialen Realität beschrieben und hinsichtlich seiner Entstehung und Wirkung geklärt wird. Eine Theorie über einen Gegenstand fasst also das Wissen, welches zur Beschreibung desselben sowie zur Erklärung seiner Entstehungs- und Wirkungsweise notwendig ist, in systematischer Form zusammen. Unter dem Ausdruck "Ontologie des Sozialen" wird hier ein Ordnungs- und Begriffsschema verstanden, das der Existenz eines sozialen Gegenstandes zugrunde liegt. Eine Ontologie ist insofern kein beschreibendes oder klassifizierendes Aussagensystem, sondern die Ontologie eines sozialen / institutionellen Gegenstandes besteht in den notwendigen sprachlich-geistigen Operationen und logischen Verknüpfungen, die für diesen konstitutiv sind. (Dennoch hatte ich die auf Searle und Berger/Luckmann zurückgehenden Ontologien oben als "Theorien des Seienden" bezeichnet [vgl. Kapitel 5.6.], weil es in dem dortigen Zusammenhang um eine Darstellung sprachlich vorliegender Behauptungen ging.) 


\subsection{Sozialkapital und gesellschaftliche Position: Das Kon- zept Pierre Bourdieus}

Pierre Bourdieu darf wohl als derjenige Autor bezeichnet werden, der als erster ein systematisches Sozialkapitalkonzept erarbeitet hat. "Sozialkapital" ist hier Bestandteil einer Kapitalientheorie, mit der eine Engführung der Ökonomie auf reine Marktbeziehungen kritisiert werden soll. Eine solche Engführung verhindere "das Entstehen einer allgemeinen Wissenschaft von der Ökonomie der Praxis ..., die den Warenaustausch lediglich als speziellen Fall unter mehreren möglichen Formen sozialen Austauschs behandelt."290 (Bourdieu 1992: 51) Die Kapitalientheorie zielt insofern darauf ab, "das Kapital und den Profit in allen ihren Erscheinungsformen zu erfassen" (ebenda: 52).

\section{Definition}

Unter "Kapital" versteht Bourdieu ganz allgemein "akkumulierte Arbeit, entweder in Form von Materie oder in verinnerlichter, 'inkorporierter' Form" (ebenda: 49). Drei zentrale Kapitalarten sind zu unterscheiden: ökonomisches, kulturelles, und soziales Kapital ${ }^{291}$. Vor allem die über Erwerbsarbeit akkumulierten Güter wie Geld, Immobilien oder Eigentumstitel firmieren als "ökonomisches Kapital". "Kulturelles Kapital" bezeichnet diejenigen Entitäten, die über Bildungs-, Berufsoder sozialen Status institutionell abgesichert sind ${ }^{292}$. In inkorporierter Form ist es "ein Besitztum, das zu einem festen Bestandteil der 'Person', zum Habitus

\footnotetext{
290 Hinsichtlich des in diesem Zusammenhang zentralen Aufsatzes "Ökonomisches Kapital Kulturelles Kapital - Soziales Kapital" (in Deutschland zuerst 1983) beziehe ich mich im Folgenden auf dessen Abdruck in Bourdieu (1992): Die verborgenen Mechanismen der Macht. Schriften zu Politik und Kultur 1, Hamburg, S. 49-80. Generell ist anzumerken, dass die Literatur von und zu Bourdieu Legion ist. Im vorliegenden Kontext geht es jedoch nicht um eine Würdigung von Bourdieus Gesamtwerk, sondern um eine Rekonstruktion seines Sozialkapitalkonzeptes. Vor dem Hintergrund dieser Zielsetzung tendiert der Grenznutzen einer ausgedehnten Literaturanalyse rasch gegen Null (mit Blick auf eine Sättigung der Argumentation werde ich natürlich nachfolgend dennoch diverse Beiträge von und zu Bourdieu heranziehen; grundsätzlich lässt sich mit Swain [2003: 187] jedoch behaupten: "Social capital ist not a major concept in Bourdieu's oeuvre").

${ }^{291}$ Daneben ist auch noch von weiteren Kapitalarten, wie etwa politischem (Bourdieu 1998: 28) oder juristischem (ebenda: 109) Kapital die Rede (das symbolische Kapital wird weiter unten noch eigens angeführt), "so daß Beobachter und Kritiker schon von einer 'Inflationierung' des Kapitalbegriffs in seiner (Bourdieus, D.K.) Theorie gesprochen haben." (Joas/Knöbl 2004: 539) Esser (2000: 209) fügt - augenscheinlich hier an Bourdieu orientiert - sogar noch institutionelles Kapital hinzu.

${ }^{292}$ Kulturelles Kapital kann so in Abgrenzung (aber zugleich auch in Erweiterung) des aus der Ökonomie heraus "entdeckten" Humankapitals (vgl. zu diesem Becker 1993) betrachtet werden. Das individuelle Humankapital besteht diesem Konzept zu Folge vor allem aus den familiär bezogenen Fertigkeiten (wobei diese auch teilweise angeboren sein können) und Kenntnissen sowie aus dem über den Markt erworbenen Bildungswissen. Humankapitaltheoretiker übersähen, so Bourdieu, "daß der schulische Ertrag schulischen Handelns vom kulturellen Kapital abhängt, das die Familie zuvor investiert hat" (Bourdieu 1992: 55). Der Bildungsbegriff soll so nicht einem normativen, sondern einem "globaleren ethnologischen Begriff von 'Kultur' eingefügt" werden (Bourdieu 1987: 17).
} 
geworden ist; aus 'Haben' ist 'Sein' geworden". (ebenda: 56) Man kann es am Auftreten, am Verhalten, an der Bildung, an der Sprechweise oder an den ästhetischen Wertungen - kurz: am Habitus - einer Person erkennen ${ }^{293}$.

Objektiviertes Kulturkapital begegnet uns in Form kultureller Güter wie etwa Büchern, Gemälden oder Maschinen. Zu ihrer Aneignung ist i.d.R. die Aufwendung ökonomischen Kapitals notwendig. Inkorporiertes Kulturkapital wiederum wird erforderlich, sollen die objektivierten Formen verstanden, angewendet und wertgeschätzt werden. Mit einem Buch kann man bspw. nur dann "etwas anfangen", wenn man zuvor Lesen (und Verstehen) gelernt hat. Institutionalisiertes Kulturkapital tritt insbesondere in Form statusindizierender Titel in Erscheinung: "Titel schaffen eine Unterschied zwischen dem kulturellen Kapital des Autodidakten, das ständig unter Beweiszwang steht, und dem kulturellen Kapital, das durch Titel schulisch sanktioniert und rechtlich garantiert ist." (Bourdieu 1992: 61) Der Autodidakt ist "Opfer seines Mangelns an schulisch verbrieftem Wissen" (Bourdieu 1987: 515).

Ökonomisches, kulturelles oder soziales Kapital unterliegen einer Bewertung durch die Gemeinschaft und treten so als symbolisches Kapital in Erscheinung. Letzteres ist insofern keine unabhängig zu betrachtende Größe, sondern "die Form, die jede Kapitalsorte annimmt, wenn sie über Wahrnehmungskategorien wahrgenommen wird" (Bourdieu 1998: 108f.). Damit geht es also um die Anerkennung und Bewertung des Besitzes an den drei zentralen Kapitalformen; oder wie Richard Münch es vereinfachend formuliert: "Symbolisches Kapital ist der Ruf, den man aufgrund der Bewertung anderer in Bezug auf die erworbene Menge ökonomischen, sozialen und kulturellen Kapitals genießt."294 (Münch 2004: 432)

Unter "Sozialkapital" versteht Bourdieu nun "die Gesamtheit der aktuellen und potentiellen Ressourcen, die mit dem Besitz eines dauerhaften Netzes von mehr oder weniger institutionalisierten Beziehungen gegenseitigen Kennens und Anerkennens verbunden sind; oder, anders ausgedrückt, es handelt sich dabei um Ressourcen, die auf der Zugehörigkeit zu einer Gruppe beruhen." (Bourdieu 1992: 63) Sozialkapital ist ferner - wie jedes Kapital - "akkumulierte Arbeit" (ebenda: 49)

293 Das Habituskonzept gehört sicherlich zu Bourdieus meistbeachtetsten wissenschaftlichen Arbeiten und entstammt seinen Untersuchungen zu Handlungsregelmäßigkeiten von Angehörigen bestimmter sozialer Klassen bzw. Schichten. Der Habitus einer Person ist gewissermaßen die Verkörperung des über Sozialisation einverleibten sozialen Kontexts, in dem ein Individuum lebt. Er schlägt sich, wie oben bereits angedeutet, in einem Ensemble von als selbstverständlich erachteten Denk- und Verhaltensweisen, in typischen Deutungsmustern der gesellschaftlichen Praxis nieder, die einen Menschen zu dem machen, was er ist. Über ihren Habitus wirken die Individuen umgekehrt aber auch auf die gesellschaftliche Klassenstruktur zurück und reproduzieren diese (vgl. zum Habituskonzept bspw. Bourdieu 1987: 277ff.).

294 Andererseits gilt aber auch: "Das hohe Prestige einer Person, der gute Ruf einer Familie, der demonstrativ zur Schau gestellte Reichtum eines großen Mannes eröffnen häufig Möglichkeiten, um auch an ökonomisches Kapital zu gelangen, nach dem Motto: Wer (symbolisches) Kapital hat, dem wird auch (ökonomisches) Kapital gegeben. ... Die symbolische Kapitalform ist eine Art 'Kredit an Vertrauen', auf dessen Basis sich immer wieder ökonomische Chancen ergeben." (Joas/Knöbl 2004: 538) 
sowie eine "Art von Macht"295 (ebenda: 52), da es "ein Kapital langfristig nützlicher Verpflichtungen" (ebenda: 73), ein Kapital an "Beziehungen" (ebenda: 52), ist. Dementsprechend muss es sich auf Basis dieser Definition bei Sozialkapital um akkumulierte Arbeit und eine Ressource handeln, die sowohl aktuell wie potentiell verfügbar sein kann, deren Verfügbarkeit abhängig ist von der Zugehörigkeit zu einer Gruppe bzw. eines Beziehungsnetzes, die (einforderbare) langfristig nützliche Verpflichtungen sowie eine Form von Macht darstellt.

Nicht eindeutig zu klären ist die Frage, inwiefern es sich bei Sozialkapital nun um eine justiziable Ressource handelt, oder ob es sich gerade durch seinen informellen Charakter auszeichnet. So heißt es bei Bourdieu zwar, Sozialkapital werde durch Tauschbeziehungen geschaffen, "die Kalküle und Garantien explizit ausschließen und damit das Risiko der 'Undankbarkeit' heraufbeschwören; denn es besteht immer die Gefahr, dass die Anerkennung einer Schuldverpflichtung ... verweigert wird"296 (ebenda: 73). Zugleich aber können "Verpflichtungen auf ... institutionellen Garantien (Rechtsansprüchen) beruhen" (ebenda: 66).

Darüber hinaus verweisen Bourdieus Ausführungen auf ein instrumentelles resp. funktionalistisches Begriffsverständnis, das - ob vom Autor nun beabsichtigt oder nicht - durchaus auch in der Rational-Choice-Theorie seinen Platz finden könnte; "it fits easily into strategic models of economic behavior." (Sobel 2002: 139) So betont Bourdieu, "daß man maximiert" (Bourdieu 1997: 81); es geht ihm um "die Rationalität. Rationalisieren heißt, auf eine Art und Weise zu kalkulieren, die das bestmögliche Resultat mit den geringsten Kosten zu erreichen erlaubt. Es scheint mir, daß dieser selbe Mechanimsus in (...) sehr unterschiedlichen Ökonomien funktioniert."297 (ebenda: 80)

\footnotetext{
295 Bourdieu (1992: 52) spricht von den "verschiedenen Arten von Kapital (oder, was auf dasselbe herauskommt, die verschiedenen Arten von Macht)", die dafür sorgen, "daß nicht alles gleich möglich oder unmöglich ist." (ebenda: 50) Für Schechler (2002: 45) sollte daher im Zusammenhang mit Bourdieus Konzept nicht von "Kapital", sondern von "Vermögen" gesprochen werden: "Da Bourdieu ... den Ressourcen- bzw. Vermögenscharakter von Kapital mit Macht assoziiert, bedeutet die Verfügungsgewalt über Kapital ein Handlungspotential. Damit ist Bourdieus Kapitalbegriff mit dem hier verwendeten Vermögensbegriff gleichzusetzen." Andererseits betont Schechler (2002: 24), "der Kapitalbegriff impliziert stets die Intention der Investition mit dem Ziel der Renditeerwirtschaftung", und nennt als Beispiel die Erzeugung eines Verpflichtungsgefühls durch das Erweisen einer Gefälligkeit. Genau dann verfügt jene Person, der es gelungen ist, beim Gegenüber eine Verpflichtung zu erzeugen, aber über ein neu gewonnenes Handlungspotential, weswegen Schechlers Argumentation gegen den Kapitalbegriff mich nicht überzeugt.

296 "Anerkennung" ist definiert als ein "allgemeines Schuldanerkenntnis ohne 'Titel und Vertrag"" (Bourdieu 1992: 70).

${ }^{297}$ Freilich spricht sich Bourdieu (2005: 143) an anderer Stelle auch dezidiert gegen eine intentionale bzw. rationale Handlungstheorie aus: "Die Handlungstheorie, die ich (...) vorschlage, besagt letzten Endes, dass die meisten Handlungen der Menschen etwas anderes als die Intention zum Prinzip haben, nämlich erworbene Dispositionen, die dafür verantwortlich sind, dass man Handeln als zweckgerichtet interpretieren kann und muss, ohne deshalb von einer bewussten Zweckgerichtetheit als dem Prinzip dieses Handelns ausgehen zu können". Ein Anhänger des soziologischen SEUKonzepts wird hier m.E. aber kaum substantiell widersprechen.
} 
Bourdieu möchte durch seine Kapitalientheorie ein umfassenderes Verständis dessen, was Ökonomie bewirkt, erreichen; dennoch aber soll ökonomisches Kapital "in letzter Instanz" (Bourdieu 1992: 71) weiterhin Grundlage aller anderen Kapitalarten sein. Damit erweitert Bourdieu jedoch nicht den Ökonomie- sondern lediglich den Kapitalbegriff. Dieses Problem hätte er umgehen können, wenn er anstelle von "ökonomischem", bspw. von "physischem" oder "materiellem Kapital" gesprochen hätte. So wäre vermieden worden, dass "Ökonomie" sowohl als Ober- wie als Subkategorie firmiert, was schließlich zu der genannten Inkonsistenz führen muss ${ }^{298}$. Tatsächlich möchte Bourdieu Sozialkapital als Kapitalform im ökonomischen Sinne verstanden wissen; ist dies aber so, dann kann das als "ökonomisch" ausgewiesene Kapital begriffslogisch nicht sauber hiervon getrennt werden.

\section{Ebene}

Bei Bourdieu findet sich soziales Kapital vorrangig auf der Mikroebene. Bourdieu spricht zwar davon, "sie (Sozialkapitalbeziehungen, D.K.) können auch gesellschaftlich institutionalisiert und garantiert werden, und zwar sowohl durch die Übernahme eines gemeinsamen Namens, der die Zugehörigkeit zu einer Familie, einer Klasse, einem Stamm oder auch einer Schule, einer Partei usw. kennzeichnet, als auch durch eine Vielzahl anderer Institutionalisierungsakte, die die davon Betroffenen gleichzeitig prägen und über das Vorliegen eines Sozialkapitalverhältnisses informieren." (ebenda: 64) Die gesellschaftliche Institutionalisierung und Garantie der bzw. die Informierung über die Sozialkapitalbeziehung stellt aber keinesfalls selbst Sozialkapital dar. Sozialkapital ist eine Ressource, die dem Einzelnen dank seiner Einbindung in einen sozialen Kontext zur Verfügung steht; weder der soziale Kontext noch die diesen kennzeichnenden Normen lassen sich damit unter Rekurs auf Bourdieu in die Begriffsbestimmung mit einschließen.

Dennoch thematisiert Bourdieu die Aggregatebene, wenn er etwa von einem "gruppenkonstituierenden Kapital" (ebenda: 68) spricht, womit er wohl die Etablierung eines kollektiven Systems reziproker Verpflichtungen und Erwartungen meint. Aber es ist nicht nur die Konstitution, sondern ebenso die Gruppendynamik, die beeinflusst wird: "Das Gesamtkapital, das die einzelnen Gruppenmitglieder besitzen, dient ihnen allen gemeinsam als Sicherheit und verleiht ihnen - im weitesten Sinne des Wortes - Kreditwürdigkeit." (ebenda: 63) Die Frage ist davon ausgehend nun jedoch, ob diese unterstellte Folge einer Akkumulation individuellen sozialen Kapitals innerhalb einer Gruppe die gleiche Entität auf einer höherstufigen Ebene zum Entstehen bringt. Auf Basis dessen, was sich bei

298 Wobei Bourdieu (2005: 145) auch - was zwar m.E. nicht ganz glücklich aber immerhin trennschärfer ist - von der "ökonomischen Ökonomie" spricht. 
Bourdieu finden lässt, ist dies zu verneinen; es handelt sich vielmehr um einen Aggregateffekt, der begrifflich anders gefasst werden muss.

\section{Lokalisierung}

Sozialkapital ist bei Bourdieu eine Ressource, die vor allem dem Individuum zur Verfügung steht. Dezidiert spricht Bourdieu (ebenda: 64) bspw. "vom Umfang des Sozialkapitals, das der einzelne besitzt". Sozialkapital residiert insofern auch nicht in den Relationen zwischen den Individuen; es ist ein privates Gut, da es vorrangig um die von Personen realisierten gesellschaftlichen Statusvorteile geht $^{299}$. Ferner spricht Bourdieu im Zusammenhang mit der Entstehung von Sozialkapital auch von "kollektiven Investitionsstrategien" (ebenda: 66), womit Sozialkapital augenscheinlich - und damit in Erweiterung der oben getroffenen Aussagen zur Ebenenproblematik - ebenso auf der Mesoebene residieren kann, insofern es einer als handelnder Einheit in Erscheinung tretenden Gruppe oder Organisation zur Verfügung steht. Allgemein lässt sich Sozialkapital damit als eine Ressource eines individuellen oder kollektiven Akteurs begreifen.

\section{Entstehung}

Wenn "Sozialkapital" als "die Gesamtheit der aktuellen und potentiellen Ressourcen, die mit dem Besitz eines dauerhaften Netzes von mehr oder weniger institutionalisierten Beziehungen gegenseitigen Kennens und Anerkennens verbunden sind" (Bourdieu 1992: 63), definiert ist, dann entsteht der so bezeichnete Gegenstand durch den Aufbau, die Vererbung (vgl. ebenda: 55) oder durch die über soziale Rollenzuweisung (vgl. ebenda: 76, Fußn. 13) erfolgende Übernahme eben jener Beziehungen gegenseitigen Kennens und Anerkennens. Damit liegt hier ein austauschtheoretisches Verständnis zugrunde, d.h. "Sozialkapitalbeziehungen können nur in der Praxis auf der Grundlage von materiellen und/oder symbolischen Tauschbeziehungen existieren" (ebenda: 63) ${ }^{300}$. In der Anerkennung manifestiert sich selbst schon eine symbolische Tauschbeziehung, denn sie ist "ein allgemeines Schuldanerkenntnis 'ohne Titel und Vertrag'" (ebenda: 70).

\footnotetext{
299 Damit widerspreche ich etwa der Argumentation Haugs (2000: 96), soziales Kapital bei Bourdieu sei keine "persönliche, private Ressource, da es nicht unabhängig von anderen Personen erworben oder genutzt werden kann." Leider verweist Haug in diesem Zusammenhang auf keine Referenz bei Bourdieu, sondern behauptet lediglich, "eine genaue definitorische Abgrenzung von sozialem Kapital (zu anderen Kapitalformen, D.K.) ist in den Arbeiten von Bourdieu relativ schwierig, da er selbst eine unscharfe Definition liefert" (ebenda).

300 Damit der investive Charakter der sozialen Tauschprozesse nicht offen zu Tage tritt, folgt der Tausch "immer der Logik der Gabe und nicht des Kredits" (Bourdieu 2005: 154); und zwischen Gabe und Erwiderung liegt eine zeitliche Distanz, um so den eigentlich ökonomischen Charakter des Tuns zu "verschleiern" (ebenda: 140).
} 
Dabei betont Bourdieu den konstruktivistischen Charakter des Sozialkapitals. Ein Beziehungsnetz sei "weder eine natürliche noch eine soziale 'Gegebenheit', die aufgrund eines ursprünglichen Institutionalisierungsaktes ein für allemal fortbesteht", sondern "das Produkt einer fortlaufenden Institutionalisierungsarbeit. ... Diese Institutionalisierungsarbeit ist notwendig für die Produktion und Reproduktion der dauerhaften und nützlichen Verbindungen, die Zugang zu materiellen und symbolischen Profiten verschaffen." (ebenda: 66)

Fraglich bleibt allerdings, warum diese Profite zwangsläufig die Zugehörigkeit zu einer Gruppe voraussetzen, erscheint doch schon eine Relation zwischen zwei Personen als ausreichend, um Sozialkapital zu produzieren. Man könnte dieses Problem umgehen, indem man - wie allgemein üblich - eine Dyade als kleinstmögliche Gruppe begreift. Inwieweit dies jedoch im Bourdieuschen Sinne wäre, muss dahingestellt bleiben. Des Weiteren wäre zu klären, ob der Bezug von Sozialkapital die Zugehörigkeit zu jener Gruppe bedingt, welche die Ressource bereithält. Schließlich erscheint es plausibel, auch intergruppale Beziehungsmuster als Sozialkapital befördernd zu bewerten (etwa wenn sich Unternehmen bei Lieferproblemen wechselseitig unterstützen).

Man könnte natürlich dann von einer erweiterten oder einer anderen Gruppe sprechen (man würde somit begrifflich nicht von "Unternehmen A" und "Unternehmen B", sondern etwa von einer "Branche" ausgehen oder aber u.U. ein zwischen einzelnen Unternehmen liegendes Netzwerk von Vertriebsleitern identifizieren [im Sinne von Vereinigungs-, Teil- oder Schnittmengen]); wenn aber schließlich alle Beziehungen grundsätzlich als Gruppenbeziehungen firmieren, dann verliert der Gruppenbegriff im vorliegenden Zusammenhang an Informationswert und wird weitgehend redundant.

Das Beziehungsnetz, auf dem Sozialkapital beruht, wird als "das Produkt individueller oder kollektiver Investitionsstrategien, die bewußt oder unbewußt auf die Schaffung und Erhaltung von Sozialbeziehungen gerichtet sind, die früher oder später einen unmittelbaren Nutzen versprechen", begriffen (Bourdieu 1992: 66). Ziel dieser durch Geschenke, Gefälligkeiten oder Besuche gekennzeichneten Investitionsstrategien (vgl. ebenda: 73) ist die Etablierung von Verpflichtungen, denn "die einzige anerkannte Macht, in Form von Dankbarkeit, persönlicher Treue oder Prestige, verschafft man sich gebend." (Bourdieu 1993: 229) So "werden Zufallsbeziehungen, z.B. in der Nachbarschaft, bei der Arbeit oder sogar unter Verwandten, in besonders ausgewählte und notwendige Beziehungen umgewandelt, die dauerhafte Verpflichtungen nach sich ziehen." (Bourdieu 1992: 66)

Um nun Verpflichtungen zu erzeugen bedarf es einer "besonderen Kompetenz", unter der Bourdieu "die Kenntnis genealogischer Zusammenhänge und reeler Beziehungen sowie die Kunst, sie zu nutzen" versteht (ebenda: 67). Diese ist ein "fester Bestandteil des Sozialkapitals" (ebenda: 67), womit an dieser Stelle eine mögliche Entstehungsursache - die man auch als die soziale Kompetenz einer 
Person begreifen könnte - quasi zum Begriffsumfang gerechnet wird. Ferner stellt diese Kompetenz sicherlich keine Ressource dar, die im eigentlichen Sinne auf einem Beziehungsnetz beruht - genau dies müsste sie aber, soll sie der grundlegenden Bourdieuschen Definitionsbestimmung für "Sozialkapital" genügen.

Für Bourdieu sind alle Kapitalarten auf ökonomisches Kapital zurückzuführen; dieses bestimme in "letzter Instanz" (ebenda: 71) die Wirkung der anderen. Die Austauschbeziehungen auf denen Sozialkapital beruht, zählen zu jenen "Praxisformen ..., die zwar objektiv ökonomischen Charakter tragen, aber als solche im gesellschaftlichen Leben nicht erkannt werden und auch nicht erkennbar sind." (ebenda: 52) Dennoch aber wird "bei der Beziehungsarbeit ... Zeit und Geld und damit, direkt oder indirekt, auch ökonomisches Kapital verausgabt" (ebenda: 67), womit "die anderen Kapitalarten ... mit Hilfe von ökonomischem Kapital erworben werden" können (ebenda: 70).

\section{Wirkung}

Hinsichtlich der Wirkungen von Sozialkapital bleibt Bourdieu relativ abstrakt. Sozialkapital ist im Kontext seiner allgemeinen Wissenschaft von der Ökonomie der Praxis eben eine Kapitalform, die "einen Multiplikatoreffekt auf das tatsächlich verfügbare Kapital" ausübt (Bourdieu 1992: 64). Es verbessert insofern die Stellung, die der Einzelne innerhalb eines sozialen Kontextes, innerhalb einer Feldstruktur ${ }^{301}$, einnimmt. Zugleich ermöglicht dieser Kontext jedoch erst seine Entstehung und bestimmt seinen Umfang in maßgeblicher Weise mit. Letztlich und dies ist eben das Anliegen des gesellschaftskritisch konzipierten Ansatzes sollen Klassen- bzw. Schichtgegensätze nicht mehr nur unter Rekurs auf einen engen, lediglich traditionell ökonomischen, sondern über einen erweiterten Kapitalbegriff erklärt werden. Daraus folgt nun, dass Sozialkapital selektiv wirkt: Es bestimmt gesellschaftliche Positionen in maßgeblicher Weise mit und trägt zu ihrer Reproduktion bei.

Wurde eben gesagt, hinsichtlich der Wirkungen von Sozialkapital bleibe Bourdieu relativ abstrakt, so muss einschränkend hinzugefügt werden, dass schon mit Blick auf die bei Bourdieu vorfindbaren Ebenen, auf denen Sozialkapital residieren kann, die Äußerungen zur Aggregatebene als Beschreibung der Effekte der individuellen Ressource zu kennzeichnen sind. Entscheidend in diesem Kontext ist vor allen Dingen der Begriff der "Sozialkapitalbeziehung" bzw. des "Sozialkapitalverhältnis" (Bourdieu 1992: 63). Was darunter exakt verstanden werden soll, wird zwar nicht explizit ausgeführt; am wahrscheinlichsten erscheint es aber, dass hiermit ein bestehendes System reziproker Verpflichtungen und Erwartungen gemeint ist.

301 "Feld" ist ein weiterer zentraler Begriff der Bourdieuschen Theorieproduktion. Die Struktur des Feldes spezifiziert erst die Wirkung einer Kapitalform. 
Sind solche Systeme bspw. durch "die Übernahme eines gemeinsamen Namens, die Zugehörigkeit zu einer Familie, einer Klasse, einem Stamm oder auch einer Schule, einer Partei usw. gekennzeichnet", so können sie "gesellschaftlich institutionalisiert und garantiert" genannt werden (ebenda: 63). Gleichwohl stellen sie selbst kein Sozialkapital dar, sondern ermöglichen vor allem dessen Austausch, d.h. die mit Sozialkapital verbundenen gegenseitigen Austauschbeziehungen können mit einer Norm der Reziprozität ein Kollektivgut begründen. (Die Norm kann ihrerseits eine Voraussetzung für die Entstehung von Sozialkapital sein, wenn etwa eine Person einer anderen Ressourcen zur Verfügung stellt, weil sie sich hierzu z.B. moralisch aufgefordert fühlt.)

\section{Operationalisierung}

Zur Operationalisierung des Konstrukts finden sich bei Bourdieu explizit fast keine Angaben (Adam/Roncevic [2003: 161] sprechen von "fragments of empirical analysis"). Immerhin heißt es, die Höhe des Sozialkapitals hänge "sowohl von der Ausdehnung des Netzes von Beziehungen ..., die er (der Einzelne, D.K.) tatsächlich mobilisieren kann, als auch von dem Umfang des (ökonomischen, kulturellen oder symbolischen) Kapitals, das diejenigen besitzen, mit denen er in Beziehung steht" $\mathrm{ab}^{302}$ (Bourdieu 1992: 64). Eine ähnliche Formulierung existiert auch im Kontext des netzwerktheoretischen Sozialkapitalkonzeptes, womit die dort vorfindbaren Operationalisierungsvorschriften durchaus auch für Bourdieu übernommen werden können ${ }^{303}$ (vgl. also Kapitel 7.4.).

\section{Wissenschaftstheoretischer Status}

Hinsichtlich der Bourdieuschen Theoriekonstruktion kann von einem induktiven und phänomenologischen Vorgehen gesprochen werden. Mittels einer gedanklichen Systematisierung auf Basis empirischer Plausibilitäten und ethnologischer wie soziologischer Untersuchungen vor allem zur algerischen und französischen Gesellschaft (sei es zur Kunst, zur Religion, zur Bildung oder zur Administration;

\footnotetext{
302 Freilich wäre hier zu fragen, warum bei der Aufzählung der Kapitalarten das soziale Kapital ungenannt bleibt, erscheint es doch plausibel, dass ein "Mehr" an Sozialkapital auf seiten desjenigen, mit dem man in Beziehung steht, i.d.R. auch das eigene Sozialkapital (sei es qualitativ oder quantitativ) positiv beeinflusst.

${ }^{303}$ Damit kann an dieser Stelle auch auf die generelle Sinnhaftigkeit einer Analyse von Operationalisierungsvorschriften im Rahmen eines Theorienvergleichs hingewiesen werden: Selbst wenn wir annehmen würden, dass verschiedene Sozialkapitalexponenten weitgehend identische Definitionen für "Sozialkapital" vorgenommen hätten, dann müssten wir immer noch auf die anvisierten Messverfahren schauen, denn die jeweils festgelegten Indikatoren könnten sich derart stark unterscheiden, dass wir de fakto dann - trotz der weitgehenden definitorischen Gleichheit - von unterschiedlichen Konstrukten zu reden hätten (hier stoßen wir also auf die instrumententheoretische Problematik des Basissatzproblems).
} 
vgl. etwa Bourdieu 1979, 1987, 2000, Bourdieu/Passeron 1971) konzeptualisiert der Autor die aus den Beziehungen zwischen Personen resultierenden nutzbaren Ressourcen für den Einzelnen über ein neues (bzw. ein bis dato kaum bekanntes) theoretisches Konstrukt ${ }^{304}$.

Gleichwohl behaupten Schuller et al. mit Blick auf Bourdieus Konzept: "The contrast between sophisticated theoretical claims and weak empirical data is stark." (Schuller et al. 2000: 4) Diese von den Autoren nicht weiter begründete Einschätzung ist wohl - so meine Vermutung - weniger auf die Anzahl der von Bourdieu durchgeführten empirischen Analysen, als vielmehr auf eine Bewertung hinsichtlich deren methodischer wie methodologischer Qualität zurückzuführen. In der Tat lässt sich Bourdieu nur schwer als einheitswissenschaftlich orientierter Sozialforscher begreifen. Seine empirische Vorgehensweise ist in weiten Teilen dafür nicht systematisch genug und steht nahezu grundsätzlich im Dienst der an Umfang dominierenden theoretischen, zumeist kultursoziologischen Reflexionen. Bourdieu hat die kritische methodologische Rezeption wohl nicht weiter gestört: "Für die Theoretiker bin ich zu empiristisch, für die Empiriker zu theoretisch. (...) Für die Theoretiker ist meine Arbeit merkwürdig und für die Empiriker ist sie ebenfalls merkwürdig, weil ich nicht arbeite wie sie. Ich habe nicht den Fetischismus des Empirismus" (Bourdieu 1997: 91).

Theoriegeschichtlich sollen an dieser Stelle der Vollständigkeit halber noch die strukturalistischen Wurzeln Bourdieus Erwähnung finden ${ }^{305}$. So stehen wie beim Habituskonzept auch bei der Einführung und Analyse von Sozialkapital die Produktions- und Reproduktionsmechanismen gesellschaftlicher Strukturen und damit die Frage, wie diese die individuellen Lebensstile und Gestaltungschancen

\footnotetext{
304 Sein methodisches Vorgehen hinsichtlich der Errichtung seiner Kapitalientheorie umschreibt Bourdieu selbst wie folgt: "Ich bin von klassischen ethnologischen Analysen ausgegangen, ich habe den Leuten zugehört, als sie über Probleme der Ehre etc. redeten. Und dann habe ich ein kleines Modell konstruiert: Wenn jemand herausgefordert wird, wird er antworten. Dann habe ich nach und nach 'Ehre' durch 'symbolisches Kapital' ersetzt. Das ist sehr langsam vor sich gegangen, ich habe Jahre dazu gebraucht. Und ich glaube, daß ich an dem sehr einfachen Gesetz des Phänomens angekommen bin." (Bourdieu 1997: 79f.) Und speziell auf soziales wie kulturelles Kapital sowie die hiermit einhergehende Macht bezogen: "Ja, es ist die Beziehung zwischen den Leuten, zwischen den Herrschenden und den Beherrschten, die Beziehung zwischen beiden. Ich habe den Fall von Hyppolite als Beispiel genommen. Er ist ein französischer Philosophieprofessor, der auf universitärem Gebiet ziemlich bedeutend war. Ich habe die Liste der Leute erstellt, die bei ihm Dissertationen vorgelegt hatten. Alle, fast alle Leute meiner Generation, Foucault, Derrida etc., alle bekannten Leute hatten bei ihm ihre Dissertationen vorgelegt. Aber dieser Mann war kein großer Philosoph. Unter jenen, die bei ihm eingeschrieben waren, war Michael Serres, der über Leibniz arbeitete, Foucault, der die Klinik erforschte, währende Hyppolite ein Hegelspezialist war. Man fragt sich, warum die Leute sich an diesen Mann wandten. Dies ist ein sehr typischer Fall. Dieser Mann hat Macht, weil Leute, die sich hervorragend fühlen, weil sie schon Schüler der gleichen 'Ecole normale' waren, weil sie schon vom Schulsystem geweiht worden sind, ihm Macht zuführen. Aber sie führen ihm Macht zu, weil er schon Macht hat etc. Um das wirklich zu verstehen, muß man alles studieren: Man muß die 'Ecole normale' untersuchen, die soziale Herkunft jener, die dort sind, warum einige von ihnen Philosophie studieren etc. Anders gesagt, es geht um das ganze System." (ebenda: 83)

305 Mit "Strukturalismus" ist hier nicht der wissenschaftstheoretische oder der linguistische, sondern der anthropologische Strukturalismus von Lévi-Strauss gemeint.
} 
beeinflussen, im Vordergrund. Ob umgekehrt über innovative soziale Praxen auch gesellschaftliche Strukturen verändert werden können, bleibt weitgehend unthematisiert, obwohl es Bourdieu ursprünglich (etwa in seiner ethnologischen Untersuchung des Berbervolkes der Kabylen in Algerien [vgl. Bourdieu 1979]) gerade um diese Veränderungsmöglichkeiten ging.

Bourdieu verfolgt mit seinen Überlegungen ein gesellschaftskritisches Anliegen: Als neo-marxistisch orientierter Soziologe möchte er die gesellschaftlichen Machtverhältnisse, die Reproduktion der Privilegien von Eliten, aufdecken ${ }^{306}$. In Modifizierung einer marxistischen Perspektive gilt nun nicht mehr lediglich die Verfügungsgewalt über ökonomisches Kapital als kritische Variable gesellschaftlicher Schichtung bzw. Klassenzugehörigkeit; vielmehr tritt innerhalb einer erweiterten Kapitalientheorie nun u.a. Sozialkapital als erklärende Komponente hinzu. Bourdieus Konzept richtet sich daher gerade auch gegen eine "Verklärung der ökonomischen Beziehungen und vor allem der Ausbeutungsbeziehungen" (Bourdieu 2005: 144): "Wenn nämlich der Wirtschaft nur die am unmittelbaren Nutzenkalkül ausgerichteten Praktiken und die direkt und unmittelbar in Geld umsetzbaren (und damit 'quantifizierbaren') Güter zugerechnet werden, dann erscheint in der Tat die Gesamtheit der bürgerlichen Produktion und Austauschbeziehungen als von der Wirtschaft ausgenommen; sie kann sich dann als eine Sphäre der Uneigennützigkeit begreifen und darstellen." (Bourdieu 1992: 51f.) Die Relevanz des sozialen Kapitals zeigt sich Bourdieu zu Folge jedoch gerade dann, wenn Individuen zwar über einen relativ gleich großen Betrag an ökonomischen und kulturellen Kapital verfügen, damit jedoch "sehr ungleiche Erträge erzielen" (ebenda: 76, Endn. 12).

Methodologisch gesprochen hat Bourdieu hier die Variablen "ökonomisches Kapital" und "kulturelles Kapital" isoliert, um so die Frage zu klären, ob das soziale Kapital einen Unterschied macht. De fakto wird hier allerdings lediglich auf Basis empirischer Plausibilität argumentiert; an eine methodisch saubere empirische Anwendung oder Überprüfung dürfte Bourdieu wohl erst an zweiter Stelle gedacht haben. Insgesamt lässt sich sein Konzept als quantitatives, gesellschaftskritisches Realmodell kennzeichnen: Es ist (a) quantitativ - obwohl ein expliziter Verweis auf eine Berechnung nicht gegeben wird -, weil die mikrotheoretische, netzwerkanalytisch interpretierbare Konzeptualisierung eine Quantifizierung des Sozialkapitals grundsätzlich zulässt, (b) gesellschaftskritisch, zumal Bourdieu in die soziale Praxis bewusst eingreifen und Veränderungen bewirken möchte und es ist (c) ein Realmodell, weil es auf Grundlage von empirischen Plausibilitäten und ethnologischen bzw. soziologischen Studien (vor allem zur französischen Gesellschaft) induktiv konstruiert wird.

\footnotetext{
306 Insofern ist Bourdieus Blick auf die Gesellschaft konflikttheoretischer Provenienz; Coleman und Putnam hingegen zielen - wie wir noch sehen werden - mit ihren Vorstellungen auf die Modellierung von Solidarität und sozialer Integration ab (vgl. Siisiäinen 2000: 10).
} 


\section{Strukturalistische Darstellung}

Ziel der Bourdieuschen Ausführungen ist es - wie bereits erwähnt -, den Begriff des "Sozialkapitals" in ein erweitertes Ökonomieverständnis einzuführen, um hierüber einer materialistischen Reduzierung der Erklärung sozialer Schichtung und Klassenzugehörigkeit entgegenzuwirken. Jenseits dieses Erkenntnisinteresses kann das Konzept jedoch unabhängig von seiner gesellschaftskritischen Stoßrichtung als analytisches Instrument zur Erfassung der aus sozialen Beziehungen resultierenden Ressourcen systematisiert werden ${ }^{307}$. In diesem Sinne lassen sich die zentralen Aspekte der Bourdieuschen Überlegungen zunächst noch einmal grob in einer tabellarischen Übersicht zusammenfassen, bevor sie dann in Form von Postulaten dargestellt werden.

Tabelle 1: Bourdieus Sozialkapitalkonzept

Definition

Ebene

Lokalisierung

Entstebung

Wirkung

Operationalisierung
Sozialkapital ist

aktuelle od. potentielle Ressource, die mit dem Besitz eines institutionalisierten Beziehungsnetzes verbunden ist eine Form von Macht akkumulierte Arbeit einforderbare nützliche Verpflichtung funktional informell

Mikro, Meso

Besitz des Akteurs; Privatgut

Tauschbeziehungen Vererbung bzw. Transferierung Investitionen in Beziehungen (vor allem Zeit) Erzeugung von Verpflichtungen

Bestimmung / Reproduktion gesell. Positionen Multiplikatoreffekt auf alle für den Akteur verfügbaren Kapitalarten Kollektivgüter wie Normen

keine expliziten Angaben aber netzwerkanalytische Operationalisierung möglich

$307 \mathrm{Ob}$ man damit dem eigentlichen Anliegen Bourdieus gerecht wird, sei an dieser Stelle einmal dahingestellt. Hier geht es nicht um biographische oder hermeneutische Zugangsweisen zu sozialwissenchaftlichen Autoren und deren Erkenntnisinteressen, sondern um wissenschaftstheoretische Rekonstruktionen und Beurteilungen ihrer Aussagensysteme. 
empirisch-induktive und phänomenologische

Theoriekonstruktion quantitatives Realmodell

gesellschaftskritisches Aufklärungsmodell

Vor der strukturalistischen Darstellung des Bourdieuschen Konzeptes möchte ich nochmals in Erinnerung rufen, dass über die Axiomatisierung natürlich keine von den verbalen Erörterungen abweichenden Behauptungen formuliert werden. Vielmehr geht es darum, die zentralen terminologischen und theoretischen Zusammenhänge in übersichtlicher, präziser und ökonomisch-komprimierter Form sowie in einer den Theorienvergleich erleichternden normierten Einheitssprache festzuhalten.

\section{Erster Rekonstruktionsschritt (Formulierung der zentralen Postulate)}

1. Die einem Akteur (A) in Folge seiner Zugehörigkeit zu einem Beziehungsnetz (B) 308 informell (Inf) zufließenden (sei es tatsächlich oder potentiell) und funktional (Fun) der eigenen Zielverwirklichung ( $Z$ ) dienenden Ressourcen (R) sind sein soziales Kapital ( $\mathrm{S}^{\mathrm{B}}\left[\mathrm{S}^{\mathrm{B}}=\right.$ Soziales Kapital bei Bourdieu]).

2. Sozialkapital findet sich grundsätzlich auf der Mikro- ( $\mathrm{L}^{\mathrm{Mi}}[\mathrm{L}=$ Level]), aber auch auf der Mesoebene $\left(\mathrm{L}^{\mathrm{Me}}\right)$.

3. Sozialkapital ist eine dem einzelnen Akteur gehörende Ressource $\left(\operatorname{Lok}^{\mathrm{A}}\right)$ (Lokalisierung auf Seiten des Akteurs $=$ Lok $^{\mathrm{A}}$; Lokalisierung innerhalb von Relationen zwischen Akteuren wird entsprechend als Lok ${ }^{R e l}$ symbolisiert); es kann lediglich als privates Gut (Griv) (kollektives Gut $=G^{\text {koll }}$ ) in Erscheinung treten.

4. Gegenseitiges Kennen und Anerkennen (GK) zwischen Teilnehmern $\left(\mathrm{Te}^{309}\right)$ eines Beziehungsnetzes und Akteur sowie Austauschprozesse (Ta) zwischen diesen sind Voraussetzungen der Entstehung von sozialem Kapital.

5. Soziales Kapital kann Resultat von Verpflichtungen (V) erzeugenden individuellen bzw. kollektiven Investitionsstrategien (Inv) in Beziehungen sowie sozialer Kompetenz (Kom) sein. Die Investitionsstrategien erfordern den Einsatz ökonomischen Kapitals (Ö) (vor allem in Form aufzuwendender Zeit). Verpflichtungen resultieren aber auch aus nicht bewusst investiv ange-

\footnotetext{
308 Bourdieu spricht im Zusammenhang mit Sozialkapital von einer "Gruppe" (Bourdieu 1992: 63). Mit Blick auf eine leichtere Vergleichbarkeit der von mir untersuchten Autoren ersetze ich diesen Begriff durch "Beziehungsnetz" (denn "Gruppe" bezeichnet ein Netz von untereinander in Beziehung stehenden Personen).

309 Innerhalb des Aussagensystems ist Sozialkapital eine Entität, die einem (entweder individuellen oder kollektiven) Akteur zugeordnet wird. Gleichwohl muss dieser Akteur mit anderen Akteuren in Beziehung stehen. Diese "anderen Akteure" werden von mir "Teilnehmer" (eines Beziehungsnetzes) genannt, so dass die Menge A (mit nur einem Element) und die Menge Te (1-n Elemente) streng auseinander gehalten werden können.
} 
legten Tauschprozessen. Sozialkapital kann ferner vererbt werden, d.h. ein oder mehrere Teilnehmer transferieren eine Verpflichtung $(\mathrm{Tr})$, die sie anderen gegenüber verspüren, auf einen Akteur, dem so Sozialkapital ohne vorangehende Investition erwächst ${ }^{310}$. (Im Hintergrund kann hier auch die Norm der generalisierten Reziprozität stehen.)

6. Sozialkapital bestimmt die gesellschaftliche Position (P) von Akteuren in entscheidender Weise mit und ist insofern ein zentraler Faktor zur Erklärung von Klassenzugehörigkeit und sozialer Schichtung bzw. zur Erklärung der Reproduktion sozialer Ungleichheit.

Zweiter Rekonstruktionsschritt (Mengentheoretische Darstellung der Grundbegriffe; terminologische Axiome, d.h. präzise Festlegung der Begriffe und begrifflichen Zusammenhänge)

Im zweiten Rekonstruktionsschritt werden die Grundbegriffe charakterisiert. Dabei analysiere ich diese Begriffe überwiegend als komplexe Verbindungen, um hierüber insbesondere mit Blick auf die zentralen Zusammenhangssaussagen eine größtmögliche Transparenz zu erreichen. Dies bedeutet z.B., dass ich "Beziehungsnetz" nicht als Gattungs-, sondern als Relationsbegriff und insofern als abgeleitete Menge bzw. als Teilmenge eines kartesischen Produkts begreife. Balzer nennt als sozialwissenschaftliche Gattungsbegriffe u.a. "soziale Gruppe" und "soziale Rolle", weist jedoch auch auf eine abweichende Konzeptualisierungsmöglichkeit hin: "Die Objekte selbst können, 'von außen' betrachtet, komplexer Natur sein, wie zum Beispiel soziale Rollen und dennoch in einer Theorie den Status von Grundobjekten haben, deren Zusammensetzung in dieser Theorie nicht weiter analysiert wird." (Balzer 1997: 63)

Relationsbegriffe bezeichnen n-stellige Relationen, die verschiedene Komponenten in Beziehung zueinander setzen. So ist bspw. "Verpflichtung" im vorliegenden Zusammenhang ein 2-stelliger Relationsbegriff, weil damit ausgedrückt werden soll, dass ein Teilnehmer (eines Beziehungsnetzes) sich einem Akteur (dem Sozialkapital zugeordnet werden kann) verpflichtet fühlt. Oder anders ausgedrückt: "Verpflichtung" (V) ist eine 2-stellige Relation zwischen Elementen aus "Teilnehmern" (Te) und "Akteur" (A); formalisiert: $\mathrm{V} \subseteq$ Te x A.

Die unten nicht als Teilmengen kartesischer Produkte aufgeführten Begriffe sind entweder 1-stellig, d.h. nicht weiter auflösbar (wie etwa A) oder innerhalb des vorliegenden Kontextes hinsichtlich ihrer Zusammensetzung nicht von Belang. So könnte man bspw. Z (eigene Zielverwirklichung) als 4-stelligen Relationsbegriff und damit als Teilmenge des kartesischen Produkts von Akteur, Zielen, Handlun-

\footnotetext{
310 Bei Bourdieu ist von der "Vererbung" von Sozialkapital die Rede. Diese Überlegung lässt sich dahingehend umformulieren und generalisieren, dass eine Verpflichtung, die ein Akteur A einem Akteur B gegenüber verspürt, auf einen Akteur C übertragen (bzw. transferiert) wird, weil dieser mit Akteur B verbunden ist (Bsp.: Peters bester Freund ist KFZ-Mechaniker und repariert kostenlos das Auto von Peters Schwiegertochter).
} 
gen und Handlungsergebnissen begreifen ${ }^{311}$; weil Ziele, Handlungen und Handlungsergebnisse aber keine zentralen Bestandteile des untersuchten Sozialkapitalkonzeptes sind und insofern auch keine Elemente von $\mathrm{M}_{\mathrm{P}}$ darstellen, wird $\mathrm{Z}$ nicht weiter aufgeschlüsselt. Lok (Lokalisierung) und L (Ebene) ließen sich auch als Funktionen (bzw. zumindest als Abbildungen) auffassen, in denen Sozialkapital einem bestimmten Ort zugeordnet wird. Da es sich jedoch lediglich um nominalskalierte Größen handelt, wird auf eine solche Interpretation verzichtet. Von Funktionen soll hier nur dann gesprochen werden, wenn es um metrisch interpretierbare Größen und deren Veränderung durch andere geht - also ausschließlich im Kontext von Wirkungsargumentationen ${ }^{312}$. (Weitere Erläuterungen zum Vorgehen bei der strukturalistischen Darstellung und insbesondere zum logischen Vokabular finden sich vorwiegend in den Fußnoten.)

Noch zentraler ist die Bedeutung von Teilmengen kartesischer Produkte im Hinblick auf die ontologische Auseinandersetzung. Bei der Darstellung der Teilmengen werden nämlich jene Entitäten benannt, die notwendig vorhanden sein müssen, damit der Gegenstand überhaupt sinnvoll eingeführt werden kann. Während der moderate Strukturalismus schon auf wissenschaftstheoretischer Grundlage die hierzu vorfindbaren Aussagen der Sozialkapitaltheoretiker benennt, werden diese Aussagen später systematisiert und über genuin ontologische Überlegungen erweitert.

$\mathrm{Q}^{313}$ ist ein potentielles Modell des Bourdieuschen Sozialkapitalkonzeptes, gdw Q ein Tupel der Form

$\left\langle\mathrm{S}^{\mathrm{B}}, \mathrm{A}, \mathrm{B}, \mathrm{Inf}, F u n, \mathrm{Z}, \mathrm{R}, \mathrm{Rel}, \mathrm{L}^{\mathrm{Mi} / \mathrm{Me}}, \mathrm{Lok}^{\mathrm{A}}\right.$, Griv, GK,Te,Ta,V,Inv,Kom,Ö,Tr,P $\quad$ wobei gilt

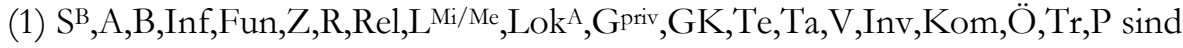

311 Zielverwirklichung setzt voraus, dass ein Akteur Ziele hat, mit Blick auf diese bestimmte Handlungen selegiert, sowie dass die Handlungsergebnisse den Zielen korrespondieren (dass "Zielverwirklichung" als Relationsbegriff aufgefasst werden kann, wird in folgender Wendung, in der die einzelnen Komponenten in Beziehung zueinander gesetzt werden, noch deutlicher: Ein Akteur verwirklicht über das Resultat einer bestimmten Handlung ein Ziel).

312 Im Übrigen sind L und Lok weitgehend redundante Elemente einer strukturalistischen Rekonstruktion der hier untersuchten Konzepte; sie tragen weder etwas zum Verständnis dessen bei, was Sozialkapital sein soll, noch geben sie wirklich Auskunft über seine Entstehung und Wirkung. Dennoch aber werden diese Komponenten hier aufgeführt, da anderenfalls sehr relevante sozialwissenschaftliche Kategorien und Streitpunkte innerhalb der Sozialkapitaldebatte aus dem Blickfeld geraten würden (L liefert bspw. Informationen über die Reichweite eines theoretischen Konzeptes). 313 An dieser Stelle ersetze ich das strukturalistische Symbol "X" durch "Q", da "X" eine zentrale Kategorie innerhalb Searles Ontologie institutioneller Tatsachen darstellt und innerhalb der vorliegenden Arbeit ausschließlich im dortigen Zusammenhang Verwendung finden soll. "Q" bezeichnet hier also die Zusammenfassung all jener Komponenten, die notwendig sind, um Bourdieus Sozialkapitalkonzept darzustellen. 
endliche, nicht-leere Mengen. Nach Ausgliederung von $\mathrm{R}$ sind alle Mengen disjunkt (der Durchschnitt dieser Mengen ist also die leere Menge: $\mathrm{S}^{\mathrm{B}} \cap \mathrm{A} \cap \mathrm{B} \cap$ Inf etc. $=\varnothing)$.

Die Mengen A, B, Z, L, Lok, G, Te, Kom und Ö werden im Folgenden nicht weiter zerlegt. Wie eben schon ausgeführt, handelt es sich dabei entweder um 1stellige bzw. Gattungsbegriffe, oder aber ihre Aufschlüsselung ist hinsichtlich der Rekonstruktion des Sozialkapitalkonzeptes nicht relevant (freilich sind die Mengen selbst relevant). Über die genannten Relationsbegriffe werden die Komponenten des Tupels Q in unterschiedlicher Weise charakterisiert: Inf, Fun, Rel und GK werden zur Charakterisierung von Eigenschaften, Ta, Inv und Tr von Handlungen und $\mathrm{V}$ von Kognitionen festgelegt ${ }^{314}$.

(2) $\mathrm{S}^{\mathrm{B}} \subseteq \mathrm{R} ; \mathrm{R} \supseteq \mathrm{S}^{\mathrm{B}} ; \mathrm{R} \supseteq \ddot{\mathrm{O}}$

(3) $\operatorname{Inf} \subseteq \operatorname{Rel} \times \mathrm{R}$

(4) Fun $\subseteq \mathrm{R} \times \mathrm{A} \times \mathrm{Z}$

(5) $\mathrm{R} \subseteq \mathrm{Te} \times \mathrm{A}$

(6) Rel $\subseteq \mathrm{A} \times \mathrm{Te}$

(7) $\mathrm{GK} \subseteq \mathrm{A} \times \mathrm{Te}$

(8) $\mathrm{Ta} \subseteq \mathrm{A} \times \mathrm{Te} \times \mathrm{R}$

(9) $\mathrm{V} \subseteq$ Te $\mathrm{x} A$

(10) Inv $\subseteq$ A x Ö x Rel

(11) $\operatorname{Tr} \subseteq \operatorname{Te} \times \mathrm{V} \times \mathrm{A}$

Diese Bedingungen meinen ${ }^{315}$ :

(1) Alle Begriffe sind empirisch bestimmbar. Nach Ausgliederung von R (Ressourcen) sind alle Begriffe zu unterscheiden, d.h. alle Begriffe bezeichnen unterschiedliche Entitäten.

(2) Sozialkapital ist bei Bourdieu eine Teilmenge von Ressourcen. Umgekehrt ist damit die Menge der Ressourcen die umfassende Menge von Sozialkapital. Die

\footnotetext{
314 Informalität beschreibt eine Eigenschaft von (Beziehungs-)Relationen in Bezug zu Ressourcen (die über diese Relationen bezogen werden), Funktionalität beschreibt eine Eigenschaft von Ressourcen hinsichtlich der Zielverwirklichung eines Akteurs, Relationen sowie gegenseitiges Kennen und Anerkennen charakterisieren die Verbindung zwischen Akteur und Teilnehmern. Tauschprozesse (ein Akteur tauscht mit Teilnehmern Ressourcen aus), Investitionen (ein Akteur investiert ökonomische Ressourcen in eine Beziehungsrelation) und Transferierungen (Teilnehmer transferieren Verpflichtungen auf einen Akteur) werden als Handlungen interpretiert. Verpflichtung gilt als kognitiv-emotionale Charakterisierung von Teilnehmern (ein oder mehrere Teilnehmer empfinden oder kognizieren eine Verpflichtung gegenüber einem Akteur).

315 Die Lektüre dieser Bedingungen wird sich zweifellos etwas - sagen wir - zäh gestalten. Gleichwohl müssen diese Bedingungen ausführlich dargestellt werden, um dem Anliegen der Arbeit nämlich über eine Axiomatisierung bestehender Sozialkapitalkonzepte eine logische Propädeutik über Sozialkapital zu entwickeln - gerecht werden zu können.
} 
Menge der Ressourcen ist außerdem die umfassende Menge von ökonomischem Kapital (oder anders formuliert: ökonomisches Kapital ist eine Teilmenge der Menge der Ressourcen).

(3) Informalität ist eine Teilmenge des kartesischen Produkts, das Ressourcen und (Beziehungs-) Relationen miteinander in Verbindung bringt, d.h. im Hinblick auf die als "Sozialkapital" bezeichnete Ressource ist die Relation zwischen A und Te informell - aus ihr resultiert kein formal-rechtlicher Anspruch auf den Bezug der Ressource, die nur so als "Sozialkapital" bezeichnet werden kann. (Wie oben bereits gezeigt, finden sich bei Bourdieu widersprüchliche Auskünfte hinsichtlich der Informalität von Sozialkapital. Mit Blick auf die später vorzunehmende integrative Theoriebildung wird diese Widersprüchlichkeit hier ignoriert. Zum einen zeichnet sich Sozialkapital bei allen anderen Autoren durch seinen informellen Charakter aus, zum anderen wäre es definitorisch wenig sinnvoll, würde man einen formellen oder auch nur semi-formellen Rechtsanspruch bezüglich jener Ressourcen, um die es gehen soll, festlegen. Hiermit würden bspw. öffentliche oder private Dienstleistungen [etwa Unterstützungen durch das Arbeitsamt oder Beratungsgespräche mit Bankangestellten] zu Sozialkapital.)

(4) Funktionalität ist eine Teilmenge des kartesischen Produkts, das Ressourcen, einen Akteur, dem Sozialkapital zugeordnet werden kann und Zielverwirklichung miteinander in Verbindung bringt, d.h. eine Ressource ist funktional für die Zielverwirklichung des Akteurs (soll sie denn unter die Definition von "Sozialkapital" fallen).

(5) Ressourcen sind eine Teilmenge des kartesischen Produkts aus Teilnehmern und Akteur, d.h. (mindestens) ein Teilnehmer ist bereit, einem Akteur (mindestens) eine Ressource zur Verfügung zu stellen. (Ein Gut eines Teilnehmers wird hier also erst dann zu einer Ressource, wenn der Akteur, dem Sozialkapital zugeordnet werden kann, hierauf grundsätzlich Zugriff erhält.)

(6) (Beziehungs-) Relationen sind eine Teilmenge des kartesischen Produktes aus Akteur und Teilnehmern, d.h. zum Auftreten von Relationen als Bedingung von Sozialkapital bedarf es eines Akteurs, dem Sozialkapital zugeordnet werden kann und mindestens eines weiteren Teilnehmers (bzw. eines weiteren Akteurs) ${ }^{316}$.

\footnotetext{
316 Anhand dieses einfachen Zusammenhangs sollen die Bedingungen kurz näher erläutert werden. In einer strukturalistischen Darstellung werden die Begrifflichkeiten einer Theorie als Mengen aufgefasst. Im Sozialkapitalkonzept Bourdieus ist Sozialkapital eine Ressource eines einzelnen Akteurs. Mengentheoretisch gesprochen handelt es sich bei diesem Akteur um die Menge A, deren Mächtigkeit 1 beträgt, die also nur ein einziges Element enthält: $A=\{x\}$. Da es sich bei Sozialkapital $(\mathrm{S} B)$ um eine sozialstrukturelle Ressource handelt, benötigt man zu seiner Realisierung (neben diversen anderen Komponenten) mindestens einen weiteren Akteur, hier (um ihn von dem fokalen Akteur zu unterscheiden) "Teilnehmer" genannt: $\mathrm{Te}=\left\{\mathrm{y}_{1}, \mathrm{y}_{2}, \mathrm{y}_{3}, \ldots \mathrm{y}_{\mathrm{n}}\right\}$. Steht nun ein Akteur mit anderen Teilnehmern in einer sozialen Relation, so erhält man die Menge Rel mit folgenden möglichen Wertepaaren (also n-gliedrigen Folgen): $\left\{\left(\mathrm{x}_{\mathrm{y}} \mathrm{y}_{1}\right),\left(\mathrm{x}, \mathrm{y}_{2}\right),\left(\mathrm{x}, \mathrm{y}_{3}\right), \ldots\left(\mathrm{x}, \mathrm{y}_{1-\mathrm{n}}\right)\right\}$. Rel ist damit eine Teilmenge von A, Te, d.h. ein bzw. das Element aus A steht in einer sozialen Beziehung mit Elementen aus Te. Da es sich um mindestens einen aber auch um alle anderen Teilnehmer aus der Menge Te handeln könnte, spricht man auch von der Menge aller möglichen Teilmengen von Te
} 
(7) Gegenseitiges Kennen und Anerkennen ist eine Teilmenge des kartesischen Produkts aus Akteur und Teilnehmern, d.h. zum Auftreten eines Systems gegenseitigen Kennens und Anerkennens bedarf es eines Akteurs, dem Sozialkapital zugeordnet werden kann und mindestens eines weiteren Teilnehmers (GK spezifiziert insofern eine [Beziehungs-] Relation).

(8) Tauschprozesse sind eine Teilmenge des kartesischen Produkts aus Akteur, Teilnehmern, und Ressourcen, d.h. zum Auftreten von Tauschprozessen als Bedingung von Sozialkapital bedarf es eines Akteurs, dem Sozialkapital zugeordnet werden kann, mindestens eines weiteren Teilnehmers sowie Ressourcen, die ausgetauscht werden (da Ta eine [Beziehungs-] Relation impliziert, kann auf Rel verzichtet werden).

(9) Verpflichtungen sind eine Teilmenge des kartesischen Produkts aus Teilnehmern und Akteur; ein Teilnehmer fühlt sich einem Akteur, dem Sozialkapital zugeordnet werden kann und mit dem er in Verbindung steht, verpflichtet (da V eine [Beziehungs-] Relation impliziert, kann auf Rel verzichtet werden).

(10) Investitionen sind eine Teilmenge des kartesischen Produkts aus Akteur, ökonomischem Kapital und (Beziehungs-) Relationen, d.h. zum Auftreten einer Investition als Bedingung von Sozialkapital bedarf es eines Akteurs, dem Sozialkapital zugeordnet werden kann, ökonomischen Kapitals (vor allem Zeit), welches investiert wird sowie mindestens einer Relationen, in die investiert wird.

(11) Transferierungen sind eine Teilmenge des kartesischen Produkts aus Teilnehmern, Verpflichtungen und Akteur, d.h. ein Teilnehmer transferiert eine Verpflichtung, die er jemand anderem gegenüber verspürt, auf den Akteur, dem Sozialkapital zugeordnet werden kann.

\section{Dritter Rekonstruktionsschritt (Quantorenlogische und mengentheoretische Darstellung der zentralen Zusammenbänge)}

Das Modell des Bourdieuschen Sozialkapitalkonzeptes benennt abschließend die substantiellen Axiome. Hierbei handelt es sich um die in Wenn-Dann- bzw. JeDesto-Form formulierbaren wichtigsten Zusammenhangsaussagen bezüglich Entstehung und Wirkung von Sozialkapital. (An dieser Stelle wird nicht nur über einzelne Komponenten, sondern ebenso über Verbindungen zwischen mehreren Komponenten quantifiziert. I.d.R. würde man in der Quantorenlogik allerdings etwa anstatt von $\exists(a, \ddot{o}, r e l)$ die Form $\exists a \exists \ddot{o} \exists r e l$ wählen, um über den Operator

(die sog. "Potenzmenge" von Te [PotTe]). Ferner ist in diesem Zusammenhang darauf hinzuweisen, dass Rel eine Grundkomponente aller vorzustellenden Sozialkapitalkonzepte ist und damit nicht mit dem allgemeinen Relationsbegriff der Mengenlehre verwechselt werden darf. Dieser wird mit "x" symbolisiert und zeigt an, welche Komponenten in Beziehung zueinander gesetzt werden (man könnte $\mathrm{A}$ und Te auch mathematisch in Beziehung zueinander setzen, ohne damit eine soziale Relation zwischen A und Te behaupten zu müssen [etwa wenn man ausdrücken möchte, es handle sich um die Menge aller A und Te, die sich nicht kennen]; daher ist die Einführung von Rel hier erforderlich). 
lediglich Komponenten bzw. Subjektvariablen zu binden. Mir erscheint jedoch die gewählte [etwas unübliche] Schreibweise im vorliegenden Zusammenhang übersichtlicher; der Skopus des Quantors - also das, was durch Letzteren gebunden wird - ist insofern hier keine Variable, sondern eine relationale Ordnung [vgl. hierzu Menne 1993: 66].)

Q ist ein Modell des Bourdieuschen Sozialkapitalkonzeptes, gdw

(1) $\left\langle\mathrm{S}^{\mathrm{B}}, \mathrm{A}, \mathrm{B}, \mathrm{Inf}, \mathrm{Fun}, \mathrm{Z}, \mathrm{R}, \mathrm{Rel}, \mathrm{L}^{\mathrm{Mi} / \mathrm{Me}}, \mathrm{Lok}^{\mathrm{A}}\right.$,Griv, GK,Te,Ta,V,Inv,Kom,Ö,Tr,P $\rangle \quad \in$ $\mathrm{M}_{\mathrm{P}}$

(2) $\exists(a, \ddot{o}$, rel $)$

$(\operatorname{Inv}[a, \ddot{o}, r e l] \rightarrow \mathrm{V}[t e, a])$

(3) $\exists(a, t e, r)$

$(\mathrm{Ta}[a, t e, r] \rightarrow \mathrm{V}[t e, a])$

(4) $\forall(t e, a)$

$\left(\mathrm{V}[t e, a] \wedge \mathrm{R}[t e, a] \wedge \operatorname{Fun}[r, a, q] \rightarrow \mathrm{R}[t e, a]:=\mathrm{S}{ }^{\mathrm{B}}[a]\right)$

(5) $\forall(t e, v, a)$

(6) $\forall(a)$

$(\operatorname{Tr}[t e, v, a] \wedge \mathrm{R}[t e, a] \wedge \operatorname{Fun}[r, a, z] \rightarrow \mathrm{R}[t e, a]:=\mathrm{SB}[a])$

$\left(\mathrm{P}[a]: \mathrm{SB}[a] \rightarrow \mathfrak{R}_{0+}\right)$

Problematisch an den von mir hier vorgenommenen Formulierungen im dritten Rekonstruktionsschritt ist - und dies sei schon vor der Erläuterung der genannten Bedingungen erwähnt -, dass bei Bourdieu auch schon eine Verpflichtung Sozialkapital darstellt (vgl. Bourdieu 1992: 73). Damit kann eine Verpflichtung eigentlich nicht zugleich auch eine notwendige Voraussetzung für dessen Entstehung sein. Wenn dies von mir dennoch behauptet wird, so deshalb, weil ich die Bourdieuschen Überlegungen inhärent korrigiere: Wenn Sozialkapital funktional definiert wird und eine handlungsbegünstigende Ressource eines Akteurs darstellen soll, dann reicht eine Verpflichtung per se nicht aus, um sinnvoll den Sozialkapitalbegriff anzuwenden (man kann sich auch noch so sehr jemandem gegenüber verpflichtet fühlen - entscheidend für den vorliegenden Zusammenhang ist lediglich, ob man über Ressourcen verfügt, die dem anderen nützlich sind).

Die genannten Bedingungen meinen:

(1) Die begrifflichen Komponenten sind erfüllt.

(2) Es gibt mindestens eine Verbindung zwischen Akteur, ökonomischem Kapital und Relationen aus $\mathrm{M}_{\mathrm{P}}$ (also aus der Menge aller möglichen Anwendungsbeispiele des Bourdieuschen Sozialkapitalkonzeptes) für die gilt: Wenn der Akteur ökonomisches Kapital in eine (Beziehungs-) Relation investiert, dann entsteht eine soziale Verpflichtung ihm gegenüber (d.h. ein Teilnehmer fühlt sich dem Akteur gegenüber verpflichtet). Die Kleinbuchstaben indizieren, dass es sich um einzelne Elemente der jeweiligen Mengen handelt (so hat etwa die Menge Te die Elemente 
$\left.\mathrm{te}_{1}-\mathrm{te}_{\mathrm{n}}\right)$. Der Existenzquantor gibt an, dass nicht jede Investition dieser Art zu einer sozialen Verpflichtung führt ${ }^{317}$.

(3) Tauschprozesse zwischen einem Akteur und Teilnehmern (Akteur und Teilnehmer tauschen Ressourcen aus) können Verpflichtungen begründen. Zur Entstehung von Verpflichtungen bedarf es also nicht notwendig einer bewussten Investition. Der Existenzquantor gibt an, dass nicht jeder Tauschprozess Verpflichtungen nach sich zieht.

(4) Für alle Verbindungen zwischen Teilnehmern und dem fokalen Akteur gilt, wenn ein Teilnehmer eine soziale Verpflichtung gegenüber dem Akteur verspürt, dann entsteht soziales Kapital. Dies jedoch nur unter der Bedingung, dass Te eine Ressource für A bereithält, für die wiederum gilt, dass sie für A funktional ist, und zwar in dem Sinne, dass A sie zu seiner Zielverwirklichung nutzen kann. M.a.W.: Bei der genannten Ressource handelt es sich dann um As Sozialkapital. Das Zeichen ":=" indiziert definitorische Gleichheit. Auch diese Festlegung bewerte ich als substantielles Axiom, weil hierüber eine für das Verständnis des Sozialkapitalkonzeptes substantielle Aussage getroffen wird. (Balzer [1997: 96] verweist im Zusammenhang mit seiner Rekonstruktion einer soziologischen Institutionentheorie darauf, dass Axiome nicht unbedingt Verknüpfungsgesetze sein müssen. Auch Plöger [2003: 127] sieht bspw. die Aussage "Kraft = Masse mal Beschleunigung" als substantielles Axiom der Newtonschen Physik an [im Unterschied zu Plöger bevorzuge ich jedoch das Zeichen für die definitorische Gleichheit ${ }^{318}$ ].)

\footnotetext{
317 Etwas umgangssprachlicher formuliert lautet die Aussage unter (2): Wenn ein Akteur ökonomisches Kapital (worunter Bourdieu gerade auch Zeit begreift) in seine (Beziehungs-) Relationen investiert, können dabei soziale Verpflichtungen ihm gegenüber geschaffen werden. Bei der Formalisierung handelt es sich um ein dreistelliges geordnetes Prädikat mit der Prädikatenvariable "Investition" (bzw. "investiert in") und den Subjektvariablen "Akteur", "Ökonomisches Kapital" und "(Beziehungs-) Relation". In der Quantorenlogik werden für Prädikatenvariablen Groß- und für Subjektvariablen Kleinbuchstaben verwendet. Zwecks deutlicherer Darstellung habe ich die Subjektvariablen mit Kommata voneinander getrennt sowie in Klammern und kursiv gesetzt. (Zur Erläuterung des logischen Vokabulars: "Individuen sind das, worüber gesprochen wird, ... . Gesprochen wird über sie mit Hilfe von Prädikaten." [Savigny 1984: 59]) In 1-stelliger Form bestimmen Prädikatenvariablen Eigenschaften von, in n-stelliger Form Beziehungen zwischen Subjektvariablen. So lässt sich etwa der Satz "Max ist Sänger" als S $(m)$ formalisieren, wobei $\mathrm{m}=$ Max und S = ist Sänger (Max hat die Eigenschaft, Sänger zu sein; S kommt m zu). Mehrstellige (bzw. nstellige) Prädikate eignen sich zur Darstellung von Verbindungen zwischen beliebig vielen Variablen. "Franz ist ein Parteifreund von Heidi" kann etwa als $\mathrm{P}(f, h)$ verkürzt werden, wobei $\mathrm{P}=$ ist ein Parteifreund von, $\mathrm{f}=$ Franz und $\mathrm{h}=$ Heidi (Anmerkung: $\mathrm{Da}$ hier konkrete Personennamen eingesetzt wurden [Max, Franz, Heidi], handelt es sich nun nicht mehr um Individuenvariablen [also Platzhalter], sondern um Individuenkonstanten). Oben beschreibt bspw. R(te) einen Teilnehmer und dessen Eigenschaft, über Ressourcen zu verfügen, wobei te $=$ Teilnehmer und $\mathrm{R}=$ verfügt über Ressourcen. V(te, a) meint, dass ein Teilnehmer (eines Beziehungsnetzes) sich einem (fokalen) Akteur gegenüber verpflichtet fühlt, wobei $\mathrm{V}=$ fühlt sich verpflichtet gegenüber, te $=$ Teilnehmer und $\mathrm{a}=$ Akteur. Die Funktionalität einer Ressource für einen Akteur hinsichtlich dessen Zielverwirklichung wird als Fun $\left(r, a, z_{2}\right)$ dargestellt, wobei Fun $=$ ist funktional für, $r=$ Ressource, $a=$ Akteur und $z=$ Zielverwirklichung. Die oben angeführten Quantoren binden die in ihrem Skopus angeführten Variablen für den kompletten Ausdruck.

318 Alternativ ließe sich Bedingung (4) auch mit Hilfe des Zeichens für die logische Äquivalenz $(\Leftrightarrow)$ darstellen. Möglicherweise wäre dies sogar korrekter, da hier ja eigentlich keine materiale Implikation
} 
(5) Für alle Verbindungen zwischen Teilnehmer, Verpflichtung und dem fokalen Akteur aus $\mathrm{M}_{\mathrm{P}}$ gilt: Wenn ein Teilnehmer eine Verpflichtung, die er einem anderen gegenüber verspürt, auf den fokalen Akteur transferiert, dann entsteht soziales Kapital ${ }^{319}$. Dies jedoch erneut nur unter der Bedingung, dass Te eine Ressource für A bereithält, für die gilt, dass A sie funktional zu seiner Zielverwirklichung nutzen kann.

Als weitere Komponente, welche die Entstehung von Sozialkapital ermöglicht, verweist Bourdieu auf die "Kunst", Beziehungen zu nutzen. Diese wurde oben als soziale Kompetenz rekonstruiert, ist jedoch keine notwendige Entstehungsbedingung, insofern sie zwar zweifelsohne das Ausmaß an sozialem Kapital, über das ein Akteur verfügt, mitbestimmt, keineswegs aber zwingend erforderlich erscheint, um Verpflichtungen zu schaffen.

(6) $\mathrm{P}$ ist eine (idealerweise über eine positive reelle Zahl $\left[\mathfrak{R}_{0+}\right]$ quantifizierbare) Funktion von $\mathrm{S}^{\mathrm{B}}$, d.h. das Ausmaß des Sozialkapitals des einzelnen Akteurs bestimmt seine gesellschaftliche Position in entscheidender Weise mit. Je mehr Sozialkapital einem Akteur zur Verfügung steht, desto höher/besser seine gesellschaftliche Position. (Natürlich hängt P von zahlreichen weiteren Größen ab. Hier geht es aber lediglich um die von Bourdieu als zentral angesehene Wirkungsweise sozialen Kapitals und diese lässt sich über die obige Funktion ausdrücken.)

Betrachten wir abschließend noch einmal den Tupel Q und streichen daraus alle Komponenten, die nichts zur Definition des Sozialkapitalbegriffs beitragen, so erhalten wir einen Tupel Q' der Form $\langle A \times$ Te x K x R x B x Inf x Fun x Z . Während der Tupel Q alle Bestandteile benennt, die das Konzept des Sozialkapitals bei Bourdieu ausmachen, umfasst Q' nur jene Elemente, die notwendig zur definitorischen Festlegung des Sozialkapitalbegriffs erforderlich sind. Herausgestrichen wurden also die Komponenten, die zur Entstehung von Sozialkapital beitragen (Ta, V, Inv, Kom, Ö, Tr), dessen Wirkung ausmachen (P) oder dessen Ort $\left(\mathrm{L}^{\mathrm{Mi} / \mathrm{Me}}, \mathrm{Lok}^{\mathrm{A}}, \mathrm{G}{ }^{\text {priv }}\right)$ charakterisieren, die insofern hinsichtlich der Definition keine zusätzlichen Informationen liefern und damit abgeleitete Werte darstellen. Zur Begriffs-Intension, d.h. zu den Eigenschaften und Merkmalen, die notwendig vorhanden sein müssen, damit man überhaupt sinnvoll von "Sozialkapital" reden kann, zählen bei Bourdieu:

vorliegt. Mit der im Text präferierten Schreibweise lässt sich indes verdeutlichen, dass es sich bei Sozialkapital um eine Ressource handelt, die bestimmten Bedingungen genügt.

319 War V unter (3) eine Prädikatenvariable so firmiert v nun in Kleinschreibung als Subjektvariable. Erneut sei erwähnt, dass dies prädikaten- bzw. quantorenlogisch unproblematisch ist (vgl. Zoglauer 1999: 72). Alternativ dazu ließe sich die Prädikation "fühlt sich verpflichtet gegenüber" auch mit einem neuen Symbol belegen. Dies würde jedoch m.E. die Argumentation unübersichtlicher gestalten und die Verbindung zwischen Subjekt- und Prädikatenvariable wäre nicht mehr unmittelbar zu erschließen. 
ein Akteur (A), dem Sozialkapital zugeordnet werden kann, mindestens ein weiterer Teilnehmer (Te) (aus einem Beziehungsnetz, dem auch der Akteur angehört),

gegenseitiges Kennen und Anerkennen (GK) zwischen Akteur und Teilnehmer (impliziert eine Beziehungsrelation [Rel]),

Ressourcen (R), die zur Verfügung gestellt werden können bzw. zur Verfügung gestellt werden,

ein Beziehungsnetz (B), in dem sich A und Te befinden,

die Informalität (Inf) der Beziehungsrelation mit Blick auf die (tatsächlich oder potentiell) zur Verfügung gestellten Ressourcen sowie

die Funktionalität (Fun) der (tatsächlich oder potentiell) zur Verfügung gestellten Ressource hinsichtlich einer (ebenfalls tatsächlichen oder potentiellen) Zielverwirklichung des Akteurs.

Die Festlegung Q', d.h. die Auflistung der die Begriffs-Intension bestimmenden Merkmalskriterien für alle untersuchten Sozialkapitalkonzepte wird später einen Vergleich der jeweiligen Definitionen von "Sozialkapital" und damit in der Folge auch die Konstruktion eines eigenen Theoriemodells systematisieren helfen und erleichtern.

\subsection{Sozialkapital und schulischer Erfolg: Das Konzept James S. Colemans}

James S. Colemans Vorstellungen zu Sozialkapital haben insbesondere die angloamerikanische Debatte (also auch Robert D. Putnam) geprägt und resultieren analytisch aus dem Bestreben, explanative Perspektiven aus Soziologie und Ökonomie zusammenzuführen: "The conception of social capital as a resource for action is one way of introducing social structure into the rational action paradigm." (Coleman 1988: 95) Coleman antwortet mit seinen konzeptionellen Überlegungen auf eine fundamentale Frage sozialwissenschaftlicher Interdisziplinarität: "What can economists and sociologists learn from each other ...?" (Winship/Rosen 1988: 5) Damit handelt es sich bei "Sozialkapital" um einen "Fachausdruck aus dem Überschneidungsbereich von Ökonomie und Soziologie" (Gehmacher 2004: 4) ${ }^{320}$.

Colemans inhaltliches Erkenntnisinteresse richtet sich vor allem auf die Verbindung von schulischem Erfolg und sozialer Unterstützung. Empirisch hat sich

\footnotetext{
320 Das interdisziplinäre, analytisch-explanative Anliegen Colemans wurde sicherlich durch seine Zusammenarbeit mit dem ebenfalls an der Universität von Chicago lehrenden Ökonomen Gary Becker befördert. Diese Zusammenarbeit war freilich "by no means accidental given their mutual commitment to rational choice." (Fine 2001: 51)
} 
Coleman etwa mit den Unterschieden staatlicher und kirchlicher Schulen in den USA auseinandergesetzt (vgl. Coleman 1988: 109ff. sowie Coleman/Hoffer 1987). Humankapital - so die zentrale These - sei keineswegs der grundsätzliche Erklärungsfaktor schulischen Erfolges, vielmehr habe Sozialkapital einen entscheidenen Einfluss auf die Leistungen der Schüler und damit letztlich auch auf die Ausstattung des Einzelnen mit Humankapital ${ }^{321}$.

\section{Definition}

In einer grundlegenden Formulierung heißt es bei Coleman (1991: 392): "Ich werde diese sozialstrukturellen Ressourcen (gemeint sind die unten aufgeführten, D.K.) als Kapitalvermögen für das Individuum bzw. als soziales Kapital behandeln. Soziales Kapital wird über seine Funktion definiert. Es ist kein Einzelgebilde, sondern ist aus einer Vielzahl verschiedener Gebilde zusammengesetzt, die zwei Merkmale gemeinsam haben. Sie alle bestehen nämlich aus irgendeinem Aspekt der Sozialstruktur, und sie begünstigen bestimmte Handlungen von Individuen, die sich innerhalb der Struktur befinden. Wie andere Kapitalformen ist soziales Kapital produktiv, denn es ermöglicht die Verwirklichung bestimmter Ziele, die ohne es nicht zu verwirklichen wären."

Im Anschluss an diese Bestimmung diskutiert Coleman verschiedene Formen des Sozialkapitals wie sie als Aspekte der Sozialstruktur mit Ressourcencharakter in Erscheinung treten: Verpflichtungen und Erwartungen, Informationspotentiale bzw. -kanäle, Normen und wirksame Sanktionen, Herrschaftsbeziehungen, übereignungsfähige soziale Organisationen ${ }^{322}$, zielgerichtete soziale Organisationen. Zusammenfassend versteht Coleman unter "Sozialkapital" somit eine sozialstrukturelle Handlungsressource, welche die Verfolgung von Zielsetzungen ermöglicht und die in Form der genannten sozialstrukturellen Aspekte auftritt.

Zur Verdeutlichung dessen, was mit "Sozialkapital" konkret gemeint ist, illustriert Coleman die Erscheinungs- und Wirkungsweise der hierüber bezeichneten Gegenstände anhand von Beispielen (vgl. Coleman 1991: 392ff.). So berichtet er über die Solidarität in südkoreanischen Studiengruppen, nachlassende Vertrauensbeziehungen zwischen Ärzten und Patienten in den USA, soziale Organisationsformen der Händler des zentralen Marktes in Kairo sowie unterschiedliche normative Strukturen in US-amerikanischen Groß- und Kleinstädten: "In Jerusalem stellt die normative Struktur sicher, dass Kinder, die ohne Begleitung sind,

321 Schon kurz vor Coleman hatte der Ökonom Glen Loury den Sozialkapitalbegriff gegen eine Überbetonung des Humankapitals ins Spiel gebracht: "The merit notion that, in a free society, each individual will rise to the level justified by his or her competence conflicts with the observation that no one travels that road entirely alone." (Loury 1977: 176) Für eine Diskussion des Verhältnisses von Human- und Sozialkapital unter besonderer Berücksichtigung der Colemanschen Überlegungen siehe Field et al. 2001.

322 Damit ist gemeint, dass "eine Organisation, die für einen bestimmten Zweck ins Leben gerufen wurde, für andere Zwecke übereignungsfähig (ist)" (Coleman 1991: 405). 
von den Erwachsenen der engeren Umgebung beaufsichtigt werden, wohingegen eine solche normative Struktur in den meisten großstädtischen Bereichen der Vereinigten Staaten nicht existiert. Man kann sagen, daß Familien in Jerusalem ein soziales Kapital zur Verfügung steht, daß man in großstädtischen Gebieten der Vereinigten Staaten nicht vorfindet." (Coleman 1991: 393)

Auf Basis dieses Beispiels - dessen empirische Korrektheit hier der Einfachheit halber sowie auf Basis von Plausibilitätserwägungen unterstellt wird - ließe sich allerdings fragen, ob nun (a) die angesprochene informelle Norm "Erwachsene sollten nicht nur ihre eigenen, sondern auch die Kinder aus der engeren Umgebung beaufsichtigen, insofern diese ohne Begleitung sind", (b) die gespürte Verpflichtung bzw. der Wille zur Normbefolgung, (c) die tatsächliche Normbefolgung und insofern eine zur Verfügung gestellte Gutschrift ${ }^{323}$, (d) die hierüber den nicht anwesenden Eltern zuteil werdende Betreuung ihrer Kinder durch Erwachsene des näheren Umfeldes oder (e) sogar alles zusammen soziales Kapital darstellt. Da Sozialkapital bei Coleman eine für das Individuum handlungsbegünstigende Ressource und zugleich ein Aspekt der Sozialstruktur sein soll (siehe oben), ist wohl primär die genannte Norm als Sozialkapital anzusehen; begünstigt wird die Handlung "Nicht-Beaufsichtigung der eigenen Kinder"324 und damit implizit auch die Ausführung alternativer Aktivitäten, die dank des Zugewinns an Zeit nun möglich werden. Aber ist es wirklich sinnvoll, Normen einen Ressourcenstatus zuzuweisen ${ }^{325}$ ?

Das Interesse daran, die eigenen Kinder durch Erwachsene der näheren Umgebung beaufsichtigen zu lassen, ist nur dann zu realisieren, wenn die entsprechende Norm befolgt wird. Dies ist nun aber abhängig von der konkreten Situation und von der Art und Weise, wie ein Individuum die Norm für sich ausdeutet. Damit ist die Norm per se keineswegs handlungsbegünstigend, sondern vielmehr der über die Normbefolgung erwiesene Dienst. Folgen wir den Sozialpsychologen Uriel und Edna Foa, so lassen sich sechs unterschiedliche Klassen von Ressourcen identifizieren: Dienste, Liebe, Güter, Geld, Informationen und Status. "Thus for example, fixing someone's stereo would be giving a service. Telling someone how to complete a complex assignment would give him or her

\footnotetext{
${ }^{323}$ Denn auch eine solche Gutschrift wird von Coleman als Sozialkapital begriffen: Eine "Verpflichtung kann man als soziales Kapital, als eine 'Gutschrift' betrachten, die A besitzt und die von B mit irgendeiner Leistung eingelöst werden muss." (Coleman 1991: 396)

324 Eigentlich eine Nicht-Handlung; freilich sind auch Handlungsunterlassungen als Handlungen zu interpretieren: "'Handeln' soll ... ein menschliches Verhalten (einerlei ob äußeres oder innerliches Tun, Unterlassen oder Dulden) heißen, wenn und insofern als der oder die Handelnden mit ihm einen subjektiven Sinn verbinden." (Weber 1980: 1)

325 Genau das tut Coleman jedenfalls, wenn er Normen als Sozialkapital ansieht und darunter wiederum Ressourcen begreift, mit Hilfe derer Akteure ihre Interessen realisieren können, wie aus folgender Formulierung ersichtlich ist: "Die Funktion, die der Begriff 'soziales Kapital' identifiziert, ist der Wert, den diese Aspekte der Sozialstruktur für Akteure haben, und zwar in Gestalt von Ressourcen, die von den Akteuren dazu benutzt werden können, ihre Interessen zu realisieren" (Coleman 1991: 395).
} 
information, and treating someone with respect would give the person status. ... Try to locate a way of benefiting another person that does not fall into any of these classes." (Gergen/Gergen 1986: 286)

Nimmt man den Kapitalbegriff im vorliegenden Kontext wirklich ernst - und das tut Coleman, insofern er sagt, "I have attempted to introduce into social theory a concept, 'social capital', paralleling the concepts of financial capital, physical capital, and human capital" (Coleman 1988: 118) -, dann muss die Interpretation von Aspekten der Sozialstruktur als Ressourcen zu Problemen führen. Nicht nur deshalb, weil diese Aspekte nicht innerhalb der von Foa/Foa genannten Klassen auftauchen bzw. dort zuortbar sind, sondern auch, weil sie in einem kapitaltheoretischen Sinne weder investierbar, noch gegeneinander austauschbar sind (man kann die Befolgung einer Norm gegen eine Verpflichtung eintauschen, nicht aber die Norm schlechthin; siehe hierzu auch die Erörterungen zum Kapitalbegriff in Kapitel 8.1.).

Die von Coleman beschriebenen Formen des Sozialkapitals lassen sich ferner kaum trennscharf oder gar unabhängig voneinander bestimmen und führen somit zu einer gewissen Diffusität des gesamten Konzeptes. Sozialkapital scheint Sozialkapital zu bedingen und zugleich auch wieder lediglich im gemeinsamen Auftreten seiner Formen erst tatsächlich vorhanden zu sein, denn es ist ja "kein Einzelgebilde, sondern ist aus einer Vielzahl verschiedener Gebilde zusammengesetzt" (Coleman 1991: 392). So sind etwa Normen - vor allem der Reziprozität und diese überwachende Sanktionen bzw. befördernde Anreizstrukturen häufig notwendig, damit sich ein System von Verpflichtungen und Erwartungen und insofern soziale Organisation überhaupt etablieren kann. Herrschaftsbeziehungen wiederum indizieren eine rigorose Möglichkeit der Handlungskontrolle, die bei gegebenen Verpflichtungen oder normativen Vorgaben manifest werden. Oder nochmals anders formuliert: Normen und Sanktionen sind Voraussetzungen für die Herausbildung eines Systems reziproker Verpflichtungen und Erwartungen, das dann den Bezug spezifischer Ressourcen ermöglicht. Ein solches System bedingt Austauschprozesse und damit ebenfalls Formen sozialer Organisation. (Durch die Einführung des Sozialkapitalbegriffs verwischen aber alle diese Differenzierungen.)

Überdies argumentiert Coleman hinsichtlich der Bedeutung von Beziehungsrelationen nicht konsistent. Auf der einen Seite stellen diese Sozialkapital dar. So heißt es etwa: "The social capital of the family is the relations between children and parents" (Coleman 1988: 110). Zugleich "wohnt soziales Kapital den Beziehungsstrukturen zwischen zwei und mehr Personen inne" (Coleman 1991: 392), womit es etwas anderes ist, als eben diese Beziehungsstrukturen. Solche kaum zu vereinbarenden Formulierungen ziehen nicht zuletzt auch Probleme hinsichtlich der Verortung von Sozialkapital nach sich. Inhaltlich erscheint diskutabel, ob die Beziehungen zwischen Eltern und Kindern grundsätzlich als Sozialkapital zu betrachten sind. Dass diese Beziehungen in vielen Fällen wenig handlungsbegüns- 
tigend auf Kinder wirken, ist ein Gemeinplatz. Insofern man unterstellt, Coleman ziele darauf ab, Beziehungen dann als Sozialkapital zu klassifizieren, wenn diese es ermöglichen, auf bestimmte Ressourcen, die im Besitz anderer Personen sind, zuzugreifen, wenn also Gutschriften zur Verfügung gestellt werden, müsste er diese Beziehungen qualifizieren ${ }^{326}$.

\section{Ebene}

Wenn sowohl eine Verpflichtung (die etwa A gegenüber B verspürt), soziale Organisationen (etwa Studiengruppen) als auch normative gesellschaftliche Strukturen (etwa Aufsichtspflicht gegenüber fremden Kindern) Sozialkapital darstellen, dann lässt sich Sozialkapital bei Coleman auf der Mikro-, der Mesound der Makroebene finden. Entscheidend ist daher an dieser Stelle, inwiefern es begriffstheoretisch bzw. modellbauarchitektonisch sinnvoll und kohärent ist, alle diese Entitäten unter einen einzigen Oberbegriff zu subsummieren (eine Frage, die weiter unten wieder aufgegriffen und später innerhalb der Ausführungen zur Konstruktion eines eigenen Theoriemodells verneint wird).

Ferner bleibt Coleman einsichtige Erläuterungen hinsichtlich der Aggregationsproblematik schuldig. Mit seiner Aussage, der Sozialkapitalbegriff verhelfe dazu, "unterschiedliche Ergebnisse auf der Ebene der individuellen Akteure zu erklären und den Übergang von der Mikro- zur Makroebene vorzunehmen, ohne näher auf die sozialstrukturellen Einzelheiten einzugehen, die ihn ermöglichen" (Coleman 1991: 395f.), stuft er zwar augenscheinlich die Aggregation als analytisch unproblematisch ein, wie diese jedoch konkret aussehen soll, bleibt unklar. Der in diesem Zusammenhang nur ganz kurz gegebene Hinweis, Studiengruppen in Südkorea seien Ressourcen, deren sich die individuellen Aktivisten bedienten, um eine organisierte Revolte auf den Weg zu bringen (vgl. Coleman 1988: 101), kann m.E. kaum als überzeugende Modellierung bezeichnet werden. Bei dieser Verknüpfung zwischen Meso- (Studiengruppen), Mikro- (individueller Aktivismus) und Makroebene (Revolte) bleibt fraglich, was der Sozialkapitalbegriff zur analytischen Lösung des Aggregationsproblems beiträgt, lässt sich doch an dieser Stelle ohne Einbuße an analytischem Gehalt auf ihn verzichten: Wo ist der explanative "added value", wenn man die Studiengruppen als Sozialkapital begreift?

Sicherlich können im Rahmen des insbesondere auf Coleman selbst zurückgehenden soziologischen Mehrebenenmodells auf der Makroebene etwa bestimmte

\footnotetext{
326 Im Rahmen der Ausführungen zur Operationalisierung wird von Coleman überdies auch noch "Fürsorge" implizit zu Sozialkapital erklärt. So spricht er von "the ratio of adults to children as a measure of social capital in the family", um dann mit der mütterlichen Erwartung hinsichtlich eines zukünftigen College-Besuchs des Kindes "another indicator of adult attention in the family" anzuführen (Coleman 1988: 112). An wieder anderer Stelle scheint auch die Netzwerkschließung soziales Kapital darzustellen: "Closure and continuity provide a form of social capital on which the effectiveness of social norms depends." (Coleman 1993a: 9)
} 
Reziprozitätsnormen verortet werden, die auf der Mikroebene zu Verpflichtungen und so etwa zum Austausch von Gefälligkeiten führen, die dann in Folge von Iteration wiederum spezifische Formen sozialer Organisation nach sich ziehen. Auf allen drei Aggregationsebenen finden sich dann Formen des sozialen Kapitals. Damit firmiert "Sozialkapital" aber als catch-all-Kategorie, handelt es sich doch bei allgemeinen Reziprozitätsnormen, konkreten Verpflichtungen und sozialen Organisationen um deutlich voneinander abzugrenzende Entitäten (ein Aspekt, der in Zusammenhang mit Putnams Konzept noch detaillierter besprochen wird). Dieser Einwand ist auch nicht zu entkräften, indem man den Aspekt der Handlungsbegünstigung in den Vordergrund rückt, denn keine der drei genannten Entitäten wirkt per se handlungsbegünstigend (was nützt bspw. A das Verpflichtungsgefühl von B, wenn Letzterer über keine für A hilfreichen Ressourcen verfügt?).

\section{Lokalisierung}

Bei Coleman ist Sozialkapital kein Kapitalvermögen des Individuums, sondern lediglich "für das" Individuum (Coleman 1991: 392); "it is not lodged ... in the actors themselves" (Coleman 1988: 98). Zwar ist es ein privates Gut, dennoch kann "keiner der Personen, die von ihm profitieren, es als Privateigentum betrachten" (Coleman 1991: 409). In einer graphentheoretischen Darstellungsweise lässt es sich durch die die einzelnen Punkte verbindenden Linien symbolisieren, während die Punkte selber als Humankapital aufzufassen sind (vgl. ebenda: 395).

Fraglich bleibt dabei, wo genau bspw. eine Norm oder eine soziale Organisation, als von Coleman behauptete Formen des Sozialkapitals, innerhalb der Relationen zwischen Personen anzusiedeln sind. Denn das müssten sie, sollen sie den Behauptungen hinsichtlich der Lokalisierung von Sozialkapital genügen. Kann denn eine Norm überhaupt etwas zwischen Personen Befindliches sein, oder strukturiert sie nicht vielmehr eine Beziehungsrelation - und damit dieses "Zwischen"- auf eine spezifische Weise? Um wirksam zu werden, müssen Normen von Individuen internalisiert, kognitiv repräsentiert und über Handlungen "gelebt" werden; alternativ oder unterstützend können Sanktionsinstrumente zur Verfügung stehen. $\mathrm{Zu}$ behaupten, eine Norm residiere innerhalb von Beziehungen ist allenfalls in einem metaphorischen Sinne akzeptabel (siehe hierzu die Ausführungen in Kapitel 8.1.).

Normen oder soziale Organisationen können natürlich auch nicht einem einzelnen Individuum gehören. Diese Formen des Sozialkapitals scheinen sich gewissermaßen sowohl gegen eine Lokalisierung innerhalb von Relationen wie auf Seiten des Akteurs zu sperren, ohne dass Coleman dies irgendwo problematisieren würde. Eine Verpflichtung als Form von sozialem Kapital lässt sich kognitiv bei einem Schuldner antreffen (er fühlt sich verpflichtet); sie "gehört" aber demjenigen, dem gegenüber sich der Schuldner verpflichtet fühlt. Damit liegt hier eine 
Analogie zum Finanzkapital (Bankwesen) auf der Hand. Der Unterschied besteht jedoch darin, dass eine Bank rechtlich zu einer Auszahlung der Einlagen verpflichtet ist, während im Zusammenhang mit Sozialkapital die Beziehungsstruktur sich gerade durch Informalität auszeichnet. Die Frage, ob man nun Sozialkapital in Form einer Verpflichtung einen individuellen Eigentumsstatus zuweisen möchte oder nicht, ist dann keine Frage, die durch eine Analyse des Sozialkapitalbegriffs zu klären wäre; ihre Beantwortung hängt vielmehr davon ab, ob man den Eigentumsbegriff ausschließlich für rechtlich-kodifizierte Zusammenhänge reservieren möchte oder nicht.

Sozialkapital ist bei Coleman zwar kein Privateigentum, es kann jedoch sowohl privates wie kollektives bzw. Öffentliches Gut sein. So ziehen etwa einzelne Personen private Vergünstigungen aus ihren Positionen innerhalb von Beziehungsnetzen; Eltern profitieren kollektiv von der Etablierung eines Vertrauenssystems, das die nachbarschaftliche Aufsicht über spielende Kinder sicherstellt; und "die erzieherischen Standards, die über eine aktive Eltern-Lehrer-Vereinigung verbreitet werden, (verändern, D.K.) eine Schule auf eine Art und Weise, die für Nichtbeteiligte sowie für Beteiligte gewinnbringend ist." (Coleman 1991: 407)

Aus der begrifflichen Definition von "Sozialkapital" als sozialstrukturelle Aspekte und insofern als Ressource, die nicht als Privatbesitz anzusehen ist, folgt nun auch das Trittbrettfahrerproblem. "Beispielsweise verschaffen die verschiedenen Sozialstrukturen, die soziale Normen und die dazugehörigen Sanktionen ermöglichen, nicht primär denjenigen Personen einen Gewinn, deren Bemühungen die Normen und Sanktionen ins Leben gerufen haben, sondern all denen, die der betreffenden Struktur angehören" (ebenda: 410). Insofern kann es opportun sein, nichts zur Entstehung oder zur Aufrechterhaltung solcher Sozialstrukturen aufzuwenden, aber dennoch von ihrer Existenz zu profitieren. Wird ein solches Verhalten von einer Vielzahl von Akteuren bevorzugt, kommt es zu einer "Unterinvestition" in Sozialkapital. Damit scheint dieses über den Markt kaum organisierbar zu sein, insofern ein "Ungleichgewicht zwischen der relativen Investition in Organisationen, die private Güter für einen Markt produzieren, und der Investition in Organisationen (oftmals freiwillige Vereinigungen), wo die Gewinne nicht uneingeschränkt den Investoren zugute kommen" festzustellen ist (ebenda: 412). (Vgl. ausführlicher zum Kollektivgutaspekt der Colemanschen Konzeption von Sozialkapital Diekmann 1993; aber auch Ostrom/Ahn 2003 [die allerdings stärker an Putnam angelehnt argumentieren].)

\section{Entstehung}

Grundlegend für das Entstehen von Sozialkapital sind bei Coleman soziale Interdependenzen, die zu Tauschprozessen führen: "Soziale Interdependenz und systemische Funktionsweisen ergeben sich aus der Tatsache, daß Akteure an Ereignissen interessiert sind, die vollständig oder teilweise von anderen Akteuren 
kontrolliert werden." (Coleman 1991: 389) Damit geht es hier um die Frage, auf welche Weise Individuen auf für sie strategisch wichtige Ressourcen anderer Personen zugreifen und zu welchen Konsequenzen dies führt. Kritisch ist an dieser Stelle erneut auf die von Coleman vorgenommene Zuweisung eines Ressourcenstatus an Aspekte der Sozialstruktur hinzuweisen. Wenn eine Norm Sozialkapital darstellen soll, Sozialkapital aber aus Tauschprozessen resultiert, dann kann allenfalls die konkrete Befolgung der Norm eingetauscht werden (etwa wenn Erwachsene die Kinder ihrer Nachbarn beaufsichtigen, weil ihnen dies normativ "nahegelegt" wird); und nur dann kann auch sinnvoll von einer Ressource gesprochen werden, derer sich ein Akteur bedient.

Coleman argumentiert hinsichtlich der Entstehung von Sozialkapital teilweise wenig präzise. So äußert er bspw., "soziales Kapital ... entsteht, wenn sich die Beziehungen zwischen Personen so verändern, daß bestimmte Handlungen erleichtert werden." (Coleman 1991: 394) Was ist allerdings mit "so verändern" und "bestimmte Handlungen" gemeint? Immerhin lässt sich vermuten, dass nicht jede Relation Sozialkapital darstellt. Aber genau das behauptet Coleman wiederum an anderer Stelle, insofern er - wie oben bereits gezeigt - eine Verbindung zwischen Personen per se als Sozialkapital begreift.

Für jede von Coleman angeführte Form des Sozialkapitals müssten die Entstehungsgesetze separat aufgeführt werden. Problematisch ist jedoch, dass Coleman kaum diesbezügliche Äußerungen macht. Dies ist auch nicht weiter verwunderlich, möchte er doch weniger das Entstehen von Normen, Organisationen oder Informationspotentialen erklären, sondern mit Blick auf deren Wirkungen die Sinnhaftigkeit der Einführung des Sozialkapitalbegriffs begründen. Normen und Vertrauensbeziehungen werden insbesondere durch soziale SchlieBung befördert (ebenda: 413f.). Auch "eine Ideologie kann soziales Kapital hervorrufen, indem sie in einem Individuum, das ihr folgt, das Bedürfnis weckt, im Interesse von etwas anderem oder jemand anderem, als es selbst, zu handeln." (ebenda: 416)

Lediglich mit Blick auf Verpflichtungen und Erwartungen wird die Entstehungsweise von Sozialkapital konkreter analysiert. Verpflichtungen und Erwartungen erwachsen aus alltäglichen interpersonellen Austauschprozessen und heben auf die Reziprozität von Geben und Nehmen ab. Sie entstehen zumeist durch das Erweisen von Gefälligkeiten (vgl. ebenda: 396f.), wobei das Ausmaß an Vertrauenswürdigkeit ${ }^{327}$ darüber entscheidet, ob und wie viele Gefälligkeiten "zurückgezahlt" werden (vgl. ebenda: 398). Rational-strategisch handelnde Akteure schaffen bewusst Verpflichtungen, wenn sie erwarten, im Gegenzug ein für sie wertvolleres Gut zu erlangen. "Die Rentabilität für den Geber besteht darin, daß der Empfänger den Gefallen erst dann erwidert, wenn der Geber selber Hilfe braucht." (ebenda)

327 Der Vollständigkeit halber sei erwähnt, dass Coleman auch "Vertrauenswürdigkeit als eine Form von sozialem Kapital" ansieht (Coleman 1991: 398). 
Das Schaffen von Verpflichtungen wird damit zu einer "Art Versicherungspolice", "deren Prämien in einer schwachen Währung bezahlt werden und deren Gewinn in einer starken Währung ausbezahlt wird."(ebenda: 402) Je höher die Anzahl der ausstehenden Verpflichtungen, die ein Akteur einfordern kann, desto umfangreicher sein "Sparguthaben an sozialem Kapital" (ebenda: 411). Die Herstellung von Sozialkapital - insbesondere in seiner Form als Verpflichtungen - muss allerdings nicht grundsätzlich Produkt intentionaler Handlungen sein. Vielmehr wird es häufig "als ein Nebenprodukt anderer Tätigkeiten erzeugt oder zerstört ... . Ein Großteil an sozialem Kapital entsteht oder vergeht, ohne das irgendjemand bewusst dazu beiträgt." (ebenda: 412)

\section{Wirkung}

Hinsichtlich der genannten Wirkungsweisen von Sozialkapital ist in erster Linie auf die von Coleman selbst durchgeführten empirischen Studien zur Verbindung von Sozialkapital und Schulerfolg zu verweisen, wobei diese Verbindung wiederum auf einer abstrakteren Ebene "the importance of social capital in the creation of human capital" indiziert (Coleman 1988: 116). Anhand von Schulabbruchquoten stellt Coleman eine signifikante Relevanz des Sozialkapitals, verstanden als ein unterstützendes Netzwerk innerhalb wie außerhalb der Familie ${ }^{328}$, fest.

Bei einem Vergleich von "public high schools, religiously based private high schools, and nonreligiously based private high schools" weisen die religiösen (genauer: katholischen) Schulen die deutlich niedrigsten Abbruchquoten auf (nämlich 3,4\%; im Gegensatz zu 14,4\% bei öffentlichen und 11,9\% bei privaten, aber nicht-religiösen Schulen). Die Unterschiede werden mit einem größeren Bestand an Sozialkapital erklärt, der den Schülern in religiösen Schulen zur Verfügung stehe: "It is the religiously based private high schools that are surrounded by a community based on the religious organization. These families have intergenerational closure that is based on a multiplex relation: whatever other relations they have, the adults are members of the same religious body and parents of children in the same school. In contrast, it is the independent private schools that are typically least surrounded by a community" (Coleman 1988: 114).

Darüber hinaus finden sich bei Coleman zu den Wirkungen von Sozialkapital zahlreiche Angaben, die er über eine sekundäranalytische Betrachtung verschiedenartiger Untersuchungen bezieht, d.h. auf dem Hintergrund seiner konzeptionellen Überlegungen reinterpretiert er Forschungsergebnisse unterschiedlicher Sozialwissenschaftler (siehe hierzu auch die Ausführungen unter Wissenschaftstheoretischer Status). Die genannten Wirkungen reichen von finanziellen Vorteilen durch

\footnotetext{
328 Die Effekte werden also - wie schon dem Titel des Buches von Coleman/Hoffer (1987) zu entnehmen ist - auf den "impact of communities" zurückgeführt.
} 
die Einrichtung eines rotierenden Kreditwesens, über den Bezug von trendigen Modeinformationen bis hin zur Vermittlung neuer Arbeitsstellen.

Ganz generell begünstigt Sozialkapital "bestimmte Handlungen von Individuen" (Coleman 1991: 392). So etwa die schon mehrfach genannte Handlung von Eltern in kleinstädtischen Wohngegenden, ihre Kinder nicht permanent selbst beaufsichtigen zu müssen. In einer anderen, wenig konkreten Wendung stellt soziales Kapital "eine bedeutende Ressource für Individuen dar", die in der Lage ist, deren "Handlungsmöglichkeiten und ihre Lebensqualität stark zu beeinflussen" (Coleman 1991: 412). Auf Gemeinschaften bezogen bedeutet dies: "A group within which there is extensive trustworthiness and extensive trust is able to accomplish much more than a comparable group without trustworthiness and trust." (Coleman 1988: 101) Insbesondere hieran wird dann später Putnam in seiner Wirkungsargumentation anknüpfen (vgl. Kapitel 7.3.).

\section{Operationalisierung}

Zahlreiche Angaben zur Operationalisierung des Konstrukts finden sich bei Coleman nicht. Nauck registriert "an astonishing contrast between the richness of Coleman's explanations ... and his application of it to the empirical analysis of ... social capital." (Nauck zitiert nach Fine 2001: 100) Diekmann (1993: 23) beklagt: "So wichtig und ernst zu nehmen die Idee von Coleman auch ist, so wird doch gleichzeitig eine Schwäche des Konzepts deutlich. Im Gegensatz zur Humankapitaltheorie liegt weder eine operationale Fassung des Begriffs vor (wie ist Sozialkapital meßbar?), noch ist der Begriff Teil einer formalen, deduktiven Theorie, deren Theoreme empirisch prüfbar sind." (vgl. hierzu auch Diekmann 2004a: 488)

Implizit ist die Bestimmung von Sozialkapital über netzwerkanalytische oder spieltheoretische Instrumente aber bei Coleman angelegt. So verdeutlicht er seine Ausführungen immer wieder unter Zuhilfenahme graphentheoretischer Darstellungsweisen (vgl. etwa Coleman 1988: 106f.). In diesem Sinne heißt es auch: "Individuen in Sozialstrukturen, die sich jederzeit auf eine große Anzahl ausstehender Verpflichtungen berufen können, ..., können auf ein größeres soziales Kapital zurückgreifen. Die Dichte ausstehender Verpflichtungen bedeutet letztendlich, daß der gesamte Nutzen konkreter Ressourcen, die im Besitz von Akteuren innerhalb dieser Sozialstruktur sind, vervielfacht wird, wenn die Ressourcen im Notfall anderen Akteuren zur Verfügung stehen." (Coleman 1991: 389)

In empirischen Untersuchungen zum Zusammenhang von Sozialkapital und Schulerfolg misst Coleman das Konstrukt zunächst über die Stärke der Beziehung zwischen Eltern und Kind (vgl. Coleman 1988: 110), dann aber auch über das Verhältnis von Erwachsenen und Kindern innerhalb der Familie, über die mütterliche Erwartung hinsichtlich eines zukünftigen College-Besuchs des Kindes 
sowie über die Häufigkeit, mit der das Kind mit seinen Eltern persönliche Erfahrungen bespricht ${ }^{329}$ (vgl. ebenda: 112f.).

Eine daran angelehnte Möglichkeit der Operationalisierung wird von Portes (2000: 5ff.) aufgezeigt. In der konzeptionellen wie inhaltlichen Tradition Colemans untersucht er mittels einer bivariaten Analyse die Auswirkungen von Sozialkapital auf den schulischen Erfolg von Immigrantenkindern in den USA. Als Indikatoren für das Sozialkapital, über das die Schüler verfügen, wählt er (a) "Family composition", (b) "Parental school involvement" sowie (c) "Closure of parental networks"330. Bei Einführung der Kontrollvariablen "Alter", "Geschlecht", "sozioökonomischer Status der Eltern", "Kenntnis der Englischen Sprache" und "Dauer des bisherigen Aufenthaltes in den USA" werden die Effekte von Sozialkapital auf den schulischen Erfolg allerdings insignifikant. Folglich gelangt Portes auch zu einer ernüchternden Einschätzung: "There is a need for both logical clarity and analytic rigor in the study of these processes, lest we turn social capital into an unmitigated celebration of community." 331 (ebenda: 10)

\section{Wissenschaftstheoretischer Status}

Coleman ist analytisch um eine Zusammenführung von ökonomischen und soziologischen Forschungsperspektiven bemüht. Über "Sozialkapital" möchte er die soziale Dimension nutzenmaximierenden Handelns herausstreichen. Der Begriff verweist überdies in der wirtschaftssoziologischen Tradition der Granovetterschen "Embeddedness" (vgl. Granovetter 1985) auf die Notwendigkeit einer Beachtung sozialer Kontextbedingungen - seien diese restringierend oder ermöglichend - für ökonomisches Handeln ${ }^{332}$. "Coleman is arguing that social context can be of fundamental importance to all kinds of exchanges." (Winship/Rosen 1988: 7) Insofern handelt es sich um eine theorieintegrative Arbeit, wobei an dieser Stelle unter "Theorieintegration" zunächst einmal nicht die Zusammenführung von empirisch-analytischen Aussagensystemen, sondern von explanativen Paradigmen (homo oeconomicus versus homo sociologicus) verstanden werden soll.

\footnotetext{
329 Aus erziehungswissenschaftlicher Perspektive kritisiert Stecher (2001: 314) an Coleman die weitgehende Reduzierung einer Operationalisierung von Sozialkapital über die Eltern-KindBeziehung: "Unsere empirischen Ergebnisse legen nahe, den Beziehungen zu den Gleichaltrigen eine bedeutende Position im Sozialkapital-Ansatz einzuräumen."

330 Mit den jeweiligen Ausprägungen (a) "Both biological parents present" und "Other type of family", (b) "Little or none", "Some", "Moderate", "High" und (c) "Weak", "Moderate", "Strong", "Very strong".

331 Ähnlich nüchtern klingt Stecher (2001: 317), wenn er auf Basis seiner empirischen Daten feststellt, dass "der stärkste Effekt auf die Schulleistungen von den elterlichen Bildungsaspirationen aus(geht)".

332 Ist es bei Granovetter jedoch die soziale Komponente, die innerhalb des genuin ökonomischen Bereichs sichtbar gemacht werden soll, so intendiert der Sozialkapitalbegriff gerade umgekehrt, das Ökonomische im Sozialen aufzuspüren.
} 
Die empirischen Aussagen basieren auf Plausibilitäten hinsichtlich der Bei-spiele, mit denen die konzeptuellen Überlegungen illustriert werden - Händler auf dem Zentralmarkt in Kairo, Studiengruppen in Südkorea, dem US-amerikanischen Senatsclub etc. - sowie auf empirischen Untersuchungen. Bei Letzteren handelt es sich um Colemans eigene Forschungen zum Verhältnis von Sozialkapital und Schulerfolg aber auch um Studien aus ganz unterschiedlichen Zusammenhängen (etwa von Festinger, Banfield, Geertz, Ashton, Turnbull, Mauss, Lazarsfeld, Zablocki, Merton etc.), die Coleman sekundäranalytisch auf dem Hintergrund seines Sozialkapitalverständnisses reinterpretiert. Mit dem wissenschaftstheoretischen Strukturalismus gesprochen lassen sich all diese Verweise als paradigmatische intendierte Anwendungen interpretieren, d.h. es sind Beispiele, die vom Autor als passende Anwendungsfälle seines Konzepts angeführt werden.

Ähnlich wie Bourdieu sieht Coleman Macht als eine Ressource an, die Sozialkapital darstellen kann. Im Unterschied zu Bourdieu arbeitet er jedoch mit einem Machtverständnis, das der Sozialpsychologie bzw. der soziologischen Netzwerkanalyse entlehnt ist (vgl. Coleman 1991: 409), d.h. ideologiekritische Elemente sind hier allenfalls marginal zu finden. Es werden im Gegenteil sogar die positiven Aspekte einer über Sozialkapital bewirkten Machtkonzentration herausgestrichen, wie sie bei der Lösung des Trittbrettfahrerproblems möglich sind ${ }^{333}$ (vgl. ebenda: 404).

Gleichwohl ist Coleman um die Relativierung der Bedeutung von Humankapital und im Anschluss um die Aufdeckung gesellschaftlicher Ursachen schulischen Erfolges bzw. Misserfolges bemüht. Dadurch scheint aber auch eine politischaufklärerische Komponente in seinem Konzept durch (zu einer ähnlichen Einschätzung gelangt Cody 2002: 32), ohne dass dies allerdings zu einer nennenswerten normativen Ladung führen würde. Allerdings kann man Coleman durchaus einen sozialtechnologischen Impetus attestieren. So finden sich etwa in einer Veröffentlichung zum Heranwachsen von Jugendlichen explizit Vorschläge zu "institutional innovations to aid youth" und damit Empfehlungen an die Politik (vgl. Coleman/Husén 1985: 65ff.).

Auch wenn Coleman in seinen unmittelbaren Stellungnahmen zu Sozialkapital keine explizite Quantifizierung vornimmt, deuten seine netzwerkanalytischen Argumentationen - innerhalb derer zumindest von "relativen Quantitäten" die Rede ist (Coleman 1991: 407) - und seine entsprechenden mathematischen Hinweise in Band III seiner "Grundlagen der Sozialtheorie" ("Die Mathematik der sozialen Handlung") auf eine Quantifizierung hin. Dezidiert spricht Coleman bspw. auch von der Möglichkeit, das "Sparguthaben an sozialem Kapital aufzu-

\footnotetext{
333 Hierzu auch Anthony Giddens (1992: 337): "Es ist ein Fehler, Macht dem Wesen nach als entzweiende Qualität zu behandeln." Bertrand Russell (1977: 162) formuliert diesen Standpunkt besonders zugespitzt: "Der einzige Mensch, dem Macht völlig gleichgültig ist, ist derjenige, dem auch seine Mitmenschen völlig geichgültig sind. Manches Machtstreben muß daher als ein Teil des Rüstzeuges von Menschen angesehen werden, wie sie ein gutes Gemeinwesen nötig hat."
} 
stocken" (Coleman 1991: 411). Insgesamt kann man das Sozialkapitalkonzept als ein integratives, quantitatives Realmodell kennzeichnen: Es ist (a) integrativ, weil ökonomische und soziologische Erklärungsperspektiven vereint werden, (b) quantitativ, weil eine mathematische Berechnung prinzipiell (wenn auch nicht für alle akklamierten Formen) möglich ist und (c) ein Realmodell, weil die Argumentation auf empirischen Plausibilitäten, eigenen empirischen Forschungsleistungen sowie sekundäranalytischen Reinterpretationen empirischer Studien beruht.

\section{Strukturalistische Darstellung}

Coleman argumentiert hinsichtlich der definitorischen Bestimmung von Sozialkapital bisweilen diffus und inkonsistent. Einerseits begreift er ganz dezidiert Aspekte der Sozialstruktur wie Normen, wirksame Sanktionen oder Herrschaftsbeziehungen als Sozialkapital; andererseits legen viele seiner Äußerungen aber ein stark ressourcen- bzw. austauschtheoretisches Verständnis von Sozialkapital nahe. Dadurch werden aber relativ unterschiedliche Entitäten zu Sozialkapital erklärt.

Eine (a) Norm zur Zurückzahlung von Gefälligkeiten ist bspw. etwas anderes als (b) eine Befolgung dieser Norm, (c) eine gespürte Verpflichtung bzw. der Wille zur Zurückzahlung der Gefälligkeit, (d) eine diesbezügliche Vertrauenswürdigkeit, (e) eine darauf gerichtete Erwartung, (f) eine konkrete Gutschrift über eine Gefälligkeit, (g) die Gefälligkeit selbst und schließlich (h) die Ressource, die in einem konkreten Anwendungsfall zur Verfügung gestellt wird und die einem anderen Akteur zu seiner wie auch immer gelagerten Zielverwirklichung dient. Wie meine Ausführungen gezeigt haben, werden aber mindestens die Norm, die Verpflichtung, die Vertrauenswürdigkeit, die Erwartung und die Gutschrift von Coleman unter den Sozialkapitalbegriff subsummiert.

An manchen Stellen wiederum zählt eine Beziehungsrelation als Sozialkapital, an anderen gilt sie lediglich als Ort, wo dieses residiert. Unter dem hier interessierenden Erkenntniskonstrukt werden also innerhalb des Aussagensystems ganz unterschiedliche Gegenstände wenig trennscharf rubriziert. Es ist daher eigentlich nicht möglich, Colemans Konzept auf Grundlage des Moderaten Strukturalismus stringent darzustellen. Im Folgenden werde ich mich schwerpunktmäßig auf die von Coleman am ausführlichsten besprochene Form von Sozialkapital beziehen: dem System von Verpflichtungen und Erwartungen.

Dieses Vorgehen weist drei Vorzüge auf: Die Colemanschen Überlegungen sind so a) vereinfacht darstellbar, b) anschlussfähig an Bourdieus Sozialkapitalkonzept sowie das der Netzwerksoziologen und c) nutzbar als eine fundierte Grundlage für das noch zu konstruierende integrative Theoriemodell. Dabei gilt jedoch zu beachten, dass Coleman ähnlich wie Bourdieu eine Verpflichtung als 
Voraussetzung von und zugleich auch als Sozialkapital begreift ${ }^{334}$. Da innerhalb einer funktionalistischen Begriffsfassung eine Verpflichtung alleine aber noch keine handlungsbegünstigende Ressource begründet, korrigiere ich das Konzept an dieser Stelle und weise Verpflichtungen lediglich als eine mögliche Voraussetzung der Ressource Sozialkapital aus (wobei es sich bei Sozialkapital dann etwa um die Beaufsichtigung der eigenen Kinder durch die Nachbarn handeln kann).

Wie Eingangs des Anwendungsteils erwähnt, werden außer "Sozialkapital" alle Begriffe über die unterschiedlichen Konzepte hinweg konstant gehalten. Unter dieser Voraussetzung können - soweit als möglich - innerhalb der noch folgenden strukturalistischen Darstellungen die in Zusammenhang mit Bourdieus Ansatz eingeführten Formulierungen und Erläuterungen übernommen werden. Dies gewährleistet nicht nur eine relativ hohe Transparenz der Argumentation, sondern erleichtert im Anschluss dann auch einen Vergleich und eine integrative Theoriebildung. (Hinsichtlich der Erläuterung des verwendeten logischen Vokabulars verweise ich auf die Ausführungen im Zusammenhang mit der Rekonstruktion des Bourdieuschen Konzeptes sowie auf Kapitel 4.3.) Vor dem ersten strukturalistischen Rekonstruktionsschritt sollen die zentralen Vorstellungen Colemans in einer Tabelle überblicksartig zusammengefasst werden.

\section{Tabelle 2: Colemans Sozialkapitalkonzept}

\section{Definition}

Ebene

Lokalisierung

\begin{tabular}{|l} 
Sozialkapital ist \\
- $\quad$ sozialstrukturelle, handlungsbegünstigende \\
Ressource für einen Akteur (gemeint sind In- \\
formationskanäle, Verpflichtungen und Erwar- \\
tungen, Normen und Sanktionen, Herrschafts- \\
beziehungen, soziale Organisat.) \\
- $\quad$ eine Gutschrift \\
- $\quad$ eine Beziehungsrelation \\
- $\quad$ eine Form von Macht \\
- $\quad$ Vetzwerkschließung \\
- $\quad$ funktionswärdigkeit \\
- $\quad$ informell \\
- $\quad$ Mikro, Meso, Makro \\
- innerhalb von Beziehungsrelationen; Privatgut \\
sowie kollektives bzw. öffentliches Gut
\end{tabular}

\footnotetext{
334 Eine "Verpflichtung kann man als soziales Kapital, als eine 'Gutschrift' betrachten, die A besitzt und die von B mit irgendeiner Leistung eingelöst werden muss." (Coleman 1991: 396)
} 


\begin{tabular}{|c|c|}
\hline Entstehung & $\begin{array}{ll}\text { - } & \text { Tauschbeziehungen (soziale Interdependenz) } \\
- & \text { Vererbung bzw. Transferierung } \\
- & \text { Investitionen in Beziehungen } \\
\text { - } & \text { Erzeugung von Verpflichtungen } \\
\text { - } & \text { Ideologien }\end{array}$ \\
\hline Wirkung & $\begin{array}{ll}\text { - } & \text { Handlungsbegünstigung } \\
\text { - } & \text { Verbesserung der Lebensqualität } \\
\text { - } & \text { Schulerfolg } \\
\text { - } & \text { Humankapital }\end{array}$ \\
\hline Operationalisierung & - $\quad$ vor allem Netzwerkanalyse \\
\hline Wissenschaftstheoretischer Status & $\begin{array}{l}\text { empirisch-induktive (eigene Forschungen und } \\
\text { Sekundäranalysen) sowie integrativ-analytische } \\
\text { (homo oeconomicus - homo sociologicus) } \\
\text { Theoriekonstruktion } \\
\text { quantitatives Realmodell }\end{array}$ \\
\hline
\end{tabular}

\section{Erster Rekonstruktionsschritt}

1. Die einem Akteur (A) in Folge seiner Zugehörigkeit zu einem Beziehungsnetz (B) informell (Inf) zufließenden (sei es tatsächlich oder potentiell) und funktional (Fun) der eigenen Zielverwirklichung ( $Z$ ) dienenden Ressourcen (R) sind sein soziales Kapital ( $\mathrm{S}^{\mathrm{C}}\left[\mathrm{S}^{\mathrm{C}}=\right.$ Soziales Kapital bei Coleman]). Ein System von Verpflichtungen und Erwartungen (VE), Informationspotentiale (Infos), Normen und Sanktionen (NS), Herrschaftsbeziehungen (He) sowie Soziale Organisationen (SO) stellen allesamt Formen von Sozialkapital dar.

2. Sozialkapital findet sich auf der Mikro- ( $\left.\mathrm{L}^{\mathrm{Mi}}\right)$, der $\mathrm{Meso}-\left(\mathrm{L}^{\mathrm{Me}}\right)$ und der Makroebene (L $\mathrm{L}^{\mathrm{Ma}}$ ).

3. Sozialkapital ist eine innerhalb von Relationen (Rel) zwischen Akteuren (Lok $\left.{ }^{R e l}\right)$ angesiedelte Ressource, derer sich ein Akteur mit Blick auf seine Zielverwirklichung bedient bzw. bedienen kann; soziales Kapital tritt sowohl als privates (Gpriv) wie als kollektives Gut ( $\left.\mathrm{G}^{\mathrm{koll}}\right)$ in Erscheinung.

4. Soziale Interdependenzen (Inter) zwischen Teilnehmern (Te) eines Beziehungsnetzes und Akteur sowie Austauschprozesse (Ta) zwischen diesen sind Voraussetzung der Entstehung von sozialem Kapital.

5. Soziales Kapital kann Resultat individueller bzw. kollektiver Investitionsstrategien (Inv) in Beziehungen sein. Über Gefälligkeiten (Gef) lässt sich bspw. ein System von Verpflichtungen und Erwartungen etablieren. Ein System von Erwartungen und Verpflichtungen resultiert aber auch vielfach aus nicht be- 
wusst investiv angelegten Tauschprozessen. Sozialkapital kann auch Ergebnis einer Transferierung (Tr) $\operatorname{sein}^{335}$.

6. Soziales Kapital ist ein Erklärungsfaktor schulischen Erfolges (SE) und damit auch von Humankapital (Hum).

\section{Zweiter Rekonstruktionsschritt}

Q ist ein potentielles Modell des Colemanschen Sozialkapitalkonzeptes, gdw Q ein Tupel der Form

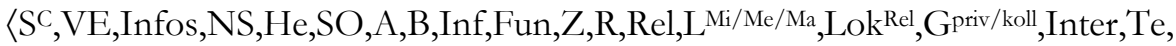
Ta,Gef,Inv,Tr,SE,Hum $\rangle$ wobei gilt

(1) SC,VE,Infos,NS,He,SO,A,B,Inf,Fun,Z,R,Rel,L ${ }^{\mathrm{Mi} / \mathrm{Me} / \mathrm{Ma}}, \mathrm{Lok}^{\mathrm{Rel}}, \mathrm{G}^{\text {priv/koll }}$,Inter,Te, $\mathrm{Ta}$,Gef,Inv,Tr,SE,Hum sind endliche, nicht-leere Mengen. Nach Ausgliederung von R, VE, NS, He, SO sind alle Mengen disjunkt.

(2) $\mathrm{S}^{\mathrm{C}} \subseteq \mathrm{R} ; \mathrm{R} \supseteq \mathrm{S}^{\mathrm{C}}$

(3) $\mathrm{VE} \subseteq \mathrm{S}^{\mathrm{C}} ; \mathrm{Infos} \subseteq \mathrm{S}^{\mathrm{C}} ; \mathrm{NS} \subseteq \mathrm{S}^{\mathrm{C}} ; \mathrm{He} \subseteq \mathrm{S}^{\mathrm{C}} ; \mathrm{SO} \subseteq \mathrm{S}^{\mathrm{C}}$

(4) $\operatorname{Inf} \subseteq$ Rel x R

(5) Fun $\subseteq \mathrm{R} \times \mathrm{A} \times \mathrm{Z}$

(6) $\mathrm{R} \subseteq \mathrm{Te} \times \mathrm{A}$

(7) $\mathrm{Rel} \subseteq \mathrm{A} \times \mathrm{Te}$

(8) $\mathrm{Ta} \subseteq \mathrm{A} \times \mathrm{Te} \times$ Inter $\mathrm{x}$

(9) $\mathrm{V} \subseteq$ Te $\times \mathrm{A}($ wobei $\mathrm{VE}=\mathrm{V} \cup \mathrm{E})$

(10) Inv $\subseteq$ A x Gef x Rel

(11) $\operatorname{Tr} \subseteq \operatorname{Te} \times \mathrm{V} \times \mathrm{A}$

Die Bedeutung der Bedingungen, die nicht schon in Zusammenhang mit dem Sozialkapitalkonzept Bourdieus erläutert wurden, lauten:

(3) Ein System von Verpflichtungen und Erwartungen, Informationspotentiale, Normen und Sanktionen, Herrschaftsbeziehungen sowie soziale Organisationen können allesamt Formen von Sozialkapital darstellen, d.h. es handelt sich mengentheoretisch gesprochen um Teilmengen von Sozialkapital.

(8) Tauschprozesse sind eine Teilmenge des kartesischen Produkts aus Akteur, Teilnehmern, Interdependenz und Ressourcen, d.h. zum Auftreten von Tauschprozessen als Bedingung von Sozialkapital bedarf es eines Akteurs, dem Sozialka-

335 Etwa wenn Eltern, die neu in eine Gegend ziehen, von der von Coleman beschriebenen Aufsichtspflicht gegenüber spielenden Kindern profitieren. In diesem Zusammenhang lassen sich auch Ideologien, die nach Coleman Sozialkapital begründen können, im Sinne einer Transferierung interpretieren: Vom christlichen Ideal der Nächstenliebe profitieren bspw. Personen, die zuvor nicht in Beziehungen investiert haben. Das Gleiche gilt sicherlich ebenso für generalisierte Reziprozität. 
pital zugeordnet werden kann, mindestens eines weiteren Teilnehmers, Interdependenz zwischen Akteur und Teilnehmer(n) sowie Ressourcen, die ausgetauscht werden (Bourdieu verzichtet auf die Anführung von Interdependenzen).

(9) Verpflichtungen sind eine Teilmenge des kartesischen Produkts aus Teilnehmern und Akteur; ein Teilnehmer fühlt sich einem Akteur, dem Sozialkapital zugeordnet werden kann und mit dem er in Verbindung steht, verpflichtet (da V eine [Beziehungs-] Relation impliziert, kann auf Rel verzichtet werden). Um dies im Zusammenhang mit Coleman formulieren zu können, wird V (Verpflichtungen) aus VE (System von Verpflichtungen und Erwartungen) ausgegliedert, d.h. $\mathrm{VE}$ wird als Vereinigungsmenge von $\mathrm{V}$ und $\mathrm{E}$ interpretiert $(\mathrm{VE}=\mathrm{V} \cup \mathrm{E})$.

(10) Investitionen sind eine Teilmenge des kartesischen Produkts aus Akteur, Gefälligkeiten und (Beziehungs-) Relationen, d.h. zum Auftreten einer Investition als Bedingung von Sozialkapital bedarf es eines Akteurs, dem Sozialkapital zugeordnet werden kann, Gefälligkeiten, die investiert werden sowie mindestens einer Relationen, in die investiert wird. (Gefälligkeit taucht als Modellkomponente auch bei Bourdieu auf, wird von diesem aber als aufzuwendende Zeit und insofern als ökonomisches Kapital generalisiert)

\section{Dritter Rekonstruktionsschritt}

$\mathrm{Q}$ ist ein Modell des Colemanschen Sozialkapitalkonzeptes, gdw

(1)〈SC,VE,Infos,NS,He,SO,A,B,Inf,Fun,Z,R,Rel,L ${ }^{\mathrm{Mi} / \mathrm{Me} / \mathrm{Ma}}{ }^{\mathrm{L}} \mathrm{Lok}^{\mathrm{Rel}}, \mathrm{G}^{\text {priv/koll }}$,Inter, Te,Ta,Gef,Inv,Tr,SE,Hum $\rangle \in \mathrm{M}_{\mathrm{P}}$

(2) $\exists(a, g e f, r e l)$

$$
(\mathrm{Inv}[a, g e f, r e l] \rightarrow \mathrm{V}[\mathrm{te}, a])
$$

(3) $\exists(a, t e, r)$

$(\mathrm{Ta}[a, t e, r] \rightarrow \mathrm{V}[t e, a])$

(4) $\forall(t e, a)$

$(\mathrm{V}[t e, a] \wedge \mathrm{R}[t e, a] \wedge \mathrm{Fun}[r, a, z] \rightarrow \mathrm{R}[t e, a]:=\mathrm{S}[[a])$

(5) $\forall(t e, v, a)$

(6) $\forall(a)$

$\left(\operatorname{Tr}[t e, v, a] \wedge \mathrm{R}[t e, a] \wedge \operatorname{Fun}[r, a, z] \rightarrow \mathrm{R}[t e, a]:=\mathrm{SC}^{C}[a]\right)$

(7) $\forall(a)$

$\left(\mathrm{SE}[a]: \mathrm{SC}^{\mathrm{C}}[a] \rightarrow \mathfrak{R}_{0+}\right)$

(8) $\forall(a)$

$\left(\operatorname{Hum}[a]: \mathrm{SE}[a] \rightarrow \mathfrak{R}_{0+}\right)$

$\left(\mathrm{SE}[a]: \mathrm{SC}^{\mathrm{C}}[a] \rightarrow \mathfrak{R}_{0+} \wedge \mathrm{Hum}[a]: \mathrm{SE}[a] \rightarrow \mathfrak{R}_{0+}\right) \rightarrow$

$\left(\operatorname{Hum}[a]: \mathrm{SC}[a] \rightarrow \mathfrak{R}_{0+}\right)$

Insgesamt ergeben sich für die Bedingungen 2, 6, 7 und 8 Abweichungen vom Bourdieuschen Konzept:

(2) Es gibt mindestens eine Verbindung zwischen einem Akteur, ökonomischem Kapital und (Beziehungs-) Relationen aus $\mathrm{M}_{\mathrm{P}}$ für die gilt, wenn ein Akteur Gefälligkeiten in eine (Beziehungs-) Relation investiert, dann entsteht eine soziale Verpflichtung ihm gegenüber. 
(6 - 8) SE ist eine Funktion von SC, d.h. das Ausmaß des Sozialkapitals des einzelnen Akteurs bestimmt seinen schulischen Erfolg und hierüber auch seine Ausstattung an Humankapital in entscheidender Weise mit; damit ist Humankapital ebenfalls eine Funktion von Sozialkapital (alle Funktionen sind idealerweise über eine positive reelle Zahl [ $\left.\mathfrak{R}_{0^{+}}\right]$quantifizierbar).

Wie bei der Rekonstruktion des Bourdieuschen Konzeptes soll abschließend ein Tupel Q' festgelegt werden, der all jene Merkmale enthält, welche die BegriffsIntension von "Sozialkapital" bei Coleman ausmachen. Herausgestrichen werden damit aus Q alle Komponenten, die abgeleitete Werte darstellen, d.h. die zur Entstehung von Sozialkapital beitragen, dessen Wirkung ausmachen oder dessen Ort charakterisieren und insofern hinsichtlich der Definition keine zusätzlichen Informationen liefern. Q' ist ein Tupel der Form $\langle A \times$ Te $x$ Rel $x \mathrm{R} \times \mathrm{B} \times \operatorname{Inf} \times$ Fun $x$ Z .

\subsection{Sozialkapital und Bürgergesellschaft: Das Konzept Robert D. Putnams}

Robert D. Putnam kann sicherlich als der exponierteste Vertreter eines Sozialkapitalansatzes bezeichnet werden. Auf ihn beziehen sich nahezu sämtliche Autoren, die im Zusammenhang mit der Bürgergesellschaft, dem dritten Sektor sowie sozio-ökonomischen oder steuerungstheoretischen Problemen den Sozialkapitalbegriff verwenden. Putnam selbst ist zudem u.a. als Berater des ehemaligen USamerikanischen Präsidenten Bill Clinton, der CIA oder der Weltbank tätig gewesen bzw. immer noch tätig; seine Überlegungen haben sowohl Eingang in den politischen wie in den journalistisch-publizistischen Bereich gefunden.

Mit Putnams Buch "Making Democracy work. Civic Traditions in Modern Italy" aus dem Jahre 1993 wurde die Sozialkapitaldebatte in konzeptioneller und empirischer Hinsicht erst so richtig entfacht. In dieser kanonisch zu nennenden Untersuchung erklärt Putnam (gemeinsam mit seinen Mitarbeitern) die Unterschiede in der ökonomischen wie politisch-administrativen Performanz zwischen den nördlichen und den südlichen Regionen Italiens nach der Verwaltungsreform von 1970 über das Vorhandensein von und das Ausmaß an Sozialkapital (und das meint in diesem Zusammenhang vor allem zivilgesellschaftliche Traditionen und hieraus resultierendes generalisiertes Vertrauen). 


\section{Definition}

In einer allgemeinen Formulierung heißt es bei Putnam (1995: 67): "Social capital refers to features of social organizations such as networks, norms, and social trust that facilitate coordination and cooperation for mutual benefit." 336

"Sozialkapital" ist damit eine Summenbezeichnung für mindestens drei verschiedenartige, soziale Gegenstände bzw. Gegenstandsbereiche: Netzwerke, Normen und Vertrauen. Dabei wird gleichwohl nicht deutlich, ob diese nun als Formen, Komponenten, Facetten, Eigenschaften, Konturen, Dimensionen etc. konzeptualisiert sind. Ist Vertrauen alleine bspw. schon Sozialkapital oder bedarf es hierfür noch weiterer Bedingungen? So heißt es u.a. wahlweise: "Trust is an essential component of social capital" (Putnam, R. 1993: 170); "social capital ... refers to features of social organizations, such as trust" (Putnam, R.D. 1993: 167); "trust and engagement are two facets of ... social capital" (Putnam 1995: 73); "the touchstone of social capital is the principle of generalized reciprocity" (Putnam 2000: 134); "the norm of generalized reciprocity is a highly productive component of social capital" (Putnam, R.D. 1993: 172); "networks of civic engagement are an essential form of social capital" (Putnam, R.D. 1993: 173); "social capital (is, D.K.) embodied in horizontal networks of civic engagement" (Putnam, R.D. 1993: 176). Macht es aber nicht bspw. einen Unterschied, ob Netzwerke eine Form des Sozialkapitals darstellen oder ob dieses in Netzwerken eingeschlossen ist bzw. dadurch verkörpert wird ${ }^{337}$ ?

Die "relevanten Wesensmerkmale der Bürgergesellschaft" sollen nach Putnam "Konturen des Sozialkapitals" sein (Putnam/Goss 2001: 20). Expressis verbis heißt es: "Your extended family represents a form of social capital, as do your sunday school class, the regulars who play poker on your commuter train, your college roommates, the civic organizations to which you belong, the Internet chat

\footnotetext{
336 Dabei sind die meisten Formen des Sozialkapitals "'moral resources' - that is, resources whose supply increases rather than decreases through use and which become depleted if not used. The more two people display trust towards one another, the greater the mutual confidence." (Putnam, R.D. 1993: 169) Aber warum handelt es sich dabei um "moral resources"? Haug (2000: 98, Fußn. 47) sieht dies ähnlich, wenn sie formuliert, "die Wahl des Begriffs 'moralisch' für diesen Sachverhalt erscheint hier nicht besonders einsichtig." Ein Blick auf Fukuyama (1999: 2) kann hier weiterhelfen. Er qualifiziert jene Normen, die er als "Sozialkapital" verstanden wissen möchte, hinsichtlich ihrer Wirkungen und glaubt so, den Ressourcenaspekt zu fokussieren: "They must lead to cooperation in groups and therefore are related to traditional virtues like honesty, the keeping of commitments, reliable performance of duties, reciprocity, and the like." Und an anderer Stelle ordnet er diese Perspektive dann sogar dezidiert einer moralphilosophischen Richtung zu: "Social capital in this view is an utilitarian way of looking at culture." (Fukuyama 2002: 27) Laut Meier (1996: 14) dreht es sich bei der Sozialkapitaldebatte darum, "durch Ethik Transaktionskosten zu sparen". Bei Gehmacher (2004: 14) ist von "'schadstoff-freiem', 'beglückendem' Sozialkapital mit einem hohen Gehalt an Gerechtigkeit und humanitärer Ethik" die Rede (inwiefern man diesbezüglich allerdings noch von einer wissenschaftlichen Ausdrucksweise sprechen darf, mag jeder Leser selbst beurteilen).

337 Die Uneindeutigkeit setzt sich dann in der Sekundärliteratur fort. Serageldin/Grootaert (1999: 45) meinen etwa, "Putnam views social capital as a set of 'horizontal associations' among people". Nach Graf (1999: 94) umfasst Putnams Sozialkapitalbegriff "eine Reihe sehr unterschiedlicher Tätigkeiten des Menschen".
} 
groups in which you participate, and the network of professional acquaintances recorded in your address book." (Putnam 2000: 21) Ferner werden auch Elternvereinigungen, Gewerkschaften, Stammtische, ein spontan stattfindendes Basketballspiel, ein Abendessen mit der Verwandschaft, flüchtige Grußbekanntschaften oder zufällige Begegnungen im Fahrstuhl zu Sozialkapital erklärt (vgl. Putnam/Goss 2001: 25f.).

All diesen Entitäten wohnt eine "gewisse Form der Gegenseitigkeit" inne (Putnam/Goss 2001: 26). Ist nun eine "gewisse Form der Gegenseitigkeit" oder "soziale Verbundenheit" - wie es an anderer Stelle (Putnam 2002: 270) heißt damit der Kern des Putnamschen Sozialkapitalverständnisses, sozusagen sein allgemeinstes Bestimmungsmerkmal? Auf welchem Hintergrund macht es Sinn, ein gemeinsames Abendessen mit der Familie, bestimmte Normen, Wesensmerkmale der Bürgergesellschaft, Vertrauen und Grußbekanntschaften hierüber zusammenzufassen? M.a.W.: Was sind die Bedingungen, unter denen all diese weitgehend als informell zu kennzeichnenden Entitäten zu Sozialkapital werden? Vergegenwärtigt man sich nochmals die oben genannte grundlegende Begriffsdefinition, so sind sie wohl nur dann Sozialkapital, insofern sie - wie Putnam (1995: 67) sagt - Koordination und Kooperation zum wechselseitigen Nutzen erleichtern, insofern ihnen also ein Ressourcenstatus zukommt.

Problematisch ist dabei, dass Putnam diese Bedingungen nur selten anführt, wenn er Formen, Komponenten, Facetten, Eigenschaften etc. des Sozialkapitals benennt; so entsteht vielfach der Eindruck, als wären sie alle per se Sozialkapital. Dann würde es jedoch überhaupt keinen Sinn machen, von Ressourcen zu sprechen, denn nur am konkreten Fall lässt sich die Nützlichkeit und damit der Ressourcencharakter dessen beurteilen, was nach Putnam Sozialkapital sein soll.

Kritikabel an Putnams Begriffsdefinition ist vor allem, dass es sich vor dem Hintergrund unseres Sprachgebrauchs (sowohl im Alltag wie in der Wissenschaft) bei den als Sozialkapital bezeichneten Entitäten um ganz unterschiedliche Dinge handelt. Diese hängen zweifelsfrei in vielerlei Hinsicht wechselseitig voneinander ab und wirken möglicherweise gesamtgesellschaftlich in eine ähnliche Richtung. Aber würde man - um eine Analogie zu wagen - etwa in der Klinischen Psychologie auf die Idee kommen, Sozialphobien, Depressionen, und Minderwertigkeitskomplexe über einen einzigen Begriff zusammenzufassen, nur weil diese Krankheitsformen korrelieren, häufig gemeinsam auftreten und u.a. auch kausal zum Selbstmord führen? Stattdessen spricht man von "Komorbidität", um damit therapeutisch das Krankheitsgeschehen als System kommunizierender Röhren begreifen zu können. Konstatiert man nun eine "soziale Dekapitalisierung" (Putnam 1999: 56), also den Rückgang von Sozialkapital in modernen Gesellschaften, so mag es auch im vorliegenden Zusammenhang - um im Bild zu bleiben - 
gewissermaßen "polit-therapeutisch" sinnvoll sein ${ }^{338}$, Vertrauen, Reziprozitätsnormen und Netzwerke als ein solches System zu begreifen und es über "Sozialkapital" zu kategorisieren. Dann aber hat der Oberbegriff allenfalls einen ganz groben, systematisierenden Charakter bzw. Wert.

In diesem Zusammenhang kann auf die Apologie der weiten und "ambitionierten" Putnamschen Begriffsfassung durch Ostrom/Ahn (2003: 36) verwiesen werden: "Die Erkenntnis wichtiger Gemeinsamkeiten verschiedener Variablen, die zuvor als voneinander unabhängig behandelt wurden, ist in den Sozial- und Politikwissenschaften ein Schritt nach vorn." Schließlich verwende man ja auch den Ausdruck "physisches Kapital" zur Bezeichnung einer Fabrik, einer Straße oder eines Computers. Genauso sei es nun auch legitim und sinnvoll, unterschiedliche Entitäten unter den Sozialkapitalbegriff zu rubrizieren. "So können gesellschaftliche und wirtschaftliche Entwicklungen vernünftig analysiert werden." (ebenda: 36)

Was konkret unter "vernünftig" verstanden werden soll, bleibt an der entsprechenden Textstelle zwar unbeantwortet, allerdings wird kurz zuvor der Beitrag des Sozialkapitalansatzes darin gesehen, "dass er diese scheinbar unterschiedlichen Faktoren (zu denen Ostrom/Ahn neben Vertrauen, Normen und Netzwerken auch noch formelle und informelle Regeln und Institutionen zählen, D.K.) in den Rahmen des kollektiven Handelns einbettet." (ebenda: 35) Insofern haben wir es an dieser Stelle mit einer begriffstheoretischen und einer methodologischen Argumentation zu tun: Erstens wird behauptet, "Vertrauen", "Normen" und "Netzwerke" stünden in etwa so zu "Sozialkapital" wie "Fabrik", "Straße" und "Computer" zu "physischem Kapital". Zweitens heißt es, eine Zusammenfassung unterschiedlicher Variablen sei mit Blick auf das Problem kollektiven Handelns analytisch sinnvoll.

Letzteres scheint zunächst einsichtig: Je mehr Variablen man zur Analyse des Problems kollektiven Handelns heranzieht, desto vertiefter dürfte die gewonnene Erkenntnis schließlich ausfallen (vorausgesetzt freilich, man zieht adäquate Variablen heran). Dann aber handelt es sich methodologisch gesprochen in erster Linie um einen Index, dem man einen griffigen Namen gegeben hat. Ist der Name nun aber auch aus begriffstheoretischer Sicht sinnvoll? Stehen denn "Vertrauen", "Normen" und "Netzwerke" in der Tat so zu "Sozialkapital" wie "Fabrik", "Straße" und "Computer" zu "physischem Kapital"?

Fasst man die jeweiligen Unterbegriffe als Bezeichnungen für Variablen auf, so vermag ich nicht zu erkennen, welche analytischen Abhängigkeiten zwischen "Fabrik", "Straße" und "Computer" bestehen sollten ${ }^{339}$. Bei "Vertrauen", "Nor-

\footnotetext{
338 In der Tat spricht Putnam (1996: 76) hinsichtlich des Zustandes der Demokratien in Europa, den USA und Japan von "Symptomen der Schwäche" und unterbreitet dementsprechend "einige Vorschläge zur Therapie".

339 Man kann mit einem in einer Fabrik hergestellten Computer eine Straße planen, die an einer Fabrik entlang führt, die Computer herstellt (und diese Fabrik muss keineswegs jene Fabrik sein, in
} 
men" und "Netzwerken" liegt der Fall sicherlich anders. Netzwerke können z.B. Vertrauen begründen und umgekehrt sind Netzwerke vielfach Resultat von vorgängigen Vertrauensbeziehungen zwischen Personen, die wiederum in Folge bestehender Normen ermöglicht wurden. D.h. hier haben wir es mit ordinal bzw. metrisch skalierbaren Variablen zu tun ${ }^{340}$, die sich häufig wechselseitig beeinflussen. Diese nun unter den Oberbegriff "Sozialkapital" zu subsummieren (bzw. in einen Topf zu werfen), so sinnvoll oder nützlich dies methodologisch betrachtet auch möglicherweise sein mag, führt zu einer begriffsextensionalen Unschärfe, über die man nicht so einfach hinwegsehen darf ${ }^{341}$.

Unterschiedliche Aspekte der sozialen Realität erfordern eine differenzierte Betrachtung: Unter "Vertrauen" versteht man im Allgemeinen eine kognitive oder affektive Leistung eines Individuums bezüglich eines anderen (also einen Bewusstseinsakt, eine Einstellung), unter "sozialer Norm" einen Wertmaßstab hinsichtlich menschlichen Zusammenlebens (d.h. eine zwar von Menschen aufgestellte, aber den Einzelnen transzendierende Verhaltensregel) und unter "soziales Netzwerk" eine wie auch immer begründete, vorwiegend kommunikative Koordination zwischen mehreren Akteuren (und insofern eine [wenn auch nicht mit Luhmann] zumindest in Teilen doch sehr physikalisch-biologische Entität).

Man könnte nun sagen, Vertrauen, soziale Normen und soziale Netzwerke weisen aber eine gemeinsame Eigenschaft auf, die es erlaubt, sie als eine Kapitalform zu begreifen: Sie sind Ressourcen, derer sich Akteure zu ihrer Zielverwirklichung bedienen. Wenn der Ressourcenbegriff "im Allgemeinen die Mittel bezeichnet, die vorhanden sind, um eine bestimmte Aufgabe zu lösen" ${ }^{342}$, dann erscheint aber äußerst diskutabel, ob man hier sinnvoll einen Ressourcenstatus zuschreiben kann: Mit der Norm generalisierter Reziprozität kann man bspw. nur dann etwas "anfangen", wenn andere sich in konkreten Situationen in ihrem Verhalten hieran orientieren - das ist aber nun sicherlich etwas anderes, als die

welcher der Computer hergestellt wurde, mit Hilfe dessen die Straße geplant wurde). Eine Aussage über einen analytischen Zusammenhang ist damit aber noch nicht getroffen.

340 Es geht bei Putnam immer um ein quantitatives "Mehr" an Vertrauen (Netzwerken, Normen) bzw. ein qualitativ "besseres" Vertrauen ("bessere" Normen, "bessere" Netzwerke).

341 Diekmann (2004a: 488f.) äußert, bei Sozialkapital handele es sich um "a conglomerate of several components". Dies sieht er als Defizit an, welches sich eliminieren lasse, "if one focuses more precisely on the basic elements" des Sozialkapitals. So untersucht Diekmann dann konsequenterweise lediglich (die Norm der) Reziprozität. Damit bleibt jedoch aus meiner Sicht fraglich, warum noch der Sozialkapitalbegriff benötigt wird; es reicht völlig aus, lediglich von "Reziprozität" zu sprechen. Dieser Einwand trifft auch Adloff/Mau (2005b: 10), wenn diese im Anschluss an Putnam behaupten, "das Sozialkapital einer Gesellschaft ermöglicht soziale Integration durch Muster generalisierter Reziprozität". Damit wird nun aber nichts anderes gesagt, als dass soziale Integration durch Muster generalisierter Reziprozität ermöglicht werde. Vergleichbares ist in Bezug zu Uslaner (1999) formulierbar, denn dieser beschäftigt sich lediglich mit dem Zusammenhang von Demokratie und Vertrauen, obgleich er im Titel seines Artikels eine Untersuchung zum Zusammenhang von "Democracy and Social Capital" ankündigt.

342 wikipedia.org. Die Wikipedia Enzyklopädie ist in Folge ihrer Verbreitung und Veränderbarkeit (jeder Nutzer kann Einträge online erstellen oder vorhandene Artikel ändern) auf dem Hintergrund einer sprachlichen Gebrauchstheorie eine m.E. sehr sinnvolle Referenz. 
Norm selbst bzw. ihr Inhalt (hier gelten also weitgehend die gleichen Einwände, die schon im Zusammenhang mit Colemans Ressourcenbegriff formuliert wurden [vgl. Kapitel 7.2.].). Kurz und knapp: Das, was von Putnam alles unter "Sozialkapital" subsummiert wird, ist in der Realität nicht als kohärente Entität aufweisbar; der Begriff erfährt damit keine mehrdimensionale, sondern lediglich eine mehrdeutige Bestimmung. Wenn all das mit "Sozialkapital" gemeint sein kann, was Putnam anvisiert, dann ist der Begriff ungemein vage. Ist aber nur ein Teil des anvisierten Spektrums gemeint, wäre es sinnvoller, gleich exakt anzugeben, worum es gehen soll ${ }^{343}$.

Im Rahmen seiner begrifflichen Erörterungen - dies sei hier abschließend erwähnt - errichtet Putnam auch noch eine Typologie der netzwerkförmigen Form des Sozialkapitals, "die neuerdings seinen Forschungsschwerpunkt bildet" (Braun 2001: 20). Dabei unterscheidet er zwischen formellem versus informellem, innenorientiertem versus außenorientiertem, brückenbildendem versus bindendem Sozialkapital sowie Sozialkapital mir hoher versus geringer Dichte. Formelles Sozialkapital stellt für Putnam bspw. "eine Elternvereinigung oder eine Gewerkschaft" dar. Eine "Personengruppe, die sich jeden Donnerstagabend in einer Kneipe trifft" (Putnam/Goss 2001: 25), wird hingegen als "informelle Kapitalform" bezeichnet. Verfolgt eine Gruppe vorwiegend die Interessen ihrer Mitglieder, dann ist von innenorientiertem, bei Fokussierung auf die Bereitstellung öffentlicher Güter von außenorientiertem Sozialkapital die Rede. Beispiele für den ersten Fall wären etwa "Herrenclubs und Handelskammern ... . In der zweitgenannten Kategorie finden wir wohltätige Bruderschaften wie die Lions Clubs" (ebenda: 28).

Die wichtigste Unterscheidung im Rahmen der Typologie ist für Putnam "the distinction between bridging (or inclusive) and bonding (or exclusive)." (Putnam 2000: 22) "Brückenbildendes Sozialkapital" meint eine Form zwischenmenschlicher, idealiter nicht hierarchischer, horizontaler Vernetzung, bei der Trennungslinien wie Ethnie, Religion, Alter oder gesellschaftliche Schicht überwunden werden (etwa Bürgerinitiativen, die sich im Bereich allgemeiner Thematiken wie dem Umweltschutz engagieren oder Sportvereine). Bindendes (bonding) Sozialkapital liegt in sozial homogenen, kleinen Gruppen vor und befördert Mechanismen der sozialen Schließung 344 . Eine "flüchtige Grußbekanntschaft" konstituiert eine

\footnotetext{
343 Kenneth Newton (1997: 583) sieht dies in ähnlicher Weise, wenn er hinsichtlich der Putnamschen Begriffsfassung äußert: "The advantage of the definition is that it combines three aspects of social capital that make it an interesting and provocative concept. The disadvantage is that it runs different conceptual things together that should be separated, the better to study their empirical relationships." Es kann allerdings kaum davon gesprochen werden, Putnam kombiniere bei seiner Definition drei Aspekte von Sozialkapital; vielmehr kombiniert er drei tradierte sozialwissenschaftliche Begriffe, um diese dann jeweils einzeln aber auch gemeinsam "Sozialkapital" zu nennen.

344 Die Differenzierung zwischen "bridging" und "bonding" wird in der Sekundärliteratur breit aufgenommen und führt dort bisweilen zu doch recht sonderlich anmutenden Formulierungen (für die man freilich Putnam nicht verantwortlich machen darf). Beispielhaft sei hier Gehmacher (2004:
} 
geringe, eine "Gruppe von Stahlarbeitern, die tasgüber in der Firma zusammenarbeitet, sich am Samstag zum Kegeln trifft und am Sonntag die katholische Messe besucht" (Putnam/Goss 2001: 26) eine hohe Dichte an Sozialkapital.

\section{Ebene}

Putnam richtet den Fokus in erster Linie auf die makrosoziologische Ebene. Der Bestand an Sozialkapital von Regionen und ganzen Gesellschaften wird bestimmt. Durch den Bezug bspw. auf eine flüchtige Grußbekanntschaft oder eine Gewerkschaft wird dezidert auch die Mikro- und die Mesoebene mit einbezogen. Ferner weist Putnams Rekurs auf die Rational Choice-Theorie auf eine generelle Mikrofundierung hin $^{345}$. Da - wie unten noch deutlich werden wird - Sozialkapital als wichtigstes Instrument zur Lösung des Problems kollektiven Handelns gilt, ist die Aggregation von besonderem Interesse. "How does personal trust become social trust?" (Putnam, R.D. 1993: 171) Putnams eigene Antwort: "Social trust in complex modern settings can arise from two related sources - norms of reciprocity and networks of civic engagement." (ebenda) An dieser Stelle wird damit die Aggregierung einer Form von Sozialkapital - nämlich des Vertrauens - durch das Vorhandensein zweier anderer Formen - nämlich Normen der Reziprozität und zivilgesellschaftlichen Netzwerken - erklärt. Die sich dahinter verbergende Logik beschreibt Putnam illustrativ: "Social networks allow trust to become transitive and spread: I trust you, because I trust her and she assures me that she trusts you." (ebenda: 169)

Damit wäre ein Hinweis darauf gegeben, wie zwischenmenschliches Vertrauen als Sozialkapital auf der Mikro- zu generalisiertem Vertrauen als Sozialkapital auf der Makroebene werden kann. Die Norm der generalisierten Reziprozität ist ohnehin eine makrotheoretisch zu interpretierende Entität und hängt mit sozialem Vertrauen unmittelbar zusammen: "I'll do this for you now without expecting anything immediately in return and perhaps without even knowing you, confident that down the road you or someone else will return the favour." (Putnam 2000: 134; siehe zu Reziprozität im Kontext von Sozialkapital auch Diekmann 2004a)

Aber wie ist es mit Netzwerken? Dass Individuen vielfach von ihrer Einbettung in Netzwerke profitieren, ist relativ leicht zu plausibilisieren und wird ebenso von Bourdieu, Coleman und (natürlich) den Netzwerktheoretikern betont. Nach Putnam verfügt nun eine Gesellschaft über einen großen Bestand an dieser Form von Sozialkapital, wenn sie ein reges Vereins- und Organisationsleben aufweist

8) zitiert, der ohne jegliche Angabe empirischer Daten oder Quellen behauptet: "In der Habsburger Monarchie waren die sozialen Bindungen zwischen Österreich und Ungarn (oder Böhmen) noch 'Bonding', nach 1918 wurden sie zum 'Bridging', das gerade deshalb recht erfolgreich geworden ist, weil von dem versagendem 'Bonding' viel ins 'Bridging' herübergerettet wurde."

345 Es ist also keineswegs der Fall - wie in der Literatur vielfach behauptet (vgl. etwa Paxton 1999: 95) -, dass Sozialkapital bei Putnam lediglich makrosoziologisch konzeptualisiert bzw. lediglich "a feature of a community" sei. 
(vgl. die Ausführungen unter Operationalisierung). Damit wird aber nun nicht wirklich viel über die Aggregationsmechanismen ausgesagt. Stattdessen werden (weitestgehend) lediglich die offiziellen Vernetzungsformen innerhalb einer Gemeinschaft aufsummiert und dann behauptet, hierbei handele es sich um eine auf der Makroebene vorfindbare Form von Sozialkapital. M.a.W.: Mikrotheoretisch gilt die soziale Integration, die Netzwerkeinbindung, als Sozialkapital des Individuums; makrotheoretisch soll das Netzwerk-Sozialkapital einer ganzen Gesellschaft bzw. Gemeinschaft aus der Anzahl an Vereinen bzw. an organisationellen Mitgliedschaften hervorgehen.

Wollte man analog zum individuellen Sozialkapital argumentieren, dann müsste man aber bspw. die Einbindung einzelner Länder in die internationale Staatengemeinschaft untersuchen. Anders formuliert: Wenn Sozialkapital auf der mikrotheoretischen Ebene grundlegend durch die Verbindung eines Individuums mit anderen, also durch dessen Außenbeziehungen, durch Einbettung zustande kommt, dann müsste, will man die Analogie wahren und kohärent argumentieren, dies auch für den kollektiven Akteur gelten. Bei Putnam trifft das aber nun nicht zu. Das, was auf der Makroebene als Sozialkapital ausgewiesen wird, ist das operationelle Resultat von Innenbeziehungen, d.h. die Beziehungen zwischen den ein Kollektiv konstituierenden Akteure sind Grundlage des Sozialkapitals. Damit begeht Putnam aber einen Kategorienfehler; es ist logisch nicht konsistent, wenn man Sozialkapital mikrotheoretisch über externe Tausch- bzw. Einbettungsprozesse herleitet und den entsprechenden Begriff dann zugleich auf ein Aggregationsergebnis anwendet, das internen Mechanismen geschuldet ist.

\section{Lokalisierung}

Da Putnam mit seiner Konzeptualisierung von Sozialkapital als Normen, Vertrauen und Netzwerke insbesondere an Coleman anknüpft, handelt es sich auch bei ihm um Ressourcen, die Beziehungsrelationen innewohnen ${ }^{346}$. Putnam selbst dürfte an der Frage der Lokalisierung allerdings wohl nicht allzu sehr interessiert sein. In Folge seines anwendungsorientierten und schwerpunktmäßig auf dem Thema Bürgergesellschaft liegenden Ansatzes beschäftigt ihn vorrangig, inwiefern man hinsichtlich von Sozialkapital von einem öffentlichen oder einem privaten Gut sprechen sollte; das Olsonsche Kollektivgutproblem steht also im Mittelpunkt. Beides ist möglich, d.h. Sozialkapital kann "gleichzeitig sowohl privates als auch öffentliches Gut sein. In vielen seinen Erscheinungsformen fällt ein Teil des Nutzens Unbeteiligten zu, während ein weiterer Teil des Nutzens die unmittelbaren Interessen der Person befriedigt, welche die Investition tätigt." (Putnam/Goss 2001: 22)

\footnotetext{
346 Explizit heißt es bspw.: "Trust embedded in personal relations that are strong, frequent, and nested in wider networks is sometimes called 'thick trust'." (Putnam 2000: 136)
} 


\section{Entstebung}

Der Entstehung von Sozialkapital schenkt Putnam weniger Aufmerksamkeit als dessen Wirkung. Dies mag erneut an seiner Orientierung an der politischen Praxis liegen. Die Argumentation Putnams ist in erster Linie funktionalistisch, d.h. sie zielt weniger darauf ab, zu erklären, was denn nun konkret die über "Sozialkapital" bezeichneten Gegenstände begründet, sondern welche Probleme hierüber bearbeitet bzw. gelöst werden. Insofern handelt es sich eigentlich um eine Benennung der Wirkung, wenn es etwa heißt, zur Überwindung kollektiver Dilemmata seien "soft solutions" wie Vertrauen und Gemeinschaft geeignete Instrumente 347 (vgl. Putnam, R.D. 1993: 167).

Dennoch streicht Putnam (1993: 172) auch sozialen Austausch als grundlegende Quelle des Sozialkapitals heraus: "Repeated exchange over a period of time tends to encourage the development of a norm of generalized reciprocity". Zugleich bleibt in diesem Zusammenhang aber unklar, ob Austausch nun eine Entstehungsursache von Sozialkapital (hier also in Form generalisierter Reziprozität) ist, es indiziert, oder aber zu dessen Aufrechterhaltung beiträgt. Wenn etwa reziproke Hilfesysteme eine Investition in Sozialkapital bedeuten (vgl. Putnam, R.D. 1993: 169), überdies aber auch Kennzeichen seines Vorhandensein sind sowie für seinen Fortbestand sorgen, dann sind aufgrund eines Begriffsverständnisses, demzufolge im allgemeinen soziale Netzwerke, Vertrauen, Normen der Reziprozität sowie im Speziellen chat-groups im Internet, Abendessen, Zimmernachbarn etc. allesamt Formen des Sozialkapitals darstellen, Entstehungsgründe, Definitionskriterien und Wirkungen nicht trennscharf voneinander abgegrenzt. Ist Vertrauen nun eine Folge von Kooperation, Reziprozitätsnormen und Netzwerken zivilen Engagements (vgl. Putnam, R.D. 1993: 171) oder deren Voraussetzung (vgl. Putnam 1995: 67 u. Putnam, R.D. 1993: 172)?

Oben wurde beschrieben, dass Putnam ein spontan stattfindendes Basketballspiel als Soziakapital ansieht. An anderer Stelle heißt es jedoch: "Spontaneous cooperation is facilitated by social capital" (Putnam, R.D. 1993: 167). Ist diese Kooperation nun Sozialkapital oder wird sie dadurch erleichtert bzw. sogar erst hervorgerufen? Oder etwa alles gemeinsam? Ganz offenkundig zirkulär klingt es, wenn behauptet wird, "voluntary cooperation is easier in a community that has inherited a substantial stock of social capital in the form of norms of reciprocity and networks of civic engagement." (ebenda: 167) Das Vorhandensein von Reziprozitätsnormen und Netzwerken zivilen Engagements impliziert aber gemeinhin freiwillige Kooperation, womit Letztere eigentlich nicht so richtig von Ersteren abhängig sein kann. Variablensoziologisch wie begriffstheoretisch wird hier also unpräzise argumentiert (vgl. kritisch zu Putnams zirkulärer Argumentation u.a. auch Harris/de Renzio 1997: 924).

\footnotetext{
347 Man kann also formulieren: Der Wunsch nach Vermeidung kollektiver Dilemmata ist eine Ursache der Entstehung von Sozialkapital (Motivkausalität); oder aber: Sozialkapital erklärt die Überwindung kollektiver Dilemmata.
} 
Diesem Einwand begegnet Putnam (2000: 137), indem er behauptet, die kausalen Abhängigkeiten seien "as tangled as well-tossed spaghetti." Oder in weniger blumigen (bzw. kulinarischen) Worten: "Social trust, norms of reciprocity, networks of civic engagement, and successful cooperation are mutually reinforcing."348 (Putnam, R.D. 1993: 180) Für die Zwecke seiner Untersuchungen sei es ausreichend "that they form a coherent syndrom." (Putnam 2000: 137) Sicherlich könnte man an dieser Stelle versuchen, unterschiedliche Formen des Sozialkapitals als Beobachtungsdimensionen zu bestimmen ${ }^{349}$. Dann aber müsste man dafür Sorge tragen, deren wechselseitige Ausschließlichkeit zu gewährleisten. In operationeller Hinsicht misst Putnam aber bspw. Vertrauen doppelt, wenn er es sowohl über Netzwerke als auch über seperate Items (wie etwa der Frage, ob man seinen Mitmenschen generell Vertrauen schenken kann) bestimmt.

\section{Wirkung}

"The core idea of social capital theory is that social networks have value."350 (Putnam 2000: 19) Wie schon mit Blick auf die funktionale Erklärung von Sozialkapital erwähnt, ist der zentrale Effekt eine Lösung kollektiver Dilemmata. Hierauf weist Putnam immer wieder hin (vgl. etwa: "certain sorts of social networks themselves facilitate the resolution of dilemmas of collective action" [1993: 172); "soziale Interaktion hilft bei der Lösung von Dilemmata des kollektiven Handelns" [2001: 21]; "norms of generalized reciprocity and networks of civic engagement encourage social trust and cooperation" [1993: 177]; "dense networks of interaction probably broaden the participants' sense of self, developing the 'I' into the 'we"' [Putnam 1995: 67]). Dieser zentrale Effekt verhilft nun seinerseits dazu, dass Sozialkapital in entscheidender Weise positiven Einfluss auf die Politik - im Sinne von "good government" bzw. "good governance" - sowie die Ökonomie - im Sinne von "economic development" bzw. "economic growth" - ausübt ${ }^{351}$.

\footnotetext{
348 "An effective norm of reciprocity is likely to be associated with dense networks of social exchange. In communities where people can be confident that trusting will be requited, not exploited, exchange is more likely to ensure. Conversely, repeated exchange over a period of time tends to encourage the development of a norm of generalized reciprocity. In addition, certain sorts of social networks themselves facilitate the resolution of dilemmas of collective action." (Putnam, R.D. 1993: 172)

349 An einer Stelle weist Putnam auch auf eine solche Multidimensionalität hin, spricht sodann jedoch erneut von "Formen": "Weil Sozialkapital multidimensional ist und manche seiner Formen auch ganz unterschiedlich verstanden werden können, dürfen wir im Hinblick auf seine Veränderungsprozesse nicht einfach Fragen stellen nach dem Muster 'mehr oder weniger Sozialkapital'." (Putnam/Goss 2001: 28)

350 Damit werden hier augenscheinlich Vertrauen und Normen der Reziprozität zu weniger relevanten Formen des Sozialkapitals degradiert. Oder sollten diese Formen impliziter Bestandteile sozialer Netzwerke sein?

351 Oder wie es Offe bezüglich Putnams Konzept lapidar formuliert: "Jedenfalls wird von der Vermutung ausgegangen, daß Gesellschaften, die über 'mehr' Sozialkapital verfügen, ökonomisch
} 
Dies ist Putnams zentrale Argumentation in seinem Buch über die Unter-schiede zwischen den nördlichen und den südlichen Regionen Italiens. Zusammenfassend heißt es dort: "Historically, ..., norms and networks of civic engagement have fostered economic growth, not inhibited it. This effect continues today. ... Similarly, ..., civic associations are powerfully associated with effective public institutions. The theory sketched in this chapter helps explain why social capital, as embodied in horizontal networks of civic engagement, bolsters the performance of the polity and the economy, rather than the reverse: Strong society, strong economy; strong society, strong state." 352 (Putnam, R.D. 1993: 176) Und an anderer Stelle: "Voter turnout, newspaper readership, membership in choral societies and football clubs - these are the hallmarks of a successful region. In fact, historical analysis suggested that these networks of organized reciprocity and civic solidarity, far from being an epiphenomen of socioeconomic modernization, were a precondition for it." 353 (Putnam 1995: 66)

Problematisch an dieser Wirkungsargumentation ist aus wissenschaftstheoretischer Sicht das schon im Zusammenhang mit den Entstehungsursachen ge-

und politisch irgendwie 'besser' funktionieren." (Offe 1999: 114) Die von Putnam unterstellte ökonomische Wirkungsdimension dürfte konzeptionell wohl nicht zuletzt auf den Überlegungen Granovetters (1985) zu "Economic action and social structure" gründen.

352 In ähnlicher Weise heißt es bei Fukuyama: "Social capital is important to the efficient functioning of modern economies, and is the sine qua non of stable liberal democracy." (Fukuyama 1999: 1) Im Unterschied zu Putnam schließt Fukuyama jedoch bei seiner definitorischen Bestimmung von Sozialkapital Vertrauen und zivilgesellschaftliche Vernetzung explizit aus und fokussiert einzig "norms that promote cooperative behavior" (Fukuyama 2004: 62). Konkret heißt es: "Social capital is an instantiated informal norm that promotes cooperation between two or more individuals. The norms that constitute social capital can range from a norm of reciprocity between two friends, all the way up to complex and elaborately articulated doctrines like Christianity or Confucianism. They must be instantiated in an actual human relationship ... . By this definition, trust, networks, civil society, and the like which have been associated with social capital are all epiphenominal, arising as a result of social capital but not constituting social capital itself." (Fukuyama 1999: 1f.) Im gleichen Artikel misst Fukuyama dann aber (Putnam folgend) den Sozialkapitalbestand in einer Gesellschaft über die Summe von organisationellen Mitgliedschaften, wobei er diese über einen Kohässionskoeffizienten qualifiziert und Externalitäten über einen Vertrauens- (positiv) und einen Misstrauenskoeffizienten (negativ) berücksichtigt (ebenda: 6ff.). Wenn zuvor jedoch "trust, networks, civil society" definitorisch ausgeschlossen wurden und lediglich in Bezug auf Normen von "Sozialkapital" die Rede war, dann ist diese Vorgehensweise wenig überzeugend. Auch zu der Frage, wie das grundsätzlich auf der Mikroebene verortete Sozialkapital zu einer gesellschaftlichen Bestands- und damit zu einer Makrogröße wird, finden sich bei Fukuyama keine Hinweise.

353 Mehr noch als Putnam verwendet Fukuyama (1995: 356f.) den Sozialkapitalbegriff in diesem Zusammenhang zu Affirmation des westlichen Politik- und Ókonomiemodells: "The concept of social capital makes clear why capitalism and democracy are so closely related. A healthy capitalist economy is one in which there will be sufficient social capital in the underlying society to permit business, corporations, networks, and the like to be self-organizing. ... The self-organizing proclivity is exactly what is necessary to make democratic political institutions work as well." Eine besonders harsche Kritik an Fukuyama kommt ausgerechnet vom Ökonomen Robert M. Solow, wird dabei aber teilweise in einem wissenschaftstheoretischen Sinne vorgetragen: "I do conclude, ..., that his (Fukuyama's, D.K.) sort of loose parlor-theorizing, replete with fudge factors, is elusive and dangerous. Plausibility is important in a theory, but it is not enough." (Solow 1995: 37) 
nannte Zirkularitätsproblem ${ }^{354}$. So zielt der Ausdruck "good governace" in demokratietheoretischer Hinsicht vor allem auf die so weit als möglich auf Kooperation, Vertrauen und Gegenseitigkeit beruhende, kollektiv verbindliche Regelung öffentlicher Angelegenheiten ab - "democratic self-government" wird dies von Putnam (2000: 336) auch genannt. Damit aber ist fraglich, ob das Putnamsche Sozialkapitalverständnis - insbesondere in seiner Fokussierung auf bürgerschaftliche Netzwerke - eindeutig von "good governance" zu trennen ist; es kann insofern keine überzeugende unabhängige Variable hierfür abgeben ${ }^{355}$.

Zirkulär an Putnams Argumentation ist aber keinesfalls alles, was etwa Portes (1998: 19) aufgedeckt zu haben glaubt: "As a property of communities and nations rather than individuals, social capital is simultaneously a cause and effect. It leads to positive outcomes, such as economic development and less crime, and its existence is inferred from the same outcomes." Sozialkapital fällt demnach irgendwie mit den Ressourcen zusammen, die hierüber doch erst bezogen werden sollen. Zweifellos ist es wenig überraschend, wenn in einer Gesellschaft mit hohen Vertrauensscores, starken organisationalen Vernetzungsgrad sowie einer weitgehenden Akzeptanz von Reziprozitätsnormen niedrige Verbrechensraten zu

\footnotetext{
$354 \mathrm{Ob}$ die Ergebnisse empirsch in der Tat stichhaltig sind oder ob etwa wichtige Einflussvariablen hinsichtlich der behaupteten Zusammenhänge unberücksichtigt bleiben, soll hier nicht beurteilt werden. Dies ist vorrangig Aufgabe einer sozialtheoretischen Kritik (vgl. hierzu die vielfältige Literatur zu Putnams Untersuchungen, stellvertretend seien etwa Berman 1997 oder Foley/Edwards 1996 genannt).

355 Gleichwohl lässt sich auch hinsichtlich von "good governance" der Tautologievorwurf in Frage stellen. So beklagen insbesondere zivil- bzw. bürgergesellschaftlich orientierte Politikwissenschaftler die "politische Leerstelle" (Evers 2002: 59) bzw. die "Blindstelle" (Mayer 2002: 44) im Konzept Robert Putnams. Dabei wird bezweifelt, dass etwa Gesangs- oder Sportvereine - die in der Einschätzung Landolts (2004: 37) von Putnam gleichsam zu "gutartigen Brutkästen des Vertrauens" stilisiert werden - wirklich mit "guter" Politik assoziiert sind (bei Putnam [1993: 176] heißt es: "Good government ... is a by-product of singing groups and soccer clubs"). Vielmehr scheint es aus dieser Perspektive gerade umgekehrt die Politik zu sein, die für die Entwicklung eines vielfältigen Vereinslebens Sorge trägt ("Eine vitale Demokratie ist der Schlüssel zur Entwicklung von Sozialkapital" [Evers 2002: 74]). Nun ließe sich freilich einwenden, es sei bei einem Tautologievorwurf ja gerade egal, was nun als Ursache und was als Wirkung konzipiert werde. Richtet man den Fokus jedoch dezidiert auf die Variable "Netzwerke zivilgesellschaftlichen Engagements", dann wird immerhin diskutabel, ob hierunter Vernetzungsformen wie Gesangsvereine, Gewerkschaften oder Grass-Root-Organisationen relativ undifferenziert subsummiert werden können. In demokratietheoretischer Hinsicht ist zweifellos recht unterschiedliches von diesen Organisationsformen zu erwarten (vgl. hierzu auch Foley/Edwards 1996: 42). "Putnam zeigt in all seinen Texten die Tendenz, die bürgerliche Privatsphäre in den Mittelpunkt zu stellen. Vor allem dort und in einem überschaubaren Umfeld sollen die Menschen untergebracht sein und sich vor Ort für ihre Menschenrechte einsetzen. Polemisch gewendet könnte man sagen, Demokratie werde durch diejenigen Werte bestimmt, welche Coleman bei Gesellschaften des 18. Jahrhunderts ausmachte". (Roth 2003: 51) Ferner stellt sich die Frage, inwiefern eine stark, dabei aber partelliert vernetzte Gesellschaft nicht auch eine Gesellschaft der sozialen Schließung, d.h. eine exkludierende Gesellschaft mit hohem intragruppalem jedoch niedrigem intergruppalem Sozialkapital ist. In diesem Falle, so argumentiert etwa Berman (1997) mit Blick auf die Weimarer Republik, sind keineswegs positive Effekte auf die Politik zu erwarten. Im Zusammenhang des Verhältnisses von Bürgergesellschaft und Politik wird zunehmend auch auf eine globale Perspektive verwiesen. So glaubt etwa Smith (1998: 103), "even without face-to-face contact, transnational social movements can generate social capital that is crucial to democratizing the global political process."
} 
verzeichnen sind, und wenn dieser outcome wiederum insbesondere das Vertrauen positiv beeinflusst.

Ein Henne-Ei-Problem muss aber nicht grundsätzlich einer zirkulären Argumentation geschuldet sein. Man würde doch auch nicht bestreiten, dass sich eine positive Lebenseinstellung und körperliches Wohlbefinden wechselseitig beeinflussen. Solange die Zusammenhänge fallibel sind (es gibt bspw. empirisch nachweislich viele positiv denkende Menschen, denen es körperlich schlecht geht), solange also keine Tautologie vorliegt (und bei Putnam kann nicht davon die Rede sein, "Sozialkapital" und "niedrige Verbrechensrate" seien sprachlogisch miteinander verknüpft), ist dieser von Portes vorgetragene methodologische Einwand zurückzuweisen.

Neben den genannten gesellschaftspolitischen und sozioökonomischen Implikationen (zu denen u.a. noch "better schools" [Putnam 1995: 66f.] sowie "collective well-being" [1993: 177] zählen) betont Putnam unter Berufung auf psychologische und medizinische Forschungen - und damit implizit auch auf ein mikrotheoretisches Begriffsverständnis - zusätzlich individuelle Effekte. Danach ist Sozialkapital ganz generell ein "Prädiktor für Glück" (Putnam/Goss 2001: 176), es macht uns "smarter, healthier, safer, richer"356 (Putnam 2000: 290). "The more integrated we are with our community, the less likely we are to experience colds, heart attacks, strokes, cancer, depression, and premature death of all sorts" (ebenda: 326).

Ist Sozialkapital bei Putnam zunächst nahezu ausschließlich mit positiven outcomes verknüpft, so wird diese Perspektive später einer Revision unterzogen. "Social capital, in short, can be directed toward malevolent, antisocial purposes, just like any other form of capital." (Putnam 2000: 22) Bspw. sei das Bombenattentat auf das Murrah Federal Building in Oklahoma City durch die innerhalb regierungsfeindlicher, paramilitärischer Gruppen in den USA geltenden Normen, das dort herrschende Vertrauen und der Vernetzung zwischen den Mitgliedern ermöglicht worden (vgl. ebenda: 21). Konzeptionell kann daher nicht mehr davon die Rede sein, Putnams Sozialkapitalverständnis sei grundsätzlich funktional und normativ (gleichwohl werde ich unten bei der strukturalistischen Darstellung das Funktionalitätskriterium unterstellen, um so mit Blick auf den Theorienvergleich weitgehende Gemeinsamkeiten der analysierten Autoren herausstreichen zu können ${ }^{357}$ ).

\footnotetext{
356 Da es Putnam nahezu ausschließlich um die Makroeffekte des Sozialkapitals geht, nehmen Einzelakteure (und vor allem einzelne Personen) in seinem politologischen Konzept auch eine eher randständige Position ein. So ist bspw. weniger die ökonomische Performanz eines einzelnen Unternehmens, sondern die einer gesamten Region oder eines gesamten Landes Gegenstand seiner Überlegungen, wobei von einem bestimmten Kapitalstock ausgegangen und dessen Wirkungen in das Blickfeld gerückt wird. In Folge der rational choice orientierten Mikrofundierung und dem Bezug Putnams auf Coleman ist das Sozialkapital einzelner Akteure in seinem Ansatz weitgehend analog zu Coleman konzeptualisiert.

357 Tatsächlich war das Sozialkapital des Täters des Oklahoma City-Attentats funktional für eben diesen Täter; unter den furchtbaren Folgen hatten andere zu leiden.
} 


\section{Operationalisierung}

Gemäß seines bürgergesellschaftlich motivierten, in erster Linie auf die Makroebene zielenden Sozialkapitalverständnisses versucht Putnam das Konstrukt prinzipiell über insgesamt 14, in fünf verschiedene Teilgruppen zusammengefasste Indikatoren zu bestimmen (es handelt sich um Aggregatdaten; als Erhebungsquelle dient ihm und seinen Mitarbeitern u.a. das General Social Survey sowie das DDB Needham Archive [vgl. etwa Putnam 2000: Kapitel 16]) ${ }^{358}$ :

(1) Vereinsleben innerhalb einer Gemeinschaft (gemessen etwa anhand der Anzahl sozialer Organisationen und Vereine pro 1000 Einwohner ${ }^{359}$ ),

(2) Engagement für öffentliche Angelegenheiten (gemessen etwa anhand der Wahlbeteiligung bei Präsidentschaftswahlen ${ }^{360}$ ),

(3) freiwillige Arbeitsleistungen innerhalb der bzw. für die Gemeinschaft (gemessen etwa anhand der Anzahl an Non-Profit-Organisationen pro 1000 Einwohner),

(4) informelle Soziabilität (gemessen etwa anhand der im vorangegangenen Jahr durchschnittlich zuhause verbrachten Zeit von Individuen ${ }^{361}$ ) sowie

\footnotetext{
358 Über die Indikatoren soll vor allem bestimmt werden, (a) inwiefern ein commitment bzw. eine Folgebereitschaft hinsichtlich der politischen und zivilgesellschaftlichen Einrichtungen von Gemeinschaften vorhanden ist, (b) inwiefern eine Gemeinschaft über die Fähigkeit verfügt, kollektive Probleme zu bewältigen sowie (c) inwiefern eine Gemeinschaft kohäsiv organisiert ist, d.h. über welche Solidaritätspotentiale sie verfügt.

359 In seinen Untersuchungen zu Sozialkapital in den USA beklagt Putnam insbesondere die Tendenz der Amerikaner, Freizeitaktivitäten zunehmend außerhalb von Vereinen durchzuführen. Dies macht er insbesondere am Bowling-Verhalten seiner Landsleute fest. Daher lautet auch sowohl der Titel eines Aufsatzes aus dem Jahre 1995 wie der seines 2000 erschienenen Buches "Bowling alone". Unter anderem heißt es dort: "The rise of solo bowling threatens the likelihood of bowling lane proprietors because those who bowl as members of leagues consum three times as much beer and pizza as solo bowlers, and the money in bowling is in beer and pizza, not the balls and shoes. The broader social significance, however, lies in the social interaction and even occassionally civic conversations over beer and pizza that solo bowlers forgo. Whether or not bowling beats balloting in the eyes of most Americans, bowling teams illustrate yet another vanishing form of social capital." (Putnam 1995: 70) Insbesondere der gestiegene Fernsehkonsum wird von Putnam für die Abnahme von informeller Soziabilität und damit für den Rückgang von Sozialkapital in den USA verantwortlich gemacht ("Ein Teil der Schuld geht zu Lasten des Fernsehens" [Putnam 1996: 68]). Faust/Marx (2004: 13) behaupten in diesem Zusammenhang, Putnam verwende Erklärungsansätze aus zwei unterschiedlichen Forschungsparadigmen. Mit dem Verweis auf die Konsequenzen des gestiegenen Fernsehkonsums rekurriere er etwa auf eine Rational-Choice-, mit dem Verweis auf Pfadabhängigkeiten hingegen auf eine polit-kultur-historische Perspektive, um eine Veränderung im Bestand an Sozialkapital zu erklären. Indes möchte ich bezweifeln, dass Putnam damit - wie Faust/Marx glauben (ebenda) - "schwer vereinbare Forschungsansätze" bemüht. Eine solche Bewertung scheint mir auf die beliebte Unterteilung in Homo Oeconomicus und Homo Sociologicus zu gründen; eine Dichotomisierung also, die Putnam mit seiner intellektuellen Orientierung an Coleman aus meiner Sicht gerade integrativ überwindet (dies kann hier freilich nicht weiter ausgeführt werden; vgl. zu dieser Problematik Marx 2005 [Marx vertritt die Position, die Konzepte Colemans und Putnams seien unterschiedlichen Paradigmen zuzuordnen]).

${ }^{360}$ Für die USA stellt Putnam fest, dass die Wahlbeteiligung zwischen 1960 und 1990 um ein Viertel zurückgegangen sei: "Americans' direct engagement in politics and government has fallen steadily and sharply over the last generation, despite the fact that average levels of education - ... - have risen sharply throughout this period. Every year over the last decade ... millions more have withdrawn from the affairs of their communities." (Putnam 1995: 68)
} 
(5) soziales Vertrauen (gemessen vor allem anhand der Antworten auf die Frage: "Manche meinen, dass man den meisten Leuten vertrauen könne. Andere sagen, dass man im Umgang mit anderen Menschen nicht vorsichtig genug sein kann. Was meinen Sie?")

Gleichwohl schränkt Putnam die Bedeutung quantitativer Daten ein, da Fragen nach einem "mehr oder weniger Sozialkapital" häufig nicht aussagekräftig seien. "Vielmehr müssen wir die Veränderungen in qualitativen Begriffen beschreiben. So könnte man sich bspw. mit Blick auf den Nationalstaat vorstellen, dass ein bestimmter Bestand an Sozialkapital immer formeller, jedoch zugleich weniger 'brückenbildend' wurde" (Putnam/Goss 2001: 28f.). Inwiefern eine solche Aussage allerdings ohne quantitatives Datenmaterial getroffen werden kann, soll hier in Frage gestellt werden.

Grundsätzlich lässt sich an Putnams Operationalisierung von Sozialkapital und damit indirekt auch an den von ihm propagierten Wirkungen kritisieren, dass die hierüber erhältlichen Informationen die konzeptionellen Grundlagen vielfach nur unzureichend reflektieren: "Grossing up the numbers of organizations to which people belong tells us very little about the strength of social capital if it is not accompanied by information on two scores: what people actually do as members of an assoziation, and how this relates to public as well as private goals. Similarily, including petition-signing as an index of political participation sets such a low threshold for civic activity that it becomes virtually vacuous." 362 (Schuller et al. 2000: 27)

In der Tat scheint es problematisch etwa die auf ganze Staten bezogene Anzahl an Vereinen bzw. von organisationellen Mitgliedschaften als Proxy für zivilgesellschaftliche Netzwerke in einer Gemeinschaft heranzuziehen (denn das macht Putnam da seine Makroorientierung eine netzwerkanalytische Forschungs-

361 Eine Verminderung der innerhalb der Familie verbrachten Zeit muss nicht zwangsläufig ein Indikator für eine Schwächung von Sozialkapital sein. Banks verweist etwa auf die Zunahme von mutual aid groups, die ein Substitut für Familienaktivitäten darstellen können (vgl. Schechler 2002: 79). Der Theologe Friedrich W. Graf (1999a: 17) kritisiert in diesem Zusammenhang, Putnam vernachlässige "die von Religions- und Kulturwissenschaftlern intensiv geführten Debatten über den strukturellen Wandel von Assoziations- oder Vergemeinschaftungsformen in der Moderne und neue Formen der Bildung von Sozialvertrauen. ... Für die behauptete 'social decapitalisation' stützt er (Putnam, D.K.) sich darauf, daß in den USA der 'social evening' mit den Nachbarn immer mehr abnehme und man stattdessen häufiger mit Freunden in der Ferne kommuniziere. Nun haben Freunde den großen Vorzug, daß man sie sich aussuchen kann".

362 Ferner kritisieren Schuller et al. (2000: 27) im Kontext mit der (auch von anderen Wissenschaftlern vorgenommenen) Operationalisierung des Putnamschen Sozialkapitalkonzeptes das Vorliegen von "towers of elaborate statistics on shaky foundations". Konkret nennen die Autoren eine Studie von Knack/Keefer aus dem Jahre 1997: "Single questions about trust levels are used as indices of social capital, and then linked through sophisticated regressions to very broad measures of national economic performance, with conclusions drawn to several decimal points." (Schuller et al. 2000: 27) Tatsächlich sind konzeptionelle Überlegungen in dem Artikel von Knack/Keefer nicht zu finden. $\mathrm{Zu}$ Beginn heißt es lediglich: "Trust, cooperative norms, and associations within groups each fall within the elastic definitions that most scholars have applied to the term social capital." (Knack/Keefer 1997: 1251f.) 
perspektive nicht zulässt ${ }^{363}$. Selbst wenn hierüber eine gute Annäherung erzielt würde, so liegt Sozialkapital doch erst dann vor, wenn zugleich Koordination und Kooperation zum wechselseitigen Nutzen erleichtert werden.

Putnam steht dann aber vor einem Dilemma: Entweder (a) er gesteht die Zirkularität seiner Argumentation ein ("zivilgesellschaftliche Netzwerke" dürften sich kaum definieren lassen, ohne dabei auf "Koordination und Kooperation zum wechselseitigen Nutzen" zurückzugreifen) oder (b) er muss konstatieren - einmal unterstellt, das Zirkularitätsproblem bestehe nicht -, dass das vorhandene Datenmaterial eine Isolierung jener Assoziationen, die diesem Kriterium genügen, nicht erlaubt. Wenn dies doch möglich wäre, so stieße man (c) u.U. an dieser Stelle wieder auf einen Zirkularitätseinwand, der oben schon im Zusammenhang mit der Begriffsbestimmung angeführt wurde: Sozialkapital fiele mit den Ressourcen, die hierüber bezogen werden, in eins ${ }^{364}$.

\section{Wissenschaftstheoretischer Status}

Putnam gründet sein Konzept empirisch auf eigenen Erhebungen aber auch Sekundäranalysen; Letztere stammen aus ganz unterschiedlichen Disziplinen. Bspw. zieht Putnam im Rahmen seiner Italienstudie insbesondere historische und politologische Arbeiten heran, zum Beleg eines Zusammenhangs zwischen Vertrauen und gemeinschaftlichen Unterstützungssystemen verwendet er Ergebnisse aus der soziologischen Kleingruppenforschung und zur Bedeutung von sozialer Integration für die individuelle Gesundheit verweist er auf psychologische wie medizinische Untersuchungen.

Analytisch speist sich der Sozialkapitalansatz vor allem aus der Begriffsgeschichte des Konstrukts, der Rational-Choice-, der Spiel- sowie der Theorie kollektiver Güter und demokratietheoretischer Überlegungen zur Relevanz der Zivil- und/oder Bürgergesellschaft (vor allem Tocqueville). Aber Putnam rekurriert auch auf die Netzwerkanalyse. Seine Klassifizierung verschiedener Typen von

\footnotetext{
363 Arrow (1999: 4) gelangt daher auch zu der Einschätzung, Putnams Sozialkapitalansatz besage grundlegend, "that membership in associations strengthens political and economic efficiency".

364 Unter Bezug auf das Putnamsche Begriffsverständnis wird Sozialkapital mittlerweile auch retrospektiv bestimmt - allerdings (verständlicherweise) ohne den methodischen Aufwand, den Putnam betreibt (was die Ergebnisse der historischen Betrachtungen aus meiner Sicht sehr fragwürdig erscheinen lässt). Im Sammelband von Rotberg (2001) finden sich u.a. Untersuchungen über das Sozialkapital in englischen Gemeinden zwischen 1300-1640 (der entsprechende Artikel trägt den m.E. doch etwas befremdenden Titel "The diversity of social capital in English communities, 1300-1640 [with a glance at modern Nigeria]" und beginnt mit dem Satz: "Social capital was produced by many types of human interaction in the villages and market centers of later medieval and early modern England" [Mc Intosh 2001: 121]), zu dem Sozialkapital von Frauenvereinigungen in den USA zwischen den 1880er und 1920er Jahren (Clemens 2001) oder zu "social capital in the early industrial revolution" (Rosenband 2001).
} 
Sozialkapital weist eindeutig auf die ursprüngliche Unterscheidung von strong und weak ties bei Granovetter zurück ${ }^{365}$.

Das theorieintegrative Vorgehen erfolgt intentional und explizit. So heißt es etwa in "Making Democracy work": "The theoretical approach we develop, drawing on the logic of collective action and the concept of 'social capital', is intended not merely to account for the Italian case, but to conjoin historical and rational choice perspectives in a way that can improve our understanding of institutional performance and public life in many other cases." (Putnam, R.D. 1993: 16)

Daneben ist Putnam aber auch ein normativer Impetus zu attestieren. Immer wieder spricht er sich für eine starke demokratische Bürgergesellschaft aus, da eine solche in Folge ihres hohen Bestands an und ihrer effizienten Nutzung von Sozialkapital "gutes" Regierungshandeln und ökonomische Prosperität verbürge. Obgleich Putnam die Quantifizierbarkeit von Sozialkapital einschränkt ${ }^{366}$, kann aufgrund seiner empirischen und statistischen Vorgehensweise von einer Quantifikation durchaus die Rede sein. Schechler (2002: 65) schlägt für Putnams Konzept u.a. folgende Gleichung vor:

Sozialkapital $=\frac{\sum_{j=1}^{M} c_{j} z_{j}}{N}$

365 Granovetter wird von Putnam (2000: 22) auch in diesem Zusammenhang zitiert. Umgekehrt zeigt sich, dass die konzeptionellen Vorstellungen von Granovetter genau wie die Putnams auch auf die Aggregatebene bezogen sind, etwa wenn Granovetter Stadterneuerungspläne in zwei Bostoner Vorstädten diskutiert: "The case of Charlestown, a working-class community which successfully organized against the urban renewal plan of the same city (Boston) against which the West End was powerless, is instructive in this respect: unlike the West End, it had a rich organizational life, and most male residents worked within the area." (Granovetter 1973: 1375)

366 "Sozialkapital widersteht jeder Quantifizierung, und aus genau diesem Grund können wir auch nicht behaupten, eine Jugendinitiative, die einen städtischen Kinderspielplatz säubert, trage mehr zum Bestand an Sozialkapital bei als eine 'innenorientierte' Kreditgemeinschaft, die daran mitwirkt, eine neue Einwanderergemeinde wirtschaftlich erfolgreich zu machen." (Putnam/Goss 2001: 28) Andererseits weist aber Putnam nahezu grundsätzlich darauf hin, dass ein "Mehr" an Sozialkapital positive Effekte auf die demokratischen Institutionen und die Ökonomie eines Landes bzw. einer Region hat. In "Bowling alone" (2000) konstruiert er einen Sozialkapitalindex, der sich aus der Addition der scores seiner insgesamt 14 Indikatoren (vgl. die obigen Ausführungen zu Operationalisierung) errechnet (vgl. Putnam 2000: Kapitel 16, Endn. 7). Mit Hilfe dieses Index bestimmt er dann das Ausmaß an Sozialkapital in US-amerikanischen Bundesstaaten. Was also nicht quantifiziert werden kann, ist die Frage, welche Formen des Sozialkapitals in besonderem Maße und auf welche Weise förderlich für Gemeinschaften sind. Um dies wenigstens qualitativ bestimmen zu können, hat Putnam die schon genannte Unterscheidung in informelles versus formelles, innenorientiertes versus außenorientiertes, brückenbildendes versus bindendes sowie Sozialkapital mit hoher und geringer Dichte eingeführt. (Vgl. zu einer ähnlichen, aber ausführlicher dokumentierten Vorgehensweise zu einer Sozialkapitalindexbildung auf weitgehender Grundlage des Putnamschen Konzepts die Erläuterungen von Schnur 2003: 249ff.; Schnur bezieht sich allerdings auf Stadtquartiere und bewegt sich damit im Rahmen von Vorstellungen zu bürgerschaftlichem Engagement, in denen Konzepte über Sozialkapital in "Raumtheorien verankert" [Stern 2004: 209] gesehen werden: "Sozialkapital ist das analytische Instrument des Lokalen und Kleinräumigen." [Karstedt 2004: 47] [Vgl. kritisch zur Verwendung des Sozialkapitalbegriffs in diesem Zusammenhang Eick 2004]) 
Hierbei ist $\mathrm{N}$ die Bevölkerungszahl, $\mathrm{M}$ die Anzahl der sozialen Vereinigungen, $\mathrm{z}$ die Anzahl der Mitgliedschaften pro Vereinigung sowie c ein Koeffizient, der die Qualität der Mitgliedschaftsbeziehungen (die durch die Aspekte Vertrauen [mikro], bürgerschaftliche Orientierung [meso] und Reziprozitätsnormen [makro] auf allen soziologischen Ebenen bestimmt wird) berücksichtigt.

Putnams Konzept kann damit als ein theoretisch integratives, quantitatives, aber auch normatives Realmodell gekennzeichnet werden: Es ist (a) integrativ, weil Ausschnitte unterschiedlicher Theorieansätze (wie etwa der Spieltheorie, RationalChoice-Theorie, Netzwerktheorie, Theorie kollektiver Güter, Demokratietheorien etc.) selektiv zusammengeführt werden und ein expliziter Rekurs auf die Begriffsgeschichte von und eine aktuelle Kritik an "Sozialkapital" erfolgt, (b) quantitativ, weil eine Mathematisierung angestrebt und eine vergleichende Berechnung über den Bestand an Sozialkapital innnerhalb von Gesellschaften bzw. Gemeinschaften vorgenommen wird, (c) normativ, weil (nach wie vor) die Effekte von Sozialkapital vorwiegend als positiv und politisch erstrebenswert erachtet werden ${ }^{367}$ sowie (d) ein Realmodell, weil Putnam seine konzeptionellen Äußerungen auf Basis eigener empirischer Forschungsarbeiten und Sekundäranalysen von sowohl historischen, politologischen, soziologischen wie psychologischen und medizinischen Untersuchungen begründet und den Stand seiner konzeptionellen Entwicklung immer wieder über neue empirische Studien überprüft.

Insgesamt lässt sich festhalten, dass sich wohl bei keinem anderen Autor eine umfangreichere, aufwendigere, zugleich aber auch ungenauere, bunt durcheinander gehende Begriffsbestimmung findet. Das, was die Gesundheit des Individuums begünstigt, kann wohl nur unter Aufbringung eines großen exegetischen Engagements als das Gleiche gelten, wie das, was sich positiv auf die Ökonomie oder das Regierungshandeln eines Landes auswirkt. Dennoch wird eben dies suggeriert, wenn man in allen Zusammenhängen von "Sozialkapital" spricht. Ist es jedoch nicht das Gleiche und kann man trotzdem über das theoretische Konstrukt alle genannten outcomes erklären, dann verweist der Sozialkapitalbegriff auf zu unterscheidende Entitäten und firmiert als catch-all Kategorie bzw. als "a rather loose assortment of things" (Taylor 1993: 73). Das wissenschaftstheoretische Kriterium der Einfachheit einer Definition, nach dem die Regeln zum Gebrauch eines Ausdrucks so unkompliziert wie möglich sein sollen (vgl. hierzu etwa Essler 1972: 117f.), kann kaum als erfüllt angesehen werden.

\footnotetext{
367 Platthaus (1999: 161) will bei Putnam nicht nur eine normative, sondern sogar eine "ideologische Note" entdeckt haben. In jedem Fall möchte sich Putnam aktiv in die Politik einmischen: "Finally, and perhaps most urgently, we need to explore creatively how public policy impinges (or might impinge) social capital formation." (Putnam 1995: 76) Und mit dezidiert appellativem Charakter: "Let us find ways to ensure that by 2010 Americans will spend less leisure time sitting passively alone in front of glowing screens and more time in active connections with our fellow citizens." (Putnam 2000: 410)
} 
Insofern muss es den wissenschaftstheoretisch motivierten Leser verwundern, warum gerade Putnams Konzept in der aktuellen Diskussion eine derart dominante Rolle spielt. Dies zu klären, wäre jedoch Aufgabe einer wissenschaftssoziologischen Untersuchung. Hypothesen dabei könnten etwa sein, dass zivilgesellschaftlichen Organisationsmustern im Zuge einer Reformulierung von Wohlfahrtsstaatlichkeit eine immer stärkere Bedeutung zugemessen werden. Da Putnam sein Begriffsverständnis gerade in diesen Kontext stellt, ist sein Ansatz von besonderem aktuellen Belang. Sowohl Politiker wie unmittelbar anwendungsorientiert arbeitende Gesellschaftsforscher - seien es Soziologen, Politikwissenschaftler oder Ökonomen - können hier anschließen.

Für diese Forscher bietet sich überdies die Möglichkeit, in den Bereich der Politik vorzudringen und somit über ihre Expertise an kollektiven Entscheidungsprozessen mitzuwirken, denn Putnams Überlegungen zielen gerade auch auf Politikberatung $\mathrm{ab}^{368}$. Mit Blick auf Veröffentlichungs- und Rezeptionsstrategien sowie Drittmittelaquisition erscheint es ferner wesentlich "klüger" (wenn nicht sogar opportun), auf ein weitreichend diskutiertes und akzeptiertes Begriffsverständnis, denn auf eine randständige Definition zu setzen, um so "Redakteure und Gutachter wissenschaftlicher Zeitschriften und andere Torwächter der Wissenschaft" (Merton 1985: 169) von der Qualität der eigenen Arbeit leichter überzeugen zu können ${ }^{369}$.

Trotz aller bisher geäußerten Kritik an Putnams Sozialkapitalbegriff ist m.E. auf Putnams kaum zu überschätzende empirische Forschungsleistung zu verweisen, die den Anstoß zu weitgehend ähnlich angelegten Untersuchungen in zahlreichen Ländern gegeben hat. Über die Abhängigkeiten zwischen Vertrauen, bürgerschaftlichem Engagement, Demokratie oder ökonomischem Wachstum weiß man dank Putnams Konzept (und den Modifikationen daran) heute sicherlich wesentlich mehr als noch vor 15 Jahren. Dies könnte man durchaus als ein

\footnotetext{
368 In Deutschland ist diesbezüglich etwa an die vom deutschen Bundestag im Dezember 1999 eingesetzte Enquete-Kommission "Zukunft des bürgerschaftlichen Engagements" (Deutscher Bundestag, Drucksache 14/8900, 03.06.02 [Abschlussbericht]) zu denken, in der u.a. Sozialforscher mitwirkten, die insbesondere auf Putnams Begriffsverständnis rekurrieren. Im Laufe meiner Arbeit an der vorliegenden Studie hatte ich die Gelegenheit, mit einem englischen Wissenschaftler zu sprechen, der in Downing Street 10 zeitweise als Mitarbeiter Tony Blairs fungierte und diesen gerade im Zusammenhang mit Fragen der Bürgergesellschaft beriet. Zu meinem Erstaunen war ihm gar nicht bekannt, dass auch James S. Coleman sich zu Sozialkapital geäußert hat.

369 So schreibt Inkeles (2000: 246) etwa: "I would rather use some other term (...) but we have been set on a path, and there are considerable costs to anyone who deviates too far from the read laid down, so I will continue to use the standard term social capital". Insofern haben wir es hier auch mit der Frage nach dem Zusammenhang zwischen Definition und Interesse zu tun. "Es kann z.B. in gewissen Grenzen sehr wesentlich für die Bewertung und die damit häufig verbundene Finanzierung bestimmter Tätigkeiten sein, daß sie unter Begriffe wie 'Wissenschaft', 'Kunst', u.a. fallen. Ob sie aber darunter fallen, hängt nicht zuletzt von der Definition dieser Begriffe ab." (Gabriel 1972: 88) Es hat jedenfalls für hohe interdisziplinäre und politische Aufmerksamkeit gesorgt, dass Putnam im Rahmen seiner Forschungsbemühungen den Sozialkapitalbegriff an eine so exponierte Stelle gesetzt hat; eine solche Aufmerksamkeit wurde der inhaltlich wie konzeptionell durchaus ähnlich orientierten politischen Kulturforschung in dieser Form ganz sicher nicht zuteil.
} 
Indiz für die enorm hohe Problemrelevanz des Putnamschen Sozialkapitalbegriffs interpretieren. Anzweifeln möchte ich indes, ob man im Zusammenhang mit diesen Problemen wirklich von "Sozialkapital" sprechen sollte. Mir erscheint dies weder mit Blick auf die Begriffsgeschichte, noch auf die innere Kohärenz der Putnamschen Aussagen, noch auf den Kapitalcharakter dessen, was von Putnam als "Sozialkapital" bezeichnet wird, gerechtfertigt oder sinnvoll (vgl. Kapitel 8.1.). Mit dem Ökonomen Robert M. Solow (1995: 38) möchte ich daher gegen das Putnamsche Begriffsverständnis einwenden: "If 'social capital' is to be more than a buzzword, something more than mere relevance or even importance is required."

\section{Strukturalistische Darstellung}

Bei der strukturalistischen Darstellung verzichte ich darauf, alle von Putnam genannten Formen von Sozialkapital aufzulisten, denn ein spontan stattfindendes Basketballspiel, ein Abendessen mit der Familie oder ein Nachbar im Studentenwohnheim können - strukturalistisch gesprochen - als paradigmatische intendierte Anwendungen zivilgesellschaftlicher Netzwerke begriffen werden. Die Unterscheidung in informelles versus formelles, innenorientiertes versus außenorientiertes, brückenbildendes versus bindendes sowie Sozialkapital mit hoher und geringer Dichte interpretiere ich als eine nominalskalierte Typisierung einer bestimmten Form von Sozialkapital, nämlich von zivilgesellschaftlichen Netzwerken - nur in diesem Kontext wird die Einteilung von Putnam vorgenommen und nur hier macht sie Sinn.

Auch Putnam betrachtet Sozialkapital als eine Ressource von Akteuren. Im Unterschied zu allen anderen hier untersuchten Konzepten wird der Akteurstatus dabei allerdings bis auf die Makroebene ausgeweitet: "Given that social capital can benefit individuals, it is perhaps no surprise that it also can help neighborhoods, and even entire nations, to create wealth." (Putnam 2000: 322) Bei Putnam kann also sehr wohl das Sozialkapital einer Region, einer Stadt oder einer Nation bzw. eines Staates eine Ressource darstellen, nämlich in dem Sinne, dass die genannten Einheiten davon politisch wie ökonomisch profitieren ${ }^{370}$. Problematisch hieran ist freilich - und darauf wurde schon im Zusammenhang mit der Aggregationsthematik aufmerksam gemacht -, dass die makrotheoretische Akteursperspektive bei Putnam einem Kategorienfehler geschuldet ist: Während mikro- und mesotheoretisch das Sozialkapital eines Akteurs aus dessen Außenbeziehungen zu anderen resultiert, ist das makrotheoretische Sozialkapital das operationelle Ergebnis von

\footnotetext{
370 Auch Offe/Fuchs (2001: 417) teilen diese Interpretation explizit: "Sozialkapital wird hier (in einem an das Putnamsche Konzept angelehnten Verständnis, D.K.) als Ressource verstanden, die regionalen und nationalen Gesellschaften oder Teilen davon zur Verfügung steht. ... Ist ein hoher Bestand an Sozialkapital in einer Gesellschaft vorhanden und gleichmäßig verteilt, bestehen die 'Erträge' hypothetisch in positivem Einfluss auf ökonomische Performanz und effiziente Administration."
} 
Innenbeziehungen, nämlich den Beziehungen zwischen den die makrotheoretische Entität konstituierenden Akteuren (vgl. die Ausführungen unter Ebene).

Das Sozialkapital eines auf der Makroebene angesiedelten Akteurs (z.B. eines Staates) kann auch als Strukturmerkmal konzeptualisiert werden, welches bspw. den innerhalb einer Gemeinschaft handelnden Akteuren als Ressource dient, d.h. nicht nur das Kollektiv, sondern auch die dies konstituierenden Akteure können handlungsbegünstigt werden. Diese Perspektive führt dann jedoch zu dem Problem, dass es sich nicht um das Sozialkapital des begünstigten Akteurs, sondern um das des Kollektivs handelt. Anders formuliert: Nicht derjenige Akteur, dem Sozialkapital zugeordnet wird, nutzt es als Ressource, sondern das Sozialkapital erscheint in Form eines Strukturmerkmals - etwa einer bestimmten Kooperationskultur -, die dann von anderen genutzt wird (ohne dass diese anderen zuvor Investitionen geleistet haben müssen).

Um dies innerhalb der strukturalistischen Darstellung sichtbar zu machen, werde ich im Folgenden sowohl zwei verschiedene Arten von Akteuren als auch von Sozialkapital differenzieren:

a) auf der Mikro- und Mesoebene angesiedelte Akteure, die aufgrund ihrer Außenbeziehungen, ihrer Einbettung in Netzwerke, dem Vertrauen, das ihnen entgegengebracht wird bzw. konkreter Normen, die sie ausnutzen, über Sozialkapital als Handlungsressource verfügen sowie

b) auf der Makroebene angesiedelte Akteure (insbesondere Regionen oder Staaten), die aufgrund einer spezifischen inneren Verfasstheit (z.B. Vereinsleben) Sozialkapital als gemeinschaftliches Strukturmerkmal aufweisen.

Zur Kennzeichnung verwende ich die Abkürzungen "A außen" und "Ainnen" sowie "SP_hand" und "SP_struk". Jene Akteure, die von dem Sozialkapitalbestand einer Region oder eines Staates und damit von einem Strukturmerkmal profitieren, die also im eigentlichen Sinne nicht wie die unter Punkt a) genannten Akteure über Sozialkapital verfügen, werden trotzdem unter "Aaußen" subsummiert, da ihnen Sozialkapital gewissermaßen dank ihrer Außenbeziehung zu einem "Ainnen" zuteil wird (etwa wenn ein neu auf dem Markt platziertes Unternehmen von dem hohen Sozialkapitalbestand der Region profitiert [etwa durch Agglomerationsvorteile], in der es sich niedergelassen hat). 
Tabelle 3: Putnams Sorialkapitalkonzept

Definition

Ebene

Lokalisierung

Entstehung

Wirkung

Operationalisierung

Wissenschaftstheoretischer Status
Sozialkapital ist

Norm der Reziprozität

Vertrauen

Netzwerke zivilen Engagements ein Zimmernachbar, eine Sonntagsschule, eine flüchtige Grußbekanntschaft etc. eine Ressource für einen Akteur soziales Zugehörigkeitsgefühl funktional informell

Mikro, Meso, Makro

innerhalb von Beziehungsrelationen, Privatgut aber hauptsächlich öffentliches Gut

Tauschbeziehungen

Vertrauen entsteht durch Reziprozitätsnormen oder zivilem Engagement

dichte soziale Interaktion lässt robuste Normen der Gegenseitigkeit entstehen

Reduzierung von Transaktionskosten Lösung kollektiver Dilemmata ökonomische Modernisierung good governance physische Gesundheit und persönliches Glück informelle Soziabilität (insbesondere Vereinsleben und Engagement für öffentliche Angelegenheiten)

soziales Vertrauen

Empirisch (historisch, politologisch, sekundäranalytisch)

theorieintegrativ

quantitatives Realmodell

\section{Erster Rekonstruktionsschritt}

1. Netzwerke zivilgesellschaftlichen Engagements (Net), Normen der (generalisierten) Reziprozität (Nor) und soziales (generalisiertes) Vertrauen (Tru [Tru = Trust]) können von Akteuren (A ${ }^{\text {außen }}$ ) funktional (Fun) zu deren Zielverwirklichung $(Z)$ genutzt werden und stellen insofern informell (Inf) zufließen- 
de Ressourcen (R) dar, bei denen es sich um Formen sozialen Kapitals (SP_hand) handelt. Die genannten Ressourcen konstituieren überdies Sozialkapital als Strukturmerkmal und damit das Sozialkapital ( $\mathrm{S}^{\mathrm{P}}$ struk $)$ von makrotheoretisch zu begreifenden Akteuren (A $\left.\mathrm{A}^{\text {innen }}\right)$.

2. Sozialkapital als Handlungsressource ( $\mathrm{S}^{\mathrm{P}}{ }^{\text {hand }}$ ) findet sich auf der Mikro- $\left(\mathrm{L}^{\mathrm{Mi}}\right)$, der Meso- $\left(\mathrm{L}^{\mathrm{Me}}\right)$ und der Makroebene $\left(\mathrm{L}^{\mathrm{Ma}}\right)$; Sozialkapital als gemeinschaftliches Strukturmerkmal (SP_struk) findet sich auf der Makroebene.

3. Sozialkapital (SP_hand/_struk) ist eine innerhalb der Relationen (Rel) zwischen Akteuren angesiedelte Ressource (Lok $\left.{ }^{\text {Rel}}\right)$, deren sich ein Akteur (A $\mathrm{A}^{\text {außen/innen }}$ ) bedient bzw. bedienen kann; es tritt sowohl als privates (Gpriv) wie als kollektives bzw. Öffentliches Gut $\left(\mathrm{G}^{\mathrm{koll}}\right)$ in Erscheinung.

4. Austauschprozesse ( $\mathrm{Ta}$ ) zwischen Akteuren (A $\left.\mathrm{A}^{\text {außen}}\right)$ sind Voraussetzung der Entstehung von Sozialkapital.

5. Sozialkapital kann Resultat individueller oder kollektiver Investitionsstrategien (Inv) von Akteuren (A außen) sein. Es ist aber vielfach auch nicht bewusst intendiertes Resultat von Tauschprozessen zwischen Akteuren (A $\mathrm{Au}^{\text {auen}}$ ) und kommt damit auch ohne vorangehende Investition zustande. Sozialkapital kann ferner Ergebnis einer Transferierung ( $T r$ ) sein (sei es, dass ein Aaußen bspw. im Bourdieuschen Sinne Sozialkapital erbt, oder sei es, dass ein Aauen von dem Sozialkapital eines A ${ }^{\text {innen }}$ profitiert.)

6. Sozialkapital (SP_struk) löst Dilemmata kollektiven Handelns (Dilö) (bzw. vermeidet solche Dilemmata) und ist ein zentraler Erklärungsfaktor von good government bzw. good governance (Ggov) und ökonomischer Modernisierung (Ömod).

\section{Zweiter Rekonstruktionsschritt ${ }^{371}$}

Q ist ein potentielles Modell des Putnamschen Sozialkapitalkonzeptes, gdw Q ein Tupel der Form

$\left\langle\mathrm{S}_{\mathrm{P} \_ \text {hand/_struk,Net,Nor,Tru,Aaußen/innen,Inf,Fun,Z,R,Rel,LMi/Me/Ma }}\right.$ Lok $^{\mathrm{Rel}}, \mathrm{Gpriv}^{\mathrm{M} / \mathrm{koll}}$, Ta,Inv,Tr,Dilö,Ggov,Ömod $\rangle$ wobei gilt:

(1) SP_hand/_struk,Net,Nor,Tru,Aaußen/innen,Inf,Fun,Z,R,Rel,LMi/Me/Ma ${ }^{\text {Lok }}{ }^{\text {Rel }}, G^{\text {priv/koll, }}$, Ta,Inv,Tr,Dilö,Ggov,Ömod sind endliche, nicht-leere Mengen. Nach Ausgliederung von $\mathrm{R}$, Net, Nor und Tru sind alle Mengen disjunkt.

(2) $\mathrm{S}^{\mathrm{P}}$ hand/_struk $\subseteq \mathrm{R} ; \mathrm{R} \supseteq \mathrm{S}^{\mathrm{P}}$-hand/_stru; $\mathrm{Net} \subseteq \mathrm{S}^{\mathrm{P}}$ hand/_stru; $\mathrm{Nor} \subseteq \mathrm{S}^{\mathrm{P} \_ \text {hand/_stru; }}$ Tru $\subseteq$ SP_hand/_stru

(3) $\operatorname{Inf} \subseteq$ Rel x R

${ }^{371}$ Erneut möchte ich hinsichtlich der Erläuterung des logischen Vokabulars auf die Ausführungen im Zusammenhang mit der Rekonstruktion des Bourdieuschen Konzeptes sowie auf Kapitel 4.3. verweisen. 
(4) Fun $\subseteq \mathrm{R} \times \mathrm{A}^{\text {außen/innen }} \times \mathrm{Z}$

(5) $\operatorname{Rel} \subseteq \mathrm{A}^{\text {außen }_{i}} \mathrm{x} \mathrm{A}^{\text {außen }_{j}}$

(6) Ta $\subseteq A^{\text {außen }_{i} \times A^{a u ß e n}}$ x R

(7) $\operatorname{Inv} \subseteq \mathrm{A}$ außen/innen $\times \mathrm{R}$

(8) $\operatorname{Tr} \subseteq A^{\text {außen }_{i}}$ x Net x Nor x Tru x $A^{\text {außen; }}$; Tr $\subseteq A^{\text {innen }} \times$ Net x Nor x Tru x $A^{\text {außen }}$

Ergänzend bzw. abweichend von den bereits vorgestellten Sozialkapitalkonzepten meinen einige Bedingungen:

(2) Sozialkapital ist eine Teilmenge von Ressourcen; Ressourcen ist wiederum die umfassende Menge von Sozialkapital. Netzwerke bürgerschaftlichen Engagements, Normen der Reziprozität und soziales Vertrauen sind Teilmengen der Menge des Sozialkapitals. Die Menge Net besteht ihrerseits aus unterschiedlichen Formen, die sich als Net ${ }^{\text {infor/for/innen/außen/brück/bind }}$ (informell versus formell, innenorientiert versus außenorientiert, brückenbildend versus bindend) darstellen lassen.

(4) Funktionalität ist eine Teilmenge des kartesischen Produkts aus Ressourcen, Akteuren und Zielverwirklichung (wobei es sich bei den Ressourcen u.a. um Net, Nor und Tru handeln kann).

(5) Relationen sind eine Teilmenge der Menge von Akteuren (also das kartesische Produkt der Menge A mit sich selbst, etwa eine Verbindung zwischen den Akteuren i und j). Da Putnam Sozialkapital nicht so konzeptualisiert, dass ein Akteur - dem Sozialkapital zugeordnet wird - und dessen Verknüpfung mit anderen Teilnehmern eines Beziehungsnetzes relevant ist, wird die Unterscheidung zwischen A und Te (die ich bei allen übrigen untersuchten Sozialkapitalkonzepten treffe) obsolet und Te nicht eigens eingeführt; damit enthält die Menge A mehr als nur ein Element $\left(\mathrm{A}^{\text {außen }}=\left\{\mathrm{x}_{1}, \mathrm{x}_{2}, \mathrm{x}_{3}, \ldots\right\}\right)$.

(6) Tauschprozesse sind eine Teilmenge des kartesischen Produkts zwischen Akteuren und Ressourcen, d.h. zum Auftreten von Tauschprozessen bedarf es mindestens zweier Akteure, die Ressourcen austauschen.

(7) Investitionen ist ein 2-stelliger Relationsbegriff (denn es wird von Putnam nicht ausgeführt, in was genau investiert wird).

(8) Akteure transferieren die Geltung von Normen der Reziprozität und/oder Vertrauen auf andere Akteure, die nicht zu deren Entstehung beigetragen haben und die auch nicht zwangsläufig in dem Netzwerk eingebunden sein müssen, dem erstere Akteure angehören. Um eine Transferierung handelt es sich ebenfalls dann, wenn ein Akteur von Net, Nor und Tru als gemeinschaftlichen Strukturmerkmalen profitiert. 


\section{Dritter Rekonstruktionsschritt}

Q ist ein Modell des Putnamschen Sozialkapitalkonzeptes, gdw

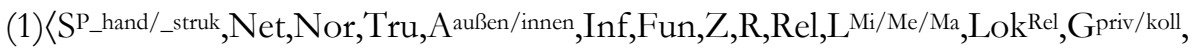
Ta,Inv,Tr,Dilö,Ggov,Ömod $\rangle \in \mathrm{M}_{\mathrm{P}}$

(2) $\forall$ (net) $\forall($ nor $) \forall($ tru $)$

(Fun $[$ net $\vee$ nor $\vee$ tru, a ausen/inneen,,$z] \rightarrow$ net $\vee$ nor $\vee$ tru $:=\mathrm{S}^{\mathrm{P}} \_$hand/_struk $\left.\left[a^{\text {aus } / \text { en } / \text { innen }}\right]\right)$

(3) $\exists\left(a^{\text {aussen }}, r\right)$

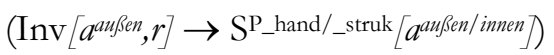

(4) $\exists\left(a^{\text {aursen }, r)}\right.$

(5) $\forall\left(a^{\text {innen }}\right)$

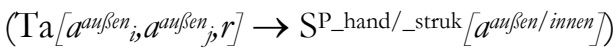

(Dilö_[annen]: $\mathrm{S}^{\mathrm{P}}$ struk $\left[a^{\text {innen }}\right]$ )

$\left(\right.$ Ggov $\left[a^{\text {innen }}\right]: \mathrm{S}_{-} \_$struk $\left.\left[a^{\text {innen }}\right] \rightarrow \mathfrak{R}_{0+}\right)$

$\left(\mathrm{O} \bmod \left[a^{\text {innen }}\right]: \mathrm{S}^{\mathrm{P}}-\right.$ struk $\left.\left[a^{\text {innen }}\right] \rightarrow \mathfrak{R}_{0+}\right)$

Diese Bedingungen meinen:

(2) Für alle Netzwerke zivilgesellschaftlichen Engagements, für alle Normen der Reziprozität und auch grundsätzlich für das gesamte soziale Vertrauen gilt: Wenn der Akteur sie/es funktional zu seiner eigenen Zielverwirklichung nutzen kann, stellen sie/es (sei es einzeln oder gemeinsam) Sozialkapital (sei es als Handlungsressource oder als gemeinschaftliches Strukturmerkmal) dar.

(3) Wenn Akteure Ressourcen investieren, dann kann Sozialkapital entstehen. Der Existenzquantor gibt an, dass nicht jede Investition zu Sozialkapital führt. Da hier nicht klar ist, was und worin genau investiert wird (Investition firmiert in der obigen Wendung nur als 2-stelliges Prädikat), ist diese Wenn-Dann-Verknüpfung unterkomplex.

(4) Tauschprozesse zwischen Akteuren (Akteure tauschen Ressourcen aus) können Sozialkapital sowohl als Handlungsressource wie als Strukturmerkmal begründen. Zur Entstehung von Sozialkapital bedarf es also keinesfalls notwendig einer bewussten Investition eines Akteurs. Der Existenzquantor gibt an, dass nicht jeder Tauschprozess Sozialkapital nach sich zieht.

(5) Die Lösung von Dilemmata kollektiven Handelns, good government und ökonomische Modernisierung sind (idealerweise bei letzteren beiden über eine positive reelle Zahl quantifizierbare) Funktionen von sozialem Kapital ( $\mathrm{S}^{\mathrm{P}}$ struk), d.h. je größer ein Kapitalstock eines $A^{\text {innen, }}$ desto eher lassen sich Dilemmata kollektiven Handelns lösen, desto "besser" wird die Regierungs- und Verwaltungsleistung eines Gemeinwesens sein und desto höher auch der Grad an ökonomischer Modernisierung.

Abschließend soll erneut ein Tupel Q' festgelegt werden, der alle zur intensionalen Begriffsbestimmung von "Sozialkapital" bei Putnam notwendigen Komponenten enthält: 
$Q^{\prime}$ ist ein Tupel der Form $\left\langle A^{\text {außen }_{i} / \text { innen }} \times A^{\text {außen }_{j}} \times \mathrm{R} \times\right.$ Inf x Fun x Z $\rangle$. Angesichts der Putnamschen Fokussierung auf die Wirkungen von Sozialkapital bleibt weitgehend unklar, welche Komponenten nun eigentlich vorhanden sein müssen, damit von "Sozialkapital" gesprochen werden kann. Mit Sicherheit lassen sich hier lediglich Akteure, Ressourcen, Informalität, Funktionalität und Zielverwirklichung angeben.

\subsection{Sozialkapital und beruflicher Erfolg: Das Konzept der Netzwerktheoretiker}

Besonders in Abgrenzung zum Putnamschen Begriffsverständnis wird in der Netzwerktheorie Sozialkapital dezidiert nicht auf der makrosoziologischen Ebene verortet. Insofern spielt diese Version einer Konzeptualisierung von Sozialkapital innerhalb der politischen Diskussionen zur Reformulierung von Wohlfahrtsstaatlichkeit auch keine nennenswerte Rolle. Fundamentale Unterschiede zwischen einzelnen Netzwerktheoretikern lassen sich im vorgezeichneten Kontext kaum auffinden. Im Folgenden wird daher ein weitgehend homogenes Begriffsverständnis unter Rekurs auf die drei prägendsten Vertreter einer Netzwerktheorie des Sozialkapitals, Henk Flap, Ronald Burt sowie Nan Lin, präsentiert ${ }^{372}$.

\section{Definition}

Was eine Netzwerktheorie des Sozialkapitals kennzeichnet, lässt sich mit Ronald S. Burt folgendermaßen zuspitzen: "New life is given to the proverb that says success is determined less by what you know than by whom you know." (Burt 1992: 10) Umgangssprachlich würde man hier zumeist wohl von "Vitamin B" (Vitamin Beziehung) sprechen. Eine typische Definition von Sozialkapital in diesem Sinne präsentiert Nan Lin: "Social capital can be defined as resources embedded in a social structure which are accessed and/or mobilized in purposive actions. By this definition the notion of social capital contains three ingredients: resources embedded in a social structure; accessibility to such social resources by individuals; and use or mobilization of such social resources by individuals in purposive actions. Thus conceived, social capital contains three elements intersecting structure and action: the structural (embeddedness), opportunity (accessibility) and action-oriented (use) aspects." 373 (Lin 2001: 12)

\footnotetext{
372 Der ein oder andere Leser wird hier den Namen Mark S. Granovetter vermissen. Granovetter hat sicherlich genuin zur Ausformulierung einer Netzwerktheorie des Sozialkapitals beigetragen. Seine Ausführungen wurden gleichwohl erst später mit "Sozialkapital" in Verbindung gebracht.

373 Anfang der achtziger Jahre sprach Lin in diesem Zusammenhang lediglich von "sozialen Ressourcen": "Social resources are defined as the wealth, status, power as well as social ties of those persons who are directly or indirectly linked to the individual." Und weiter: "The concept of social
} 
Während Lin unter "Sozialkapital" "assets in networks" begreift (Lin 2001: 3), sieht Flap (2002: 35) egozentrierte soziale Netzwerke selber als Ressource und damit als Sozialkapital an: "Social networks are not seen simply as yet another constraint in the choice process, but as social capital". Und an anderer, früherer Stelle: "Social capital is the access to the economic, human and network resources of those persons who are linked to the individual." (Weesie/Verbeek/Flap 1991: 624). Damit lassen sich innerhalb der Netzwerkperspektive zwei unterschiedliche Richtungen identifizieren: "The first one describes the network as a conduit, the second line describes how networks are themselves a form of social capital." (Burt 1992: 12) Burt sieht beide Richtungen als elementar an, um zu einer generellen Definition zu gelangen: "Social capital is at once the resources contacts hold and the structure of contacts in a network." (ebenda: 12) Das heißt zum einen, "the player has social capital: relationships with other players" (ebenda: 8). Andererseits soll aber ebenso gelten: "Time and energy invested to reach a player with more resources generates more social capital" (ebenda: 44).

Kritisch kann Burt hinsichtlich dieser "doppelten" Begriffsverwendung u.a. vorgeworfen werden, dass Sozialkapital dabei vielfach kontextfrei bestimmt wird. So heißt es etwa in einem von Burts (graphisch illustrierten) Beispielen: "In sum, the hole prediction is that in comparison between otherwise similar people like James and Robert in Figure 1, it is Robert who has more social capital. His network across structural holes gives him broad, early access to, and entrepreneurial control over, information." (Burt 2001: 37) Eine Brokerageposition bedeutet aber per se zunächst einmal überhaupt nichts. Was sollte es einem Akteur nützen, wenn er zwar prinzipiell in der Lage ist, zwei Netzwerke zu verbinden, diese jedoch thematisch derart unterschiedlich operieren, dass ein Ressourcenaustausch höchst unwahrscheinlich ist? Erst unter bestimmten Bedingungen wird die Instrumentalisierung dieser Position mit Blick auf die eigene Zielverwirklichung möglich und der Akteur kann Vorteile realisieren. Selbst wenn man - wie unten noch deutlich werden wird - unter den Sozialkapitalbegriff auch potentielle Vorteile subsummieren möchte, so hängen auch diese von konkreten Begebenheiten ab. Von Burt wird hier völlig ausgeblendet, ob der Zugang zu und die Kontrolle über Informationen, die einem Akteur (nämlich Robert) unterstellt wird, in irgendeiner Weise für diesen nützlich sind; ohne genau diese Bestimmung wird es aber mithin wenig sinnvoll, überhaupt von "Kapital" zu sprechen.

Auch bei den Netzwerktheoretikern erscheint Sozialkapital als Ressource, die auf informellen Vereinbarungen beruht: "When solutions can be routinized and standardized through technology or universal legal laws and rules, the value of social capital usually shrinks." (Flap 2002: 41) Burt äußert im Zusammenhang mit

resources encompasses two components: social relations and the resources embedded in positions reached through such relations." (Lin/Ensel/Vaughn 1981: 395) Insofern müsste eigentlich beantwortet werden, welchen added value die Kapitalterminologie nun bietet. In Kapitel 8.1. wird auf diese Frage noch zurückzukommen sein. 
seinen Ausführungen zur Sozialstruktur des Wettbewerbs, dass man im Falle einer imperfekten Konkurrenzsituation auf seine informellen Kontakte zurückgeworfen sei. "The matter comes down to the question of interpersonal debt. If I do her, will she for me?" (Burt 1992: 15)

\section{Ebene}

Nach Lin ist gerade die Konzeptualisierung von Sozialkapital als eine in Netzwerken eingebettete Ressource geeignet, kausale Mechanismen soziologischer Aggregation und damit die Verbindung zwischen Handlung und Struktur zu analysieren $^{374}$ (vgl. Lin 2001: 3). Auch wenn sich der analytische Fokus vielfach auf die strukturelle Ebene richtet (vgl. Flap 2002: 34), so stellen die dort zu verortenden Entitäten selbst kein Sozialkapital dar; es handelt sich dabei allenfalls um seine Effekte. "Causual propositions may be formulated (e.g., that collective assets, such as trust, promote the relations and networks and enhances the utility of embedded resources, or vice versa), but it should not be assumed that they are all alternative forms of social capital or are defined by one another (e.g. trust is capital)." (Lin 2001: 10)

Wenn Sozialkapital nicht auf der Makroebene zu finden ist, dann kann man lediglich danach fragen, welchen Beitrag es strukturell zur Entstehung bestimmter Makroentitäten, wie etwa generalisiertem Vertrauen oder Normen der Reziprozität, leistet oder wie diese Entitäten umgekehrt Sozialkapital beeinflussen. Sinnvollerweise sollten diese Überlegungen auch Teil einer Theorie des Sozialkapitals sein; sie erscheinen im Kontext seiner Wirkungen oder Entstehungsbedingungen, stellen aber eben selbst kein Sozialkapital dar. Da Burt jedoch behauptet, "the social capital of people aggregates into the social capital of organizations" (Burt 1992: 9), findet sich Sozialkapital bei den Netzwerktheoretikern zumindest auch auf der Mesoebene (es ist dann aber kein Strukturmerkmal, sondern einem organisationellen Akteur zugeordnet).

\section{Lokalisierung}

Auch bei Lin ist Sozialkapital eine Ressource, die innerhalb der Relationen zwischen Personen zu suchen ist. Dezidiert grenzt er es von "forms of personal capital such as economic capital or human capital" ab (Lin 2001: 7; ebenso Burt 1992: 9). Es kann jedoch aus seiner Sicht nicht als kollektives Gut angesehen

\footnotetext{
374 Jansen (2000: 44) betont ebenfalls aus netzwerktheoretischer Perspektive "die Scharnierfunktion des sozialen Kapitals zwischen Mikro-, Meso- und Makroebene". An anderer Stelle (2003: 27) spricht sie Sozialkapital recht bildreich sogar eine "Zwitterstellung zwischen Individuen und Sozialstruktur" zu. Schon in Granovetters vielzitiertem Artikel über "the strength of weak ties" heißt es: "I will argue, in this paper, that the analysis of processes in interpersonal networks provides the most fruitful micro-macro bridge." (Granovetter 1973: 1360)
} 
werden, da es in einer solchen Diktion wieder in aggregierter Form vorliegen müsste und dann eben besser "Norm" oder "Vertrauen" genannt werden sollte. Dennoch ist Sozialkapital kein privates Eigentum in dem Sinne, dass es einem Einzelnen gehörte: "it is a thing owned jointly by the parties to a relationship. ... If you or your partner in a relationship withdraws, the connection, with whatever social capital is contained, dissolves." (Burt 1992: 9) Da jedoch der Akteur (sei dieser singulär oder kollektiv) davon profitiert, ist es - trotz des Einwandes Burts und analog zur Argumentation bei Coleman - als Privatgut zu betrachten.

\section{Entstehung}

Wie allen anderen Konzeptualisierungen von Sozialkapital liegt ebenfalls (und gerade) der netzwerkanalytischen Variante eine austauschtheoretische Modellierung der Entstehung des Gegenstandes zugrunde. Die Reziprozität der kooperierenden Parteien wird zum zentralen Kriterium der Sozialkapitalbeziehung (vgl. etwa Flap 2002: 36f.). Dabei ist Vertrauen eine wichtige Vorbedingung einer Investition: "Because there is a time delay between investments and returns, one has to trust the others that he or she will repay the service delivered and not act opportunistically." 375 (ebenda: 38)

Obwohl auch innerhalb einer Netzwerktheorie des Sozialkapitals immer wieder auf den hierüber realisierten Gewinn des Einzelnen aufmerksam gemacht wird (etwa "Social capital can be defined as resources embedded in a social structure which are accessed and/or mobilized in purposive actions" [Lin 2001: 12]; "people will invest in social capital according to its instrumental value in producing their ends" [Flap 2002: 34f.]; "the more social capital someone has, the better he can achieve his goals." [ebenda: 39]), kann nicht davon gesprochen werden, hier läge explizit ein funktionalistisches Begriffsverständnis vor. So kritisiert Lin sogar den Funktionalismus Colemans als zirkulär: "The cause factor is defined by the effect factor. ... It would be incorrect to allow the outcome variables to dictate the specification of the causual variable (e.g., for actor X, kin ties are social capital because these ties channel $\mathrm{X}$ to get a better job, and for actor $\mathrm{Y}$, kin ties are not social capital because these ties do not channel Y to get a better job)" (Lin 2001: 11) (auf diesen Vorwurf wird in Kapitel 8.1. noch ausführlich zurückzukommen sein).

Ein wichtiger Teil des Sozialkapitals eines Menschen soll zufällig bzw. ohne vorangehende Investition entstehen, etwa durch das Hineingeborenwerden in eine Familie (also durch Vererbung). "Or think of all the indirect ties created by the ties of one's colleagues, acquaintances, friends and kin." (Flap 2002: 38) Problematisch

375 Um nun überhaupt in Austauschprozesse eintreten zu können, bedarf es ganz basaler Gelegenheitsstrukturen: "Without meeting there will be no mating." (Flap 2002: 39) Und: "The most obvious condition influencing contact opportunities, apart from absolute numbers, are places and facilities." (ebenda: 40) 
erscheint dadurch an dieser Stelle, dass Flap seinen Sozialkapitalansatz einerseits als "investment theory" (ebenda) begreift, andererseits jedoch behauptet, manche Verbindungen und das hieraus resultierende Sozialkapital "grow 'at random"' (ebenda), d.h. ohne bewusst vorgenommene Vorleistungen.

Lin argumentiert in vergleichbarer Weise. Insofern man den Kapitalbegriff im vorliegenden Zusammenhang nicht lediglich metaphorisch gebrauche, gelte für Sozialkapital, was grundlegend für alle anderen Kapitalarten auch gelte: "Fundamentaly, capital remains a surplus value and respresents an investment with expected returns." (Lin 2001: 4) Warum sollte aber bspw. ein durch Schenkung erzieltes Geldvermögen einen Mehrwert darstellen? Wo bzw. in was wurde hier eigentlich investiert? Und wie ist es bei Sozialkapital? Investiert man dies denn tatsächlich? Oder investiert man nicht viel eher - wie insbesondere Bourdieu behauptet - ökonomisches Kapital (sei es in Form von Mühe, Zeit, Gesprächen etc.) in Beziehungen, um darüber Sozialkapital beziehen zu können? M.a.W.: Es erscheint wenig sinnvoll, Lin darin zu folgen, Kapital grundsätzlich als Mehrwert und/oder als Investition zu begreifen.

Sicherlich ließe sich sagen, Beziehungsbroker investierten ihr Sozialkapital, wenn sie Kontakte über Netzwerke hinweg vermittelten, um im Anschluss einen wie auch immer gearteten Mehrwert zu erzielen. Dieser Aspekt steht aber in keinem Sozialkapitalkonzept im Mittelpunkt. Entscheidend ist vielmehr, dass man mit Sozialkapital bestimmte Zielstellungen realisieren kann, dass also bspw. A einen neuen Job bekommt, weil B für ihn als Beziehungsbroker fungierte. Hierzu sind nun aber keineswegs vorhergehende Investitionen zwingend erforderlich. Genau dies wird von Bourdieu betont, wenn er von Vererbung spricht; ein Aspekt, der von mir innerhalb der strukturalistischen Rekonstruktion seines Konzeptes als "Transferierung" bezeichnet wurde (etwa wenn ein Teenager davon profitiert, dass ein KFZ-Meister zum Bekanntenkreis seines Vaters zählt und dieser Mechaniker ihm eine Stelle als Lehrling anbietet).

\section{Wirkung}

Nehme man den Kapitalbegriff im vorgezeichneten Kontext wörtlich, so erneut Lin, dann engagierten sich Individuen "in interaction and networking in order to produce profits." (Lin 2001: 6) Sozialkapital erleichtere den Informationsfluss und reduziere damit Transaktionskosten, eröffne Einflussnahme auf andere, indiziere soziale Referenzen und verstärke die persönliche Identität und zwar sowohl im Sinne von emotionaler Unterstützung wie im Sinne von öffentlicher Anerkennung (vgl. ebenda: 7).

Flap spricht zwar davon, Netzwerke stellten selber Sozialkapital dar, andererseits läge "the beauty" des Sozialkapitalansatzes darin, "that we have one key-idea, explaining the principle effects of social networks as well as the emergence and change of social networks." (Flap 2002: 38) Sind nun soziale Netzwerke aber eine 
Form des Sozialkapitals, so entsteht Sozialkapital nach Flap durch Sozialkapital und wirkt auch als solches; insofern ist später im Kontext der integrativen Begriffs- und Theoriebildung zu fragen, ob es tatsächlich sinnvoll ist, soziale Netzwerke als Sozialkapital zu konzeptualisieren.

Innerhalb des Netzwerkverständnisses wird hinsichtlich der Wirkungen von Sozialkapital immer wieder auf die Untersuchungen von Granovetter $(1973,1974)$ verwiesen, der mit seiner Differenzierung zwischen strong und weak ties insbesondere auf die Relevanz von Beziehungsrelationen bei der Jobsuche aufmerksam gemacht hat. Hier sind es gerade die schwächeren Bindungen zwischen Personen, die es ermöglichen, das engere Umfeld zu transzendieren, um so nützliche Kontakte mit Außenstehenden zu knüpfen ${ }^{376}$. Existiert zwischen zwei Personen innerhalb eines Netzwerkes keine Verbindung, so spricht man von "structural holes". Jene Personen, die nun gewissermaßen als Beziehungsbroker diese holes überwinden helfen, verfügen über "control benefits" und damit über eine "favourable exchange-rate in transactions with others." (Flap 2002: 6) Sie besitzen andere Personen interessierende Güter und können im günstigsten Fall als "strukturell autonom" bezeichnet werden, d.h. sie sind mit Blick auf ihre eigene Zielverwirklichung nicht darauf angewiesen, dass andere structural holes für sie überbrücken; sie sind aber in der Position ${ }^{377}$, dies für andere zu tun (vgl. Burt 1992: 45). Je knapper die Güter sind, die solche Personen dank ihrer Brokerstellung kontrollieren, desto größer wird nicht nur ihre soziale Attraktivität, sondern auch ihre Machtfülle sein.

Während dichte Netzwerke und generalisierte Reziprozität bzw. kontinuierliche Austauschbeziehungen geeignet scheinen, die aus den Relationen zwischen Akteuren resultierenden Ressourcen auf Dauer zu stellen, um so etwa Lebenszufriedenheit mittel- bzw. langfristig zu sichern, wird es Akteuren durch offene Netzwerke und durch die Überwindung von structural holes ermöglicht, Ressourcen zu beziehen, die der Realisierung neuer, eher instrumenteller Zielstellungen dienen $^{378}$ (vgl. Lin 2001: 20; vgl. Burt 2001: 52; vgl. Granovetter 1973: 1371).

Die positive Wirkung von Sozialkapital hinsichtlich des beruflichen Karriereerfolges wurde seit den ersten Untersuchungen von Granovetter zu Beginn der

\footnotetext{
376 Die Vorstellung "vom Nutzen entfernter Bekannter" (Wegener 1987) ist auch als Kritik an der traditionellen ökonomischen Theorie des vollkommenen Marktes zu sehen. Der Arbeitsmarkt gilt eben nicht als ein solch vollkommener Markt, sondern Angebot und Nachfrage werden häufig über Netzwerke vermittelt. Dies erweist sich gerade für den Unternehmer als eine kostengünstige Praxis: "If current employees serve as recruiters by recommending appropriate associates from outside the organization, the employer can realize substantial savings in both recruiting and screening costs." (Marsden 2001: 109) Ferner weist die Relevanz von Sozialkapital bei der Stellenbesetzung auch zurück auf die insbesondere von Coleman lancierte Relativierung von Humankapital: "Education and work experience predict job outcomes not only because they have market value in their own right, but at least in part because they lead to greater network diversity, so that controlling for social capital reduces (and explains) part of the apparent effect of human capital." (Erickson 2001: 129)

377 Esser (2000: 247f.) spricht daher auch von "Positionskapital".

378 Diese Differenzierung deckt sich weitgehend mit der schon erwähnten Unterteilung in "support capital" und "leverage capital" (vgl. Täube 2002: 73ff.).
} 
siebziger Jahre in immer neuen netzwerkanalytischen Studien belegt ${ }^{379}$ (vgl. etwa den Sammelband von Lin/Cook/Burt [2001]). Dabei wird nicht nur auf die positiven Effekte von weak, sondern ebenso auf die von strong ties verwiesen. Während Erstere eine Brücke zwischen sozialen Milieus schlagen, ist bei Letzteren die soziale Schließung der entscheidene Mechanismus (etwa wenn neu zu besetzende Stellen ohne öffentliche Ausschreibung betriebsintern vergeben werden [vgl. Runia 2002]). Die erzielten Ergebnisse dürfen in Folge des im Großen und Ganzen widerspruchsfrei und eindeutig formulierten netzwerkanalytischen Sozialkapitalkonzepts sowie des relativ ausgereiften und standardisierten methodischen Instrumentariums i.d.R. als valide gelten ${ }^{380}$.

Neben den genannten Effekten ist Sozialkapital innerhalb des Netzwerkansatzes für eine ganze Reihe weiterer Dinge "gut", die der Vollständigkeit halber kurz angeführt werden sollen. So wirkt sich Sozialkapital positiv auf Freundschaft, soziale Anerkennung, Gesundheit usw. aus (vgl. Flap 2002: 35). Es steigert die Profitrate von Human- und Finanzkapital (vgl. ebenda: 36) und es ist "a lubricant in dealings with others, it promotes trust in people, agreements of quality of products ... it helps to jump a few places in the waiting row of persons who want to be served" (ebenda: 17).

Das Netzwerkkonzept über Sozialkapital ist strikt an den Rational-ChoiceAnsatz angelehnt, womit Flap auch auf Basis der Theorie sozialer Produktionsfunktionen bzw. -faktoren argumentiert und Sozialkapital als einen solchen Faktor ansieht. Demnach streben Menschen anthropologisch grundlegend nach physischem Wohlbefinden und sozialer Anerkennung. Weniger generelle Ziele (eigenes Haus, hohes Einkommen, Bildungsabschlüsse, Urlaubsreisen etc.) können in dieser Perspektive als instrumentell im Hinblick auf die Erreichung dieser beiden "Fluchtpunkte" menschlichen Daseins gewertet werden. "People produce their own subjective well-being by optimizing these instrumental goals. ... In many contexts social capital is part of the production function for status and physical well-being." (Flap 2002: 34)

\section{Operationalisierung}

Die Operationalisierung von Sozialkapital erfolgt innerhalb eines Netzwerkverständnisses natürlich in weiten Teilen über die Netzwerkanalyse, geht es doch um "location effects in differentiated markets" (Burt 2001: 32). Flaps Zusammenfassung der drei bzw. vier Elemente, die soziales Kapital umfasst, ermöglicht eine Systematisierung des Operationalisierungsvorgangs, insofern hierüber deutlich

379 Dieses Untersuchungsfeld "provides key insights into the notion of social capital" (Fernandez/Castilla 2001: 99) und wird wohl aus diesem Grunde heraus immer wieder von netzwerkanalytischen Sozialkapitaltheoretikern bearbeitet.

380 Wobei dies freilich abschließend immer nur für eine konkrete Untersuchung beurteilt werden kann. 
wird, was genau zu messen ist: "Social capital is made up of at least three elements: the number of others prepared or obliged to help ego when called upon to do so, the extent to which they are ready to help, and what is at the other end of the tie. One could include the structure of the network as a fourth dimension of the social capital concept." (Flap 2002: 36; vgl. auch Flap/Boxman 2001: 167f.)

Wenn man Sozialkapital als über soziale Strukturen realisierbare Ressourcen eines Akteurs begreift, dann muss man zu seiner Umfangsbestimmung prinzipiell zwei Aspekte untersuchen: Welche Ressourcen benötigt ein Akteur zur Erreichung bestimmter Zielsetzungen und welche Beziehungsrelationen bzw. strukturen sind vorhanden, um diese Ressourcen zu beziehen? Es kann an dieser Stelle nicht die Aufgabe sein, detailliert das methodische Procedere einer Netzwerkanalyse zu beschreiben (vgl. hierzu ausführlich etwa Jansen 2003 oder Scott 1991). Genannt werden sollen aber zumindest die gängigsten Maße und ihre Beziehung zu Sozialkapital.

Die Abfolge einzelner Linien/Verbindungen zwischen Punkten/Akteuren eines Graphen/Netzwerkes wird Walk genannt. Ein Walk, bei dem keine Linie mehr als einmal begangen wird, ist ein Path. Dessen Length errechnet man über die Addition seiner Linien. Die Distance zwischen zwei Punkten ist die Length des kürzesten Path's (bspw. beträgt die Distance zwischen A und C genau 2, wenn A nicht in Beziehung zu C aber zu B steht, der wiederum direkt mit $\mathrm{C}$ verbunden ist). Je geringer die Distance zwischen Akteuren innerhalb eines Netzwerkes, desto leichter dürfte es in vielen Fällen für ego (jenem Akteur, dessen Sozialkapital bestimmt werden soll) sein, auf die Ressourcen der anderen zuzugreifen. Die Gesamtzahl der Akteure in der Nachbarschaft von ego entsprechen seinem Degree. Der indegree gibt an, wie viel Akteure sich auf ego beziehen, damit verweist das $\mathrm{Maß}$ darauf, von wie vielen Akteuren ego u.U. Hilfestellungen erwarten darf ${ }^{381}$.

Density beschreibt, inwiefern die Punkte/Akteure eines Graphen/Netzwerkes aneinandergrenzen. In einem kompletten Graph (Density $=1)$ ist jeder Punkt mit jedem anderen verbunden ${ }^{382}$. In der Gruppenspsychologie Morenos ist Density ein $\mathrm{Ma} ß$ für die Gruppenkohäsion. Im Anschluss daran lässt sich hinsichtlich von Sozialkapital Density als Maß für die Solidar- und Vertrauenspotentiale von Kollektiven begreifen. Je größer diese Potentiale, desto eher darf ego Unterstützung erwarten.

Centrality-Maße beleuchten die strukturelle Position von Akteuren und indizieren, inwiefern einzelne Akteure möglichst leicht Ressourcen beziehen bzw. inwiefern sie den Informationsfluss im Netzwerk steuern können. Ein Akteur ist

\footnotetext{
381 Bei gerichteten Graphen ist der Indegree eines Punktes die Anzahl der anderen Punkte, die auf ihn gerichtet sind (= Spaltensumme). Die Bestimmung des Outdegrees erfogt enstprechend (also über die Zeilensumme).

382 "Density" ist definiert als die tatsächliche Anzahl der Linien eines Graphs geteilt durch die maximal mögliche Anzahl.
} 
globally central, wenn er nah an vielen anderen Akteuren liegt ${ }^{383}$. Ein weiteres Centrality-Maß ist Betweeness. Es bestimmt den Grad, in dem ein Akteur zwischen den anderen Akteuren eines Netzwerkes liegt (Broker- oder Gatekeeperposition).Unter einer Clique wird zumeist ein maximal kompletter Subgraph (also ein Ausschnitt eines Netzwerkes) zusammengefasst, d.h. alle Punkte/Akteure sind miteinander verbunden und die Clique ist nicht eingebettet in eine andere Clique. Realiter ist ein solch kompletter Subgraph selten zu finden. Daher spricht man von n-cliquen. Cliquen können anzeigen, inwiefern einige Bereiche eines Netzwerks durch besonders hohe Solidar- und Vertrauenspotentiale gekennzeichnet sind, was dann wiederum den Bezug von wichtigen Ressourcen erleichtern wird.

Während die Definition für die Clique auf soziometrischen Überlegungen basiert, ist das Definitionskriterium für Cluster die strukturelle Äquivalenz von Akteuren (in einem Unternehmen lassen sich etwa i.d.R. ein Angestellten- und ein Arbeiter-Cluster identifizieren). Cluster können anzeigen, welche Machtbeziehungen innerhalb eines Netzwerkes bestehen, d.h. wer welche Ereignisse kontrolliert, die für andere relevant sind.

\section{Wissenschaftstheoretischer Status}

Ganz grundlegend entstammt das netzwerkanalytische Sozialkapitalkonzept (natürlich) der soziologischen und sozialpsychologischen (Moreno und Heider) Netzwerkanalyse. Das Forschungsprogramm "is encompassed by the idea of egocentred social networks as social resources. Such a program systematizes the results of social network research, creates a system that was lacking before." (Flap 2002: 35) Empirische Studien zu den Vorteilen von Sozialkontakten sind Legion (siehe etwa die in diesem Kapitel angeführten Referenzen) und rekurrieren auf die Granovetterschen Studien zur erfolgreichen Jobsuche sowie zur sozialen Einbettung ökonomischer Transaktionen. Insofern handelt es sich bei dem Sozialkapitalkonzept um ein quantitatives Realmodell.

\section{Strukturalistische Darstellung}

Vor der strukturalistischen Darstellung soll auch das netzwerkanalytische Sozialkapitalkonzept zunächst noch einmal tabellarisch zusammengefasst werden.

383 Die global centrality eines Punktes ist die Summe der distances zu allen anderen Punkten. Standardisiert: $\mathrm{n}-1 / \Sigma$ distances. 
Tabelle 4: Netzwerkanalytisches Sozialkapitalkonzept

Definition

Ebene

Lokalisierung

Entstehung

Wirkung

Operationalisierung

Wissenschaftstheoretischer Status

\author{
Sozialkapital ist \\ Netzwerk \\ in Netzwerken eingebettete Ressourcen für den \\ Einzelnen/Akteur \\ informell \\ Mikro, Meso \\ innerhalb von Beziehungsrelationen, Privatgut \\ Tauschbeziehungen \\ Vererbung bzw. Transferierung \\ Investition in Beziehungen \\ Schaffung von Verpflichtungen \\ Reduzierung von Transaktionskosten \\ Eröffnung von Einflussmöglichkeiten (also \\ Macht) \\ Sicherung von Ressourcen wie Gesundheit \\ oder Lebenszufriedenheit durch geschlossene \\ Netzwerke; Zugriff auf Ressourcen wie neue \\ Jobmöglichkeiten durch offene Netzwerke
}

Netzwerkanalyse

befragungstechnische Bestimmung jener Ressourcen innerhalb eines Netzwerks, die für den fokalen Akteur bedeutsam sind

analytischer Rekurs auf Netzwerkanalyse/theorie und Theorie sozialer Produktionsfunktionen permanente empirische Theorieüberprüfungen (deduktiv-nomologisch)

quantitatives Realmodell

\section{Erster Rekonstruktionsschritt}

1. Die einem Akteur (A) infolge seiner Zugehörigkeit zu einem Beziehungsnetz (B) informell (Inf) zufließenden (sei es tatsächlich oder potentiell) und der eigenen Zielverwirklichung $(\mathrm{Z})^{384}$ dienenden Ressourcen (R) sowie auch

\footnotetext{
${ }^{384}$ Im Gegensatz zu allen bisher rekonstruierten Konzepten wird hier nur von "Zielverwirklichung" gesprochen, d.h. der Hinweis auf Funktionalität entfällt, da sich insbesondere Lin dezidiert gegen die Funktionalität von Sozialkapital ausspricht (siehe oben). Inwiefern die Ablehnung von Funktionalität
} 
schon das Beziehungsnetz selber sind sein soziales Kapital $\left(\mathrm{S}^{\mathrm{N}}\right)\left[\mathrm{S}^{\mathrm{N}}=\right.$ Sozialkapital innerhalb des Netzwerkansatzes]).

2. Sozialkapital findet sich auf der Mikro- $\left(\mathrm{L}^{\mathrm{Mi}}\right)$ und auf der Mesoebene $\left(\mathrm{L}^{\mathrm{Me}}\right)$.

3. Sozialkapital ist eine innerhalb der Relationen (Rel) zwischen Akteuren (Lok ${ }^{R e l}$ ) angesiedelte Ressource, derer sich ein Akteur mit Blick auf seine Zielverwirklichung bedient bzw. bedienen kann; es ist ein privates Gut (Gpriv).

4. Austauschprozesse ( $\mathrm{Ta}$ ) zwischen einem Akteur und weiteren Teilnehmern (Te) eines Beziehungsnetzes sind Voraussetzungen der Entstehung von Sozialkapital.

5. Sozialkapital kann Resultat von Verpflichtungen (V) erzeugenden individuellen bzw. kollektiven Investitionsstrategien (Inv) in Beziehungen sein. Verpflichtungen resultieren aber auch aus nicht bewusst investiv angelegten Tauschprozessen. Sozialkapital kann ferner auch Ergebnis von Transferierungen $(\mathrm{Tr})$ sein.

6. Sozialkapital (insbesondere in Form von weak ties) ist vielfach ein entscheidender Faktor erfolgreicher Jobsuche bzw. einer erfolgreichen beruflichen Karriere (BE [= beruflicher Erfolg]).

\section{Zweiter Rekonstruktionsschritt}

$\mathrm{Q}$ ist ein potentielles Modell des netzwerkanalytischen Sozialkapitalkonzeptes, gdw Q ein Tupel der Form

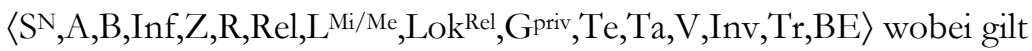

(1) $\mathrm{S}^{\mathrm{N}}, \mathrm{A}, \mathrm{B}, \mathrm{Inf}, \mathrm{Z}, \mathrm{R}, \mathrm{Rel}, \mathrm{L}^{\mathrm{Mi} / \mathrm{Me}}, \mathrm{Lok}^{\mathrm{Rel}}, \mathrm{G}{ }^{\mathrm{riv}}, \mathrm{Te}, \mathrm{Ta}, \mathrm{V}, \mathrm{Inv}, \mathrm{Tr}, \mathrm{BE}$ sind endliche, nichtleere Mengen. Nach Ausgliederung von B und R sind alle Mengen disjunkt.

(2) $\mathrm{S}^{\mathrm{N}} \subseteq \mathrm{R} ; \mathrm{S}^{\mathrm{N}}=\mathrm{B}$

(3) $\operatorname{Inf} \subseteq$ Rel x R

(4) $\mathrm{R} \subseteq \mathrm{Te} \times \mathrm{A}$

(5) $\mathrm{Rel} \subseteq \mathrm{A} \times \mathrm{Te}$

(6) $\mathrm{Ta} \subseteq \mathrm{A} \times \mathrm{Te} \times \mathrm{R}$

(7) $\mathrm{V} \subseteq$ Te $\mathrm{x} A$

(8) Inv $\subseteq$ A x R x Rel

(9) $\operatorname{Tr} \subseteq \operatorname{Te} \times \mathrm{V} \times \mathrm{A}$

Ergänzend zu bzw. abweichend von den bereits vorgestellten Sozialkapitalkonzepten meint die zweite Bedingung:

wirklich sinnvoll ist, wird im Rahmen der Errichtung eines integrativen Theoriemodells (Kapitel 8.1.) noch ausführlich erörtert werden. 
(2) Sozialkapital ist nicht nur eine Teilmenge von Ressourcen, sondern auch ein Beziehungsnetz alleine ist schon eine Sozialkapital darstellende Ressource.

\section{Dritter Rekonstruktionsschritt}

Q ist ein Modell des netzwerkanalytischen Sozialkapitalkonzeptes, gdw

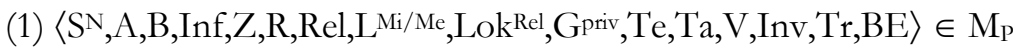

(2) $\exists(a, r, r e l)$

$(\mathrm{Inv}[a, r, r e l] \rightarrow \mathrm{V}[t e, a])$

(3) $\exists(a, t e, r)$

$(\mathrm{Ta}[a, t e, r] \rightarrow \mathrm{V}[t e, a])$

(4) $\forall(t e, a)$

$\left(\mathrm{V}[t e, a] \wedge \mathrm{R}[t e, a] \wedge \mathrm{Z}[a, r] \rightarrow \mathrm{R}[t e, a]:=\mathrm{S}^{\mathrm{N}}[a]\right)$

(5) $\forall(t e, v, a)$

(6) $\forall(a)$

$\left(\operatorname{Tr}[t e, v, a] \wedge \mathrm{R}[t e, a] \wedge \mathrm{Z}[a, r] \rightarrow \mathrm{R}[t e, a]:=\mathrm{S}^{\mathrm{N}}[a]\right)$

(7) $\forall(a)$

$\left(\mathrm{B}[a] \wedge \mathrm{Z}[a, b] \rightarrow \mathrm{B}:=\mathrm{S}^{\mathrm{N}}[a]\right)$

$\left(\mathrm{BE}[a]: \mathrm{S}^{\mathrm{N}}[a] \rightarrow \mathfrak{R}_{0+}\right)$

Diese Bedingungen meinen:

(2) Es gibt mindestens eine Verbindung zwischen einem Akteur, Ressourcen und (Beziehungs-) Relationen aus $\mathrm{M}_{\mathrm{P}}$ (also aus der Menge aller möglichen Anwendungsbeispiele des netzwerkanalytischen Sozialkapitalkonzeptes) für die gilt, wenn ein Akteur Ressourcen in eine (Beziehungs-) Relation investiert, dann entsteht eine soziale Verpflichtung. Der Existenzquantor gibt an, dass nicht jede Investition dieser Art zu einer sozialen Verpflichtung führt.

(3) Tauschprozesse zwischen einem Akteur und Teilnehmern (Akteur und Teilnehmer tauschen Ressourcen aus) können Verpflichtungen (seitens Te) begründen. Zur Entstehung von Verpflichtungen bedarf es also nicht notwendig einer bewussten Investition. Der Existenzquantor gibt an, dass nicht jeder Tauschprozess Verpflichtungen nach sich zieht.

(4) Für alle Verbindungen zwischen einem Teilnehmer und dem fokalen Akteur aus $M_{P}$ gilt, wenn ein Teilnehmer eine soziale Verpflichtung gegenüber dem fokalen Akteur verspürt, dann entsteht soziales Kapital. Dies jedoch nur unter der Voraussetzung, dass Te eine Ressource für A bereithält, für die wiederum gilt, dass A sie zu seiner Zielverwirklichung nutzen kann. Der Allquantor gibt an, dass jede soziale Verpflichtung, die diesen Bedingungen genügt, zu Sozialkapital führt ${ }^{385}$. (Hier geht es also um die Entstehung von Sozialkapital als eine aus Beziehungen resultierende Ressource.)

(5) Für alle Verbindungen zwischen Teilnehmer, Verpflichtung und dem fokalen Akteur aus $\mathrm{M}_{\mathrm{P}}$ gilt, wenn ein Teilnehmer eine Verpflichtung die er einem anderen gegenüber verspürt auf den fokalen Akteur transferiert, dann entsteht soziales

385 Zielverwirklichung firmiert hier (und unter der nachfolgenden Bedingungen) als 2-stelliger Prädikator, während Z in allen anderen untersuchten Sozialkapitalkonzepten lediglich als Individuenvariable vorkommt, die über die Prädikatenvariable Fun in Bezug zu R und A gesetzt wird. 
Kapital. Dies jedoch erneut nur unter der Bedingung, dass Te eine Ressource für A bereithält, für die gilt, dass A sie zu seiner Zielverwirklichung nutzen kann. (Im Gegensatz zu allen anderen untersuchten Sozialkapitalkonzepten verzichten die Netzwerktheoretiker auf das Funktionalitätskriterium.)

(6) Für alle Beziehungsnetze gilt: Wenn der Akteur an Beziehungsnetzen partizipiert und sie zu seiner eigenen Zielverwirklichung nutzen kann, stellen sie soziales Kapital dar. (Hier geht es also um Beziehungsnetze als Sozialkapital. Die Entstehung eines Beziehungsnetzes selber ist kein Gegenstand der netzwerkanalytischen Theoretiker im vorliegenden Kontext.)

(7) $\mathrm{BE}$ ist eine (über eine positive reelle Zahl quantifizierbare) Funktion von $\mathrm{S}^{\mathrm{N}}$, d.h. das Ausmaß bzw. die Qualität des Sozialkapitals des Einzelnen bestimmt dessen beruflichen Erfolg (sei es hinsichtlich der Jobsuche oder hinsichtlich der Karriereentwicklung) in entscheidender Weise mit. $\mathrm{S}^{\mathrm{N}}$ bezeichnet dabei sowohl die Ressource(n), die dank einer oder mehrerer Verbindungen bezogen wird (werden), als auch die Verbindung(en) selber (bspw. in Form von weak ties). (Natürlich hängt $\mathrm{BE}$ von zahlreichen weiteren Größen ab. Hier geht es aber lediglich um die von den Netzwerktheoretikern als zentral angesehene Wirkungsweise sozialen Kapitals bzw. um jenen Effekt, der hauptsächlicher Gegenstand netzwerkanalytischer Untersuchungen zu Sozialkapital ist.)

Erneut soll zum Abschluss ein Tupel Q' festgelegt werden, der alle Komponenten enthält, die zur intensionalen Begriffsbestimmung von "Sozialkapital" bei den Netzwerktheoretikern notwendig sind:

$\mathrm{Q}^{\prime}$ ist ein Tupel der Form $\langle\mathrm{A} \times \mathrm{Te} \times \mathrm{R} \times \mathrm{B} \times \operatorname{Inf} \mathrm{x} \mathrm{Z}\rangle$ (wobei allerdings auch gilt, dass $\mathrm{B}=\mathrm{S}^{\mathrm{N}}$ ). 



\section{Eine integrative Theorie über Sozialkapital und Bestimmung des ontologischen Status}

\subsection{Sozialkapitalbegriff und theoretisches Aussagensystem}

In diesem Kapitel werden die rekonstruierten Sozialkapitalkonzepte gegenübergestellt und verglichen, um dann ein integratives Theoriemodell zu entwickeln. Dieses Modell wird insofern nicht - wie vielfach im Logischen Positivismus gefordert - in direkter Auseinandersetzung mit der Empirie, sondern durch theorieintegrative sowie ergänzend durch analytische Verfahren gewonnen.

Ein solches Vorgehen steht keineswegs im Widerspruch zu grundsätzlichen wissenschaftstheoretischen Forderungen an die Theoriebildung. Popper - auf den im Rahmen einheitswissenschaftlich orientierter Forschung zumeist rekurriert wird - begreift diese bekanntermaßen sehr unspezifisch als mehr oder weniger inspirierten Akt des Forschers. In seiner deduktiven Wissenschaftsauffassung ging es Popper eigentlich "gar nicht um Theorien, sondern um die Bewertung und den Test von empirischen Hypothesen, die auf Theorien beruhen." 386 (Stegmüller 1980b: 118)

\footnotetext{
386 Im ersten Satz der Einleitung zu seiner "Logik der Forschung" heißt es bei Popper: "Die Tätigkeit des wissenschaftlichen Forschers besteht darin, Sätze oder Systeme von Sätzen aufzustellen und systematisch zu überprüfen." (Popper 1982: 3) Insofern liegt die Systematik bei Popper nicht (wie innerhalb der vorliegenden Untersuchung) im Bereich der Theoriekonstruktion, sondern im Bereich des Theorietests.
} 
Im Zentrum der strukturalistischen Wissenschaftstheorie steht i.d.R. nicht die Formulierung neuer, sondern die Rekonstruktion und empirische Nutzbarmachung bestehender Theorien. Kriz et al. (1987: 195) behaupten sogar, "ein ernstzunehmender Nachteil der Nicht-Aussagen-Konzeption liegt sicherlich in dem Umstand, dass die Frage nach der Verbesserung und Veränderung von Theorien hier konzeptionell ausgeblendet wird". Dem stimme ich jedoch nicht zu. Gerade eine strukturalistische Darstellung erhöht die Transparenz der untersuchten Theorien und ermöglicht damit mithin erst deren systematische Vergleichbarkeit sowie Veränderung bzw. ggflls. Verbesserung. In diesem Sinne kann eine Theorie aus einer synoptischen Zusammenschau unterschiedlicher Konzepte hervorgegangen sein. Solche integrativ angelegten Entwürfe sind gewissermaßen Resultat eines vor dem Hintergrund wissenschaftstheoretischer Anforderungen erstellten Stärken-und-Schwächen-Profils. Vielfach lassen sich offen gebliebene Probleme dann zusätzlich noch durch deduktive Überlegungen beseitigen, um so ein stringentes Theoriemodell zu erhalten ${ }^{387}$.

Mit Blick auf das Rationalitätspostulat wissenschaftlicher Forschung wurden bereits im Rahmen der Auseinandersetzungen mit den unterschiedlichen Sozialkapitalkonzepten die jeweiligen zentralen Kritikpunkte benannt und damit bestimmte Aspekte für die hier vorzunehmende Theoriebildung ausgeschlossen. Im Folgenden werden einige dieser Punkte nochmals zusammenfassend innerhalb der einzelnen Gliederungsabschnitte diskutiert, um hierüber die Argumentation hinsichtlich des zu entwickelnden Theoriemodells transparent zu gestalten.

Reduktive Rekonstruktionen (bei denen die Aussagen einer Theorie auf die einer anderen reduziert werden) und die Kriterien der Einfachheit und Nützlichkeit sind nur dann wirklich sinnvoll durchführ- bzw. anwendbar, wenn unterschiedliche Konzepte den gleichen Gegenstand anvisieren und man von hier aus dann beurteilen möchte, welches Aussagensystem als "überlegen" gelten darf (welches also über einen höheren theoretischen Gehalt verfügt und sowohl einfacher formuliert wie fruchtbarer im empirischen Einsatz ist ${ }^{388}$.

\footnotetext{
387 Empirisch argumentierende bzw. an einem konkreten Explanandum orientierte Theorieintegrationen sind im Bereich der Sozialwissenschaften insbesondere in der Sozialpsychologie verbreitet. Ein illustratives Beispiel stellt etwa Bierhoffs Versuch einer Integration von Reaktanztheorie und Theorie der erlernten Hilflosigkeit dar (vgl. Bierhoff 2000: 166ff.).

388 Vgl. hierzu für die Sozialwissenschaften bspw. Seipel 1999 oder die Beiträge des Sammelbandes von Opp/Wippler 1990a. Dabei geht es grundsätzlich um "die Anwendung und den Vergleich verschiedener Theorien im Hinblick auf ein und dasselbe Erklärungsproblem" (Opp/Wippler 1990b: 12). Die Explananda innerhalb der Sozialkapitaldebatte sind hingegen heterogen, womit ein empirischer Theorienvergleich wenig fruchtbar wäre. Einschränkend muss allerdings gesagt werden, dass sich das Verhältnis der Konzepte Colemans und Putnams durchaus auch als "linear" charakterisieren ließe, insofern Putnam an Coleman unmittelbar anschließt, dabei jedoch einen umfassenderen Bereich an möglichen Explananda zulässt bzw. sogar fordert.
} 
Da im vorliegenden Zusammenhang - wie die bisherigen Ausführungen deutlich gemacht haben sollten - jedoch keinesfalls davon die Rede sein kann, hier stehe grundsätzlich derselbe Gegenstand im Mittelpunkt der Überlegungen, d.h. es lägen empirisch äquivalente Aussagensysteme vor, in denen die gleichen Daten beschrieben, erklärt und prognostiziert würden, sind entsprechende, theoriendynamische Betrachtungen bei einer vergleichenden Beschäftigung mit "Sozialkapital" wenig sinnvoll.

Tatsächlich aber weisen alle Untersuchungseinheiten eine gemeinsame analytische Fundierung auf (Quine würde möglicherweise von einem einheitlichen begrifflichen Zentrum sprechen); es wird nämlich grundsätzlich von nutzenmaximierend und zielgerichtet handelnden Akteuren ausgegangen. Bei Coleman, Putnam und den Netzwerktheoretikern finden wir explizit die Berufung auf den Rational-Choice-Ansatz. Bei Bourdieu ist dieser implizit ebenfalls Grundlage der Argumentation, spricht Bourdieu (1992: 66) doch u.a. davon, Akteure investierten "bewußt" in die Schaffung von Beziehungen, "die früher oder später einen unmittelbaren Nutzen versprechen".

Insofern wird die hier mit dem Ziel der Theoriebildung anzustellende synoptische Gegenüberstellung eine Art "Inventarisierungsvergleich" (Greshoff o.J.: 3) sein, d.h. sie wird auf die gemeinsamen Ausgangselemente der Sozialkapitalkonzepte abstellen: In allen untersuchten Konzepten finden sich bestimmte zentrale Überlegungen hinsichtlich des Sozialkapitalbegriffs, also Komponenten der Begriffs-Intension, die ich - nach einigen Modifikationen und zunächst in nominalistischer Tradition - zusammenfassend als dessen "key idea" kennzeichnen möchte.

Mit der Ausarbeitung der key idea bleibt gewährleistet, dass die hier vorgenommene Begriffs- und Theoriebildung den insbesondere von Carnap formulierten Adäquatheitsbedingungen der Ähnlichkeit genügt (vgl. Mittelstraß 1981: 90), dass also nicht etwas völlig anderes bezeichnet bzw. konzeptualisiert wird, als das, was die untersuchten Autoren anvisieren. Ausgangspunkt sind somit die Aussagen über Sozialkapital, hinsichtlich derer innerhalb der Wissenschaft Einverständnis besteht ${ }^{389}$.

Hiervon ausgehend lassen sich dann die Folgerungen für alle anderen Untersuchungsaspekte - Ebene, Lokalisierung, Entstehung etc. - analytisch herleiten. Da die weiteren Gliederungspunkte also stark von der Begriffsdefinition abhängen, wird diese im Folgenden am Ausführlichsten besprochen. Bedeutungstheore-

\footnotetext{
389 Auch Bjornskov/Svendsen (2003) suchen nach einem "underlying rock upon which all the various definitions of the concept rest" (ebenda: 1). Zu diesem Zweck analysieren sie insgesamt zehn unterschiedliche Operationalisierungsweisen von Sozialkapital, um auf dieser Basis dann qua Faktorenanalyse die jeweilig genannten Variablen auf eine zu reduzieren. Grundlegende definitorische Probleme lassen sich über ein solches Vorgehen aber nicht lösen. Tatsächlich gehen die Autoren weitgehend vom Sozialkapitalbegriff Putnams aus und präzisieren dann diesen über ihre methodologischen Betrachtungen.
} 
tisch ließe sich formulieren: Ein Vorschlag zu einem regelhaften Gebrauch von "Sozialkapital" wird unterbreitet.

\section{Definition}

Die genannte key idea ist sozusagen das, was die Einführung von "Sozialkapital" begründet und den Begriff - soll er denn sinnvoll sein - von anderen sozialwissenschaftlichen Konstrukten unterscheiden muss. Implizit heißt dies zugleich, dass diese key idea - zumindest in dieser Form - zuvor noch keine wissenschaftliche Konzeptualisierung erfahren haben sollte. Grundsätzlich wird über "Sozialkapital" eine relativ trivial erscheinende Tatsache thematisiert: Individuen bzw. Akteure ziehen Nutzen aus ihren Beziehungen zu anderen; der Ausdruck fokussiert "vornehmlich auf die positiven Effekte sozialer Beteiligung" (Beckert 2003: 19). "In this sense", so Portes (1998: 2) unter Verweis auf theoriegeschichtliche Wurzeln bei Durkheim und Marx, "the term ... simply recaptures an insight present since the very beginnings of the (sociological, D.K.) discipline."390 Hinsichtlich dieser Einsicht nun von "Sozialkapital" zu sprechen, sei, "to a large extent, just a means of presenting them in a more appealing conceptual garb." (ebenda: 21)

Um festzustellen, ob doch "mehr" hinter dem Begriff steckt, möchte ich in einem ersten Schritt die innerhalb der untersuchten Konzepte genannten Komponenten vergleichen, die definitorisch vorliegen müssen, damit hinsichtlich eines sozialen Gegenstandes von "Sozialkapital" die Rede sein darf (es geht also um die intensionalen Begriffsbestimmungen; in meiner strukturalistischen Diktion hatte ich von "Q'-Tupeln" gesprochen). In der Tradition der logischen Definitionstheorie zielt dieses Vorgehen auf eine Sprachnormierung, d.h. auf eine Ausarbeitung der notwendigen und hinreichenden Verwendungsbedingungen, respektive der Regeln des korrekten Gebrauchs von "Sozialkapital" ab ${ }^{391}$.

Schauen wir uns also nach dieser Zwischenbemerkung die von den einzelnen Autoren vertretenen begrifflichen Intensionen nochmals genauer an:

\footnotetext{
390 Was das Putnamsche Makroverständnis angeht, kann - wie Schechler (2002: 19f.) anmerkt - auf Adam Smiths "Theorie der ethischen Gefühle" zurückgegangen werden: Gesellschaftliche Ziele werden hier nicht durch Eigennutz, sondern vielmehr durch "Wohlwollen und Selbstlosigkeit" erreicht. Bekannter als diese Einschätzung von Smith ist gleichwohl seine "invisible hand", d.h. seine Behauptung, trotz gezielt ihrem individuellen Interesse folgenden Bürgern ließen sich gesellschaftliche Belange über den Markt harmonisieren.

391 Als wissenschaftstheoretisch motivierter Forscher mag man die Tatsache, dass Begriffe uneinheitlich und unpräzise gebraucht werden, durchaus auch einmal als Vorteil begreifen, hat dies doch "ohne Zweifel für die Weiterentwicklung unseres Begriffsystems auch nützliche Effekte; diese Tatsache führt uns nämlich immer wieder vor Augen, daß die Intensionen nicht unlösbar mit den Ausdrücken verknüpft sind und daß wir uns bemühen müssen, unser Begriffsystem zu verbessern" (Essler 1972: 116).
} 
$S^{B}:$

$\langle A \times$ Te x GK x R x B x Inf x Fun x Z $\rangle$

$S C:$

$\langle A \times$ Te x Rel x R x B x Inf x Fun x Z

$S^{P}:$

$\left\langle A^{\text {außen }}{ }_{i} /\right.$ innen $_{x} A^{\text {außen }_{j}} \times \mathrm{R} \times \operatorname{Inf} \times$ Fun $\left.x \mathrm{Z}\right\rangle$

SN:

$\langle A \times$ Te x Rel x R x B x Inf x Z $\rangle$ (wobei auch B = SN)

Um von "Sozialkapital" sprechen zu können, müssen über alle untersuchten Konzepte hinweg demnach die Komponenten A, Te (bzw. bei Putnam ein weiterer Akteur), Rel (bzw. bei Bourdieu GK), R und Z auftauchen; sie bilden gewissermaßen eine Schnittmenge, d.h. es bedarf

(1) eines Akteurs (A), dem Sozialkapital zugeordnet werden kann,

(2) mindestens eines weiteren Teilnehmers (Te) (aus einem Beziehungsnetz, dem auch der Akteur angehört),

(3) einer Beziehungsrelation (Rel) zwischen einem Akteur und mindestens einem Teilnehmer (aus dem Beziehungsnetz, dem auch der Akteur angehört) (bei Bourdieu ist zusätzlich von gegenseitigem Kennen und Anerkennen [GK] die Rede, was eine Beziehungsrelation impliziert),

(4) Ressourcen (R), die zur Verfügung gestellt werden können bzw. zur Verfügung gestellt werden (wobei insbesondere bei den Netzwerktheoretikern das Beziehungsnetz selbst als eine Ressource angesehen wird),

(5) der Informalität (Inf) der Beziehungsrelation mit Blick auf die (tatsächlich oder potentiell) zur Verfügung gestellten Ressourcen sowie

(6) einer Zielverwirklichung (Z), die der Akteur deswegen bewerkstelligt (bzw. bewerkstelligen kann), weil ihm diesbezüglich Ressourcen (tatsächlich oder potentiell) zur Verfügung stehen.

Falls an dieser Stelle der Eindruck erweckt wird, als seien die jeweiligen Sozialkapitalbegriffe weit weniger unterschiedlich als bislang von mir behauptet, so ist darauf hinzuweisen, dass die axiomatisierten Darstellungen schon ein Resultat der zuvor erfolgten Rekonstruktionen sind, bei denen strategisch auf die Entwicklung eines integrativen Theoriemodells hingearbeitet wurde. Lindenberg/Wippler (1978: 229f.) schlagen bei ihrer "Forschungsanleitung für den Theorienvergleich" vor, "im Hinblick auf ihre Verwendbarkeit für die Theoriebildung", Aussagen so weit als möglich "unter dem Gesichtspunkt zu rekonstruieren, daß sie vergleichsfähig werden."

Ganz in diesem Sinne hatte ich bspw. in Zusammenhang mit Coleman dessen Festlegung von Normen als Sozialkapital in Frage gestellt und mich bei der strukturalistischen Darstellung vorrangig auf die aus Verpflichtungen resultierenden Ressourcen als Form von Sozialkapital konzentriert. Über die oben genannten Punkte hinaus herrscht aber hinsichtlich der definitorischen Bestimmung kein Konsens bzw. es besteht Präzisierungsbedarf:

Soll unter "Sozialkapital" eine Ressource, die aus einem Beziehungsnetz emergiert, verstanden werden, oder sind Beziehungsnetze selbst schon als "Sozialkapi- 
tal" zu bezeichnen? Ist es überhaupt sinnvoll, Sozialkapital als eine Ressource zu betrachten? Wieviele Akteure sind notwendig, um von der Entstehung von "Sozialkapital" sprechen zu können? Firmieren auch schon einzelne Akteure als "Sozialkapital"? Muss ein Akteur wirklich schon vorab Ziele formuliert haben, um diese dann über den Einsatz von Sozialkapital zu realisieren?

Die Vorstellung, ein Beziehungsnetz (bzw. ein soziales Netzwerk) stelle Sozialkapital dar, ist m.E. als wenig sinnvoll zu charakterisieren. In einer solchen Wendung wird lediglich ein Begriff durch einen anderen ersetzt ${ }^{392}$. Weder ein Beziehungsnetz, eine Beziehungsrelation (ob nun als weak oder strong tie) noch eine bestimmte Position innerhalb eines sozialen Netzwerks bedeuten per se einen Vorteil für einen Akteur; erst wenn hierüber ein Ressourcenbezug erfolgt und dieser wiederum einer Zielverwirklichung dient, ist dies der Fall.

Eine Konzeption von Beziehungsnetzen als Sozialkapital steht zudem in Spannung zu dem funktionalistischen Definitionskriterium, denn die aus sozialen Netzwerken erwachsenden Handlungspotentiale können zwar, müssen aber nicht funktional sein. Sicherlich lassen sich spezifische Aspekte von Beziehungsrelationen über die Einführung eines neuen Begriffs fokussieren. Möchte man damit aber im vorliegenden Fall vor allem auf emergierende Ressourcen aufmerksam machen, dann sollte man dies auch durchgehend so darstellen; ansonsten vermischt man Definitionskriterien mit Entstehungsbedingungen.

Bourdieus Verweis auf die Notwendigkeit einer Gruppe, um vom Vorhandensein von sozialem Kapital sprechen zu können, gehört auch in diesen Kontext und kann zumindest missverständlich sein, wenn nicht klar ist, ob eine Dyade schon als Gruppe gelten darf oder nicht. Begreift man unter sozialem Kapital Ressourcen, die aus Beziehungsrelationen erwachsen bzw. die hierüber realisiert werden, dann reicht prinzipiell eine soziale Struktur in dyadischer Form aus ${ }^{393}$. Natürlich kann man viele Beziehungsrelationen mit einer kaum überschaubaren Anzahl von Individuen pflegen. Eine Beziehungsrelation - als singuläres Ereignis - ist jedoch grundsätzlich nur zwischen zwei Individuen anzusiedeln 394 .

Noch problematischer sind allerdings Putnams Ausführungen, in denen schon der einzelne Akteur, mit dem ein anderer in Verbindung steht, zu Sozialkapital erklärt wird. Möglicherweise resultieren - um ein Beispiel Putnams zu nennen aus der Beziehung zum Zimmernachbarn bestimmte nutzbare Ressourcen; über eine diesbezügliche Automatik liegen jedoch keine empirischen Befunde vor ${ }^{395}$. Selbst wenn dem so wäre, bliebe die Rede von "Sozialkapital" hinsichtlich des

\footnotetext{
392 Aussagen wie "ein zweiter Aspekt Sozialen Kapitals neben Effektivität, ist die Effizienz des Netzwerks" (Kröll 2003: 121) verdeutlichen diesen redundanten Sprachgebrauch besonders.

393 Auch Granovetter (1973: 1360) spricht von "the strength of dyadic ties".

394 Deswegen macht es auch keinen Sinn, hinsichtlich von lediglich bilateralen Kontexten von "relationalem Kapital" zu sprechen (vgl. Kale et al. 2000) und damit noch einen weiteren Ausdruck in die Debatte zu werfen.

${ }^{395}$ Und falls doch, dann könnte ich sie in Folge eigener Erfahrungen umgehend falsifizieren.
} 
Zimmernachbarn vage und missverständlich; es kann keineswegs der komplette Mensch sein, der als Ressource fungiert, sondern allenfalls spezifische Eigenschaften oder Fähigkeiten desselben (und diese Präzisierung muss in einer wissenschaftlichen Debatte schon eingefordert werden).

Damit sind weder ein Beziehungsnetz noch eine Beziehungsrelation als Sozialkapital auszuweisen, und ein Beziehungsnetz kann darüber hinaus auch kein notwendiges Element der Begriffs-Intension sein. Ferner erscheint mir eine Spezifizierung dessen angezeigt, was genau unter "Ressourcen" zu verstehen ist. Es handelt sich nämlich um Ressourcen, die mindestens ein Akteur (von mir innerhalb der strukturalistischen Betrachtungsweise "Teilnehmer" genannt, um ihn von dem fokalen Akteur zu unterscheiden) einem anderen zur Verfügung stellt. Dabei können dies so unterschiedliche Entitäten sein wie Informationen, Empfehlungen oder Geld. Wollen wir aber bspw. einen Geldbetrag, den A seinem Freund B überlässt, damit dieser seine monetären Verbindlichkeiten begleichen kann, als Sozialkapital ansehen? Das erscheint äußerst kontraintuitiv. Die Beziehungsrelation ist aber - wie gezeigt - auch kein geeigneter Kandidat für die Zuschreibung eines Ressourcenstatus. Insofern es gerade um die Zur-VerfügungStellung von etwas für jemanden geht, insofern also gerade der Vermittlungsaspekt in den Vordergrund rückt, sollte man aus Gründen der Präzision von einer "Gutschrift" (Gut) (die in gewisser Weise als eine Metaressource aufzufassen ist, die auf eine konkrete Handlungsressource verweist) reden. Diese Formulierung weist drei Vorzüge auf:

a) sie gewährleistet den Einbezug des Ressourcenaspekts (denn etwas wird ja gutgeschrieben; die gutgeschriebene Ressource ist aber kein Sozialkapital),

b) sie berücksichtigt den Beziehungsaspekt (um etwas gut zu schreiben, bedarf es mindestens zweier miteinander verbundener Akteure; auch die Beziehungsrelation ist selbst kein Sozialkapital) und

c) sie impliziert eine auf die Zukunft gerichtete Zeitperspektive (die Gutschrift muss eingelöst werden); bei Einlösung erlischt die Gutschrift (i.d.R.) und das Sozialkapital wird im Anwendungsvorgang zunächst einmal verbraucht.

Mit dieser auf die Zukunft gerichteten Zeitperspektive wird insbesondere der Potential- bzw. Dispositionscharakter des Sozialkapitals hervorgehoben. "Genauso wie es ein wichtiger Aspekt der Eichel ist, zu einer Eiche heranwachsen zu können, ist es ein wichtiger Aspekt eines Elektrons, dass es die Möglichkeit hat, ungleiche Ladungen anzuziehen und abzustoßen oder Strahlung abzugegeben, wenn es beschleunigt wird." (Chalmers 2001: 175) Ein wichtiger Aspekt des Sozialkapitals ist es nun, dass es Akteure in die Lage versetzt, Erträge zu erwirtschaften, wenn sie es einsetzen; Sozialkapital ist u.a. das, was es ist, weil es genau dieses Potential in sich birgt.

An einer zentralen Stelle findet sich die Gutschrift-Perspektive explizit auch bei Coleman (1991: 396): Eine "Verpflichtung kann man als soziales Kapital, als 
eine 'Gutschrift' betrachten, die A besitzt und die von B mit irgendeiner Leistung eingelöst werden muss." Problematisch an dieser Colemanschen Festlegung ist gleichwohl die behauptete Identität von Verpflichtung, Sozialkapital und Gutschrift. Bei einer Verpflichtung kann es sich nur um ein Entstehungskriterium von Sozialkapital handeln (vgl. meine Kritik in Kapitel 7.2.). Wenn nämlich über alle Konzepte hinweg hinsichtlich des Sozialkapitals von zweckdienlichen Ressourcen die Rede ist, dann fällt eine Verpflichtung nicht unter diese Festsetzung: Was nützt die Verpflichtung, die A gegenüber B verspürt, wenn A hinsichtlich eines konkreten Interesses seitens Bs über keinerlei funktionale Ressourcen verfügt? Besitzt A jedoch solche Ressourcen, dann ist nicht die Verpflichtung, sondern die Gutschrift das, was B potentiell bzw. (bei Einlösung) tatsächlich zu seiner Interessenverwirklichung dienlich ist.

Was aber, wenn eine Gutschrift unabsichtlich zur Verfügung gestellt wird, wenn sich also etwa $A$ gegenüber $B$ über $C$ äußert und $B$ dem $C$ gerade wegen dieser Äußerung eine Arbeitsstelle anbietet (die C auch möchte, womit die Gutschrift zunächst als funktional zu kennzeichnen ist), ohne dass dies von A bewusst intendiert wird? Sollte man dann trotzdem von "Sozialkapital" sprechen? Immerhin fehlt hier das interaktive Moment, das etwa Weber (1980: 11) als für soziales Handeln grundlegend ansieht: "Nicht jede Art von Berührung von Menschen ist sozialen Charakters, sondern nur ein sinnhaft am Verhalten des Anderen orientiertes eigenes Verhalten. Ein Zusammenprall zweier Radfahrer z.B. ist ein bloßes Ereignis wie ein Naturgeschehen. Wohl aber wäre ihr Versuch, dem anderen auszuweichen und die auf den Zusammenprall folgende Schimpferei, Prügelei oder friedliche Erörterung soziales Handeln."

Hinter dieser Aussage steht Webers Konzept der Zweckrationalität, das kennzeichnend für sinnhaftes Verhalten sein soll. Zweckrational kann man natürlich nur dann agieren, wenn man etwas mit Absicht tut. Dies scheint im genannten Beispiel nicht der Fall zu sein (das Verhalten As mag zweckrational gewesen sein; nicht aber in Bezug auf die dann eingetretenen Konsequenzen für C). Auf dem Hintergrund der oben entwickelten Definitionskriterien müsste man dennoch das Vorliegen von Sozialkapital attestieren. Sollte man nun also diese Kriterien verändern?

Ich meine nein. Ein Handeln sollte "sozial" genannt werden, wenn es Wirkungen auf andere hat, also selbst dann, wenn es in seinem Ablauf nicht auf diese anderen hin orientiert war. Ob eine kooperative Unterstützung bewusst oder als nicht-intendiertes Resultat einer Handlung erfolgt, ist damit für Sozialkapital irrelevant. Gleichwohl wäre es sicherlich wenig sinnvoll, von Sozialkapital zu sprechen, wenn A im obigen Beispiel C überhaupt nicht kennt, denn dann würde das Konstitutionskriterium einer Beziehungsrelation fehlen.

Sozialkapital sollte auch nicht davon abhängig sein, ob unser Akteur C um das Vorhandensein einer entsprechenden Gutschrift weiß. Er muss im Zweifelsfall noch nicht einmal eine Ahnung davon haben, dass ihm Sozialkapital zur Errei- 
chung seiner Zielsetzung verholfen hat. Wieviele Menschen sind (nicht zuletzt zum Schutz ihres Selbstwertgefühles) fest davon überzeugt, ihre berufliche Position fachlicher Kompetenz und eigener Leistung zu verdanken, obgleich ein Empfehlungsschreiben ursächlich war?

Als weitere zu klärende Variante ließe sich in diesem Zusammenhang eine Situation vorstellen, in der sich A gegenüber B abfällig hinsichtlich $\mathrm{C}$ äußert und gerade deswegen $\mathrm{B}$ dem $\mathrm{C}$ eine Arbeitsstelle anbietet. Es scheint kontraintuitiv zu sein, von Sozialkapital zu sprechen, wenn A willentlich C schaden wollte. Da sich Sozialkapital aber von seiner Funktion her bestimmt, müsste es eigentlich irrelevant sein, ob eine positive Kooperationsabsicht zugrunde liegt oder nicht. Allerdings findet sich bei keinem der untersuchten Autoren die Vorstellung, Sozialkapital könne auch Ergebnis einer antagonistischen Haltung sein. Insofern sollte in einem solchen Fall auch der Sozialkapitalbegriff vermieden werden. Damit ist aber die begriffliche Definition um den Aspekt der positiven Kooperationshaltung zu ergänzen bzw. zu präzisieren ${ }^{396}$. In Anlehnung an Bourdieu spreche ich diesbezüglich von "gegenseitigem Kennen und Anerkennen", wobei mit "Anerkennung" der genannte Aspekt erfasst werden soll.

Nach diesen Modifikationen - also Eliminierung von B, Substitution von $\mathrm{R}$ durch Gut sowie Einführung von GK lautet die definitorische key idea des Sozialkapitals (wobei "SI" im Folgenden für "Sozialkapitalbegriff in integrativer Perspektive" stehen soll):

$S^{I}$ :

$\langle A$ x Te x Rel x Gut x GK x Inf x Fun x Ert〉

Um von "Sozialkapital" sprechen zu können, bedarf es demnach notwendig

(1) eines Akteurs (A), dem Sozialkapital zugeordnet werden kann,

(2) mindestens eines weiteren Akteurs bzw. Teilnehmers (Te),

(3) einer Beziehungsrelation (Rel) zwischen einem Akteur und mindestens einem Teilnehmer,

(4) mindestens einer Gutschrift (Gut) über Ressourcen (R), die dem Akteur durch mindestens einen Teilnehmer (tatsächlich oder potentiell) zur Verfügung gestellt wird,

(5) einer positiven Kooperationshaltung, worunter hier ein gegenseitiges Kennen und Anerkennen (GK) zwischen Teilnehmer und Akteur verstanden wird (dies lässt unberücksichtigt, ob eine konkrete Unterstützungsleistung nun intentional oder nicht-intentional erfolgt),

(6) der Informalität (Inf) der Beziehungsrelation zwischen Teilnehmer und Akteur mit Blick auf die (tatsächlich oder potentiell) zur Verfügung gestellte Gutschrift sowie

\footnotetext{
396 Bei Paxton (1999: 93) heißt es in ähnlicher Weise, um von "Sozialkapital" sprechen zu können, müsse eine Beziehung "positive emotion" beinhalten.
} 
(7) der Funktionalität (Fun) der Gutschrift, d.h. der Akteur erwirtschaftet einen Ertrag (Ert), weil ihm die Gutschrift zur Verfügung gestellt wird, bzw. der Akteur könnte einen Ertrag erwirtschaften, würde ihm die Gutschrift zur Verfügung gestellt.

Bei den angeführten sieben Punkten handelt es sich um die Angabe der Regeln, die den Ausdruck zu einem Begriff machen. M.a.W.: Unter "Sozialkapital" sollen funktionale (Fun), nicht-justiziable (Inf) Gutschriften (Gut) über Ressourcen (R) anderer Akteure $(\mathrm{Te})$ verstanden werden, auf die Ego (A) dank seiner Beziehungen (Rel) zu diesen anderen Akteuren sowie deren positiver Kooperationshaltung (GK) absichtlich oder unabsichtlich mit dem Ergebnis einer Erwirtschaftung eines Ertrages (Ert) aktuellen Zugriff nimmt bzw. potentiell Zugriff nehmen könnte. Die Begriffs-Extension - also gewissermaßen die Liste, auf der alle Gegenstände verzeichnet sind, die den regelhaften intensionalen Bestimmungen genügen - kann dann Gutschriften über Ressourcen wie bspw. eine Information hinsichtlich einer günstigen Wohnung, eine Bereitstellung finanzieller Mittel zum Abtrag einer fälligen Hypothek, eine öffentliche Belobigung zur Erhöhung sozialer Reputation, Orientierungsangebote für eine als sinnhaft empfundene Lebensführung ${ }^{397}$, eine entspannungsfördernde Rückenmassage etc. umfassen ${ }^{398}$.

Die Einführung des intensionalen Eigenschaftsmerkmals "Ertrag" macht abschließend noch eine Präzisierung dessen, was mit "Funktionalität" gemeint ist, notwendig. Zumeist wird hierüber von den untersuchten Autoren auf die Realisierung einer Zielsetzung durch den Einsatz von Sozialkapital verwiesen. Wollte man daran festhalten, dann müsste man in Kauf nehmen, dass ein Akteur vor dem Einsatz von Sozialkapital schon Ziele formuliert hat. Davon kann wohl keineswegs generell die Rede sein. Vielmehr profitieren Menschen häufig von Sozialkapital, ohne irgendetwas bewusst angestrebt zu haben.

Insofern soll hier nicht von Ziel- oder Interessenverwirklichung, sondern in einem kapitaltheoretischen Sinne ganz allgemein von einem Ertrag (Ert) gesprochen werden; Sozialkapital ist funktional, weil hierüber ein Ertrag erwirtschaftet wird. Auf das Tautologieproblem, das durch das Festhalten am Funktionalitätskriterium vermeintlich entsteht, wird weiter unten noch ausführlich eingegangen (vgl.

\footnotetext{
397 Diese Überlegung verdanke ich Stecher (2001: 43), der als Pädagoge darauf hinweist, "dass unter sozialisationstheoretischen Gesichtspunkten auch 'Sinn' - .. - zu den austauschbaren Gütern zwischen Eltern und Kindern zu rechnen ist."

398 Natürlich ließe sich einwenden, es bestehe ein großer Unterschied darin, ob man einem Ortsfremden den Weg zum Bahnhof erklärt oder ob man über eine bestimmte Äußerung bewusst und nachhaltig das Selbstwertgefühl einer nahestehenden Person stärkt. In beiden Fällen handelt es sich jedoch um Sozialkapital darstellende Gutschriften - ihr Wert dürfte jedoch stark differieren. An dieser Stelle ist dies jedoch unerheblich. Die vorgeschlagene Definition ist natürlich offen für Änderungen. Sollte man bspw. einen bestimmten Gegenstand zunächst intuitiv als Sozialkapital einstufen, obgleich dieser zumindest eines der intensionalen Merkmale nicht erfüllt (etwa GK), dann wäre zu diskutieren, ob man die Definition verändert, so dass auch dieser Gegenstand unter den Begriff fallen kann.
} 
die Ausführungen unter Wirkung). Zunächst führt uns der Hinweis auf einen erwirtschafteten Ertrag aber direkt zu der Frage, mit welcher Berechtigung hier überhaupt von "Kapital" die Rede sein darf ${ }^{399}$.

Kapitalproblematik. Dieser Frage liegt implizit das sprachphilosophische Kompositionalitätsprinzip zugrunde, wonach man zwecks Bedeutungsanalyse die Begriffe "sozial" und "Kapital" gewissermaßen aufaddieren muss. So betrachtet ließen sich "sozial" und "Kapital" als nicht T-theoretische Terme begreifen, d.h. zu ihrer Bestimmung müsste man auf andere Theorien bzw. auf die in einer Sprachgemeinschaft geltenden Gebrauchsregeln rekurrieren. Bisher hatte ich aber "Sozialkapital" als T-theoretischen Term gekennzeichnet, insofern es sich dabei um einen relativ jungen, erst seit ca. 15 Jahren in der Wissenschaft nennenswert verbreiteten und in der Umgangssprache gar nicht bzw. allenfalls sporadisch vorkommenden Begriff handelt. Andererseits wurde der Ausdruck von den untersuchten Autoren vor allem deshalb eingeführt, weil man glaubte, eine spezifische, bisher nicht beachtete Kapitalform entdeckt zu haben, d.h. man bezog sich dezidiert auf die wirtschaftswissenschaftliche und umgangssprachliche Verwendungsweise von "Kapital".

Hatte ich in Zusammenhang mit der Rekonstruktion verschiedener Sozialkapitalkonzepte also auf Grundlage des sprachphilosophischen Kontextprinzips (sozusagen von innen) gefragt, welche Bedeutung "Sozialkapital" von den jeweiligen Autoren zugewiesen wurde, möchte ich nun die Bedeutungsproblematik einmal aus der Perspektive des Kompositionalitätsprinzips betrachten: Ist es wirklich schlüssig - und das meint unter Zugrundelegung anerkannter Gebrauchsregeln statthaft - hinsichtlich der Gegenstände, die soeben über den Sozialkapitalbegriff systematisiert wurden, von "Kapital" zu sprechen?

Angenommen, eine Antwort auf diese Frage fiele negativ aus, dann bezeichnete "Sozialkapital" natürlich trotzdem etwas; "Kapital" würde qua Gebrauch eine weitere Bedeutung hinzugefügt, wenngleich mit Blick auf die übliche Begriffsverwendung von einem inkorrekten Sprachgebrauch die Rede sein müsste. Eine solche Perspektive grenzt sich grundsätzlich von einem essentialistischen Begriffsverständnis ab, bei dem lediglich eine einzige und zeitlos "richtige" Verwendung von "Kapital" propagiert wird, an der dann das Vorkommen des Begriffs in unterschiedlichen sprachlichen Kontexten zu messen ist.

Im Folgenden werde ich argumentieren, dass das Verständnis von "Kapital" in "Sozialkapital" den derzeitigen Gebrauchsregeln des Kapitalbegriffs in ausreichendem Maße entspricht, um als eine "korrekte" Anwendung klassifiziert werden

\footnotetext{
399 Von Hanifan (1920: 78) wird der Sozialkapitalbegriff in einem lediglich metaphorischen Sinne zuerst eingeführt: "In the use of the phrase 'social capital' no reference here is made to the actual acception of the term 'capital', except in a figurative sense. We not refer to real estate or to personal property or to cash, but rather to that in life which tends to make those tangible substances count most in the daily lives of people: namely good will, fellowship, sympathy, and social intercourse among individuals and families who make up a social unit."
} 
zu können. Zugleich plädiere ich jedoch für einige speziell auf "Sozialkapital" zugeschnittene, nuancierte Erweiterungen des zulässigen Gebrauchs; ich erachte also - mit Wittgenstein gesprochen - die Einführung weiterer Sprachspiele als sinnvoll. Da sich Sprache als soziale Entität permanent verändert, ist dies keineswegs ungewöhnlich - die Humankapitaltheoretiker haben vor einigen Jahrzehnten Analoges gemacht. Es ist die Sprachgemeinschaft (sei es in der Wissenschaft, im Alltag oder in beiden Bereichen), die letztlich darüber entscheidet, ob sich neue Vorschläge für Definitionen und Sprachspiele auch durchsetzen.

Der Kapitalbegriff führt in "Sozialkapital" zu einer Spezifikation dessen, was ansonsten lediglich als "soziale Ressourcen" bezeichnet wurde, indem er - so nüchtern das auch klingen mag - diese unter besonderen Aspekten systematisiert und so zu einer "Ökonomie sozialer Beziehungen" beiträgt: "calling attention to investments rates of return, opportunity costs, the future, investing and divesting, discounting, portfolio's of various types of capital, substitution, and the ability to appropriate the returns from investments." (Flap 2002: 17; hierzu ähnlich auch Lin/Fu/Hsung 2001: 61, Coleman 1991: 402 oder Bourdieu 1992: 51f.)

Claus Offe (1999: 116ff.) spricht sich jedoch gegen die Verwendung des Kapitalbegriffs in "Sozialkapital" aus und schlägt stattdessen die Bezeichnung "Sozialvermögen" vor. Der Kapitalbegriff zeichne sich nämlich durch mindestens vier Bestimmungsmerkmale aus: a) Kapital habe einen rechtlich-kodifizierten Eigentümer, b) durch Kapital ließen sich Erträge erwirtschaften, womit c) Eigentümer in Kapital investierten, um Profite zu realisieren, sowie d) Kapital verbrauche sich im Prozess seiner Anwendung und verliere an Wert. Bei dem, was in den Wissenschaften als "Sozialkapital" bezeichnet werde, sei all dies nicht gegeben: a) Sozialkapital habe keine Eigentümer und weise daher auch keine justiziablen Eigentumsrechte auf, b) über Sozialkapital könnten keine in eine monetäre Form transferierbaren Erträge erwirtschaftet werden, c) Sozialkapital lägen keine intentionalen Investitionsentscheidungen zugrunde, sowie d) der Wert von Sozialkapital vermindere sich nicht durch Gebrauch (was bei Sachkapital jedoch der Fall sei).

Offe steht mit dieser kritischen Haltung an der Seite namhafter Ökonomen, die im vorliegenden Kontext ebenfalls die Angemessenheit der Rede von sozialem "Kapital" anzweifeln. Bspw. beinhaltet "Kapital" für Kenneth J. Arrow (1999: 4) drei grundlegende Aspekte: "a) extension in time; b) deliberate sacrifice in the present for future benefits; and c) alienability. (...) It is especially b) that fails" (hinsichtlich von sozialem Kapital). Nach Robert M. Solow (1999: 7) is "any stock of capital (...) a cumulation of past flows of investment, with past flows of depreciation netted out. What are those past investments in social capital?"

Die von Offe, Arrow und Solow hier vorgebrachten Einwände sind jedoch lediglich mit Blick auf ein in Anlehnung an Putnam formuliertes Begriffsverständ- 
nis berechtigt ${ }^{400}$. Eben ein solches vertritt Offe (1999: 116), wenn er etwa von "unter dem Begriff des Sozialkapitals zusammengefaßten zivilgesellschaftlichen Tugenden" spricht bzw. unter "Sozialkapital" "Eigenschaften von ganzen Gesellschaften oder (regionalen, religiösen usw.) Teilgesellschaften" begreift (ebenda 117; vgl. zur Orientierung Offes an Putnam insbesondere auch Offe/Fuchs 2001). Arrow und Solow, die in ihren Äußerungen insbesondere den Investitionsaspekt in den Blick nehmen, beziehen sich in ihrer Kritik ebenfalls auf Putnam (bzw. den im Grundsatz ähnlich argumentierenden, makrotheoretisch orientierten Fukuyama). Ihr Augenmerk gilt "the way a society's institutions and shared attitudes interact with the way its economy works" (Solow 1999: 6); und in diesem Kontext ist der Kapitalbegriff in "Sozialkapital" tatsächlich "a metaphor that misleads" (Fischer zitiert nach Quibria 2003: 7, Fußn. 10).

Das hier vorgeschlagene integrative Theoriemodell wendet sich nun aber in weiten Teilen gerade gegen den von Putnam vertretenen Ansatz: Sozialkapital besitzt hier einen Eigentümer, steht also in der Verfügungsgewalt eines Akteurs (vgl. die Ausführungen unter Lokalisierung ${ }^{401}$ ), Erträge lassen sich erwirtschaften sowie über die Zeit hinweg akkumulieren (vgl. die Ausführungen unter Wirkung) und es kann (muss aber keinesfalls) Ergebnis bewusster, auf die Zukunft gerichteter Investitionsentscheidungen sein (vgl. die Ausführungen unter Entstehung).

Gleichwohl ist es in der Tat nur schwer monetär zu tarifieren, es ist nicht beliebig einsetz- und übertragbar (geringe Fungibilität), es vermindert sich nicht grundsätzlich durch Gebrauch (aber eben doch oft: wenn A eine Verpflichtung B gegenüber einlöst, dann wird dabei Sozialkapital vielfach aufgebraucht; je flüchtiger die Beziehung, desto weniger wahrscheinlich wird reziprozisiert), und die Eigentumsrechte sind nicht juristisch einklagbar. Wenn Offe behauptet, Sachkapital verliere im Verlauf seiner Anwendung an Wert - wie es sich etwa bei güterproduzierenden Maschinen in Abschreibungen dokumentiere - dann könnte er mit diesem Hinweis genauso gut den Kapitalbegriff im Zusammenhang mit Geld verwerfen ${ }^{402}$. Keineswegs verliert dieses bei Gebrauch an Wert; wäre dem so, dann würde das rege Treiben an den Börsen kaum erklärbar sein.

Sozialkapital ist jedoch tatsächlich keine rechtlich-kodifizierte Eigentumsform, d.h. unter anderem die Informalität einer Beziehungsrelation mit Blick auf eine bestimmte Gutschrift indiziert, ob es sich bei dieser Gutschrift überhaupt um Sozialkapital handelt. Ferner bedarf es zu seiner Herstellung nicht zwingend einer bewussten Investition und ein Ertrag kann ebenfalls zustandekommen, ohne aktiv

\footnotetext{
400 Und Putnam (2002: 258) behauptet: "Soziales Kapital ist in jedem Fall auch eine Analogiebildung $\mathrm{zu}$ anderen Formen von Kapital."

401 Es ist mit Bezug auf die Kapitalproblematik tatsächlich - wie Waldstrom (2003: 4) in einem organisationstheoretischen Zusammenhang behauptet - "a fundamental question ... whether social capital resides in actors or in the relations between them".

402 Außerdem könnte man durchaus davon sprechen, Sozialkapital unterliege "immer dann einer Abschreibungsrate ..., wenn Vertrauensbeziehungen nicht erneuert werden, Reziprozitätsnormen nicht angewendet werden" (Schechler 2002: 67).
} 
darauf hingewirkt zu haben. Die beiden letztgenannten Einwände treffen aber auch auf Human- und Finanzkapital zu.

Humankapital kann teilweise angeboren sein oder es entsteht beiläufig (wer hat nicht einmal im Geschichtsunterricht ein klein wenig von der Lektüre des ein oder anderen Asterix-Comics profitiert), sein Ertrag (etwa die Lösung eines intellektuellen Problems) resultiert wohl nur in den seltensten Fällen aus einem bewussten Kapitaleinsatz (vielmehr hat man eben einfach nachgedacht). Wenn ein junger Erwachsener sich den Bausparvertrag auszahlen lässt, den seine Eltern für ihn unmittelbar nach seiner Geburt abgeschlossen haben, dann kann weder von einer vorangehenden Investition des Kapitaleigners, noch von einem bewusst von ihm angestrebten Ertrag die Rede sein.

Der Aspekt der informellen Eigentümerschaft des Sozialkapitals sollte alleine keinen ausreichenden Grund darstellen, den Kapitalbegriff im vorliegenden Zusammenhang zu verwerfen, verhilft dieser doch analytisch dazu, die Aufmerksamkeit des Forschers auf das zu lenken, was den Produktionsfaktor Kapital in einer kapitaltheoretischen Diktion in basaler Weise auszeichnet: die tatsächliche oder zumindest potenzielle Realisierung eines individuellen bzw. akteurstypischen Nutzens dank des Einsatzes zur Verfügung stehender (Wettbewerbs-) Mittel und zu diesen Mitteln zählen u.a. Werkzeuge bei physischem Kapital, intellektuelle Fähigkeiten bei Humankapital oder aus sozialen Beziehungen emergierende Gutschriften über relevante Informationen bei Sozialkapital.

Ist Sozialkapital Ergebnis einer Investition, dann kann es sich bei dieser nicht nur um den Einsatz von Finanz-, Human- oder physischem, sondern durchaus auch von Sozialkapital selbst handeln: Ob man einen Geldbetrag, handwerkliche Fertigkeiten, einen Gebrauchsgegenstand oder aber über Beziehungen realisierbares Insider-Wissen zur Verfügung stellt, um auf die Entstehung von Sozialkapital hinzuwirken, ist letztlich abhängig davon, welche Ressourcen für andere attraktiv erscheinen, aber vom Investor kontrolliert werden; es ist also abhängig von einer konkreten Knappheit.

Wenn Eingangs dieses Kapitels unter Bezugnahme auf Alejandro Portes gefragt wurde, ob über "Sozialkapital" doch nur die insbesondere schon bei Durkheim und Marx zu findende Einsicht, dass aus Beziehungen nützliche Ressourcen erwachsen, "in a more appealing conceptual garb" präsentiert wird (Portes 1998: 21), dann kann dies nun beantwortet werden. Die Innovation hinsichtlich der schon bei den soziologischen Klassikern (und im Übrigen selbstverständlich auch beim Alltagsmenschen) vorfindbaren Einsicht besteht darin, dass man die aus Beziehungen resultierenden nützlichen Ressourcen unter kapitaltheoretischen Aspekten betrachtet.

Aus erkenntnistheoretischer Sicht kann hier auf die im Grundlagenteil dieser Arbeit ausführlich diskutierte sprachliche Struktur menschlicher Erfahrung hingewiesen werden. In Abhängigkeit von den uns zur Verfügung stehenden konzeptuellen Schemata wird das, was wir in der Realität identifizieren, eine für 
uns andere Form annehmen, die dann auch unser Handeln affiziert. Eine über das Erkenntniskonstrukt "Sozialkapital" eingeführte kapitaltheoretische Perspektive hinsichtlich der aus Beziehungen resultierenden Vorteile für das Individuum richtet unsere bewussten Erfahrungsprozesse auf:

den Preis, den Unterstützung vielfach hat,

die Akkumulation von Sozialkapital, d.h. (gewissermaßen) die Anhäufung ausstehender Unterstützungsleistungen,

Investitionen in soziale Beziehungen zwecks Bezug von Unterstützungsleistungen ${ }^{403}$,

die effiziente Gestaltung solcher Investitionen,

die Erträge, die man dank seiner Investitionen erzielt bzw. erzielen kann und damit auch die Abschöpfung eines über den Einsatz von Sozialkapital erzielten Mehrwertes,

die Bedingungen, unter denen sich Erträge ohne Investitionen erwirtschaften lassen,

soziale Ressourcen interpretiert als Faktor innerhalb des biophysischen wie sozialen Produktionsprozesses ${ }^{404}$,

die Wettbewerbsvorteile (und die Macht) die man über ein "Mehr" an Sozialkapital auf verschiedenen Märkten (u.a. Arbeitsmarkt, Bildungsmarkt, Heirats- bzw. Partnerschaftsmarkt) erzielen kann,

die Konvertierbarkeit von Sozial- in Human-, Finanz- oder physisches Kapital (und vice versa).

Im Anschluss ließe sich nun genauso diskutieren, ob "sozial" in "Sozialkapital" konventionellen Gebrauchsregeln genügt. Auch hierauf möchte ich zum Ende dieser definitorischen Betrachtungen wenigstens kurz eingehen, "denn das Wort 'sozial' hat", wie Durkheim (1999: 107) in seinen "Regeln der soziologischen Methode" betont, "einen bestimmten Sinn einzig unter der Voraussetzung, daß

403 Mit dem "Tabu der Berechnung" (Bourdieu 2005: 150) bei sozialem Austausch und Gabe ist damit gebrochen. Natürlich mutet es zunächst zynisch an, wenn es heißt, wir betrachteten unsere Sozialkontakte wie Wertanlagen. Dennoch aber tun wir dies mitunter. In einem ManagementRatgeber zum Thema "Richtig Verhandeln" ist von der "Gewohnheit" bzw. vom "Automatismus sich zu revanchieren" die Rede, der, wenn er bewusst beachtet würde, eines der "wirksamsten Instrumente zur Beeinflussung" anderer Menschen darstelle. "Infolge dieser Gewohnheit sind wir geradezu verpflichtet, einen Gefallen, ein Geschenk, eine Einladung oder ähnliches zu erwidern." Ganz so einfach scheint es aber dann doch nicht zu sein, denn: "Geschenk ist nicht gleich Geschenk. Wenn man als Kunde zum zehnten Mal ein Feuerzeug erhalten hat, verliert das Geschenk an Bedeutung." (Neubarth 1996: 19)

404 Insbesondere hierüber wird die Rational-Choice-Orientierung des Sozialkapitalverständnisses betont, denn auch bei der Verwendung von Sozialkapital geht es um die "gelingende Reproduktion des Organismus ... . Diese Variable kann auch als Nutzen bezeichnet werden. Handeln ist demnach im Prinzip eine Produktion von Nutzen. Und die Effizienz dieser Produktion ist davon abhängig, wie wirksam die Mittel dafür sind, die die Akteure einsetzen (können)." (Esser 1996a: 6) 
lediglich die Erscheinungen damit benannt werden, die in keine andere schon bestehende Kategorie fallen." Bei Robinson (2002a: 6), dessen Begriffsverständnis dem Putnamschen zumindest ähnelt, wird bspw. "sozial" in die beiden Dimensionen "kollektive Zuschreibung / Eigentümerschaft" und "wechselseitiger Nutzen" unterteilt: "In social capital, these two meanings are brought together to indicate both the form of the capital (that it belongs to a collective) and an underlying value base (for the mutual benefit of that particular group or society)."

Innerhalb des hier vorgeschlagenen Theoriemodells meint "sozial" in "Sozialkapital", dass dieses Kapital durch die Beziehungen, die ein individueller oder kollektiver Akteur mit anderen unterhält, vermittelt bzw. realisiert wird. Zunächst handelt es sich um Ressourcen anderer, die einem Akteur in Folge seiner Verbindungen $\mathrm{zu}$ diesen anderen im Sinne von Gutschriften zur Verfügung stehen. Diese Gutschriften sind der Gewinn, den die Akteure aus ihren Beziehungen herausziehen (können) und die deshalb (sowie mit Blick auf ihren Ertragsaspekt) "Sozialkapital" genannt werden sollen. Der Begriff "sozial" kennzeichnet insbesondere auch die spezifische Art der Erreichbarkeit bzw. Allokation dieser Kapitalform: gegenseitiges Kennen und Anerkennen und nicht bloß Kontakt ist notwendig 405 .

\section{Ebene}

In einem integrativen Theoriemodell ist Sozialkapital individuellen wie kollektiven Akteuren zuzuordnen (vgl. die Ausführungen unter Lokalisierung). Insofern findet es sich in jedem Falle auf der Mikro- und der Mesoebene. Behauptet man nun den Kapitalcharakter des Sozialkapitals, dann muss es sich ganz grundsätzlich auch auf der Makroebene finden lassen. Staaten verfügen etwa über einen finanziellen Kapitalbestand sowie Anlagenkapital. In dieser Perspektive nutzt der Staat das ihm zur Verfügung stehende Kapital als Ressource.

Sozialkapital auf der Meso- und Makroebene bezeichnet die Zuordnung dieser Kapitalart zu einem kollektiven Akteur. Die Sozialwissenschaften können aus analytischen wie pragmatischen Gründen heraus gar nicht anders, als auch auf kollektiver Ebene einen Akteursstatus zuzuschreiben, denn nur so "läßt sich die Komplexität vieler Vorgänge auf ein noch zu bearbeitendes Maß reduzieren"406

\footnotetext{
405 Diese Verständnisweise dürfte m.E. weder sozialwissenschaftlich noch alltagsweltlich besonders strittig sein; indes wird sie an dieser Stelle explizit offengelegt, weil sie so im Sinne des Rationalitätspostulats einer begrifflichen Kritik unmittelbar zugänglich wird. Grundsätzlich ist darauf zu verweisen, dass jede Form von Kapital Teil der institutionellen Realität ist und insofern "sozial" genannt werden kann (vgl. hierzu ausführlich auch Fine 2001). Ein normatives Verständnis von "sozial" - wie es etwa in Levis Artikel vom "unsocial capital" auftaucht (Levi 1996) -, entspricht zwar ebenso anerkannten Verwendungsweisen, ist aber analytisch bzw. explanativ im vorliegenden Kontext wenig brauchbar.

406 Zentral hinsichtlich der Zuschreibung eines Akteursstatus für kollektive Einheiten ist jedoch im Sinne des RC-Ansatzes, dass "für diese Einheiten eine spezifische und begründbare, über den
} 
(Mayntz/Scharpf 1995: 50). Die Problematik der Aggregation stellt sich hier damit gewissermaßen in entschärfter Form. Beantwortet werden muss lediglich, wie es von individuellem Sozialkapital zu dem von Gruppen (bzw. Organisationen) und Ländern (bzw. Regionen) kommen kann.

Hier sind unterschiedliche Aggregationsweisen denkbar. Wenn bspw. individuelle Akteure zweier Unternehmen geschäftlich miteinander kooperieren, dann wird in Folge von Typisierungs- bzw. Zurechnungsprozessen eine Verbindung zwischen den beteiligten Unternehmen etabliert. Diese kann dann wiederum Gruppensozialkapital nach sich ziehen (etwa wenn ein Mitarbeiter eines Heimwerkermarktes den Geschäftsführer eines Baugeschäftes auf eine öffentliche Ausschreibung aufmerksam macht). Einmal etabliertes Sozialkapital wird vielfach personenunabhängig mit sozialen Rollenträgern verknüpft sein, d.h. es wird vererbt (Transferierung). Im einfachsten Fall ist das Sozialkapital eines kollektiven Akteurs die Aufsummierung des mit Blick auf die Gruppeninteressen nützlichen Sozialkapitals seiner Individuen ${ }^{407}$ sowie des nicht personen-, sondern rollengebundenen Sozialkapitals der Organisation.

Für die Makroebene ergibt sich nun eine ganz andere Sichtweise als die von Putnam vorgeschlagene. Das Sozialkapital einer Sozietät kann nur aus den Beziehungen resultieren, die diese (im Sinne eines Akteurs) mit anderen pflegt. Dabei muss es sich bei den "anderen" keineswegs selbst um Sozietäten (wie etwa Länder oder Regionen) handeln. So unterhält etwa ein deutsches Bundesland Beziehungen mit Unternehmen, Schulen, Gewerkschaften, Sportvereinen und Bürgern (vor allem seinen eigenen). Sozialkapital gemäß der obigen Definition erwächst dem Bundesland nun, wenn es von jenen Akteuren, mit denen es in Verbindung steht, Gutschriften zur Verfügung gestellt bekommt. Dabei gilt aus definitorischen Gründen zu beachten, dass die Beziehungsrelationen mit Blick auf die Gutschrift informellen Charakter tragen müssen, damit von "Sozialkapital" die Rede sein darf. Persönliche Freundschaftsbeziehungen zwischen dem hessischen Ministerpräsidenten und einem ausländischen Investor können bspw. für die Entscheidung dieses Investors ausschlaggebend sein, in Hessen und nicht in einem anderen Bundesland eine Produktionsstätte zu errichten. Dies wäre ein Beispiel für Hessens Sozialkapital ${ }^{408}$.

Einzelfall hinausweisende Regel für die Logik der Selektion benennbar ist." (Esser/Troitzsch 1991: 19)

407 Wobei bei dieser Aufsummierung Doppelungen (A und B aus Gruppe X verfügen in Folge ihrer Verbindung zu D aus Gruppe Y über das "gleiche" Sozialkapital) in subtiler - hier nicht detailliert aufzuschlüsselnder - Weise zu berücksichtigen sind.

408 Wenn es einem in Hessen angesiedelten Unternehmer gelingt, einen befreundeten ausländischen Kollegen zur Errichtung einer Produktionsstätte in Hessen zu bewegen, dann profitiert zwar auch das Bundesland im Normalfall davon (etwa durch das zusätzliche Angebot an Arbeitsplätzen, höhere Steuereinnahmen, einer Verbesserung der Standortattraktivität etc.), aber es profitiert dank des Sozialkapitals des Unternehmers und nicht dank seines eigenen (m.a.W.: um das Sozialkapital Hessens würde es sich nur dann handeln, wenn das Individuum zugleich ein befugter Vertreter 


\section{Lokalisierung}

Bei Sozialkapital handelt es sich um eine einem individuellen oder kollektiven Akteur gehörende Gutschrift über eine Ressource. Sicherlich hängt die Verfügbarkeit von der Kooperationswilligkeit bzw. der positiven Kooperationshaltung des Akteurs ab, der eine Gutschrift potentiell bereitstellt. Daraus folgt aber keineswegs, Sozialkapital sei innerhalb von Beziehungsrelationen zu verorten. Angenommen A kontrolliert eine für B relevante Information, die er B übermitteln würde, wenn er um deren Relevanz für B wüsste bzw. wenn B ihn darum bäte. In einem solchen Fall ist das, was später eine Information darstellen wird, zunächst einmal lediglich ein Wissen As. Zu Sozialkapital kann es erst in dem Moment kommen, in dem A bereit ist, sein Wissen B mitzuteilen. Sobald also aus dem bloßen Wissen As eine Gutschrift über eine nützliche Information für B geworden ist, handelt es sich um Sozialkapital, das dann keineswegs der Beziehungsrelation innewohnt, sondern diese vielmehr zur Voraussetzung hat.

Wie soll man sich überhaupt vorstellen, dass eine Gutschrift oder eine Ressource zwischen Akteuren angesiedelt ist? Was auch immer zwischen Akteuren steht (insofern es nichts Materielles ist), steht dazwischen, weil Akteure (resp. die innerhalb kollektiver Akteure handelnden Personen) bestimmte Kognitionen prozessieren, d.h. dieses "Dazwischen" kann nur als eine Metapher begriffen werden. Die über "Sozialkapital" bezeichnete Gutschrift ist eine Gutschrift für den Akteur, der sie in Folge existenter sozialstruktureller Konfigurationen nutzen kann, auch wenn es mindestens zweier Beteiligter bedarf, um sie zu realisieren. Allenfalls lässt sich sagen, Sozialkapital werde niemals vom Eigentümer alleine kontrolliert oder verwaltet.

Das Problem um die Lokalisierung resultiert wohl nicht zuletzt auch aus der im Vergleich zu ökonomischem Kapital vermeintlich größeren Labilität des Sozialkapitals. Transaktionen weisen unsichere Zeithorizonte, unklare Verpflichtungs- und Erwartungsstrukturen auf. Hingegen scheinen die sich im Portemonnaie befindlichen Münzen ihrem Eigentümer zur Verfügung zu stehen, ohne dass dieser unmittelbar von anderen Akteuren abhängig wäre. Sozialkapital wird von anderen jedoch mit kontrolliert. Man ist unabdingbar auf Kooperation angewiesen; wird diese versagt - so die implizite Argumentation - kann Sozialkapital nicht zum Einsatz gelangen.

Natürlich steht es einer Partei offen, aus einem Beziehungsnetz auszusteigen oder zu defektieren, wodurch sich das Sozialkapital verflüchtigt. Sollte aber etwa eine Anlage in einen Hedge-Fond wirklich "sicherer" sein als die einem Individuum aus seiner Beziehung zu einem langjährigen Freund erwachsenden Gutschriften über Ressourcen? Und ist monetärer oder intellektueller Besitz nicht grundsätzlich ebenfalls abhängig von den Handlungen anderer, kann er ohne

Hessens wäre [was die Beziehung zu seinem ausländischen Kollegen natürlich noch nicht automatisch zu einer formellen macht]). 
interpersonelle Relationen zustandekommen oder genutzt werden? Wer so etwas ernsthaft behauptet, der muss sich dann konsequenterweise von einer austauschtheoretischen Perspektive im Zusammenhang mit Kapital - von der Vorstellung, Kapital drücke ein Besitzverhältnis aus - verabschieden ${ }^{409}$.

Sozialkapital ist im hier vorgelegten Verständnis auch keineswegs - wie Burt (1992: 9) behauptet - "a thing owned jointly by the parties to a relationship", denn es "funktioniert" immer nur in eine Richtung, d.h. das Sozialkapital, über das A aufgrund seiner Beziehung zu B verfügt, ist ein anderes, als das, welches B aufgrund seiner Beziehung zu A besitzt. Und die jeweils Sozialkapital darstellenden Gutschriften sind grundsätzlich Gutschriften für nur einen Akteur innerhalb der Beziehungsstruktur. Was für einen Sinn würde es machen, die Empfehlungen, die B bei einem potentiellen Arbeitgeber für A abgibt, nicht nur als Ausdruck von As, sondern auch von Bs Sozialkapital zu begreifen? Die Burtsche Vorstellung verstößt ganz elementar gegen grundsätzliche Gebrauchsregeln des Kapitalbegriffs $^{410}$.

Für das hier vorgeschlagene Sozialkapitalverständnis möchte ich die Frage nach dem Charakter des über "Sozialkapital" bezeichneten Gutes begrifflich anders als gemeinhin üblich formulieren. Sozialkapital wird von mir sowohl individuellen als auch kollektiven Akteuren zugesprochen. Insofern ist es grundsätzlich ein privates Gut, womit die Unterscheidung zwischen Privat- und Kollektiv- zu Gunsten einer Unterscheidung zwischen individuellem und kollektivem Gut aufgegeben wird. Wenn in der Literatur unter Bezug auf wirksame Normen - wie etwa die von Coleman angeführte nachbarschaftliche Aufsichtspflicht über spielende Kinder von einem Kollektivgut die Rede ist, so handelt es sich dabei in meiner Diktion um ein öffentliches bzw. ein Gemeingut.

Eine Klassifizierung von Sozialkapital als öffentliches Gut macht aber auf Basis der hier vorgeschlagenen Definition wenig Sinn. Ich möchte diese Position

409 M.E. überstrapaziert bspw. Hartmut Esser die Bedeutung der Kontrolle und argumentiert inkonsistent, wenn er behauptet, "die Kontrolle ist die - selbstverständliche - notwendige Bedingung dafür, daß bestimmte Ressourcen als Kapital ... fungieren können." (Esser 2000: 210) Das soll nun aber für Sozialkapital irgendwie so nicht mehr gelten. Individuen könnten Geld, Bildung, Geschmack, Rechte und Mitgliedschaft "verhältnismäßig autonom kontrollieren"; bei Sozialkapital sei dies aber "ganz anders" (ebenda: 235). Dann dürfte aber eigentlich gar keine Rede mehr davon sein, es handele sich um Kapital. Wahrscheinlich deswegen heißt es dann bei Esser auch später wieder, soziales Kapital werde doch vom einzelnen Akteur kontrolliert (vgl. ebenda: 260). Ferner formuliert Esser auf Basis seines Kapitalverständnisses (für das er auf allgemeiner Ebene überdies auch keine Referenzen anführt) eine Tautologie, insofern er, nachdem er Kontrolle implizit als ein zentrales Definitionskriterium von "Kapital" festgelegt hat, von "kontrollierte(m) Kapital" spricht (ebenda: 210) - würde es nicht kontrolliert, dann wäre es (im Esserschen Verständnis) ja gar kein Kapital.

410 Wenn man Sozialkapital als Beziehungen begreift, dann muss es in der Tat an alle an der Beziehung beteiligten Akteure zugewiesen werden. Beziehungen sind jedoch - wie oben schon argumentiert - per se keinesfalls nutzbringend, sondern nur dann, wenn aus ihnen Ressourcen emergieren, die der Zielverwirklichung dienen, d.h. es ist nicht sinnvoll, hinsichtlich von Beziehungen überhaupt von "Sozialkapital" zu reden. 
in Auseinandersetzung mit Hartmut Esser verdeutlichen. Sozialkapital sei "einerseits ... das, was ein individueller Akteur an seinen entfernten Bekannten oder seinen engeren Freunden hat, andererseits aber auch das, was das gesamte Netzwerk in seiner Struktur für alle darin eingeschlossenen Akteure leistet, beispielsweise die rasche Zirkulation von Informationen, wodurch die Einhaltung von Normen, etwa der Unterstützung eines Freundes in Not, in einem Kollektiv deutlich erleichtert wird" (Esser 2000: 240). Nun leistet das gesamte Netzwerk möglicherweise exakt das, was von Esser hier behauptet wird. Gleichwohl ist es grundsätzlich der einzelne Akteur, der bspw. von zirkulierenden Informationen profitiert - auch dann, wenn neben ihm alle weiteren Netzwerkteilnehmer üblicherweise Nutzen daraus ziehen. Möchte man nun aber genau diesen letzteren Aspekt betonen, so sollte man hierfür einen anderen Begriff wählen.

Tatsächlich tut dies Esser auch, wenn er von "Beziehungskapital" und "Systemkapital" spricht ${ }^{411}$ (ebenda: 241ff.). Vor dem Hintergrund bedeutungsheoretischer Überlegungen können diese Bezeichnungen aber wenig überzeugen, denn von "Kapital" darf nur dann die Rede sein, insofern die für den Akteur nützlichen Ressourcen im Fokus stehen - sei es, dass diese Ressourcen ursächlich auf die Beziehung zu engeren Freunden oder auf ein komplettes Netzwerk zurückzuführen sind ${ }^{412}$. Geht es hingegen um die begriffliche Bezeichnung eines dauerhaft verlässlichen kollektiven Hilfesystems bzw. von "Aspekte(n) einer übergreifenden 'Einstellung' der Akteure auf das jeweilige soziale System insgesamt" (ebenda: 241), also allgemein um aggregierte Größen, dann stehen bspw. mit "Solidarität", "Norm", "Moral" oder "Vertrauen" geeignetere und erprobte Ausdrücke zur Verfügung.

Bei Ablehnung einer Gemeingutperspektive fehlt es Sozialkapital auch an einer Spezifik, die ihm von Coleman und in dessen Nachfolge insbesondere von Putnam zugesprochen wird, nämlich dem "underinvestment" in Folge der Trittbrettfahrerproblematik. Da Sozialkapital im hier vorgeschlagenen Verständnis aber i.d.R. dem Akteur zufließt, der auch entsprechende Investitionen getätigt hat, verliert dieses Problem an Bedeutung ${ }^{413}$.

Will man mit dem Sozialkapitalbegriff hingegen insbesondere Probleme der Koordination kollektiven Handelns thematisieren und tauchen dabei Vokabeln wie "Vertrauen", "Netzwerke", "bürgerschaftliches Engagement" oder "Normen" auf - wie dies insbesondere bei Putnam oder Ostrom der Fall ist -, dann wird

411 Bei Warden/Tampubolon (2002) ist nahezu gleichlautend von "associational social capital" (ebenda: 163) und "interpersonal social capital" die Rede (ebenda: 177).

412 Wobei überdies diskutabel ist, wo denn nun die von Esser genannte Trennlinie (Beziehungen zwischen engen Freunden versus komplettes Netzwerk) genau verlaufen soll, denn immerhin konstituieren enge Beziehungen zwischen Freunden und Bekannten i.d.R. ein Netzwerk.

${ }^{413}$ Dies betrifft auch die vielfach geäußerte Behauptung, Sozialkapital verringere sich nicht durch Gebrauch, sondern steige dabei sogar an, unterliege also einer "negativen Abschreibung" (Haug 2000: 98). Im Rahmen eines Privatgutverständnisses ist hingegen auf Prinzipien der balancierten Reziprozität zu verweisen (Ein- und Auszahlungen halten sich die Waage). 
nicht nur den alltagssprachlichen und wissenschaftlichen Gebrauchsregeln des Kapitalbegriffs widersprochen, sondern "Sozialkapital" degeneriert zu einer Summenbezeichnung auf der Aggregatebene, welche lediglich methodologischen Wert besitzt (als Variablenindex; vgl. die diesbezüglichen Ausführungen in Kapitel 7.3.). So komplex die vor einem solchen thematischen Hintergrund angestellten Untersuchungen und so aufschlussreich wie problemrelevant die hierüber erzielten Ergebnisse sozialwissenschaftlich, politisch wie ökonomisch auch sein mögen, sie sollten auf einem anderen begrifflichen Inventar fußen ${ }^{414}$.

\section{Entstehung}

Eine synoptische Gegenüberstellung der in den untersuchten Sozialkapitalkonzepten behaupteten Entstehungszusammenhänge ergibt folgendes Aussehen:

\begin{tabular}{|c|c|c|}
\hline \multirow[t]{2}{*}{ Bourdieu: } & $\forall(t e, a)$, & $\left(\mathrm{V}[t e, a] \wedge \mathrm{R}[t e, a] \wedge \operatorname{Fun}[r, a, z] \rightarrow \mathrm{R}[t e, a]:=\mathrm{S}^{\mathrm{B}}[a]\right)$ \\
\hline & $\forall(t e, v, a)$ & $\left(\operatorname{Tr}[t e, v, a] \wedge \mathrm{R}[t e, a] \wedge \operatorname{Fun}[r, a, z] \rightarrow \mathrm{R}[t e, a]:=\mathrm{S}^{\mathrm{B}}[a]\right)$ \\
\hline \multirow[t]{2}{*}{ Coleman: } & $\forall(t e, a)$ & $\left(\mathrm{V}[t e, a] \wedge \mathrm{R}[t e, a] \wedge \operatorname{Fun}[r, a, z] \rightarrow \mathrm{R}[t e, a]:=\mathrm{S}^{\mathrm{C}}[a]\right)$ \\
\hline & $\forall(t e, v, a)$ & $\left(\operatorname{Tr}[t e, v, a] \wedge \mathrm{R}[t e, a] \wedge \operatorname{Fun}[r, a, z] \rightarrow \mathrm{R}[t e, a]:=\mathrm{S}^{C}[a]\right)$ \\
\hline \multirow[t]{3}{*}{ Putnam: } & $\forall($ net,nor,tru $)$ & 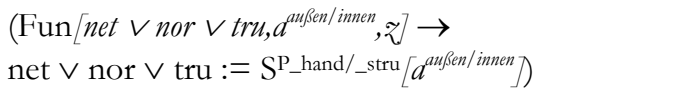 \\
\hline & $\exists\left(a^{\text {aupen }}, r\right)$ & $\left(\operatorname{Inv}\left[a^{\text {auf } \beta e n}, r\right] \rightarrow \mathrm{S}^{\mathrm{P}}\right.$ _hand/_stru $\left.\left[a^{\text {aufsen/innen }}\right]\right)$ \\
\hline & $\exists\left(a^{a u ß \beta e n}, r\right)$ & 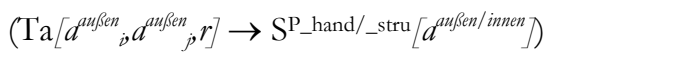 \\
\hline \multirow[t]{2}{*}{ Netzwerk.th:: } & $\forall(t e, a)$ & $\left(\mathrm{V}[t e, a] \wedge \mathrm{R}[t e, a] \wedge \mathrm{Z}[a, r] \rightarrow \mathrm{R}[t e, a]:=\mathrm{S}^{\mathrm{N}}[a]\right)$ \\
\hline & $\forall(t e, v, a)$ & $\left(\operatorname{Tr}[t e, v, a] \wedge \mathrm{R}[t e, a] \wedge \mathrm{Z}[a, r] \rightarrow \mathrm{R}[t e, a]:=\mathrm{S}^{\mathrm{N}}[a]\right)$ \\
\hline
\end{tabular}

Bei Bourdieu, Coleman und den Netzwerktheoretikern findet sich also zentral die Vorstellung, Sozialkapital entstehe: a) wenn ein Teilnehmer (ein Kooperationspartner) eine Verpflichtung gegenüber einem Akteur (dem Sozialkapital zugeordnet werden soll) verspürt und wenn dieser Teilnehmer über Ressourcen verfügt, die der Akteur funktional zu seiner Zielverwirklichung nutzen kann, oder: b) wenn ein Teilnehmer eine Verpflichtung, die er einem anderen gegenüber verspürt, auf

\footnotetext{
${ }^{414}$ Damit ist etwa deutlich: Eine Sozialstruktur, in der das Sozialkapital der beteiligten Individuen überwiegend reziprok bestimmbar ist (Bsp.: A nimmt Zugriff auf Ressourcen Bs [bzw. könnte Zugriff nehmen]; B nimmt Zugriff auf Ressourcen As oder [komplexer] A nimmt Zugriff auf Ressourcen Bs, C nimmt Zugriff auf Ressourcen As und D nimmt wiederum Zugriff auf Ressourcen Bs etc.), konstituiert kein Sozialkapital auf der Aggregatebene. Eine solche Sozialstruktur indiziert lediglich eine bestimmte Norm, die dafür sorgt, dass man auf die Ressourcen eines Akteurs Zugriff nehmen kann, ohne doch zuvor eine Vorleistung erbracht zu haben.
} 
unseren Akteur transferiert, wobei der Teilnehmer erneut über Ressourcen verfügen muss, die als funktional hinsichtlich der Zielverwirklichung des Akteurs gelten können. (Allerdings verzichten die Netzwerktheoretiker in beiden Fällen auf das Funktionalitätskriterium, da sie dessen Einführung als tautologisch erachten.) Diese Konzeption ist weitgehend kompatibel mit der oben entworfenen Definition von Sozialkapital und soll daher auch für das hier vorgeschlagene Theoriemodell übernommen werden, wobei allerdings der Ressourcenbegriff durch "Gutschrift" ersetzt wird.

Weitergehend lässt sich nun noch fragen, wie es denn zu einer Verpflichtung als Vorstufe der Entstehung von Sozialkapital kommt. Bei den untersuchten Autoren finden wir hierzu Folgendes:

$\begin{array}{lll}\text { Bourdieu: } & \exists(a, \ddot{o}, \text { rel }) & (\mathrm{Inv}[a, \ddot{o}, r e l] \rightarrow \mathrm{V}[t e, a]) \\ & \exists(a, t e, r) & (\mathrm{Ta}[a, t e, r] \rightarrow \mathrm{V}[t e, a]) \\ & & \\ \text { Coleman: } & \exists(a, g e f, r e l) & (\mathrm{Inv}[a, g e f, r e l] \rightarrow \mathrm{V}[t e, a]) \\ & \exists(a, t e, r) & (\mathrm{Ta}[a, t e, r] \rightarrow \mathrm{V}[t e, a])\end{array}$

Putnam: $\quad$ Keine Angaben ${ }^{415}$

\begin{tabular}{|c|c|c|}
\hline Netzwerkth.: & $\exists(a, r, r e l)$ & $(\mathrm{Inv}[a, r, r e l] \rightarrow \mathrm{V}[t e, a])$ \\
\hline & $\exists(a, t e, r)$ & $(\mathrm{Ta}[a, t e, r] \rightarrow \mathrm{V}[t e, a])$ \\
\hline
\end{tabular}

Erneut erhalten wir von Bourdieu, Coleman und den Netzwerktheoretikern damit weitgehend identische Antworten: Eine Verpflichtung entsteht erstens, wenn ein Akteur in eine Beziehungsrelation investiert (sei es ökonomisches Kapital [Bourdieu], Gefälligkeiten [Coleman] oder ganz allgemein Ressourcen [Netzwerktheoretiker]), wenn er also etwas für die Belange, Bedürfnisse, Wünsche anderer verausgabt, weil er an Ressourcen interessiert ist, die von diesen anderen kontrolliert werden ${ }^{416}$. Eine Verpflichtung entsteht zweitens, wenn Austauschprozesse

415 Putnams konzeptuelle Überlegungen spielen für die hier vorgeschlagene integrative Theoriebildung keine nennenswerte Rolle - lediglich seine mikrotheoretischen Ausgangsüberlegungen sind deckungsgleich mit denen der anderen Autoren. Insbesondere die von Putnam behaupteten Wirkungszusammenhänge bewerte ich als "theoretisch überschießend" und damit für eine integrative Theoriebildung als unbrauchbar.

416 Wobei diese Kontrolle wohl nahezu grundsätzlich relativ zu sehen ist: Menschen stehen in vielfältigen Interaktionsbeziehungen und so würde A eine für B relevante Ressource nur dann absolut kontrollieren, wenn keine anderen Akteure B diese Ressource oder ein Äquivalent verschaffen könnten. (Zusätzlich ist in Zusammenhang mit der Erzeugung von Verpflichtungen noch darauf zu verweisen, dass die Investitionen "den anderen sichtbar und merklich in die Schuld 
eine Verpflichtung als nicht-intendiertes Ergebnis nach sich ziehen. Nach der Substitution von Ö (bzw. Gef und R) durch Gut, können die Formulierungen für das von mir vorgeschlagene Theoriemodell übernommen werden.

Dass Sozialkapital nicht zwangsläufig einer Investition bedarf, wird paradoxerweise gerade dann besonders deutlich, wenn bewusst in Sozialkapitel investiert wird. Angenommen A möchte B dazu veranlassen, d.h. bei B die Verpflichtung erzeugen, ihm bei seinem anstehenden Wohnungsumzug behilflich zu sein. Zur Erreichung dieses Vorhabens erteilt er Bs Tochter kostenfrei Nachhilfeunterricht in Englisch. In diesem Fall profitiert also B davon, dass A seiner (also Bs) Tochter in Erwartung einer durch B zu realisierenden Gegenleistung (also keiner Vorleistung) eine wichtige Ressource zur Verfügung stellt, ohne dass B zuvor irgendetwas investiert hätte. Vielmehr ist das B hier zufließende Sozialkapital Ergebnis einer Investition in Sozialkapital durch $\mathrm{A}^{417}$; das der Tochter von B zufließende Sozialkapital ist Ergebnis einer Transferierung, denn sie ist die Tochter jener Person, die A zu seinem Umzug verpflichten möchte ${ }^{418}$.

Selbstverständlich können bewusste Investitionen in Sozialkapital auch ihre intendierte Wirkung zeitigen. Insbesondere eine hohe Kapitalakkumulation wird in den meisten Fällen in diesem Sinne strategisch verlaufen und gründet - da Sozialkapital nicht justiziabel ist - sicherlich im Vertrauen auf die Befolgung von Reziprozitätsnormen. Je stärkeren Verbindlichkeitscharakter diese Normen besitzen, desto weniger wichtig wird das Vertrauen. Ferner dürften iterierte Spiele im Sinne eines tit-for-tat und/oder eine hohe Dauerhaftigkeit einer Beziehung wie eine Versicherungspolice wirken, die gegenseitige "Schuldverschreibungen" gleichsam überwachen.

Aber nicht jede Investition erzeugt automatisch Verpflichtungen, Vertrauen ist nie enttäuschungssicher. So kann etwa ein Schuldner bestreiten, ein Schuldner zu sein, d.h. ein System balancierter Reziprozität kommt nicht zustande, das "Prinzip distributiver Gerechtigkeit ..., wenn jeder das bekommt, was ihm oder ihr aufgrund seiner/ihrer Vorleistung zusteht" (Bierhoff 2000: 382), wird verletzt. Bei wieder anderen (vermeintlichen Vor-) Leistungen handelt es sich nicht wirklich um Investitionen, weil der Geber keine Gegenleistung erwartet, weil er mit dem

setzen" müssen [Esser 2000: 253] - dies wird im Rahmen der ontologischen Reflexionen noch berücksichtigt.)

${ }^{417}$ Es sei erlaubt, an dieser Stelle noch einmal kurz auf die oben bereits diskutierte Kapitalproblematik zurückzukommen. Im beschriebenen Fall handelt es sich dann um eine Investition in Sozialkapital, wenn A später mehr "herausbekommt", als er zuvor "eingezahlt" hat. D.h. seine Arbeitsleistung muss für A von geringerem Wert sein, als der seiner Tochter zuteil werdende Nachhilfeunterricht. Auch Investitionen in Sozialkapital implizieren insofern immer Konsumverzicht: In dem Moment, wo A einem anderen bei dessen Wohnungsumzug behilflich ist, wendet er Zeit auf und verzichtet auf für ihn angenehmere Aktivitäten; seine Hilfeleistung verursacht also zunächst einmal unmittelbar Kosten.(Unlängst habe ich gelesen, Investitionen in Alkohol seien besonders lohnend - mehr Prozente bekomme man nämlich sonst nirgends. [Dies sei freilich nur so nebenbei erwähnt.])

418 Damit die beschriebenen Prozesse auch "funktionieren", müssen bestimmte gesellschaftliche Normen und kognitive Prozesse wirksam sein. Diese werden im ontologischen Teil näher beleuchtet. 
Geben nur seinen Sozialstatus indizieren möchte oder weil generalisierte Reziprozität gilt bzw. weil ein Kollektivgut vorhanden ist ${ }^{419}$. Zusätzlich ist noch darauf zu verweisen, dass keineswegs ausschließlich einem Investor soziales Kapital zufließen muss. Beim Vorliegen entsprechender Normen, routinisierter Handlungsmuster und Typisierungsprozessen können auch andere Personen profitieren, etwa wenn - im Granovetterschen Sinne - C dank B auf die Ressourcen von A zugreifen kann ${ }^{420}$.

Prinzipiell muss weder die Sozialkapitalbildung noch der -einsatz intentional verlaufen. Betrachtet man also Kapital im Allgemeinen als bewusst akkumulierten und bewusst eingesetzten Faktor innerhalb des Produktionsprozesses, dann wird dies auf Sozialkapital vielfach nicht zutreffen. Dieses kann Ergebnis einer Transferierung (Vererbung mit ihren unterschiedlichen Facetten, also auch generalisierte Reziprozität) und sein Einsatz ein beiläufiges Nebenprodukt der Interaktion sein ${ }^{421}$.

\section{Wirkung}

Lin wirft Coleman vor, aus dessen funktionalistischer Definition resultiere eine Tautologie, da Wirkung und Ursache in eins fielen: "The cause factor is defined by the effect factor. ... It would be incorrect to allow the outcome variables to dictate the specification of the causual variable (e.g., for actor X, kin ties are social capital because these ties channel $\mathrm{X}$ to get a better job, and for actor $\mathrm{Y}$, kin ties are not social capital because these ties do not channel $\mathrm{Y}$ to get a better job)" 422 (Lin 2001: 11).

Lin fordert also, man dürfe die Anwendung des Sozialkapitalbegriffs auf Beziehungsrelationen nicht davon abhängig machen, ob Vorteile bezogen würden. In ähnlicher Weise kritisieren Portes/Landolt (1996: 19), "social capital and the benefits derived from it are confused." Eine funktionalistische Definition von

419 Coleman weist etwa darauf hin, dass die Norm, das Eigeninteresse zurückzustellen und sich für das öffentliche Wohl zu engagieren, u.a. durch Belohnungsanreize in Form von gesellschaftlichem Status oder Ansehen entsteht (Coleman 1991: 403). Man kann also bspw. konkrete Gefälligkeiten gegen einen erhöhten Sozialstatus eintauschen; welche Art der Gratifikation ein Akteur wählt, ist eine nur empirisch zu beantwortende Frage.

${ }^{420}$ Dennoch handelt es sich auch in einem solchen Fall bei Sozialkapital nicht um ein Gemeingut.

421 Einwände, die freilich auch auf Humankapital zutreffen.

422 Auch Portes hält dies für tautologisch: "Saying, for example, that student A has social capital because he obtained access to a large tuition loan from his kin and that student B does not because she failed to do so neglects the possibility that B's kin network is equally or more motivated to come to her aid but simply lacks the means to do." (Portes 1998: 5, Fußn. 2) Eben genau aus diesem Grund, weil eben die Familie von B nicht über die Mittel verfügt, ist aber von (in dem Fall nicht oder nur unzureichend vorhandenem) "Sozialkapital" und nicht von der "Motivation andere zu unterstützen" die Rede. Möchte Portes sich also mit dem tatsächlichen Wert sozialer Beziehungen (in Hinsicht auf ein bestimmtes Problem) - und insofern mit der konkreten Hilfe durch andere oder aber mit den Absichten dieser anderen befassen? Wenn mit Blick auf ein konkretes Ziel keine nützlichen Ressourcen zur Verfügung gestellt werden, dann ist der Kapitalbegriff fehl am Platz. 
"Sozialkapital", so Edwards/Foley (1997: 669), "makes it impossible to separate what it is from what it does."

Davon kann zumindest hinsichtlich der von mir vorgenommenen Begriffsbestimmung trotz des expliziten Funktionalismus keine Rede sein. Zunächst wird "Sozialkapital" genauer als eine Gutschrift bestimmt. Weder bei den Voraussetzungen, die zu der Gutschrift führen, noch bei dem Ertrag, der bei deren Einlösung (im gelingenden Fall) erwirtschaftet wird, handelt es sich um Sozialkapital. So wäre etwa die Nutzung einer Information über einen freiwerdenden Arbeitsplatz eine Anwendung bzw. ein Einsatz von Sozialkapital; der Ertrag bestünde in einem neuen Job und die Voraussetzung der Informationsnutzung könnte bspw. in einer Verpflichtung bestehen.

Dennoch scheint die funktionale Definition irgendwie in eine Art Tautologie zu münden: Wenn nur jene Gutschriften als "Sozialkapital" bezeichnet werden können, die einen Ertrag einbringen, dann verschafft Sozialkapital dem Akteur grundsätzlich und ohne Ausnahme eben einen Ertrag. Eine Falsifikation ist ausgeschlossen. Eine Beziehungsrelation bedeutet aber per se - und dies sei an dieser Stelle nochmals betont - keineswegs einen Nutzen für die beteiligten Individuen $^{423}$; erst wenn sich hierüber tatsächliche oder potentielle Gewinne realisieren lassen, wird sie im vorliegenden Zusammenhang relevant.

Was für einen Sinn hätte es, würde man beim Vorliegen einer Verbindung zwischen Akteuren grundsätzlich von "Sozialkapital" reden? Man hätte dann lediglich einen neuen Begriff für "Beziehungsrelation" bestimmt. Außerdem können die Beziehungen eines Akteurs auch vorwiegend Kosten verursachen, dann nämlich, wenn dessen Ressourcen von anderen genutzt werden, jedoch kein Rückfluss erfolgt. Insofern aber eben nicht die Relation, sondern der dem Akteur erwachsende Ertrag im Zentrum der Überlegungen zu Sozialkapital steht, ist der Hinweis auf die Funktionalität des Sozialkapitalbegriffes nicht nur sinnvoll, sondern notwendig: das Produktive, das Handlungsbegünstigende, das Nutzenbringende an Sozialkontakten soll ja gerade in den Fokus gerückt werden.

Bei einer Tautologie handelt es sich um ein analytisches Erkenntnisurteil. Putnam argumentiert bspw. tautologisch, wenn er behauptet, "voluntary cooperation is easier in a community that has inherited a substantial stock of social capital in the form of norms of reciprocity and networks of civic engagement." (Putnam 1993: 167) Die Ausdrücke "Reziprozitätsnormen" und "Netzwerke zivilen Engagements" sind nun jedoch - zumindest im deutschen und englischen Sprachraum - wohl kaum definierbar, ohne dabei auf "freiwillige Kooperation" zu

${ }^{423}$ Und an einigen Stellen sehen dies auch die Netzwerktheoretiker so: "It is clear that the use of informal contacts does not produce a better job, unless the contact person has good resources himself." (Flap 2002: 3) Bei Jansen (2000: 45) heißt es aber: "Der einfachste Indikator für das soziale Kapital eines Akteurs ist sein so genannter Degree ('degree of connection'). Dies ist die Zahl seiner Beziehungen im Netzwerk. Einen positiven Beziehungstyp vorausgesetzt, ist sein soziales Kapital um so größer, je größer die Anzahl der mit ihm verbundenen Personen ist." Jansen blendet damit den Etragsaspekt vollkommen aus. 
verweisen. Sie sind also im Rahmen des Sozialkapitalkonzeptes als nicht Ttheoretisch zu begreifen und unterliegen den Gebrauchsregeln der Sprachgemeinschaft, in der sich Putnam bewegt, stehen also in einer weitgehend normierten semantischen Relation zueinander. Gegenständlich formuliert heißt dies nun: Das Vorhandensein von Reziprozitätsnormen und Netzwerken zivilen Engagements impliziert freiwillige Kooperation, d.h. Letztere kann nicht von den Ersteren abhängig sein (bzw. erleichtert werden); wer das behauptet, präsentiert eine apriorische Erkenntnis ohne jeglichen Informationsgehalt.

Nur auf einen ersten Blick erscheint die Unterstellung hinsichtlich der Funktionalität des Sozialkapitals hiermit vergleichbar: "Sozialkapital" ist definiert als eine aus Beziehungsrelationen emergierende Gutschrift, die dem Akteur von Nutzen ist. Wird nun behauptet, Sozialkapital wirke funktional, so scheint eine Tautologie vorzuliegen. Wir müssen aber nun zwischen einem formalen und einem gewissermaßen inhaltlichen Definitionskriterium unterscheiden. Wir behaupten lediglich, dass die Wirkung von Sozialkapital - wie sie sich auch immer inhaltlich darstellen mag - funktional sein muss. Dies ist nun in der Tat eine analytische Aussage; aber sie ist notwendig, um dem Begriff seine spezifische Bedeutung verleihen zu können und "Sozialkapital" überhaupt als sinnhaft innerhalb einer Sprache auszuweisen. Neben der Funktionalität betrifft dies ebenso alle anderen Definitionskriterien, die oben im Rahmen der key idea aufgeführt wurden. Definitionen sind nun einmal im positivistischen und nominalistischen Sinne lediglich tautologische Umformungen, bei denen ein Definiendum als bedeutungsgleich mit einem Definiens gesetzt wird (wir würden auch nicht bestreiten, dass es aus unterschiedlichen Gründen heraus sinnvoll ist, zu sagen, eine Woche habe 7 Tage - und dennoch handelt es sich dabei um eine gleichsam tautologische wie kontingente Formulierung).

"Kapital" ist ein Terminus, der formal auf den Ertrag im Produktionsprozess gerichtet ist ${ }^{424}$. Genauso wie bspw. das Freudsche "Unbewusste" auf das vom Individuum mit Blick auf die Bewältigung problematischer Lebensereignisse Verdrängte aufmerksam macht. Um was es sich bei dem Ertrag oder dem Verdrängten konkret handelt, ist eine empirisch zu klärende Frage. Nur wenn dies schon in der jeweiligen begrifflichen Definition erscheinen würde, wäre ein Tautologievorwurf gerechtfertigt. Stellt man also empirisch fest, dass es einem Akteur trotz der Information über einen vakanten Arbeitsplatz nicht gelingt, die entsprechende Stelle zu besetzen ${ }^{425}$, oder dass ein Patient ein persönlich sehr

\footnotetext{
${ }^{424}$ Der Marburger Politologe Georg Füllberth (2004) bringt diese Position für Finanzkapital m.E. in salopper Weise auf den Punkt: Wenn kein Gewinn oder Ertrag zu verzeichnen ist, "war es kein Kapital, sondern nur hinausgeworfenes Geld." Ertrag ist also ein für die Verwendung des Kapitalbegriffs notwendiges Charakteristikum; es handelt sich insofern um einen bedeutungstheoretischen Irrtum, zu behaupten - wie etwa neben Portes und Lin auch Durlauf (1999: 2) dies tut dieses Charakteristikum und die Wirkung von Sozialkapital müsse strikt voneinander unterschieden werden.

${ }^{425}$ Einmal unterstellt, andere Einflussgrößen seien kontrolliert.
} 
belastendes Kindheitserlebnis auf Nachfrage schon in den Anfangsminuten der ersten Therapiesitzung schildert, dann handelt es sich eben nicht um Sozialkapital, oder um Unbewusstes ${ }^{426}$.

Sozialkapital hat zunächst einmal grundsätzlich positive Wirkungen für denjenigen, der es besitzt: Ein konkreter Nutzen - etwa ein finanziell lukrativer Job wird hierüber generiert. Dass sich später bspw. eine durch einen Bekannten vermittelte Arbeitsstelle als persönliche Belastung herausstellt, kann nicht sinnvoll eine negative Wirkung des Sozialkapitals darstellen, denn die in Frage stehende Gutschrift ist im Zusammenhang mit der Vermittlung der Arbeitsstelle und nicht mit der folgenden persönlichen Belastung zu sehen.

Was aber nun, wenn sowohl ein finanziell lukrativer als auch ein belastungsfreier Job angestrebt, jedoch lediglich das erstgenannte Ziel erreicht wurde? Coleman (1994: 302) würde hierauf wohl antworten: "A given form of social capital that is valuable in facilitating certain actions may be useless or even harmful in others". Damit widerspricht er aber seiner eigenen Festlegung von Sozialkapital als grundsätzlich funktional. Auf Basis der vorgestellten Definition bedeutet dies nun, dass hinsichtlich des Zieles "belastungsfreier Job" die Gutschrift über die Vermittlungsleistung des Bekannten eben kein Sozialkapital war; der Bekannte verfügte nicht über die sozialen Ressourcen, um die Erreichung dieses Zieles zu gewährleisten ${ }^{427}$.

Die Funktionalität von Kapital ist m.E. sinnvoll lediglich mit Blick auf die hierüber erfolgende unmittelbare Bedürfnisbefriedigung - für Sozialkapital etwa den Bezug einer Unterstützungsleistung - einführbar. Kapital ist insofern funktional, als es etwas zugänglich macht. Methodologisch gesprochen, firmiert

\footnotetext{
426 Coleman sieht die funktionale Definition von "Sozialkapital" analog zu der von "Stuhl" (vgl. Coleman 1991: 395). Macht es Sinn, etwas als "Stuhl" zu bezeichnen, wenn man darauf nicht sitzen kann? Hierzu auch Kromrey (2000: 151): "Und es zeigt sich an den vagen Merkmalsformulierungen wie 'im allgemeinen eine waagrechte Platte', daß 'Tisch' von seiner Funktion und nicht so sehr von seiner Erscheinung her definiert wurde, daß also von der Verwendungsmöglichkeit oder der tatsächlichen Verwendung her entschieden wird, ob etwas als Tisch gilt oder nicht." Dass diese Orientierung am Funktionalitätskriterium durchaus Ähnlichkeiten mit der eidetischen Reduktion in der Phänomenologie hat, obgleich Coleman und Kromrey weitgehend nominalistisch argumentieren, soll hier zumindest am Rande erwähnt werden: die Funktion ist gewissermaßen das, was in invarianter Weise übrigbleiben muss, damit man noch von einem "Tisch" sprechen kann. (An dieser Stelle scheint damit auch die in Kapitel 5.3. diskutierte Verbindung zwischen linguistischer und soziologischer Bedeutung - im Sinne des Schützschen um-zu-Motivs - durch. Den literarisch interessierten Leser möchte ich erneut auf den dieser Untersuchung vorangestellten Auszug aus Paul Austers Roman "Stadt aus Glas" verweisen.)

427 Diese Antwort mag den ein oder anderen Leser nicht zufrieden stellen. Eine Analogie zum Finanzkapital soll die Sinnhaftigkeit der Argumentation jedoch verdeutlichen: Man kann bspw. in einer Kneipe 1,50 Euro in ein Kölsch investieren. Schmeckt das Kölsch nicht, dann stellt dies keineswegs unmittelbar eine dysfunktionale Folge des Kapitaleinsatzes dar, sondern liegt u.U. an der schlechten Ausbildung des Brauherren oder an den Geschmacksnerven des Verbrauchers. Letzterer wird sich möglicherweise wünschen, doch lieber ein Pils bestellt zu haben. Dies ändert allerdings nichts daran, dass sein Kapital funktional hinsichtlich der Realisierung seines primären Interesses war, nämlich ein Kölsch zu trinken; es wurde also faktorstrategisch innerhalb des Produktionsprozesses verwendet.
} 
"Sozialkapital" in diesem Verständnis grundsätzlich als unmittelbarer Prediktor, d.h. als Variable, die einen seitens des Kapitalverwenders erwünschten outcome in direkter Weise, ohne Zwischengrößen, ermöglicht. Der outcome selbst - also ein Nutzen bzw. eine Rendite - kann wiederum ein Produktionsfaktor zur Erreichung übergeordneter Zielstellungen sein.

Wollte man alle mit einem Kapitaleinsatz mittelbar irgendwie verbundenen Folgeerscheinungen in einen Zusammenhang mit diesem Einsatz bringen, so ließe sich die Frage nach der Funktionalität oder Dysfunktionalität nur in den seltensten Fällen beantworten (wer weiß bspw. schon, ob eine über Sozialkapital realisierte Einkommenserhöhung später nicht $\mathrm{zu}$ einer affektiven Entfremdung von wichtigen Bezugspersonen führt - dies hängt von so vielen Faktoren ab, dass daran die Funktionalität oder Dysfunktionalität eines Sozialkapitaleinsatzes nicht bewertbar sein kann) ${ }^{428}$.

\section{Abbildung 11: Die Funktionalität von Sozialkapital}

\begin{tabular}{|c|c|c|c|c|}
\hline $\begin{array}{l}\text { Sozialkapital } \\
\text { (z.B. Gutschrift } \\
\text { über Info über } \\
\text { vakante Position in } \\
\text { einem Unterneh- } \\
\text { men) }\end{array}$ & funktional & $\begin{array}{c}\text { Unmittelbarer } \\
\text { Outcome (1) } \\
\text { (Ertrag) } \\
\text { (₹.B. neue } \\
\text { Arbeitsstelle) }\end{array}$ & $\begin{array}{l}\text { oder dys- } \\
\text { funktional } \\
\longrightarrow\end{array}$ & $\begin{array}{c}\text { Mittelbarer } \\
\text { Outcome (2) } \\
\text { (z.B. familiäre } \\
\text { Spannungen wegen } \\
\text { boher Arbeitsbelas- } \\
\text { tung) }\end{array}$ \\
\hline
\end{tabular}

In dieser hier von mir vorgeschlagenen Lesart wäre die gesellschaftliche Position eines Individuums, die Bourdieu als in zentraler Weise von Sozialkapital abhängig erachtet, lediglich ein mittelbarer outcome. M.a.W.: Je höher der über Sozialkapital realisierte Gesamtertrag, desto höher die gesellschaftliche Position des Einzelnen $^{429}$.

Vor dem Hintergrund dieser Überlegungen sollen nun auch häufig wiederkehrende Einwände gegen ein funktionalistisches Verständnis - und der damit

\footnotetext{
${ }^{428}$ Ein Verstoß gegen das Prinzip vom ausgeschlossenen Widerspruch bedeutet der von Dederichs (1999: 133) stammende Satz: "soziales Kapital ist funktional und kann dysfunktional werden." Mit der Behauptung, soziales Kapital sei funktional, wird gleichsam eine definitorische Festlegung getroffen, unter die das, was dann später dysfunktional sein soll, nicht mehr subsummierbar sein kann. Allenfalls ließe sich sagen, soziales Kapital könne sowohl funktional wie dysfunktional sein; in dem Fall wäre Funktionalität keine intensionale Merkmalsbestimmung mehr.

${ }^{429}$ Es ließe sich allerdings auch formulieren, nicht der Gesamtertrag, sondern das akkumulierte Sozialkapital (mit dessen Hilfe Erträge erst noch erwirtschaftet werden sollen) hinge mit der gesellschaftlichen Position zusammen. Immerhin bezeichnet Bourdieu mit dem Sozialkapitalbegriff "die Gesamtheit der aktuellen und potentiellen Ressourcen, die mit dem Besitz eines dauerhaften Netzes von mehr oder weniger institutionalisierten Beziehungen gegenseitigen Kennens und Anerkennens verbunden sind" (Bourdieu 1992: 63). Dann könnte aber nur schwerlich von einer Wirkbeziehung die Rede sein; vielmehr fungierte das akkumulierte Sozialkapital als ein Indikator der gesellschaftlichen Position.
} 
zusammenhängenden Behauptung einer grundsätzlich positiven Wirkungsweise von Sozialkapital - einer kritischen Prüfung unterzogen werden. Hierzu beziehe ich mich paradigmatisch auf Portes (1998; vgl. auch Portes/Landolt 1996), dessen Sozialkapitalbegriff zumindest für die Zwecke der nachfolgenden Argumentation meiner oben vorgenommenen Definition in ausreichendem Maße ähnelt: Unter "Sozialkapital" ist bei Portes nämlich die individuelle "ability to secure benefits through membership in networks and other social structures" zu verstehen 430 (ebenda: 8). Portes identifiziert vier negative Folgen von Sozialkapital: "exclusion of outsiders, excess claims on group members, restrictions on individual freedoms, and downward leveling norms." (Portes 1998: 15)

Erster Einwand: "First, the same strong ties that bring benefits to members of a group comonly enable it to bar others from access." (ebenda: 15)

Sicherlich werden bspw. die von A bereitgestellten Ressourcen und damit das Sozialkapital, das B möglicherweise dazu verholfen hat, die berufliche Karriereleiter ein Stück weit emporzuklettern, zum Problem für C, den Mitbewerber von B. Aber das Sozialkapital, um das es geht, war funktional für jene Person, die in der Lage war, es zu mobilisieren. Die negativen Konsequenzen entstehen lediglich für Dritte, also jene Betroffenen, die eben kein oder zu wenig Sozialkapital in die Waagschale werfen konnten. Das Sozialkapital für B hatte also - wenn man so will - einen negativen externen Effekt auf C. Man kann diesen Effekt natürlich untersuchen, aber es handelt sich bei diesem eben nicht um eine Folge von Cs Sozialkapital. M.a.W.: Sozialkapital ist funktional für seinen Eigentümer - und genau das behauptet auch Portes selber, wenn er unter dem Begriff die individuelle "ability to secure benefits" (ebenda: 8) versteht. Was für einen Sinn würde es machen, wollte man grundsätzlich bei jedem über Sozialkapital erzielten Ertrag, sämtliche Folgeerscheinungen für alle hiervon sonst noch irgendwie betroffenen anderen Akteure betrachten?

Zweiter Einwand: "The second negative effect of social capital is the obverse of the first because group or community closure may, under certain circumstances, prevent the success of business initiatives by their members." Ein Unternehmer, der in Folge bestimmter normativer Erwartungen permanent den Ansprüchen seiner Bekannten und Verwandten nachgebe, diesen Jobs verschaffe bzw. Kredite gewähre, könne nicht erfolgreich sein. "Thus, cozy intergroup relations of the kind

430 Eine Definition von "Sozialkapital" als eine spezifische Fäbigkeit von Akteuren findet sich auch bei der mit Portes zusammenarbeitenden Landolt (2004: 22) sowie bei Faist: "Social capital here means the capacity of individuals to employ (scarce) resources" (Faist zitiert nach Haug 2000: 41). Faist lehnt sich an Portes an; beide argumentieren u.a. im Rahmen von Analysen zu Migrantennetzwerken. Wenn "Sozialkapital" aber zur Bezeichnung von spezifischen Fähigkeiten verwendet wird, dann gerät der Begriff m.E. rasch in die Nähe von "Humankapital". In den Sozialkapitalvorstellungen von Williams/Robinson (2002: 14) scheint "Fähigkeit" hingegen zunächst eine abhängige Variable zu sein: "Social capital is the relationships among actors that create a capacity to act for mutual benefit or a common purpose." Bei genauerer Betrachtung wird aber deutlich, dass es sich hier um eine Festlegung handelt: Nur die Beziehungsrelationen sollen "Sozialkapital" genannt werden, die die entsprechende Handlungskapazität hervorbringen. 
found in highly solidary communities can give rise to a gigantic free-riding problem, as less diligent members enforce on the more successful all kinds of demands backed up by a shared normative structure." (ebenda: 16)

Geschädigt werden jedoch im Beispiel ausschließlich die Individuen, die sich des genannten normativen Drucks nicht widersetzen können oder wollen; diese besitzen aber in dem geschilderten Zusammenhang gar kein Sozialkapital, sondern stellen dieses anderen zur Verfügung, die dann natürlich davon profitieren. Dass ein auf Grundlage einer solchen Handlungspraxis geführtes Unternehmen sich nur schwer auf dem Markt behaupten kann und dass dies dann wiederum auch negative Folgen für die zuvor begünstigten Personen hat, fällt nicht mehr in den unmittelbaren Wirkungsbereich des Sozialkapitals.

Dritter Einwand: "Third, community or group participation necessarily creates demands for conformity. ... The level of social control in such settings is strong and also quite restrictive of personal freedoms" (ebenda).

An dieser Stelle setzt Portes soziale Kontrolle schlichtweg mit sozialem Kapital in eins ${ }^{431}$, obgleich er doch (a) zuvor unter Letzterem explizit die "ability" von Individuen versteht, "to secure benefits through membership in networks and other social structures" (ebenda: 8) und (b) soziales Kapital mit Blick auf seine (positiven) Wirkungen als "source of social control" (ebenda: 9) sieht. Portes ist hier also ein widersprüchlicher und äußerst unpräziser Sprachgebrauch vorzuwerfen. Dieser wird auch nicht aufgehoben, wenn später unter Bezug auf Simmel von dem "age-old dilemma between community solidarity and individual freedom" die Rede ist (ebenda: 17), denn dabei geht es um das Auseinanderfallen von normativen kollektiven Ansprüchen und individuellen Bedürfnissen - Sozialkapital ist bei Portes aber weder das eine noch das andere.

Vierter Einwand: "Fourth, there are situations in which group solidarity is cemented by a common experience of adversity and opposition to mainstream society. In these instances, individual success stories undermine group cohesion because the latter is precisely grounded on the alleged impossibility of such occurrences. The result is downward leveling norms that operate to keep members of a downtrodden group in place" (ebenda: 17).

Erneut thematisiert Portes hier die mögliche Inkompatibilität einer kohäsiven sozialen Gruppennorm und individuellen Bedürfnissen bzw. Freiräumen. Wie Sozialkapital hier negative Konsequenzen aufweisen kann, obwohl es doch - auf Basis der Definition Portes - überhaupt nicht vorkommt, bleibt unklar.

Kurz und knapp: Negative direkte Konsequenzen des Sozialkapitals können auf Basis des von mir hier vorgeschlagenen Theoriemodells nicht entstehen ${ }^{432}$. Wenn

\footnotetext{
431 So auch, wenn er von "social capital, in the form of social control" spricht (Portes 1998: 18).

432 Für ein Makroverständnis à la Putnam gilt dies freilich nicht uneingeschränkt. Hier könnte ein hoher Bestand an Sozialkapital als Strukturmerkmal in der Tat negative Auswirkungen für Mitglieder der Gemeinschaft aufweisen. Unter Umständen verfügt eine Gesellschaft mit einer Vielzahl krimineller Vereinigungen über einen sehr hohen Sozialkapitalbestand. Allerdings darf Putnam nicht
} 
Portes für seinen Sozialkapitalbegriff etwas anderes behauptet, argumentiert er inkonsistent.

\section{Operationalisierung}

Zur Operationalisierung der von mir hier vorgenommenen Konzeptualisierung von "Sozialkapital" kann weitgehend auf die oben schon dargestellten Verfahren der Netzwerkanalytiker verwiesen werden. Dies deshalb, weil Sozialkapital als eine über Relationen zu beziehende Gutschrift über Ressourcen verstanden wird. Dabei gilt jedoch zu bedenken, dass es sich bei der Netzwerkanalyse - wie der Name schon sagt - eben um eine Netzwerk- und nicht um eine Sozialkapitalanalyse handelt, d.h. es muss immer genau begründet werden, warum man glaubt, über netzwerkanalytische Maßzahlen, Sozialkapital bestimmen zu können. Auch dies hatte ich in Kapitel 7.4. schon angedeutet.

Ein zentrales Problem hinsichtlich der Operationalisierung von Sozialkapital ist ferner darin zu sehen, dass eine Gutschrift nur dann "Sozialkapital" genannt werden darf, wenn sich hierüber ein Ertrag erwirtschaften lässt. Dies ist aber niemals sicher im Vorhinein zu bestimmen. Insofern wäre die Frage, ob es sich bei einer Gutschrift um Sozialkapital handelt oder nicht, lediglich ex-post beantwortbar. Dieses Problem betrifft aber ebenso Human- und in abgeschwächter Form sogar Finanzkapital; bei einer Operationalisierung müssen insofern bestimmte, über den Einsatz von Kapital erreichbare Zielstellungen unterstellt werden (es ist bspw. plausibel, dass man auf günstige Flugreisen aufmerksam gemacht wird, wenn man mit einem Reisekaufmann befreundet ist und dieser weiß, wie gerne man in den Urlaub fliegt).

\section{Wissenschaftstheoretischer Status}

Wie schon mehrfach erläutert, ist das hier entwickelte Theoriemodell Resultat eines wissenschaftstheoretisch angeleiteten, systematisch-integrativen Vergleichs schon ausformulierter Sozialkapitalkonzepte und weiterführender analytischer Überlegungen. Da das Vorgehen detailliert dokumentiert wurde, erübrigen sich an dieser Stelle weitere Angaben. Insgesamt lässt sich das hier vorgeschlagene Theoriemodell als theorieintegratives, quantitatives Realmodell kennzeichnen. Lediglich auf die Frage der Quantifizierbarkeit von Sozialkapital ist - auch anknüpfend an die Überlegungen zur Operationalisierung - noch zu verweisen. Damit die Analogie zu anderen Kapitalarten gewahrt bleibt, muss es zumindest grundsätzlich möglich sein, Sozialkapital einen metrischen Wert zuzuordnen. Dies

vorgeworfen werden, er würde wahllos alle erdenklichen Assoziationsformen in die Bestimmung von "Sozialkapital" mit einfließen lassen, so dass dieser Einwand weder vor dem Hintergrund der Putnamschen konzeptionellen Überlegungen noch der diesbezüglichen empirischen Forschungspraxis Stand hält. 
ist jedoch insofern problematisch, als Kapital i.d.R. einem objektiven, über den Markt vermittelten Bewertungsmaßstab unterliegt. Es wäre von daher ein Analogieverstoß, würde man das einem Akteur zur Verfügung stehende Sozialkapital anhand dessen individueller Ertragsbewertung bestimmen wollen.

Über alle Sozialkapital darstellenden Gutschriften werden daher die potentiellen Erträge mittels eines Koeffizienten $b$ objektiviert und aufsummiert (also was kann ein Akteur mit seinem Sozialkapital erreichen) ${ }^{433}$. Hiervon ist nun noch der Passiva-Bestand zu subtrahieren, der neben "zu zahlenden" Gutschriften (also dem Sozialkapital, das andere über den Akteur realisieren) auch Investitions- und Opportunitätskosten impliziert. Dabei kann es sich bei den zu zahlenden Gutschriften allerdings wiederum um Investitionen in Sozialkapital handeln, d.h. neue, Sozialkapital begründende Verpflichtungen werden vielfach hierüber geschaffen. Dieser externe Effekt führt zu einer Relativierung der Bewertung des Passiva-Bestandes, was innerhalb der Gleichung über den Koeffizienten $e$ berücksichtigt wird ${ }^{434}$.

$$
\Sigma \mathrm{S}^{\mathrm{I}}=\sum_{\mathbf{j}=1}^{\text {Gut }} h_{j} \mathrm{Ert}_{\mathrm{j}}-e \mathrm{PaS}
$$

\section{Strukturalistische Darstellung}

Die strukturalistische Darstellung fasst die zentralen begrifflichen wie theoretischen Zusammenhänge des integrativen Theoriemodells über Sozialkapital in übersichtlicher, ökonomisch-komprimierter und präziser Form zusammen. Mit Blick auf die Erzielung wissenschaftlichen Fortschritts genügt insbesondere die Axiomatisierung dem Bedarf "an einheitlich strukturierten Theorien" (Chalmers 2001: 88). "The increase of the conceptual clarity of a theory through careful clarifications and specifications of meaning is, ..., one of the most important ways in which science progresses." (Laudan 1977: 50)

Vor dem ersten Schritt der strukturalistischen Darstellung gibt die folgende Tabelle nochmals einen zusammenfassenden Überblick über zentrale Ergebnisse des Theorienvergleichs. Kursiv sind jene Bestimmungen hervorgehoben, die in abgewandelter Form in meine integrative Begriffs- und Theoriebildung Eingang gefunden haben.

\footnotetext{
433 Wie eine solche Berechnung de fakto aussehen könnte, ist damit natürlich noch nicht gesagt. Realiter dürfte sich das Sozialkapital ohnehin nur in Bezug auf konkrete Zielstellungen ermitteln lassen. Eine Diskussion der Quantifizierungsprobleme von Sozialkapital würde den Rahmen dieser Untersuchung sprengen und wäre Gegenstand weiterführender methodischer Reflexionen. Hier soll die Problematik lediglich skizziert und ein möglicher erster Lösungsschritt aufgezeigt werden.

434 Wenn innerhalb der Gleichung das Summenzeichen vor Sozialkapital auftaucht, so soll darauf aufmerksam gemacht werden, dass zwar schon eine einzelne Gutschrift Sozialkapital darstellen kann, es hier jedoch um den Gesamtbestand an dieser Kapitalform geht.
} 
Tabelle 5: Gemeinsamkeiten der rekonstruierten Sozialkapitalkonzepte

\begin{tabular}{|c|c|}
\hline & Gemeinsamkeiten der Konzepte \\
\hline Definition & $\begin{array}{l}\text { - } \quad \text { Sozialkapital als die aus Beziehungsstrukturen emergierenden Ressourcen, deren } \\
\text { sich ein Akteur zwecks Zielverwirklichung bedienen kann (alle) } \\
\text { Sozialkapital als Netzwerke (alle) } \\
\text { - Sozialkapital als Verpflichtungen alters (Bourdieu, Coleman) } \\
\text { - Informalität der Beziehungsstruktur, aus der Sozialkapital emergiert (alle) } \\
\text { - Funktionalistische Begriffsfassung (Bourdieu, Coleman, Putnam; de facto auch } \\
\text { Netzwerk.theoretiker) } \\
\text { Mikrofundierung, RC-Ansatz (alle) }\end{array}$ \\
\hline Ebene & $\begin{array}{ll}\text { - } & \text { Mikro und Meso (alle) } \\
\text { - } & \text { weitgehend ungeklärte Aggregation (alle) }\end{array}$ \\
\hline Lokalisierung & $\begin{array}{l}\text { - innerhalb von Beziehungsrelationen (Coleman, Putnam, Netzwerk- } \\
\text { theoretiker) } \\
\text { - Privates Gut (alle) } \\
\text { - Öffentliches Gut (Coleman, Putnam) }\end{array}$ \\
\hline Entstehung & $\begin{array}{l}\text { Tauschbeziehungen in Folge von Interdependenz (ohne Rechtsverbindlichkeit) } \\
\text { (alle) } \\
\text { Erzengung von Verpflichtungen resp. Investitionen in Beziebungen (Vorleistun- } \\
\text { gen eines Trengebers) (alle) } \\
\text { Vertrauen (Bourdieu, Coleman, Netzwerktheoretiker) }\end{array}$ \\
\hline Wirkung & $\begin{array}{l}\text { Handlungsbegünstigung (alle) } \\
\text { Minimierung von Transaktionskosten (Coleman, Putnam, } \\
\text { Netzwerktheoretiker) } \\
\text { Positive Beeinflussung des persönlichen Wohlbefindens (Putnam, } \\
\text { Coleman, Netzwerktheoretiker) } \\
\text { Eröffnung von Einflussmoeglichkeiten, also Macht (Bourdieu, } \\
\text { Coleman) }\end{array}$ \\
\hline $\begin{array}{l}\text { Operationa- } \\
\text { lisierung }\end{array}$ & Aspekte der Netzwerkanalyse (alle) \\
\hline $\begin{array}{l}\text { Wissen- } \\
\text { schaftstheo- } \\
\text { retischer Status }\end{array}$ & $\begin{array}{ll}\text { - } & \text { Empirisch (alle) } \\
\text { - } & \text { Sekundäranalytisch (Coleman, Putnam) } \\
\text { - } & \text { Theorieintegrativ (Coleman, Putnam) } \\
\text { - } & \text { Theorievergleichend (Putnam, Netzwerktheoretiker) } \\
\text { - } & \text { Realmodell (alle, aber unterschiedliche Stadien und Herleitungswei- } \\
\text { sen) }\end{array}$ \\
\hline
\end{tabular}




\section{Erster Rekonstruktionsschritt}

1. Die einem Akteur (A) in Folge seiner sozialen Beziehungen (Rel) informell (Inf) zufließenden (sei es tatsächlich oder potentiell) und funktional (Fun) der Erwirtschaftung eines Ertrags (Ert) dienenden Gutschriften (Gut) über Ressourcen $(\mathrm{R})$ sind sein soziales Kapital $\left(\mathrm{S}^{\mathrm{I}}\left[\mathrm{S}^{\mathrm{I}}=\right.\right.$ Soziales Kapital in integrativer Perspektive]).

2. Sozialkapital findet sich auf der Mikro- $\left(\mathrm{L}^{\mathrm{Mi}}\right)$, der Meso- $\left(\mathrm{L}^{\mathrm{Me}}\right)$ und der Makroebene ( $\left.\mathrm{L}^{\mathrm{Ma}}\right)$ (ist aber im Sinne des RC-Ansatzes grundsätzlich eine mikrotheoretisch zu interpretierende Entität).

3. Sozialkapital ist eine dem einzelnen Akteur gehörende Gutschrift $\left(\operatorname{Lok}^{A}\right)$; es ist grundsätzlich ein Privatgut, das jedoch sowohl in individueller wie in kollektiver Form vorliegen kann $\left(\mathrm{G}^{\text {ind/koll}}\right)$.

4. Gegenseitiges Kennen und Anerkennen (GK) zwischen Akteur und Teilnehmern (Te) einer Beziehungsstruktur sind Voraussetzung der Entstehung von sozialem Kapital. Austauschprozesse sind nicht zwingend erforderlich. Sozialkapital kann bspw. in Folge der Geltung der Norm generalisierter Reziprozität vorliegen (es wurde also zuvor nichts direkt ausgetauscht).

5. Soziales Kapital kann Resultat von Verpflichtungen (V) erzeugenden individuellen bzw. kollektiven Investitionsstrategien (Inv) in Beziehungen sein. Die Investitionsstrategien erfordern den Einsatz von Human- (Hum), Finanz- (Fin), physischem (Phy) oder von anderem Sozialkapital (wobei Kap $=$ "Kapital"). Verpflichtungen können aber auch nicht bewusst intendiertes Resultat von Tauschprozessen ( $\mathrm{Ta}$ ) sein und damit auch ohne vorangehende Investition Sozialkapital begründen. Sozialkapital kann ferner auch in dem Sinne ohne vorhergehende Investition zur Verfügung stehen, als ein oder mehrere Teilnehmer eine Verpflichtung, die sie einem anderen gegenüber oder in Folge der Wirksamkeit der Norm generalisierter Reziprozität verspüren, auf einen Akteur transferieren ( $\mathrm{Tr}$ ), dem so Sozialkapital erwächst, ohne dass dieser bewusst darauf hingearbeitet hätte.

6. Eine spezifische Wirkungsweise wird im hier vorgeschlagenen, wissenschaftstheoretisch angeleiteten (also nicht auf empirischer Forschungsarbeit gründenden) Theoriemodell dem Sozialkapital nicht zugeordnet. Allgemein lässt sich lediglich formulieren: Sozialkapital ermöglicht bzw. sichert einem Akteur die Realisierung eines persönlichen (wie auch immer inhaltlich bestimmten) Ertrages (Ert). Da dies jedoch aufgrund der definitorischen Bestimmung so festgelegt ist, handelt es sich um eine analytische Aussage. 


\section{Zweiter Rekonstruktionsschritt 435}

Q ist ein potentielles Modell des hier vorgeschlagenen Sozialkapitalkonzeptes, gdw Q ein Tupel der Form

$\left\langle\right.$ S, A,Rel,Inf,Fun,Ert,Gut,R,L ${ }^{\text {Mi/Me/Ma }}$, Lok $^{\mathrm{A}}, \mathrm{G}^{\text {ind/koll }}, \mathrm{GK}, \mathrm{Te}, \mathrm{Ta}, \mathrm{V}, \mathrm{Inv}$, Hum,Fin, Phy,Kap,Tr $\rangle$ wobei gilt

(1) SI,A,Rel,Inf,Fun,Ert,Gut,R,L ${ }^{\mathrm{Mi} / \mathrm{Me} / \mathrm{Ma}}, \mathrm{Lok}^{\mathrm{A}}, \mathrm{G}^{\text {ind/koll }}, \mathrm{GK}, \mathrm{Te}, \mathrm{Ta}, \mathrm{V}, \mathrm{Inv}$, Hum,Fin, Phy,Kap,Tr sind endliche, nicht-leere Mengen. Nach Ausgliederung von Kap und Gut sind alle Mengen disjunkt.

Die Mengen A, Ert, R, L, Lok, G, Te, Hum, Fin und Phy werden im Folgenden nicht weiter aufgeschlüsselt. Dabei handelt es sich entweder um Gattungsbegriffe oder ihre Aufschlüsselung ist hinsichtlich der strukturalistischen Darstellung des vorgeschlagenen Sozialkapitalkonzeptes nicht relevant (freilich sind die Mengen selbst relevant). In der Reihenfolge ihres Auftretens im obigen Tupel Q gilt für die weiteren Mengen:

(2) $\mathrm{S}^{\mathrm{I}} \subseteq$ Gut

(3) $\mathrm{Rel} \subseteq \mathrm{A} \times \mathrm{Te}$

(4) Inf $\subseteq$ Rel x Gut

(5) Fun $\subseteq$ Gut x A x Ert

(6) Gut $\subseteq$ Te x R x A

(7) $\mathrm{GK} \subseteq \mathrm{A} \times \mathrm{Te}$

(8) $\mathrm{Ta} \subseteq \mathrm{A} \times \mathrm{Te} \times \mathrm{R}$

(9) $\mathrm{V} \subseteq$ Te x A

(10) Inv $\subseteq$ A x Kap x Rel $\left(\operatorname{Kap}=\mathrm{S}^{I} \cup\right.$ Hum $\cup$ Fin $\cup$ Phy $)$

(11) $\operatorname{Tr} \subseteq \operatorname{Te} \times \mathrm{V} \times \mathrm{A}$

Diese Bedingungen meinen:

(1) Alle Begriffe sind empirisch bestimmbar. Nach Ausgliederung von Kap und Gut sind alle Begriffe zu unterscheiden, d.h. alle Begriffe bezeichnen Verschiedenes.

(2) Sozialkapital ist eine abgeleitete Menge der Menge der Gutschriften.

(3) (Beziehungs-) Relationen sind eine Teilmenge des kartesischen Produkts aus Akteur und Teilnehmern, d.h. zum Auftreten von Relationen als Bedingung von Sozialkapital bedarf es eines Akteurs, dem Sozialkapital zugeordnet werden kann und mindestens eines weiteren Teilnehmers (bzw. eines weiteren Akteurs)

435 Gerne bekenne ich abermals den wenig lyrischen Charakter der folgenden Ausführungen. Die Darstellungsweise ist jedoch unvermeidlich, will man dem Anliegen dieser Arbeit (Axiomatisierung, Entwicklung einer Logischen Propädeutik über Sozialkapital) gerecht werden. 
(mengentheoretisch formuliert: $\mathrm{Zu}$ jedem $\mathrm{x} \in \mathrm{A}$ [wobei A grundsätzlich nur ein Element enthält, weil es hier lediglich um das Sozialkapital eines Akteurs geht] gibt es mindestens ein $\mathrm{y} \in \mathrm{Te}$ ).

(4) Informalität ist eine Teilmenge eines kartesischen Produkts, das Gutschriften und (Beziehungs-) Relationen miteinander in Verbindung bringt, d.h. im Hinblick auf die als Sozialkapital bezeichnete Gutschrift ist die (Beziehungs-) Relation informell - aus ihr resultiert kein verbindlicher Anspruch auf den Bezug der Gutschrift, die nur so als Sozialkapital gelten darf. Eine Sozialkapitalbeziehung kann also durchaus innerhalb eines institutionellen Kontextes, etwa eines Vereins, einer Gewerkschaft, eines Unternehmens etc. angesiedelt sein. Entscheidend ist jedoch, dass eine Gutschrift nur dann Sozialkapital darstellt, wenn hinsichtlich ihres tatsächlichen oder potentiellen Bezugs keine formelle Rechtsgrundlage vorhanden ist.

(5) Funktionalität ist eine Teilmenge des kartesischen Produkts, das einen Akteur, dem Sozialkapital zugeordnet werden kann, Gutschriften und Erträge zueinander in Beziehung setzt, d.h. eine Gutschrift ist nur dann Sozialkapital, wenn sie für den Akteur funktionalen Charakter aufweist und damit einen Ertrag produziert.

(6) Gutschriften sind eine Teilmenge des kartesischen Produkts aus Teilnehmern, Ressourcen und Akteur, d.h. um von einer Gutschrift reden zu können, muss ein Teilnehmer bereit sein, dem Akteur, dem Sozialkapital zugeordnet werden kann, Ressourcen zur Verfügung zu stellen.

(7) Gegenseitiges Kennen und Anerkennen ist eine Teilmenge des kartesischen Produkts aus Akteur und Teilnehmern, d.h. zum Auftreten eines Systems gegenseitigen Kennens und Anerkennens bedarf es eines Akteurs, dem Sozialkapital zugeordnet werden kann und mindestens eines Teilnehmers (da GK eine [Beziehungs-] Relation impliziert, kann auf Rel verzichtet werden). Gegenseitiges Kennen und Anerkennen soll eine positive Kooperationshaltung implizieren.

(8) Tauschprozesse sind eine Teilmenge des kartesischen Produkts aus Akteur, Teilnehmern und Ressourcen, d.h. zum Auftreten von Tauschprozessen als eine mögliche Bedingung von Sozialkapital bedarf es eines Akteurs, dem Sozialkapital zugeordnet werden kann, mindestens eines Teilnehmers sowie Ressourcen, die ausgetauscht werden.

(9) Verpflichtungen sind eine Teilmenge des kartesischen Produkts aus Teilnehmern und Akteur; ein Teilnehmer fühlt sich einem Akteur, dem Sozialkapital zugeordnet werden kann und mit dem er in Verbindung steht, verpflichtet (da V eine [Beziehungs-] Relation impliziert, kann auf Rel verzichtet werden).

(10) Investitionen sind eine Teilmenge des kartesischen Produkts aus Akteur, Kapital und (Beziehungs-) Relationen, d.h. zum Auftreten einer Investition als Bedingung von Sozialkapital bedarf es eines Akteurs, dem Sozialkapital zugeordnet werden kann, Kapitals (sei es Human-, Sozial- oder physisches Kapital), das 
investiert wird sowie mindestens einer Relation, in die investiert wird. (Kapital ist die Vereinigungsmenge von Sozial-, Human-, Finanz- und Physischem Kapital.)

(11) Transferierungen sind eine Teilmenge des kartesischen Produkts aus Teilnehmer, Verpflichtungen und Akteur, d.h. ein Teilnehmer transferiert eine Verpflichtung, die er jemand anderem gegenüber verspürt, auf den Akteur, dem Sozialkapital zugeordnet werden kann.

\section{Dritter Rekonstruktionsschritt}

$\mathrm{Q}$ ist ein Modell der integrativen Theorie über Sozialkapital, gdw

(1) $\left\langle\mathrm{S}^{\mathrm{I}}, \mathrm{A}, \mathrm{Rel}, \mathrm{Inf}\right.$, Fun,Ert,Gut,R,L $\mathrm{Li}^{\mathrm{Me}}, \mathrm{Lok}^{\mathrm{A}}, \mathrm{G}^{\text {ind }}{ }^{\mathrm{koll}}, \mathrm{K}, \mathrm{Te}, \mathrm{Ta}, \mathrm{V}, \mathrm{Inv}, \mathrm{Hum}$, Fin,Phy, $\mathrm{Kap}, \mathrm{Tr}\rangle \in \mathrm{M}_{\mathrm{P}}$

(2) $\exists(a, k a p, r e l) \quad(\operatorname{Inv}[a, k a p, r e l] \rightarrow \mathrm{V}[t e, a])$

(3) $\exists(a, t e, r) \quad(\mathrm{Ta}[a, t e, r] \rightarrow \mathrm{V}[t e, a])$

(4) $\forall(t e, a) \quad\left(\mathrm{V}[t e, a] \wedge \mathrm{Gut}[t e, r, a] \wedge\right.$ Fun $[g u t, a, e r t] \rightarrow$ Gut $\left.[t e, r, a]:=\mathrm{S}^{\mathrm{I}}[a]\right)$

(5) $\forall(t e, v, a) \quad\left(\operatorname{Tr}[t e, v, a] \wedge\right.$ Gut $[t e, r, a] \wedge$ Fun $[g u t, a, e r t] \rightarrow$ Gut $\left.[t e, r, a]:=\mathrm{S}^{\mathrm{I}}[a]\right)$

(6) $\neg \exists(a, t e) \quad(\operatorname{Rel}[a, t e] \rightarrow \operatorname{Rel}:=\mathrm{S}[a])$

(7) $\neg \exists(t e, a) \quad(\mathrm{V}[t e, a] \rightarrow \mathrm{V}:=\mathrm{S}[a])$

(8) $\exists(a) \quad\left(\right.$ Ertemp $\left.[a]: \mathrm{SI}[a] \rightarrow \mathfrak{R}_{0+}\right)$

Diese Bedingungen meinen:

(2) Es gibt mindestens eine Verbindung zwischen einem Akteur, Kapital und (Beziehungs-) Relationen aus $\mathrm{M}_{\mathrm{P}}$ (also aus der Menge aller möglichen Anwendungsbeispiele des Sozialkapitalkonzeptes) für die gilt, wenn ein Akteur Kapital in eine (Beziehungs-) Relation investiert, dann entsteht eine soziale Verpflichtung ihm gegenüber. Der Existenzquantor gibt an, dass nicht jede Investition eine Verpflichtung nach sich zieht. (Inv ist also weder eine notwendige noch eine hinreichende Bedingung für $\mathrm{V}$; die entscheidende Mittlerfunktion sprachlicher Kognition wird im nachfolgenden Kapitel unter die Lupe genommen.)

(3) Tauschprozesse zwischen einem Akteur und Teilnehmern (Akteur und Teilnehmer tauschen Ressourcen aus) können Verpflichtungen begründen. Zur Entstehung von Verpflichtungen bedarf es - wie soeben gesagt - nicht notwendig einer bewussten Investition. Der Existenzquantor gibt an, dass nicht jeder Tauschprozess Verpflichtungen nach sich zieht.

(4) Für alle Verbindungen zwischen Teilnehmer und dem fokalen Akteur gilt, wenn ein Teilnehmer eine soziale Verpflichtung gegenüber dem Akteur verspürt, dann entsteht soziales Kapital. Dies jedoch nur unter der Bedingung, dass Te eine Gutschrift über Ressourcen für A bereithält, für die wiederum gilt, dass sie für A funktional ist, so dass A hierüber einen Ertrag realisieren kann. Der Allquantor 
gibt an, dass jede soziale Verpflichtung, die diesen Bedingungen genügt, zu Sozialkapital führt.

(5) Für alle Verbindungen zwischen Teilnehmer, Verpflichtung und dem fokalen Akteur aus $\mathrm{M}_{\mathrm{P}}$ gilt, wenn ein Teilnehmer eine Verpflichtung, die er einem anderen gegenüber (bspw. in Folge der Internalisierung der Norm generalisierter Reziprozität) verspürt, auf den fokalen Akteur transferiert, dann entsteht soziales Kapital. Dies jedoch erneut nur unter der Bedingung, dass Te eine Gutschrift über Ressourcen bereithält, für die gilt, dass A hierüber funktional einen Ertrag realisieren kann.

(6 u. 7) Beziehungsrelationen und Verpflichtungen sind innerhalb des hier vorgeschlagenen Theoriemodells dezidiert kein Sozialkapital. Es gibt also keine Relation zwischen einem Akteur und einem Teilnehmer und auch keine Verpflichtung, die ein Teilnehmer gegenüber einem Akteur verspürt, für die gelten würde, sie seien Sozialkapital; da ich mich hier von den untersuchten Autoren strikt unterscheide, wird dies an dieser Stelle eigens angeführt.

(8) Erträge sind eine (metrisch skalierte, über eine positive reelle Zahl ausdrückbare) positive Funktion von Sozialkapital. Der Existenzquantor gibt an, dass Erträge nicht nur auf Sozialkapital, sondern auf alle anderen Kapitalformen zurückgeführt werden können. Bei der Aussage "Erträge sind eine Funktion von Sozialkapital" handelt es sich um eine analytische Formulierung. Ein Ertrag kann damit nicht sinnvoll als Wirkung von Sozialkapital ausgewiesen werden; lediglich seine empirischen Manifestationen stellen Wirkungen dar (was oben durch das hochgestellte "emp" zwecks Verdeutlichung zusätzlich symbolisiert wurde). Da diese Manifestationen die unterschiedlichsten Ausprägungen aufweisen und in den verschiedensten Bereichen anzutreffen sein können, verfügt das hier vorgeschlagene Theoriemodell über eine generelle Reichweite (und das, obwohl es auf der Individualebene anzusiedeln ist). 


\subsection{Sozialkapitalbegriff und sozialer Gegenstand}

Nachdem wir festgelegt haben, was konkret unter "Sozialkapital" verstanden werden soll, wollen wir uns nun das Verhältnis von Begriff und Gegenstand etwas genauer anschauen. Der Gegenstand, den wir mit "Sozialkapital" meinen, ist nicht einfach so in der Welt und wird von Sozialwissenschaftlern lediglich aufgenommen und etikettiert. Vielmehr ist er Resultat komplexer sprachlicher Ordnungsleistungen, d.h. es geht im Folgenden um eine Ontologie des Sozialkapitals. Diese Ontologie ist aus dreierlei Gründen lediglich eine "mögliche":

1. Das den Überlegungen zugrundeliegende Theoriemodell wurde unter Verweis auf theoretische Pluralität ebenfalls nur als möglich ausgewiesen; andere Konstruktionen (etwa makrotheoretische, die ich gleichwohl für begriffstheoretisch problematisch halte) zögen insofern auch abweichende ontologische Formulierungen nach sich.

2. Hier wird eine reale Situation lediglich simuliert, d.h. ich unterstelle etwa bestimmte sprachliche und geistige Leistungen von Akteuren sowie einen bestimmten institutionellen Kontext; sowohl die Leistungen wie der Kontext, könnten realiter auch andere Formen annehmen bzw. anders repräsentiert sein und dann immer noch Sozialkapital im durch das Theoriemodell propagierten Verständnis als Konsequenz nach sich ziehen (weiter unten wird hierauf noch näher eingegangen).

3. Schließlich müssten andere allgemeine Ontologien über die soziale Realität als die von Searle und Berger/Luckmann auch andere spezielle Ontologien über Sozialkapital zur Folge haben.

Die nun zu entwickelnde Ontologie setzt fundamentaler an als die Betrachtung der abhängigen Variable "Sozialkapital" innerhalb einer sozialwissenschaftlichen Theorie. Im letztgenannten Fall wird Sozialkapital etwa als Resultat von Interdependenzen und Austauschprozessen zwischen Akteuren gesehen, als Folge von Transferierungen oder von Investitionen in Beziehungen. Wenn es sich bei ontologischen Reflexionen allgemein um die Ordnungs- und Begriffsbestimmungen des Seienden dreht, dann erhalten wir die Ontologie über Sozialkapital, wenn wir die Ordnungs- und Begriffsbestimmungen analysieren, die Menschen konkret vornehmen müssen, damit es Sozialkapital geben kann.

Bei der folgenden Analyse handelt es sich um ein reduktives Verfahren; reduktiv deshalb, weil die Entstehung eines sozialen Gegenstandes auf die Bedingungen seiner Möglichkeit zurückgeführt wird. So kommt es zu einer strukturlogischen und dabei konstitutiven Begriffsreihe, in der Bedingtes und Unbedingtes in eine notwendige Beziehung zueinander gebracht werden. Das wissenschaftliche Auge wird dabei auf sprachliche und geistige Prozesse, die ich als Handlungen interpretiere, gelenkt. 


\section{Sozialkapital und "innere" Sprechakte}

Um diesen Standpunkt zu verdeutlichen, möchte ich zunächst die Vorstellung von potentiell-investivem Sozialkapital, d.h. von einem Vermögenswert bzw. einem Sparguthaben einführen. So soll auf die Bedingungen verwiesen werden, dank derer ein Akteur erst sein Sozialkapital zum Einsatz bringen kann ${ }^{436}$. Vor allem muss ein anderer nämlich eine Verpflichtung gegenüber dem Akteur verspüren und willens sein, diese bei entsprechender Gelegenheit auch einzulösen. Damit werden - erneut stark vereinfacht gesprochen - Kognitionen wie etwa "Ich schulde ihm/ihr eine Gefälligkeit" und "Ich werde diese Gefälligkeit auch einlösen" zu Bedingungen der Möglichkeit von Sozialkapital (dies wird unten noch ausführlich dargestellt). Die Kognitionen sind also geistige Prozesse, die in ihrer Sprachlichkeit zu untersuchen sind, denn "um etwas Objektives zu erwischen etwas, woran wir uns festbeißen können -, müssen wir den Worten nachspüren" (Quine 1985: 11).

Obwohl es sich bei Kognitionen grundsätzlich um geistige Akte von Individuen handelt, lassen sie sich als "sozial" kennzeichnen: a) Sie sind sprachlich und die Sprache legt durch ihre sozial kodifizierten Gebrauchsregeln in nur schwer zu überschätzendem Maße den kognitiven Möglichkeitsraum fest; b) sie sind als eine Reaktion auf das Tun und Lassen anderer Akteure sowie c) als eine Selbstkommunikation bzw. - mit Mead (1980: 245) gesprochen - als "ein nach innen verlagertes Gespräch" interpretierbar. "Wir übernehmen die Rollen anderer uns selbst gegenüber nicht deshalb, weil wir einen bloßen Nachahmungstrieb unterliegen, sondern weil wir in Reaktion auf uns selbst nach Lage der Dinge die Einstellung einer anderen Identität annehmen, als der direkt handelnden."437 (ebenda: 246)

Insofern möchte ich Kognitionen an dieser Stelle als "innere" Sprechakte kennzeichnen. Damit wird eine Handlungsperspektive konzeptionell ermöglicht,

436 Im Unterschied zu ökonomischem Kapital weiß man natürlich nie genau, ob das (zunächst) nicht-investiv verwendete soziale Kapital bei Bedarf auch tatsächlich verfügbar ist: Angespartes Geld ist i.d.R. jederzeit einsetzbar, und man kann ziemlich genau angeben, was hierüber zu erwerben ist. Über Sozialkapital lässt sich hingegen nicht permanent verfügen, und man ist vielfach auch nicht imstande, konkret anzugeben, welcher Gegenwert nun erwartet werden darf; die Konvertibilität muss als relativ unsicher gelten. Freilich ist dies kein grundsätzlicher Unterschied zu ökonomischem Kapital, steht dies doch permanent in Abhängigkeit vom Marktgeschehen und von politischen Entscheidungen.

437 Schirn (1974a: 12) sieht die Kommunikationstheorie Meads "als mittelbare Vorläuferin der Sprechakttheorie", da sie "im Horizont sozialer Interaktion die sog. pragmatische Dimension der Sprache zu erschließen versucht." Bei Berger/Luckmann (1980: 32) heißt es im Meadschen Sinne: "Meine Einstellung auf mich selbst ist ein typischer Spiegelreflex auf Einstellungen des Anderen zu mir". Natürlich finden sich solche Überlegungen auch innerhalb der Kognitionspsychologie: "In social interaction with somebody else, how do we decide whether smile, gaze, voice tone or speech content are the most reliable signals of the partner's anxiety? The way we categorize, represent and react to social information is ... impossible to comprehend without a careful analysis of the surrounding culture. The first point is thus that social cognition may not be reduced to individual cognition" (Forgas 1981: 266f.). 
d.h. die handlungstheoretisch interpretierbaren Operationen, die wir in der und über die Sprache vollziehen, treten in den Blickpunkt: "Haben wir uns einmal klargemacht, daß wir nicht den Satz, sondern die Äußerung in einer Sprechsituation untersuchen müssen, dann können wir überhaupt nicht mehr übersehen, daß eine Handlung vollzieht, wer eine Feststellung trifft." (Austin 1979: 158) Aber auch das "innere Reden ist stets aktuelle sprachliche Handlung" (Kamlah/Lorenzen 1996: 61) im Sinne einer individuellen Verständigung; kommunikationstheoretisch formuliert, fallen Sender und Adressat zusammen ${ }^{438}$.

Nun lässt sich fragen, ob diese Perspektive hinsichtlich sozialwissenschaftlicher Handlungstheorien anschlussfähig ist. Man könnte etwa argumentieren, die inneren Sprechakte seien lediglich Intentionen oder Überzeugungen und insofern Teil des Präferenzsystems einer Person. Da sie Konsequenzen in der Außenwelt aufweisen - sie bringen nämlich Sozialkapital zum Entstehen und führen dazu, dass es auch eingelöst werden kann - ist es jedoch notwendig, auch diese als Handlungen zu klassifizieren ${ }^{439}$. Die Bereitschaft etwa, einem weitläufigen Bekannten zu einem Arbeitsplatz zu verhelfen, besitzt keinen von ihrer Repräsentation unabhängigen ontologischen Status, d.h. sie existiert nur dank einer konstitutiven sprachlich vorliegenden Kognition - wie wollte man willens sein, einem anderen Menschen einen Job zu vermitteln, wenn man nicht über die Sprache verfügte, dies zu denken?

In seinen "metatheoretischen Reflexionen über Handlungstheorien" bringt auch Volker Dreier auf Basis einer vergleichenden Analyse ein Handlungsverständnis, das zwischen inneren und äußeren Handlungen unterscheidet, zum Ausdruck: "Zunächst können wir festhalten, daß eine Handlung das ist, was wahrnehmbar ist, also Verhalten, eine Tat. Ebenso ist aber auch zu fragen, ob die Ausführung innerpsychischer Prozesse, wie bspw. Nachdenken oder kognitives Problemlösen, als Handlungen bezeichnet werden können. Diese Frage können wir unter theoretischen Gesichtspunkten mit 'Ja' beantworten, da auch solche Prozesse durch die Wahl von Alternativen verursacht werden können. Eine Handlung besitzt dieser Auffassung zufolge sowohl eine innere als auch eine äußere Seite, wobei sich mit der inneren Seite insbesondere die psychologischen Kognitionstheorien befassen." (Dreier 1996: 64)

Während Dreier hier jedoch vorrangig Handlung von der Selektion einer Alternative her bestimmt, letztlich die inneren Prozesse hauptsächlich als

\footnotetext{
438 "Wir kommunizieren primär mit anderen, doch ebenso mit uns selbst" (Searle zitiert nach Chomsky 1977: 71). In Anbetracht der Zeit, die wir nicht in Gesellschaft anderer verbringen bzw. in der wir uns nicht kommunikativ am sozialen Geschehen beteiligen, dürften wir Menschen m.E. sogar primär mit uns selbst kommunizieren.

439 Auch Max Weber (1980: 1) möchte unter "Handeln" u.a. ein "innerliches Tun" verstanden wissen. Bei Alfred Schütz ist Handeln in phänomenologischer Tradition ohnehin untrennbar mit Intentionalität und insofern mit Bewusstseinsaktivität verbunden. Besonders deutlich formuliert diese Position Thomas Luckmann (2002). Handeln ist für ihn eine "subjektive Bewußtseinsleistung" (ebenda: 96) bzw. ein "subjektiv vorentworfene(r) Erfahrungsverlauf" (ebenda: 97).
} 
Komplement zu äußerem Handeln interpretiert (und daher auch Psychologen analytisch zuständig sieht), hebe ich vor allen Dingen auf die Eigenständigkeit der von mir oben als "innere" Sprechakte bezeichneten, sozial zu interpretierenden Kognitionen sowie ihrer Konsequenzen in der Außenwelt ab; Konsequenzen, die nicht unbedingt aus einem externen Gegenstück bestehen müssen, denn allein die Existenz eines Sparguthabens an Sozialkapital ist schon eine solche Konsequenz, die sich u.a. kausal auf eine sich über einen inneren Sprechakt konstituierende Intention zurückführen lässt.

Sprachlich-kognitive Prozesse, innere Sprechakte, sind - so lässt sich die vorangehende Argumentation nochmals zusammenfassen - als Handlungen zu rekonstruieren, weil sie letztlich Wirkungen in der Außenwelt entfalten und die Existenz bestimmter sozialer Gegenstände begründen können. Gleichwohl sind diese Handlungen andere als jene, die wir gemeinhin in den Sozialwissenschaften untersuchen. Eine innere Handlung kann auch alleine stehen; jede äußere Handlung basiert indes auf kognitiven Prozessen, auf mentalen Modellen von der Welt, so dass aus ontologischer Perspektive die inneren Handlungen zentral sind; sie sind konstitutiv für die Gegenstände der institutionellen Realität, denn sie sind es, dank derer Bedeutungsproduktion stattfindet. Mit Searle (2001: 127f.) lässt sich diesbezüglich von einer Welt-auf-Wort-Ausrichtung sprechen, d.h. die Realität wird dank und gemäß einer sprachlichen Repräsentation verändert. So schaffen die oben genannten inneren Sprechakte teleologisch qua der Fähigkeit des Bewusstseins zur Intentionalität eben jenen Gegenstand, den wir wissenschaftlich dann als "Sozialkapital" bezeichnen.

\section{Sozialkapital und vorwissenschaftliche Theorie}

Können wir nun auf Basis der erkenntnis- und wissenschaftstheoretischen Erörterungen die Referenz von "Sozialkapital" genau bestimmen, um so möglicherweise Informationen hinsichtlich einer Ontologie des Sozialkapitals zu gewinnen? Dies war ja eines unserer Ziele: Ausgehend von dem wissenschaftlichen Erkenntniskonstrukt, wollten wir zu den Bedingungen der Möglichkeit des hierüber bezeichneten realweltlichen Gegenstandes vorstoßen.

Unterstellen wir, der Sozialkapitalbegriff habe mittlerweile weitreichend Eingang in die Alltagssprache gefunden, so bezieht sich "Sozialkapital" (der Begriff) deshalb auf Sozialkapital (den Gegenstand), weil er jene Gedanken expliziert, die eine Person hat, wenn sie an Sozialkapital denkt, d.h. diesen Gegenstand kognitiv repräsentiert ${ }^{440}$. Da intentionales Bewusstsein ein Bewusstsein von etwas ist, hat es ein Objekt (sei dieses auch nur fiktional), womit Referenz über Intentionalität etabliert wird und nicht mehr - wie noch in einer Abbildtheorie der Bedeutung -

\footnotetext{
440 Oder etwas komplizierter formuliert: "The intentional content of one's thought is the meaning of one's thought by means of which one represents the object." (Johansson 2003: 242)
} 
eine metaphysische Beziehung zwischen einem außersprachlichen Sachverhalt und einem sprachlichen Ausdruck darstellt.

Damit müssen wir eine Idee davon haben, was Sozialkapital zu Sozialkapital macht, um einen Aspekt der Realität entsprechend zu kennzeichnen und zu erfahren. (Genauso wie wir wissen müssen - wie Popper anmerkt [vgl. die Ausführungen in Kapitel 4.4.] - was ein Glas zu einem Glas macht, damit wir auf ein bestimmtes Individuum als "dieses Glas" referieren können - allerdings werden wir Sozialkapital nicht in gleicher Weise in der Außenwelt aufzeigen können, wie ein Glas.) In dieser Lesart haben wir es bei Sozialkapital mit einer Universalie zu tun; diese manifestiert sich nun aber in nichts anderem als in der Theorie des Sozialkapitals, weil die Theorie eben genau das zum sprachlichen Inhalt hat, was Sozialkapital zu Sozialkapital macht.

Wenn nun aber der Sozialkapitalbegriff noch keineswegs weitreichend in die Alltagssprache Eingang gefunden hat, wir aber dennoch davon ausgehen, dass die hierüber bezeichnete Universalie und in weiterer Ableitung individuelle Gegenstände - konkrete Vorkommnisse bzw. Instanzierungen der Universalie existieren, dann ist an dieser Stelle mit "Theorie" zunächst einmal nur das gemeint, was im Alltag kognitiv benötigt wird, also das, was wir wissen müssen, um jenen Gegenstand, den Wissenschaftler als "Sozialkapital" bezeichnen, vorzustellen. D.h. es ist nicht notwendig, dass in diesen Vorstellungen genau das Wort "Sozialkapital" auftaucht.

Genauso wie wir keine Schwierigkeiten haben, zu akzeptieren, dass man in unterschiedlichen Sprachen verschiedene Worte verwendet, um das auszudrücken, was im Deutschen als "Sozialkapital" firmiert (man benutzt also verschiedene Worte für einen Begriff), so lassen sich auch in ein und derselben Sprache unterschiedliche sprachliche Wendungen dafür finden. Die benutzten Ausdrucksweisen sind insoweit kontingent, als es lediglich notwendig ist, einen bestimmten Vorstellungsinhalt hierüber zu formulieren bzw. zu transportieren. Die Bedingungen der Möglichkeit der Existenz dieses Vorstellungsinhalts bestehen dann eben genau in seiner Formulierung und eine korrekte Anwendung in sozialweltlichen Situationen setzt eine Synthetisierung mit der Anschauung, mit konkreten menschlichen Verhaltensweisen voraus. Dies führt uns dann zum Gegenstand, auf den "Sozialkapital" referiert.

Sozialkapital ist kein Bestandteil der Außenwelt wie dies Menschen, Schallwellen oder Papierstücke sind. Wir benötigen sprachlich vorliegende Vorstellungsinhalte, um etwa aus Schallwellen eine Äußerung, aus dieser eine Information und daraus wiederum eine Hilfeleistung zu machen. So wird ein dem Konzeptualismus nahestehender Standpunkt ermöglicht, bei dem die Universalie Sozialkapital zwar in Abhängigkeit von sprachlich-kognitiven Leistungen, ihre Existenz aber außerhalb von menschlichem Denken und Sprechen, dabei aber instanziert - d.h. 
am Konkreten vorkommend - begriffen werden kann ${ }^{441}$. Sozialkapital ist gemäß dieser Position ontologisch subjektiv - es existiert nur, weil es bewusstseins- und sprachbegabte Wesen gibt; Aussagen über es sind hingegen epistemisch objektiv, d.h. ist Sozialkapital einmal etabliert, dann hat die Wahrheit oder Falschheit der Aussagen über dies keineswegs etwas mit subjektiven Einstellungen zu tun.

Die Entstehung von Sozialkapital ist also abhängig vom Vorliegen eines bestimmten Wissens, das wir in philosophischer Diktion auch als alltagsweltliche bzw. vorwissenschaftliche Theorie und in der Psychologie als mentales Modell oder kognitives Schema des Sozialkapitals begreifen können ${ }^{442}$. Da wir uns hier für das konkrete Auftreten von Sozialkapital interessieren, ist nun zu klären, wie die Universalie instanziert wird. Dies geschieht, indem die alltagsweltliche Theorie bzw. das mentale Modell des Sozialkapitals im Kontext einer Beziehungsrelation Anwendung findet, d.h. die individuellen konzeptionellen Vorstellungen sowie das Wissen um ihre "angemessene" Anwendung entscheiden darüber, ob und wann es einen diesbezüglichen realweltlichen Gegenstand geben kann. Eine Instanzierung von Sozialkapital lässt sich in diesem Sinne ontologisch auch als konzeptgesteuert begreifen: Ein Konzept wird auf eine konkrete Situation angewandt, die so im soziologischen Sinne eine bestimmte, gegenstandskonstitutive Bedeutung erhält.

Nun stellt sich allerdings noch die Frage, auf welche Weise Konzepte auf soziale Situationen angewandt werden? Um dies mit Blick auf Sozialkapital zu beantworten, benötigen wir Inhalt und Form, d.h. wir benötigen ein Konzept von Sozialkapital (Inhalt) und ein allgemeines Bestimmungsschema über die Entstehung institutioneller Realität (Form). Bezüglich des Konzepts rekurriere ich auf das erarbeitete integrative Theoriemodell und daraus ableitbare Überlegungen für die Bewusstseinsprozesse der in der Alltagswelt handelnden Personen; bezüglich des Bestimmungsschemas rekurriere ich auf die innerhalb des ontologischen Grundlagenteils dargestellten sprachlich-konstitutiven Regeln, die den institutionellen Sachverhalten zugrundeliegen.

Der Regelablauf der Konzeptsteuerung für Sozialkapital lässt sich nun anhand des auf Searle gründenden ontologischen Bestimmungsschemas herausarbeiten. Nochmals sei darauf hingewiesen, dass die Regelanwendung keineswegs voll bewusst verlaufen wird; genauer gesagt, dürfte sie dies wohl nur in den seltensten Fällen tun. Aber die vorbewusste Anwendung setzt die Erlernung der lediglich sprachlich denkbaren ("linguistically loaded" [Searle 1999b]) Regeln und diese

441 Nominalisten halten Universalien für rein sprachliche Entitäten, mit der innerhalb von Sprachgemeinschaften Kategorien gebildet werden (universalia post rem); in der platonistischen Tradition wird den Universalien hingegen ein unabhängiger ontologischer Status zugebilligt (universalia ante rem). Der Konzeptualismus wiederum folgt dem Nominalismus darin, dass er Universalien zwar zunächst als begriffliche Entitäten auffasst, dennoch aber sollen diese Entitäten reale Eigenschaften der Dinge wiedergeben.

442 Fischer/Wiswede (2002: 187) sprechen hinsichtlich von kognitiven Schemata auch von "Denkregeln", womit sie insbesondere die sprachliche und normative Komponente eines Schemas herausstreichen. Diese Komponenten werde ich weiter unten für Sozialkapital noch genauer explizieren. 
Erlernung wiederum Bewusstsein voraus. "Der Prozeß der Schaffung institutioneller Tatsachen kann vor sich gehen, ohne daß sich die Teilnehmer dessen bewußt sind, daß er sich in dieser Form vollzieht." (Searle 1997a: 57)

\section{Sozialkapital und sprachlogische Struktur}

Um also das Entstehen und die Existenzweise von Sozialkapital zu bestimmen, müssen die zentralen Komponenten und Axiome der Searleschen Ontologie sozialer Realität in Beziehung zu den innerhalb des entwickelten Theoriemodells genannten Bestimmungen hinsichtlich (des zu diesem Zeitpunkt der Argumentation nun als realweltlich existierend unterstellten ${ }^{443}$ ) Sozialkapitals gesetzt werden. Die konstitutiven sprachlogischen Regeln, die nach Searle verantwortlich für institutionelle Realität zeichnen, sollen gegenstandsspezifisch aufgefüllt werden.

Sozialkapital eignet sich insofern besonders für eine Illustration der Searleschen Überlegungen, weil darin institutionelle Tatsachen dadurch ausgezeichnet sind, dass hierüber ein System von Rechten und Pflichten etabliert wird. Gerade dies lässt sich für Sozialkapital anschaulich zeigen. Die innerhalb des entwickelten Theoriemodells erarbeitete begriffliche Definition lautete: Unter "Sozialkapital" sollen funktionale (Fun), nicht-justiziable (Inf) Gutschriften (Gut) über Ressourcen (R) anderer Akteure (Te) verstanden werden, auf die ego (A) dank seiner Beziehungen (Rel) zu diesen anderen Akteuren sowie deren positiver Kooperationshaltung (GK) absichtlich oder unabsichtlich mit dem Ergebnis einer Erwirtschaftung eines Ertrages (Ert) aktuellen Zugriff nimmt bzw. potentiell Zugriff nehmen könnte.

Ein ganz elementarer Fall einer gemäß des Theoriemodells möglichen Entstehung von Sozialkapital lautet: Wenn A etwas für B tut, erwächst daraus in Abhängigkeit von gegebenen Kontextbedingungen für B eine Verpflichtung, hierauf mit einer Gegenleistung zu antworten. Besteht nun seitens B der Wille, eine solche Gegenleistung auch tatsächlich zu erbringen, so kann von einer Gutschrift über Ressourcen gesprochen werden, die A besitzt und die in dem Fall für A Sozialkapital darstellt, wenn sie bei Einlösung für A in Hinblick auf mindestens eine Zielstellung nützlich (bzw. ertragreich) wäre ${ }^{444}$.

Unsere Ausgangssituation scheint also zu sein, dass A etwas für B tut (A könnte bspw. B bei der Wohnungsrenovierung behilflich sein). Was könnten nun mögliche Bedingungen sein, unter denen in dieser Situation Sozialkapital entsteht? Zur Erinnerung stelle ich zunächst noch einmal das auf Searle gründende

\footnotetext{
443 Denn: "Vom Standpunkt einer Beschreibung eines Vorgangs der Theoriebildung ist alles, dem wir Existenz zubilligen, eine Setzung und, vom Standpunkt der gebildeten Theorie, gleichzeitig real." (Quine 1980: 53f.)

${ }^{444}$ Das Beispiel ist relativ abstrakt formuliert, denn es geht ja nicht um eine detaillierte Analyse einer ganz bestimmten Interaktion, sondern um sprachlogische Tiefenstrukturen der Entstehung und Existenz eines sozialen Sachverhalts.
} 
Rekonstruktionsschema vor: Für alle X gilt, sie werden ein $\mathrm{Y}$ und damit ein Teil der institutionellen Wirklichkeit, wenn einem $\mathrm{X}$ eine Bedeutung zugewiesen wurde, für die wiederum gilt, dass sie über kollektive Intentionalität erfolgte und innerhalb eines spezifizierbaren Kontext, der die Bedingungen enthält, unter denen der Übergang von X zu Y möglich wird, Akzeptanz beanspruchen kann (ein geschaffenes $\mathrm{Y}$ bleibt so lange ein Element der institutionellen Wirklichkeit, wie die Bedeutungszuweisung anerkannt $[\mathrm{An}]$ wird). Formal:

$\forall(x) \quad(\mathrm{Bz}[x] \wedge \mathrm{I}[b z] \wedge \mathrm{Ak}[b z, k]) \rightarrow \mathrm{x}=\mathrm{y}\left(\right.$ wobei $\left.\mathrm{y} \in \mathrm{W}^{\mathrm{i}}\right)$ d.h.:

welchen Entitäten $(\mathrm{X})$ wird

über kollektive Intentionalität (I)

die unter bestimmten Bedingungen $(\mathrm{K})$ akzeptierte (Ak)

Bedeutung zugewiesen $(\mathrm{Bz})$,

als Sozialkapital (Y)

zu zählen? Ferner:

in Folge welcher Iterierungen (It) kommt es dazu und

welche Form kontinuierlicher Anerkennung (An) trägt zum Fortbestand von Sozialkapital bei?

A tut etwas für B erscheint nur auf einen ersten Blick als die vermeintlich rohe Tatsache - also die Tatsache, die aus der reinen Physik des Geschehens hervorgeht. Dass A nun aber etwas für B tut, bedarf schon einer ersten Interpretation und damit einer (kollektiven) Bedeutungszuweisung:

1. Der rohen Tatsache "A tut etwas"445 (X) wird von den beteiligten Akteuren qua kollektiver Intentionalität (I) die Bedeutung zugewiesen (Bz), als "A tut etwas für B" (Y) zu zählen; dies unter der Bedingung (also innerhalb eines sachlichen Kontextes) "A tut etwas, von dem A und B glauben, dass es für B von Vorteil ist" (K).

Intentionalität meint, dass die beteiligten Bewusstseine sich auf den beschriebenen Sachverhalt richten und diesem dann eine bestimmte Bedeutung zuweisen. Dabei kommt Teleologie ins Spiel, d.h. es erfolgt eine Ausrichtung auf Normen, Zwecke und Ziele, die der durch den Sachverhalt bedingte Reiz aus sich heraus nicht hergibt. Dieser erste Schritt begründet aber noch keineswegs die Existenz

\footnotetext{
${ }^{445}$ Natürlich ließe sich einwenden, auch hier handele es sich bereits um eine Bedeutungszuweisung. Erneut möchte ich daher darauf aufmerksam machen, dass etwa eine Handlung wie das Hochheben eines Armes (repräsentiert durch den X-Terminus) eine rein physikalische Tatsache darstellt, die deutlich davon zu unterscheiden ist, dass hiermit unter bestimmten Bedingungen $(K)$ eine Wortmeldung $(\mathrm{Y})$ ausgedrückt werden soll. Da wir die rohe Tatsache aber niemals ohne Sprache darstellen oder repräsentieren können, ensteht der Eindruck, als handele es sich schon hierbei um einen von menschlicher Bedeutungszuschreibung abhängigen Sachverhalt. Aber erst wenn das Heben eines Armes für etwas anderes stehen soll als eben für dieses Heben, können wir sinnvoll von einer institutionellen Tatsache reden.
} 
von Sozialkapital; mit "A tut etwas für B" ist jetzt allerdings aus der rohen eine soziale (genauer: eine informelle institutionelle ${ }^{446}$ ) Tatsache geworden. Nunmehr muss die logische Struktur, welche konstitutiv für die Entstehung institutioneller Tatsachen ist, mehrmalig iteriert (It) werden, um zum anvisierten Gegenstand führen zu können.

2. "A tut etwas für B" (der durch Iterierung [It] erzeugte neue X-Term, [also der Y-Term der vorangegangenen Stufe, die geschaffene institutionelle Tatsache]) wird unter der Bedingung "A ist formell nicht verpflichtet, etwas für B zu tun" (K) qua kollektiver Intentionalität (I) die Bedeutung zugewiesen (Bz), als "Gefälligkeit" (Y), zu zählen.

Die Akteure müssen hier keineswegs zwangsläufig die Situation als "Gefälligkeit" ("habe ihm einen Gefallen erwiesen" / "hat mir einen Gefallen erwiesen") repräsentieren. Ebenso konstitutiv wären etwa "favour" ("did him a favour" / "did me a favour") oder "habe ihm geholfen" / "hat mir geholfen", "habe ihm einen Vorteil verschafft" / "hat mir einen Vorteil verschafft" etc. Dieser wort- bzw. satzbezogener und insofern formaler Varianz steht jedoch eine inhaltliche, d.h. begriffliche wie propositionale Invarianz gegenüber. Ferner ist die genannte Kontextbedingung, unter der es zu dem Y-Terminus kommt, in einem gewissen Rahmen veränderbar, d.h. auch hier wären andere Konstellationen vorstellbar. U.a. dies war oben gemeint, wenn lediglich von "möglichen" Bedingungen für die Existenz von Sozialkapital die Rede war. (Da eine formale Logik auf einen spezifischen Gegenstand sozialer Realität angewandt wird, richtet sich das Interesse nur auf X, Y und K, denn ausschließlich hier treten Veränderungen auf; auf die explizite Anführung von I und Bz wird somit nachfolgend verzichtet.)

3. Die "Gefälligkeit" (X) zählt unter der Bedingung der "sozialen Reziprozität" (etwa: "im vorliegenden sozio-kulturellen Kontext sind Gefälligkeiten zurückzuzahlen") (K) als "Vorleistung" (Y) ${ }^{447}$.

Erneut wären abweichende sprachliche Wendungen denkbar; für "Vorleistung" etwa (schon sehr ökonomisch formuliert) "Kreditvergabe", "Vertrauensvorschuss" oder - etwas lebensweltnäher - "ich hab was gut bei ihm" / "er hat was gut bei mir" etc. Auf diese alternativen sprachlichen Wendungen werde ich innerhalb der nächsten Schritte nicht mehr eigens verweisen. Mit ihrer Anführung sollte hier lediglich gezeigt werden, inwiefern die Repräsentationsformen durchaus kontingent genannt werden können.

Gleichwohl hat diese Kontingenz ihre Grenzen. Es wäre bspw. durchaus fraglich, ob es zu dem Y-Terminus "Vorleistung" kommen würde, wenn auf der

\footnotetext{
446 Auf diese Formulierung wird weiter unten noch zurückzukommen sein.

447 Es würde den Rahmen dieser Untrsuchung sprengen, wollte man das Verhältnis von Sozialkapital und sozialer Reziprozität eingehender diskutieren. Einen solchen Versuch (weitgehend) im Anschluss an den Colemanschen Sozialkapitalbegriff unternimmt Diekmann (2004a). Für einen grundlegenden Überblick über die Soziologie der Reziprozität siehe bspw. den Sammelband von Adloff/Mau (2005a).
} 
vorangehenden Stufe nicht "Gefälligkeit", sondern lediglich so etwas wie "selbstverständliche kleine Aufmerksamkeit" gestanden hätte. Insofern bestimmt auch die Art der Beziehung zwischen Personen (eher emotional oder strategisch) sowie die vom Kontext abhängige Bewertung (die selbst eine Bedeutungszuweisung ist) des qualitativen und/oder quantitativen Ausmaß dessen, was eine Person für eine andere tut, darüber, ob es zur Bedeutungszuweisung "Vorleistung" kommen kann oder nicht (was später noch mit Blick auf die Normativität von Bedeutungszuweisungen hervorgehoben wird und die Verwobenheit zwischen Sprache und sozialer Praxis im Sinne des Wittgensteinschen Sprachspiels unterstreicht). Wer es für selbstverständlich erachtet, von seinem Bruder zu nachtschlafender Zeit von einer Party abgeholt zu werden, der wird diesen "Dienst" u.U. lediglich mit einer zeremoniellen Geste, etwa einer besonders herzlichen Umarmung, begleichen. Genau dies kann als Vergütung vollkommen ausreichend sein, denn über die Akzeptabilität der Gratifikation entscheidet letzten Endes der Empfänger (allerdings vor dem Hintergrund dessen, was sozial üblich ist).

4. Die "Vorleistung" (durch A) (X) führt (erneut) unter der Bedingung sozialer Reziprozität (etwa: "im vorliegenden sozio-kulturellen Kontext begründen Vorleistungen [also Kredite] bestimmte Ansprüche") (K) zur "Verpflichtung" (Y) (von B).

Die Vorleistung durch A zieht unter den genannten Kontextbedingungen eine Verpflichtung seitens Bs nach sich. Hier zeigt sich damit, inwiefern eine pragmatische Bedeutungstheorie notwendig ist, will man die konstitutive Logik institutioneller Wirklichkeit verstehen. Genauso wie der Satz "Ich habe eine 1 in Mathematik geschrieben" - geäußert von einem Sohn gegenüber seinen Eltern - i.d.R. darauf abzielt, Letztere zu einem bestimmten Verhalten zu bewegen und das heißt in einem ersten Schritt eine Befindlichkeit hervorzurufen, die eine Belobigung oder Belohnung nach sich ziehen kann, so ist mit einer Vorleistung die Evozierung einer Verpflichtung verbunden. Was also insbesondere sprechakttheoretisch als ein Aspekt der Bedeutung - nämlich als perlokutionärer Akt - und damit auch ontologisch in Erscheinung tritt, kann auf Grundlage einer referenztheoretischen Bedeutungstheorie gar nicht in den Blick geraten.

5. Die "Verpflichtung" (von B) (X) führt unter der Bedingung "B besitzt aktuell oder zukünftig bestimmte Ressourcen, die er bereit ist, A im Abgleich zu dessen Vorleistung zur Verfügung zu stellen" (K) zur "Gutschrift" (für A) (Y).

Hier ist die Bedingung sozialer Reziprozität nicht mehr erforderlich; diese war normativ wirksam, um aus einer "Gefälligkeit" eine "Vorleistung" und aus dieser wiederum eine "Verpflichtung" zu machen.

6. Die "Gutschrift" (X) zählt unter der Bedingung "die A durch B zur Verfügung gestellten Ressourcen bzw. die Ressourcen, die B bereit ist, A zur Verfügung zu stellen, verhelfen A zur Erwirtschaftung eines Ertrages" (K) als "Sozialkapital" (Y). 
Nur wenn die Ressourcen, bezüglich derer B willens ist, sie A zur Verfügung zu stellen, A tatsächlich zu dessen Zielverwirklichung dienlich sind, kann hinsichtlich der Gutschrift von Sozialkapital gesprochen werden, da dies innerhalb des Theoriemodells definitorisch so festgelegt wurde. Ist dies nicht der Fall, d.h. sind die Ressourcen für A nutzlos, liegt auch kein Sozialkapital vor. Damit tritt an dieser Stelle auch nochmals pointiert die beobachterrelative Eigenschaft des Sozialkapitals hervor, ist es doch nur dann das, was es ist, wenn das Kriterium der Funktionalität tatsächlich vorliegt.

Graphisch lässt sich dies nun wie folgt veranschaulichen:

Abbildung 12: Eine sprachphilosophische Ontologie des Sozialkapitals

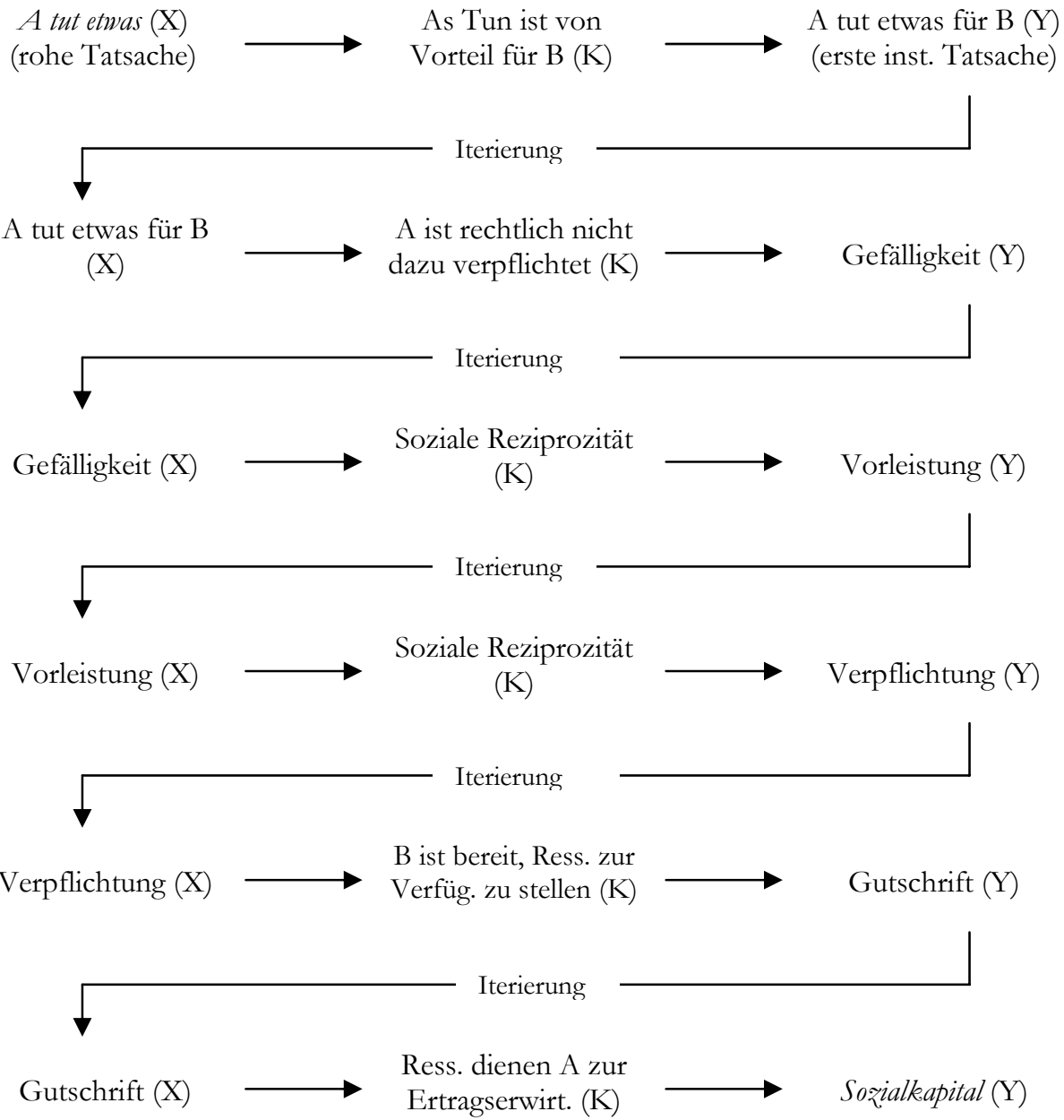


Die bisherigen Erörterungen zwingen auch zu Modifikationen an Searles allgemeiner Ontologie des Sozialen. Die Existenz des untersuchten institutionellen Sachverhalts - also von Sozialkapital - setzt nämlich keineswegs eine Bedeutungszuweisung qua kollektiver Intentionalität (und damit eine Übereinkunft) voraus. Wenn ego - wie innerhalb des Theoriemodells festgehalten wurde - nicht zwangsläufig um das Vorhandensein von Sozialkapital wissen oder bewusst darauf hingewirkt haben muss, sondern wenn einzig die Bereitschaft bzw. die empfundene Verpflichtung alters, ego bestimmte Ressourcen zur Verfügung stellen zu wollen, die Existenz von Sozialkapital begründet, dann bedarf es der Intentionalität und der Bedeutungszuweisung notwendig lediglich auf seiten alters, denn Kooperation ist an dieser Stelle nicht erforderlich. Es ist ausreichend, wenn die Intentionalität alters "auf das Verhalten anderer bezogen ... und daran in seinem Ablauf orientiert ist" (Weber 1980: 1). Gleichwohl wäre im Sinne einer Gebrauchstheorie zu erwarten, dass alle Beteiligten die notwendigen Bedeutungszuweisungen vornehmen, da sie innerhalb einer Sprechergemeinschaften den gleichen Sprachkonventionen unterliegen.

Im Falle einer bewussten Schaffung und Nutzung von Sozialkapital ist Kooperation zwingend; hier muss ego bemüht sein, den Bedeutungszuweisungen Verbindlichkeitscharakter zu verleihen, womit kollektive Intentionalität erforderlich und d.h. alter zur Kooperation aufgefordert wird. Ego muss alter dazu bringen, seinen, egos, Erwartungen zu entsprechen, also aktuell oder zukünftig eine bestimmte Gutschrift zur Verfügung zu stellen, die ihm, ego, bei Einlösung zur Nutzenrealisierung dienlich is $\mathrm{t}^{448}$.

In einem solchen Fall wäre es u.U. sinnvoll, zwischen "Gefälligkeit" und "Vorleistung" noch die Bedeutungszuweisung "Investition" einzufügen, da hierüber insbesondere der Absicht As Rechnung getragen würde, auf die Entstehung von Sozialkapital bewusst hinzuwirken. Dies könnte dann folgendes Aussehen aufweisen:

Die "Gefälligkeit" (X) zählt unter der Bedingung "A möchte bewusst auf die Entstehung von Sozialkapital hinwirken, erwartet eine Gegenleistung und vertraut auf die Anwendung der Reziprozitätsnorm" (K) als "Investition" (Y); die "Investition" (X) zählt unter den Bedingungen "sozialer Reziprozität sowie B erkennt As Bemühungen als Investition an" als "Vorleistung" (Y).

Die "Investition" kann den institutionellen Sachverhalt "Vorleistung" allerdings nicht substituieren, da sich zwar aus einer Vorleistung, nicht jedoch aus einer Investition eine Verpflichtung von B sprachlogisch (hier wie gezeigt sprechakttheoretisch als perlokutionärer Akt) ableiten lässt. Wenn institutionelle Tatsachen durch ein System von Rechten und Pflichten ausgezeichnet sind, dann liegt die Betonung bei Sozialkapital sicherlich eindeutig auf den Pflichten, denn es

448 Dies kann natülich auch misslingen: "You can be mistaken about the nature of activity you are engaged in, if you have an assumption about the collective intentionality, which is not shared by your apparent cooperators." (Searle 1998: 150f.) 
handelt sich in Searlescher Diktion um einen "informellen" institutionellen Sachverhalt. Allenfalls in einem hoch verregelten und überwachten Handlungskontext können auch die Rechte - also der Anspruch auf die Gutschrift - eine ähnliches Gewicht erlangen.

Sozialkapital bleibt nun so lange als Faktum bestehen, wie Akteur B seine Schuldverpflichtung gegenüber A anerkennt und willens ist, sie zu gegebener Zeit auch einzulösen. Damit ist auch die Speicherung von Sozialkapital auf Sprache angewiesen, weil dieses Medium eine temporäre Abstraktion, die für die Existenz des Gegenstandes notwendig ist, möglich macht: Erfahrung und Bedeutung werden gleichsam aufbewahrt, um sie zu gegebener Zeit in aktive, äußere Handlung umzusetzen.

Gemäß der Searleschen Logik lässt sich nun zusätzlich noch die für die Entstehung der genannten Gutschrift notwendige soziale Rollenzuschreibung der beteiligten Personen aufschlüsseln.

1. "A" (X) wird unter der Bedingung "A hat B eine Gefälligkeit erwiesen und erwartet dafür eine Gegenleistung" (K) über kollektive Intentionalität (I) die Bedeutung zugewiesen (Bz), als "Gläubiger" (oder "Treugeber") (Y) zu zählen.

2. "B" (X) zählt unter der Bedingung "A hat B eine Gefälligkeit erwiesen und B fühlt sich verpflichtet, diese Gefälligkeit zu erwidern" $(K)$ als "Schuldner" (oder "Treuhänder") (Y).

Die etablierten sozialen Rollen sind institutionelle Tatsachen, die aus der Bedeutungszuweisung an rohe Tatsachen (Akteure bzw. Menschen A und B) resultieren. Auch hier kann gleichwohl eine Iteration notwendig werden; so etwa, wenn A im vorliegenden Beispiel zunächst als "Hilfeleister" und erst dann als "Gläubiger" gelten würde. Der Übergang könnte bspw. abhängig von der Frage sein, inwiefern die Qualität oder die Quantität dessen, was A für B getan hat, (in jedem Falle) eine Gegenleistung begründet.

\section{Sozialkapital und Bedeutungsnormativität}

Innerhalb des Grundlagenteiles dieser Arbeit (insbesondere Kapitel 6) hatte ich argumentiert, die Bedeutungszuweisung bzw. -erfahrung (worunter dasselbe verstanden werden soll, da Erfahrung auf Basis erkenntnistheoretischer Überlegungen als konstruktiver Prozess rekonstruierbar ist) sei ein für die institutionelle Realität konstitutives synthetisches Erkenntnisurteil - etwa der Form "ich weiß, dass dies bedeutet, dass ...". Trifft dies nun aber zu, so setzt eine Ontologie des Sozialkapitals u.a. voraus, dass alter weiß, unter welchen Bedingungen eine Handlung egos als Vorleistung zu gelten hat. M.a.W.: Nur weil wir fähig sind, auf dem Hintergrund unseres Wissens eine bestimmte Bedeutungserfahrung zu machen, kann es Sozialkapital geben. Dies war ebenfalls gemeint, als oben die Rede davon war, Sozialkapital sei konzeptgesteuert. 
Andererseits ist die Bedeutungserfahrung eine konditionale, insofern sie an situative Bedingungen geknüpft ist. Innerhalb eines bestimmten Kontexts - der abhängig von einer Sprachgemeinschaft ist - bedeutet bspw. der "Wurf eines Balles in einen Korb" eben "zwei Punkte". Obwohl es sich dabei um eine zunächst willkürliche Festlegung handelt, kann doch gefolgert werden, dass Bedeutungszuweisungen mit Bezug auf eine angebbare Sprechergemeinschaft normativ sind. Wenn qua Normativität die Ausdrücke "Wurf eines Balles in einen Korb" und "zwei Punkte" in eine Ableitungsbeziehung gebracht werden, dann lässt sich die Aussage "In einem Basketballspiel zählt der Wurf eines Balles in einen Korb zwei Punkte" in gewissem Sinne als analytisches Erkenntnisurteil auffassen - Erfahrung ist zu ihrer Überprüfung jedenfalls ein ungeeignetes Mittel.

Ist also die Beziehung zwischen dem X- und dem Y-Terminus innerhalb der Formel $\mathrm{X}$ zählt als $\mathrm{Y}$ in $\mathrm{K}$ - und insofern die für die institutionelle Realität konstitutive Bedeutungszuweisung - nicht nur normativ, sondern auch analytisch? Wäre dies der Fall, so erläuterte der Y-Terminus lediglich näher, was der XTerminus für sich alleine schon aussagt. Die Idee Searles schien nun aber doch gerade zu sein, dass Menschen über Intentionalität neue Bedeutungen (in einem soziologischen Sinne) einführen, die dann institutionelle Realität konstituieren. Kann dies auf Basis von Analytizität überhaupt möglich sein?

Um dies zu klären, wollen wir die Anwendung der Formel X zählt als $\mathrm{Y}$ in $\mathrm{K}$ nochmals näher betrachten:

"A tut etwas" (X) zählt als "A tut etwas für B" (Y); dies unter der Bedingung "A tut etwas, von dem A und B glauben, dass es für B von Vorteil ist" (K). "A tut etwas für B" (X) zählt als "Gefälligkeit" (Y); dies unter der Bedingung "A ist formell nicht verpflichtet, etwas für B zu tun" (K).

Bei der erstmaligen Anwendung der Formel wird einem brute fact - nämlich der Handlung "A tut etwas" - die Bedeutung zugewiesen, als "A tut etwas für B" zu zählen. Dies ist nun jedoch ein nur dank Sprache entstandener Sachverhalt, dem seinerseits wiederum die Bedeutung zugewiesen wird, eine Gefälligkeit darzustellen. Damit haben wir es lediglich auf der ersten Stufe der Iterationslogik, also dort, wo einer rohen Tatsache eine Funktion zugewiesen wird, mit einem nichtanalytischen Link zu tun. Alle höherstufigen institutionellen Wirklichkeiten scheinen zunächst einmal prinzipiell aus einer analytischen Verbindung zwischen dem X- und dem Y-Terminus hervorzugehen, da mit dem Y-lediglich der propositionale Gehalt des X-Terminus angegeben wird - womit auch deutlich wird, warum Searle von der "Logik" der institutionellen Wirklichkeit spricht. Diese Analytizität ist aber nach der im erkenntnistheoretischen Grundlagenteil dieser Arbeit beschriebenen Ablehnung der analytisch-synthetisch-Dichotomie lediglich kontextspezifisch (und damit konventionalistisch bzw. sprachrelativ) aufrechtzuerhalten und zu rechtfertigen. Analytizität lässt sich also unter den Bedingungen von K behaupten (vgl. hierzu eine ähnliche Argumentation bei Wendel 1990). 
Nun mag eingewandt werden, hier werde ein soziologisches und ein sprachphilosophisches Bedeutungsverständnis vermischt; bei der Frage nach Analytizität ginge es um Worte und Aussagen, hier jedoch um realweltliche Sachverhalte. Allerdings benötigen wir, wie schon mehrfach erwähnt, Worte, um "Dingen" eine Bedeutung zuweisen zu können, denn ohne ein symbolisches Repräsentationsmedium bewirken wir nichts. Sprache ist gewissermaßen der "Wirt", dem die "Dinge" ihre Bedeutung verdanken ${ }^{449}$. Oder nochmals anders formuliert: Bedeutung im soziologischen Sinne zuzuweisen, heißt, sprachlich vorliegende Wissensinhalte in spezifischer Weise auszuwählen und anzuordnen, Worte und Sätze kontextgebunden anzuwenden; es heißt, mittels Sprechakten zu handeln bzw. bestimmte Sprachspiele zu spielen.

Und dies tun wir gemäß sozial erlernter Regeln, da die Bedeutung von Worten bzw. Sätzen durch den korrekten Gebrauch in einer Gemeinschaft bestimmt ist. Insofern spielt die Sprache mit uns sicherlich nicht weniger als wir mit ihr ${ }^{450}$. Bei der Formel $\mathrm{X}$ zählt als $\mathrm{Y}$ in $\mathrm{K}$ setzen wir sprachliche Zeichen in eine sozial etablierte und überwachte regelhafte Beziehung zueinander, wobei die Formel über den für den Y-Terminus konstitutiven Gebrauch informiert. Möchte man es im Sinne Wittgensteins formulieren, so geht es um die Sprachspiele, denen der YTerminus seine Bedeutung verdankt. Wenn aber der Y-Terminus angibt, welche Bedeutung (im soziologischen Sinne) wir einer Entität zugewiesen haben, diese Entität aber über den X-Terminus bezeichnet wird, dann können wir eine analytische Beziehung zwischen $\mathrm{X}$ - und Y-Terminus innerhalb eines finiten Kontextes behaupten.

Mit Blick auf eine Ontologie des Sozialkapitals führt dies nun zu einem zunächst überraschenden Ergebnis: Unter bestimmten gegebenen Bedingungen muss Sozialkapital geradezu zwangsläufig entstehen, weil die Verwendung der zu seiner Existenz notwendigen Begriffe normierten Gebrauchsregeln und damit gesellschaftlich anerkannten Handlungsschemata folgt. Freilich ließe sich entgegnen, im dem Fall, in dem A etwas ohne formale Verpflichtung für B tue, könne B das Verhalten As ja u.U. auch nicht als "Gefälligkeit" bewerten. Damit sei bewiesen, dass zwischen X und Y keine analytische Verbindung bestehe.

Die Antwort auf diesen Einwand lautet: ja und nein. Ja, weil in der Tat prinzipiell alle Erkenntnis (also auch die Erkenntnis von Bedeutung) synthetisch ist und

\footnotetext{
449 Insofern widerspreche ich an dieser Stelle auch Thomas Luckmann (2002: 208), der äußert, subjektiver Sinn werde qua sprachlicher Zeichen in sozial artikulierte Bedeutung verwandelt; Sinn sei, so Luckmann, insofern in Sprache "einverleibt". In einer solchen Diktion erscheint Sinn als etwas den sprachlichen Zeichen Vorgängiges. Mit dem Verweis auf Bedeutungsnormativität wird hier hingegen behauptet, dass Sinn nur dank sprachlicher Zeichen bzw. Symbolen einführbar ist.

450 Diese philosophische Betrachtung findet sich bekanntermaßen in L. Carolls Geschichte "Through the Looking Glass": "When I use a word", Humpty Dumpty said in rather a scornful tone, "it means just what I choose it to mean - neither more nor less." "The question is", said Alice, "whether you can make words mean so many different things." "The question is", said Humpty Dumpty, "which is to be master - that's all." (L. Carrol: Through the Looking Glass, abgedruckt im internet: www.cs.indiana.edu/metastuff/looking/lookingdir.html; Seite aufgerufen am 04.04.05)
} 
weil B über Entscheidungsalternativen verfügt. Nein, weil unter bestimmten gegebenen Kontextbedingungen die Verbindung zwischen X und Y eine logischlinguistische Ableitungsbeziehung darstellt: Gegeben "A ist nicht formell verpflichtet, etwas für B zu tun" (K), dann zählt "A tut etwas für B" (X) als "Gefälligkeit" (Y); dies ganz einfach deshalb, weil "Gefälligkeit" innerhalb der heutigen deutschen Sprechergemeinschaft qua Konvention so definiert ist: Jemand tut etwas für einen anderen, obwohl dazu keine rechtliche Verpflichtung besteht. Unter einer Bedeutungszuweisung dürfen wir daher auch eine definitorische Festlegung verstehen, wobei das, was da festgelegt wird, gegenständlichextensional betrachtet erst konkret zum Entstehen gebracht wird ${ }^{451}$.

Insofern kann man nun wiederum mit Wittgensteins Überlegung, nach der sich die Bedeutung der Worte von ihrem Gebrauch her bestimmt, fragen, ob Bedeutung radikal aus sozialer Regelhaftigkeit ableitbar sei, so dass ein Mitglied der Sprechergemeinschaft bedeutungslos handelt, wenn es gegen die Regeln dieser Gemeinschaft verstößt. So könnte B - im obigen Beispiel - etwa der Ansicht sein, er sei ein wertvollerer Mensch als A und es sei insofern selbstverständlich, dass A etwas für ihn tue; von einer Gefälligkeit könne daher keine Rede sein. Innerhalb der Sprechergemeinschaft einer antiken Sklavenhaltergesellschaft wäre dies möglicherweise ein wenig strittiger Standpunkt gewesen, nicht jedoch unter den sozialen, kulturellen und historischen Bedingungen des heutigen Deutschlands hier wäre das eine Verletzung von konventionalistischen Verknüpfungsregeln bzw. ein Verstoß gegen die kontextuellen Bedingungen, unter denen wir Analytizität behaupten dürfen. Eine Sprache korrekt zu sprechen, bedeutet, viabel an einer Lebensform teilzunehmen.

Natürlich besitzt das einzelne Individuum die Freiheit, sich absichtlich gegen die soziale Regelhaftigkeit der Sprache zu entscheiden. Es verwendet dann jedoch mit Blick auf eine Gemeinschaft die Worte auf eine inkorrekte Art und Weise und tritt so aus einem umfassenden Sprachspiel aus, vergleichbar einer Person, die die Regeln des Schachs in Teilen nicht mehr akzeptiert. "But, if the game ceases to have rules, it ceases to be a game, and, if there cease to be right and wrong uses of a word, the word loses its meaning." (Dummett 1991: 85) Dann wird ein Alternativ- bzw. im Extremfall ein nicht-viables Privatverständnis etabliert ${ }^{452}$, weil

\footnotetext{
451 Weswegen sich eine Abbildtheorie der Bedeutung als ungenügend erweist, da diese Entstehung hier gar nicht explizierbar wäre.

452 Ein literarisches Beispiel für ein solch nicht-viables Privatverständnis findet sich in Peter Bichsels (Kinder-)Erzählung "Ein Tisch ist ein Tisch". Bichsel schildert hier die Geschichte eines Mannes, der aus Überdruss am Immergleichen damit beginnt, den Dingen (und dann auch Tätigkeiten und Eigenschaften) seiner Umgebung neue Namen zu geben und der später nicht mehr in der Lage ist, seine Mitmenschen zu verstehen respektive sich mitzuteilen: "Aber eine lustige Geschichte ist das nicht. ... Der alte Mann im grauen Mantel konnte die Leute nicht mehr verstehen, das war nicht so schlimm. Viel schlimmer war, sie konnten ihn nicht mehr verstehen. Und deshalb sagte er nichts mehr. Er schwieg, sprach nur noch mit sich selbst, grüßte nicht einmal mehr." (www.yolanthe.de/stories/bichsel01.htm, Seite aufgerufen am 10.08.05)
} 
Ausdrücke sinnlos werden, wenn sie den normierten Anwendungsbedingungen widersprechen, unter denen sie mit Recht gebraucht werden können.

So etwa, wenn man sich standhaft weigerte, unter "Junggeselle" einen "unverheirateten Mann" zu verstehen und stattdessen hierüber einen "verheirateten Familienvater" bezeichnete ${ }^{453}$. Mit Mead gesprochen, wäre "Junggeselle" nun kein signifikantes Symbol mehr, weil es in dieser Verwendung eine empirisch nachweislich unzulässige Ausdrucksform der Sprachgemeinschaft darstellen würde und ergo auch die Funktion einer sozialen Verhaltenskoordination nicht mehr erfüllen könnte. Bei Dummett oder Wittgenstein hätte "Junggeselle" schlichtweg keine Bedeutung mehr, denn der Sprecher könnte mit dem Wort "ein bestimmtes Sprachspiel nicht mehr spielen." (PU \57) Hilary Putnam (1979: 41) würde einen Verstoß gegen das "Stereotyp des Terms" identifizieren ${ }^{454}$.

Durch die Negation der Regeln des Sprachgebrauchs lässt sich Analytizität nicht einfach zum Verschwinden bringen (so ist fünf auch dann noch eine ungerade Zahl, wenn man - wie es ein bekanntes Sprichwort rät - fünf auch einmal gerade sein lässt). Analytische Sätze sind "als empirisch überprüfbare Behauptungen darüber zu verstehen, wie gewisse Sprecher ihre Sprache zu verwenden pflegen." (Müller 1998: 16) Wenn dies aber so ist, dann kann man Analytizität (zumindest im Rahmen der hier angestellten Überlegungen) als

${ }^{453}$ Die Beliebigkeit der Verbindung zwischen dem Bezeichneten und dem Bezeichnendem macht es zwar möglich, mit "Junggeselle" auch einen Familienvater zu meinen; allerdings wäre eine solche Verbindung nur dann korrekt, wenn sie von der Sprachgemeinschaft geteilt würde. Das Problem ist jedoch, dass gerade in Folge der genannten Beliebigkeit keine Vernunftgründe für die eine oder andere Alternative angebbar sind: Es ist genauso sinnvoll oder unsinnig, mit "Junggesellen" einen unverheirateten Mann wie einen Familienvater zu bezeichnen. Da in unserer Sprachgemeinschaft jedoch die (nicht-rationale) Norm besteht, mit dem genannten Ausdruck einen unverheirateten Mann zu meinen, ist ein Individuum nicht mehr frei in seiner Wortwahl. "Gerade deshalb, weil das Zeichen beliebig ist, gibt es für dasselbe kein anderes Gesetz als das der Überlieferung, und weil es auf der Überlieferung begründet ist, kann es beliebig sein." (de Saussure 1967: 87) Auch de Saussure war ein dezidierter Vertreter einer Gebrauchstheorie der Bedeutung.

${ }^{454}$ Und bei Ferdinand de Saussure heißt es: "Die Sprache ist von allen sozialen Einrichtungen diejenige, welche am wenigsten zur Initiative Gelegenheit gibt. Sie gehört unmittelbar mit dem sozialen Leben der Masse zusammen, und diese ist natürlicherweise schwerfällig und hat vor allem eine konservierende Wirkung." (de Saussure zitiert nach Joas/Knöbl 2004: 482) Wenn nun das Zeichensystem "mit einer gebieterischen Kraft ausgestattet" ist (Durkheim 1999: 105f.), dann werden wir in abgewandelter Form auf Freges Behauptung, die Bedeutung eines Satzes entspreche seinen Wahrheitsbedingungen, zurückgeworfen: Wer die Bedingungen bzw. Umstände missachtet, unter denen ein Satz wahr ist (wer also die innerhalb einer Sprachgemeinschaft geltenden Bedingungen bzw. Umstände missachtet), der missachtet zugleich die Bedeutung des Satzes; seine Äußerungen sind demnach bedeutungslos. Natürlich kann man Worte aus ironischen oder metaphorischen Gründen heraus absichtlich anders verwenden, als dies normalerweise in einer Sprachgemeinschaft üblich ist. Aber diese abweichende Verwendung liegt dann immer noch im Bereich möglicher Sprachspiele, da sie nur so überhaupt als ironisch oder metaphorisch begriffen werden kann (der an der Metapherthematik interessierte Leser sei auf Davidson 1986 verwiesen). Dass Worte vielfach auch eine inkorrekte Verwendung finden, weil man sich hinsichtlich der korrekten Anwendung im Irrtum befindet, ändert nichts an der obigen Argumentation. Natürlich können Ausdrücke falsch verwendet werden, aber dennoch ist "die Bedeutung eines Ausdrucks ... sein Gebrauch in der Sprache, nicht sein Missbrauch." (Glock 2000: 438) Wenn nun im Extremfall alle Menschen mit ihren Worten etwas unterschiedliches ausdrücken würden, dann könnte man das Vorliegen einer Sprache nicht mehr behaupten. 
Resultat von sozio-historisch gewachsener Normativität begreifen - und gegen normative Auflagen kann man eben verstoßen. Sprachregeln implizieren zwar einen anonymen Imperativ, treten dem Menschen aber nicht als expliziter Befehl entgegen (vgl. Heringer et al. 1977: 41); es handelt sich lediglich um "Wegweiser" (PU \ 85) bzw. "Maßstäbe für den sinnvollen bzw. richtigen Gebrauch der Ausdrücke." (Glock 2000: 438)

Sobald wir nun zur Etablierung institutioneller Tatsachen über die semantische Bedeutung eines Ausdrucks bzw. einer Äußerung hinausgehen müssen, können wir die Behauptung einer analytischen und/oder normativen Verbindung zwischen dem X- und dem Y-Terminus nicht mehr so ohne weiteres aufrechterhalten. Dass eine "Hilfeleistung ohne formale Verpflichtung" als "Gefälligkeit" zählt, lässt sich relativ schnell als eine Festlegung akzeptieren; dass aber eine "Vorleistung" als "Verpflichtung" gelten darf, erscheint bei flüchtiger Betrachtung kaum einsichtig. Wie oben schon angeführt, hilft an dieser Stelle allerdings die Bedeutungskonzeption der Sprechakttheorie weiter, da Bedeutung hier in einen lokutionären, einen illokutionären und einen perlokutionären Akt zerfällt ${ }^{455}$.

Mit einer Vorleistung ist - ein gleiches Verständnis und die Akzeptanz des korrespondierenden Terminus bei den beteiligten Personen vorausgesetzt - eben die Evozierung einer Verpflichtung verbunden. Rein semantisch dürfen wir unter "Vorleistung" (ohne monetären und compulsiven Zugenschlag wie er wohl bei "Kreditvergabe" schon implizit wäre) im überwiegenden Teil der Fälle verstehen, dass jemand für einen anderen etwas getan hat und nun erwartet, hierfür in Zukunft eine adäquate Gegenleistung (mithin einen Mehrwert) zu erhalten. Betrachtet man nun "Vorleistung" als X-Terminus innerhalb einer ontologischen Reflexion, so ist dessen perlokutionärer Bedeutungsaspekt "Verpflichtung" (YTerminus) im Sinne der Sprechakttheorie durchaus aus einer Verbindung von Xund K-Terminus ("Vorleistung" und "soziale Reziprozität") deduzierbar"56.

455 Ich begreife also im Kontext einer gebrauchstheoretischen Perspektive auch den illokutionären und - in Abweichung zu Austin - den perlokutionären Akt als Bestandteil eines regelgeleiteten Sprachspiels und damit zur Sprachbedeutung hinzugehörend; der illokutionäre wie der perlokutionäre Akt sind abhängig davon, dass man die sozial erlernte Technik der Zeichenverwendung beherrscht. Gleichwohl gilt der perlokutionäre Akt im Allgemeinen als nicht konventional: "Man kann ... auch ohne Konventionen etwas bewirken." (Meggle 1997: 33) Aber das meiste von dem, was wir bewirken, bewirken wir, weil andere wissen, wie sie auf unsere kommunikativen Einlassungen konventionell reagieren sollten. Lueken (1997: 9) sieht in ähnlichem Zusammenhang in einer Kritik an Searle jedoch einen Rückfall in die Idealsprachenphilosophie: "Wer A sagt oder tut, soll verpflichtet werden, auch B zu sagen oder zu tun. Hier scheinen noch Reste idealsprachlicher Ambitionen zur Reglementierung unserer Rede durch. ... Unsere Gebrauchsweisen und Sprachspiele verändern sich im Kontext von und mit der Lebenspraxis." Aber diese Veränderungen - die natürlich auch hier nicht bestritten werden - schließen normative Implikationen der Sprachverwendung doch nicht aus. Diese normativen Implikationen unterliegen nur ebenso der Historizität wie Sprache generell.

${ }^{456}$ Freilich ließe sich fragen, ob man Verpflichtung sinnvoll als einen sozialen Gegenstand ausweisen sollte; immerhin ist das Gefühl, einem anderen gegenüber verpflichtet zu sein, nur psychologisch zu denken. Da aber dieses Gefühl i.d.R. a) auf erlernten und eingeübten Normen gründet, b) sich direkt auf andere Menschen bezieht und c) im Sinne Wittgensteins von der öffentlichen Gebrauchsregeln 
Wenn wir den Übergang vom X-zum Y-Terminus mit Blick auf eine bestimmte Sprachgemeinschaft als analytisch behaupten können, dann wird hier zugleich die kulturelle Bedingtheit einer korrekten Begriffsverwendung deutlich. Sollte etwa innerhalb einer Sprachgemeinschaft eine freiwillige Hilfestellung nicht (oder zumindest nicht in allen Fällen - wie in den schon genannten Sklavenhaltergesellschaften) als Gefälligkeit zählen, existiert also ein diesbezüglicher analytischer Link nicht, so entsteht auch kein Sozialkapital.

Oben hatte ich allerdings angemerkt, wenn A ohne rechtliche Verpflichtung etwas für B tue, könne dies durchaus einmal als "Gefälligkeit" und ein anderes Mal lediglich als so etwas wie "selbstverständliche kleine Aufmerksamkeit" zählen. Ist dies jedoch der Fall, dann scheint die Behauptung von Analytizität zwischen X und Y zu stark zu sein. In der Tat gibt es Freiheitsgrade bezüglich dieser Verbindung und zwar zumindest einmal in dem Maße, wie die Bedeutung unserer Alltagssprache als vage zu kennzeichnen ist. In vielen Fällen dürfte eine Analyse des Kontextes (also von $\mathrm{K}$ ) allerdings Aufschluss darüber geben, ob es sich wirklich sowohl bei "Gefälligkeit" wie bei "selbstverständliche kleine Aufmerksamkeit" um einen - trotz aller vorhandenen Ambiguität - korrekten Sprachgebrauch handelt.

Wenn A sich bspw. über Stunden hinweg unentgeltlich mit der Steuererklärung von B beschäftigt, dann darf kaum von einer "selbstverständlichen kleinen Aufmerksamkeit" gesprochen werden. Gleichwohl müsste der Forscherblick sich (dezidiert soziologisch) nicht nur auf die Sprachgemeinschaft, sondern - kleinräumiger - ebenso auf das soziale Milieu, dem A und B angehören, auf die konkrete Art der Beziehung zwischen den beiden und auf die zwischen ihnen etablierte Form der Handlungspraxis richten, um ein abschließendes Urteil über die Adäquanz bestimmter Äußerungen (bzw. Bedeutungszuweisungen) innerhalb eines Sprachspiels treffen zu können ${ }^{457}$.

folgenden Anwendung von "Verpflichtung" (oder eines vergleichbaren Wortes) nicht zu trennen ist, kann Verpflichtung als sozialer Gegenstand interpretiert werden.

457 Die Messlatte für das, was als Gefälligkeit gelten darf, kann auch recht niedrig liegen. Bspw. entspricht das deutsche "Danke" dem portugiesischen "obrigado", das allerdings in einer subtileren Übersetzung so viel wie "du hast etwas gut bei mir" bedeutet ("obrigacao" entspricht weitgehend unserem Wort "Verpflichtung") - man bedankt sich also im Portugiesischen nicht bloß für etwas, sondern man erkennt zugleich eine Schuldverschreibung an, sichert also dem anderen informell eine Gegenleistung zu. (Diesen Hinweis verdanke ich Manuel de Soto und Peter Matuschek. Obrigado!) $\mathrm{Ob}$ das portugiesische "obrigado" allerdings tatsächlich im oben beschriebenen Sinne "mehr" impliziert als das deutsche "Danke", müsste eine vergleichende (m.E. extrem aufwendig durchzuführende) empirische Analyse klären. Die hier angestellten Überlegungen hinsichtlich einer auf eine Sprachgemeinschaft hin relativierten Analytizität der Bedeutungszuweisung lassen sich auch über psychologische Theorien zur sozialen Organisation menschlicher Kognition abstützen. Es sind unsere sprachlich vorliegenden Alltagstheorien, die uns nahelegen, wie wir wahrnehmen und welche Bedeutung wir hiervon ausgehend den Entitäten zusprechen. Auch unter Bezugnahme auf den symbolischen Interaktionismus tritt der sprachrelative Charakter der möglichen Bedeutung in den Vordergrund: "Ruft man sich den gesellschaftlichen Charakter signifikanter Symbole - den Umstand, daß diese Besitz der ganzen Gruppe sind, der das Individuum zugehört - in Erinnerung, so bedeutet dies, daß auch daß individuelle Bewußtsein sozial organisiert ist." (Preglau 1999: 59) 
Grundsätzlich ist allerdings festzuhalten: Obgleich Sozialkapital unter bestimmten Bedingungen geradezu zwangsläufig entstehen muss, weil der Sprachgebrauch den Akteuren normativ bestimmte Bedeutungszuweisungen auferlegt, so existieren doch Freiheitsgrade und man kann sowohl absichtlich wie unabsichtlich gegen Normen verstoßen. Auf Basis der Searleschen Iterationslogik sind die genannten Freiheitsgrade auf den ersten Stufen noch relativ groß - ob man hinsichtlich eines bestimmten Verhaltens von einer "Gefälligkeit" oder einer "selbstverständlichen kleinen Aufmerksamkeit" sprechen sollte, mag diskutabel bzw. gelegentlich unentscheidbar sein. Je weiter wir uns jedoch von rohen Tatsachen entfernen, desto normativer wird die durch den zulässigen Sprachgebrauch vermittelte Bedeutungszuweisung sein - auf eine "Vorleistung" wird in aller Regel automatisch eine "Verpflichtung" folgen; wer "A" sagt, muss eben auch "B" sagen. "Die Abweichungen vom Muster" - so möchte ich es an dieser Stelle mit Luckmann (2002: 165) formulieren, "werden als Erwartungsverletzungen erfahren und werden mit Sanktionen verschiedenster Art belegt."

Schließlich ist noch darauf hinzuweisen, dass Searle in seinen Illustrationen institutioneller Realität zumeist auf einen formal-rechtlichen Kontext rekurriert, unter dessen Zugrundelegung dann Y logisch aus X folgt. So zählt bspw. ein bestimmtes, von der Europäischen Zentralbank autorisiertes Stück Papier als Zahlungsmittel im Wert von 5 Euro. Bei Sozialkapital hingegen existiert ein solch formaler Kontext nicht; das Fehlen von offiziellen Statusindikatoren (wie etwa eines verbrieften Zertifikats) ist sogar ein Kriterium für die korrekte Anwendung des Begriffs. Insofern stellt Sozialkapital auch einen wesentlich labileren institutionellen Gegenstand dar, als die von Searle beschriebenen.

Dennoch ist auch Sozialkapital als institutionell zu begreifen: Ein institutioneller Gegenstand zeichnet sich dadurch aus, dass ihn Menschen qua Bedeutungszuweisung geschaffen haben. Eine Begrenzung des Umfangs dieser Form der Realität auf ausschließlich rechtlich-kodifizierte Arten findet sich bei Searle nicht. Dezidiert spricht Searle (1997a: 97f.) bspw. hinsichtlich von Cocktailpartys, Freundschaften oder Verabredungen von "nicht-kodifizierten Mustern" institutioneller Realität. Diese "Muster könnten kodifiziert werden, wenn es furchtbar wichtig wäre, ob etwas wirklich eine Cocktailparty oder nur eine Teegesellschaft ist. Wenn die Rechte und Pflichten der Freundschaft plötzlich zu einer schwerwiegenden rechtlichen oder moralischen Frage würden, dann könnten wir uns vorstellen, daß diese informellen Institutionen explizit kodifiziert würden".

Sozialkapital wäre damit mit Searle gesprochen ein informeller institutioneller Gegenstand, der auch keine Statusindikatoren besitzt. Die an seiner Schaffung beteiligten Akteure sind auf jeder Stufe der Iterationslogik in der Lage, sich ohne rechtliche Konsequenzen gegen eine für Sozialkapital konstitutiv-notwendige Bedeutungszuweisung oder komplett gegen die Akzeptanz des Sachverhaltes zu entscheiden. Dennoch bleibt der Übergang vom X-zum Y-Terminus ein im 
beschriebenen Sinne normativer; gleichwohl sind andere, nicht-rechtlichkodifizierte Kontextbedingungen erforderlich. Diese wurden zwar im Rahmen der obigen Ausführungen schon über den K-Terminus beschrieben, sie treten jedoch - wie zu zeigen sein wird - unter einem sozialkonstruktivistischen Blickwinkel insbesondere als Mechanismen sozialer Kontrolle noch deutlicher in Erscheinung.

\section{Sozialkapital und Externalisierungen}

Im Berger/Luckmannschen Verständnis lautet die Grundfrage der soziologischen Theorie: "Wie ist es möglich, daß subjektiv gemeinter Sinn zu objektiver Faktizität wird?" (Berger/Luckmann 1980: 20) Wenn nun aber - wie oben argumentiert Bedeutungskonstitution als ein normativer Vorgang zu bezeichnen ist, der aus der innerhalb einer Sprachgemeinschaft geltenden regelhaften Verknüpfung von sprachlichen Zeichen resultiert, dann scheint es subjektiven Sinn nicht geben zu können. Bedeutung (bzw. Sinn) ist damit grundsätzlich sozial bzw. öffentlich.

Diese anti-psychologistische Position, die sowohl in der analytischen Philosophie (Frege) wie in der Phänomenologie (Husserl) vertreten wird, scheint mit der soziologisch-subjektiven Sinn-Konzeption zunächst nicht zusammenzugehen. Gleichwohl handelt es sich nur um einen vermeintlichen Widerspruch, denn damit Bedeutung überhaupt prozessiert werden kann, bedarf es individuellen Bewusstseins. Subjektiven Sinn zu setzen, heißt damit, aus den zur Verfügung stehenden normativ zu interpretierenden Verknüpfungsoptionen eine Auswahl zu treffen. Wenn also ein Individuum auf "Sets von Bedeutungen und ... Interpretationsentwürfe(n)" (Blumer 1973: 100) zurückgreift, um sie vor dem Hintergrund bestimmter Erfahrungsdaten zu aktualisieren, dann greift es - insofern es die Sprache der Gemeinschaft, in der es lebt, korrekt verwendet - auf sozial-kodifizierte Verknüpfungsregeln zurück. In diesem Rahmen bewegt sich die interpretatorische Kreativität der Sprachvermögenden ${ }^{458}$.

Am Relevantesten erscheinen die subjektiven Freiheitsgrade auf der - mit Searle gesprochen - ersten Iterationsstufe, wenn einer rohen Tatsache eine Bedeutung zugewiesen wird: Ob Person B "A tut etwas" wirklich als "A tut etwas für mich" begreift, entscheidet maßgeblich über die weiteren Iterationen. Aber auch auf der zweiten Stufe ist ein Variationsraum denkbar, der alle im Bereich analytisch korrekten Verknüpfungen umfasst. So lässt sich "A tut etwas für B" in Abhängigkeit von den individuellen Vorstellungen über und Erwartungen an die Welt aber grundsätzlich in Kongruenz zur deutschen Sprachgemeinschaft von B als "Gefälligkeit" oder als "kleine Aufmerksamkeit" fassen. Im zweiten Fall wird die Entstehung von Sozialkapital unwahrscheinlicher.

\footnotetext{
458 In ähnlicher Weise klingt dies auch bei Thomas Luckmann (2002: 209) an, wenn er Sinn "in den historischen Sprachen vor-konstruiert" sieht. "Sprachen als Bedeutungssysteme (bestimmen, D.K.) den Rahmen des Sinns subjektiver Erfahrung, und sie determinieren auch weitgehend die intersubjektive Rekonstruktion des Sinns und des Handelns."
} 
Im Sinne von Berger/Luckmann haben wir es bei Sozialkapital mit einer Objektivation menschlicher Tätigkeit zu tun. Wir müssen insofern fragen:

welche symbolisch vermittelten Externalisierungsprozesse (E) und insbesondere

reziproken Typisierungen von Situationen $\left(\mathrm{T}^{\mathrm{S}}\right)$ und Personen $\left(\mathrm{T}^{\mathrm{P}}\right)$ (also situationsspezifische Festlegungen sozialer Rollen [Rs]) setzt die Bildung von

Sozialkapital $(\mathrm{O})$ voraus,

wie wird es von den Individuen kognitiv / normativ internalisiert (In),

welche habitualisierten reziproken Handlungsabläufe $(\mathrm{H})$ (verstehbar als eingeübte Interaktionsschemata) führen zu seiner Existenz oder dienen der Aufrechterhaltung eines bestehenden Kapitalstocks,

welche Legitimationen (L) führen dazu, dass Handlungen selegiert werden, die auf die Entstehung von Sozialkapital hinwirken,

welche sozialen Kontrollmechanismen (Ks) sorgen dafür, dass Sozialkapital auch zur "Auszahlung" gelangt (dass also eine Gutschrift auch eingelöst wird)?

Hinsichtlich der Entstehung von Sozialkapital auf Basis wissenssoziologischer bzw. sozialkonstruktivistischer Überlegungen möchte ich erneut auf die mit dem entwickelten Theoriemodell kompatible Formulierung einer grundlegenden Situation einer Entstehung von Sozialkapital rekurrieren: Wenn A etwas für B tut, erwächst daraus in Abhängigkeit von gegebenen Kontextbedingungen für $\mathrm{B}$ eine Verpflichtung, hierauf mit einer Gegenleistung zu antworten. Besteht nun seitens B der Wille, eine solche Gegenleistung auch tatsächlich zu erbringen, so kann von einer Gutschrift über Ressourcen gesprochen werden, die A besitzt und die in dem Fall für A Sozialkapital darstellt, wenn sie bei Einlösung für A im Hinblick auf mindestens eine Zielstellung nützlich wäre. Wie lässt sich nun das auf Berger/Luckmann gründende Analyseraster auf diese Situation anwenden?

1. Objektivation. Sozialkapital ist die Objektivation, deren Konstruktion analysiert werden soll.

2. Externalisierung. Der ursprüngliche Externalisierungsvorgang mit Blick auf Sozialkapital liegt hinsichtlich des angeführten Beispiels darin, dass A etwas tut.

Analog zur sprachphilosophischen Analyse müssen wir auch wissenssoziologisch auf die rohe Tatsache "A tut etwas" zurückgehen, da diese den Ausgangspunkt der folgenden Typisierungsprozesse bildet.

3. Typisierung der Situation. Der soeben beschriebene Externalisierungsvorgang stellt nun die Situation dar, mit der sich die beteiligten Akteure auseinanderzusetzen und die sie grundlegend als sozial zu interpretieren haben. Damit Sozialkapital entstehen kann, muss "A tut etwas" daher als "A tut etwas für B" (denn "A tut etwas" unterliefe die Ebene des Sozialen) und weiterführend etwa als "Gefälligkeit" und "Vorleistung" bzw. "Kreditvergabe" typisiert werden. 
Eine vorsoziale ("A tut etwas") wird als eine nicht weiter zurückführbare soziale Situation ("A tut etwas für B") und diese dann in Form zweier verschiedenartiger, höherstufiger sozialer Situationen repräsentiert. Dabei ist die Typisierung als "Vorleistung" unter der Bedingung, dass kein formal-rechtlicher Anspruch auf eine Vergütung existiert, sachlich von der Typisierung der Situation als "Gefälligkeit" abhängig. Im ontologischen Grundlagenteil dieser Arbeit wurde von einem kontinuierlichen Verweisungszusammenhang der Typisierung gesprochen, d.h. wird eine Situation in bestimmter Weise festgelegt, so entstehen vor dem Hintergrund des bereits vorhandenen Wissens Erwartungen hinsichtlich potentieller Interaktionsverläufe; eine Gefälligkeit wird bei einer entsprechenden Vorstellung über die Welt etwa die Erwartung einer Gegenleistung hervorrufen und bekommt damit de fakto den Status einer Kreditvergabe.

4. Typisierung der Personen. Wird die soziale Situation als "Vorleistung" bzw. "Kreditvergabe" typisiert, dann impliziert dies die Typisierung der beteiligten Akteure als "Gläubiger" (oder in anderen sprachlichen Wendungen wie etwa "Treuhänder" bzw. lebensweltlicher: "habe bei ihm was gut" / "hat bei mir was gut" etc.) und "Schuldner" (bzw. "Treugeber", "schulde ihm was" / "schuldet mir was" etc.). Eine bestimmte Situation löst eine Erwartung an hiermit korrespondierende Handlungen der beteiligten Akteure - und damit an die Ausübung eines gesellschaftlich akzeptierten Rollenverhaltens - aus ${ }^{459}$. Idealiter werden die beteiligten Akteure jeweils die soziale Rolle des Gläubigers für A und die des Schuldners für B festlegen. Dabei folgt bspw. die Rolle des Schuldners ganz von selbst aus der Festlegung der Rolle des Gläubigers, denn wo ein Gläubiger ist, muss logischerweise auch ein Schuldner sein, und in der genannten Situation kommt dafür nur B in Frage (Verweisungszusammenhang; vgl. hierzu Schütz 1971: 21).

Die beschriebenen Typisierungsprozesse stellen genau wie die Definition der Situation als "A tut etwas für B" konkrete Externalisierungen dar. Hier wird also aktiv auf die Entstehung einer Objektivation und d.h. in dem Fall auf die Existenz von Sozialkapital hingewirkt. Die beteiligten Akteure weisen sich bestimmte Plätze zu. Sie werden - in Goffmanscher Diktion - zu Darstellern ihres eigenen Schauspiels, indem sie über einen sprachlichen Labelling-Prozess ihre Relation auf eine spezifische Art strukturieren ${ }^{460}$.

Da Sozialkapital keine justiziable Größe darstellt, bedürfen die Typisierungsprozesse grundsätzlich einer konstruktiven Leistung der beteiligten Akteure. Auch innerhalb einer Eltern-Kind-Relation wird man daher keineswegs folgern dürfen, Eltern stellten quasi grundsätzlich ihrem Kind Sozialkapital zur Verfügung: Sind

459 Oder mit dem Thomas-Theorem: "If men define situations as real, they are real in their consequences" (Thomas/Thomas 1928: 572).

460 Anselm Strauss (1968: 20) hebt die Handlungsimplikationen dieses Prozesses besonders prägnant hervor. Die Benennung liefere nämlich eine Richtlinie, "als verkünde das Objekt geradeheraus: 'Du sagst, ich bin dies, also behandle mich entsprechend."' 
die Eltern rechtlich zu einer bestimmten Hilfestellung verpflichtet, kann aus definitorischen Gründen heraus kein Sozialkapital vorliegen; sind sie nicht verpflichtet, dann müssen über Typisierungen bestimmte, die biologische ElternKind-Bindung transzendierende, soziale Rollen erst zugewiesen werden. Eine Sozialkapitalbeziehung wird hier nur durch eine sprachlich vermittelte Rollenübernahme konstituiert.

Innerhalb des Berger/Luckmannschen Sozialkonstruktivismus muss nun noch die strukturelle Ebene in ihrem Effekt auf die Akteure wie auf die in Frage stehende Objektivation Berücksichtigung finden.

5. Legitimation. Legitimationen erklären bzw. begründen Objektivationen und antworten insofern auf die Frage, warum diese ein Teil der sozialen Wirklichkeit sind. Sie sagen dem Einzelnen aber auch, "warum er eine Handlung ausführen soll und die andere nicht ausführen darf." (Berger/Luckmann 1980: 100) Betrachtet man die Entstehung von Sozialkapital, so ist insbesondere der letzte Aspekt von Interesse, insofern gefragt wird, wie es überhaupt zu Sozialkapital kommen kann und d.h. bspw. aufgrund welcher gesellschaftlicher Normen die Akteure die genannten konstitutiven Typisierungen vornehmen. Mit Blick auf das Eingangs angeführte Illustrationsbeispiel wäre in erster Linie an die Norm der Reziprozität zu denken, nach der etwa Gefälligkeiten (oder Gaben im Sinne von Mauss) zurückzuzahlen sind ${ }^{461}$.

Gleichwohl bedarf es keineswegs grundsätzlich einer Gefälligkeit als Vorleistung. Denken wir an den Fall, in dem ein Einheimischer einem Touristen den kürzesten Weg zum Bahnhof erläutert, ohne dass der Tourist in irgendeiner Form überhaupt Gelegenheit gehabt hätte, zuvor etwas für den Einheimischen zu tun. Hinter einem solchen Verhalten des Einheimischen steht i.d.R. die Norm, nach der man ortsunkundigen Fremden hinsichtlich ihrer Orientierung behilflich sein sollte (jedenfalls soweit dies keine größeren Umstände bereitet). Hier finden wir also die Anwendung einer generalisierten Reziprozitätsnorm (bei der Sozialkapital durch eine Transferierung im Sinne des entwickelten Theoriemodells ermöglicht wird), die der Einheimische über sein Verhalten reproduziert ${ }^{462}$.

Wenn nun weltweit täglich Einheimische ortsunkundigen Fremden tausendoder womöglich sogar millionenfach bei der Orientierung behilflich sind, dann liegt hier ein (gewissermaßen personentranszendentes) habitualisiertes Handlungsschema mit Verbindlichkeitscharakter vor; und dies, obgleich man sich doch

461 Dabei kann eine solche Norm selbst wiederum Resultat von Ideologien sein, etwa wenn eine religiöse Lehre ihre Gläubigen dazu auffordert, dem Seelenheil zuliebe Rücksicht auf andere Menschen zu nehmen (vgl. Coleman 1991: 416).

462 In ethischer Diktion könnte man auch von der Bezugnahme auf einen Moralkodex sprechen: "Dabei beziehen wir uns auf Handlungsmuster, von denen wir annehmen, daß ihre allgemeine Verbindlichkeit außer Frage steht. Auf die Frage, warum jemand auf bestimmte Weise gehandelt hat oder zu handeln beabsichtigt, werden dann Antworten folgenden Typs gegeben: weil die Kirche eine Scheidung verbietet; weil man seine Versprechen halten muß; weil Ehrlichkeit eine Tugend ist" (Pieper 2003: 195). 
jederzeit und (zumeist auch) ohne von außen kommende negative Sanktionen befürchten zu müssen, gegen die Ausübung der normativen Auflagen entscheiden könnte. Es handelt sich daher auch nicht um eine direkte Investition in Sozialkapital, d.h. das Verhalten wird nicht deswegen ausgeführt, weil man sich in Zukunft eine Gegenleistung erhofft (schon gar nicht von derselben Person, der man behilflich war), sondern weil dahinter die grundsätzliche Legitimation des "Das macht man so" steht ${ }^{463}$ (vgl. Berger/Luckmann 1980: 100f.).

6. Soziale Kontrollmechanismen. Soziale Kontrollmechanismen beschreiben entweder die handlungsleitende Wirkung institutioneller Strukturen oder darüber hinausgehend eigens eingerichtete Sanktionsmaßnahmen, die menschliches Verhalten in eine bestimmte Richtung lenken. Zumeist wird die auf einen sozialen Kontext hin relativierte, angemessene Typisierung von Personen - und somit eine Rollenzuweisung - unter sozialer Kontrolle stehen. Hinsichtlich der Externalisierung "A tut etwas für B" dürfte etwa eine zu erwartende soziale Missbilligung nach einem Verstoß gegen die (zwar nicht formell) institutionalisierte Norm, nach der Gefälligkeiten zurückzuzahlen sind, die Entstehung von Sozialkapital begünstigen. Handelt es sich bei A und B um gute Bekannte, dann könnte die Nichtbeachtung der Norm zu einer Belastung des interpersonalen Verhältnisses und damit zu einer Beziehungsverschlechterung führen. Diese u.U. auch bewusst eingesetzte, über den inhärenten Zwangscharakter von Institutionen hinausgehende Sanktionsdrohung wird sich wahrscheinlich positiv auf die Entstehung von Sozialkapital auswirken bzw. die Geltungsansprüche eines bereits bestehenden Kapitalstocks verfestigen.

Im Gegensatz zu sozialen Kontrollmechanismen sollte Vertrauen keinen exponierten Platz innerhalb einer Ontologie des Sozialkapitals erhalten ${ }^{464}$. Wenn A etwas für B tut, dann entsteht keineswegs deshalb Sozialkapital, weil A in B das Vertrauen setzt, diese Vorleistung später einmal vergütet zu bekommen. Entscheidend ist die Haltung Bs, die aber sachlich unabhängig von den Einstellungen As ist. Freilich könnte B sich verpflichtet fühlen, A eine Gutschrift über Ressourcen bereitzustellen, da dieser ihm vertraut. In einem solchen Falle wäre Vertrauen

\footnotetext{
463 Die hier zum Ausdruck gelangende Norm der generalisierten Reziprozität ist zwar (möglicherweise) ein Gemeingut, sie ist indes kein Sozialkapital. Genausowenig wie das sich im Beispiel manifestierende prosoziale Verhalten. "Altruistisches oder prosoziales Verhalten eines Akteurs ist dann gegeben, wenn er/sie die Absicht hat, einer konkreten Person eine Wohltat zu erweisen und wenn der Akteur freiwillig handelt" (Bierhoff 2002: 178). Zunächst einmal kann prosoziales Verhalten kein Sozialkapital darstellen, weil es sich bei Letzterem um eine Gutschrift handelt, d.h. bei prosozialem Verhalten wird allenfalls Sozialkapital zur Verfügung gestellt. Dies muss aber keineswegs der Fall sein, denn Bierhoffs Definition von "prosozialem Verhalten" lässt offen, ob ein konkretes Verhalten tatsächlich funktional für die Person ist, der eine "Wohltat" angedacht wird. Ferner wird Sozialkapital oftmals dezidiert aus egoistischen Motiven heraus bereitgestellt, d.h. der Investitionsaspekt - wenn auch definitorisch nicht zwingend - wird über den Sozialkapitalbegriff hinsichtlich von Unterstützungsleistungen besonders exponiert (und dies passt kaum zu prosozialem Verhalten).

464 Warum man Vertrauen nicht als Sozialkapital betrachten sollte, wurde von mir schon innerhalb des entwickelten Theoriemodells ausgeführt.
} 
jedoch Ausdruck einer (mehr oder minder stark) institutionalisierten Beziehungsstruktur und damit interpretierbar als sozialer Kontrollmechanismus, denn das Vertrauen eines anderen zu enttäuschen, entspräche einem sozial unerwünschten Verhalten.

7. Internalisierung. Legitimationen und soziale Kontrollmechanismen als Elemente der vergegenständlichten gesellschaftlichen Welt können ihre Wirkung nur dann entfalten, wenn sie von den beteiligten Akteuren internalisiert werden und in konkrete Handlungen münden. Wurde etwa die Norm, nach der Gefälligkeiten zurückzuzahlen sind nicht in irgendeiner Form sprachlich repräsentiert, ist sie also konzeptionell innerhalb des mentalen Modells über Gefälligkeiten nicht vorhanden, so wird die Entstehung von Sozialkapital zwar nicht ausgeschlossen, aber unwahrscheinlicher (es kann ja immerhin auch andere Gründe für die Bereitstellung von Sozialkapital geben: eine religiöse Doktrin, eine Geber-Laune, Fatalismus etc.).

Vergleichbares gilt für die aus den Typisierungen erwachsenden sozialen Rollen der beteiligten Akteure. Hier bedarf es ebenfalls der Internalisierung der mit diesen Rollen einhergehenden Rechten und Pflichten, um schließlich Sozialkapital zur Existenz zu bringen. So weiß man etwa in Folge seiner Sozialisation, wie man sich einem ortsunkundigen Fremden gegenüber angemessen zu verhalten hat; man weiß um die sozio-kulturellen Implikationen der sozialen Rolle "Einheimischer" in der Situation "Tourist fragt Einheimischen nach dem Weg". In Abwandlung eines Zitats von Berger/Luckmann (1980: 143) lässt sich sagen, der entscheidende Schritt wird getan, wenn man erkennt, dass jedermann etwas gegen unhöfliches Verhalten gegenüber ortsunkundigen Touristen hat. In den meisten Fällen wird sowohl die Drohung einer negativen Sanktionierung bei Verstoß gegen diese Norm (sei es ein externaler ["wie konntest du nur so unhöflich sein"] oder ein internaler ["wie konnte ich nur so unhöflich sein"] Kontrollmechanismus ${ }^{465}$ ) als auch ein positiver Belohnungsreiz (man fühlt sich gut, wenn man Fremden behilflich ist) das Verhalten bestimmen.

Im Unterschied zu Berger/Luckmann erscheint mir eine Unterteilung in kognitive und normative Aspekte einer Internalisierung wenig sinnvoll zu sein. Wenn Normen nur sprachlich zu denken sind, dann gründet etwa die normative Forderung "Man soll ortsunkundigen Fremden bei der Orientierung behilflich sein" nicht nur auf einer entsprechenden propositionalen Kognition, sondern sie fällt mit dieser in eins. Umgekehrt wurde auf Basis sprechakttheoretischer Überlegungen gezeigt, inwiefern etwa eine Kognition der Form "A hat mir (nämlich B) eine Gefälligkeit erwiesen" zu einer normativen Verpflichtung Bs führt (bedeutungstheoretisch handelt es sich um eine Perlokution); eine strikte

465 Tatsächlich ist die Unterscheidung zwischen externalem und internalem Kontrollmechanismus wenig trennscharf, denn Letzterer verdankt sich einer von außen kommenden Sozialisationserfahrung und kann insofern als Einverleibung des Ersteren begriffen werden; der generalisierte Andere, der ein Verhalten missbilligt, ist ein Teil der Selbstbetrachtung geworden. 
Trennung zwischen kognitiven und normativen Internalisierungsaspekten ist daher inhaltlich weitgehend redundant und aus erkenntnistheoretischen wie ontologischen Überlegungen heraus eine problematische Simplifizierung, die zwar mit unserem alltagsweltlichen Verständnis korrespondiert, einer wissenschaftlichen Betrachtung im hier vorgelegten Sinne jedoch nicht standhält.

8. Habitualisierte Handlungen. Als habitualisierte Handlungen im Zusammenhang mit einer Ontologie des Sozialkapitals können vor allen Dingen die konstitutiv notwendigen Typisierungsprozesse genannt werden. Aufgrund ihrer Allgemeinheit sowie weitgehenden Verbindlichkeit werden sie quasi automatisch durchgeführt und begrenzen dabei die mögliche Handlungsvielfalt. "Das entlastet", wie bereits im ontologischen Grundlagenteil angeführt, "Personen von beträchtlichen Spannungen. Sie sparen Zeit und Kraft nicht nur für beliebige äußere Aufgaben, die sie getrennt oder gemeinsam haben, sondern für ihre ganze seelische Ökonomie." (Berger/Luckmann 1980: 61)

So weiß man etwa, dass die Situation "A tut etwas für B" eine "Gefälligkeit" darstellt und welche soziale Rollenerwartungen hieraus erwachsen. Mit Schütz (1971: 79) ließe sich von die Interaktion anleitendem "Rezeptwissen" sprechen, also von "Handlungsmaximen, die mehr oder minder automatisch befolgt werden, ohne als Handlungsregeln für den Einzelfall thematisiert zu werden" (Luckmann 1981: 40f.). Die habitualisierte Wissensanwendung sorgt nicht nur für die Entstehung, sondern ebenso für die Reproduktion und die Akkumulation von Sozialkapital - man hält an getroffenen Typisierungen fest und greift in vergleichbaren Situationen immer wieder auf die schon erprobten Muster zurück.

Bei allen vorgestellten Schrittfolgen ist zunächst einmal vorrangig die Haltung Bs ausschlaggebend. So wäre es de fakto bspw. völlig hinreichend, wenn lediglich B sein Gegenüber als Gläubiger und mit dieser Rollenfestlegung sich selbst damit in der Situation "A tut etwas für B" automatisch als Schuldner typisiert. Ob A in analoger Weise vorgeht (also sich selbst die soziale Rolle des Gläubigers und B die des Schuldners zuschreibt), ist insofern irrelevant, als Sozialkapital - gemäß dem oben entwickelten Theoriemodell - unabhängig von der Einstellung As entsteht, sobald B willens ist, A Ressourcen zur Verfügung zu stellen, die diesem dann auch noch von Nutzen sind. Erst wenn A bewusst die Schaffung seines Sozialkapitals induzieren möchte, wird eine "Situation wechselseitiger Reichweite" (Luckmann 2002: 162) vorliegen, wenngleich diese selbst dann keineswegs unabdingbar erforderlich wäre. Mit Blick auf die sprachphilosophischen Implikationen einer Ontologie des Sozialkapitals hatte ich diesbezüglich davon gesprochen, Sozialkapital bedürfe keiner kollektiven Intentionalität.

Möchte nun A mit seiner Handlung konkret auf die Entstehung von Sozialkapital hinwirken, so muss er B die für den Gegenstand konstitutiven Typisierungen - und das heißt eine bestimmte Situationsdefinition und bestimmte soziale Rollenzuweisungen - nahelegen. Dies wird ihm vor allem dann mit Aussicht auf 
Erfolg gelingen, wenn er die strukturelle Ebene in seine Strategie miteinbezieht und bspw. Öffentlichkeit erzeugt, um so soziale Kontrollmechanismen verstärkt wirksam werden zu lassen.

Aber vor allem setzt die bewusste Induzierung von Sozialkapital eine Rollenübernahme voraus, denn nun muss alter nicht nur eine Verpflichtung gegenüber ego verspüren und willens sein, diese auch einzulösen; vielmehr muss ego auch (im gelingenden Fall) um die Relevanzstrukturen von alter wissen ${ }^{466}$. Insofern wird ein "epistemical takeover" notwendig, wobei ego im Meadschen Sinne die Rolle von alter ihm selbst, also ego, gegenüber einnimmt; er versetzt sich in die Position seines Gegenübers und kann bei Antizipation von dessen Bedeutungszuschreibungen sein eigenes Verhalten strategisch anpassen.

Die Trennung der beschriebenen Schrittfolgen ist lediglich analytisch zu verstehen. Realiter wird man kaum davon ausgehen können, dass etwa zunächst eine soziale Situation und daraufhin dann die daran beteiligten Akteure in bestimmter Weise typisiert werden. Lediglich der ursprüngliche Externalisierungsvorgang ist temporär als vorgeschaltet zu begreifen. Freilich dürfte es sich auch hier innerhalb der sozialen Wirklichkeit als problematisch erweisen, einen solchen Anfang genau zu bestimmen. Der Sachverhalt "A tut etwas für B" kann schon das Vorliegen von Sozialkapital indizieren, wenn nämlich das Handeln As Resultat einer gespürten, nicht formal-rechtlichen Verpflichtung gegenüber B ist und wenn das, was A in dieser Situation B handelnd zur Verfügung stellt, B zu dessen Nutzenrealisierung dient bzw. eine Rendite einbringt (etwa wenn - wie oben beschrieben - ein Einheimischer einem Touristen den kürzesten Weg zum Bahnhof erläutert). Ein Anfang muss dennoch grundsätzlich irgendwo vorhanden sein, und eine wissenschaftliche Analyse kann gar nicht anders, als diesen aus darstellungstechnischen und -systematischen Gründen zu benennen. Sozialkapital stellt sich übersichtlich als ein Sinnzusammenhang dar, der die von Berger/Luckmann identifizierten Elemente zur Herstellung objektiver gesellschaftlicher Faktizität synthetisiert.

466 Oder mit Berger/Luckmann: "Meine Relevanzstrukturen überschneiden sich jedoch an vielen Punkten mit denen anderer. Daher kommt es, daß wir uns 'etwas interessantes zu sagen haben'. Ein wichtiger Bestandteil meines Alltasgwissens ist das Wissen um die Relevanzstrukturen von anderen." (Berger/Luckmann 1980: 47) 
Abbildung 13: Eine wissenssoziologische Ontologie des Sozialkapitals

Strukturelle Ebene

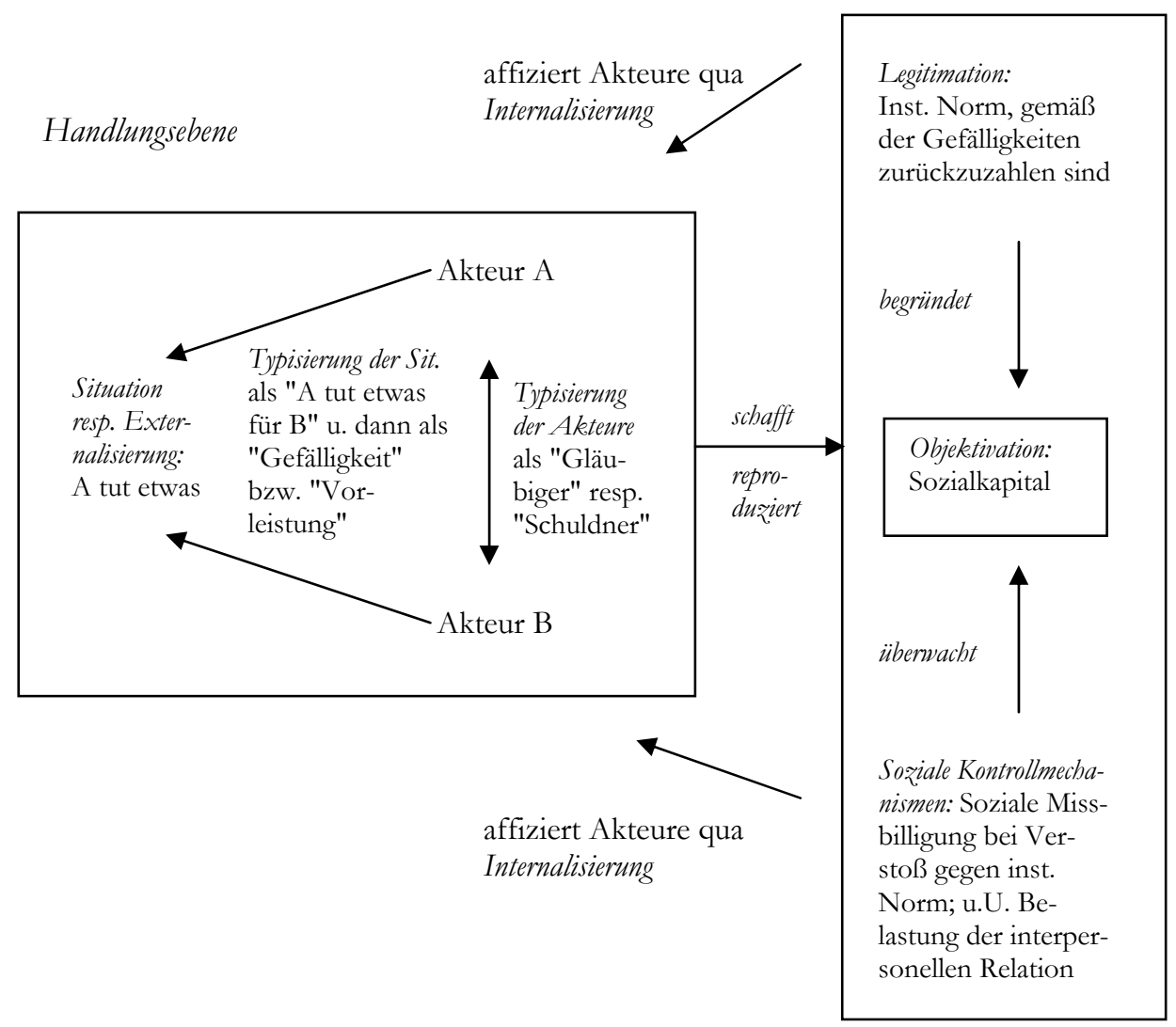

Zur Ausarbeitung einer Ontologie des Sozialkapitals kann sowohl auf linguistische wie auf soziologische Bedeutung rekurriert werden. Dabei sind beide untrennbar miteinander verwoben. In besonderem Maße wird diese Verwobenheit durch die Sprechakttheorie hervorgehoben, gilt hier doch die Bedeutung eines Satzes als abhängig von sozial erlernten und überwachten Gebrauchsregeln sowie von einem konkreten Äußerungskontext. Menschen vollziehen über Sprechakte sinnsetzende Handlungen im Schützschen Verständnis: Die Bedeutung von "Ich habe dir eine Gefälligkeit erwiesen" (Lokution) impliziert die Aufforderung (Illokution), hierfür eine Gegenleistung zu bekommen (Perlokution). M.a.W.: Die linguistische Bedeutung der Aussage ist nur dann verstehbar, wenn man diese soziologischen Aspekte, den subjektiven Sinn, den der Sprecher mit der Äußerung verbindet, 
berücksichtigt. Andererseits kann der subjektive Sinn über den Möglichkeitsraum der Sprache nicht hinausreichen.

Bestimmt man den ontologischen Status von Sozialkapital einmal mit Searle und dann mit Berger/Luckmann, so lässt sich zunächst erkennen, dass die auch in der oben angeführten Grafik genannten sozialen Kontrollmechanismen nicht in beiden Konzeptionen auftauchen. Insofern scheinen sprachphilosophische und wissenssoziologische Ontologie - und auch das ist ein Resultat dieses Anwendungsteils - möglicherweise weniger komplementär als zunächst auf der abstrahierenden Ebene angenommen (vgl. die Kapitel 3. und 5.6.). Jedenfalls dann, wenn es wie im hier diskutierten Fall um die Entstehung eines alltagsweltlichen Gegenstandes und nicht um die historische Betrachtung kulturspezifischer Institutionen geht; um einen Gegenstand also, zu dessen Ausbildung prinzipiell "schon eine rudimentäre 'Geschichtlichkeit' wechselseitigen Handelns" (Luckmann 2002: 109) genügt.

Es bestünde nun u.U. die Möglichkeit, die wissenssoziologische auf die sprachphilosophische Ontologie zu reduzieren (bzw. die vorangegangenen Überlegungen entsprechend zu interpretieren). Dies mit der Begründung, im Sinne von Ockhams razor seien die sprachlichen Prozesse grundlegend. Auf einen solchen Versuch möchte ich indes verzichten. Vielmehr interpretiere ich die Bearbeitung der ontologischen Aspekte der Sozialkapitalproblematik über das Konzept Berger/Luckmanns als Indiz für die methodische Validität des "ZurSprache-Bringens" von Sozialkapital über die sprachphilosophische Analyse. Obwohl man mit Searle und Berger/Luckmann von zwei verschiedenen Orten aus bzw. durch unterschiedliche Brillen auf den Gegenstand schaut, werden doch dadurch keinesfalls grundsätzlich voneinander abweichende oder sogar sich widersprechende Ergebnisse produziert.

In einer anderen Wendung ließen sich die mit Hilfe der Wissenssoziologie aufgezeigten Abläufe auch als Funktionen der sprachlogischen Prozesse betrachten. Und genau so hatte ich ja auch im Grundlagenteil argumentiert: Mit Searle lassen sich die allgemeinen Tiefen- bzw. Regelstrukturen ausarbeiten, die die Voraussetzung dafür bilden, dass wirklichkeitsschaffende Praktiken im Sinne Berger/Luckmanns überhaupt möglich werden. 


\section{Epilog}

\subsection{Zusammenfassende Ergebnisbewertung}

Die Debatte um Sozialkapital ist derzeit sowohl in Wissenschaft wie Politik in Mode. Schaut man sich Untersuchungen zur Thematik an, so scheint Sozialkapital irgendwie für nahezu alles gut zu sein: Angefangen von einer Erhöhung des persönlichen Wohlbefindens, über eine Revitalisierung benachteiligter Stadtquartiere bis hin zur Stärkung der Volkswirtschaft im globalisierten Standortwettbewerb - je mehr Sozialkapital, desto besser!

Doch gerade die behauptete enorme Wirkungsbreite sollte zu begrifflicher und theoretischer Wachsamkeit anhalten. Was dient Wissenschaftlern als Gegenstand ihrer Erkenntnisbemühungen, wenn von "Sozialkapital" die Rede ist, d.h. was bedeutet "Sozialkapital"? Diese Frage, so banal sie zunächst klingen mag, ist noch nirgends systematisch bearbeitet oder gar in befriedigendem Maße beantwortet worden, obwohl doch zahlreiche Beiträge zur Begriffsdebatte vorliegen. Insofern ist zwar vielen Sozialwissenschaftlern das Problem aufgefallen, doch im Kontext eines ausschließlich sozialwissenschaftlichen Reflexionsrahmens konnte gar keine Lösung gefunden werden. Hierfür ist nämlich die dezidierte Einnahme einer metasprachlichen respektive sprachphilosophischen Position erforderlich.

Unter Aspekten wissenschaftlichen Fortschritts kann also der Stand der Sozialkapitaldebatte gar nicht als befriedigend eingeschätzt werden, weil eine erforderliche Präzisierungsarbeit noch nicht geleistet wurde. Es besteht kein Konsens hinsichtlich dessen, was eigentlich unter "Sozialkapital" verstanden werden soll und damit auch hinsichtlich der realweltlichen Objekte, die über den Begriff zu bezeichnen sind. Wenn gelingende Kommunikation davon abhängig ist, dass die Individuen einer Sprachgemeinschaft den gleichen Inhalt und die gleichen Entitäten mit einem Begriff wissentlich verbinden, dann ist eine solche semantische Vielfalt und Ambiguität - zumal in der Wissenschaft - nur als schwerwiegendes Defizit zu kennzeichnen. 
Um diese Forschungslücke zu schließen, wurde innerhalb der vorliegenden Untersuchung ein in der analytischen Sprachphilosophie gründendes, komplexes Analyseinstrumentarium entwickelt, um so erst eine metasprachliche Rekonstruktion und darauf aufbauend dann einen systematischen Vergleich ausformulierter, schulenbildender Sozialkapitalkonzepte möglich zu machen, der dann in die Formulierung einer integrativen Begriffs- und Theoriebildung mündete.

Mit dem hier erarbeiteten Theoriemodell liegt nun ein Vorschlag für einen einheitlichen begrifflichen Gebrauch vor. Unter "Sozialkapital" sollen funktionale, nicht-justiziable Gutschriften über Ressourcen anderer Akteure verstanden werden, auf die ego dank seiner Beziehungen zu diesen anderen Akteuren sowie deren positiver Kooperationshaltung (absichtlich oder unabsichtlich) mit dem Ergebnis einer Erwirtschaftung eines Ertrages aktuellen Zugriff nimmt bzw. potentiell nehmen könnte. Die Begriffs-Extension - also alle Gegenstände, die als "Sozialkapital" gelten dürfen - kann dann Gutschriften über Ressourcen wie bspw. eine Information über eine günstige Wohnung, eine Bereitstellung finanzieller Mittel zum Abtrag einer fälligen Hypothek, eine öffentliche Belobigung zur Erhöhung sozialer Reputation, Orientierungsangebote für eine als sinnhaft empfundene Lebensführung, eine entspannungsfördernde Rückenmassage etc. umfassen.

Sozialkapital findet sich auf allen drei soziologischen Ebenen, residiert nicht innerhalb von Beziehungsrelationen, sondern ist (informelles) Eigentum des individuellen oder kollektiven Akteurs. Es handelt sich ausschließlich um ein Privatgut. Zu seiner Entstehung bedarf es in Analogie zu allgemeinen kapitaltheoretischen Vorstellungen Investitionen in Beziehungsrelationen. Es kann aber auch als nicht-bewusst intendiertes Resultat von Tauschprozessen oder in Folge einer Vererbung bzw. Transferierung zustande kommen. Eine bestimmte Wirkung wird Sozialkapital hier nicht zugeordnet. Grundsätzlich lässt sich über Sozialkapital ein Ertrag erwirtschaften. Um was es sich dabei konkret handelt, ist eine immer nur empirisch zu beantwortende Frage. In den soeben genannten Fällen bestünden die Erträge etwa in der Anmietung einer günstigen Wohnung, dem Abtrag einer Hypothek, der Erhöhung des Sozialstatus, einem zufriedenen Leben sowie einsetzender Entspannung.

Auf Grundlage des vorgeschlagenen integrativen Theoriemodells entsteht Sozialkapital also vor allem durch Investitionen in Beziehungsrelationen. In einem konkreten Fall könnte bspw. A an B eine für B wichtige Information weitergeben. $B$ fühlt sich daraufhin A verpflichtet und ist willens, sich bei nächster Gelegenheit zu revanchieren. Unterstellen wir der Einfachheit halber, alle weiteren definitorischen Bestimmungskriterien für "Sozialkapital" seien erfüllt, dann kann vom Vorliegen eines Objekts aus dem Begriffsumfang gesprochen werden.

Eine ontologische Betrachtung geht nun insofern darüber hinaus, als wir es im angeführten Beispiel zwar mit einer bestimmten Handlung zu tun haben (A äußert etwas), dass aber nicht ersichtlich ist, wieso die Äußerung As eine Information 
bzw. eine Hilfestellung darstellt, die dann eine Verpflichtung begründet aus der schließlich eine Gutschrift erwächst.

Nochmals in anderen Worten: Die Theorie sagt uns, ein Weg, Sozialkapital zu schaffen, besteht etwa darin, Verpflichtungen zu erzeugen. Ontologisch ist hiervon ausgehend nun von Interesse, wie es überhaupt zu so etwas wie einer Verpflichtung kommen kann, d.h. es wird angenommen, bei einer Verpflichtung handelt es sich um etwas, das nicht in der gleichen Weise in der Welt ist, wie sprachliche Laute es sind. Damit in Folge von akustischen Emissionen eine Information und darauf dann eine Verpflichtung entstehen kann, damit also eine Verbindung zwischen physikalischer und sozialer Wirklichkeit zustande kommt, ist eine anschauungstranszendente Bedeutungswelt erforderlich. Diese aufzudecken und damit die Ordnungsprinzipien institutionaler Realität zu entschlüsseln, war die Aufgabe der durchgeführten ontologischen Analyse.

Mit Quine ließe sich nun zunächst fragen, auf was die Theorie über Sozialkapital ontologisch verpflichtet, d.h. über welche Bereiche quantifiziert die Theorie konkret ${ }^{467}$. Was muss es also geben bzw. was muss als existent angenommen werden, damit wir überhaupt sinnvoll von "Sozialkapital" reden können? Schauen wir uns zunächst noch einmal die Begriffs-Intension an. Um vom Vorliegen von Sozialkapital zu sprechen, bedarf es demnach notwendig eines Akteurs, dem Sozialkapital zugeordnet werden kann, mindestens eines Teilnehmers (d.h. eines weiteren Akteurs), Relationen zwischen Akteur und Teilnehmer, einer vom Teilnehmer bereitgestellten Gutschrift, die dem Akteur funktional hinsichtlich der Erwirtschaftung eines Ertrages dienlich ist, einer positiven Kooperationshaltung seitens des Teilnehmers sowie der Informalität der Beziehungsrelationen mit Blick auf Sozialkapital. Die Theorie verpflichtet ontologisch auf das Vorhandensein all dieser Merkmale bzw. Eigenschaften, da nur so ein sozialer Gegenstand als "Sozialkapital" zu kennzeichnen ist; besitzt ein Objekt eines der genannten Merkmale nicht, so fällt es nicht unter den Begriff.

Nun kommen aber noch die "eigentlichen" ontologischen Größen hinzu, d.h. die notwendigen Ordnungs- und Begriffsbestimmungen, so wie sie unter Zugrundelegung des Bedeutungskonstruktivismus herausgearbeitet wurden. Auf Basis der Searleschen Ontologie (auf die ich mich hier aus darstellungsökonomischen Gründen beschränke) benötigen wir als formale "Zutaten" X-, Y- und KTermini mitsamt der konstitutiven Regel, die diese zusammenbringt. Inhaltlich folgt für einen konkreten Gegenstand aus dem Begriffsumfang dann bspw.:

"A tut etwas" (X; sprachlich repräsentierter brute fact); unter der Bedingung der Funktionalität für Akteur B (K) folgt,

\footnotetext{
467 Ich gehe insofern über Quine (weit) hinaus, als die hier angenommene Ontologie gerade keine reduktionistisch-physikalistische ist; das, was es in der institutionellen Realität gibt, hängt maßgeblich von Bedeutungen ab, die gleichwohl naturalistisch verankert sind (auch Hilary Putnam [1993: 71f.] quantifiziert im Unterschied zu Quine über Eigenschaften).
} 
"A tut etwas für B" (Y); unter der Bedingung der Informalität (K) handelt es sich bei dem was $\mathrm{A}$ für $\mathrm{B}$ tut $(\mathrm{X})$ um eine

"Gefälligkeit" (Y); unter der Bedingung sozialer Reziprozität (K) zählt die Gefälligkeit $(\mathrm{X})$ als eine

"Vorleistung" (Y); unter der Bedingung sozialer Reziprozität (K) erwächst aus der Vorleistung $(\mathrm{X})$ eine

"Verpflichtung" (Y); unter der Bedingung, dass B Ressourcen besitzt, die er A zur Verfügung stellen möchte $(\mathrm{K})$, kommt es von einer Verpflichtung $(\mathrm{X})$ zu einer

"Gutschrift" (Y); unter der Bedingung, dass bei Einlösung der Gutschrift A ein Ertrag erwächst (K), zählt die Gutschrift (X) als "Sozialkapital" (Y).

Wenn innerhalb der Einleitung nach dem Zusammenspiel von dem für Sozialkapital konstitutiven sprachlichen Ordnungsapparat und dem Sozialkapitalbegriff gefragt wurde, so lässt sich dieses Zusammenspiel nun genauer explizieren. "Sozialkapital" ist zunächst einmal ein Allgemeinbegriff, so wie er durch die Begriffs-Intension bestimmt ist, d.h. er bezeichnet keineswegs unmittelbar eine raum-zeitlich lokalisierbare singuläre Entität, sondern er ist als Universalie aufzufassen. Diese wird nun aber erst dann als Teil der sozialen Realität erkennbar, wenn sie instanziert wird, d.h. wenn der Allgemeinbegriff im Rahmen einer konkreten Beziehungsrelation Anwendung findet, so wie das soeben nochmals beschrieben wurde.

Die Universalie ist nun nicht etwas hinter dem sprachlichen Ausdruck liegendes, sondern sie ist nur dank des sprachlichen Ausdrucks, kann also keine von Bewusstsein und regelhaftem menschlichen Sprachgebrauch unabhängige Realität darstellen oder begründen. Sozialkapital ist nichts, was einer Beziehungsrelation als von Sprache unabhängiger Substanz inhärieren würde, was irgendwie schon vorhanden wäre, um dann nur noch eine Bezeichnung zu erhalten. Die Frage, wie wir nun zu einem konkreten Gegenstand gelangen, respektive nach einem bestimmten Objekt aus der Begriffs-Extension, stellt sich damit als Frage nach der korrekten bzw. - vorsichtiger formuliert - sozial angemessenen Anwendung des Allgemeinbegriffs. Diese kann - wie gezeigt - mit Searle und einer gebrauchstheoretischen Bedeutungsperspektive beantwortet werden, in welcher die Regel "X zählt als Y in K" konstitutiven Charakter für institutionelle Gegenstände besitzt. Die Instanzierung lässt sich sowohl als Anwendung einer alltagsweltlichen Sozialkapitaltheorie wie als Dynamisierung der Begriffs-Intension kennzeichnen, insofern die temporären und inhaltlichen Abhängigkeiten zwischen den intensionalen Merkmalen zu Tage treten. 
Eine tabellarische Synopsis von Begriffs-Intension und Ontologie zeigt das Zusammenspiel zwischen Sozialkapitalbegriff und gegenstandskonstitutiven sprachlichen Ordnungsleistungen ${ }^{468}$.

Tabelle 6: Sozialwissenschaftliche Semantik und Ontologie des Sozialkapitals

\begin{tabular}{|l|l|l|}
\hline Begriffs-Intension & Ontologie & Ontologische Terminologie \\
\hline A & A tut etwas & X-Terminus; brute fact \\
Rel & A tut etwas für B (wobei B = Te) & $\begin{array}{l}\text { X-Terminus; erste institutionelle } \\
\text { Tatsache } \\
\text { X-Terminus; erste (informelle) }\end{array}$ \\
Gut & $\begin{array}{l}\text { Gutschrift (weil B bereit ist, A } \\
\text { Ressourcen zur Verfügung zu stellen) }\end{array}$ & $\begin{array}{l}\text { Terminus } \\
\text { A kennt und anerkennt B }\end{array}$ \\
Inf & $\begin{array}{l}\text { A ist rechtlich nicht verpflichtet, } \\
\text { etwas für B zu tun } \\
\text { Fun }\end{array}$ & $\begin{array}{l}\text { Kutschrift dient A zur Ertragserwirt- } \\
\text { schaftung } \\
\text { Eer Ertrag selbst zählt nicht mehr }\end{array}$ \\
Ert & $\begin{array}{l}\text { Kum Berminus } \\
\text { lediglich der Aspekt der Ertragser- } \\
\text { wirtschaftung }\end{array}$ & K-Terminus \\
\hline
\end{tabular}

Was wir allerdings unter dem Allgemeinbegriff verstehen dürfen - als Ausgangspunkt der Instanzierung - ist im Falle von "Sozialkapital" eine von der Wissenschaft abhängige Frage, denn dort taucht der Begriff in dieser Form zwecks einer Systematisierung sozialer Begebenheiten als theoretisches Konstrukt zunächst auf. Wenn wir nach einer Begriffsexplikation dann die Intension kennen, können wir auch zur Extension und damit zur Instanzierung übergehen, die den sprachlichen Gebrauch angibt, den Sozialkapital im Alltag bedarf. Während also der Begriff erkenntnistheoretisch als Leitfaden dafür dient, welche konkreten, singulären Gegenstände wir erfahren und entsprechend identifizieren können, so ist er ontologisch zugleich das Substrat jener Ordnungsleistungen, die Menschen vornehmen müssen, um diese Gegenstände zu etablieren. Der Sozialkapitalbegriff

468 Als über die Begriffs-Intension hinausgehende Komponenten der Ontologie sind zusätzlich noch Gefälligkeit, Vorleistung und Verpflichtung zu nennen, die jedoch im Kontext der Theorie als Entstehungsbedingungen auftauchen. Erst ihr Einbezug ermöglicht überhaupt eine Dynamisierung der Begriffs-Intension. 
bezeichnet demnach nichts, was unabhängig von ihm vorhanden sein könnte (für das Wort "Sozialkapital" gilt dies freilich nicht).

Die bislang geäußerten Überlegungen sollen abschließend noch vor dem Hintergrund der Dichotomisierung von Begriffsnominalismus und -realismus verortet werden. Während im Nominalismus die Beziehung zwischen Begriff und Gegenstand als Ausdruck einer sozialen Konvention gilt, betrachtet man im Realismus Begriffe als Wesensabbilder der Wirklichkeit. Natürlich wird durch die wissenschaftstheoretische Analyse mit dem gewonnenen Sozialkapitalbegriff zunächst einmal ein Gegenstand abgegrenzt bzw. spezifiziert. Die derzeitige begriffliche Diffusität - das war die Ausgangsposition - zwingt zu einer semantischen Klärung. Dies und jenes - so möchte ich meine Analyse einmal verallgemeinert darstellen - sind die intensionalen Merkmale des Begriffs, die bei allen Autoren vorkommen. Davon ausgehend macht es Sinn, "Sozialkapital" auf diese und jene Art und Weise zu definieren. Und zwar so zu definieren, dass für die Zwecke der Kommunikation eine sinnvolle konsensuale Verwendungsweise ermöglicht wird. Bis dahin handelt es sich also bei der Begriffsanalyse lediglich um einen Vorschlag für eine präzise Verwendung von "Sozialkapital" im Sinne einer Nominaldefinition.

Wenn man hierauf fußend aber ontologisch weiterfragt, welche Ordnungsleistungen denn zur Begriffs-Extension führen, dann treten die konstitutiven Merkmale der entsprechenden sozialen Gegenstände ins Blickfeld. Diese Merkmale sind nun aber sprachlicher Natur, womit der wissenschaftliche Sozialkapitalbegriff hiervon nicht unabhängig sein kann. In einer solchen Sichtweise stehen dann der Begriff und der soziale Gegenstand plötzlich doch wieder in einer Korrespondenzbeziehung 469 . Die Wirklichkeit von Sozialkapital ist eine durch sprachlich-kognitive Prozesse von Personen geschaffene und aufrechterhaltene Wirklichkeit. Sie zählt nicht in der gleichen Weise zur Außenwelt wie etwa Steine oder Bäume. Es handelt sich um eine semantische Existenz, d.h. Sozialkapital befindet sich - wenn man so will - in den Köpfen der Menschen, weil diese sich selbst bewahrheitenden sprachlichen Gebrauchsregeln folgen. Wenn das aber so ist, dann sind wir sehr wohl in der Lage, über unsere wissenschaftlichen Begriffe eine Form der Korrespondenz zwischen Begriff und Gegenstand zu leisten, denn wir haben es auf beiden Seiten mit Sprache zu tun.

Die Begriffe, mit denen wir die institutionelle Wirklichkeit zu beschreiben versuchen, sind dann durchaus im Sinne des Begriffsrealismus eine Art Wesensabbild dieser Wirklichkeit, d.h. die Bedeutung der in der Wissenschaft verwendeten Zeichen fällt mit den ontologischen Konstitutionsmerkmalen des Gegenstands weitgehend zusammen, denn der Gegenstand existiert ja nur dank sprachlicher Zeichen. Es ist also keineswegs so, dass wir qua Sprache einen hiervon

${ }^{469}$ Es kann sich nicht um eine Kohärenzbeziehung handeln, weil Begriff und Gegenstand nach wie vor als kategorial unterschiedlich gelten müssen. 
unabhängigen Gegenstand beschreiben; vielmehr beschreiben wir mit der Sprache einen sprachabhängigen Gegenstand (der freilich mehr als "bloß" Sprache ist). Damit dürfen und können aber die wissenschaftlich-analytische (bzw. deskriptive) und die alltagsweltlich-konstitutive Sprache nicht auseinanderfallen ${ }^{470}$. "Sozialkapital" referiert insofern nicht nur auf, sondern qua menschlicher Sprechhandlung in gewissem Sinne mit den so bezeichneten Gegenständen; der Begriff expliziert jene Gedanken, die Personen aufweisen müssen, soll es zu Sozialkapital kommen. Mit Hilary Putnam (1993: 74) lässt sich dann formulieren: "Eine Abbildtheorie der Bedeutung ist nicht vollkommen falsch, nur einseitig; ebenso wie eine Gebrauchstheorie der Bedeutung nicht falsch, sondern nur einseitig ist."

Abbildung 14: Alltagssprache, Sozialkapital und Wissenschaftssprache

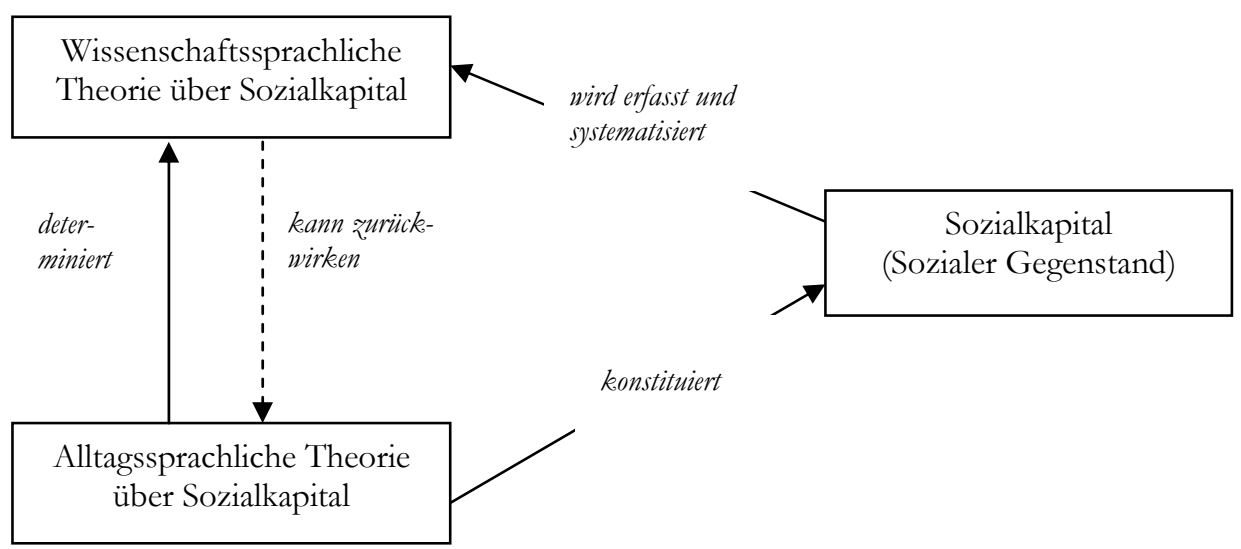

\subsection{Ausblick auf anknüpfende Forschungsfragen}

Zum Abschluss dieser Untersuchung möchte ich noch einige ausgewählte mögliche Forschungsfragen umreißen, die sich an die hier vorgelegte Theorie und Ontologie über Sozialkapital anschließen lassen. Grundsätzlich ging es bei meiner Auseinandersetzung mit der Sozialkapitalthematik freilich um eine Präzisierung des Erkenntniskonstrukts. Unter Gesichtspunkten einer logischen Propädeutik bestand das Untersuchungsziel darin, zu klären, was sich überhaupt vernünftiger-

\footnotetext{
${ }^{470}$ Nun ließe sich freilich sagen, hier werde eine Tautologie präsentiert: Wenn den Gegenständen der institutionellen Welt semantische Existenz zukomme, dann könnten die gegenstandskonstitutive und die -deskriptive Sprache gar nicht auseinanderfallen. Dem stimme ich in der Tat zu. Aber diese Einsicht ermöglicht uns m.E. ein vertieftes Verständnis hinsichtlich des Zusammenhangs zwischen Sprache und institutioneller Welt.
} 
weise sagen lässt. Insofern ist zunächst darauf zu verweisen, welche Dinge besser nicht im Rahmen der Sozialkapitaldebatte diskutiert werden sollten.

Was man nicht machen sollte. Über "Sozialkapital" lässt sich m.E. ausschließlich ein Privatgut beschreiben. Im Zusammenhang mit kollektiven Gütern sollte auf Begriffe wie "Solidarität", "Reziprozität", "Vertrauen" oder "Normen" zurückgegriffen werden. Wobei ich damit keineswegs behaupte, diese Begriffe seien allesamt präzise bestimmt. Die in dieser Arbeit entwickelten sprachphilosophischen Analysewerkzeuge können - insofern hieran Bedarf besteht - auch zu deren Klärung eingesetzt werden. Für den vorliegenden Kontext sind jedenfalls weder demokratietheoretische Überlegungen zu "good governance" noch Überlegungen zu ökonomischen Wachstumsbedingungen sinnvolle Forschungsfelder.

Dennoch ist die Problemrelevanz des hier vorgeschlagenen Sozialkapitalbegriffs vor allem auf der mikrotheoretischen Ebene enorm hoch. Wenn man so will, handelt es sich um eine anspruchsvolle wissenschaftliche Formulierung dessen, was umgangssprachlich als "Vitamin B" bekannt ist. Die Ausstattung von Akteuren mit Sozialkapital ist ein Schlüsselkriterium ihres privaten wie beruflichen Erfolges. Insofern sind auch die meisten Forschungsfragen, welche die Netzwerktheoretiker über "Sozialkapital" stellen, weiterhin mit dem hier vorgeschlagenen Verständnis bearbeitbar - nun allerdings mit einem präzisierten Vokabular, bei dem u.a. das Netzwerk lediglich als eine potentielle Voraussetzung bzw. als besonders geeignete "Brutstätte" von Sozialkapital anzusehen ist.

Quantifizierung. An dieser Stelle ist dann auch auf die Quantifizierungsproblematik zu verweisen. Es dürfte wohl kaum möglich sein, den Sozialkapitalbestand eines Akteurs in toto zu bestimmen. Allenfalls mit Blick auf eine bestimmte Zielstellung - etwa der Abfassung einer sehr guten Examensarbeit - lassen sich Maßzahlen errechnen. Problematisch ist messtheoretisch ferner, dass Sozialkapital zwar für den Akteur einen Nutzwert, aber in Folge seiner relativ eingeschränkten Fungibilität einen nur schwer bestimmbaren bzw. mitunter sogar überhaupt keinen Tauschwert aufweist. Wenn aber die "Umrechnung" eines individuellen Nutzwertes in einen generalisierten Tauschwert nur schwer zu leisten ist, wie soll dann das Sozialkapital unterschiedlicher Akteure sinnvoll auf einer allgemeinen Vergleichsebene quantitativ bestimmt werden? Zur Lösung dieses Problems ließen sich die über Sozialkapital bezogenen Erträge mittels eines Koeffizienten objektivieren. Dies macht zweifellos weiterführende methodische und statistische Überlegungen erforderlich.

Typologie. Die Entwicklung einer (qualitativen) Sozialkapitaltypologie wäre im Rahmen dieser messtheoretischen Probleme möglicherweise nützlich. Es macht mithin wenig Sinn, etwa Gutschriften über konkrete Hilfestellungen zur beruflichen Karriereentwicklung mit Gutschriften über finanziellen Unterstützungsleistungen zwecks Rückzahlung einer fälligen Hypothek miteinander zu vergleichen oder gemeinsam zu einem Sozialkapitalbestand aufzuaddieren. Damit ist ein möglicher Ansatz für eine Typenbildung aber auch schon angedeutet: Auf Basis 
einer entsprechend notwendigen Fallzahl intendierter Anwendungen könnten mit Blick auf die spezifischen Merkmale realisierter Erträge, unterschiedliche Formen des Sozialkapitals (bspw. berufsförderndes, psychische Stabilisierung begünstigendes, Sozialstatus erhöhendes etc.) identifiziert werden. Zweifellos dürfte es vielfach nur schwer möglich sein, alle Formen trennscharf gegeneinander abzugrenzen. Indes sollte dies m.E. eher als Herausforderung für, denn als Argument gegen eine Sozialkapitaltypologie gelten.

Ethik. Die Anwendung von Sozialkapital wird vielfach negative externe Effekte für diejenigen produzieren, die in einer konkreten Wettbewerbssituation nicht genügend soziale Unterstützung mobilisieren können. Dieses Problem ist vor allem im Zusammenhang mit der auf Granovetter zurückgehenden netzwerkanalytischen Debatte um beruflichen Erfolg hinlänglich empirisch nachgewiesen (und wir alle kennen Nepotivismus aus unserem Alltag - sei es in der Position des Profiteurs oder des Benachteiligten). Vielfach handelt es sich im Kontext der Anwendung von Sozialkapital wohl um Nullsummenspiele. Im Spannungsfeld zwischen Selbst- und Sozialverantwortung, zwischen der kaum bestreitbaren Notwendigkeit des Besitzes an bzw. des Gebrauchs von Sozialkapital und den oftmals impliziten negativen externen Effekten wäre eine Ethik des Sozialkapitals zu entwickeln.

In diesem Rahmen ließen sich dann auch forschungsethische Betrachtungen anstellen. Ist es nur konsequent bzw. realitätsangemessen, wenn wir mit einem weiteren wissenschaftlichen Konstrukt detailliert die implizite Ökonomie sozialer Beziehungen ausarbeiten? Oder müssen wir als Wissenschaftler nicht befürchten, dass durch die Übernahme des Begriffs in die Alltagssprache einer "Durchökonomisierung" selbst enger, freundschaftlicher Beziehungsrelationen Vorschub geleistet wird? Dürfen wir es als Wissenschaftler akzeptieren, wenn Menschen in Folge unserer begrifflichen Innovation den Besuch einer Geburtstagsparty als "Portfolioinvestition" und ihre besten Freunde als "Emittenten" oder "Blue Chips" begreifen? Oder sind dies überzogene, unrealistische Szenarien?

Operationalisierung und Erklärungsgehalt. Eine Operationalisierung des von mir vorgeschlagenen Sozialkapitalkonzeptes kann auf Basis strukturalistischer Überlegungen nur heißen, dass man intendierte Anwendungen sucht. Dabei könnte es sich (neben vielen anderen) etwa um wissenschaftlichen Karriereerfolg (gerade auch in diachron-vergleichender Perspektive - also wie notwendig war Sozialkapital früher und wie notwendig ist es heute), Lebenszufriedenheit oder Sozialstatus handeln. Eine Passung zwischen Theoriekern und Gegenstandsbereich impliziert dann eine Erklärung der untersuchten Phänomene. Interessant dürfte dabei außerdem sein, ob man damit wirklich über das deduktivnomologische Schema hinausgehen würde. Insofern wäre es (gerade unter Berücksichtigung der hier angestellten metatheoretischen Grundsatzüberlegungen) über einen empirischen Theorietest bzw. die Suche nach intendierten Anwendungen durchaus möglich, auch die Diskussionen zwischen Positivismus und 
Strukturalismus um einen erkenntnistheoretisch angemessenen Erklärungsbegriff zu befruchten.

Theoretische Diskussion. Auf der sozialtheoretischen Ebene wären verschiedene konzeptionelle Ein- bzw. Anbindungen denkbar. So ließen sich Überlegungen zu sozialer Reziprozität, zu sozialem Austausch, oder zu sozialer Unterstützung bzw. Solidarität andocken. Im Unterschied zu vorliegenden Sozialkapitalkonzepten würde dabei nun "Sozialkapital" als eigenständige Größe behandelt. Bspw. könnte man fragen, welche Formen sozialen Austauschs die Entstehung von Sozialkapital begünstigen oder inwiefern es mit Blick auf spezifische Erträge einen Unterschied macht, ob einem Akteur Sozialkapital nun als Folge bewusster vorangehender Investitionen oder auf Grund von Transferierungen (etwa in Form generalisierter Reziprozität) erwächst. Auch die Aggregationsproblematik wäre in diesen Kontext zu stellen. Dabei kann es nun allerdings nicht mehr darum gehen, die Aggregierung von Sozialkapital von einer niederen auf eine höhere Ebene zu diskutieren. Vielmehr wäre $\mathrm{zu}$ fragen, welche Konsequenzen sich aus einer bestimmten mikrotheoretischen Verteilung von Sozialkapital für Sozietäten ergeben.

Möchte man das Sozialkapital von Regionen oder Staaten auf Basis des hier entwickelten Sozialkapitalverständnis bestimmen, müsste man etwa untersuchen, inwiefern die informellen Beziehungen, die bspw. ein Staatssekretär im Wirtschaftsministerium zu ausländischen Investoren unterhält, zu nationalen Wettbewerbsvorteilen führen. Sicherlich wären entsprechende Daten besonders schwer zu erheben. Dies sollte indes keinen Grund darstellen, solche Forschungsfragen nicht wenigstens zu formulieren und ihre Bearbeitung in Angriff zu nehmen. Insbesondere Erfahrungen und Techniken aus dem Bereich des investigativen Journalismus könnten hier in innovativer Weise mit erprobten Methoden der empirischen Sozialforschung verbunden werden (was freilich nicht jedermanns Sache sein dürfte).

Ontologische Diskussion. Hinsichtlich der hier erarbeiteten Ontologie des Sozialkapitals wäre zunächst einmal auf eine empirische Überprüfung der unterstellten Zusammenhänge zu verweisen. Mit dem wissenschaftstheoretischen Strukturalismus gesprochen, ließen sich intendierte Anwendungen suchen. Wenn es bei der Ontologie über Sozialkapital um den Anteil der Sprache an der Entstehung von Sozialkapital geht, dann müssten nun Extensionsbereiche gefunden werden, in denen exakt die von mir in Kapitel 8.2. beschriebenen Prozesse auch tatsächlich zu Sozialkapital führen. Methodisch könnte diesbezüglich auf die im Rahmen der Sozial- bzw. der kognitiven Psychologie verwendeten Instrumente zur Identifizierung mentaler Modelle zurückgegriffen werden (z.B. die "Methode des lauten Denkens" oder narrative Verfahren).

Die Ontologie lässt ferner insbesondere Forschungsfragen zur bewussten Induzierung von Sozialkapital zu. An dieser Stelle tritt dann abermals deutlich hervor, inwiefern ontologische Überlegungen über Reflexionen zu Sozialkapital als abhängige Variable (im Rahmen einer explanativen Theorie) hinausgehen. Es 
können dann nämlich exakt die konstitutiven Bedingungen identifiziert werden, die bspw. sicherstellen, dass aus einer Investition in eine Beziehungsrelation auch Sozialkapital für den Investor erwächst. Hierzu müssen nämlich bei alter bestimmte sprachliche Typisierungen "nahegelegt" werden, die jedoch immer vor dem Hintergrund eines spezifischen Umweltkontextes zu reflektieren sind, was eine ethnographisch orientierte Forschungsausrichtung an dieser Stelle als erfolgsversprechend erscheinen lässt. In Anknüpfung an eine Typologie des Sozialkapitals wäre dann zu fragen, welche konkreten Handlungen denn als "Investitionen" mit Blick auf eine bestimmte Form des Sozialkapitals zählen.

$\mathrm{Ob}$ und in welche Richtung die vorliegende Untersuchung tatsächlich Anstoß zu weiterführenden Forschungsbemühungen gibt, muss freilich der scientific community bzw. dem einzelnen Sozialwissenschaftler überlassen werden. $\mathrm{Zu}$ hoffen ist jedoch, dass man nun klarer sieht, was man über den Sozialkapitalbegriff vernünftigerweise zur Sprache bringen kann. Vor allem zu einer solchen Entwicklung wollte diese Untersuchung einen Beitrag leisten, denn auf Basis der hier erzielten Ergebnisse lässt sich behaupten, dass Sozialkapital sicherlich zu den Dingen gehört - um das diesem Buch vorangestellte Zitat aus Paul Austers Roman "Stadt aus Glas" abschließend nochmals zu bemühen - "die uns wirklich etwas angehen". 



\section{Literatur}

Adam, F./Roncevic, B. (2003): Social capital: recent debates and research trends, in: Social Science Information 42 (2), S. 155-183, internet download unter: www.socialcapital.org

Adler, A. (1974): Praxis und Theorie der Individualpsychologie, Frankfurt am Main

Adler, A. (1977): Der Sinn des Lebens, Frankfurt am Main

Adloff, F./Mau, S. (Hrsg.) (2005a): Vom Geben und Nehmen. Zur Soziologie der Reziprozität, Frankfurt am Main

Adloff, F./Mau, S. (2005b): Zur Theorie der Gabe und Reziprozität, in: dieselben (Hrsg.): Vom Geben und Nehmen. Zur Soziologie der Reziprozität, Frankfurt am Main, S. 9-57

Albert, H. (1987): Kritik der reinen Erkenntnislehre: Das Erkenntnisproblem in realistischer Perspektive, Tübingen

Albert, H. (1991): Traktat über kritische Vernunft, 5. Aufl., Tübingen

Almond, G.A./Verba, S. (1965): The civic culture. Political attitudes and democracy in five nations, Princetown

Apel, K.O. (1991): Is intentionality more basic than linguistic meaning? In: Lepore, E./Gulick, R. van (Hrsg.): John Searle and his critics, Cambridge, S. 30-55

Arendt, H. (1990): Was ist Existenzphilosophie? Frankfurt am Main

Arrow, K.J. (1999): Observations on social capital, in: Dasgupta, P./Serageldin, I. (Hrsg.): Social capital. A multifaceted perspective, Washington, S. 3-5

Auster, P. (2004): Stadt aus Glas, München

Austin, J.L. (1962): How to do things with words, London, Oxford, New York

Austin, J.L. (1974): Wahrheit, in: Schirn, M. (Hrsg.): Sprachhandlung - Existenz Wahrheit. Hauptthemen der sprachanalytischen Philosophie, Stuttgart, S. 162-179

Austin, J.L. (1979): Zur Theorie der Sprechakte, Stuttgart

Balzer, W. (1982): Empirische Theorien: Modelle, Strukturen, Beispiele, Braunschweig u. Wiesbaden

Balzer, W. (1997): Die Wissenschaft und ihre Methoden. Grundsätze der Wissenschaftstheorie, Freiburg u. München

Balzer, W./Moulines, C.U. (2000): Introduction, in: Balzer,W./Sneed, J.D./Moulines, C.U. (Hrsg.): Structuralist knowledge representation. Paradigmatic examples, Amsterdam u. Atlanta, S. 5-19

Balzer,W./Sneed, J.D./Moulines, C.U. (Hrsg.) (2000): Structuralist knowledge representation. Paradigmatic examples, Amsterdam u. Atlanta

Barnes, B. (1983): Social life as bootstrapped induction, in: Sociology, 17, S. 524-545 
Baron, S./Field, J./Schuller, T. (Hrsg.) (2001): Social capital. Critical perspectives, Oxford Bateson, G. (1982): Geist und Natur. Eine notwendige Einheit, Frankfurt am Main Becker, G. (1993): Human capital, 3. Aufl., Chicago

Beckermann, A. (1999): Analytische Einführung in die Philosophie des Geistes, Berlin u. New York

Beckermann, A. (2002): Prozesse, die für Gründe zugänglich sind. Ende der Willensfreiheit? Die avancierte Hirnforschung hängt einem cartesianischen Weltbild an, in: Frankfurter Rundschau, 17.12.2002, S. 24

Beckert, J. (2003): Scharnierstelle zwischen Markt und Staat, in: Frankfurter Rundschau, 21.10.03, S. 19

Berger, P.L. (1991): Auf den Spuren der Engel. Die moderne Gesellschaft und die Wiederentdeckung der Transzendenz, Freiburg i.B.

Berger, P.L./Luckmann, Th. (1980) Die gesellschaftliche Konstruktion der Wirklichkeit Eine Theorie der Wissenssoziologie, Frankfurt am Main

Berger, P.A./Vester, M. (Hrsg.) (1998): Alte Ungleichheiten - Neue Spaltungen, Opladen

Bergmann, J.R. (2004): Ethnomethodologie, in: Flick, U./Kardoff, E.v./Steinke, I. (Hrsg.): Qualitative Sozialforschung. Ein Handbuch, 3. Aufl., Reinbek bei Hamburg, S. 119135

Berman, S. (1997): Civil society and the collaps of the Weimar Republic, in: World Politics, vol. 49, S. 401-439

Bierhoff, H.-W. (2000): Sozialpsychologie. Ein Lehrbuch, Stuttgart, Berlin, Köln, 5. Aufl.

Bierhoff, H.W. (2002): Theorien hilfreichen Verhaltens, in: Frey, D./Irle, D. (Hrsg.): Theorien der Sozialpsychologie, Bd. 2.: Gruppen-, Interaktions- und Lerntheorien, 2. Aufl., Bern u.a., S. 178-197

Bieri, P. (Hrsg.) (1987): Analytische Philosophie der Erkenntnis, Frankfurt am Main

Bilgrami, A. (1994): Belief and meaning. The unity and locality of mental content, Cambridge

Bjornskov, C./Svendsen, G.T. (2003): Measuring social capital - Is there a single underlying explanation?, Aarhus School of business, Departement of Economics, Working paper 03-05

Blume, Th./Demmerling, Ch. (1998): Grundprobleme der analytischen Sprachphilosophie. Von Frege zu Dummett, Paderborn, München, Wien u. Zürich

Blumer, H. (1973): Der methodologische Standort des symbolischen Interaktionismus, in: Arbeitsgruppe Bielefelder Soziologen (Hrsg.): Alltagswissen, Interaktion und gesellschaftliche Wirklichkeit, Bd. 1: Symbolischer Interaktionismus und Ethnomethodologie, Reinbek bei Hamburg, S. 80-146

Bochenski, I.M. (1993): Die zeitgenössischen Denkmethoden, 10. Aufl., Tübingen u. Basel

Bochumer Arbeitsgruppe für Sozialen Konstruktivismus und Wirklichkeitsprüfung (2000): Erkenntnistheoretische Probleme der Psychologie: Über das Verhältnis von Wirklichkeit, Sinnesdaten und Sprache, Arbeitspapier Nr. 2, Ruhr-Universität Bochum, Fakultät für Psychologie, Januar 2000

Bohnsack, R. (1999): Rekonstruktive Sozialforschung. Einführung in die Methodologie und 
Praxis qualitativer Forschung, Opladen, 3. Aufl.

Bourdieu, P. (1979): Entwurf einer Theorie der Praxis auf der ethnologischen Grundlage der kabylischen Gesellschaft, Frankfurt am Main

Bourdieu, P. (1986): The forms of capital, in: Richardson, J.G. (Hrsg.): Handbook of theory and research for the sociology of education, Greenwood, S. 241-258

Bourdieu, P. (1987): Die feinen Unterschiede. Kritik der gesellschaftlichen Urteilskraft, Frankfurt am Main

Bourdieu, P. (1992): Ökonomisches Kapital - Kulturelles Kapital - Soziales Kapital, in: derselbe: Die verborgenen Mechanismen der Macht. Schriften zu Politik \& Kultur 1, herausgegeben von Margareta Steinrücke, Hamburg, S. 49-80

Bourdieu, P. (1993): Sozialer Sinn. Kritik der theoretischen Vernunft, Frankfurt am Main

Bourdieu, P. (1997): Für einen anderen Begriff von Ökonomie, in: derselbe: Der Tote packt den Lebenden. Schriften zu Politik \& Kultur 2, herausgegeben von Margareta Steinrücke, Hamburg, S. 79-100

Bourdieu, P. (1998): Praktische Vernunft. Zur Theorie des Handelns, Frankfurt am Main

Bourdieu, P. (2000): Die zwei Gesichter der Arbeit. Interdependenzen von Zeit- und Wirtschaftsstrukturen am Beispiel einer Ethnologie der algerischen Übergangsgesellschaft, Konstanz

Bourdieu, P. (2005): Die Ökonomie der symbolischen Güter, in: Adloff, F./Mau, S. (Hrsg.): Vom Geben und Nehmen. Zur Soziologie der Reziprozität, Frankfurt am Main, S. 139-155

Bourdieu, P./Chamboredon, J.-C./Passeron, J.-C. (1991): Soziologie als Beruf. Wissenschaftstheoretische Voraussetzungen soziologischer Erkenntnis, Berlin u. New York

Bourdieu, P./Passeron, J.-C. (1971): Die Illusion der Chancengleichheit, Stuttgart

Braun, S. (2001): Kooperation und Korruption, in: Frankfurter Rundschau, 31.07.01, S. 20

Brauner, E. (1994): Soziale Interaktion und mentale Modelle. Planungs- und Entscheidungsprozesse in Planspielgruppen, Münster u. New York

Bremer, M. (o.J.): Einfachheit, im internet unter: http://manuel.bremer/bei.tonline.de/einfachheit.pdf, aufgerufen am 10.03.04

Brentano, F. (1982): Deskriptive Psychologie, herausgegeben und eingeleitet von Roderick M. Chisholm, Hamburg

Brinker, K. (2001): Linguistische Textanalyse: Eine Einführung in Grundbegriffe und Methoden, Berlin, 5. Aufl.

Brown, L.D. (1998): Creating Social Capital: Nongovernmental Development. Organizations and Intersectoral Problem Solving, in: Powel, W. et al. (Hrsg.): Private Action and the Public Good, New Haven, S. 228-241

Bruner, J.S./Goodman, C.C. (1947): Value and need as organizing factors in perception, in: Journal of Abnormal and Social Psychology, 42, S. 33-44, internet download unter: http://psychclassics.yorku.ca

Bublitz, H. (2001): Differenz und Integration. Zur diskursanalytischen Rekonstruktion der Regelstrukturen sozialer Wirklichkeit, in: Keller, R./Hirseland, A./Schneider, W. (Hrsg.): Handbuch Sozialwissenschaftliche Diskursanalyse, Bd. 1: Theorien und Me- 
thoden, Opladen, S. 225-260

Bühler, A. (1990): Bedeutungsunbestimmtheit, Unerforschlichkeit des Gegenstandsbezugs und subjektive Gewißheit, in: Sukale, M. (Hrsg.): Sprache, Theorie und Wirklichkeit, Frankfurt am Main, S. 235-251

Burchardt, M. (1986): Mikrotheorie. Kritische Einführung mit einem Kompendium mikrotheoretischer Fachbegriffe, Köln

Burkhardt, A. (Hrsg.) (1990): Speech Acts, meaning and intentions. Critical approaches to the philosophy of John R. Searle, Berlin, New York

Burt, R.S. (1992): Structural Holes. The Social Structure of Competition, Cambridge, Massachusetts, London

Burt, R.S. (1999): The social capital of opinion leaders, in: Annals of the american academy of political and social science, vol. 566, S. 37-54

Burt, R.S. (2001): Structural Holes versus Network Closure as Social Capital, in: Lin, N./Cook, K./Burt, R.S. (Hrsg.): Social Capital. Theory and Research, New York; S. $31-56$

Burth, H.P. (1999): Steuerung unter der Bedingung struktureller Kopplung: Ein Theoriemodell sozio-politischer Steuerung, Opladen

Bußhoff, H. (Hrsg.) (1992): Politische Steuerung, Baden-Baden

Camus, A. (2000): Der Mythos des Sisyphos, Reinbek bei Hamburg

Carnap, R. (1928): Der logische Aufbau der Welt, Berlin

Carnap, R. (1931a): Überwindung der Metaphysik durch logische Analyse der Sprache, in: Erkenntnis, 2, S. 219-241

Carnap, R. (1931b): Die physikalische Sprache als Universalsprache, in: Erkenntnis, 2, S. $432-465$

Carnap, R. (1932): Psychologie in physikalischer Sprache, in: Erkenntnis, 3, S. 107-142

Carnap, R. (1976): Empirismus, Semantik und Ontologie, in: Sukale, M. (Hrsg.): Moderne Sprachphilosophie, Hamburg, S. 53-67

Carnap, R. (1992): Die Aufgabe der Wissenschaftslogik, in: Schulte, J./McGuinness (Hrsg): Einheitswissenschaft, Frankfurt am Main, S. 90-117

Carnap, R./Hahn, H./Neurath, O. (1929): Wissenschaftliche Weltauffassung. Der Wiener Kreis, Veröffentlichungen des Vereins Ernst Mach, Wien

Castaneda, H.-N. (1982): Sprache und Erfahrung: Texte zu einer neuen Ontologie, Frankfurt am Main

Chalmers, A.F. (2001): Wege der Wissenschaft. Einführung in die Wissenschaftstheorie, 5. Aufl., Berlin u.a.

Charpa, U. (1996): Grundprobleme der Wissenschaftsphilosophie, Paderborn u.a.

Cherwitz. R.A./Darwin, T.J. (1995): Toward a relational theory of meaning, in: Philosophy and rhetoric, vol. 28, no. 1, S. 17-29

Chisholm, R.M. (1996): A realistic theory of categories. An essay on ontology, Cambridge

Chomsky, N. (1977): Reflexionen über die Sprache, Frankfurt am Main

Chomsky, N. (1988): Language and problems of knowledge, Cambridge 
Clemens, E.S. (2001): Securing political returns to social capital: women's associations in the United States, 1880s-1920s, in: Rotberg, R.J. (Hrsg.): Patterns of social capital. Stability and change in historical perspective, Cambridge, S. 247-272

Cody, J. (2002): Conceptualising social capital, in: Robinson, D. (Hrsg): Building social capital, Wellington, S. 31-40

Coleman, J.S. (1988): Social capital in the creation of human capital, in: American journal of sociology, vol. 94, supplement, S. 95-120

Coleman, J.S. (1991): Grundlagen der Sozialtheorie, Bd. 1: Handlungen und Handlungssysteme, München

Coleman, J.S. (1993): Reply to Blau, Tuomela, Dieckmann and Baurmann, in: Analyse und Kritik: Zeitschrift für Sozialwissenschaften, H. 1, Jg. 15, S. 62-69

Coleman, J.S. (1993a): The rational reconstruction of society: 1992 presidential address, in: American sociological review, vol. 58, no. 1, S. 1-15

Coleman, J.S. (1994): Foundations of Social Theory, Cambridge

Coleman, J.S./Hoffer, T.B. (1987): Public and private schools: The impact of communities, New York

Coleman, J.S./Husén, T. (1985): Becoming adult in a changing society, Centre for educational research and innovation (CERI), Paris

Crosby, J.F. (1990): Speech act theory and phenomenology, in: Burkhardt, A. (Hrsg.): Speech Acts, meaning and intentions. Critical approaches to the philosophy of John R. Searle, Berlin, New York, S. 62-88

Cusack, T.R. (1999): Social capital, institutional structures, and democratic performance. A comparative study of german local governments, in: European journal of political research, 35, S. 1-34

Dasgupta, P./Serageldin, I. (Hrsg.) (1999): Social capital. A multifaceted perspective, Washington

Davidson, D. (1986): Was Metaphern bedeuten, in: derselbe: Wahrheit und Interpretation, Frankfurt am Main, S. 343-371

Davidson, D. (1987): Was ist eigentlich ein Begriffsschema?, in: Bieri, P. (Hrsg.): Analytische Philosophie der Erkenntnis, Frankfurt am Main, S. 390-405

Davidson, D. (2000): Die zweite Person, in: Deutsche Zeitschrift für Philosophie, 3/2000, S. $395-407$

Dederichs, A.M. (1999): Das soziale Kapital in der Leistungsgesellschaft. Emotionalität und Moralität in "Vetternwirtschaften", Münster u.a.

Deth, J.W. van (2001): Ein amerikanischer Eisberg: Sozialkapital und Erzeugung politischer Verdrossenheit, in: Politische Vierteljahreszeitschrift, 42, S. 275-282

Deutscher Bundestag, Drucksache 14/8900: Bericht der Enquete-Kommission "Zukunft des Bürgerschaftlichen Engagements". Bürgerschaftliches Engagement: auf dem Weg in eine zukunftsfähige Bürgergesellschaft, 03.06.02

Diederich, W. (1981): Strukturalistische Rekonstruktionen, Braunschweig

Diefenbach, U. (2000): Schöner schleimen. Networking ist das 'Sesam öffne dich' für den beruflichen Aufstieg. Dem Chef begegnen wir mit Ehrfurcht - aber so oft wie mög- 
lich, in: Frankfurter Rundschau, 29.04.2000, Magazin, S. 7

Diekmann, A. (1993): Sozialkapital und das Kooperationsproblem in sozialen Dilemmata, in: Analyse und Kritik, Jg. 15, H. 1, S. 22-35

Diekmann, A. (2004a): The power of reciprocity. Fairness, reciprocity, and stakes in variants of the dictator game, in: Journal of conflict resolution, vol. 48, no. 4, August 2004, S. 487-505

Diekmann, A. (2004b): Elemente des Sozialkapitals, Paper zum Vortrag auf der Frühjahrstagung "Sozialkapital. Grundlagen, Modelle und Anwendungen" der DGS-Sektion "Modellbildung und Simulation", 9./10. Juli 2004, Zürich, im internet unter: www.soz.unibe.ch/dgsmodsim/zuerich04.asp

Dilthey, W. (1970) Der Aufbau der geschichtlichen Welt in den Geisteswissenschaften, Frankfurt am Main

Dreier, V. (1996): Metatheoretische Reflexionen über Handlungs- und Entscheidungstheorie(n), in: Druwe, U./Kunz, V. (Hrsg): Handlungs- und Entscheidungstheorie in der Politikwissenschaft. Einführung in Konzepte und Forschungsstand, Opladen, S. 5682

Dreier, V. (1997): Empirische Politikforschung, München u. Wien

Dreyfus, H.L. (o.J.): The primacy of Phenomenology over Logical Analysis, im internet unter: http://ist-socrates.berkeley.edu/ dreyfus $/ \mathrm{html} /$ papers $/ \mathrm{html}$

Druwe, U. (1985): Theoriendynamik und wissenschaftlicher Fortschritt in den Erfahrungswissenschaften. Evolution und Struktur politischer Theorien, Freiburg

Druwe, U. (1991): Moralische Pluralität: Grundlegung einer analytischen Ethik der Politik, Würzburg

Druwe, U. (1995): Politische Theorie, Neuried, 2. Aufl.

Druwe, U./Kühnel, S./Kunz, V. (Hrsg.) (2000): Kontext, Akteur und strategische Interaktion - Untersuchungen zur Organisation politischen Handelns in modernen Gesellschaften, Opladen

Druwe, U./Kunz, V. (Hrsg) (1996): Handlungs- und Entscheidungstheorie in der Politikwissenschaft. Einführung in Konzepte und Forschungsstand, Opladen

Duhem, P. (1996): Essays in the history and philosophy of science, Indianapolis

Dummett, M. (1976): What is a theory of meaning? (II), in: Evans, G./McDowell, J. (Hrsg): Truth and meaning. Essays in semantics, Oxford, S. 67-137

Dummett, M. (1991): The logical basis of metaphysics, Cambridge

Dummett, M. (1992): Ursprünge der analytischen Philosophie, Frankfurt am Main

Durkheim, E. (1999): Regeln der soziologischen Methode, herausgegeben und eingeleitet von René König, 4. Aufl., Frankfurt am Main

Durlauf, S.N. (1999): The case 'against' social capital, Focus 20 (3), im internet unter: www.ssc.wisc.edu/econ/archive/wp9929.pdf

Edwards, B./Foley, M. (1997): Social capital and the political economy of our discontent, in: American behavioral scientist, vol. 40, no. 5, S. 669-678

Eick, V. (2004): Profiteure des sozialen Kapitals. Zur Genese sozialer Sicherheitsregime durch Nonprofits, kommerzielle Sicherheitsdienste und den lokalen Staat, in: Kessl, 
F./Otto, H.U. (Hrsg.): Soziale Arbeit und soziales Kapital. Zur Kritik lokaler Gemeinschaftlichkeit, Wiesbaden, S. 139-154

Eley, L. (1974): Sprache als Sprechakt. Die phänomenologische Theorie der Bedeutungsintention und -erfüllung und die sprachphilosophische Theorie der Sprechakte, in: Simon, J. (Hrsg.): Aspekte und Probleme der Sprachphilosophie, Freiburg, München, S. 137-184

Ellis, A. (1983): Rational-Emotive Therapy and Cognitive Behavior Therapy, New York Enquete-Kommission "Zukunft des bürgerschaftlichen Engagements" (2002), Band 1: Bürgerschaftliches Engagement und Zivilgesellschaft, herausgegeben vom Deutschen Bundestag, Opladen

Enquete-Kommission "Zukunft des bürgerschaftlichen Engagements" (2003), Band 2: Bürgerschaftliches Engagement von Unternehmen, herausgegeben vom Deutschen Bundestag, Opladen

Erickson, B.H. (2001): Good Networks and Good Jobs: The Value of Social Capital to Employers and Employees, in: Lin, N./Cook, K./Burt, R.S. (Hrsg.): Social Capital. Theory and Research, New York, S. 127-158

Esser, H. (1991): Die Rationalität des Alltagshandelns. Alfred Schütz und 'Rational Choice', in: Esser, H./Troitzsch, K. (Hrsg.): Modellierung sozialer Prozesse: Neuere Ansätze und Überlegungen zur soziologischen Theoriebildung, Bonn, S. 235-282

Esser, H. (1996a): Die Definition der Situation, in: Kölner Zeitschrift für Soziologie und Sozialpsychologie, Jg. 48, H. 1, S. 1-34

Esser, H. (1996b): Soziologie: Allgemeine Grundlagen, 2. Aufl., Frankfurt am Main u. New York

Esser, H. (2000): Soziologie. Spezielle Grundlagen, Band 4: Opportunitäten und Restriktionen, Frankfurt am Main u. New York

Esser, H. (2001): Soziologie. Spezielle Grundlagen, Band 6: Sinn und Kultur, Frankfurt am Main u. New York

Esser, H./Klenovitz, K./Zehnpfennig, H. (1977): Wissenschaftstheorie I - Grundlagen und Analytische Wissenschaftstheorie, Stuttgart

Esser, H./Troitzsch, K. (Hrsg.) (1991): Modellierung sozialer Prozesse, Bonn

Essler, W.K. (1972): Analytische Philosophie 1: Methodenlehre, Sprachphilosophie, Ontologie, Erkenntnistheorie, Stuttgart

Essler, W.K. (1982): Wissenschaftstheorie 1. Definition und Reduktion, 2. Aufl., Freiburg u. München

Estany, A. (2001): The thesis of theory-laden observation in the light of cognitive psychology, in: Philosophy of Science, 68, S. 203-217

Etzioni, A. (1997): Im Winter einen Pullover ablehnen, weil es im Sommer warm war? Ein kommunitaristischer Versuch, den Wohlfahrtsstaat neu zu definieren, in: Blätter für deutsche und internationale Politik, H. 2, S. 232-243

Etzrodt, C. (2003): Sozialwissenschaftliche Handlungstheorien. Eine Einführung, Konstanz

Evans, G./McDowell, J. (Hrsg) (1976): Truth and meaning. Essays in semantics, Oxford

Evans, P. (1996): Government action, social capital and development: reviewing the 
evidence on synergy, in: World Development, 24 (6), S. 178-109, internet download unter: www.socialcapitalgateway.org

Evers, A. (2002): Bürgergesellschaft und soziales Kapital. Die politische Leerstelle im Konzept Robert D. Putnams, in: Haus, M. (Hrsg.): Bürgergesellschaft, soziales Kapital und lokale Politik. Theoretische Analysen und empirische Befunde, Opladen, S. 59-75

Evers, A. et al. (2000): Soziales Kapital mobilisieren. Gemeinwesenorientierung als Defizit und Chance lokaler Beschäftigungspolitik, Dortmund

Evers, A./Koob, D. (2001): The policies of social integration in Europe - Systems of collective action, Hrsg.: Directorate General Science, Research and development EUROPEAN COMMISSION, Final Report of project ERB-SOE2-CT97-3036 funded under the Targeted Socio-Economic Research (TSER) programme, Brüssel, Oktober 2001

Faist, T. (1997): Migration und der Transfer sozialen Kapitals oder: Warum gibt es relativ wenige internationale Migranten? In: Pries, L. (Hrsg.): Transnationale Migration, Soziale Welt, Sonderband 12, S. 63-84

Faust, J./Marx, J. (2004): Zwischen Kultur und Kalkül: Vertrauen, Sozialkapital und wirtschaftliche Entwicklung, in: Swiss political science review, Jg. 10, H. 1, im internet unter: www.students.uni-mainz.de/marxj000/FaustMarx.pdf

Ferber, R. (1998): Philosophische Grundbegriffe. Eine Einführung, München, 4. Aufl.

Fernandez, R.M./Castilla, E.J. (2001): How much is that network worth? Social capital in employee referral networks, in: Lin, N./Cook, K./Burt, R.S. (Hrsg.): Social capital. Theory and research, New York, S. 85-104

Feyerabend, P. (1978): Das Problem der Existenz theoretischer Entitäten, in: derselbe: Ausgewählte Schriften, Bd. 1: Der wissenschaftstheoretische Realismus und die Autorität der Wissenschaften, S. 40-74

Field, J./Schuller, T./Baron, S. (2001): Social capital and human capital revisited, in: Baron, S./Field, J./Schuller, T. (Hrsg.): Social capital. Critical perspectives, Oxford, S, 243263

Fine, B. (1999): The developmental state is dead - long live social capital?, in: Development and change, vol. 36, S. 1-19

Fine, B. (2001): Social capital versus social theory. Political economy and social science at the turn of the millennium, London $\mathrm{u}$. New York

Fischer, L./Wiswede, G. (2002): Grundlagen der Sozialpsychologie, 2. Aufl., München u. Wien

Fiske, S.T./Taylor, S.E. (1991): Social Cognition, 2. Aufl., New York u.a.

Flap, H. (1995): No man is an island. The research program of a social capital theory, paper pres. workshop on rational choice and social networks, Jan. 26-28, Nias, Wassenaar

Flap, H./Boxman, E. (2001): Getting Started: The Influence of Social Capital on the Start of the Occupational Career, in: Lin, N./Cook, K./Burt, R.S. (Hrsg.): Social Capital. Theory and Research, New York, S. 159-183

Flap, H. (2002): No man is an island, in: Favereau, O./Lazega, E. (Hrsg.): Conventions and structures in economic organization: markets, networks and hierarchies, London, S. 
29-59

Fleck, L. (1980): Entstehung und Entwicklung einer wissenschaftlichen Tatsache. Einführung in die Lehre vom Denkstil und Denkkollektiv, Frankfurt am Main

Fleck, L. (1983): Erfahrung und Tatsache. Gesammelte Aufsätze, Frankfurt am Main

Flick, U. (1999): Qualitative Forschung. Theorie, Methoden, Anwendung in Psychologie und Sozialwissenschaften, Reinbek bei Hamburg, 4. Aufl.

Flick, U./Kardoff, E.v./Steinke, I. (Hrsg.) (2004): Qualitative Sozialforschung. Ein Handbuch, 3. Aufl., Reinbek bei Hamburg

Foerster, H.v. (2001): Einer, der riecht, schmeckt, hört und sieht. Die Rolle des Beobachters und die Konvergenz von Natur- und Geisteswissenschaften: Heinz von Foerster im Gespräch mit Bernhard Pörksen, in: Frankfurter Rundschau, 07.04.01, S. 19

Foley, M./Edwards, B. (1996): The paradox of civil society, in: Journal of Democracy, vol. 7, S. 39-52

Forgas, J.P. (1981): Every day understanding and social cognition, in: derselbe (Hrsg.): Social cognition - Perspectives on everyday understanding, London u.a., S. 259-272

Forgas, J.P. (1995): Soziale Interaktion und Kommunikation: Eine Einführung in die Sozialpsychologie, Weinheim, 3. Aufl.

Foucault, M. (1991): Die Ordnung des Diskurses, Frankfurt am Main

Frege, G. (1892): Über Begriff und Gegenstand, in: Vierteljahresschrift für wissenschaftliche Philosophie, 16, S. 192-205, im internet unter: www.gavagai.de/HHP34.htm

Frege, G. (1987): Die Grundlagen der Arithmetik. Eine logisch-mathematische Untersuchung über den Begriff der Zahl, Stuttgart

Frege, G. (2002): Funktion - Begriff - Bedeutung, herausgegeben von Max Textor, Göttingen

Freitag, M. (2000): Soziales Kapital und Arbeitslosigkeit. Eine empirische Analyse zu den Schweizer Kantonen, in: Zeitschrift für Soziologie, Jg. 29, H. 3, S. 186-201

Freitag, M. (2004): Das Konzept des Sozialkapitals und Ansätze zu seiner Messung, in: Wilbers, K. (Hrsg.): Das Sozialkapital von Schulen. Die Bedeutung von Netzwerken, gemeinsamen Normen und Vertrauen für die Arbeit von und in Schulen, Bielefeld, S. 7-24

Freud, S. (1988): Das Ich und das Es. Und andere metapsychologische Schriften, Frankfurt am Main

Frey, D./Irle, D. (Hrsg.) (2002): Theorien der Sozialpsychologie, Bd. 2.: Gruppen-, Interaktions- und Lerntheorien, 2. Aufl., Bern u.a.

Frey, D./Irle, M. (Hrsg.) (1984): Theorien der Sozialpsychologie, Bd. 1: Kognitive Theorien der Sozialpsychologie, Stuttgart u.a., 2. Aufl

Fukuyama, F. (1995): Trust. Social virtues and the creation of prosperity, New York

Fukuyama, F. (1997): Social capital, The Tanner lectures on human values, vol. 19, S. 375 484

Fukuyama, F. (1999): Social Capital and civil society, paper prepared for delivery at the IMF conference on second generation reforms, im internet unter: www.imf.org/external/pubs/ft/seminar/1999/reforms/fukuyama.htm 
Fukuyama, F. (2002): Social capital and development: The coming agenda, in: SAIS Review, vol. XXII, no. 1, S. 23-37

Fukuyama. F. (2004): State building. Governance and world order in the $21^{\text {st }}$ century, Ithaca u. New York

Füllberth, G. (2004): Sozialkapital, im internet unter: www.linksnet.de/linkslog/index.php?itemid $=95$

Gabriel, G. (1972): Definitionen und Interessen. Über die praktischen Grundlagen der Definitionslehre, Stuttgart-Bad Canstatt

Gabriel, O.W./ Kunz, V./ Roßteutscher, S./ Deth, J.v. (2002): Sozialkapital und Demokratie: Zivilgesellschaftliche Ressourcen im Vergleich, Wien

Gadenne, V. (1996): Bewußtsein, Kognition und Gehirn. Einführung in die Psychologie des Bewußtseins, Bern, Göttingen, Toronto und Seattle

Gebauer, G. (2000): Die Konstruktion der Gesellschaft aus dem Geist? Searle versus Bourdieu, in: Kölner Zeitschrift für Soziologie und Sozialpsychologie, Jg. 52, H. 3, S. 428-449

Geertz, C. (1983): Dichte Beschreibung. Beiträge zum Verstehen kultureller Systeme, Frankfurt am Main

Gehlen, A. (1950): Der Mensch. Seine Natur und seine Stellung in der Welt, Bonn, 4. Aufl.

Gehmacher, E. (2004): Sozialkapital. Basisinformationen, im internet unter: www.umweltnet.at/article/archive/7804/

Geißel, B./Kern, K./Klein, A, Berger, M. (2004): Einleitung: Integration, Zivilgesellschaft und Sozialkapital, in: Klein, A./Kern, K./Geißel, B./ Berger, M. (Hrsg.): Zivilgesellschaft und Sozialkapital. Herausforderungen politischer und sozialer Integration, Wiesbaden, S. 7-18

Gergen, K.J./Gergen, M.M. (1986): Social psychology, 2. Aufl., New York u.a.

Gethmann, C.F. (1981): Wissenschaftsforschung? Zur philosophischen Kritik der nachKuhnschen Reflexionswissenschaften, in: Janich, P. (Hrsg.): Wissenschaftstheorie und Wissenschaftsforschung, München, S. 9-38

Giddens, A. (1992): Die Konstitution der Gesellschaft. Grundzüge einer Theorie der Strukturierung, Frankfurt am Main

Giddens, A. (2000): The third way and its critics, Cambridge

Gipper, H. (1987): Das Sprachapriori. Sprache als Voraussetzung menschlichen Denkens und Erkennens, Bad Canstatt

Gittell, R./Vidal, A. (1998): Community organizing: Building social capital as a development strategy, Thousend Oaks

Glock, H.-J. (2000): Wie kam die Bedeutung zur Regel?, in: Deutsche Zeitschrift für Philosophie, 3/2000, S. 429-447

Glüer, K. (1993): Donald Davidson - Zur Einführung, Hamburg

Glüer, K. (2000): Bedeutung zwischen Norm und Naturgesetz, in: Deutsche Zeitschrift für Philosophie, 3/2000, S.449-468

Goffman, E. (2001): Wir alle spielen Theater. Die Selbstdarstellung im Alltag, München, 9.Aufl. 
Goldberg, E. (2005): Intuition spart Energie, Silvia Sanides im Interview mit Elkohon Goldberg, in: Focus, Nr. 24, 13. Juni 2005, S. 84-87

Graf, F.W. (1999): 'In God we trust'. Über mögliche Zusammenhänge von Sozialkapital und kapitalistischer Wohlfahrtsökonomie, in: Graf, F.W./Platthaus, A./Schleissing, S. (Hrsg.): Soziales Kapital in der Bürgergesellschaft, Stuttgart, Berlin u. Köln, S. 93130

Graf, F.W. (1999a): Zur Einführung, in: Graf, F.W./Platthaus, A./Schleissing, S. (Hrsg.): Soziales Kapital in der Bürgergesellschaft, Stuttgart, Berlin u. Köln, S. 9-20

Graf, F.W./Platthaus, A./Schleissing, S. (1999) (Hrsg.): Soziales Kapital in der Bürgergesellschaft, Stuttgart, Berlin u. Köln

Granovetter, M. S. (1973): The strength of weak ties, in American journal of sociology, vol. 78, no. 6, S. 1360-1380

Granovetter, M. S. (1974): Getting a job: A study of contacts and careers, Cambridge

Granovetter, M.S. (1985): Economic action and social structure: the problem of embeddedness, in: American journal of sociology, no. 3, S. 481-510

Grayling, A.C. (o.J.): Wittgenstein, Freiburg, Basel u. Wien

Greshoff, R. (o.J.): Eine Soziologie oder mehrere Soziologien? Zum Stellenwert des Vergleichs für die Orientierung in einer "multiparadigmatischen" Wissenschaft, im internet unter: www.univie.ac.at.OEGS-Kongress-2000/On-line-

Publikation/greshoff.pdf

Grice, P. (1979): Sprecher-Bedeutung und Intentionen, in: Meggle, G. (Hrsg.): Handlung, Kommunikation, Bedeutung, Frankfurt am Main, S. 16-51

Grondin, J. (2002): Kant - Zur Einführung, Hamburg, 2. Aufl.

Grunwald, A. (1998): Das prädiskursive Einverständnis - Wissenschaftlicher Wahrheitsbegriff und prozedurale Rechtfertigung, in: Journal for General Philosophy of Science, 29, S. 205-223

Habisch, A. (1998): Social capital investments, property rights and the ethics of win-win. Why multinational enterprise management should engage in institution building of their host countries, in: Kumar, B.N./Steinmann, H. (Hrsg.): Ethics in international management, Berlin, New York, S. 109-127

Hacking, I. (1997): Searle, Reality and the Social, in: History of the human sciences, Vol. 10, No. 4, S. 83-92

Hacking, I. (1999): Was heißt 'soziale Konstruktion'? Zur Konjunktur einer Kampfvokabel in den Wissenschaften, Frankfurt am Main

Hall, P. (2001): Sozialkapital in Großbritannien, in: Putnam, R.D. (Hrsg.): Gesellschaft und Gemeinsinn. Sozialkapital im internationalen Vergleich, Gütersloh, S. 45-113

Haller, M. (1999): Soziologische Theorie im systematisch-kritischen Vergleich, Opladen

Hanifan, L.J. (1916): The rural school community center, in: Annals of the american academy of political and social science, 67, S. 130-138

Hanifan, L.J. (1920): The community center, Boston

Hannemann, C. (2002): Miteinander kegeln: Soziales Kapital in ostdeutschen Kleinstädten, in: Haus, M. (Hrsg.): Bürgergesellschaft, soziales Kapital und lokale Politik. Theore- 
tische Analysen und empirische Befunde, Opladen, S. 255-273

Hanson, N. (1969): Perception and Discovery. An Introduction to Scientific Inquiry, San Francisco

Hardin, R. (1999): Social capital, in: Alt, J./Levi, M./Ostrom, E. (Hrsg.): Competition and co-operation: conversations with nobelists about economics and political science, New York, S. 170-189

Harré, R. (1987): The social construction of the self, in: Yardley, K./Honess, T. (Hrsg.): Self and identity. Psychological perspectives, Chichester u.a., S. 41-52

Harriss, J./de Renzio, P. (1997): Missing link or analytically missing? The concept of social capital. An introductory bibliographic essay, in: Journal for international development, vol. 9, no. 7, S. 919-937

Haug, S. (1997): Soziales Kapital. Ein kritischer Überblick über den aktuellen Forschungsstand, Mannheimer Zentrum für europäische Sozialforschung (MZES), Arbeitspapiere Arbeitsbereich II/15, Mannheim

Haug, S. (2000): Soziales Kapital und Kettenmigration. Italienische Migranten in Deutschland, Wiesbaden

Haus, M. (Hrsg.) (2002): Bürgergesellschaft, soziales Kapital und lokale Politik. Theoretische Analysen und empirische Befunde, Opladen

Hautzinger. M. (Hrsg.) (2000): Kognitive Verhaltenstherapie bei psychischen Störungen, Weinheim, 3. Aufl

Hastedt, H. (2005): Gefühle. Philosophische Bemerkungen, Stuttgart

Heidbrink, H. (1996): Einführung in die Moralpsychologie, 2. Aufl., Weinheim

Heidegger, M. (1977): Sein und Zeit, Martin Heidegger Gesamtausgabe, 1. Abteilung: Veröffentlichte Schriften 1914-1970, Band 2, Frankfurt am Main

Heinrich, K. (1966): Parmenides und Jonas - Vier Studien über das Verhältnis von Philosophie und Mythologie, Frankfurt am Main

Hellmann, K.-U. (2004): Solidarität, Sozialkapital und Systemvertrauen, in: Klein, A./Kern, K./Geißel, B./ Berger, M. (Hrsg.): Zivilgesellschaft und Sozialkapital. Herausforderungen politischer und sozialer Integration, Wiesbaden, S. 131-150

Heringer, H.-J./Öhlschläger, G./Strecker, B./Wimmer, R. (1977): Einführung in die Praktische Semantik, Heidelberg

Hitzler, R./Eberle, T.S. (2004): Phänomenologische Lebensweltanalyse, in: Flick, U./Kardoff, E.v./Steinke, I. (Hrsg.): Qualitative Sozialforschung. Ein Handbuch, 3. Aufl., Reinbek bei Hamburg, S. 109-118

Hoche, H.U./Strube, W. (1985): Analytische Philosophie, Freiburg u. München

Hofmann, A. (1995): Bedeutungsbegriff und Bedeutungstheorie. Zur Erklärung eines Rätsels, Tübingen, Basel

Hondrich, K.O./Matthes, J. (Hrsg.) (1978): Theorienvergleich in den Sozialwissenschaften, Darmstadt u. Neuwied

Horwich, P. (1998): Meaning, Oxford

Hug, T. (Hrsg.) (2001): Wie kommt Wissenschaft zu Wissen? Bd. 4: Einführung in die

Wissenschaftstheorie und Wissenschaftsforschung, Hohengehren 
Hülst, D. (1975): Erfahrung - Gültigkeit - Erkenntnis. Zum Verhältnis von soziologischer Empirie und Theorie, Frankfurt am Main

Hume, D. (1955): Eine Untersuchung über den menschlichen Verstand, Hamburg

Hurlbert, J.S./Beggs, J.J./Haines, V.A. (2001): Social networks and social capital in Extreme environments, in: Lin, N./Cook, K./Burt, R.S. (Hrsg.): Social capital. Theory and research, New York, S. 209-232

Husserl, E. (1910/11): Philosophie als strenge Wissenschaft, in: Logos 1, S. 289-341

Husserl, E. (1963): Cartesianische Meditationen und Pariser Vorträge, Husserliana I, herausgegeben von S. Strasser, Den Haag

Husserl, E. (2003): Phänomenologische Psychologie, herausgegeben und eingeleitet von Dieter Lohmar, Hamburg

Immerfall, S. (1999): Sozialkapital in der Bundesrepublik, Thesen zu Konzept und Größenordnung, in: Kistler, E./Noll, H.H./Piller, E. (Hrsg.): Perspektiven gesellschaftlichen Zusammenhalts: Empirische Befunde, Praxiserfahrungen, Meßkonzepte, Berlin, S. 121-128

Inglehart, R. (1999) Trust, well-being and democracy, in: Warren, M.E. (Hrsg.): Democracy and trust, Cambridge, S. 88-120

Inkeles, A. (2000): Measuring social capital and its consequences, in: Policy sciences, 33, S. $245-268$

Inwagen, V (1990): Material beings, Ithaca, London

Irle, M. (1975): Lehrbuch der Sozialpsychologie, Göttingen, Toronto, Zürich

Irrgang, B. (1993): Lehrbuch der Evolutionären Erkenntnistheorie: Evolution, Selbstorganisation, Kognition, München u. Basel

Iványi, N. (2003): Die Wirklichkeit der gesellschaftlichen Konstruktion. Ein institutionalisierungstheoretischer Medienwirkungsansatz, Konstanz

Janich, P. (Hrsg.) (1981): Wissenschaftstheorie und Wissenschaftsforschung, München

Jansen, D. (2000): Netzwerke und soziales Kapital. Methoden zur Analyse struktureller Einbettung, in: Weyer, J. (Hrsg.): Soziale Netzwerke: Konzepte und Methoden der sozialwissenschaftlichen Netzwerkforschung, München, S. 35-62

Jansen, D. (2003): Einführung in die Netzwerkanalyse, 2. Aufl., Opladen

Joas, H./Knöbl, W. (2004): Sozialtheorie. Zwanzig einführende Vorlesungen, Frankfurt am Main

Johansson, I. (2003): Searle's monadological construction of social reality, in: American journal of economics and sociology, vol. 62, no. 1, S. 233-255

Johnson, C. (2003): A model of social capital formation, SRDC working paper series 03-01, im internet unter: www.srdc.org/english/publications/socialcapital.pdf

Johnston, G./Percy-Smith, J. (2003): In search of social capital, Policy \& Politics, vol. 31, no. 3, S. 321-334

Jungbauer-Gans, M. (2004): Soziales Kapital - Eine kritische Diskussion des Begriffs, Paper zum Vortrag auf der Frühjahrstagung "Sozialkapital. Grundlagen, Modelle und Anwendungen" der DGS-Sektion "Modellbildung und Simulation", 9./10. Juli 2004, Zürich, im internet unter: www.soz.unibe.ch/dgsmodsim/zuerich04.asp 
Kaiser-El-Safti (2001): Die Idee der wissenschaftlichen Psychologie. Immanuel Kants kritische Einwände und ihre konstruktive Widerlegung, Würzburg

Kale, P./Singh, H./Perlmutter, H. (2000): Learning and protection of proprietary assets in strategic alliances: building relational capital, in: Strategic management journal, vol. 21, S. $217-237$

Kamlah, W./Lorenzen, P. (1996): Logische Propädeutik. Vorschule des vernünftigen Redens, 3. Aufl., Stuttgart

Kant, I. (1998): Kritik der reinen Vernunft, nach der ersten und zweiten Originalausgabe herausgegeben von Jens Timmermann, Hamburg

Kanzian, C. (1999): Analytische Ontologie, in: Sandkühler, H.J. (Hrsg.): Enzyklopädie Philosophie, Bd. 2, Hamburg, S. 1147-1154

Karstedt, S. (1997): Recht und soziales Kapital im Wohlfahrtsstaat, in: Soziale Probleme, H. 2, Jg. 8, S. 103-137

Karstedt, S. (2004): Linking capital. Institutionelle Dimensionen sozialen Kapitals, in: Kessl, F./Otto, H.U. (Hrsg.): Soziale Arbeit und soziales Kapital. Zur Kritik lokaler Gemeinschaftlichkeit, Wiesbaden, S. 45-62

Katz, J.J. (1990): The metaphysics of meaning, Cambridge u. London

Kaufmann, F.X. (2004): Sozialpolitik zwischen Gemeinwohl und Solidarität, in: Münkler, H./Fischer, K. (Hrsg.): Gemeinwohl und Gemeinsinn. Rhetoriken und Perspektiven sozial-moralischer Orientierung, Berlin

Keil, G. (2002): Quine. Zur Einführung, Hamburg

Kelle, U./Erzberger, C. (1999): Integration qualitativer und quantitativer Methoden, in: Kölner Zeitschrift für Soziologie und Sozialpsychologie, Jg. 51, H. 3, S. 509-531

Keller, R. (2001): Wissenssoziologische Diskursanalyse, in: Keller, R./Hirseland, A./Schneider, W. (Hrsg.): Handbuch Sozialwissenschaftliche Diskursanalyse, Bd. 1: Theorien und Methoden, Opladen, S. 113-144

Keller, R./Hirseland, A./Schneider, W. (2001) (Hrsg.): Handbuch Sozialwissenschaftliche Diskursanalyse, Bd. 1: Theorien und Methoden, Opladen

Kelly, G. (1986): Die Psychologie der persönlichen Konstrukte, Paderborn

Kern, K. (2004): Sozialkapital, Netzwerke und Demokratie, in: Klein, A./Kern, K./Geißel, B./ Berger, M. (Hrsg.): Zivilgesellschaft und Sozialkapital. Herausforderungen politischer und sozialer Integration, Wiesbaden, S. 109-130

Kessl, F./Otto, H.U. (2004) (Hrsg.): Soziale Arbeit und soziales Kapital. Zur Kritik lokaler Gemeinschaftlichkeit, Wiesbaden

Kistler, E./Noll, H.H./Piller, E. (Hrsg.) (1999): Perspektiven gesellschaftlichen Zusammenhalts: empirische Befunde, Praxiserfahrungen, Meßkonzepte, Berlin

Kistler, E./Schäfer-Walkmann, S. (1999): Garant für Gemeinsinn oder gar soziales Kapital? Ehrenamtliches Engagement zwischen Über- und Unterforderung, in: Sozialmagazin: Zeitschrift für soziale Arbeit; H. 3, Jg. 24, S. 49-56

Klein, A./Kern, K./Geißel, B./ Berger, M. (Hrsg.) (2004): Zivilgesellschaft und Sozialkapital. Herausforderungen politischer und sozialer Integration, Wiesbaden

Klein, B. (1995): Die strukturalistische Theorienkonzeption in der Psychologie, Diplomar- 
beit in der Fachrichtung Psychologie der Universität des Saarlandes, Saarbrücken

Knack, S./Keefer, P. (1997): Does social capital have an economic payoff? A cross-country investigation, in: The quaterly journal of economics, S. 1251-1288

Knoblauch, H. (Hrsg.) (1996): Kommunikative Lebenswelten. Zur Ethnographie einer geschwätzigen Gesellschaft, Konstanz

Knoblauch, H./Raab, J./Schnettler, B. (2002): Wissen und Gesellschaft. Grundzüge der sozialkonstruktivistischen Wissenssoziologie Thomas Luckmanns, in: Luckmann, Th.: Wissen und Gesellschaft. Ausgewählte Aufsätze 1981-2002, herausgegeben und eingeleitet von Knoblauch, H./Raab, J./Schnettler, B., Konstanz, S. 9-39

Knorr-Cetina, K. (1989): Spielarten des Konstruktivismus, in: Soziale Welt 40, S. 86-96

Koepsell, D./Moss, L.S. (2003): Editor's introduction, in: American journal of economics and sociology, vol. 62 , no. 1 , S. 1-3

Koob, D. (1999): Gesellschaftliche Steuerung. Selbstorganisation und Netzwerke in der modernen Politikfeldanalyse, Marburg

Krämer, S./König, E. (Hrsg) (2002): Gibt es eine Sprache hinter dem Sprechen?, Frankfurt am Main

Krishna, A. (1999): Creating and harnessing social capital, in: Dasgupta, P./Serageldin, I. (Hrsg.): Social capital. A multifaceted perspective, Washington, S. 71-93

Kriz J./Lück, H.E./Heidbrink, H. (1987): Wissenschafts- und Erkenntnistheorie, Opladen

Kriz, J. (2001): Grundkonzepte der Psychotherapie, Weinheim, 5. Aufl.

Kröll, A.-M. (2003): Interorganisationelle Markteintrittsnetzwerke. Nutzung Sozialen Kapitals für Eintrittszeitstrategien, Wiesbaden

Kromrey, H. (2000) Empirische Sozialforschung, Opladen, 9. Aufl.

Kron, F.W. (1999): Wissenschaftstheorie für Pädagogen, München

Kropp, B. (1998): Berufserfolg im Transformationsprozess - Eine theoretisch-empirische Studie über Gewinner und Verlierer der Wende in Ostdeutschland, Utrecht

Kuhn, Th. (1967): Die Struktur wissenschaftlicher Revolutionen, Frankfurt am Main

Kühne, U. (2005): Die Methode des Gedankenexperiments, Frankfurt am Main

Kühnel, S.-M. (1993): Zwischen Boykott und Kooperation. Teilnahmeabsicht und Teilnahmeverhalten bei der Volkszählung 1987, Frankfurt am Main

Kumar, B.N/Steinmann, H. (Hrsg.) (1998): Ethics in international management, Berlin, New York

Kunz, V./Gabriel, O.W. (2000): Soziale Integration und politische Partizipation. Das Konzept des Sozialkapitals - Ein brauchbarer Ansatz zur Erklärung politischer Partizipation?, in: Druwe, U./Kühnel, S./Kunz, V. (Hrsg.): Kontext, Akteur und strategische Interaktion - Untersuchungen zur Organisation politischen Handelns in modernen Gesellschaften, Opladen, S. 47-74

Kutschera, F.v. (1971): Sprachphilosophie, München

Kutschera, F.v. (1982): Grundfragen der Erkenntnistheorie, Berlin u. New York

Kutschera, F.v./Breitkopf, A. (1992): Einführung in die moderne Logik, Freiburg u. München, 6. Aufl. 
Lamb, S. (2004): Language and reality, London, New York

Landolt, P. (2004): Eine Abwägung der Grenzen sozialen Kapitals: Lehren aus den transnationalen Gemeinde-Initiativen El Salvadors, in: Kessl, F./Otto, H.U. (Hrsg.): Soziale Arbeit und soziales Kapital. Zur Kritik lokaler Gemeinschaftlichkeit, Wiesbaden, S. 22-44

Langenmayr, A. (1997): Sprachpsychologie. Ein Lehrbuch, Göttingen, Bern, Toronto u. Seattle

Laudan, L. (1977): Progress and its problems. Toward a theory of scientific growth, Berkeley, Los Angeles, London

Lauth, B./Sareiter, J. (2002): Wissenschaftliche Erkenntnis. Eine ideengeschichtliche Einführung in die Wissenschaftstheorie, Paderborn

Lay, R. (1992): Die Macht der Wörter. Sprachsystematik für Manager, Frankfurt am Main u. Berlin

Lazega, E./Pattison, P.E. (2001): Social capital as social mechanisms and collective assets: The example of status auctions among colleagues, in: Lin, N./Cook, K./Burt, R.S. (Hrsg.): Social capital. Theory and research, New York, S. 185-208

Leicht, M. (1998): Facing globalization - More social capital and the ability to act as a global player as response from the EU, in Schweizerische Zeitschrift für Politische Wissenschaft, Vol 4, S. 197-214

Leicht, M. (2000): A reformed european model - Social capital as competitive advantage, thesis presented to the faculty of arts of the university of Zurich, Zurich

Lenk, H. (1986): Zwischen Wissenschaftstheorie und Sozialwissenschaft, Frankfurt am Main

Lenk, H. (1998): Einführung in die Erkenntnistheorie. Interpretation - Interaktion Intervention, München

Lensing, J. (1999): Ontologie, in: Sandkühler, H.J. (Hrsg.): Enzyklopädie Philosophie, Bd. 2, Hamburg, S. 1140-1147

Lenzen, M. (2002): Natürliche und künstliche Intelligenz, Frankfurt am Main

Lepore, E./Gulick, R. Van (Hrsg) (1991): John Searle and his critics, Cambridge

Levi, M. (1996): Social and unsocial capital: A reciew essay of Robert Putnam's Making democracy work, in: Politics and society, vol. 24, S. 45-55

Lilli, W. (1984): Die Hypothesentheorie der sozialen Wahrnehmung, in: Frey, D./Irle, M. (Hrsg.): Theorien der Sozialpsychologie, Bd. 1: Kognitive Theorien der Sozialpsychologie, Stuttgart u.a., 2. Aufl., S. 19-47

Lin, N. (2001): Building a network theory of social capital, in: Lin, N./Cook, K./Burt, R.S. (Hrsg.): Social capital. Theory and research, New York, S. 3-30

Lin, N./Cook, K./Burt, R.S. (Hrsg.) (2001): Social capital. Theory and research, New York

Lin, N./Ensel, W.M./Vaughn, J.C. (1981): Social resources and strength of ties: structural factors in occupational status attainment, in: American sociological review, vol. 46, S. 393-405

Lin, N./Fu, Y./Hsung, R.M. (2001): The position generator: Measurement techniques for investigations of social capital, in: Lin, N./Cook, K./Burt, R.S. (Hrsg.): Social capi- 
tal. Theory and research, New York, S. 57-81

Lindenberg S./Wippler, R. (1978): Theorienvergleich: Elemente der Rekonstruktion, in: Hondrich, K.O./Matthes, J. (Hrsg.): Theorienvergleich in den Sozialwissenschaften, Darmstadt u. Neuwied, S. 219-231

List, E. (1983): Alltagsrationalität und soziologischer Diskurs. Erkenntnis- und wissenschaftstheoretische Implikationen der Ethnomethodologie, Frankfurt am Main u. New York

Luckmann, Th. (1980): Lebenswelt und Gesellschaft, Paderborn, München, Wien u. Zürich

Luckmann, Th. (1981): Vorüberlegungen zum Verhältnis von Alltagswissen und Wissenschaft, in: Janich, P. (Hrsg.): Wissenschaftstheorie und Wissenschaftsforschung, München, S. 39-51

Luckmann, Th. (2002): Wissen und Gesellschaft. Ausgewählte Aufsätze 1981-2002, herausgegeben und eingeleitet von Knoblauch, H./Raab, J./Schnettler, B., Konstanz

Lueken, G.-L. (Hrsg.) (1997): Kommunikationsversuche. Theorien der Kommunikation, Leipzig

Lueken, G.-L./Raatzsch, R. (1999): Philosophie der normalen Sprache, in: Sandkühler, H.J. (Hrsg.): Enzyklopädie Philosophie, Bd. 2, Hamburg, S. 1229-1239

Luhmann, N. (1984): Soziale Systeme, Frankfurt am Main

Lütkemeier, E. (2001): Strukturalistische Konzeption des Wissens. Entwicklung und empirische Anwendung, Frankfurt am Main u.a.

Maasen, S. (1999): Wissenssoziologie, Bielefeld

Mannheim, K. (1985): Ideologie und Utopie, Frankfurt am Main

Marsden, P.V. (2001): Interpersonal Ties, Social Capital, and Employer Staffing Practices, in: Lin, N./Cook, K./Burt, R.S. (Hrsg.): Social Capital. Theory and Research, New York, S. 105-126

Marx, J. (2005): Sozialkapital und seine handlungstheoretischen Grundlagen. Eine wissenschaftstheoretische Untersuchung, Marburg

Matthes, J. (1978): Die Diskussion um den Theorienvergleich in den Sozialwissenschaften seit dem Kasseler Soziologentag 1974, in: Hondrich, K.O./Matthes, J. (Hrsg.): Theorienvergleich in den Sozialwissenschaften, Darmstadt u. Neuwied, S. 7-20

Matthes, J. (1987) Erfahrung durch Konstrukte. Empirische Sozialforschung als Kommunikationsproblem, in: Rühl, M. (Hrsg.): Kommunikation und Erfahrung. Wege anwendungsbezogener Kommunikationsforschung, Kommunikationswissenschaftliche Studien, Bd.4, Nürnberg, S. 115-132

Maturana, H./Varela, F. (1987): Der Baum der Erkenntnis. Die biologischen Wurzeln des menschlichen Erkennens, Bern u.a.

Maurer, I. (2003): Soziales Kapital als Erfolgsfaktor junger Unternehmen. Eine Analyse der Gestaltung und Entwicklungsdynamik der Netzwerke von Biotechnologie Start-Ups, Opladen

May, M. (2004): Versuch einer Entmystifizierung sozialen Kapitals. Zur unterschiedlichen begrifflichen Fassung sozialen Kapitals, in: Kessl, F./Otto, H.U. (Hrsg.): Soziale Arbeit und soziales Kapital. Zur Kritik lokaler Gemeinschaftlichkeit, Wiesbaden, S. 79- 
93

Mayer, M. (2002): Soziales Kapital und Stadtentwicklungspolitik - Ein ambivalenter Diskurs, in: Haus, M. (Hrsg.): Bürgergesellschaft, soziales Kapital und lokale Politik. Theoretische Analysen und empirische Befunde, Opladen, S. 33-58

Mayntz, R./Scharpf F.W. (1995): Der Ansatz des akteurszentrierten Institutionalismus, in: dieselben (Hrsg.): Gesellschaftliche Selbstregelung und politische Steuerung, Frankfurt am Main, S. 39-72

Mc Intosh, M.K. (2001): The diversity of social capital in english communities, 1300-1640 (with a glance at modern Nigeria), in: Rotberg, R.J. (Hrsg.): Patterns of social capital. Stability and change in historical perspective, Cambridge, S. 121-152

McDowell, J. (2001): Geist und Welt, Frankfurt am Main

Mead, G.H. (1980): Gesammelte Aufsätze, Bd. 1, Frankfurt am Main

Meggle, G. (1997): Theorien der Kommunikation. Eine Einführung, in: Lueken, G.-L.

(Hrsg.): Kommunikationsversuche. Theorien der Kommunikation, Leipzig, S. 14-40

Meggle, G. (Hrsg.) (1979): Handlung, Kommunikation, Bedeutung, Frankfurt am Main

Meier, B. (1996): Sozialkapital in Deutschland. Eine empirische Skizze, Köln

Meinefeld, W. (1995): Realität und Konstruktion. Erkenntnistheoretische Grundlagen einer Methodologie der empirischen Sozialforschung, Opladen

Meleghy, T. (2001): Einführung in die Wissenschaftstheorie der Soziologie, in: Hug, T.

(Hrsg.): Wie kommt Wissenschaft zu Wissen? Bd. 4: Einführung in die Wissenschaftstheorie und Wissenschaftsforschung, Hohengehren, S. 288-301

Menne, A. (1993): Einführung in die Logik, Tübingen und Basel, 5. Aufl.

Merten, K. (1995): Inhaltsanalyse. Einführung in Theorie, Methode und Praxis, 2. Aufl. Opladen

Merton, R.K. (1985): Entwicklung und Wandel von Forschungsinteressen. Aufsätze zur Wissenschaftssoziologie, Frankfurt am Main

Metzinger, T. (1996a) (Hrsg.): Bewußtsein. Beiträge aus der Gegenwartsphilosophie, 3. Aufl., Paderborn, München, Wien u. Zürich

Metzinger, T. (1996b): Das Problem des Bewußtseins, in: derselbe (Hrsg.): Bewußtsein. Beiträge aus der Gegenwartsphilosophie, 3. Aufl., Paderborn, München, Wien u. Zürich, S. 15-53

Micko, H.C. (2001): Psychologie: Von der Geistes- zur Naturwissenschaft - und weiter wohin? Erkenntnistheoretische Erwägungen vor und nach dem Aufkommen des philosophischen Konstruktivismus, in: Zeitschrift für Psychologie, 209, S. 54-68

Mittelstraß, J. (1974): Die Möglichkeit von Wissenschaft, Frankfurt am Main

Mittelstraß, J. (1981): Rationale Rekonstruktion der Wissenschaftsgeschichte, in: Janich, P. (Hrsg): Wissenschaftstheorie und Wissenschaftsforschung, München, S. 89-111

Morel, J. et al. (Hrsg.) (1999): Soziologische Theorie: Abriß ihrer Hauptvertreter, München, Wien, 6. Aufl.

Moscovici, S. (1981): On social representation, in: Forgas, J.P. (Hrsg.): Social cognition -

Perspectives on everyday understanding, London u.a., S. 181-210

Moulines, C. U. (1994): Wer bestimmt, was es gibt?, in: Zeitschrift für philosophische 
Forschung, Band 48, 2, S. 174-192

Moulines, C.U. (o.J.): Der wissenschaftstheoretische Strukturalismus, im internet unter: www.information-philosophie.de/philosophie/strukturalismus.htm

Müller, O. (1998): Synonymie und Analytizität. Zwei sinnvolle Begriffe, Paderborn u.a.

Münch, R. (2003): Soziologische Theorie. Band 2: Handlungstheorie, Frankfurt am Main u. New York

Münch, R. (2004): Soziologische Theorie. Band 3: Gesellschaftstheorie, Frankfurt am Main u. New York

Münkler, H./Fischer, K. (Hrsg.) (2002): Gemeinwohl und Gemeinsinn. Rhetoriken und Perspektiven sozial-moralischer Orientierung, Berlin

Nagel, T. (1990): Was bedeutet das alles? Eine ganz kurze Einführung in die Philosophie, Stuttgart

Naumann, R. (1990): Quines Holismusthese, in: Sukale, M. (Hrsg.): Sprache, Theorie und Wirklichkeit, Frankfurt am Main, S. 200-234

Neubarth, R. (1996): Richtig Verhandeln. Erfolgreich durch bessere Argumente, Köln

Newen, A./Savigny, E.v. (1996): Analytische Philosophie. Eine Einführung, München

Newton, K. (1997): Social capital and democracy, in: American behavioral scientist, vol. 40, no. 5, March/April 97, S. 575-586

Nielandt, J. (2002): (Klassen-)Gesellschaft und Gemeinsinn. Sozialkapital im internationalen Vergleich, in: Sozialismus, 2, S. 23-32

Noll, H.H. (1999) Dimensionen der empirischen Erfassung von Ehrenamt, Gemeinsinn und Sozialkapital, in: Kistler, E./Noll, H.H./Piller, E. (Hrsg.): Perspektiven gesellschaftlichen Zusammenhalts: empirische Befunde, Praxiserfahrungen, Meßkonzepte, Berlin, S. 395-398

OECD (2002): Social capital: the challenge of international measurement, OECD/ONS conference, London, 26/27 September 2002, im internet unter: www.oecd.org/findDocument/0.2350.en_2649_34543_1_119666_1_1_1.00. html

Offe, C. (1999): "Sozialkapital" - Begriffliche Probleme und Wirkungsweise, in: Kistler, E./Noll, H.H./Piller, E. (Hrsg.): Perspektiven gesellschaftlichen Zusammenhalts: empirische Befunde, Praxiserfahrungen, Meßkonzepte, Berlin, S. 113-120

Offe, C./Fuchs, S. (2001): Schwund des Sozialkapitals? Der Fall Deutschland, in: Putnam, R.D. (Hrsg.): Gesellschaft und Gemeinsinn - Sozialkapital im internationalen Vergleich, Gütersloh, S. 417-514

Opp, K.D. (1978): Probleme und Strategien des Theorienvergleichs, in: Hondrich, K.O./Matthes, J. (Hrsg.): Theorienvergleich in den Sozialwissenschaften, Darmstadt u. Neuwied, S. 213-218

Opp, K.D. (1995): Methodologie der Sozialwissenschaften. Einführung in Probleme ihrer Theorienbildung und praktischen Anwendung, 3. Aufl., Opladen

Opp, K.D./Wippler, R. (1990a) (Hrsg.): Empirischer Theorienvergleich. Erklärungen sozialen Verhaltens in Problemsituationen, Opladen

Opp, K.D./Wippler, R. (1990b): Theoretischer Pluralismus und empirische Forschung, in: dieselben (Hrsg.): Empirischer Theorienvergleich. Erklärungen sozialen Verhaltens 
in Problemsituationen, Opladen, S. 3-15

Osborne, T. (1997): The Limits of Ontology, in: History of the human sciences, Vol. 10, No. 4, pp. $97-102$

Ostrom, E. (1999): Social capital: A fad or a fundamental concept?, in: Dasgupta, P./Serageldin, I. (Hrsg.): Social capital. A multifaceted perspective, Washington, S. 172-214

Ostrom, E./Ahn, T-K. (2003): Soziales Kapital und kollektives Handeln: Eine sozialwissenschaftliche Perspektive auf soziales Kapital, in: Enquete-Kommission "Zukunft des bürgerschaftlichen Engagements", Band 2: Bürgerschaftliches Engagement von Unternehmen, herausgegeben vom Deutschen Bundestag, Opladen, S. 35-84

Ott, K. (2005): Moralbegründungen, 2. Aufl., Hamburg

Paldam, M. (2000): Social capital: One or many? Definition and measurement, Journal of economic surveys, 14, 5, S. 629-653

Parmenides (1986): Vom Wesen des Seienden. Die Fragmente, griechisch und deutsch, herausgegeben, übersetzt und erläutert von Uvo Hölscher, Frankfurt am Main

Paxton, P. (1999): Is social capital declining in the United States? A multiple indicator assessment, in: American journal of sociology, vol. 105, no. 1, S. 88-127

Pervin, L.A./John, O.P. (2001): Personality. Theory and Research, New York u.a., 8. Aufl.

Pfingsten, U. (2000): Soziale Ängste, Unsicherheiten und Defizite, in: Hautzinger. M. (Hrsg.): Kognitive Verhaltenstherapie bei psychischen Störungen, Weinheim, 3. Aufl., S. 115-148

Piaget, J. (1973): Einführung in die genetische Erkenntnistheorie, Frankfurt am Main

Pieper (2003): Einführung in die Ethik, Tübingen u.a.

Pieper, A. (1994a) (Hrsg.): Die Gegenwart des Absurden. Studien zu Albert Camus, Tübingen u. Basel

Pieper, A. (1994b): Camus Verständnis des Absurden in 'Der Mythos von Sisyphos', in: dieselbe (Hrsg): Die Gegenwart des Absurden. Studien zu Albert Camus, Tübingen u. Basel, S. 1-15

Platthaus, A. (1999): Aller seiten Freund. Was darf der Begriff 'Sozialkapital' hoffen?, in: Graf, F.W./Platthaus, A./Schleissing, S. (Hrsg.): Soziales Kapital in der Bürgergesellschaft, Stuttgart, Berlin u. Köln, S. 161-176

Plessner, H. (1979): Zwischen Philosophie und Gesellschaft, Frankfurt am Main

Plöger, W. (2003) Grundkurs Wissenschaftstheorie für Pädagogen, Paderborn

Ponthieux, S. (2004): The concept of social capital: a critical review, paper presented at the 10th ACN Conference, Paris, 21-23 January 2004, im internet unter: www.insee.fr/en/nom_def_met/colloques/acn/colloqu_10/ponthieux.pdf

Popper, K.R. (1973): Objektive Erkenntnis. Ein evolutionärer Entwurf, Hamburg

Popper, K.R. (1982): Logik der Forschung, 7. Aufl., Tübingen

Portes, A. (1998): Social capital: Its origins and applications in modern sociology, in: Annual review of sociology, vol. 24, S. 1-24

Portes, A. (2000): The two meanings of social capital, in: Sociological forum, vol. 15, no. 1 
Portes, A./Landolt, P. (1996): The downside of social capital, in: The american prospect, vol. 26, S. $18-23$

Poser, H. (2001): Wissenschaftstheorie. Eine philosophische Einführung, Stuttgart

Poulsen, A./Svendsen, G.T. (2003): Rise and decline of social capital - Excess co-operation in the one-shot prisoner's dilemma game, Aarhus School of business, Departement of Economics, Working paper 03-10

Powel, W. (Hrsg.) (1998): Private Action and the Public Good, New Haven

Prauss, G. (1993): Einführung in die Erkenntnistheorie, 3. Aufl., Darmstadt

Prechtl, P. (2002): Edmund Husserl. Zur Einführung, Hamburg, 3. Aufl.

Preglau, M. (1997): Phänomenologische Soziologie: Alfred Schütz, in: Morel, J. et al.

(Hrsg.): Soziologische Theorie: Abriß ihrer Hauptvertreter, München, Wien, 5. Aufl., S. $67-90$

Preglau, M. (1999): Symbolischer Interaktionismus: George Herbert Mead, in: Morel, J. et al. (Hrsg.): Soziologische Theorie: Abriß ihrer Hauptvertreter, München, Wien, 6. Aufl., S. 52-66

Prim, R./Tilmann, H. (1997): Grundlagen einer kritisch-rationalen Sozialwissenschaft, 7. Aufl., Wiesbaden

Putnam, H. (1962): What theories are not, in: Nagel, E./Suppes, P./Tarski, A. (Hrsg): Logic, methodology and the philosophy of science, Stanford, S. 240-251

Putnam, H. (1975): Mind, language and reality, Cambridge

Putnam, H. (1979): Die Bedeutung von "Bedeutung", Frankfurt am Main

Putnam, H. (1993): Von einem realistischen Standpunkt. Schriften zu Sprache und Wirklichkeit, Reinbek bei Hamburg

Putnam, H. (1999): The threefold cord - Mind, body and world, New York, Chichester, West Sussex

Putnam, R.D. (1993): Making Democracy Work. Civic Traditions in Modern Italy, Princeton, New Jersey

Putnam, R.D. (1995): Bowling alone: America's declining social capital, in: American journal of democracy, vol. 6, S. 65-78

Putnam, R.D. (1996): Symptome der Krise. Die USA, Europa und Japan im Vergleich, in: Weidenfeld, W. (Hrsg.): Demokratie am Wendepunkt. Die demokratische Frage als Projekt des 21. Jahrhunderts, Berlin, S. 52-80

Putnam, R.D. (1999): Demokratie in Amerika am Ende des 20. Jahrhunderts, in: Graf, F.W./Platthaus, A./Schleissing, S. (Hrsg.): Soziales Kapital in der Bürgergesellschaft, Stuttgart, Berlin u. Köln S. 21-70

Putnam, R.D. (2000): Bowling alone: The collapse and revival of american community, New York

Putnam, R.D. (2001) (Hrsg.): Gesellschaft und Gemeinsinn - Sozialkapital im internationalen Vergleich, Gütersloh

Putnam, R.D. (2002): Soziales Kapital in der Bundesrepublik Deutschland und in den USA, in: Enquete-Kommission "Zukunft des bürgerschaftlichen Engagements", Band 1: Bürgerschaftliches Engagement und Zivilgesellschaft, herausgegeben vom Deut- 
schen Bundestag, Opladen, S. 257-272

Putnam, R.D./Goss, K.A. (2001): Einleitung, in: Putnam, R.D. (Hrsg.): Gesellschaft und Gemeinsinn - Sozialkapital im internationalen Vergleich, Gütersloh, S. 15-43

Quibria, M.G. (2003): The puzzle of social capital. A critical review, Asian development bank, Economics and research departement, Working paper No. 40, May 03

Quine, W.v.O. (1979): Von einem logischen Standpunkt - Neun logisch-philosophische Essays, Frankfurt am Main, Berlin u. Wien

Quine, W.v.O. (1980): Wort und Gegenstand, Stuttgart

Quine, W.v.O. (1985): Theorien und Dinge, Frankfurt am Main

Ratzinger, J. (2006): Credo für heute. Was Christen glauben, Freiburg im Breisgau

Read, S. (1997): Philosophie der Logik. Eine Einführung, Reinbek bei Hamburg

Reich, K. (2001): Konstruktivistische Ansätze in den Sozial- und Kulturwissenschaften, in: Hug, T. (Hrsg.): Wie kommt Wissenschaft zu Wissen? Bd. 4: Einführung in die Wissenschaftstheorie und Wissenschaftsforschung, Hohengehren, S. 356-376

Rescher, N. (1986): Conceptual idealism, Washington

Richardson, J.G. (Hrsg.): Handbook of theory and research for the sociology of education, Greenwood

Rings, H. (1987): Das strukturalistische Problem der theoretischen Begriffe und seine Lösung, in: Zeitschrift für allgemeine Wissenschaftstheorie, 18, S. 296-312

Robinson, B./Robinson, D. (2002): Possible aids from physics and engineering to assist understanding of social capital, in: Robinson, D. (Hrsg.): Building social capital, Wellington, S. 41-66

Robinson, D. (2002) (Hrsg.): Building social capital, Wellington

Robinson, D. (2002a): Introduction, in: Robinson, D. (Hrsg): Building social capital, Wellington, S. 1-13

Rogers, C.R. (2004): Therapeut und Klient. Grundlagen der Gesprächspsychotherapie, 18. Aufl., Frankfurt am Main

Röhrle, B. (1994): Soziale Netzwerke und soziale Unterstützung, Weinheim

Rorty, R. (1981): Der Spiegel der Natur. Eine Kritik der Philosophie, Frankfurt am Main

Rosenband, L.N. (2001): Social capital in the early industrial revolution, in: Rotberg, R.J. (Hrsg.): Patterns of social capital. Stability and change in historical perspective, Cambridge, S. 97-120

Rosenthal, G. (2005): Interpretative Sozialforschung. Eine Einführung, Weinheim und München

Rotberg, R.J. (Hrsg.) (2001): Patterns of social capital. Stability and change in historical perspective, Cambridge

Roth, F. (2003): Sozialkapital und Öffentlichkeit. Zwei Formen der Zivilgesellschaft, Diplomarbeit an der Sozialwissenschaftlichen Fakultät der Ludwig MaximiliansUniversität in München

Roth, G. (1987): Erkenntnis und Realität: Das reale Gehirn und seine Wirklichkeit, in: Schmidt, S.J. (Hrsg.): Der Diskurs des Radikalen Konstruktivismus, Frankfurt am 
Main, S. 229-255

Roth, G. (1992): Das konstruktive Gehirn: Neurobiologische Grundlagen der Wahrnehmung und Erkenntnis, in: Schmidt, S.J. (Hrsg.): Der Diskurs des Radikalen Konstruktivismus 2, Frankfurt am Main, S. 277-336

Roth, G. (1995): Das Gehirn und seine Wirklichkeit, Frankfurt am Main, 3. Aufl.

Rowlands, M (2001): The Nature of Consciousness, Cambridge

Rühl, M. (Hrsg.) (1987): Kommunikation und Erfahrung. Wege anwendungsbezogener Kommunikationsforschung, Kommunikationswissenschaftliche Studien, Bd.4, Nürnberg

Runggaldier,E./Kanzian, C. (1998): Grundprobleme der analytischen Ontologie, Paderborn, München, Wien, Zürich

Runia, P. (2002): Arbeitsmarkt und soziales Kapital, in: Dusiburger Beiträge zur Soziologischen Forschung, No. 1 / 2

Rusch, G. (2001): Was sind eigentlich Theorien? Über Wirklichkeitsmaschinen in Alltag und Wissenschaft, in: Hug, T. (Hrsg.): Wie kommt Wissenschaft zu Wissen? Bd. 4: Einführung in die Wissenschaftstheorie und Wissenschaftsforschung, Hohengehren, S. 93-116

Russell, B. (1967): Probleme der Philosophie, Frankfurt am Main

Russell, B. (1977) : Eroberung des Glücks. Neue Wege zu einer besseren Lebensgestaltung, Frankfurt am Main

Ryle, G. (1965): The concept of mind, New York, 7. Nachdruck

Sabatini, F. (2005): Social capital as social networks. A new framework for measurement, Working paper No. 83, University of Rome La Sapienza, Departement of Public Economics, internet download unter: www.socialcapitalgateway.org

Sandkühler, H.J. (1999): Erkenntnistheorie/Erkenntnis, in: derselbe (Hrsg.): Enzyklopädie Philosophie, Bd. 2, Hamburg, S. 1039-1059

Sandkühler, H.J. (Hrsg.) (1999): Enzyklopädie Philosophie, Bd. 2, Hamburg

Sartre, J.P. (1991): Das Sein und das Nichts. Versuch einer phänomenologischen Ontologie, Reinbek bei Hamburg

Saussure, F. de (1967): Grundfragen der allgemeinen Sprachwissenschaft, Berlin, 2. Aufl.

Savigny, E.v. (1984): Grundkurs im logischen Schließen, 2. Aufl., Göttingen

Schechler, J.M. (2002): Sozialkapital und Netzwerkökonomik, Frankfurt am Main u.a.

Scheler, U. (2000): Erfolgsfaktor Networking - Mit Beziehungsintelligenz die richtigen Kontakte knüpfen und nutzen, Frankfurt am Main

Schelsky, H. (1970): Zur soziologischen Theorie der Institution, in: derselbe (Hrsg.): Zur Theorie der Institution, Düsseldorf, S. 9-26

Schiffer, S. (2003): The things we mean, Oxford

Schimank, U. (1992): Steuerungstheorie als Akteurstheorie: Determinanten sozialer Steuerung - akteurstheoretisch betrachtet. Ein Themenkatalog, in: Bußhoff, H. (Hrsg.) Politische Steuerung, Baden-Baden, S. 165-192

Schirn, M. (1974a): Einleitung des Herausgebers, in: derselbe (Hrsg.): Sprachhandlung - 
Existenz - Wahrheit. Hauptthemen der sprachanalytischen Philosophie, Stuttgart, S. 11-32

Schirn, M. (Hrsg.) (1974): Sprachhandlung - Existenz - Wahrheit. Hauptthemen der sprachanalytischen Philosophie, Stuttgart

Schleef, M. (2001): Sozialkapital und Transaktions-Controlling. Perspektiven für institutionelle Anleger, Wiesbaden

Schmid, M. (1996): Rationalität und Theoriebildung, Amsterdam

Schmidt, S.J. (1992): Radikaler Konstruktivismus - Forschungsperspektiven für die neunziger Jahre, in: derselbe (Hrsg.): Der Diskurs des Radikalen Konstruktivismus 2, Frankfurt am Main, S. 7-23

Schmidt, S.J. (Hrsg.) (1987): Der Diskurs des Radikalen Konstruktivismus, Frankfurt am Main

Schmidt, S.J. (Hrsg.) (1992): Der Diskurs des Radikalen Konstruktivismus 2, Frankfurt am Main

Schnädelbach, H. (2002): Erkenntnistheorie - Eine Einführung, Hamburg

Schneider, H.J. (2003): Konstitutive Regeln und Normativität, in: Deutsche Zeitschrift für Philosophie, 1/2003, S. 81-97

Schneider, W.L. (2002): Grundlagen der soziologischen Theorie, Bd. 1: Weber, Parsons, Mead, Schütz, Wiesbaden

Schnell, R./Hill, P.B./Esser, E. (1999): Methoden der empirischen Sozialforschung, 6. Aufl., München u. Wien

Schnur, O. (2003): Lokales Sozialkapital für die 'soziale Stadt'. Politische Geographien sozialer Quartiersentwicklung am Beispiel Berlin-Moabit, Opladen

Schofer, B. (2000): Für einen moderaten Relativismus in der Wissenssoziologie, in: Kölner Zeitschrift für Soziologie und Sozialpsychologie, Jg. 52, H. 4, S. 696-719

Schreiber, H.J. (2002): Beruht das Sprechenkönnen auf einem Sprachwissen?, in: Krämer, S./König, E. (Hrsg): Gibt es eine Sprache hinter dem Sprechen?, Frankfurt am Main, S. $129-150$

Schreiber, H.J. (2003): Konstitutive Regeln und Normativität, in: Deutsche Zeitschrift für Philosophie, 1/2003, S. 81-97

Schröer, N. (Hrsg.) (1994): Interpretative Sozialforschung, Opladen

Schubert, H./Fürst, D./Rudolph, A./Spiekermann, H. (2001): Regionale Akteursnetzwerke. Analysen zur Bedeutung der Vernetzung am Beispiel der Region Hannover, Opladen

Schuller, T./Baron, S./Field, J. (2001): Social capital: A review and critique, in: Baron, S./Field, J./Schuller, T. (Hrsg.): Social capital. Critical perspectives, Oxford, S. 1-38

Schulte, J./McGuinness (Hrsg) (1992): Einheitswissenschaft, Frankfurt am Main

Schulz von Thun, F. (1981): Miteinander reden, Reinbek bei Hamburg

Schulze, G. (2004): Einführung in die Methoden der empirischen Sozialforschung, Teil 1: Wissenschaftstheorie, Bamberger Beiträge zur empirischen Sozialforschung, herausgegeben von Gerhard Schulz und Nina Baur, Nr. 1, 2004 
Schütz, A. (1971): Gesammelte Aufsätze 1. Das Problem der Wirklichkeit, Den Haag Schütz, A. (1993): Der sinnhafte Aufbau der sozialen Welt, Frankfurt am Main, 6. Aufl. Schütz, A./Luckmann, Th. (1975): Strukturen der Lebenswelt, Neuwied und Darmstadt Scott, J. (1991): Social Network Analysis. A Handbook, London

Searle, J.R. (1969): Speech Acts, Cambridge

Searle, J.R. (1973): Sprechakte. Ein sprachphilosophischer Essay, Frankfurt am Main

Searle, J.R. (1983): Intentionality. An essay in the philosophy of mind, Cambridge u.a.

Searle, J.R. (1992): The Rediscovery of the Mind, Cambridge u.a.

Searle, J.R. (1997a): Die Konstruktion der gesellschaftlichen Wirklichkeit. Zur Ontologie sozialer Tatsachen, Reinbek bei Hamburg

Searle, J.R. (1997b): Replies to critics of the construction of social reality, in: History of the human sciences, Vol. 10, No. 4, pp. 104-110

Searle, J.R. (1998): Social Ontology and the Philosophy of Society, in: Analyse \& Kritik, Jg. 20, H. 2, S. $143-158$

Searle, J.R. (1999a): Georg Meggle und Günter Grewendorf im Interview mit John R. Searle, im internet unter: www.uni-bielefeld.de/ZIF/InterviewSearle.htm, Seite aufgerufen am 12.04.2002

Searle, J.R. (1999b): Limits of Phenomenology, im internet unter: http://philosophy.berkeley.edu/searle/articles/rtf/limits_phenomenology.rtf

Searle, J.R. (2000): Edward Feser und Steven Postrel im Interview mit John R. Searle, im internet unter: www.reason.com/0002/fe.ef.reality.html

Searle, J.R. (2001): Geist, Sprache und Gesellschaft, Frankfurt am Main

Searle, J.R. (2003): Reply to Barry Smith, in: American journal of economics and sociology, vol. 62 , no. 1 , S. 299-309

Sears, D.O./Peplau, L.A./Taylor, S.E. (1991): Social Psychology, Englewood Cliffs, 7. Aufl.

Seibert, T. (1997): Existenzphilosophie, Stuttgart

Seipel, C. (1999): Strategien und Probleme des empirischen Theorienvergleichs in den Sozialwissenschaften. Rational Choice Theorie oder Persönlichkeitstheorie? Opladen

Serageldin, I./Grootaert, C. (1999): Defining social capital: An integrating view, in: Dasgupta, P./Serageldin, I. (Hrsg.): Social capital. A multifaceted perspective, Washington, S. 40-58

Siebert, H. (2004): Sozialkonstruktivismus: Gesellschaft als Konstruktion, in: Journal für Sozialwissenschaften und ihre Didaktik, 2, 2004, im internet unter: www.sowionlinejournal.de/2004-2/sozialkonstruktivismus_siebert.htm

Siisiäinen, M. (2000): Two concepts of social capital: Bourdieu vs. Putnam, paper presented at ISTR fourth international conference "The third sector: For what and for whom?", Trinity college, Dublin, im internet unter: www.jhu.edu/ istr/ conferences/dublin/workingpapers/siisiainen.pdf

Simmel, G. (1999): Soziologie. Untersuchungen über die Formen der Vergesellschaftung, 3. Aufl., Frankfurt am Main

Simon, J. (Hrsg.) (1974): Aspekte und Probleme der Sprachphilosophie, Freiburg, München 
Sinnreich, J. (Hrsg.) (1972): Zur Philosophie der idealen Sprache. Texte von Quine, Tarski, Martin, Hempel und Carnap, München

Smith, J. (1998): Global civil society? Transnational social movement organization and social capital, in: American behavioral scientist, vol. 42, no. 1, S. 93-107

Sneed, J.D. (1971): The Logical Structure of Mathematical Physics, Dordrecht

Sobel, J. (2002): Can we trust social capital?, in: Journal of economic literature, vol. XL, S. 139-154

Soeffner, H.-G. (2004): Auslegung des Alltags - Der Alltag der Auslegung, Konstanz

Soeffner, H.-G./Hitzler, R. (1994): Hermeneutik als Haltung und Handlung. in: Schröer, N. (Hrsg.): Interpretative Sozialforschung, Opladen, S. 28-55

Solow, R.M. (1995): But verify; review of Francis Fukuyama's 'Trust: The social virtues and the creation of prosperity', in: The new republic, September 11, S. 36-39

Solow, R.M. (1999): Notes on social capital and economic performance, in: Dasgupta, P./Serageldin, I. (Hrsg.): Social capital. A multifaceted perspective, Washington, S. 6-10

Solso, R. L. (2005): Kognitive Psychologie, Heidelberg

Speck, M. (2005): Warum Kinder früher "Tisch" statt "heiß" sagen, in: Psychologie Heute, 32. Jg., H. 1, S. 15

Spencer Brown, G. (1971): Laws of Form, London

Stavemann, H.H. (2003): Therapie emotionaler Turbulenzen. Einführung in die kognitive Verhaltenstherapie, Weinheim, Basel u. Berlin, 3. Aufl.

Stecher, L. (2001): Die Wirkung sozialer Beziehungen. Empirische Ergebnisse zur Bedeutung sozialen Kapitals für die Entwicklung von Kindern und Jugendlichen, München

Stegmüller, W. (1973): Probleme und Resultate der Wissenschaftstheorie und der analytischen Philosophie, Band IV: Personelle und statistische Wahrscheinlichkeit, Erster Teilband: Personelle Wahrscheinlichkeit und rationale Entscheidung, Berlin, Heidelberg, New York

Stegmüller, W. (1974): Probleme und Resultate der Wissenschaftstheorie und der analytischen Philosophie, Band II: Theorie und Erfahrung, Erster Halbband: Begriffsformen, Wissenschaftssprache, empirische Signifikanz und ihre theoretischen Begriffe, 2. Aufl., Berlin, Heidelberg, New York

Stegmüller, W. (1978): Hauptströmungen der Gegenwartsphilosophie: Eine kritische Einführung, Bd. 1, Stuttgart

Stegmüller, W. (1979): Rationale Rekonstruktion von Wissenschaft und ihrem Wandel, Stuttgart

Stegmüller, W. (1980): Neue Wege der Wissenschaftsphilosophie, Berlin, Heidelberg, New York

Stegmüller, W. (1985): Probleme und Resultate der Wissenschaftstheorie und der analytischen Philosophie, Band II: Theorie und Erfahrung, Zweiter Teilband: Theorienstrukturen und Theoriendynamik, Berlin, Heidelberg, New York u. Tokyo, 2. Aufl.

Stegmüller, W. (1986a): Probleme und Resultate der Wissenschaftstheorie und der 
analytischen Philosophie, Band II: Theorie und Erfahrung, Dritter Teilband: Die Entwicklung des neuen Strukturalismus seit 1973, Berlin, Heidelberg, New York

Stegmüller, W. (1986b): Hauptströmungen der Gegenwartsphilosophie: Eine kritische Einführung, Bd. 2, 7. Aufl., Stuttgart

Stenglin, J.v. (1990): Denken der Wirklichkeit. Eine sprachlich und kognitiv fundierte Theorie der Erkenntnis

Sterbling, A. (1998): Zur Wirkung unsichtbarer Hebel - Überlegungen zur Rolle des sozialen Kapitals in fortgeschrittenen Gesellschaften, in: Berger, P.A./Vester, M. (Hrsg.): Alte Ungleichheiten - Neue Spaltungen, Opladen, S. 189-209

Stern, M.J. (2004): Unter- und Überbetonung des Raums. Einige Dilemmata in der empirischen Übersetzung der Sozialkapitaltheorie, in: Kessl, F./Otto, H.U. (Hrsg.): Soziale Arbeit und soziales Kapital. Zur Kritik lokaler Gemeinschaftlichkeit, Wiesbaden, S. 209-224

Stevenson, J. (1998): The complete idiot's guide to philosophy, New York

Strasser, H. (1999): Geleitwort, in: Dederichs, A.M.: Das soziale Kapital in der Leistungsgesellschaft. Emotionalität und Moralität in "Vetternwirtschaften", Münster u.a., S. 5

Strasser, P. (1980): Wirklichkeitskonstruktion und Rationalität. Ein Versuch über den Relativismus, Freiburg u. München

Strauss, A. (1968): Spiegel und Masken. Die Suche nach Identität, Frankfurt am Main

Strauss, A./Corbin, J. (1996): Grounded Theory: Grundlagen qualitativer Sozialforschung, Weinheim

Strawson, P.F. (1974): Wahrheit, in: Schirn, M. (Hrsg.): Sprachhandlung - Existenz Wahrheit. Hauptthemen der sprachanalytischen Philosophie, Stuttgart, S. 180-206

Strawson, P.F. (1985): Skepticism and Naturalism: some varieties, Cambridge

Ströker, E. (1999): Phänomenologie, in: Sandkühler, H.J. (Hrsg.): Enzyklopädie Philosophie, Bd. 2, Hamburg, S. 1013-1016

Strombach, W. (1992): Einführung in die Systematische Philosophie, Paderborn, München, Wien u. Zürich

Stuhlmann-Laeisz, R. (2002): Philosophische Logik. Eine Einführung mit Anwendungen, Paderborn

Sukale, M. (Hrsg.) (1990): Sprache, Theorie und Wirklichkeit, Frankfurt am Main

Suppes, P. (1993): Models and methods in the philosophy of science: selected essays, Dordrecht, Boston, London

Swain, N. (2003): Social capital and its uses, in: Arch. Europ. Sociol., XLIV, 2, S. 185-212

Tarski, A. (1972): Die semantische Konzeption der Wahrheit und die Grundlagen der Semantik, in: Sinnreich, J. (Hrsg.): Zur Philosophie der idealen Sprache. Texte von Quine, Tarski, Martin, Hempel und Carnap, München

Täube, V.G. (2002): Zur Messung des Sozialkapitals von Akteuren mit Einfluß in empirischen Netzwerken, Frankfurt am Main u.a.

Taylor, M. (1993): Cooperation, norms and moral motivation, in: Analyse und Kritik: Zeitschrift für Sozialwissenschaften, H. 1, Jg. 15, S. 70-86

Tegtmeier, E. (1992): Grundzüge einer kategorialen Ontologie. Dinge, Eigenschaften, 
Beziehungen, Sachverhalte, Freiburg u. München

Tetens, H. (2004): Philosophisches Argumentieren, München

Thomas, W.I./Thomas, D.S. (1928): The child in america. Behavior problems and programs, New York

Tietz, U. (2003): Über Intentionalität, Regeln und die Intersubjektivität der Bedeutung, in: Deutsche Zeitschrift für Philosophie, 1/2003, S. 63-79

Tietz, U. (2004): Heidegger und Wittgenstein über Sinn, Wahrheit und Sprache, in: Allgemeine Zeitschrift für Philosophie, 29.1.2004, S. 19-38

Tocqueville, A. de (1976): Über die Demokratie in Amerika, München

Troitzsch, K. (1990) Modellbildung und Simulation in den Sozialwissenschaften, Opladen

Twickel, C. (2002): Beziehungen und Netzwerke in der modernen Gesellschaft. Sozialkapital und normative Institutionenökonomik, Münster

Uslaner, E.M. (1999): Democracy and social capital, in: Warren, M.E. (Hrsg.): Democracy and trust, Cambridge, S. 121-150

Uslaner, E.M. (2001): Producing and consuming trust, in: Political science quaterly, vol. 115, no. 4, 2000-01, S. 569-590

Van Inwagon (1990): Material Beings, Ithaca, London

Vater, H. (1999): Einführung in die Sprachwissenschaft, 3. Aufl., München

Waismann, F. (1976): Logik, Sprache, Philosophie, Stuttgart

Waldenfels, B. (1992): Einführung in die Phänomenologie, München

Waldstrom, C. (2003): Social capital in organizations - Beyond structure and metaphor, Aarhus School of business, Departement of Organization and management, Working paper 03-07

Walter, T. (o.J.): Die Architektur und Kultsymbolik des ezechielischen Tempels und ihre theologische Bedeutung für die Dimension der Gottesnähe unter besonderer Berücksichtigung von Ez 43, 1-9.10-12. Wissenschaftliche Hausarbeit im vorgezogenen Verfahren zum 1. Theologischen Examen bei der Ev. Kirche in Hessen und Nassau, Humboldt-Universität Berlin

Walzer, M. (1992): Sphären der Gerechtigkeit. Ein Plädoyer für Pluralität und Gleichheit, Frankfurt am Main u. New York

Warde, A./Tampubolon, G. (2002): Social capital, networks and leisure consumption, in: The sociological review, vol. 50, no. 2, S. 155-180

Warren, M.E. (1999) (Hrsg.): Democracy and trust, Cambridge

Watzlawick, P. (1998): Wie wirklich ist die Wirklichkeit? Wahn, Täuschung, Verstehen, München, 24. Aufl.

Weber, M. (1980): Wirtschaft und Gesellschaft. Grundriß der verstehenden Soziologie, Tübingen, 5. Aufl.

Weber, M. (1992): Soziologie - Universalgeschichtliche Analysen, Politik, Stuttgart

Weesie, J./Verbeek, A./Flap, H. (1991): An economic theory of social networks, in: Esser, H./Troitzsch, K. (Hrsg.): Modellierung sozialer Prozesse, Bonn, S. 63-662

Wegener, B. (1987): Vom Nutzen entfernter Bekannter, in: Kölner Zeitschrift für 
Soziologie und Sozialpsychologie, 39, S. 278-301

Weidenfeld, W. (Hrsg.) (1996): Demokratie am Wendepunkt. Die demokratische Frage als Projekt des 21. Jahrhunderts, Berlin

Weissmahr, B. (1985): Ontologie, Stuttgart, Berlin, Köln u. Mainz

Wendel, H.J. (1990): Analytizität und Erkenntnis, in: Sukale, M. (Hrsg.): Sprache, Theorie und Wirklichkeit, Frankfurt am Main, S. 172-199

Wenturis, N./Van hove, W./Dreier, V. (1992): Methodologie der Sozialwissenschaften. Eine Einführung, Tübingen

Werner, C. (2003): Allgemeinbegriffe, ihr Gebrauch in der Sprache und ihr ontologischer Status bei Wilhelm von Ockham und Ludwig Wittgenstein im Vergleich, im internet unter: www.linse.uni-essen.de

Westermann, R. (2000): Festinger's theory of cognitive dissonance: A structuralist theorynet, in: Balzer,W./Sneed, J.D./Moulines, C.U. (Hrsg.): Structuralist knowledge representation. Paradigmatic examples, Amsterdam u. Atlanta, S. 189-217

Westermann, R. (2000a): Wissenschaftstheorie und Experimentalmethodik. Ein Lehrbuch zur Psychologischen Methodenlehre, Göttingen, Bern, Toronto, Seattle

Weyer, J. (Hrsg.) (2000): Soziale Netzwerke: Konzepte und Methoden der sozialwissenschaftlichen Netzwerkforschung, München

Whorf, B.L. (1963): Sprache, Denken, Wirklichkeit. Beiträge zur Metalinguistik und Sprachphilosophie, Reinbek bei Hamburg

Williams, B. (1986): Der Begriff der Moral. Eine Einführung in die Ethik, Stuttgart

Williams, T./Robinson, D. (2002): Social capital-based partnerships: a maori perspective and a comparative approach, in: Robinson, D. (Hrsg): Building social capital, Wellington, S. 14-30

Willke, H. (1996) Systemtheorie 1, 6. Aufl., Stuttgart u. Jena

Winship, C./Rosen, S. (1988): Introduction: Sociological and economic approaches to the analysis of social structure, in: American journal of sociology, vol. 94, supplement, S. $1-16$

Wittgenstein, L. (1977): Philosophische Untersuchungen, Frankfurt am Main

Wittgenstein, L. (1984a): Tractatus logico-philosophicus, Frankfurt am Main

Wittgenstein, L. (1984b): Das blaue Buch, Frankfurt am Main

Woolcock, M. (1998): Social Capital and economic development: Toward a theoretical synthesis and policy framework, in: Theory and society, vol. 27, S. 151-208

Wuchterl, K. (1999): Methoden der Gegenwartsphilosophie, Bern, Stuttgart, Wien, 3. Aufl.

Yardley, K./Honess, T (1987) (Hrsg.): Self and identity. Psychological perspectives, Chichester u.a.

Zoglauer, T. (1991): Das Problem der theoretischen Terme. Eine Kritik an der strukturalistischen Wissenschaftstheorie, Inaugural-Dissertation, Fakultät Philosophie der Universität Stuttgart

Zoglauer, T. (1999): Einführung in die formale Logik für Philosophen, Göttingen 

Die Debatte um Sozialkapital ist seit geraumer Zeit in Wissenschaft, Wirtschaft und Politik in Mode. Schaut man sich Untersuchungen dazu an, so scheint Sozialkapital für nahezu alles gut zu sein: sei es die Erhöhung des persönlichen Wohlbefindens, die Revitalisierung benachteiligter Stadtquartiere oder die Stärkung der Volkswirtschaft im globalisierten Standortwettbewerb - je mehr Sozialkapital, desto besser!

Doch gerade die behauptete enorme Wirkungsbreite sollte zu begrifflicher und theoretischer Wachsamkeit anhalten. Was dient Wissenschaftlern als Gegenstand ihrer Erkenntnisbemühungen, wenn von »Sozialkapital« die Rede ist? Was bedeutet »Sozialkapital«? Diese Frage mag banal klingen, ist aber bisher nicht systematisch bearbeitet oder gar in befriedigendem Maße beantwortet worden, obwohl doch zahlreiche Beiträge zur Begriffsdebatte vorliegen.

Das Buch nimmt eine bisher vernachlässigte metasprachliche Perspektive ein. Es erhöht damit den wissenschaftlichen Reifegrad der SozialkapitalDebatte und trägt zur Etablierung eines wohlfundierten Systems sozialwissenschaftlicher Begriffe bei. Es bringt Sozialkapital zur Sprache, indem es über eine Kombination einer erkenntnistheoretischen und ontologischen Analyse eine Präzisierung des Objektbereiches erarbeitet. 